\title{
El Museo de La Plata y la divulgación científica en el marco de la extensión universitaria (1906 - 1930)
}

\author{
Lic. Susana V. García
}

Directores de Tesis:

Dra. Laura Miotti

Dra. Irina Podgorny

Trabajo de tesis para optar al grado de Doctor Facultad de Ciencias Naturales y Museo Universidad Nacional de La Plata. 


\section{Resumen}

El objetivo general de esta tesis apunta a analizar la relación ciencia universidad - sociedad a principios del siglo XX. Este momento corresponde a un período en el que las funciones culturales de la universidad adquieren una complejidad creciente, discutiéndose el papel que la institución universitaria debería jugar en la consolidación de la Nación. En el contexto de esos debates, esta investigación se estructura alrededor de las prácticas y los discursos generados en torno a la "función social" de la ciencia y de la educación superior en los primeros años de la Universidad Nacional de La Plata, creada en 1905. En particular, esta investigación se concentra en las ciencias naturales tal como fueron organizadas en el Museo de La Plata a partir de su incorporación a esa nueva estructura universitaria.

El objeto de estudio se construyó sobre la conformación de un conjunto particular de prácticas y discursos acerca de lo que podría denominarse una "cultura científico-académica". Para ello se analizaron las creencias explicitadas en el seno de la comunidad universitaria en relación con las actividades de enseñanza y divulgación científica, así como las relaciones sociales y las realidades institucionales en las cuales se organizaron estas actividades. En esta investigación se recurrió a un corpus documental conformado por un conjunto de fuentes éditas e inéditas como un primer paso hacia una "etnografía histórica" de la institución universitaria y de sus prácticas científicas y culturales. Se examinó la especificidad de esas prácticas en el contexto social y cultural de la época, en relación con un proyecto de universidad y su funcionamiento institucional y con los distintos significados que le atribuyeron los actores de la época. Como opción metodológica se eligió examinar estas cuestiones en un período acotado; optándose por extender el análisis horizontalmente, incluyendo a varios aspectos, actores y esferas de acción interrelacionados. El período elegido corresponde a los inicios de la Universidad Nacional de La Plata, examinándose en particular la organización de la enseñanza y de la difusión de las ciencias naturales.

El trabajo de esta tesis se estructura en dos partes. En la primera parte se analiza la emergencia del proyecto de creación de la Universidad Nacional de La Plata, principalmente en relación con los debates universitarios de la época, las lecturas de los modelos internacionales, los intereses de los sectores universitarios platenses y las distintas conceptualizaciones en torno de la figura del profesor y el estudiante universitario, temas poco trabajados en la historiografía de las universidades argentinas. Asimismo se procuró examinar la construcción de un discurso sobre la universidad, la ciencia y los grupos ligados a ella, tal como se manifestó en los inicios de esta institución. La segunda parte de esta tesis está dedicada a examinar la articulación del Museo de La Plata con la estructura universitaria, en relación con la promoción de las actividades científicas, educativas y de divulgación que se impulsaron desde la Universidad. En esta parte se atiende a las distintas modalidades y prácticas que se organizaron en torno a las tareas científicas y de enseñanza en el área de ciencias naturales, las propuestas educativas y los estilos de ciencia promovidos.

Atendiendo a las particularidades del contexto histórico y social estudiado, esta tesis se propone examinar la divulgación de la ciencia enfocándose en tres aspectos: a) la divulgación de las prácticas científicas a través de la educación de estudiantes, futuros profesionales y docentes, y la formación de un "ambiente" para el trabajo científico de nuevas generaciones de investigadores; b) las prácticas discursivas destinadas a contrarrestar las resistencias, convencer sobre el mérito de la ciencia y 
obtener condiciones favorables para el desarrollo de ciertos saberes o proyectos científicos; y c) la popularización de la ciencia en el marco de la extensión de la instrucción popular y las preocupaciones por orientar la "opinión pública" y la educación nacional. Estrechamente ligado a los dos últimos puntos surge la idea de "extensión universitaria", un término traducido textualmente del inglés -university extension- y que se comenzó a utilizar en el contexto argentino al iniciarse el siglo XX. En esa época, el uso de este término implicó al menos dos sentidos: a) la educación de trabajadores y la popularización científica, promovida por socialistas, libre-pensadores y grupos de estudiantes universitarios; y b) la presentación a un público general de los trabajos de investigación y enseñanza científica que se llevaban a cabo dentro de la institución universitaria. En esta tesis se argumenta que el entrenamiento de estudiantes y futuros profesores de enseñanza secundaria, los ciclos de conferencias y cursos, las exhibiciones, la publicación de obras de divulgación y manuales así como las actividades estudiantiles constituyeron diferentes modalidades a través de las cuales los sectores universitarios buscaron extender la influencia de sus disciplinas. En particular, se procura demostrar la estrecha relación entre investigación, educación y divulgación que existió como parte de las prácticas de los sectores científicos universitarios a principios del siglo XX.

De esta manera, el objeto de estudio de esta tesis se construye a partir del momento en que se cuestiona las conceptualizaciones y distinciones contemporáneas que dicotomizan la organización del trabajo científico-académico de las prácticas de enseñanza y de divulgación así como de las interacciones sociales y culturales con un extramuros académico. Esta separación encubre, por un lado, que la investigación científica es el resultado de un proceso que implica la educación en una práctica científica $\mathrm{y}$, con anterioridad a ella, la participación en un sistema de ideas y categorías comunes, transmitido durante la socialización primaria y secundaria. Por otro, que los procesos de profesionalización y especialización han ido delineando nuevas formas y mediatizaciones en la relación ciencia-público y diferentes distinciones entre el campo científico y otros campos disciplinarios -entre los que se cuenta el educativo-, que en el pasado fueron sumamente permeables entre sí. Asimismo, en esta tesis se procura demostrar que la institucionalización de la ciencia en el contexto universitario implicó la construcción de un discurso sobre la ciencia, y al mismo tiempo, un público para el mismo tanto en el "intramuros" como entre los sectores extraacadémicos. En este proceso, los estudiantes y graduados tendrían un papel importante en la reproducción ampliada de una cultura científica así como en las prácticas de popularización de la ciencia. 
"El investigador que se envuelve en el estudio de documentos en un archivo .... fatalmente se sentirá identificado con los relatos hechos por los etnólogos al respecto de sus investigaciones de campo entre grupos indígenas, especialmente con las fases en que, sin la certeza de saber para donde ir, anota todo lo que ve, oye y conversa, juntando detalles y más detalles, con la esperanza que de aquel conjunto, a primera vista fragmentado e incomprensible de notas, pueda surgir una idea última con la cual consiga realizar un trabajo, si es posible, original e innovador, sino, al menos correcto y convincente.

Como el etnólogo que procura establecer relaciones personales y de empatía con los que dominan saberes e información en el grupo estudiado, el investigador en archivos también procura alguna forma de entendimiento con los que son los guardianes de los documentos que busca: siempre hay una caja que no fue abierta, un documento considerado interesante o extraño, la remembranza de algo que no está registrado o está fuera de lugar...." (Grupioni 1998:13) 


\section{INDICE}

Agradecimientos. VI

Introducción. 1

Parte 1: La función social y el perfil científico de la Universidad

Capítulo I: La "cuestión universitaria" en la transición del siglo XIX al XX. 21

I.1 - El perfil profesional de las universidades argentinas 23

I.2- Los proyectos de reforma universitaria 32

I.3- La Universidad provincial de La Plata y

la nacionalización de las instituciones provinciales 46

Capítulo II: La república universitaria platense. 65

II.1- El proyecto universitario y educativo de Joaquín V. González. 67

II.2- Ideales y modelos universitarios internacionales. 74

II.3- La cuestión de la autonomía universitaria. 82

II.4- La formación de un "espíritu universitario". 94

II.5- La vida estudiantil fuera de las aulas y la emergencia de los centros de estudiantes

\section{Capítulo III: La tarea educativa de la Universidad y la transmisión}

del "espíritu cientifico".

III.1- El valor educativo de la ciencia y

la acción docente de la Universidad.

III.2- Una educación organizada científicamente

y la formación de "aptitudes de investigación".

III. 3- La extensión universitaria y la divulgación científica. 
Parte 2: El Museo de La Plata, la divulgación y la educación científica

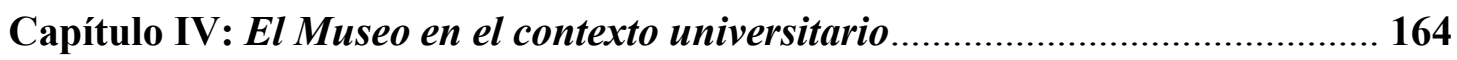

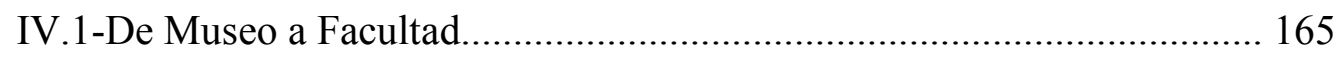

IV.2-Cuidar colecciones, investigar, enseñar.......................................... 176

IV. 3- Difundir: publicaciones y colecciones ........................................... 188

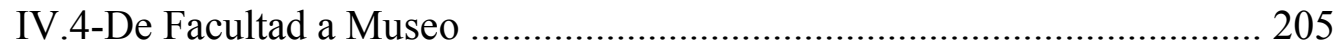

Capítulo V: La formación universitaria en ciencias naturales............................ 218

V. 1- La carrera de ciencias naturales en la Argentina. ................................220

V. 2-La organización de la enseñanza de las ciencias naturales

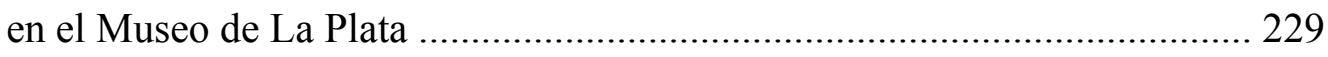

V. 3- La trasmisión de la aptitud técnica ..................................................... 241

V. 4- Especialización y formación de los primeros egresados...................... 250

V. 5- Naturalistas para el inventario del territorio nacional ......................... 264

Capítulo VI: La preparación del profesorado secundario y superior:

Facultades científicas vs. Facultad de Ciencias de la Educación ..........................272

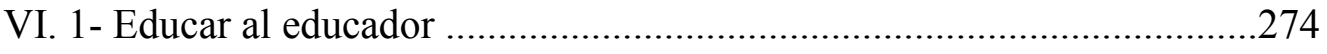

VI. 2- La organización de la Sección Pedagógica ........................................ 282

VI. 3 - El título de "profesor de enseñanza superior".................................... 291

VI. 4- La preparación científica del profesorado secundario ....................... 297

VI. 5- El reclamo de los sectores científicos ............................................... 304

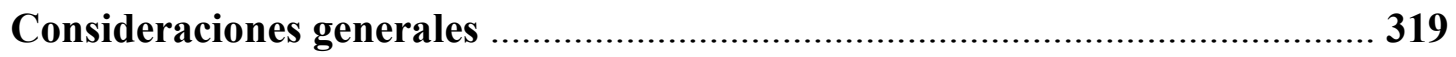

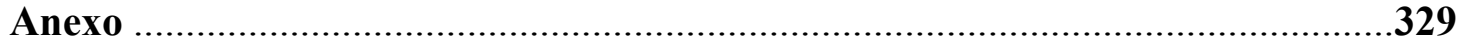

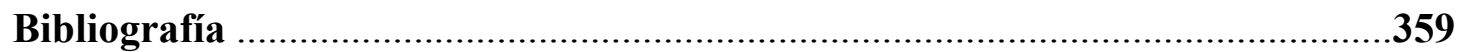




\section{Agradecimientos}

Hay muchas personas que contribuyeron de una u otra forma a que este trabajo se realizara. En primer lugar quiero agradecer a quienes me prestaron material bibliográfico, respondieron a alguna consulta o discutimos ideas en distintos momentos de esta investigación: Diego Pereyra, María Caldelari, Diego Hurtado de Mendoza, Alfonso Bruch, Analía Busala, Mariano Bagero, Hugo Biagini, Mónica Ros, Cecilia von Reichenbach, Osvaldo Graciano, Fernando Barba, Gustavo Sorá, Sandra Muriello. Especialmente a los seis primeros también debo agradecerles por aquellas reuniones periódicas para discutir trabajos sobre historia de la ciencia cuando recién comenzaba a acercarme a estos temas.

También quiero agradecer a quienes me facilitaron fuentes o el acceso a las mismas. A José Perez Gollán por las posibilidades para consultar documentación en el Archivo del Museo Etnográfico y a Silvia Ametrano por el apoyo en el trabajo del Archivo de la Facultad de Ciencias Naturales y Museo. A la familia Delachaux por brindarme información y material sobre el primer miembro de su familia que llegó a la Argentina y trabajó en el Museo de La Plata. A Genoveva Dawson de Teruggi por abrirme las puertas de su casa, mostrarme fotografías antiguas y relatarme su experiencias de estudiante en el Museo, su niñez en el Observatorio, la vida universitaria de La Plata así como muchas otras cosas interesantes. Por supuesto, los bibliotecarios y cuidadores de documentos que se llenaron de polvo trayendo las "cosas raras" que les pedía merecen también un reconocimiento especial.

Asimismo, Ana Ottenheimer, Bernarda Zubryczki, Marina Sardi, ocupan un lugar especial. Las tres estuvieron presentes a lo largo de este trabajo, apoyando con comentarios, lecturas críticas, las citas bibliográficas, llamadas por teléfono, cenas y por sobre todas las cosas: la amistad. Por los mismos motivos debo agradecer a Cecilia Gómez Montes y su colaboración ordenando la bibliografía, Andrea Pegorado y Máximo Farro, quien también prestó ayuda en la compaginación de las citas y me facilitó bibliografía. En distintos momentos otras personas estuvieron presentes: Lila Far; Adriana Menegaz y Adriana Mengasini con quienes converse algunos temas tratados en esta tesis; y Daniel y mi familia, por su apoyo logístico.

Mis directoras merecen un agradecimiento especial por el respaldo que me brindaron a lo largo de mi carrera, en el desarrollo de este proyecto y especialmente en los tramos finales de la confección de esta tesis. Laura Miotti me dio su confianza y me apoyó desde que comencé a estudiar Antropología, mostrándome lo interesante que podía ser el trabajo de tratar de reconstruir al pasado siguiendo las huellas del registro arqueológico. Sin embargo, terminé optando por otro tipo de "arqueología" vinculada al trabajo en archivos y la historia de la ciencia como el programa de investigación promovido por Irina Podgorny, con quien también estoy en deuda por la crítica y corrección exhaustiva de mi escritura, la amplia libertad de trabajo, los debates sobre numerosos temas, su palabra estimulante y el apoyo incondicional que siempre me ofrece.

Esta investigación fue posible gracias a una beca de formación de postgrado otorgada por el CONICET, un subsidio de la Fundación Rockefeller a través del programa: "Pro Scientia et Patria: los museos en la formación del patrimonio nacional" del Museo Etnográfico de la Facultad de Filosofía y Letras de la Universidad de Buenos Aires, y mi participación en el proyecto de organización del Archivo Histórico de la Facultad de Ciencias Naturales y Museo dirigido por Irina Podgorny y financiado con un Subsidio de Inicio de Carrera de la Fundación Antorchas. Finalmente quiero aclarar que ninguna de las personas e instituciones antes citadas es responsable por los errores $\mathrm{u}$ omisiones que se puedan encontrar en las siguientes páginas. 


\section{Introducción}

El objetivo general de esta tesis apunta a analizar la relación ciencia universidad - sociedad a principios del siglo XX. Este momento corresponde a un período en el que las funciones culturales de la Universidad adquieren una complejidad creciente y se discute el papel que la institución universitaria debería jugar en la consolidación de la Nación ${ }^{1}$. En el contexto de esos debates, esta investigación se estructura alrededor de los discursos y las prácticas generados en torno a la "función social" de la ciencia y de la universidad en los primeros años de la Universidad Nacional de La Plata, creada en 1905. El objeto de estudio se construyó sobre la conformación de un conjunto particular de prácticas en torno a lo que podría denominarse una "cultura científico-académica". En particular, esta investigación se concentra en las ciencias naturales tal como fueron organizadas en el Museo de La Plata a partir de su incorporación en 1906 a la estructura universitaria.

En la historiografía sobre las ciencias en la Argentina se han reconocido diversos momentos significativos en los cuales se habría impulsado, con mayor o menor éxito, la incorporación de las actividades científicas en la vida universitaria ${ }^{2}$. Entre esos acontecimientos se ha destacado la creación de la Universidad Nacional de La Plata, en cuya estructura se integraron centros científicos como el Museo General de La Plata, el Observatorio Astronómico y el Instituto de Física. Esta iniciativa se fundamentó en la idea de constituir escuelas superiores de ciencia, incorporando como una de las funciones de la universidad las actividades relacionadas con la producción del conocimiento. La anexión a la estructura universitaria de los centros científicos extraacadémicos como el Museo y el Observatorio, fundados a fines del siglo XIX como parte de las instituciones de la nueva capital de la provincia de Buenos Aires, ha sido considerada no sólo como un indicador de las nuevas funciones asignadas a la institución universitaria sino también como un traslado -del Museo a la Universidaddel centro de organización y promoción de la investigación científica ${ }^{3}$. Este desplazamiento puede asociarse, además, a la consolidación de la educación formal del

\footnotetext{
${ }^{1}$ Halperin Donghi 1962, Buchbinder 1997.

${ }^{2}$ Véase entre otros: Babini 1949, 1954; Camacho 1971; Myers 1992, 1994; Prego 1998, 2001; Tognetti 2000, Buch 1996, 2000.

${ }^{3}$ Myers 1992; Podgorny 1995.
} 
científico y la profesionalización de la ciencia en la Argentina. En ese proceso la Universidad ampliaría las posibilidades para articular las actividades científicas en torno a la cátedra universitaria y especialmente se presentaría como un ámbito propicio para el desarrollo de nuevas líneas de investigación en ciencia pura o "desinteresada". Sin embargo, pocos trabajos han examinado con profundidad la organización institucional, la articulación entre las actividades de enseñanza e investigación y el soporte específico para la promoción de las prácticas científicas dentro del contexto universitario durante la primera parte del siglo XX. La investigación que se presenta en estas páginas se ha dirigido a ampliar algunas de estas cuestiones, atendiendo principalmente a la interrelación entre las prácticas de enseñanza, la divulgación de la ciencia y las condiciones de posibilidad para la actividad científica universitaria en los inicios del siglo XX. Los estudios históricos y sociales de la ciencia frecuentemente han enfatizado en el tema de las redes sociales de sustentación necesarias para la empresa científica, pero raramente han examinado de cerca los lugares y las prácticas a través de los cuales las nuevas generaciones de investigadores y profesores son entrenados. No obstante, estos así como los programas de enseñanza, ciclos de difusión y planes de estudios juegan un papel central en: a) la definición del universo de saberes y prácticas socialmente legítimos que contribuyen a producir y reproducir programas de pensamiento; y b) la creación y condicionamiento de un público inmediato: estudiantes y futuros docentes, que posibilitan la reproducción ampliada de la práctica científica y su divulgación ${ }^{4}$.

Si bien en muchos trabajos se ha señalado la importancia de una base social para la sustentación de la práctica científica, pocas veces se ha atendido a las vinculaciones con el sistema educativo, la formación de docentes y profesionales y la delimitación de los programas de enseñanza como parte de los mecanismos de legitimación social de las disciplinas académicas. En esta tesis se trata de mostrar cómo el entrenamiento de estudiantes y futuros profesores de enseñanza secundaria; los ciclos de conferencias y cursos, las exhibiciones, la publicación de obras de divulgación y los manuales así como las actividades estudiantiles constituyeron diferentes modalidades a través de las cuales los sectores universitarios buscaron extender la influencia de sus disciplinas. En particular, se procura demostrar la

\footnotetext{
${ }^{4}$ Bourdieu 1984.
} 
estrecha relación entre investigación, educación y divulgación que existió como parte de las prácticas de los sectores científicos universitarios a principios del siglo XX.

De esta manera, el objeto de estudio de esta tesis se construye a partir del momento en que se cuestiona las conceptualizaciones y distinciones contemporáneas que dicotomizan la organización del trabajo científico-académico de las prácticas enseñanza y divulgación así como de las interacciones sociales y culturales con un "afuera". Esta separación encubre por un lado, que la investigación científica es el resultado de un proceso que implica la educación en una práctica científica y previo a ella la participación en un sistema de ideas y categorías comunes trasmitidos durante la socialización primaria y secundaria ${ }^{5}$; y por otro, que los procesos de profesionalización y especialización han ido delineando nuevas formas y mediatizaciones en la relación ciencia-público $^{6}$ y así como distinciones entre el campo científico y otros campos, como el educativo, que en el pasado fueron sumamente permeables entre sí.

El eje principal de análisis en esta tesis se estructura alrededor de las distintas conceptualizaciones y prácticas que se organizaron alrededor de las "funciones" de la institución universitaria, el profesor y el estudiante, especialmente en relación con los propósitos de adicionar "ciencia" a la tarea académica y los intentos por abrir nuevos “nichos" para la investigación. Para ello se tomó como objeto de estudio las propuestas científico-educativas promovidas en los inicios de la Universidad Nacional de La Plata y sus efectos en el caso particular de las ciencias naturales y el Museo de La Plata. En ese contexto, la divulgación de la ciencia puede ser entendida en relación a tres aspectos: a) la divulgación de las prácticas científicas a través de la educación de estudiantes, futuros profesionales y docentes; y la formación de un "ambiente" para el trabajo científico de nuevas generaciones de investigadores; b) las prácticas discursivas destinadas a contrarrestar las resistencias, convencer sobre el mérito de la ciencia y obtener condiciones favorables para el desarrollo de ciertos saberes o proyectos científicos; y c) la popularización de la ciencia en el marco de la extensión de la instrucción popular y las preocupaciones por orientar la "opinión pública" y la educación nacional. Estrechamente ligado a los dos últimos puntos aparecía la idea de "extensión universitaria", un término traducido textualmente del inglés -university extension- y que se comenzó a utilizar en el contexto argentino al iniciarse el siglo XX. En esa época, el uso de este término implicó al menos dos sentidos: a) la

\footnotetext{
${ }^{5}$ Berger y Luckmann 1979 ; Podgorny 1994, 1999.

${ }^{6}$ Fehér 1990.
} 
educación de trabajadores y la popularización científica, promovida por socialistas, libre-pensadores y grupos de estudiantes universitarios ${ }^{7}$; b) la presentación a un público general de los trabajos de investigación y enseñanza científica que se llevaban a cabo dentro de la institución universitaria. En esta tesis se examinan estos temas especialmente en relación con la organización del trabajo del profesor universitario y las actividades estudiantiles.

El trabajo de esta tesis se estructura en dos partes. En la primera parte se analiza la emergencia del proyecto de creación de la Universidad Nacional de La Plata, presentado por el entonces Ministro de Justicia e Instrucción Pública, Joaquín V. González (1863 - 1923). Generalmente se ha asociado este proyecto universitario con: a) la actuación política de González anterior a 1906, especialmente vinculado a sus preocupaciones reformistas como se manifestaría en la ley electoral de 1902, el proyecto de ley nacional del trabajo de 1904, las reformas de la enseñanza secundaria, entre otros temas ${ }^{8}$; y b) las ideas positivistas y "cientificistas". En esta tesis se toma como base esos estudios, pero se procura analizar ese proyecto en relación con los debates universitarios de la época, las lecturas de los modelos internacionales, los intereses de los sectores universitarios platenses y las distintas conceptualizaciones en torno a la figura del profesor y el estudiante universitario, temas poco trabajados en la historiografía de las universidades argentinas. En consecuencia, en el Capítulo I se presenta el clima de ideas con respecto al funcionamiento de las universidades argentinas y los proyectos de reforma universitaria que se presentaron en la transición del siglo XIX al XX, atendiendo principalmente a los debates parlamentarios y las opiniones de la elite universitaria y política. Para comprender el escenario en el que fue presentado el proyecto de la Universidad Nacional de La Plata es necesario tener en cuenta, además, los intereses de los sectores ilustrados y políticos platenses, la inestabilidad de las instituciones provinciales y los reclamos por el reconocimiento nacional de estudios de la Universidad provincial y la Facultad de Agronomía y Veterinaria de La Plata, que afectaba el ejercicio profesional de los egresados.

El Capítulo II esta dedicado a examinar la construcción de un discurso sobre la universidad y los grupos ligados a ella como se manifestó en los inicios de la Universidad Nacional de La Plata, tomando como referente empírico el proyecto

\footnotetext{
${ }^{7}$ Barrancos 1995, 1996; De Lucía 1999.

${ }^{8}$ Véase entre otros: Roldán 1993, Zimmermann 1995, Crispiani 1999. La biografía política e intelectual de Joaquín V. González es analizada especialmente por el primero.
} 
universitario y los discursos académicos de Joaquín V González y otros sectores universitarios. En particular, este capítulo se estructura alrededor del análisis de las siguientes cuestiones: a) las "misiones de la universidad" y las lecturas de los modelos e ideales universitarios internacionales que circularon en la época; b) la autonomía universitaria, la organización del gobierno interno y el profesorado ; c) los mecanismos para mantener una unidad e identidad universitaria frente a la fragmentación institucional, las crecientes especializaciones y las Facultades semi-autónomas; d) la organización de los centros de estudiantes y las actividades estudiantiles.

El Capítulo III, se centra en la "función educativa" de la universidad y la divulgación de la ciencia atendiendo a tres aspectos: a) el valor social y educativo asignado a la ciencia, donde la retórica "cientificista" puede ser entendida en función de los reclamos profesionales de los científicos y de aquellos que buscaban legitimar sus prácticas y saberes a través del prestigio técnico y simbólico de la ciencia; b) la promoción de una enseñanza científica y la organización de espacios para la formación en investigación; c) las ideas y conceptualizaciones acerca de la extensión universitaria y la diversidad de modalidades, prácticas y experiencias de divulgación científica. Asimismo, en este capítulo se hace hincapié en el problema de la conformación de un público para la ciencia, tema que se amplia en los siguientes capítulos.

La segunda parte de esta tesis esta dedicada a examinar la articulación del Museo de La Plata con la estructura universitaria, en relación con la promoción de las actividades científicas, educativas y de divulgación que se impulsaron desde la Universidad Nacional de La Plata. Principalmente en esta parte se atiende a las distintas modalidades y prácticas que se organizaron en torno a las tareas científicas y de enseñanza en el área de ciencias naturales, las propuestas educativas y los estilos de ciencia que se promovieron. En el Capítulo IV se explora las trasformaciones del Museo en Instituto/Facultad en relación con: a) la concepción de museo; b) el funcionamiento institucional y las actividades museísticas, docentes y de investigación en la organización del trabajo y del profesorado en ciencias naturales; y c) la participación en los programas de extensión universitaria y difusión promovidos desde la Universidad así como en las prácticas culturales y de divulgación específicas de la época, especialmente las vinculadas al contexto de un museo.

En el Capítulo V se examina la organización de la enseñanza de las ciencias naturales y la formación del naturalista, atendiendo a los siguientes problemas: a) el reclutamiento de estudiantes y las posibilidades laborales para los diplomados en 
ciencias naturales, b) los distintos estilos y orientaciones de trabajo científico que se promovieron a través de las clases prácticas, d) las tensiones entre procurar una formación general o especializada, e) los enfrentamientos y luchas de poder en torno a la definición del perfil del egresado en ciencias naturales. Finalmente, en el Capítulo VI se analiza la organización de la formación del docente de enseñanza secundaria y los conflictos de autoridad en el diseño de los planes de estudio de los profesorados entre pedagogos y científicos, así como en torno a la concepción del perfil del profesor de enseñanza secundaria y superior. En el Anexo se presentan tablas con datos que ilustran o complementan lo expuesto en lo capítulos; una nota sobre las fuentes utilizadas, los primeros planes de estudio del doctorado en ciencias naturales y un cuadro con los primeros estudiantes y egresados de ciencias naturales en el Museo/Facultad de Ciencias Naturales de La Plata y sus primeras inserciones institucionales y actuación profesional.

\section{$\underline{\text { Algunas cuestiones teóricas- metodológicas }}$}

En este trabajo se ha utilizado el concepto de "cultura académica" a partir de la propuesta de Fritz K. Ringer para un análisis comparativo del sistema universitario francés y alemán en la transición del siglo XIX al XX. En sus últimos trabajos este investigador propone examinar una "cultura académica" en función de dos aspectos interrelacionados: a) las creencias explícitas que se manifiestan en el seno de una comunidad universitaria en relación con las prácticas de enseñanza e investigación; y b) las relaciones sociales y las realidades instituciones en las cuales tienen lugar estas actividades ${ }^{9}$. A partir de esta propuesta, en esta tesis se busca articular analíticamente los elementos ideacionales con los escenarios institucionales y sociales, con sus reglas y normas que objetivan y permiten ciertas prácticas, sin por ello dejar de tener en cuenta que tanto las ideas como las instituciones son producto de las acciones, elecciones y estrategias de actores concretos en contextos sociohistóricos particulares. En relación con ello, en esta investigación se ha elegido un enfoque microhistórico, en el que se recurre a un modelo de la conducta humana en el mundo basado en la acción y el conflicto. Desde esta perspectiva, como señala Giovanni Levi, la acción social se

\footnotetext{
${ }^{9}$ Ringer 1991. Véase también: Ringer 1995.
} 
considera resultado de una transacción constante de los sujetos, que interpretan, manipulan, deciden y construyen con una -relativa- libertad pero insertos en los sistemas prescriptivos y normativos de la sociedad ${ }^{10}$.

Uno de los cambios en los enfoques de la historia institucional de la ciencia y las universidades se vincula con el uso de diversas fuentes y documentos de archivos, que complementan $\mathrm{y} / \mathrm{o}$ a veces reemplazan a las fuentes secundarias. Como han señalado algunos investigadores, los estudios de archivo enriquecen la literatura aportando materiales para examinar las instituciones particulares en sus detalles y diferenciaciones así como en relación con los conflictos y las luchas por los recursos tanto simbólicos como materiales. No obstante, este tipo de estudios está sujeto a ciertas limitaciones y "peligros" de producir una lectura acrítica o la aceptación de los "hechos" contenidos en las fuentes documentales como si esos materiales representaran el pasado. Esto conduce al problema más general de la revisión del valor del documento. En relación con ello, uno de los instrumentos metodológicos más importantes utilizados en esta tesis se vincula al programa de la "arqueología del saber" propuesto por Foucault, donde se utiliza la metáfora de la diferencia entre el "documento" y el "monumento" ". Mientras que en las interpretaciones históricas tradicionales se buscaba memorizar los monumentos del pasado trasformándolos en documentos: totalidades cerradas que contenían toda la información pertinente respecto a algo; por el contrario, en la propuesta de Foucault, el documento como monumento se presenta como un objeto fragmentario, incompleto, modificado. Esto implica, como señala Irina Podgorny, que el trabajo con las fuentes se asemeja a una excavación arqueológica moderna, en la que no sólo interesan los objetos sino: a) la relación entre ellos, b) la relación entre ellos y el sustrato que los contiene y c) la relación de todo lo hallado con los procesos que llevaron a que el investigador que lo observe en el presente los observe en ese contexto. De esa manera, el documento es considerado como resto material que condensa no sólo un uso original sino los procesos que median entre ese uso y el hallazgo ${ }^{12}$. Esto implica, además, considerar a los discursos y prácticas en su materialidad, como acontecimientos, como una producción concreta en un momento histórico determinado y cuyo valor es temporal.

\footnotetext{
${ }^{10}$ Levi 1993.

${ }^{11}$ Foucault 1970.

12 Podgorny 1994.
} 
Por otra parte, estos materiales analizados desde un "paradigma indiciario"13 y microhistórico permiten una primera aproximación hacia una "descripción densa" 14 de las tramas de significación en las que se inscribieron los discursos, las prácticas y las categorías que circularon en este particular contexto científico-académico. Precisamente, los estudios microhistóricos se han constituido en un lugar de intersección entre la Historia y la Antropología sociocultural ${ }^{15}$. Asimismo, la presente investigación se inspira en parte en la "historia del libro" y la "historia cultural" de la tradición francesa, especialmente en los trabajos de Roger Chartier ${ }^{16}$. Desde esta perspectiva, en esta tesis se utiliza el concepto de "lectura" como una práctica de apropiación e invención de sentido ${ }^{17}$, que no es aleatoria sino que esta inscripta dentro de restricciones, limitaciones compartidas y horizontes de expectativas ${ }^{18}$. Al mismo tiempo, esos estudios enfatizan en los múltiples procesos que intervienen en la circulación de información como: su inscripción en sustratos materiales, los canales de comunicación, las redes sociales en la que intervienen múltiples agentes y los procesos específicos de su recepción ${ }^{19}$. Asimismo, en esta tesis se ha procurado realizar una descripción de las prácticas científicas y culturales vigentes en un contexto social e histórico determinado, atendiendo a los valores, significados e interpretaciones que le otorgaban los propios actores de la época.

Como un primer paso hacia una "etnografía histórica" de la institución universitaria, en esta investigación se recurrió a un corpus documental conformado por un conjunto diverso de fuentes éditas e inéditas (véase: Nota sobre las fuentes utilizadas en el Anexo). Entre los materiales impresos correspondientes al período estudiado, se pueden mencionar: a) la prensa diaria local y de circulación nacional; las publicaciones educativas, científicas, universitarias y las revistas de los centros de estudiantes universitarios; que permitieron observar, entre otras cosas: por un lado, qué tipo de actividades y otros aspectos del mundo académico se difundían; y por otro, cómo se organizaban las prácticas de divulgación científica; b) las publicaciones oficiales de la Universidad tales como: memorias, actos públicos, digestos, planes de

\footnotetext{
${ }^{13}$ Ginzburg 1981, 1994.

${ }^{14}$ Geertz 1988.

${ }^{15}$ Entre otros trabajos se destaca el de Robert Darnton 1984, donde se propuso explorar el pasado con un mirada antropológica y tomando un episodio -la gran matanza de gatos- como la puerta de entrada a la cultura de la Francia del Antiguo Régimen. Sabato 1986, Grendi 1996, Revel 1996.

${ }^{16}$ Chartier 1992, 1994, 1996.

${ }^{17}$ Chartier 1999.

18 Jauss 1986.

${ }^{19}$ Además de los trabajos de Chartier citados anteriormente, véase entre otros: Darnton 1996.
} 
estudio, asambleas generales de profesores, entre otros; y las del Ministerio de Justicia e Instrucción Pública, especialmente las Memorias anuales, en las cuales se reúnen los decretos y proyectos oficiales, los informes y datos estadísticos de las distintas instituciones educativas nacionales, entre ellas las universidades; c) las actas de sesiones de las Cámaras de Senadores y Diputados de la Nación, que ofrecen otros indicios para aproximarnos a las distintas propuestas, disidencias y sentidos en torno a la "cuestión universitaria", en particular al presentase proyectos de reforma universitaria o en los debates anuales del presupuesto nacional. Teniendo en cuenta que el ámbito parlamentario estaba conformado por muchos académicos y profesores universitarios, estos debates se tornan doblemente pertinentes; d) discursos académicos y distintos folletos sobre educación superior que circularon en la época, tales como los que conformaron colecciones especiales reunidas en los años estudiados y que se encuentran en la Biblioteca de la Universidad Nacional de La Plata. Especialmente para todos los materiales consultados en las Bibliotecas se ha atendido a la fecha de ingreso y el donante con el objeto de aproximarnos a la circulación y recepción de la bibliografía internacional y local sobre los temas estudiados.

Otro tipo de material utilizado en esta investigación fueron los documentos inéditos. Entre ellos, los consultados en el Archivo General de la Nación, especialmente: a): los relacionados con la Universidad provincial de La Plata en el Fondo Dardo Rocha; b) los registros relacionados a la contabilidad del Ministerio de Instrucción Pública, en particular los relacionados con la instalación de la Universidad Nacional de La Plata. Las principales fuentes documentales trabajadas en esta tesis forman parte del acervo del Archivo Histórico de la Facultad de Ciencias Naturales y Museo de La Plata (AHMLP). La participación en las actividades de organización del material de este Archivo, permitió observar los criterios con que esos materiales se habían clasificado y guardado. En su mayoría el corpus documental de este Archivo es de carácter burocrático y administrativo. Entre los principales materiales utilizados en esta tesis se pueden mencionar: los copiadores de secretaria y dirección, las cartas enviadas por la Presidencia de la Universidad a la dirección de la institución, las actas del Consejo de Académico, registros de alumnos, informes de las distintas secciones y los pedidos de instituciones nacionales e internacionales, entre otros. Estos materiales constituyen un testimonio material -aunque fragmentario- que ofrece diversos indicios para aproximarnos al funcionamiento institucional de esta unidad académica y a varios aspectos de la vida universitaria en general. A partir del análisis de esos documentos 
comenzaron a emerger una serie de personajes, instituciones, proyectos, dilemas, conflictos y diversas cuestiones y problemas presentes en la época, que permitieron visualizar un conjunto de actores e instituciones integrando una compleja red de relaciones en la cotidianidad de sus prácticas.

\section{$\underline{\text { Antecedentes }}$}

En esta tesis se combinan varios enfoques y perspectivas de análisis que provienen de diferentes campos de estudio. Entre los principales trabajos con los cuales se relaciona esta investigación se pueden mencionar los que procuran analizar la organización de las prácticas científicas en sus contextos sociales e institucionales. Vinculado con ello, los antecedentes de esta investigación se pueden ubicar en relación con las siguientes áreas temáticas: la historia de las universidades argentinas y la enseñanza de las ciencias naturales; los trabajos internacionales sobre la historia institucional de la universidad y los estudios sociales y culturales de la ciencia.

En la Argentina, la investigación histórica e institucional sobre las universidades cuenta en su haber con pocos análisis sistemáticos, basados en el uso de diversas fuentes documentales. En general, la atención recibida por las universidades puede caracterizarse en términos de historia política, social e intelectual, y muy principalmente en relación con el movimiento estudiantil y el proceso de la Reforma Universitaria $^{20}$. Esta última se constituyó en una referencia central para los estudios que se abocaron al desarrollo histórico de las universidades argentinas. Horacio Crespo señala que el "ideario" o los "postulados" de la Reforma Universitaria se convirtieron en un eje articulador de la Universidad pública argentina en los tres lustros que siguieron a la recuperación de la democracia y el triunfo radical en 1983, conformando un palimpsesto de tradiciones dentro de un corpus programático, que en su simplicidad resumía su eficacia como mecanismo legitimador y a la vez defensivo de un status $q u o^{21}$. Según este investigador, esta "defensiva" significó, en los hechos, la imposibilidad de pensar abiertamente las trasformaciones estructurales de la sociedad y sus efectos sobre la posición, el sentido y el funcionamiento de las universidades. De esa forma, la historia de la Reforma Universitaria se confunde con la historia de la

${ }^{20}$ Véase entre otros: Portantiero 1978; Ciria y Sanguinetti 1987; Biagini 1987, 1999b; Caldelari y Funes 1997; Buchbinder 2000. 
institución y el paralelismo se produce en términos de elementos positivos y negativos respecto a su propio desarrollo y el "momento mítico fundacional" del movimiento de 1918. Frecuentemente, este movimiento se ha asociado al "año cero" del proceso de modernización institucional de las universidades argentinas, caracterizadas hasta ese entonces como "profesionalistas". A través de esos relatos se estableció una imagen homogénea de la organización y funcionamiento de las distintas universidades argentinas, y también latinoamericanas, que se sintetizó con el término de "universidad profesionalista", en alusión a que la principal preocupación de la institución giraba en torno a la formación de profesionales en aras de salidas laborales lucrativas, descuidando, entre otras cosas, la formación integral de sus integrantes, el desarrollo de actividades científicas, la extensión universitaria y las vinculaciones con la sociedad. No obstante, ese "mito fundacional" fue construido a partir de un conjunto de textos producidos por los mismos actores de ese movimiento ${ }^{22}$, quienes se proyectaron como "la nueva generación" que defendía una serie de valores y jerarquías de saberes, presentados como inconmensurables con la tradición precedente ${ }^{23}$. La parcializada atención montada sobre estos temas creó la ilusión de un espacio ocupado, que no incentivó la constitución de la historia de las universidades como un objeto de estudio definido en la especificidad de sus temáticas, sus metodologías de análisis y la organización de su archivo. Frente a ello, Crespo indica que es necesario pensar otro marco para examinar la historia de la Universidad, en la que la Reforma no aparezca como el eje articulador central que da inteligibilidad a esa historia, sino como un segmento de otra clave interpretativa que la incluya, la explique, pero a la vez, permita reflexionar críticamente sobre la historia de la universidad argentina ${ }^{24}$. En esta tesis se procura aportar algunos elementos para reinterpretar ese tipo de lecturas que tornan homogénea la historia de las universidades argentinas. Para ello se parte del análisis de un conjunto diverso de fuentes documentales éditas e inéditas, procurando examinar la especificidad de las prácticas científicas y culturales que se articularon alrededor de un proyecto de universidad, de su funcionamiento institucional y de los distintos

\footnotetext{
${ }^{21}$ Crespo 1999.

${ }^{22}$ Entre 1922 y 1927 se produjeron innumerables textos sobre la reforma o "revolución universitaria", a lo que le seguirían otros publicados en los siguientes años y recopilaciones de los mismos. Entre los autores más citados se puede mencionar: Gabriel del Mazo 1926/27, 1945; Julio V. González 1922, 1927, 1945, o Carlos Cossío 1923, 1927; entre otros.

${ }^{23}$ Vásquez 2000. Véase también: Portantiero 1978; Cattáneo y Rodríguez 2000. En este último se analiza, además, la participación de los líderes de la Reforma Universitaria en la creación del Partido Nacional Reformista.

${ }^{24}$ Crespo 1999.
} 
significados que le atribuyeron los actores de la época. Se eligió como opción metodológica examinar estas cuestiones en un período acotado, pero extendiendo el análisis horizontalmente a varios aspectos, actores y esferas de acción interrelacionadas. El período elegido corresponde a los inicios de la Universidad Nacional de La Plata, para examinar en particular la organización de la enseñanza y de la difusión de las ciencias naturales.

Para el período y los temas comprendidos en esta investigación se han tomado como referencia los siguientes trabajos: en primer lugar, se puede mencionar el trabajo de Tulio Halperín Donghi sobre la Universidad de Buenos Aires, escrito en 1962 y que se convirtió en una referencia central de todos los estudios posteriores sobre las universidades $\operatorname{argentinas}^{25}$. En esa obra se ofrece un marco para mirar la historia de la institución universitaria desde un enfoque que combina los aspectos institucionales con la historia de las ideas, las relaciones entre universidad y sociedad y el desenvolvimiento de esta institución en función de los cambios del país y la ciudad. También, la obra crítica de Juan Carlos Portantiero sobre la Reforma Universitaria (publicada en la década de 1970), ofrece algunas dimensiones para analizar la construcción social de la categoría del estudiante y la función de la institución universitaria $^{26}$. En esta tesis, estas cuestiones aparecen referidas al caso de la Universidad Nacional de La Plata.

También se han tomado como referencia los trabajos que examinan distintos aspectos de esta institución y los ámbitos culturales platenses a fines del siglo XIX y principios del $\mathrm{XX}^{27}$, entre los que se destaca los promovidos por Hugo Biagini ${ }^{28}$. En ellos, sin embargo, la enseñanza científica y la actuación de los sectores científicos no han sido estudiadas en profundidad. Este tema, en cambio, fue profusamente analizado en los estudios comparativos de Lewis Pyenson en torno al Instituto de Física y la comunidad científica alemana ${ }^{29}$, utilizados en esta investigación como marco para situar la actuación de los profesores alemanes del Museo de La Plata y sus propuestas para organizar la enseñanza de las ciencias naturales.

\footnotetext{
${ }^{25}$ Halperin Donghi 1962.

${ }^{26}$ Portantiero 1978.

${ }^{27}$ Véase entre otros: AAVV 1963, Paula 1987, Barcia 1992, Christmann 1992. También se han utilizado como referencia los trabajos de Fernando Barba sobre la historia de La Plata y la creación de la Universidad provincial de La Plata. Barba 1972, 1995, 1998, 1999.

${ }^{28}$ Biagini 1997, 1999.

${ }^{29}$ Pyenson 1978, 1984, 1985a, 1985b. Sobre la historia del Instituto de Física existen numerosos trabajos, véase entre otros: Loyarte 1924, Ranea 1994, Ortiz 1995, von Reichenbach et al. 2002. Para el tema de la comunidad científica alemana en La Plata, véase: Ciappa 1987, García y Podgorny 2000.
} 
El trabajo de Osvaldo Graciano sobre las vinculaciones entre la Universidad, la enseñanza agrícola y el Estado se relaciona con algunos aspectos examinados en esta tesis. Graciano se detiene en el perfil de la formación académica de los ingenieros agrónomos en relación con sus inserciones laborales en el ámbito estatal, tema que en esta tesis se refiere a los científicos formados en el Museo de La Plata ${ }^{30}$. En otros trabajos como los de Alejandro Crispiani ${ }^{31}$, Darío Roldán ${ }^{32}$ o Eduardo Zimmermann ${ }^{33}$ se ha relacionado el proyecto universitario de Joaquín V. González con su actuación política anterior a 1906 y sus proyectos reformistas. Ricardo Nassif, por su parte, se ha detenido en sus ideas pedagógicas ${ }^{34}$. Esta tesis se propone ampliar el estudio de estas cuestiones focalizándose en las representaciones sobre las funciones sociales y científicas de la universidad y las prácticas a las que dieron lugar, especialmente aquellas ligadas a las ciencias naturales y al Museo de La Plata.

Vinculado a esto último debo citar los trabajos de Mario Teruggi sobre la historia del Museo de La Plata y las ciencias geológicas ${ }^{35}$, algunos otros textos sobre la historia de las distintas disciplinas practicadas en esta institución ${ }^{36}$; y especialmente los de Irina Podgorny sobre la institucionalización de las ciencias naturales y antropológicas. Esta investigadora promueve un análisis más complejo de estos procesos atendiendo a la interacción de los aspectos cognitivos, instituciones, sociales y las acciones de los individuos así como a las prácticas de divulgación y las representaciones construidas sobre los científicos y la ciencia ${ }^{37}$. En esta tesis se los toma como base y se los enmarca en las líneas de investigación de los trabajos que analizan la relación entre la ciencia y su público y los canales de popularización de los conocimientos científicos ${ }^{38}$. Indudablemente en estrecha relación con ello se deben citar los trabajos internacionales sobre museos y la institucionalización de las

\footnotetext{
${ }^{30}$ Graciano 1998.

${ }^{31}$ Crispiani 1999.

32 Roldán 1993.

33 Zimmermann 1995.

${ }^{34}$ Nassif 1967.

35 Teruggi 1977, 1988. Sobre la historia de la geología en la Argentina a principios del siglo XX, véase también: Pastore 1925, Camacho 2001

${ }^{36}$ Véase entre otros: Cigliano y Palma 1977, Guarrera 1977, Birabén 1961; Hicken 1923; Pascual 1961; Bondesio 1977; Ringuelet 1977; Ricardi 1992, además de los trabajos sobre la historia de la geología antes citados.

${ }^{37}$ Véase entre otros: Podgorny 1994, 1995, 1997, 1999, 2000a, 2002a, 2002b; Farro y Podgorny 1998.

38 Ordoñez y Elena 1990.
} 
ciencias naturales ${ }^{39}$, así como los estudios sobre la organización de las actividades científicas en las universidades latinoamericanas ${ }^{40}$.

Los antecedentes sobre la historia de la divulgación científica y de la extensión universitaria en la Argentina en el período estudiado es un campo hasta ahora poco desarrollado. Entre ellos sobresalen los trabajos de Dora Barrancos sobre las actividades de divulgación científica y educación popular generadas por distintos grupos socialistas y anarquistas ${ }^{41}$. Asimismo, se puede mencionar el trabajo de Omar De Lucia sobre el movimiento librepensador y la extensión universitaria en La Plata $^{42}$. A ello hay que agregar los trabajos sobre la popularización de los saberes médicos y las campañas higienistas de principio del siglo $\mathrm{XX}^{43}$ y sobre las empresas culturales para los sectores populares en el período de entreguerras ${ }^{44}$. Las propuestas de extensión universitaria para la década de 1920, aparecen mencionadas en las historias del movimiento reformista universitario. Sin embargo, la circulación de las ideas y las prácticas de "extensión" y divulgación científica que se desarrollaron en el contexto universitario anterior a la reforma universitaria, no han sido analizadas en profundidad.

En relación con la historia de la enseñanza universitaria de las ciencias naturales en la Argentina, se puede mencionar especialmente el trabajo de Horacio Camacho sobre la enseñanza de estas disciplinas en la Universidad de Buenos Aires $^{45}$. Esta obra, constituye un estudio muy completo sobre el tema y se ha tomado como un referente central ya que permite articular, por un lado, el campo de la historia de la ciencia con la historia de la universidad; y por otro, la relación que se opera en las trasformaciones en la práctica científica y la forma de organizar su enseñanza.

El vínculo entre la historia de la ciencia y de la universidad argentina se encuentra, asimismo, en los estudios de Luis Tognetti sobre los conflictivos intentos de

\footnotetext{
${ }^{39}$ La bibliografía sobre la historia de los museos es bastante abundante, entre los que se relacionan con el tema de esta investigación se puede mencionar: Sheets-Pyenson 1988; Pyenson y Sheets-Pyenson 1999; Kohlstedt 1991; Winsor 1991; Blanckaert et al. 1997; Stearn 1998; Kaplan 1994; Stocking 1985; Limoges 1980; Lopes 1997; Saldaña y Cuevas Cardoña 1999; Safford 1985, Thackrray y Press 2001, Pérez Gollán 1995, Lopes y Podgorny 2000.

${ }^{40}$ Véase entre otros: Bencerra Ardilla y Restrepo Forero 1993; Vessuri 1987, 1994; Mayer y Chazaro 1992; Cueto 1989; Garcíadiego 1999.

${ }^{41}$ Barrancos 1987, 1991,1995,1996.

42 De Lucia 1999.

43 Recalde 1994.

${ }^{44}$ Armus 1990, Gutierrez y Romero 1995.

${ }^{45}$ Camacho 1971.
} 
articulación entre investigación científica y enseñanza superior en la Academia Nacional de Ciencias y la Facultad de Ciencias Físico Matemática de la Universidad de Córdoba durante la década de $1870^{46}$. Junto a ello, se pueden mencionar otros trabajos vinculados a los procesos de institucionalización de ciertas disciplinas o tradiciones científicas dados en el período estudiado en esta tesis. Entre otras, las investigaciones de Diego Pereyra sobre los intentos de consolidar la sociología como disciplina científica y académica a principios del siglo XX y la organización de su enseñanza en esa Universidad ${ }^{47}$; las de Alfonso Buch sobre el desarrollo de la fisiología en la Argentina $^{48}$; y los estudios dirigidos por Carlos Prego sobre la institucionalización de las ciencias biomédicas y la conformación de una "cultura científica del laboratorio". En relación con esto último, en esta tesis se retoma la cuestión señalada por Prego en torno al ciclo de "reproducción ampliada" de la ciencia y las posibilidades de articulación entre la labor pedagógica de formación de profesionales con las conectadas a las actividades científicas y el entrenamiento en investigación ${ }^{49}$. En esta investigación se sigue, además, la propuesta de Jorge Myers, quien propone el concepto de "ámbito de sociabilidad" para estudiar la práctica científica en la universidad $^{50}$. El interés de este concepto para el estudio histórico-cultural radica en la interrelación de cuatro componentes principales: a) el escenario o espacio físico concreto; b) la representación institucional que define ese espacio físico, pero que no debe confundirse con él; c) los sujetos sociales identificados con ese espacio y las relaciones que se establecen entre los grupos de personas que lo ocupan físicamente; d) un imaginario colectivo que reúne espacio, sujeto e institución. De esa forma, el estudio de los modos particulares de sociabilidad implica también atender a su relación con cierta definición institucional y su contexto material y social.

Mencionemos también los trabajos internacionales sobre la historia institucional de la ciencia en la universidad ${ }^{51}$. Uno de los autores más citados en este tipo de estudios es Joseph Ben-David ${ }^{52}$. A partir de la década de 1970, los análisis de este investigador y sus discípulos estimularon la discusión sobre la historia de la

\footnotetext{
46 Tognetti 2000.

${ }^{47}$ Pereyra 1998.

${ }^{48}$ Buch 2000.

49 Prego 1998.

${ }^{50}$ Myers 1992.

${ }^{51}$ Para un panorama general de los estudios sobre las relaciones ciencia-universidad en distintos países puede mencionarse entre otros: Rothblatt y Wittorck 1996, Wittrock y Elzinga 1985; los trabajos de Roger Geiger 1984, 1986 para Estados Unidos y Weisz 1983 para Francia.

52 Ben-David 1971, 1991.
} 
ciencia y la universidad desde la perspectiva del papel social de los científicos; la estructura de la organización científica; los valores e intereses sociales de la ciencia; las condiciones sociales e institucionales y sus efectos sobre la organización del trabajo científico, la profesionalización de la ciencia, la emergencia y difusión de la universidad científica alemana y el fenómeno de los institutos de investigación, entre otros temas. Desde esta perspectiva ya clásica en la historia y la sociología de la ciencia, el proceso de institucionalización de la ciencia aparece asociado al reconocimiento del papel del científico como una actividad pautada y sancionada dentro de un complejo institucional. Las categorías de estudio que se derivaron de esos análisis fueron fructíferas para ayudar a estudiar la institución universitaria y generar nuevas líneas de investigación, a partir de las cuales se produjeron varios debates y revisiones críticas alrededor de algunos supuestos que subyacían a varios de esos estudios. Entre ellos, se pueden señalar el problema de la periodización histórica, la idealización y difusión de los modelos académicos.

En 1971, Ben-David publicó el libro The Scientist's Rol in Society de amplia difusión y en el que se combinaba una perspectiva sociológica, histórica y comparativa para describir la emergencia del papel social de los científicos y la organización del trabajo científico desde el siglo XVII hasta el XX y los desplazamientos en los países que se constituyeron en un momento como centros científicos hegemónicos y modelos internacionales: Italia, Inglaterra, Francia, Alemania y Estados Unidos ${ }^{53}$. De ello se derivó un relato que enfatizó en la organización del sistema universitario alemán y su difusión internacional en la última parte del siglo XIX y primeros años del XX como un hecho significativo en la historiografía de la "ciencia moderna". Pero como Kathryn Olesko advierte para el caso de la historia de la universidad alemana, muchos de esos trabajos frecuentemente mantuvieron implícita una periodización histórica, donde el crecimiento y las reformas graduales se entrelazaban en un relato sobre el "desarrollo" o la "maduración" de la "universidad de investigación". De ese modo, se estructuraba una historia de determinados acontecimientos en función de "etapas de desarrollo" o de una cronología teleológica ${ }^{54}$. Otras críticas han remarcado el relato idealizado del modelo de la universidad alemana, mostrando que gran parte del mismo fue un producto de los escritores prusianos en la última parte del siglo XIX, como forma de propaganda para los otros estados alemanes y para celebrar el crecimiento del prestigio

\footnotetext{
${ }^{53}$ Ben-David 1971

${ }^{54}$ Olesko 1989a.
} 
de la ciencia alemana ${ }^{55}$. Con respecto a esto último, Pyenson ha mostrado las estrechas relaciones entre los investigadores en ciencias exactas y la institucionalización de esas disciplinas en centros no europeos, como en el caso de La Plata; y la difusión de los modelos de científicos-educativos alemanes como parte de la política de "imperialismo cultural" sustentado por el Gobierno prusiano ${ }^{56}$. Asimismo, la imagen de la universidad alemana como una institución dedicada a la investigación "desinteresada" en ciencia pura, ha sido contrabalanceada por estudios históricos que muestran la importancia continua de la enseñanza y la formación de profesionales en las agendas de esas universidades o las relaciones entre los científicos y los intereses económicos y políticos del Estado ${ }^{57}$.

Por otro lado, nuevas investigaciones han comenzado a mostrar el papel de los sectores extracadémicos en el apoyo de las disciplinas académicas. Entre ello se puede mencionar el trabajo Kathryn Olenko, donde examina la organización de la enseñanza secundaria de las ciencias exactas y su repercusión en el desarrollo universitario de esas disciplinas ${ }^{58}$. En general, las vinculaciones de las instituciones universitarias con el sistema general de instrucción pública no han sido trabajadas en la historiografía de las universidades. Sin embargo, en el caso del sistema universitario francés, Weisz ha argumentado que un punto importante para el fortalecimiento de las Facultades de letras y ciencias a fines del siglo XIX se vinculó con las redes que se extendieron con la profesión docente a través de la imposición de un período obligatorio de estudio para los futuros profesores de enseñanza secundaria, con lo cual se podía reclutar estudiantes y extender la influencia de esas disciplinas. Asimismo, este investigador examina la reforma de las universidades francesas producida en esa época, atendiendo a la organización de las profesiones académicas, la creación de nuevas carreras y el desarrollo económico, las investigaciones y publicaciones científicas y la función política de la universidad en relación con la extensión universitaria, las organizaciones estudiantiles y la capacitación de maestros. Este trabajo ha resultado doblemente pertinente e inspirador para esta investigación, a raíz del tipo de tratamiento dado a la serie de proyectos e ideas que circularon ampliamente en el contexto argentino, en una

\footnotetext{
55 Nyhart 1995, 1998.

${ }^{56}$ Pyenson 1985a.

${ }^{57}$ Para una revisión crítica de la historiografía sobre la universidad y la ciencia alemana, véase entre otros: Albisetti et al. 1989.

${ }^{58}$ Olenko 1989b.
} 
época en la que Francia todavía constituía una referencia ineludible para el mundo intelectual rioplatense ${ }^{59}$.

Para concluir, en las últimas décadas, los estudios de la ciencia en América Latina, especialmente como los promovidos por la Sociedad Latino-Americana de Historia de la Ciencia y la Tecnología, fomentaron una nueva dirección historiográfica, cuyo objeto central ha sido la especificidad de la ciencia en las regiones no europeas, criticando al mismo tiempo la idea de difusión unilineal y la imagen de las comunidades locales como meros agentes pasivos del trasplante europeo - y posteriormente norteamericano- de la ciencia. Al mismo tiempo, se comenzó a prestar mayor atención a la comprensión de las particularidades de los procesos de institucionalización y profesionalización de la actividad científica en los contextos locales específicos sin perder de vista los procesos de mundialización de las prácticas científicas $^{60}$. Junto a ello se problematizarían otros temas como: la ciencia y la construcción de la identidad nacional, el papel de los modelos institucionales extranjeros, la ciencia "útil” y la ideología positivista; la actividad de los científicos locales y sus "roles" profesionales, la construcción de tradiciones científicas locales y las posibilidades de excelencia científica en la periferia, las organización de instituciones científicas y la enseñanza.

Estos nuevos enfoques se relacionan con los estudios sociales y culturales de la ciencia, que procuran entender la "ciencia" como algo más que un conjunto de conocimientos o teorías, para considerarla esencialmente como un conjunto de prácticas sociales, intelectuales y culturales que se organizan en determinados contextos $^{61}$. En este sentido, se asume que existe una relación inseparable y constante entre contexto y contenido, que muchas veces se manifiesta en la forma de acciones concretas de negociación, propaganda y difusión de investigaciones científicas, intereses profesionales e institucionales, en los apoyos políticos y la sustentación a actividades científicas. Por otra parte, como ha señalado Silvia Figueirôa, la consolidación de la actividad científica en un determinado espacio y tiempo, constituye un proceso en el que se establece una red de sustentación de las actividades cuyos elementos más visibles son las llamadas instituciones científicas, pero en el que

\footnotetext{
${ }^{59}$ Vinculado con estos temas se pueden mencionar los trabajos ya citados de F. Ringer sobre la "cultura académica" francesa y alemana y los valores culturales sostenidos por los mandarines académicos alemanes de las disciplinas humanísticas.

${ }^{60}$ Lafuente et al. 1993, Figueirôa 1998, Lopes 1999.

${ }^{61}$ Latour 1992, Jardine et al. 1996.
} 
también intervienen la comunidad científica y actores sociales que se ubican en espacios no académicos, los diferentes apoyos sociales y políticos, los intereses estatales y de particulares ${ }^{62}$. Asimismo, al igual que en otros "campos" de la actividad humana, en las instituciones científicas se ponen en juego competencias, jerarquías y conflictos de poder que en cierto modo condicionan los métodos de trabajo, el perfil de ciencia a desarrollar, la producción de conocimiento, los modos de transferencia y la difusión de la información ${ }^{63}$. El contenido de lo que se investiga, publica y difunde refleja en cierto sentido esas coerciones pero también el grado de libertad e intereses de los científicos dentro de marcos institucionales específicos. En ese sentido, se considera necesario incluir las "prácticas" dentro del complejo relacional de actividades situadas social y materialmente antes que como tareas de agentes separados de sus localizaciones institucionales. 
Parte 1:

\section{$\underline{\text { La función social y el perfil científico }}$ de la Universidad}




\title{
Capítulo I
}

\section{La "cuestión universitaria" en la transición del siglo XIX al XX}

\begin{abstract}
"...la creación de nuevos institutos universitarios debe aprovecharse como una ocasión para plantear...y resolver de una manera fundamental la cuestión universitaria. Si el espiritu actual es malo, es un error darle pábulo con nuevas universidades, lo lógico es propender á que los institutos que se forman se emancipen de aquel, inspirándose en un espiritu nuevo y mejor"1.
\end{abstract}

A fines del siglo XIX se manifestó un cierto malestar general hacia la organización y las funciones que desempeñaban las universidades nacionales. A ello se sumarían los conflictos estudiantiles que se suscitaron en la Universidad de Buenos Aires en los primeros años de nuevo siglo, que hicieron de la "cuestión universitaria" un tema de actualidad dentro de la escena pública argentina ${ }^{2}$. En la década de 1890, el crecimiento de la matriculación estudiantil y el incremento significativo de los que alcanzaban el título de doctor, sobre todo en los estudios jurídicos, fue visto como una situación preocupante por sectores de la clase dirigente. Para algunos, la desconfianza hacia esa nueva situación formaba parte de una inquietud más general por los problemas derivados la "masificación" y la perdida de la propia escala de valores culturales frente al ascenso social de nuevos sectores, el fenómeno inmigratorio y el "utilitarismo"3. Para otros, el crecimiento estudiantil parecía no acompañarse con la responsabilidad que debían asumir los jóvenes universitarios en la vida pública. Junto a ello aparecía la pregunta por el tipo de educación más adecuada para formar las futuras clases dirigentes. La circulación de informes de educación superior comparada, las experiencias personales que traían los que habían pasado una estadía en el exterior y la lectura de las propuestas de reformadores académicos europeos proveyeron un marco para la comparación con instituciones similares de otras partes del mundo. Desde esa mirada, la institución universitaria argentina no parecía cumplir con las "misiones" que le correspondía asumir en la conformación de la cultura

\footnotetext{
${ }^{1}$ Comentario del diputado salteño Idalecio Gómez al debatirse la nacionalización de los títulos expedidos por la Universidad provincial de La Plata. Diario de Sesiones de la Cámara de Diputados de la Nación, 1897, I: 844.

${ }^{2}$ Halperin Donghi 1962.
} 
nacional. Muchos coincidieron en la necesidad de buscar mecanismos más efectivos para reforzar la acción docente y científica de la institución universitaria. Sin embargo, como ha sostenido Halperin Donghi el descontento hacia el sistema de educación superior no se manifestó en una clara representación de lo que la universidad debía ser sino más bien en la convicción de que ella no era lo que debía y, además, parecía no acompañar el progreso y los cambios que experimentaba el país ${ }^{4}$.

En medio de los conflictos irresueltos de la Universidad porteña, el Ministro de Justicia e Instrucción Pública, Joaquín V. González acordó en 1905 un convenio con la Provincia de Buenos Aires para crear una Universidad Nacional en la ciudad de La Plata, que respondería a un nuevo modelo de institución universitaria. Esta propuesta se justificó a partir de la situación crítica que atravesaban los centros científicos y educativos de esa ciudad, y también como una forma de experimentación y renovación de las soluciones hasta ese momento adoptadas con relación a la "cuestión universitaria". En este primer capítulo se busca contextualizar la emergencia de este proyecto a partir del clima de ideas con respecto al funcionamiento de las universidades argentinas. Para ello se examinaron los debates parlamentarios surgidos por la nacionalización de los diplomas de las casas de estudio provinciales y las propuestas de reforma universitaria que se suscitaron en la transición del siglo XIX al $\mathrm{XX}$. Asimismo, en la última parte de este capítulo se analiza la situación de la Universidad provincial de La Plata y los problemas derivados de la falta de reconocimiento oficial de los estudios que certificaba. Esto último también afectaría a la Facultad de Agronomía y Veterinaria de La Plata, que funcionaba de forma independiente a la Universidad. En ambos casos, el problema de los títulos generaría la movilización de grupos de estudiantes, profesionales y otros sectores locales en pro de la legitimación de los diplomas para el ejercicio profesional en el ámbito nacional. Luego, los reclamos se desplazarían hacia la nacionalización de esas instituciones provinciales de educación superior.

\section{$\underline{\text { I.1. El perfil profesional de las universidades argentinas }}$}

\footnotetext{
${ }^{3}$ Romero 1987; Terán 2000.

${ }^{4}$ Halperin Donghi 1962 .
} 
Hasta el siglo XX, Argentina contó con dos universidades nacionales: la de Córdoba, establecida durante la época colonial y nacionalizada en $1854^{5}$, y la de Buenos Aires, creada en 1821 y puesta bajo jurisdicción nacional en 1881, después de federalizarse la ciudad ${ }^{6}$. A fines de 1889 , en las dos provincias económicamente más importantes de la Argentina se sancionaron proyectos para el establecimiento de una universidad. En Santa Fé, el gobernador Galvez impulsó la organización de un centro de estudios superiores en la capital de la Provincia como parte de las propuestas de desarrollo y modernización provincial ${ }^{7}$. En los mismos meses, la Legislatura de la Provincia de Buenos Aires aprobaba de forma separada dos proyectos de ley: uno destinado a crear una Universidad, promovido por algunos sectores políticos e intelectuales de la Provincia; y otro, presentado por el Poder Ejecutivo para organizar una Facultad de Agronomía y Veterinaria en La Plata a partir del traslado del Instituto de Agronomía y Veterinaria de Santa Catalina, fundado en $1883^{8}$. Parte de este último proyecto se concretó al año siguiente, aunque con pocos recursos y una situación bastante inestable. En cambio, el primer proyecto se lograría materializar siete años después. El desarrollo de estas instituciones provinciales se vio condicionado no sólo por las reiteradas crisis político-institucionales y la inestabilidad económica

\footnotetext{
${ }^{5}$ Miranda 1993.

${ }^{6}$ Halperin Donghi 1962.

${ }^{7}$ El 16 de octubre de 1889 la legislatura de la Provincia de Santa Fé aprobó una ley para la creación de la Universidad de Santa Fé. El mismo día, esa ley fue sancionada por Gobernador José Galvez, quien se constituyó en el primer rector de la nueva casa de estudios. Sin bien se proyectaron los estudios de derecho y ciencias sociales; ciencias físico-matemáticas y una Facultad de teología, sólo los primeros comenzarían a funcionar. Al mismo tiempo se establecieron becas para que algunos jóvenes fueran a estudiar al Instituto de Agronomía y Veterinaria de la Provincia de Buenos Aires. La crisis financiera de 1889/90 dificultó el establecimiento de todas las Facultades programadas y posteriormente, las crisis políticas y los levantamientos radicales que se sucedieron en esa Provincia también repercutirían en el funcionamiento de esa casa de estudios. Además, al igual que la Universidad de La Plata debió enfrentase al problema de la nacionalización de los títulos para el ejercicio de las profesiones en el ámbito de todo el territorio nacional. De Marco 1998. Sobre los decretos de fundación de esa Universidad, véase entre otros: Castiñeiras 1985.

${ }^{8}$ El Instituto de Agronomía y Veterinaria en Santa Catalina fue creado en 1883 durante la gobernación de Dardo Rocha y el apoyo de la Sociedad Rural Argentina, con la finalidad de impulsar la educación en temas agrícolas-ganaderos y la experimentación en el refinamiento de ganado. Para conformar el cuerpo docente y la organización de estos estudios se contrataron egresados y profesores belgas de la Escuela de Medicina y Veterinaria del Estado y del Instituto Agronómico de Glembloux, Bélgica. El primer director del Instituto fue el hacendado y ministro de hacienda de Rocha, Mariano Demaría hasta 1888, cuando viaja a Europa. Fue reemplazado por Emilio Duportal, pero a los seis meses el Gobernador Paz decide que la Provincia no financiará más este Instituto y para ello promueve un proyecto para proveerle de rentas propias y trasladarlo a La Plata. La ley del 12 de noviembre de 1889 autorizaba el remate de los terrenos de Santa Catalina e invertir una parte en la construcción de un edificio para la Facultad en La Plata y también la compra de Títulos de la Provincia para proveerle de rentas propias. Finalmente la venta no se llevó a cabo por la depreciación del valor de la tierra que se produjo con la crisis de 1890, aunque se hipotecó ese establecimiento para llevar a cabo la construcción de edificios para la nueva Facultad.
} 
provincial, sino también por la falta de validez nacional de los certificados y títulos que otorgaba.

En esa época, las universidades argentinas se habían consolidado como centros de formación profesional, avanzando paulatinamente sobre el control "cognitivo" para el ejercicio de las profesiones liberales y "eruditas" ${ }^{9}$. Esto se dio de forma paralela a la consolidación y la centralización de funciones del Estado nacional, con el consecuente aumento y complejización de su aparato administrativo. Como parte de ese proceso, los "expertos" fueron reclamando cada vez más por la especificidad de su actividad y la autoridad "científica" para el diseño de las políticas públicas. En ese movimiento, la universidad estatal pasaría a ocupar un papel central en la legitimación de los "saberes científicos" de las profesiones así como en el control de los procedimientos educacionales y los mecanismos de iniciación para acceder al mercado ocupacional, vinculado especialmente a la esfera estatal. De esa forma, el sistema universitario nacional se consolidó a partir de su reconocimiento como la instancia oficial que fijaba las condiciones de idoneidad para otorgar los diplomas de competencia y habilitación para el ejercicio laboral de las profesiones que afectaban los "intereses" del Estado. En el marco de esa función y especialmente al lograr mantener ese monopolio, se generaron las condiciones para reafirmar una estructura universitaria cada vez más sólida y con un número creciente de alumnos. Al iniciarse el siglo XX, cumplir con las pautas y aprobar los exámenes exigidos por la Universidad estatal se

\footnotetext{
${ }^{9}$ Hasta la década de 1870 los estudios de derecho que ofrecía la Universidad sólo permitían el acceso a un diploma académico que no habilitaba para el ejercicio profesional. Para ello era necesario ingresar a la Academia de Jurisprudencia y rendir examen en el Superior Tribunal de Justicia. Bushbinder 2000. Para un análisis de estas cuestiones en relación con la profesionalización de la medicina y las ocupaciones relacionadas al área de salud, véase los trabajos de González Leandri 1997, 1999, 2000. El avance de la Universidad sobre el control profesional, se evidencia claramente en el caso de la Universidad de La Plata y los diplomas que otorgaban ciertas reparticiones públicas. Antes de la creación de esta casa de estudios, los diplomas de agrimensor eran otorgados por el Departamento de Ingenieros de la Provincia. Posteriormente estos títulos debieron ser revalidados por la Universidad, que pasó a ocupar una posición hegemónica en el otorgamiento de los mismos. También esta institución disputó su autoridad para fiscalizar los certificados y exámenes para el ejerció de otras profesiones en el ámbito provincial, como en el caso de los certificados de idóneos y auxiliares de farmacia que otorgaba el Departamento de Higiene o los de procurador que estaban bajo el control de la Corte de Justicia. Los reclamos de los sectores universitarios intentaban legitimar la competencia de sus Facultades para dictar los programas, recibir los exámenes y conceder los diplomas. En el caso de la práctica farmacéutica, una ley nacional de 1905 reglamentó que para el ejercicio de esa profesión o para abrir nuevas farmacias se necesitaba contar con un título otorgado por una universidad nacional, concediendo desde ese momento cuatro años para que los "idóneos" regularizaran su situación. En menor medida, el control sobre la distribución de estos certificados y diplomas también implicaba una fuente de ingreso significativa. Según calculaban los estudiantes platenses, con los aranceles que se cobraban por esos diplomas se podrían cubrir los gastos de mantenimiento de la Institución, por lo menos en sus tres cuartas partes. Anónimo 1902. En el caso de los exámenes libres o de reválida, la práctica común en
} 
volvió un requisito imprescindible para obtener un título habilitante en la mayoría de las carreras profesionales ${ }^{10}$. En la Argentina, a diferencia de la mayoría de los países europeos, la autoridad en la certificación y verificación del saber alcanzado por un individuo dentro del territorio para el ejercicio profesional, no se desdobló entre una instancia estatal (Examen de Estado) - o de los profesionales en ejercicio como en Inglaterra- y otra académica, sino que ello se concentró en la universidad pública como dependencia oficial del Estado ${ }^{11}$.

En el imaginario popular el acceso a los estudios superiores y la obtención del título de "doctor" era mirado como una de las vías para ascender socialmente e ingresar a los círculos cerrados de la clase dirigente, como se manifestó en la literatura en obras como M'hijo el doctor de Florencio Sánchez o el relato "La oligarquía universitaria" (1906) de Emilio Becher. La presión y aspiraciones de muchos argentinos de primera generación así como de los miembros de las elites provinciales por acceder a un título universitario generaron un aumento de la matriculación en estas instituciones, lo que paulatinamente iría produciendo una modificación en la composición social y origen del alumnado. Las credenciales universitarias permitían ejercer un amplio rango de actividades, desde la práctica profesional independiente hasta la integración de los distintos aparatos de gobierno y la docencia secundaria. Al mismo tiempo, las carreras universitarias como derecho y medicina, parecieron haber constituido un canal de reclutamiento del personal administrativo y político y un paso exigido en la trayectoria de muchos políticos ${ }^{12}$. En general, los criterios predominantes en la elección de las carreras universitarias parecieron reproducir la posición y el prestigio social que proveía el título de doctor en abogacía o medicina. De hecho, hacia 1898 el número de estudiantes matriculados en esas Facultades alcanzaba el $88 \%$ del sistema universitario argentino ${ }^{13}$. Los estudios de derecho, además, contaban con una cantidad de alumnos libres similar a la de los regulares y por otra parte, era una carrera más barata y corta que medicina o ingeniería. El régimen de asistencia libre ofrecía la oportunidad de rendir los exámenes finales en todas las materias y obtener un diploma sin necesidad de asistir a las conferencias de

aquellos años era que el $50 \%$ de lo recaudado se repartiera entre los miembros de las mesas examinadoras, mientras el resto pasaba a formar parte del fondo universitario.

10 Buchbinder 2000.

11 Sobre estas cuestiones desde una perspectiva comparada, véase entre otros: Torstendahl 1996, Burrage 1996; Neave 2001.

12 Zimmermann 1995.

13 Tedesco 1986. 
los profesores. El número de estudiantes y la participación de los académicos de las Facultades de Medicina y Derecho en el ámbito parlamentario y las distintas dependencias gubernamentales, impulsaron un proceso de jerarquización de las distintas carreras dentro del ámbito universitario, que se expresó en la mayor proporción de recursos presupuestarios, número de cátedras y en los diplomas de los rectores de las universidades hasta la década de 1920. En cambio, los estudios científicos no lograban atraer alumnos ni generar una situación estable para sus docentes pese a los esfuerzos por contratar profesores extranjeros, organizar instituciones y crear esas carreras en el último cuarto del siglo $\mathrm{XIX}^{14}$. En ese sentido, las acusaciones por el predominio de las carreras profesionales que se le ha atribuido a la institución universitaria argentina deben ser revisadas no sólo en relación con la oferta educativa sino en función de la estructuración del mercado ocupacional y el interés estudiantil por las distintas carreras universitarias.

El incremento general del número de alumnos en el sistema universitario $\operatorname{argentino~}^{15}$, fenómeno asociado a una "doctormanía" y el fácil acceso a los títulos universitarios, provocó un cierto malestar entre algunos sectores de la clase dirigente a fines del siglo XIX. En parte, ello se enmarcaba en una desconfianza hacia la masificación y la perdida de la propia escala de valores culturales y sociales frente al fenómeno inmigratorio y la emergencia nuevos sectores sociales que comenzaban a disputar los símbolos de prestigio y distinción de la élite dirigente, erosionando las diferencias sociales ${ }^{16}$. Para otros, el crecimiento estudiantil no se acompañaba con la responsabilidad social que debían asumir los jóvenes de acuerdo a su posición como universitarios y ni con la consolidación de las asociaciones y actividades propias de la vida estudiantil como se observaba en las universidades europeas y norteamericanas ${ }^{17}$.

\footnotetext{
${ }^{14}$ Sobre la organización de la educación científica universitaria en ciencias naturales y exactas, véase entre otros: Babini 1949, 1963; Camacho 1971; Montserrat 1993; Myers 1992,1994, Tognetti 2000. Estadísticas de alumnos y su distribución por carrera en las Facultades de Ciencias Exactas de Buenos Aires y Córdoba se encuentra en Besio Moreno 1915.

${ }^{15}$ En esos años la Universidad de Buenos Aires experimentó un rápido crecimiento del número de alumnos: de 715 que se mencionaban en1888, diez años después contaba con 2.665 estudiantes. En los años siguientes continuaría aumentando. A ello se sumaría la creación de las universidades provinciales.

${ }^{16}$ No faltaron comentarios como el de Héctor Perdiel, abogado y miembro de la Corte Suprema de Justicia de la Provincia de Buenos Aires, que denunciaban que "merced á ese título [de doctor] las diferencias sociales se borran como por arte de encantamiento. Gracias á el, el hijo de nuestro zapatero, del almacenero de la esquina, y el del político ó estadista, se hallan al mismo nivel social " Perdiel 1903: 11.

${ }^{17}$ A principios de la década de 1890, Ernesto Quesada, un crítico observador que comparaba la situación de las universidades argentinas con sus pares en Alemania y Francia, concluía que: "las universidades argentinas carecen de vida académica, fuera de las Facultades, de los profesores y de
} 
Según Hobsbawm, ante el crecimiento del número de estudiantes universitarios tanto en Europa como en Estados Unidos - que se triplicó en la última parte del siglo XIXfue preciso definir la elite efectiva en el seno del conjunto cada vez mayor de aquellos que poseían el pasaporte educacional exigido. En ese proceso, las fraternidades de los Colleges norteamericanos, los Korps estudiantiles alemanes o las asociaciones de antiguos alumnos representaron un papel fundamental como espacios de sociabilidad y de conformación de una identidad social, lo cual permitiría establecer redes más eficaces de interacción inter e intrageneracional ${ }^{18}$.

Durante las décadas de 1880 y 1890 varios países europeos experimentaron un gran aumento en la matriculación universitaria ${ }^{19}$. Esta situación fue percibida como una crisis de "sobreproducción" o "exceso" de graduados en relación con las oportunidades deseables de empleo para ellos. Especialmente en Alemania se acuñó el término de "proletariado académico", que también sería muy utilizado en Francia hacia el final del siglo. Muchos de los observadores contemporáneos miraron ese desequilibrio como algo socialmente disfuncional y peligroso. En particular, los temores se dirigieron hacia la sobreeducación de los jóvenes de los sectores más humildes que podría volverlos un elemento improductivo y subversivo para la sociedad $^{20}$. En el caso de Alemania, ello también se relacionaba con la percepción que tenían los académicos humanistas de que la educación universitaria estaba perdiendo algo de su influencia y vitalidad. La idea de crisis o decadencia cultural renovó las exigencias para volver a examinar los métodos y propósitos de la enseñanza superior, tema que se mantendría presente durante las siguientes décadas ${ }^{21}$. También un grupo de reformadores académicos franceses en los inicios de la Tercera República,

los empleados, los estudiantes son apenas considerados....Los estudiantes argentinos no son estudiantes, sino que; o son empleados, ò viven de la vida común del resto de la juventud....No hay vinculo de unión ninguno y apenas se conocen." Quesada 1893: 86. Como excepción señalaba los alumnos de la Facultad de Medicina de Buenos Aires que habían formado el Círculo Médico Argentino y los de ingeniería que intentaban conformar una asociación propia. Una observación parecida se encuentra en: Cárcano 1892. La falta de "verdaderos estudiantes" seguiría siendo un tópico presente en las observaciones críticas y comparaciones de varios profesores universitarios durante la siguiente década.

${ }^{18}$ Hobsbawm y Ranger 1983; Hobsbawm 1998. Los signos de exclusivismo social se manifestarían, por ejemplo, en las prestigiosas fraternidades norteamericanas que adoptaban nombres del alfabeto griego. También dentro del amplio conjunto de estudiantes alemanes, existían grupos más exclusivos como los "kösener Korp", caracterizados por ser aficionados a la cerveza y tener cicatrices como resultado de los duelos con espadas. Esto último proveía de una marca de distinción con respecto a los estamentos inferiores, ya que demostraba que eran caballeros y no plebeyos. Si bien para principios del siglo XX, el duelo había sido prohibido por ley, su práctica se mantenía relacionada al honor del estudiante y la corporación a la que pertenecía. Demaría 1902.

${ }^{19}$ Hobsbawm 1998.

${ }^{20}$ Ringer 1994. 
promovió la renovación de sus instituciones de educación superior a partir de un estudio comparado de las experiencias universitarias de distintos países ${ }^{22}$. Los resultados de esas observaciones y los informes de educación comparada que se publicaron en París tuvieron una amplia circulación internacional a partir de la década de 1890, especialmente las obras y revistas de educación superior editadas por la casa Armand Colin. En Argentina, esa bibliografía junto a las experiencias que traían los profesores que habían perfeccionados sus estudios en el extranjero se utilizaría como una referencia para analizar el funcionamiento institucional y las modalidades de enseñanza superior.

En la última parte del siglo XIX, la opinión pública y personajes influyentes de la vida política, entre los que no faltó el comentario del presidente Julio A. Roca ${ }^{23}$, expresaron una cierta preocupación por la gran cantidad de doctores, especialmente abogados que estaban produciendo las universidades argentinas y que tendían a engrosar la administración pública ${ }^{24}$. De hecho, los datos del censo de 1895 mostraron un gran crecimiento de este sector y también el predominio de abogados entre los profesionales con diploma universitario nacional. En relación con ello, los proyectos para reorganizar la enseñanza secundaria que impulsaron varios ministros durante

\footnotetext{
${ }^{21}$ Ringer 1995.

22 Weisz 1983.

${ }^{23}$ Roca opinó sobre esta cuestión en la mayoría de sus discursos presidenciales. En 1884, por ejemplo, señaló que: "el estado de nuestras universidades responde a nuestros medios y sobrepasa nuestras exigencias. Sería de desear tal vez que estos establecimientos no fueran tan concurridos, para evitar el aumento ya alarmante de los jóvenes que se dedican a carreras parásitas, cuando tantos necesitamos inteligencias y brazos productores" en: Roca 1941, I: 135. En 1902 agregó: "Nuestras universidades que llamaré clásicas por su antigüedad y por el espíritu que en ellas domina, continuaran ejerciendo su influencia en la cultura nacional y suministrando año a año a la República los hombres preparados para las altas profesiones liberales.....La de Buenos Aires tuvo una concurrencia, que ya recuerda a las más populosas de Europa y Estados Unidos, de 3562 estudiantes, y la de Córdoba de 288. Si las facultades no consiguen establecer un régimen de estrictez y severidad inflexible en los exámenes, en la disciplina interna y en la enseñanza en sí misma, tales cifras constituirán en lugar de una halagüeña promesa un grave peligro para la sociedad y las instituciones argentinas, porque en vez de hombres útiles y ejemplares ofrecerán sólo postulantes de empleos oficiales, charlatanes en todas las ciencias e incapaces para la noble lucha de trabajo y de la vida cívica". Ibíd.: 278-279.

24 Así, por ejemplo en una nota titulada "Basta de Abogados" publicada en la Revista de La Facultad de Agronomía y Veterinaria de La Plata se criticaba el exceso de abogados que se habían graduado en la Universidad de Buenos Aires en esos días, apelándose a la jerarquía de saberes de Comte : "como si no fueran bastante los que existen ya en el país, la Facultad de Derecho ha otorgado recientemente diploma á setenta doctores mas, quienes buscarán cómoda ubicación en los presupuestos nacionales y provinciales...lejos de creer que el país gane con tener mas abogados, hay que ver en el predominio de estos una de las causas y manifestaciones de nuestro atraso. Como lo ha dicho Comte, el influjo político de los abogados es propio de una época de transición é incoherencia, en que puede momentáneamente primar el brillo del estilo por sobre el pensamiento, la retórica sobre la ciencia. En la materia de instrucción superior lo que el país necesita no son más jurisconsultos y legistas, sinó buenos profesores de matemáticas, física, gimnasia y biología, agrónomos y veterinarios, ingenieros, médicos, hombres competentes en todas las grandes ramas de la técnica." Anónimo 1896: 223-224.
} 
aquellos años pusieron de manifiesto el interés del gobierno por imprimir a la instrucción pública una orientación más técnica y práctica y/o establecer una segmentación de estos estudios en los últimos años. Por medio de una reforma en el nivel medio del sistema educativo se esperaba incentivar nuevas ocupaciones y el desarrollo de actividades industriales, comerciales y agropecuarias. Por otra parte, como ha señalado Tedesco, la diversificación de los estudios permitía abrir otras vías para canalizar las demandas educativas de los sectores sociales en ascenso, y mantener el monopolio de la élite universitaria sobre la preparación para la vida política ${ }^{25}$.

El aumento de la población universitaria y su repercusión sobre el crecimiento de la burocracia estatal y la "emplomanía" fue un tema presente en los debates parlamentarios por la nacionalización de los títulos de las Universidades provinciales desde 1897. Algunos senadores defendieron estos proyectos como una forma de descentralizar la educación superior que se concentraba en la Capital Federal y que provocaba un gasto público importante, ya que generalmente los estudiantes del interior eran becados o empleados para financiar su estadía en la metrópolis. En la Cámara de Diputados, algunos legisladores señalaron que el problema de los numerosos "parásitos estatales" no estaba en el gran número de estudiantes universitarios sino en la organización de las universidades, en los planes de estudio y el carácter que se le daba a la enseñanza ${ }^{26}$. Esto suscitó algunos debates y reflexiones sobre el régimen de las universidades argentinas que desembocaron en la idea de proyectar una reforma general de la organización institucional de las mismas. Si bien esto se venía manifestando entre los académicos y otros sectores universitarios de Buenos Aires desde hacia unos años, la necesidad de reorganización de las casas de estudios superiores cobró mayor importancia cuando el gobierno sugirió recortes en el presupuesto universitario de 1898, como parte de las economías para costear los preparativos bélicos por el conflicto con Chile. La vulnerabilidad de la universidad estatal, derivada de su dependencia económica, generó una serie de propuestas para reformar el régimen de estas instituciones. Esos proyectos apuntaron a lograr una

\footnotetext{
25 Tedesco 1986.

${ }^{26}$ El diputado cordobés Juan Alvarez defendió la nacionalización de los títulos de las Universidades provinciales, señalando que el problema de los "parásitos estatales" no estaba en el gran número de estudiantes universitarios sino en el carácter de la enseñanza que brindaban las universidades. En ese sentido, indicaba que estas instituciones tenían la función de formar las clases dirigentes y para ello era necesario: "inculcar en el alumno universitario ...que por el solo hecho de haber adquirido mayores conocimientos, es más responsable ante la sociedad, tiene mayores obligaciones.....me parece, señor, que los alumnos universitarios no se penetran perfectamente bien del papel que están llamados á
} 
mayor "autonomía universitaria" y se presentaron como una renovación de la ley Avellaneda que regía sobre las casas de estudios nacionales.

La ley $\mathrm{n}^{\circ} 1597$, sancionada en 1885 a partir de un proyecto presentado por el senador y rector de la Universidad de Buenos Aires, Nicolás Avellaneda, fue la primera ley universitaria nacional ${ }^{27}$. Por medio de ella se estableció un marco de homogeneidad jurídica para las dos universidades existentes como instituciones estatales, que reafirmaba la supervisión del Estado nacional en cuanto a planes de estudios, selección docente y aspectos económicos. No obstante, ese dispositivo legal contenía sólo cuatro artículos de carácter general que permitía a las universidades nacionales disponer de un amplio margen para ajustar sus estatutos y los aspectos más detallados de su administración. De hecho, estas instituciones pudieron reformar sus estatutos, renovarse y reorganizar todo su gobierno interno sin necesidad de modificar esta ley que estuvo vigente hasta 1947 y luego restaurada en 1956, aunque de forma más bien simbólica ${ }^{28}$. En la propuesta original de Avellaneda se había reafirmado la idea de una unidad universitaria, la designación de profesores por oposición, la existencia de "docentes libres" y la constitución de un fondo universitario integrado por una parte de lo recaudado sobre los aranceles estudiantiles. Además, se contemplaba que en la composición de las Facultades - entendidas como consejos académicos o directivos, también llamadas Academias- hubiera una cierta participación de los profesores que dirigían aulas, al menos en una tercera parte. En esa época, la condición de profesor no implicaba ser miembro de la corporación universitaria ni participar en el gobierno de la misma. El tratamiento del proyecto de ley de Avellaneda en el Congreso originó algunos debates en torno a este último punto y la selección de profesores, que pusieron de manifiesto una desconfianza hacia la capacidad del personal docente para gobernar la institución ${ }^{29}$. Finalmente, se resolvió permitir como límite máximo que los docentes ocuparan hasta una tercera parte de las Academias. Al mismo tiempo se estableció que los profesores serían designados por el Poder Ejecutivo a partir de una terna presentada por las Facultades y aprobada por el Consejo Superior, y no mediante el sistema de concursos. Uno de los argumentos de

desempeñar en la sociedad". Diario de Sesiones de la Cámara de Diputados de la Nación, 1897, I: 842-843.

${ }^{27}$ Para las discusiones en torno a la sanción de esta Ley y comentarios a sus artículos, véase Rodríguez Bustamente 1985.

${ }^{28}$ Sobre las distintas leyes universitarias en la Argentina, véase: Mignone 1999, Hurtado de Mendoza y Busala 2002.

${ }^{29}$ Halperin Donghi 1962. 
peso para defender el control del Gobierno se vinculaba la cuestión de la dependencia económica que mantenían las universidades con respecto del Estado, tema que volvería a aparecer en los proyectos universitarios presentados en los últimos años del siglo.

En esa época, también se fueron multiplicando las voces que denunciaban la necesidad de organizar investigaciones originales y difundir un "espíritu crítico" o “científico". Varios académicos insistían en que la Universidad debía asumir un papel central para resolver los problemas sociales y el desarrollo económico del país a partir de estudios de carácter científico. Durante los siguientes años el debate intelectual estaría impregnado por una fe en los logros de la ciencia y en la posibilidad de aplicar su método al análisis de la sociedad y como guía de las políticas estatales ${ }^{30}$. En cuanto a la llamada "invasión de profesionales", los diferentes sectores académicos parecieron coincidir en que el crecimiento estudiantil no debía resolverse a partir de un incremento de los aranceles, es decir, con restricciones de carácter económico, sino a través del mejoramiento de la enseñanza, la intensificación de las pruebas de aptitud y el estímulo al trabajo personal. En ese sentido, reforzar la función educativa de la Universidad aparecía como la solución para lograr una selección más cuidadosa y "meritocrática"31. Paralelamente, se manifestaría una preocupación por la formación de una clase dirigente ilustrada y educada para la vida pública como parte de las aspiraciones de regeneración espiritual y transformación de las instituciones y hábitos políticos del país, en el clima ideológico del fin del siècle.

\section{2. Los proyectos de reforma universitaria}

A mediados de 1898, el diputado y académico de la Facultad de Medicina de Buenos Aires, Elíseo Cantón, presentó en el Congreso un proyecto de ley para la reorganización del régimen universitario. Esta propuesta también contó con la firma de otros legisladores y se presentó como una forma de alcanzar una mayor "autonomía

\footnotetext{
${ }^{30}$ Botana y Gallo 1993; Zimmermann 1995. Algunos autores han calificado esas actitudes como "cientificista" o como parte del heterogéneo movimiento "positivista". Véase entre otros: Soler 1968; Biagini 1985; Terán 1987, 2000.

${ }^{31}$ Véase, por ejemplo: Madrid 1901.
} 
universitaria"32. Sin embargo, no se introducían demasiadas innovaciones en el gobierno de la institución con respecto a lo establecido en la ley Avellaneda. Se proponía una mayor participación docente a través de su intervención en la elección de las autoridades universitarias. En relación con esto último, se manifestó un cierto malestar por el funcionamiento del cuerpo académico que era ajeno al claustro docente de las Facultades. Sin embargo, se mantuvo la idea de que estuvieran compuestos por quince miembros ad vitam, los cuales no necesariamente tenían que ser profesores. En realidad, el reclamo por una mayor autonomía estaba pensado desde el punto de vista de una ampliación de las atribuciones de cada Facultad con respecto a las del Consejo Superior, especialmente en lo relativo a la administración de sus propios recursos financieros. Para ello se establecía que los aranceles estudiantiles percibidos por cada Facultad se destinarían a costear los sueldos y gastos de enseñanza, en vez de ir a conformar el "fondo universitario" desde el cual posteriormente se redistribuía entre el Consejo Superior y las distintas unidades académicas. Además, se proyectaba que el Estado destinara el $25 \%$ de lo producido por la venta de las tierras públicas para formar un fondo universitario que se repartiría entre las facultades proporcionalmente al número de alumnos ${ }^{33}$. Vinculado con ello, se argumentaba que la disponibilidad de rentas propias permitiría crear la carrera del profesorado universitario, en el sentido de establecer una remuneración que posibilitara e incentivara a los docentes a dedicarse plenamente a las actividades académicas y no se repartieran el tiempo con el ejercicio liberal de sus profesiones. En este proyecto, además, se reconocía que las universidades o facultades de creación particular o provincial tendrían validez en la jurisdicción nacional si tenían un plan de estudio aprobado por el Congreso Nacional y contaban con una renta suficiente para cubrir regularmente su presupuesto.

\footnotetext{
${ }^{32}$ El proyecto también llevaba las firmas de Mariano de Vedia, Marco Avellaneda, Ponciano Vivanco, E. Lobos, José M. Guastavino, José Ignacio Llobet, M. Carlés y J. M. Gutiérrez. El texto del proyecto y la defensa realizada por Cantón se puede consultar en el Diario de Sesiones de la Cámara de Diputados de La Nación, 1898, I: 559-569. Para conocer algunos comentarios críticos del mismo, véase: Fernández 1898; Gallardo 1898. Para un análisis del contexto de discusión de estas propuestas en relación con la Facultad de Medicina de Buenos Aires, véase: Bargero 2002.

${ }^{33}$ Como antecedente a esta idea se mencionaba la propuesta de Vicente Fidel López en 1875, quien siendo rector de la Universidad de Buenos Aires había sugerido que el gobierno destinara para esta institución una cierta cantidad de tierra pública para la formación de un fondo universitario. La otra referencia eran las medidas instrumentadas en Estados Unidos a partir de la Ley Morrill de 1862 y una segunda ley en la década de 1890. Para una referencia a estas dos leyes y su efecto sobre la organización de la educación superior norteamericana, véase entre otros: Geiger 1992.
} 
En los mismos días, las autoridades de la Universidad de Buenos Aires estaban diseñando un proyecto para reorganizar algunos aspectos de esa institución, el cual fue presentado de forma paralela al de Cantón. A diferencia de este último, se defendió la unidad universitaria y un sistema federal de gobierno con mayor concentración de la autoridad del Consejo Superior ${ }^{34}$. Por otro lado, frente al incremento del número de alumnos se pensó que con un leve aumento en los aranceles se podría llegar cubrir los gastos ordinarios de enseñanza. Precisamente, este era uno de los argumentos a los que se apelaría para demandar por una mayor autonomía con respecto de la intervención estatal. En este sentido, la búsqueda de una independencia para establecer el presupuesto y disponer libremente de las rentas fue uno de los principales reclamos de las autoridades universitarias.

En esa época, se percibía que la principal limitación a la llamada "autonomía universitaria" era de orden financiero. En relación con ello, se consideraba que los presupuestos elaborados por cada Facultad debían ser sometidos a varias instancias de control y modificación: el Consejo Superior de la Universidad, el Poder Ejecutivo y las Cámara de Diputados y Senadores. Mientras las Universidades intentaban enriquecer y hacer rentable el fondo universitario previsto en la ley Avellaneda, debían depender del financiamiento estatal para completar su presupuesto. Por esa vía, los poderes públicos podían controlar y modificar la distribución interna de los recursos de cada casa de estudio, lo que, a su vez, podía repercutir sobre las actividades docentes y científicas. De esa forma, la supervivencia de algunos aspectos de la vida universitaria como el desarrollo de nuevas cátedras, laboratorios o institutos quedaba supeditada a la voluntad de los legisladores y la aprobación de leyes especiales que permitieran invertir los derechos estudiantiles u otras rentas. En varios casos se observa que la creación de algunas materias o cargos se decidió en alguna de las Cámaras del Congreso, beneficiándose generalmente a la Facultad de Medicina de Buenos Aires en detrimento de cátedras que esa Universidad solicitaban para otras Facultades. Esta situación se hizo particularmente grave en los últimos años del siglo XIX cuando la Universidad porteña experimenta un rápido crecimiento no sólo por el aumento de estudiantes con el consecuente incremento del peso de las tareas docentes, sino también ante la necesidad de acomodarse a las nuevas tendencias educativas y científicas. Para ello aparecía cada vez más necesario contar con buenas bibliotecas,

\footnotetext{
${ }^{34}$ Anónimo 1898.
} 
laboratorios bien equipados y personal especializado para fomentar los estudios prácticos y los trabajos científicos.

Los proyectos de reforma universitaria de Cantón y las autoridades de la Universidad porteña defendían la idea de Universidad estatal, mientras que un tercer proyecto presentado por el diputado Diego Scotto promovía la legalización de universidades libres ${ }^{35}$. En el marco de ese debate, se reconocía la existencia de dos regímenes o modelos universitarios internacionales: a) las universidades completamente autónomas y libres de los "pueblos anglosajones" y ejemplificadas por las universidades tradicionales inglesas de Oxford y Cambridge y las universidades y otros institutos de educación superior de Estados Unidos, y b) las oficiales o del Estado como en Europa continental, Latinoamérica y Asia. Las primeras eran admiradas por contar con una renta propia para costear sus actividades y por la independencia que gozaban con respecto a la intervención del gobierno, aunque pudieran recibir una subvención estatal. El claustro universitario elegía sus autoridades, elaboraba su presupuesto, aprobaba los planes de estudios, nombraba los profesores y el personal subalterno, y expedía los certificados que acreditaban competencia científica. Otro de los aspectos admirados era el tipo de instrucción "integral" y la disciplina que se inculcaba a los jóvenes a través del sistema de los internados de los colleges. Algunos también miraban con interés la acción social y la influencia externa que ejercía la Universidad a través de las nuevas experiencias denominadas "University Extension" y "University Settlements"36. En particular, una importante publicidad de la educación inglesa se dio a través de publicistas franceses como Max Leclerc ${ }^{37}$ y Edmond Demolins, discípulo francés de Le Play y creador de la famosa Escuela de Roches en Normandía en la que se intentó aplicar el sistema

\footnotetext{
${ }^{35}$ Diario de Sesiones de la Cámara de Diputados de la Nación, 1898, I: 603-606.

${ }^{36}$ La "University Extension" se inauguró oficialmente en Cambridge en 1873 y unos años después en Oxford y otras universidades inglesas y escocesas. Inicialmente consistió en ciclos de conferencias en diferentes localidades. Los "University Settlements" eran asociaciones o "colonias" universitarias dirigidas por profesores y estudiantes establecidas durante la década de 1880 en distritos o barrios obreros de Londres y de las ciudades industriales más importantes de Inglaterra. Entre estas instituciones se destacaría como modelo el de Toynbee-Hall en un barrio pobre del este de Londres. En estas residencias-también consideradas como "workmen' clubs"- se organizaban numerosas y variadas actividades como: clases nocturnas, prácticas de laboratorio, conferencias, conciertos, obras de caridad, excursiones, "garden partis" junto con otras actividades deportivas y de fraternidad. Asimismo, esas experiencias al igual que la extensión universitaria fueron vistas como canales para difundir una serie de reformas sociales impulsas desde los sectores universitarios. Este tipo de instituciones también se establecieron en Estados Unidos. En el continente europeo esto derivaría hacia 1900 en las llamadas universidades populares más relacionadas con iniciativas de socialistas, intelectuales de izquierda y estudiantes. Véase entre otros: Espinas 1892; Leclerc 1892, 1899; Buisson s/f.; Palacios 1904; y para su contexualización: Tiana Ferrer 1991.
} 
tutorial y la educación integral como en los colleges ingleses. Especialmente en su popular libro: A quoi tient la supériorité des Anglo-Saxones (1897), Demolins indicaba que la superioridad anglo-sajona, manifestada en su comercio, industria y política, se debía al carácter de la raza sajona y el tipo de educación dirigida a formar hombres con iniciativa, prácticos y aptos para dirigirse a sí mismos y en la vida social $^{38}$.

La idea de un régimen de universidad libre en Argentina, fue especialmente defendida por el académico y profesor de medicina Juan R. Fernández, quien también apoyaría la propuesta del diputado $\mathrm{Scotto}^{39}$. En el proyecto de este último se proponía que las universidades nacionales cuyas rentas les permitieran sufragar más de la mitad de su presupuesto serían consideradas instituciones libres con amplia autonomía para dictar sus estatutos, nombrar y destituir su personal, establecer su presupuesto y crear las Facultades o estudios que se consideraran convenientes. Asimismo, se establecía que los alumnos costearían sus estudios profesionales - es decir, con las matrículas estudiantiles se financiarían los gastos de enseñanza- mientras el Estado subvencionaría las investigaciones científicas y la creación de laboratorios y bibliotecas.

Otro de los temas principales en las propuestas de reorganización del régimen universitario se relacionaba el gobierno interno y especialmente con el funcionamiento de las academias. Una cierta tendencia a impugnar la estructura universitaria se basaba en la percepción de que esto último se había trasformado en un "gobierno cerrado", con poca capacidad de renovación y adaptación frente a los acelerados cambios que se operaban en el país. Como ha señalado Halperin Donghi, si bien la administración por parte de una minoría cerrada de profesores se intentó evitar con la Ley Avellaneda, en

\footnotetext{
${ }^{37}$ Leclerc 1892, 1894, 1899.

${ }^{38}$ Demolins s/f. Este libro fue editado posteriormente en ingles, español, polaco, japonés y árabe. También serían muy difundidas sus otras obras de propaganda como: L'éducation nouvelle: L'école des Roches, (1898) y Nos éleves en Angleterre. L'École des Roches (1899). La primera fue traducida en español y ruso. Parte de la propuesta educativa de este publicista, sobre todo en relación con la formación moral, intelectual y física de los jóvenes en una institución que contara con todas las dependencias para una educación integral y alejada de los vicios de las grandes ciudades, coincidiría con las ideas de Joaquín V. González para el sistema tutorial y de internados abiertos del Colegio Nacional. De hecho, estas obras formaron parte de la colección de folletos de instrucción pública pertenecientes a González y donados a la Biblioteca de la Universidad Nacional de La Plata. También entre otros libros de la colección de González se encontraba la obra de J. Wells sobre los Colleges de Oxford. Wells 1903.

${ }^{39}$ En esta época, este futuro Ministro de Justicia e Instrucción Pública, compartía la concepción liberal de las instituciones libres y la idea de que: "la raza anglo-sajona adquiere el hábito de independencia que es su modalidad esencial, con el goce de sus instituciones liberales, con sus corporaciones
} 
la práctica no se logró escapar a que la institución fuera dirigida por un grupo no más abierto de académicos vitalicios ${ }^{40}$. De ahí que algunos sectores reclamaran una mayor participación del cuerpo de docentes titulares y suplentes en la elección de las autoridades universitarias y en la composición de las Academias. En particular, el proyecto de Scotto fue más lejos al sostener la necesidad de participación de los graduados con más de cinco años de ejercicio profesional.

Los tres proyectos fueron enviados a los rectores de las universidades nacionales para que emitieran su opinión al respecto. Al año siguiente, el Consejo Superior de la Universidad de Buenos Aires, luego de algunos debates internos, se expidió a favor de la propuesta de las autoridades universitarias pero con algunas modificaciones $^{41}$. Se consideraba que las bases de la organización universitaria no debían modificarse, excepto para conferir una mayor autonomía en la dirección de la enseñanza con respecto al control estatal; y también en el aspecto económico, a partir de disponer libremente de los derechos estudiantiles y la subvención del Gobierno. Al mismo tiempo, se señalaba la conveniencia de que la universidad no perdiera su carácter oficial de donde derivaba principalmente su prestigio. En diferentes ocasiones, la idea de la universidad libre, que en muchos casos fue promovida por sectores católicos, sería rechazada en defensa del monopolio de las universidades estatales para otorgar los diplomas de capacitación y habilitación profesional ${ }^{42}$.

En aquellos años hubo iniciativas ministeriales como la de Mangnasco en 1899 y posteriormente la de Juan Fernández en 1904, que mencionaron la idea del examen de estado y la libertad de enseñanza para promover la educación científica. Especialmente, el plan de instrucción pública del primero buscaba reafirmar la

autónomas, con sus gremios asociados y enérgicos, los que forman otras tantas fuerzas que contrapesan siempre la acción absorbente del estado". Fernández 1899: 294.

${ }^{40}$ Halperin Donghi 1962.

${ }^{41}$ Anónimo 1899. Véase también el folleto: Proyecto de reformas universitarias. Informe del Consejo Superior a la Comisión de Instrucción Pública de la Cámara de Diputados.1899.

${ }^{42}$ La idea de una universidad católica estuvo presente desde fines del siglo XIX y se presentaron algunos proyectos promovidos desde el Episcopado en los primeros años del nuevo siglo. En 1909 se crean los Centros de Estudiantes Católicos y un año después se funda en Buenos Aires una universidad católica, sostenida con suscripciones públicas y en la cual se desarrollarían conferencias, cursos y distintas actividades por cerca de diez años. Desde 1910 se buscó, sin éxito, que la Universidad Nacional de Buenos Aires y posteriormente el Gobierno Nacional reconociera oficialmente sus certificados de estudios, especialmente en abogacía. Finalmente en 1920 fue cerrada por una "incomprensión jurídica de la Universidad oficial" y la negativa del Estado Nacional a dar reconocimiento legal a los títulos de sus egresados. Baruch Bertocchi 1987. Los estudios brindados por las universidades privadas no gozaron de validez oficial hasta el decreto 14.557 de 1958 establecido durante el gobierno de Frondizi. Pérez Lindo 1985, Hurtado de Mendoza y Busala 2002. El crecimiento de estos establecimientos fue en general lento hasta la década de 1990, época en que se expanden y diversifican considerablemente pasando a superar en número a las universidades estatales. 
autoridad del Estado para fiscalizar la organización de los estudios y la validación de los títulos de competencia profesional. Mientras que se dejaría amplia libertad a las sociedades científicas para que organizaran las investigaciones y las carreras científicas, ya que se consideraba que la ciencia era una actividad cultural que no afectaba los intereses públicos, y por lo tanto, no debía ser supervisada por el gobierno $^{43}$.

En la transición del siglo, ni el plan del Ministro Mangnasco ni los distintos proyectos de reforma universitaria presentados en la Cámara de Diputados en 1898 lograrían alcanzar una sanción oficial. Sin embargo, se produjeron algunas pequeñas transformaciones en relación con el sistema financiero de las universidades nacionales, que le permitirían disponer de una mayor autonomía para administrar sus recursos. En el caso de la Universidad de Buenos Aires, el Gobierno autorizó un aumento de cerca del $50 \%$ en los aranceles y otros derechos estudiantiles, y, además, se estableció una partida fija anual de 600.000 pesos moneda nacional en el presupuesto nacional para que esta institución lo administrara de la forma que creyera más conveniente. Para la Universidad de Córdoba se fijo un subsidio anual de cerca de 328.000 pesos, monto no demasiado inferior a su presupuesto universitario y que se mantuvo casi similar en los siguientes años. Un tiempo después, primero para el caso de las universidades de Buenos Aires y La Plata y luego para la de Córdoba, los legisladores dejarían de analizar en detalle y/o modificar los presupuestos internos de estas instituciones, atendiéndose a la discusión del monto general del subsidio o de las sumas pedidas para gastos extraordinarios. Esta tendencia, por momentos cuestionada por los legisladores socialistas a mediados de la década de 1910, permitió que las

\footnotetext{
${ }^{43}$ En 1899 el Ministro Magnasco avalado por el presidente Roca presentó un plan de instrucción general y universitaria. En ese proyecto reivindicaba las atribuciones del Poder Ejecutivo para dictar los planes de instrucción pública y promover los estudios técnico-profesionales. Además, se reafirmaba la autoridad del Estado para controlar la formación de los profesionales: "si el Estado es la representación política de la sociedad y esta no puede ser indiferente á la producción profesional, debiendo por el contrario saber quiénes de entre sus miembros serán los autorizados para defender y amparar el derecho privado, preservar ó restablecer la salud, ejercer sin explotaciones el dominio espiritual de las conciencias, promover y encaminar los grandes progresos de la industria, de la agricultura, del comercio y de las artes, etc. es lógico pensar que sólo el Estado debe elaborar esos planes, imprimirles carácter, darles tendencias y organizar la enseñanza de esta clase en órden á los fines sociales. La Universidad no puede aspirar á ser un Poder político sinó un Poder científico; nó una autoridad de gobierno, sinó un resorte particular del progreso general. Por esos mismo una Universidad no debe otorgar diplomas profesionales sin ratificación expresa de los Poderes públicos, ni producir nombramientos sin esa autorizada confirmación........ las labores de investigación científica, en cuanto constituyen no ya una fábrica de profesionales sinó de alta cultura intelectual, son labores inmediatamente ajenas á las funciones de gobierno y, en tal terreno, no se podría sin injusticia y sin peligro á veces, negar á los eruditos sostenedores de la autonomía, la verdad de sus exigencia y la necesidad de su emancipación.". Magnasco 1899: 16-17.
} 
universidades gozaran de una mayor autonomía para administrar sus recursos, contratar personal interino o extranjero, crear nuevas cátedras, laboratorios o institutos de investigación y series de publicaciones, entre otras actividades.

Los escasos recursos económicos y el pedido de aumentar el subsidio nacional continuó siendo un tema presente en las Memorias universitarias. En el caso de la Universidad de Buenos Aires, mientras en los cinco siguientes años a 1900 la subvención del Estado se mantuvo fija, el presupuesto universitario se duplicó y para cubrir el déficit se recurrió a la venta de empréstitos del fondo universitario. Por esa situación, indicaban las autoridades universitarias, la renta de ese fondo no se había podido incrementar o por lo menos mantener a un nivel rentable que permitiera una mayor autonomía económica. Por otro lado, los intentos para buscar fuentes de financiamiento alternativas como suscripciones públicas ${ }^{44}$, benefactores o donación de tierras públicas para su explotación no tuvieron éxito, por lo que cada vez más se dependió del Estado para cubrir el presupuesto ${ }^{45}$. Pese a ello, durante esta época las universidades nacionales, especialmente la de Buenos Aires y La Plata, experimentaron un importante crecimiento en sus instalaciones, laboratorios y actividades científicas y docentes. Como se analiza en el siguiente capítulo, Joaquín V. González prestó especial atención al aspecto económico de estas instituciones, aunque sin poder llegar a consolidar una alternativa plausible para su financiamiento.

$\mathrm{Si}$ bien los proyectos alternativos de reorganización universitaria que se presentaron a fines del siglo XIX no condujeron a ninguna transformación concreta en el sistema de gobierno de estas instituciones, el debate quedó abierto públicamente e interrumpiría con fuerza unos pocos años después al desatarse una serie de conflictos estudiantiles en la Facultad de Derecho de Buenos Aires y luego en la de Medicina. A fines de 1903, una huelga estudiantil por unas fechas de exámenes en la primera de estas Facultades inició un conflicto que afectaría a toda la Universidad. El

\footnotetext{
${ }^{44}$ A fines de 1886 y 1887, por ejemplo, se emprendió desde la Facultad de Medicina de Buenos Aires una suscripción popular, trunca, para la construcción de un Instituto de estudios científicos como la campaña realizada para la creación del Instituto Pasteur en Francia. Prego 2001.

${ }^{45}$ En la Memoria que elevó la Universidad de Buenos Aires al Ministro de Instrucción Pública en 1910, se sostenía que no había iniciativas privadas para ayudar a la Universidad. En esa época, se había elaborado un proyecto y organizado una amplia campaña de difusión para incentivar las donaciones entre los propietarios de grandes fortunas, pero no se recibió ningún ofrecimiento. Las autoridades universitarias coincidían en que los estudiantes - a través de los distintos aranceles que abonaban- no debían costear todos los gastos de enseñanza, lo cual, por otra parte, no alcanzaría para cubrir el desarrollo de otras actividades universitarias, y por eso apoyaban los proyectos para que el Estado asegurara una fuente permanente de rentas como las iniciativas legislativas para entregar tierras públicas a las universidades nacionales.
} 
enfrentamiento con las autoridades académicas y la novedosa intransigencia de los grupos estudiantiles, que tanto cuantitativamente como cualitativamente estaban alcanzando un mayor peso en el espacio público argentino, generaron un conflicto que desembocó en la reforma de los estatutos y del sistema de gobierno de la Universidad porteña. Halperin Donghi ha señalado que este tema puede ser pensado como la expresión de los cambios sociales por los que atravesaba la Argentina de principios de siglo, el resultado de una oposición generacional y el agotamiento de una gestión universitaria tras veinte años de continuidad ${ }^{46}$. La dinámica del proceso derivó de un pedido inicial por el cambio de las fechas de exámenes a un cuestionamiento general por el sistema de gobierno de las casas de estudio. En particular, las demandas estudiantiles giraron en torno a la modificación del cuerpo académico, la instauración de nuevos tipos de exámenes, la rebaja de los aranceles y el establecimiento de la docencia libre. A ello se sumaría un clima de oposición a la élite académica de Medicina, iniciado por sectores estudiantiles con el apoyo de algunos docentes que reclamaban por el mejoramiento de la enseñanza a partir de trabajos prácticos, laboratorios y "docencia libre" 47 . Esto último se asociaba a la posibilidad de organizar el sistema alemán del "Pritvadozent". En las interpretaciones liberales clásicas se reconocía que las innovaciones y superioridad de las universidades alemanas residía en la competencia que se establecía entre los profesores y los "docentes privados" por atraer estudiantes, de los cuales dependía el sueldo ${ }^{48}$. Se consideraba que en esa competencia cada docente intentaba conquistar la mejor reputación, promover nuevos cursos y realizar el mayor esfuerzo en la enseñanza para reclutar alumnos, quienes de esa forma adquirían una función de "jueces" sobre la actuación de los profesores. Al mismo tiempo, ello abría posibilidades de acceder a la docencia universitaria y constituía un paso inicial para aquellos interesados en desarrollar una carrera científico-académica.

De los conflictos en la Facultad de Derecho se derivó una impugnación de la composición y la autoridad moral del cuerpo académico, que provocaron la renuncia de sus miembros. En ese nuevo clima de crítica hacia la Universidad, se produjeron varios análisis y propuestas de reformas que abarcaron desde aspectos parciales en una Facultad hasta la reforma de la Ley Avellaneda. Nuevamente algunos sectores

\footnotetext{
${ }^{46}$ Halperin Donghi 1962.

${ }^{47}$ Sobre los conflictos en la Facultad de Medicina porteña, véase: Bargero 1998, 2002; Buch 2000.

${ }^{48}$ Véase entre otros: Cárcano 1892; Quesada 1893, 1910; Demaría 1902; Bunge 1903. Sobre la organización del sistema del Privatdozent véase también: Ben-David 1971,
} 
académicos asociaban el origen de la crisis universitaria con ese marco legal. En ese sentido, se presentaron proyectos para establecer una nueva ley y organización universitaria. Entre ellos, tres llegaron a ser discutidos en la Cámara de Diputados de la Nación en $1904^{49}$. En el mes de mayo, el diputado y académico Elíseo Cantón presentó una propuesta que retomaba las principales ideas expuestas en 1898 con algunos pequeños cambios. Entre ellos, se establecía un límite de 65 años para los académicos y una forma de elección en la que participaran los profesores titulares. En esta modificación se manifestaba uno de los puntos más controvertidos del régimen universitario: la falta de representación e intervención del profesorado en la dirección de la institución y la enseñanza. Vinculado con ello, nuevamente emergían críticas hacia el cuerpo cerrado y vitalicio de las Academias, que aparecían como entidades distantes con respecto a las aspiraciones y necesidades de las escuelas que dirigían ${ }^{50}$.

Dos días después, la Cámara de Diputados trató otro proyecto elaborado por el Ministro de Justicia e Instrucción Pública, Juan R. Fernández. Según este funcionario y ex decano de la Facultad de Medicina porteña, en los últimos años las universidades nacionales no satisfacían las esperanzas depositadas en ellas por los Poderes públicos, según las funciones que se le atribuían: 1) capacitar profesionales y las clases dirigentes, b) promover la producción científica, literaria e histórica. Si bien el Poder Ejecutivo admitía que la primera tarea en algunas Facultades se había realizado con éxito, la segunda función, que era la que caracterizaba a los institutos de altos estudios, no se había cumplido como era de esperar. Al igual que algunos diputados y profesores, Fernández asociaba el problema universitario con la ley de 1885 y para ello proponía un nuevo régimen basado en la enseñanza universitaria libre combinado con un tribunal estatal encargado de tomar los exámenes generales previos a la entrega de los diplomas profesionales. A diferencia de sus ideas de 1898, en las cuales manifestó una cierta inclinación por la organización anglosajona, ahora su propuesta tenía una mayor filiación con las universidades de tipo alemán. La expansión de este último modelo cobró una mayor difusión al iniciarse el siglo $\mathrm{XX}$, a partir de la propaganda de los profesores que se formaron allí y de las reformas que se introdujeron en las universidades norteamericanas y francesas siguiendo algunos aspectos de esas instituciones, pero principalmente ello puede ser asociado como parte

\footnotetext{
49 Véase los distintos proyectos en el Diario de Sesiones de la Cámara de Diputados de la Nación, 1904, I.

${ }^{50}$ El proyecto de Cantón contaría con la opinión favorable de parte de la Facultad de Ciencias Médicas, de la de Ciencias Exactas y del Consejo Superior de la Universidad de Buenos Aires.
} 
de la Kulturpolitik y la política exterior prusiana, en el marco de las rivalidades imperialistas $^{51}$. Como parte de esto último, el Ministerio de Cultura prusiano apoyó "la misión sudamericana" de los profesores alemanes que eran convocados para la organización de instituciones científicas o de enseñanza. Las preferencias del ministro Fernández por la educación alemana se evidenciaron en la compra de material didáctico a fábricas alemanas, la iniciativa de organizar un Seminario Pedagógico para completar la formación de los universitarios que se dedicarían a la docencia secundaria y en la contratación de personal alemán para dirigir y enseñar en esa institución que se realizó por intermedio de los respectivos Ministerios de Relaciones Exteriores y Educación de ambas naciones. En la misma época, otros países como Estados Unidos, Francia y España comenzarían a preocuparse por incrementar las relaciones culturales y promocionar sus instituciones educativas y científicas a través de la visita de profesores, intercambio de publicaciones y ofreciendo becas y cursos especiales para estudiantes.

Con respecto al sistema universitario, Fernández promovía una serie de cambios alrededor de tres puntos: 1) la organización del gobierno universitario, buscando simplificar los espacios de decisión y concentrar la autoridad administrativa en el rector y los decanos, sin la intervención de un cuerpo numeroso de profesores o académicos. Las Academias, en cambio, debían ser corporaciones científicas, dedicadas a promover y divulgar las investigaciones científicas y los estudios literarios; 2) la formación y perfeccionamiento del profesorado, a través de la creación del sistema del "docente libre" al estilo de universidades alemanas, costeado por los alumnos y a partir de los cuales se seleccionarían los profesores titulares; 3) el régimen económico. Con respecto a este punto, se consideraba que los derechos estudiantes que se recaudaban, como mostraba el ejemplo de la Universidad de Buenos Aires, eran bastantes para financiar los gastos de la enseñanza profesional, mientras que para las investigaciones científicas y los estudios literarios se destinaría una subvención nacional. Asimismo, al igual que en todos los proyectos de reforma universitaria, se contemplaba la entrega de tierras fiscales a las universidades, lo cual se consideraban una fortuna segura en un país que trasformaba sus desiertos con la agricultura y la ganadería. Con la creación de un fondo universitario, cada Facultad podría dotarse de bibliotecas, museos u otra infraestructura adecuada para atender las distintas necesidades pedagógicas y científicas.

${ }^{51}$ Pyenson 1984, 1985a, $1985 b$. 
A diferencia de estos dos proyectos en los que se mantenía la unidad universitaria, la propuesta del diputado Francisco Oliver, académico de la Facultad de Derecho de Buenos Aires apuntó hacia la personería jurídica y la autonomía didáctica, administrativa y financiera de cada una de las Facultades de la Capital Federal. En cambio, para la casa de estudios cordobesa se mantenía su "tradición" de centralización universitaria. Oliver propuso que las Academias estuvieran formadas por un tercio de profesores y el resto por personas ajenas a la Facultad, aunque para agilizar la administración se nombrarían a cinco delegados para formar un consejo administrativo. Para la financiación de las actividades se establecía la entrega para cada una de un subsidio nacional y 50.000 hectáreas de tierras fiscales para formar un patrimonio propio inalienable. En este proyecto también se insinuaba el desarrollo de actividades de extensión universitaria y otras vinculadas a la "universidad en el exterior", como la selección de estudiantes para que fueran a perfeccionar sus estudios en el extranjero.

La propuesta del académico de la Facultad de Derecho, retomaba algunas de las ideas que venían insinuando otros miembros de esa corporación ${ }^{52}$. Principalmente se buscaba una autonomía completa con respecto al Consejo Superior de la Universidad, donde se reconocía que participaban delegados que no tenían competencia técnica para decidir sobre los planes de estudios, programas, y otras cuestiones vinculadas a las ciencias jurídicas. Por otra parte, ello se fundamentaba en que esta Facultad se podía autofinanciar a través de lo recaudado por derechos estudiantiles. Si bien en esa época, por esa vía la Facultad podía reunir una suma mayor que la de su presupuesto, según los estatutos universitarios más de la mitad debía pasar a formar parte del fondo universitario, desde donde se redistribuía entre el Consejo Superior y las distintas Facultades. De esa forma, se argumentaba que las decisiones últimas sobre los planes de estudios o la creación de cursos para el doctorado científico que se discutía en esa época, estaban supeditadas a las decisiones del Consejo Superior, por sus atribuciones para decidir sobre el presupuesto y la permanencia o no de las cátedras. En el marco de esas ideas, la concepción de "autonomía universitaria" que manejaban varios académicos de Derecho no se refería

\footnotetext{
52 En la Facultad de Derecho se formó una comisión para examinar los proyectos universitarios que se discutieron en el Congreso en 1898 y 1899. Al año siguiente, el académico Juan Bibiloni presentó un informe argumentando en pro de la completa autonomía de esa Facultad y la descentralización universitaria, que fue apoyado por las autoridades académicas. Posteriormente, se volvería a criticar la unidad universitaria. Bibiloni 1900, 1903.
} 
a la relación Universidad-Estado, sino a una disolución de la unidad universitaria y la independencia de cada Facultad. En cierta forma esta propuesta aparecía impugnada por las tendencias internacionales que tendían a reforzar idea de la universidad, como se puso de manifiesto en la ley francesa de centralización universitaria de 1896 o la transformación de algunas de las universidades inglesas como la de Londres en 1904, en la que se reunieron varias instituciones y sociedades eruditas para impulsar la función educativa frente al predominio de la tarea examinadora de estas instituciones.

La campaña "separatista" provocó una polarización de las opiniones con respecto a los que defendían la idea de universidad. Entre estos últimos, algunos como el profesor y académico Rodolfo Rivarola (1857-1942) promovieron la reforma de la organización de la Universidad porteña a partir de nuevos estatutos y sin necesidad de cambiar la ley Avellaneda ${ }^{53}$. Para este profesor, las principales cuestiones relacionadas con la "reforma universitaria" se concentraban alrededor de seis puntos ${ }^{54}$ : 1) las atribuciones del Consejo Superior y de las Facultades, 2) la composición de los cuerpos académicos y la representación o intervención del profesorado en ellos, 3) la constitución de un cuerpo de profesores que pudiera influir en los rumbos de la institución, principalmente a través de otorgarle atribuciones electivas y la organización de reuniones anuales entre todos los docentes para discutir temas de enseñanza, 4) la representación de los intereses estudiantiles, por medio del reconocimiento oficial y la regulación de las corporaciones estudiantiles como en los estatutos de las universidades suizas. Según Rivarola estas asociaciones ayudarían a que los jóvenes se ejercitaran en los mecanismos de gobierno propios de una democracia representativa; 5) la libertad de enseñanza, reglamentando la existencia de profesores libres y remunerados por los estudiantes; y 6) la libertad de aprender. Con respecto a este último punto, reconocía que no se podía implementar el sistema alemán o el suizo donde cada estudiante podía voluntariamente ordenar sus estudios, ya que las leyes argentinas no lo permitían. A diferencia de aquellos países que tenían Examen de Estado que autorizaba el ejercicio de ciertas profesiones, para este

\footnotetext{
${ }^{53}$ Rivarola defendió la idea de unidad universitaria al igual que la idea de una república unitaria como régimen político para el país. Sus ideas sobre la cuestión universitaria se pueden seguir a través de varios artículos y notas editoriales en la Revista de la Universidad de Buenos Aires, de la cual fue el primer director entre 1904 y1906. También en la Conferencia Universitaria, que organizó la Asociación Nacional del Profesorado a principios de 1905, este profesor defendió la idea de una unidad universitaria con autonomía administrativa con respecto al Estado y una mayor participación del cuerpo docente. Rivarola 1905. Una recopilación de sus conferencias y otros escritos sobre pedagogía y educación superior se encuentran en Rivarola 1941.

${ }^{54}$ Rivarola 1904.
} 
profesor las Facultades argentinas debían supervisar y sistematizar el ordenamiento de los estudios debido a que eran las responsables por la emisión de los títulos de habilitación profesional. En cambio, proponía que las cátedras se abrieran para todos aquellos que se interesaran en aprender con el único requisito de que abonasen los derechos respectivos, pudiendo presentarse a examen y obtener un certificado, pero sin que ello los habilitara para obtener un título universitario. Esto último sería aplicado en la Universidad Nacional de La Plata bajo la forma de la figura del "oyente" como se examina en el capítulo III. También en el proyecto de creación de esta institución se buscaría dar respuesta a gran parte de las cuestiones señaladas por Rivarola. De hecho, este profesor sería convocado por Joaquín V. González para organizar y dirigir la Facultad de Ciencias Jurídicas y Sociales de La Plata, donde también participarían otros "reformistas liberales" 55 y profesores de la Universidad porteña.

Los debates que se suscitaron por la "cuestión universitaria" a partir del conflicto estudiantil de 1904, en un contexto atravesado por el movimiento político de recambio presidencial, aplazaron las decisiones de los legisladores con respecto a una nueva ley universitaria. Tampoco el nuevo Ministro de Justicia e Instrucción Pública, Joaquín V. González intervendría en esos conflictos, esperando que según el principio de autonomía universitaria fuera la propia Universidad la que resolviera esas cuestiones. Finalmente, al iniciarse una nueva gestión al frente del rectorado de la Universidad de Buenos Aires, ciertas transformaciones en el régimen de gobierno interno se resolvieron con una reforma de los estatutos en 1906, demostrando de esa forma la flexibilidad de la Ley Avellaneda ${ }^{56}$. Con la nueva reglamentación se intentó resolver el problema del gobierno universitario, a través de la creación de dos cuerpos colegiados en cada Facultad. Por un lado, se mantuvo la idea de las Academias, pero redefinidas como corporaciones científica o eruditas y no como cuerpos del gobierno universitario. Las Academias se conformarían por veinticinco miembros elegidos por cooptación y vitalicios, y mantendrían funciones de asesoramiento y consulta frente a las autoridades universitarias. En cambio, la administración y gobierno interno de cada Facultad quedó en manos de un Consejo Directivo, compuesto por quince miembros renovables periódicamente, de los cuales, al menos, un tercio debían ser profesores que dirigían aulas. La designación de nuevos consejeros estaba a cargo de

\footnotetext{
${ }^{55}$ Zimmermann 1992; 1995.

${ }^{56}$ Caldelari y Funes 1997.
} 
cada Consejo, pero a partir de las propuestas presentadas por el cuerpo de profesores. Halperin Donghi considera que ello implicó un cambio profundo en la estructura universitaria, ya que el gobierno interno pasó a quedar en manos de los profesores. Según este investigador, la capacidad de la Universidad para seguir el ritmo de una rápida renovación se puede atribuir, por lo menos en parte, a la transformación de su régimen de gobierno. A su vez, ello se enmarcó en una importante apertura científica y cultural que puede ser analizado en relación con dos movimientos: a) el predominio de lo que se ha dado en llamar "positivismo"57, que en líneas generales se podría caracterizar como un primer esfuerzo realizado en el país para dar estatuto profesional a las actividades vinculadas a la ciencia, la comprensión de la sociedad y la cultura; y b) una necesidad más sentida de ofrecer una formación científico-técnica más rigurosa y sistemática, que abriría las posibilidades para estudios más especializados y la multiplicación de museos, laboratorios e institutos donde se podrían llevar a cabo actividades de investigación ${ }^{58}$.

I. 3. La Universidad provincial de La Plata y la nacionalización de las instituciones provinciales

La creación de una Universidad provincial en La Plata se ha asociado a la figura del senador provincial Rafael Hernández y a la de su pariente Dardo Rocha, bajo cuyo gobierno se creó la ciudad de La Plata en 1882. Hernández junto con otros senadores presentaron un proyecto de ley para el establecimiento de la Universidad de La Plata, que fue sancionado en la Legislatura Bonaerense el 27 de diciembre de 1889 y ratificado unos días después por el gobernador Máximo $\mathrm{Paz}^{59}$. La creación de un centro de estudios superiores se justificó como una reparación histórica por la nacionalización de la Universidad de Buenos Aires, al federalizarse esa ciudad en 1880; y también como un elemento para arraigar y acrecentar la población de La Plata. Especialmente se esperaba que los alumnos del Colegio Nacional pudieran continuar sus estudios universitarios en la ciudad y no se tuvieran que ir a la Capital Federal. Recordemos que para la materialización de la nueva capital provincial se

\footnotetext{
${ }^{57}$ Soler 1968; Terán 1987; Biagini 1985.

${ }^{58}$ Halperin Donghi 1962.
} 
tuvieron que instrumentar distintas medidas para alentar la inmigración, atraer trabajadores en distintos ramos y asegurar un núcleo estable de población ${ }^{60}$. Para esto último, en sucesivas oportunidades se decretaron leyes que obligaban la radicación efectiva de los funcionarios y empleados que desempeñaban tareas administrativas y técnicas en la capital provincial ${ }^{61}$. Asimismo, la nueva ciudad intentó consolidarse recreando las instituciones científicas, educativas y los círculos de sociabilidad predominantes de la época. Entre ello se puede mencionar la creación del Museo General y la Biblioteca Pública en 1884, el Observatorio Astronómico en 1883, un Colegio Secundario establecido en 1885 y nacionalizado dos años después; la Escuela Normal habilitada hacia 1888, una sucursal local de la Sociedad Científica Argentina en 1887 y el Teatro Argentino en $1890^{62}$, junto a varios periódicos, cuyos salones funcionarían como espacios de reunión y exhibición de obras de arte.

Como se señaló anteriormente, al mismo tiempo que se presentaba el proyecto para crear una universidad en 1889, el Poder Ejecutivo de la Provincia impulsaba el traslado a La Plata del Instituto Agronómico de Santa Catalina en Lomas de Zamora, y su transformación en la Facultad de Agronomía y Veterinaria. A mitad del año siguiente con un edificio a medio terminar y 64 alumnos matriculados comenzó sus actividades esta nueva Facultad. Un año después, el Poder Ejecutivo provincial solicito a la Legislatura la supresión de esta institución, pero a pesar que se redujo su presupuesto, el cuerpo docente continuó con sus actividades. De hecho, fue la primera Facultad de este tipo que funcionó en el país y tanto sus profesores como los primeros egresados se preocuparían por la promoción y la regulación estatal de la práctica profesional de varias actividades vinculadas a estas disciplinas. Para ello desde la mitad de la década de 1890 comenzarían a presentarse proyectos y a gestionar la validez nacional de los títulos para ejercer fuera del ámbito provincial. Ello formó

\footnotetext{
${ }^{59}$ Los debates en la legislatura provincial sobre la creación de una universidad en La Plata y una recopilación de notas aparecidas en los periódicos locales puede consultarse en: Castiñeiras 1985; También véase: Barba 1972; 1995, 1998; Gandolfi 1999.

${ }^{60}$ Para la construcción de La Plata, las autoridades provinciales fomentaron la inmigración y contratación de trabajadores en Europa, especialmente en Italia. Vallejos 2000. Según un censo de 1884, la ciudad contaba con 10.407 habitantes, de los cuales cerca del $78 \%$ de los varones eran extranjeros, predominantemente italianos, mientras que entre la poca población femenina (1.628 mujeres) más del $51 \%$ eran argentinas. La crisis económica de 1890 redujo la población y el movimiento inmigratorio. Según el censo de 1909, La Plata contaba con 65.812 habitantes, comenzando a predominar los argentinos en un 65\%. En los siguientes años el crecimiento poblacional fue gradual y sostenido, siendo importante el aporte migratorio del interior de la Provincia. Barba 1999. Datos estadísticos de los primeros censos se encuentran en: Etchichury 1914.

${ }^{61}$ Decreto de ley del 21 de marzo de 1882 y otro similar se sancionó en 1902.

62 Paula 1987.
} 
parte de un movimiento más amplio de valorización de las ciencias agrarias y veterinarias, vinculado al afianzamiento de la economía agroexportadora y el desarrollo productivo agropecuario alentado desde la Sociedad Rural y varios funcionarios provinciales. Estas disciplinas cobrarían un mayor impulso y reconocimiento cuando el Estado Nacional comenzó a atender específicamente las cuestiones agropecuarias con la creación del Ministerio de Agricultura en 1898 y posteriormente la expansión de las escuelas y la enseñanza agrícola. De hecho, la mayoría de los profesores de la Facultad Agronomía y Veterinaria se desempeñarían en cargos jerárquicos importantes dentro de ese Ministerio ${ }^{63}$. Paralelamente, el Gobierno Nacional estableció desde 1898 becas de estudio en el extranjero para que los jóvenes completaran su formación en estas disciplinas, especialmente en institutos y universidades norteamericanos. No obstante, la situación de esta Facultad estaría sometida a los vaivenes de la política provincial y al iniciarse el nuevo siglo se comenzaría a buscar la nacionalización de esta casa de estudios con el propósito de asegurar una mayor estabilidad y recursos ${ }^{64}$.

La creación de una universidad en La Plata también se vería afectada por la crisis de 1890 y los problemas políticos provinciales. La instalación de esta casa de estudios no se concretó tras la sanción oficial de su proyecto de ley en 1889, a pesar de haber contado con el apoyo de varios legisladores y despertado un amplio entusiasmo popular y juvenil. En los siguientes años, vecinos de La Plata elevaron peticiones al Gobernador para establecer los estudios de jurisprudencia y varios magistrados se ofrecieron para dictar clases ad-honorem. En esas propuestas se preveían las condiciones materiales para el funcionamiento de los tres primeros cursos correspondientes a la carrera de abogacía de la Universidad de Buenos Aires. La idea era preparar localmente a los estudiantes platenses para que luego fueran admitidos

\footnotetext{
${ }^{63}$ Graciano 1998.

${ }^{64}$ En 1895 el senador provincial Ramón Falcón presentó un proyecto de ley, por el cual se autorizaba al Poder Ejecutivo nacional para gestionar la nacionalización de la Facultad. Si bien esta propuesta fue apoyada desde la prensa y grupos de profesionales, en la Legislatura provincial el proyecto no llegaría a discutirse. En 1900, el Ministro de Obras Públicas del Gobierno Provincial envió una nota al Ministro de Justicia e Instrucción Pública de la Nación, Osvaldo Magnasco, solicitando la nacionalización de la Facultad o autorizar a la Universidad de La Plata a que equipara los diplomas de ingeniero agrónomo y doctor en medicina veterinaria con el mismo estatus que los de las carreras de derecho e ingeniería que expedía esta última. El mismo año, los alumnos gestionaron infructuosamente ante el Ministro de Agricultura de la Nación, la nacionalización de la Facultad. La campaña en este sentido prosiguió durante los siguientes años. En 1902, al asumir como gobernador Marcelino Ugarte se comenzaron a establecer los primeros acuerdos con el Gobierno Nacional para la nacionalización de varios establecimientos provinciales. Algunos de estos acontecimientos se relataban como parte de la historia
} 
como alumnos regulares en los exámenes de la Facultad de Derecho porteña ${ }^{65}$. En esa propuesta nuevamente se rescataba la importancia de contar con una universidad propia para mantener la personalidad federativa y poder disminuir la atracción que ejercía la Capital Federal, donde residía gran parte de los funcionarios y legisladores bonaerenses. Como ha señalado Fernando Barba, a pocos años de fundada la nueva capital de la Provincia, los sueños de crear una "nueva Buenos Aires" se desvanecían rápidamente frente a la cercanía con la metrópolis ${ }^{66}$.

A principios de 1897, las gestiones de Dardo Rocha y los miembros del Centro Industrial-Agrícola lograron que el gobernador Guillermo Udaondo sancionara el decreto reglamentando la organización de la Universidad y la constitución de la primera Asamblea Universitaria. El Poder Ejecutivo provincial nombró los miembros de esa Asamblea, quienes, además, conformaron el cuerpo académico y docente de la nueva institución. En la primera reunión se eligió a Dardo Rocha como rector, quien se desempeñó en ese cargo hasta la nacionalización de la institución en 1905. También se establecieron una serie de medidas para organizar el funcionamiento de las cátedras. Entre ellas, se fijó que los cursos se abrirían con un mínimo de cinco alumnos matriculados, los aranceles costarían la mitad que en Buenos Aires y por ese primer año se aceptarían las matrículas que los estudiantes hubiesen abonado en otras universidades. Al mismo tiempo, se dejó que fuera cada Facultad la que estableciera las condiciones de admisibilidad, el nombramiento de personal y la adaptación de planes y programas de estudio a partir de los que estaban vigentes en las universidades nacionales. Se establecieron cuatro Facultades: Derecho y Ciencias Sociales, Ciencias Físico-Matemáticas, Química y Farmacia y Ciencias Médicas, pero sólo comenzaron a funcionar las tres primeras.

La Universidad se instaló en una parte del edificio del Banco Hipotecario, un edificio "comodín" entre los palacios fundacionales de la ciudad y donde anteriormente se habían ubicado las colecciones y el personal del Museo General de La Plata y la Biblioteca Pública entre 1884-1887 ${ }^{67}$. En una de las partes de ese edificio se establecieron salas para la Facultad de Derecho, un aula de dibujo, un gabinete de

\footnotetext{
de esta Facultad en los folletos de promoción de sus estudios, véase por ejemplo: Facultad de Agronomía y Veterinaria 1915.

${ }^{65}$ Una solicitud se presentó en 1891, la cual después de circular por distintas oficinas fue archivada en 1893. Al año siguiente fue presentado otro pedido también dirigido a constituir una Facultad de Derecho y Ciencias Sociales. Véase: Barba 1995; 1972.

${ }^{66}$ Barba 1972.

${ }^{67}$ Torres 1927, Palcos 1934, Gandolfi 1999.
} 
física y un laboratorio de química para la Facultad de Ciencias Físico-Matemáticas y un laboratorio de farmacia práctica para la de Química y Farmacia. El Banco había prometido que cedería dos o tres salas más si la Universidad se incrementaba. A su vez, la Legislatura destinó una manzana sobre la plaza de 7 y 60 para el futuro edificio de la Universidad, y se donaron algunas quintas para que con lo obtenido de su venta se comenzara la construcción. Sin embargo, esto no se lograría concretar al igual que el cobro del subsidio que el Gobierno había destinado para cubrir los gastos de instalación.

Para la organización de las clases prácticas, algunos profesores recurrieron a las instalaciones de otras dependencias estatales donde trabajaban y también encargaron a Europa algunas colecciones y aparatos para la enseñanza ${ }^{68}$. Con respecto a esto último, en ningún caso se proyectaron gabinetes o instalaciones especiales para que sus profesores realizaran estudios científicos o investigaciones. Esto a su vez, se relaciona con la precaria situación que atravesó el ejercicio de la docencia en esta institución, cuyos profesores sólo cobraban al dictar clases para una cierta cantidad de estudiantes matriculados, por lo que no todas las cátedras funcionaron de forma regular. Algunos profesores dictaron clases para alumnos que no se matricularon y después tuvieron problemas para cobrar su sueldo. De hecho, en los presupuestos iniciales de la Universidad no se estableció de forma fija el número de cargos docentes, aunque se estipulaba una remuneración de doscientos pesos mensuales para cada cátedra que funcionara. En 1901, el Consejo Superior sancionó que cada profesor cobraría cien pesos mensuales o ciento cincuenta por dos asignaturas dictadas, durante los nueve meses del año lectivo ${ }^{69}$. En este sentido, la enseñanza universitaria no era

\footnotetext{
${ }^{68}$ Una sección del laboratorio farmacéutico estaba en la Municipalidad en donde funcionaba la Oficina Química, dirigida por Pedro J. Pando. Este profesor se había doctorado en ciencias químicas y naturales en la Universidad de Buenos Aires y participó muy activamente en la organización de la Facultad de Química y Farmacia en La Plata, desempeñándose como decano, consejero académico y profesor de dos cátedras. Para las clases de química general de la Facultad de Ciencias Exactas se utilizaban las instalaciones de la Facultad de Agronomía y Veterinaria. También se proyectó comprar el gabinete de física de esta última Facultad, que no se usaba tras ser eliminada esa asignatura del plan de estudios; y luego completarlo con un laboratorio encargado en Europa. Para la enseñanza de la geología y mineralogía, el profesor alemán Rodolfo Hauthal (1854-1928), quien además era encargado de sección del Museo de La Plata desde 1891, promovió la formación de un gabinete con colecciones europeas y trató de vender algunas de las muestras que había reunido durante sus viajes de estudio. La venta de colecciones, especialmente en extranjero, generó una cierta desconfianza hacia los naturalistas que trabajaban en el Museo y un escándalo con este investigador, quien hacia 1904-1905 viaja por Bolivia y luego retorna a Alemania. Posteriormente Hauthal no pudo reinsertarse en esta Institución pese a sus reiterados pedidos durante la década de 1910, cada vez que se enteraba de un cargo vacante.

${ }^{69}$ Castiñeiras 1985. En el presupuesto de 1901 se establecían doce cargos de profesores para la Facultad de Derecho, ocho para Farmacia, trece para Ingeniería, de los cuales seis tenían dos cátedras, y uno
} 
desempeñada ni reconocida socialmente como una profesión sino más bien como una tarea prestigiosa aunque colateral al ejercicio de otra ocupación o fuentes de ingresos $^{70}$.

En todas las Facultades se permitió la asistencia de oyentes y alumnos libres. Además, en la Facultad de Química y Farmacia se aceptaron como estudiantes regulares a los egresados de las escuelas normales. Recordemos que en esa época, y por muchos años según las carreras, el acceso a las carreras universitarias estaba restringido a los que disponían de título de bachiller o certificado de estudios de los colegios nacionales. El alto costo de los estudios en estos establecimientos y su perfil elitista y masculino, constituyó la principal forma de restricción para la obtención de los diplomas universitarios hasta principios del siglo XX. Los grupos con memores recursos y las mujeres tendrían acceso a la educación postescolar principalmente a través de las escuelas normales. Para estos sectores, la carrera de farmacia en la casa de estudios platense constituyó una de las vías para acceder a un título universitario ${ }^{71}$. En efecto, dentro de esta carrera se graduarían las primeras dos mujeres en 1901 y tres más al año siguiente ${ }^{72}$. Especialmente la norteamericana Mary O. Graham, directora

para la Escuela de parteras. La proporción de docentes por alumno era sumamente elevada, llegando en derecho e ingeniería a ser de un profesor cada dos estudiantes matriculados.

${ }^{70}$ La posición inestable pero prestigiosa que ocupaba la docencia universitaria se puede ilustrar, por ejemplo, en una carta que el geólogo alemán Rodolfo Hauthal le envió a Dardo Rocha, el 31 de enero de 1903. En esos días, la legislatura bonaerense había eliminado del presupuesto los fondos para la Universidad y desde los sectores políticos vinculados a Rocha se intentaba derogar esa medida. En ese contexto, Hauthal exponía su situación: "soy pobre, los 294 pesos que me paga el Museo no alcanzan para mantener mi familia - por esto insisto en la venta de la colección (tenía como 200 pesos en gastos de fletes etc.) y en sueldos que me adeuda la facultad-pero aunque necesito todo mi tiempo para trabajar para mi familia, escribiendo artículos para periódicos alemanes siempre tendré bastante tiempo para trabajar en pro de la erudición de la juventud platense-estoy dispuesto de dictar mis clases gratuitamente en caso, que se suprime la subvención del gobierno para la Universidad". AGN, FDR, Leg. n 2961.

${ }^{71} \mathrm{La}$ concurrencia femenina a las aulas universitarias no era frecuente en aquella época. Las alumnas en la carrera de Farmacia llamaron la atención de Dardo Rocha. En una carta a Rafael Hernández, dando cuenta del primer año de funcionamiento de la Universidad, le comentaba: "en la Facultad de Química existen una señora y dos niñas que habían obtenido las más altas calificaciones entre sus compañeros: es pues la iniciativa de una nueva carrera para la mujer, problema tan interesante de la civilización moderna...." AGN, FDR, Leg. $\mathrm{n}^{\circ} 2958$.

${ }^{72}$ Las primeras dos egresadas fueron: Celia Zeballos de Heredia, quien había estudiado en la Escuela Normal Nacional de la Capital Federal y mientras cursaba dirigía una escuela pública. Luego continuaría estudiando en la Sección Pedagógica de la Universidad Nacional de La Plata, llegando a dirigir el Colegio de Secundario de Señoritas de la Universidad. Isabel Baldevidares, una de las primeras egresadas de la Escuela Normal de Profesoras de La Plata, desde 1884 ejercía la docencia y en 1890 había ingresado a la Escuela Normal de La Plata como profesora, cargo al que renunció cuando comenzó a estudiar en la Facultad. Esta última inició sus estudios universitarios junto a su hermana, quien falleció en 1898. En 1902 se recibieron: María Luisa Rocha, Mercedes Mouzo Oliver y María Luisa Gutiérrez, las tres habían egresado de la Escuela Normal de La Plata en 1897 e ingresado a la Facultad al año siguiente. Posteriormente Gutiérrez continuarían estudiando ciencias naturales y química en el Museo/Facultad de Ciencias Naturales. Las noticias biográficas sobre los primeros egresados de la Universidad pueden consultarse en la Revista del Centro Universitario. 
de la Escuela Normal Nacional de La Plata, promovió que sus alumnas continuaran estudiando en la Universidad.

En 1898 se intentó organizar el primer año de los estudios de medicina, una Escuela de dentistas y otra de parteras como parte de la Facultad de Medicina, pero sólo esta última Escuela comenzó a funcionar hacia 1901. Tampoco se llegó a concretar el proyecto de una escuela de electricistas, que había despertado cierto interés popular; ni los cursos del doctorado en química, que no contaron con alumnos inscriptos, o los estudios de ingeniería industrial o en minas que en cierto momento se bosquejaron. En general, los estudiantes prefirieron las carreras más cortas como agrimensura o farmacia, especialmente esta última contó con condiciones de ingreso menos rígidas y la mayor cantidad de estudiantes y egresados. Sin embargo, la Facultad de Derecho fue la que más peso tendría dentro de la estructura universitaria no sólo por el número de profesores, sino por la composición de su cuerpo docente y académico que se integraba con miembros del poder legislativo, magistratura y otros funcionarios del gobierno. Es de destacar que en la Universidad de Santa Fé, la Facultad de Derecho fue la única dependencia que se consolidó en aquellos años. La importancia de estas Facultades en los proyectos universitarios provinciales de fines del siglo XIX se relaciona con los sectores políticos desde donde se impulsaba, y también con la función que se le asignaban a estas instituciones como espacios de socialización de los futuros grupos dirigentes y de reclutamiento político ${ }^{73}$.

El consejo superior de la Universidad platense y los cuerpos académicos estuvieron compuestos en su mayoría por profesores y el número de sus miembros fue menor que en las otras universidades nacionales ${ }^{74}$. El reclutamiento de docentes y académicos pareció responder a ofrecimientos personales y a la pertenencia a los mismos círculos políticos o sociales, y de hecho, no se dictó ninguna reglamentación específica al respecto. Al igual que en las otras universidades del país, la relación entre clase gobernante, elite intelectual y conducción de esta casa de estudios era

\footnotetext{
${ }^{73}$ Zimmermann 1995; Buchbinder 2000.

${ }^{74}$ Según los Estatutos, la Universidad se regiría por una Asamblea Universitaria integrada por los miembros titulares de las Facultades. Estas últimas se compondrían de doce integrantes, de los cuales al menos una cuarta parte serían profesores. Esto marca una diferencia con la organización de las Universidades nacionales, cuyas Facultades se integraban con quince miembros y según la Ley Avellaneda se permitía que un tercio estuviera conformado por profesores. En la práctica el número de consejeros en la Institución platense fue menor y la participación de personas que también dictaban clases fue mayor de lo establecido. En parte, esto refleja el círculo estrecho dentro del cual se reclutaba su personal, pero también las dificultades para retener un cuerpo estable como se manifestó en varias renuncias y cambios de docentes. Las primeras reglamentaciones de esta institución se pueden consultar en el folleto: Universidad de La Plata 1897.
} 
sumamente estrecha y reflejaba lo reducido del grupo dentro del cual se reclutaban los miembros del gobierno y los funcionarios públicos ${ }^{75}$.

Según Fernando Gandolfi, la precaria situación de la Universidad provincial no debe ser asociada sólo a las contingencias económicas por las que atravesó la Provincia sino a otro conjunto de factores más complejos como la imposibilidad de articular un proyecto político, un modelo pedagógico y un plan edilicio acorde con sus necesidades ${ }^{76}$. Por su parte, Fernando Barba reconoce que la Universidad debió enfrentarse a dos grandes problemas: una baja inscripción de alumnos y la escasez de presupuesto $^{77}$. A su vez, esto dos obstáculos se relacionaron con la imposibilidad de lograr el reconocimiento nacional de los títulos que expedía la Universidad, con su consecuente impacto sobre el número de estudiantes. Esta situación sumada a la inestabilidad institucional de la Provincia y los juegos de alianzas políticas parecieron ser las principales condiciones que actuaron en contra de la consolidación de esta institución. Una revisión de los archivos de Dardo Rocha, las publicaciones estudiantiles y los proyectos legislativos permite constatar que la principal preocupación durante todos los años de funcionamiento de la Universidad provincial se concentró en la búsqueda de legitimación nacional de sus diplomas y certificados de estudios. Esto generó, por un lado, que el Gobierno nacional impusiera como condición previa la adopción de la organización interna, los planes de estudio, los textos y las condiciones de admisibilidad que regían en la Universidad de Buenos Aires, mientras se debía gestionar una decisión favorable tanto de parte del Poder Ejecutivo y como del Legislativo. Por otro lado, la incertidumbre sobre las incumbencias de los títulos y restricciones para el ejercicio profesional provocó que la cantidad de alumnos no se incrementara $y$ en algunos casos disminuyera notablemente. Asimismo, la falta de reconocimiento nacional serviría como argumento para que los grupos opositores a la Universidad pudieran justificar sus críticas y los recortes del subsidio provincial $^{78}$.

Las gestiones para la nacionalización de los títulos comenzaron a los pocos meses de establecerse la Institución. Respondiendo a las gestiones de Dardo Rocha,

\footnotetext{
${ }^{75}$ Botana 1985; Buchbinder 2000.

${ }^{76}$ Gandolfi 1999.

77 Barba 1972, 1995.

${ }^{78}$ Por ejemplo, en una carta que Dardo Rocha le envió a Octavio Bunge el 4 de mayo de 1903, le recordaba el asunto de los títulos de la Universidad e indicaba que: "la falta de inscripción de los diplomas la hacen valer los enemigos de la enseñanza superior para hostilizar esta institución y han estado á punto de suprimirle los recursos”, AGN, FDR, Leg. n 2958.
} 
Carlos Pellegrini presentó el 17 de julio de 1897 en el Senado Nacional un proyecto para que los diplomas de la Facultad de Derecho y Ciencias Exactas de La Plata excluyéndose explícitamente al título de farmacéutico - tuvieran validez en todo el territorio de la República Argentina. La Comisión de Legislación se expidió favorablemente al igual que para una solicitud similar que había presentado la Universidad de Santa Fé. Algunos legisladores defendieron estas propuestas como una forma de descentralización de la enseñanza superior, concentrada en la Capital Federal y que atraía a gran cantidad de estudiantes que eran empleados o becados para financiar sus estudios. De esa forma, a las universidades provinciales podrían concurrir alumnos que disponían de recursos y una vocación por el estudio ${ }^{79}$. Otro de los argumentos que se emitieron para apoyar a las universidades provinciales se relacionaba con el tratado firmado en Montevideo, por el cual se reconocía la validez de los títulos profesionales expedidos por los países americanos dentro de todo el territorio de la República Argentina ${ }^{80}$. En ese sentido, la aceptación de los diplomas de los países vecinos y no los emitidos por las provincias argentinas aparecía como una situación injusta para los graduados de las instituciones del país.

Si bien las solicitudes de las dos Universidades provinciales fueron aprobadas en la Cámara de Senadores, encontraron bastante resistencia y generaron un gran debate entre los diputados. Finalmente, el tratamiento de esta cuestión se aplazó ante la propuesta de elaborar un proyecto más general para todo el sistema universitario. En los siguientes años, tanto Dardo Rocha como los estudiantes nucleados en el Centro Universitario continuarían gestionando ante los sucesivos Ministros de Instrucción Pública y los legisladores nacionales. El expediente que se había iniciado en 1897 fue sometido a la consideración de la Universidad de Buenos Aires para que omitiera su opinión y analizara si ello afectaba sus intereses. Después de los informes favorables tanto del rector de esa Universidad como del Inspector enviado por el Ministerio, el Poder Ejecutivo decretó con fecha del 15 de enero de 1900 conceder la validez nacional de los certificados de estudios. Para ello se fijaba que los planes de estudios, los estatutos y la tarifa de los aranceles debían ser sometidos a la aprobación del Ministerio Nacional correspondiente, al cual también se tendrían que elevar

\footnotetext{
${ }^{79}$ Especialmente véase la defensa a la nacionalización de los títulos emitidos por la Facultad de Derecho de Santa Fé realizada por el senador Figueroa. Sesión del 11/9/1897, Diario de Sesiones de la Cámara de Senadores de la Nación, 1897, II.
} 
informes anuales sobre el movimiento de alumnos y el desarrollo de la enseñanza. Asimismo, se exigía la organización de la enseñanza y los requisitos de ingreso como en las otras casas de estudio de la Nación, quedando en cuanto a títulos y régimen interior en igualdad de condiciones y bajo la vigilancia de la Inspección General. No se permitía la creación de nuevas facultades o escuelas sin la aprobación de la autoridad nacional y previo informe de la Universidad de Buenos Aires. En otro de los artículos, se determinaba que se debía completar su laboratorio de farmacia y fundar: a) un curso práctico de jurisprudencia, b) un taller de enseñanza práctica en la Escuela de Matemáticas y c) una escuela de investigaciones agronómicas o veterinarias. A través de estas últimas disposiciones se volvía a manifestar el interés del presidente Roca y su Ministro Magnasco por fomentar los estudios prácticos-técnicos. Para satisfacer estas demandas se comenzó a planear la creación de una Escuela de Electricistas, que fue especialmente promovida por algunos sectores del Centro Universitario. Al mismo tiempo, la Universidad debió elevar los aranceles estudiantiles y las condiciones de ingreso para responder a las exigencias del Ministerio. Esto último implicó que no pudieran ingresar más maestros normales como alumnos regulares. Paralelamente, los estudiantes solicitaron que se aumentara las exigencias de los exámenes como una manera de legitimar la formación ofrecida por la Universidad platense.

Pese al decreto presidencial, los graduados en abogacía encontraron problemas para legalizar sus diplomas en la Corte Suprema o ante la Facultad de Derecho de Buenos Aires y los de farmacia tuvieron dificultades para anotarse en el Consejo Nacional de Higiene. Los trámites para la nacionalización volvieron a ser impulsados en diferentes ámbitos, especialmente ante los legisladores nacionales, ya que aparecía como imprescindible contar con una ley aprobada por el Congreso. Tanto los estudiantes de Santa Fé como los del Centro Universitario de La Plata se entrevistaron con el presidente Roca y los diputados de sus provincias, quienes elevaron algunos proyectos al respecto. No obstante, el Presidente de la Nación manifestó su disconformidad por legitimar más instituciones que se dedicaran a la formación de abogados. Según el relato de un estudiante, "desde el principio se mostró enemigo de la nacionalización, diciendo que el no creía que fuera una necesidad para el país: que

\footnotetext{
${ }^{80} \mathrm{El}$ convenio de Montevideo sobre ejercicio de las profesionales liberales fue aprobado por la ley nacional del 11 de Diciembre de 1894 y confirmado por decreto del Poder Ejecutivo el 30 de septiembre de 1895 .
} 
había un exceso enorme de abogados sobre las demás profesiones y que desearía que la juventud se dedicara á profesiones mas practicas, tales como el comercio, industria ect. Le manifestamos que si bien es cierto que existe esceso de abogados sobre las demás profesiones, no lo era menos que esto no constituye un peligro, como el parecia dar a entender; que había que tener en cuenta que en estos últimos tiempos las industrias y los progresos materiales habian recibido un impulso poderoso y que habia que equilibrar dichos adelantos con progresos morales é intelectuales, promoviendo la cultura superior y creando clases dirigentes por medio de las universidades." 81

La falta del reconocimiento nacional de los títulos expedidos por la Universidad platense provocó una disminución de los alumnos que comenzaban sus estudios, sobre todo en Derecho. Esto, a su vez, fue motivo para que ciertos sectores bonaerenses pudieran justificar sus críticas hacia la institución e intentaran eliminar del presupuesto provincial la asignación de fondos con los cuales se mantenía la Universidad. Uno de los momentos más difícil ocurrió a fines de 1902 cuando en las discusiones legislativas en torno al presupuesto se decidió suprimir el ítem correspondiente a esta institución y crear becas para que los estudiantes continuaran estudiando en Buenos Aires. Esto último constituyó el golpe más duro, ya que ante el recorte del subsidio algunos profesores se habían ofrecido a dictar clases ad honorem y con el fondo universitario se calculaba cubrir los gastos mínimos, pero sin alumnos la institución no podía funcionar.

La situación de incertidumbre por la que atravesó la Universidad durante esos meses fue un reflejo de la inestabilidad institucional que caracterizó a la situación política de la Provincia durante los primeros años del siglo XX. Esa fragilidad era consecuencia de los reiterados conflictos entre el Poder Ejecutivo y el Legislativo provincial, donde participaban los representantes de más de un centenar de departamentos. A lo cual se sumaban las intervenciones del Gobierno nacional ${ }^{82}$. Tras la normalización de la Legislatura provincial a principios de 1903 se consiguió el cambio de actitud de varios senadores y la reincorporación de la partida presupuestaria para la Universidad ${ }^{83}$. Asimismo, la supervivencia de esta institución fue defendida

\footnotetext{
${ }^{81}$ Carta de Zenón González de la Facultad de Derecho de Santa Fé, a los estudiantes Atanasio Rodrigues y Vicente Añon Suárez de La Plata, con fecha del 3/11/1902. AGN, FDR, Leg. n 2958.

82 Melón Pirro 1994.

${ }^{83}$ En noviembre de 1902 , la mayoría de los diputados provinciales que respondían al sector roquista del PAN pasaron a la oposición del grupo del gobernador Ugarte y expulsaron a tres diputados. Después de
} 
por la nueva gestión al frente del Poder Ejecutivo provincial. En el ámbito legislativo, el Ministro de Gobierno argumentó que esta institución era importante no sólo porque: "representa un foco de cultura, de preparación, de intelectualidad, de formación del espíritu provincial", sino porque sobre ella se proyectaba un gran porvenir para la ciudad. Con relación a ello, se señalaba que si se mantenía la Universidad y los otros centros educativos y científicos que existían en La Plata, aunque pasaran a depender del Gobierno Nacional: "se podrá realizar dentro de poco, en La Plata, un gran plan de instrucción y hacerlo un verdadero centro de ilustración y de estudios. Podemos...hacer de esta ciudad la primera facultad de altos estudios prácticos, que tendrá a su servicio, como auxiliares, una facultad de Agronomía, un gran museo y un Observatorio Astronómico de primer orden." 84

Este anuncio tenía por trasfondo una serie de convenios para el traspaso de algunas de esos establecimientos provinciales a la jurisdicción nacional. Ello formaba parte de la reforma institucional promovida por el gobernador Marcelino Ugarte, a través de la cual montaría una compleja trama de relaciones que le permitiría dominar la situación política provincial ${ }^{85}$. Al iniciar su administración a principios de 1902, se declaró que la Provincia se concentraría en la instrucción elemental y dejaría a los poderes federales la educación superior, que de esa forma dispondría de mayores recursos y al mismo tiempo permitiría aliviar el presupuesto provincial. En esos días, desde las columnas del periódico oficialista, El País, se anunciaba: "la Universidad de La Plata, su museo, su observatorio, la escuela de artes y oficios y demás institutos de enseñanza superior o técnica, serán impulsados vigorosamente en su desenvolvimiento por el tesoro nacional...Si alguno de los institutos así entregados á la superintendencia federal resultase insuficiente ó susceptible de adquirir mayor amplitud y eficacia para sus fines educativos, podría refundirse con otro análogo y constituir un monumento científico de la Nación. No ocultamos que ese sería nuestra ambición patriótica respecto al museo, que unido al de esta capital y bajo la dirección de una alta personalidad técnica como el doctor Moreno, llegaría, sin duda, á ser el primero de América y uno de los más ricos y completos del mundo....La propaganda científica, cimentada por estos grandes institutos, de que se enorgullecen las naciones más grandes de la tierra, sería de

\footnotetext{
varios conflictos, el Poder Ejecutivo logró controlar la situación y tras la intervención federal se normalizó el funcionamiento de la Legislatura. A principios de 1903, se derogaron varias de las medidas que se habían sancionado durante los meses que duro el enfrentamiento. Melón Pirro 1994.

${ }^{84}$ Sesión del 22/12/1902. Diario de Sesiones del Senado de la Provincia de Buenos Aires, 1902: 48.

${ }^{85}$ Barba 2000.
} 
particular eficacia y alta conveniencia para estimular la inmigración europea, atraer capitales y dar expansión al comercio y las industrias, promoviendo exhibiciones locales y viajeras de las riquezas naturales acumuladas en varios ejemplares, en el gran museo argentino." 86

La búsqueda de la utilidad pública de la ciencia, como ha señalado Irina Podgorny, no fue suficiente para conseguir recursos y evitar las crisis por las que atravesarían las instituciones científicas y provinciales en aquellos años ${ }^{87}$. Por otra parte, el apoyo poco sistemático que encontraban los investigadores dependía del oscilante juego de alianzas políticas y contactos personales, que terminaba por enfrentar a los grupos de científicos por los pocos espacios y favores estatales ${ }^{88}$. En este sentido, es interesante señalar que esa nota periodística apareció unos días después del fallecimiento de Carlos Berg, director del Museo Nacional de Historia Natural, y diferentes sectores comenzaron a disputarse ese espacio ${ }^{89}$. En ese contexto, Francisco P. Moreno, fundador y director del Museo de La Plata, bosquejó el proyecto de fusionar ambos Museos bajo su dirección ${ }^{90}$. No obstante, el Ministro interino de Instrucción Pública, Joaquín V. González, pareció tener otros planes para estas instituciones. En el caso del de Buenos Aires nombró como nuevo director a Florentino Ameghino y apoyó la reorganización propuesta por este último. Con respecto al Museo de La Plata, las ideas que circulaban en la prensa oficialista y entre algunos miembros del círculo de González, apuntaban hacia la integración de este instituto en un centro de educación superior al estilo de las universidades norteamericanas.

\footnotetext{
86 "Institutos de Instrucción Superior", El País, 1/3/1902

${ }^{87}$ Podgorny 2000.

${ }^{88}$ Podgorny 2001.

${ }^{89}$ Los nombres que circularon como posibles reemplazantes fueron los de Fernando Lahille, Florentino Ameghino, Angel Gallardo, Eduardo Holmberg, Francisco P. Moreno y Linch Arribálzaga. Véase entre otros, la correspondencia de Ameghino durante esa época, especialmente las notas de Ameghino al presidente Roca y a su ministro Joaquín V. González presentando su proyecto para el Museo de Buenos Aires. Ameghino 1932. También en la Facultad de Ciencias Exactas, Físicas y Naturales de Buenos Aires y en la Sociedad Científica Argentina se consideró la idea de incorporar al Museo bajo su supervisión. Sisson 1902.

${ }^{90}$ En una carta del 21/1/1902, Ameghino le comenta a Herman von Ihering que todavía no se había reemplazado a Berg y menciona las intenciones de Moreno al respecto: "el odio que éste señor me profesa es tan grande, que temiendo que quizá pudiera ser yo nombrado como reemplazante de Berg, mandó un telegrama al Presidente, pidiendo que retardaran el nombramiento del sucesor de Berg hasta que él regresara, pues tenía proyectos importantes que comunicar al Gobierno. El gran proyecto de Moreno consiste en refundir ambos Museos de La Plata y Buenos Aires en uno solo, bajo la Dirección de él!. No sé si el gobierno hará todos los caprichos de este señor....”. Ameghino 1932, XXII: 65-66, carta $\mathrm{n}^{\circ}$ 1531. Después del nombramiento de Ameghino, los planes de Moreno cambiaron con respecto al Museo de La Plata. Véase, por ejemplo, en el mismo volumen una comunicación personal de Julio Migoya García a Ameghino, con fecha del 23 de junio de 1902. Ibíd.: 421 , $\operatorname{carta}^{\circ} 1868$.
} 
El educacionista José B. Zubiaur (1856-1921) enfatizó especialmente en ello al describir la vida de los estudiantes argentinos becados en instituciones de Estados Unidos y Canadá durante su viaje en 1901. A partir de esas observaciones concluía que: "el estudiante argentino empieza á hacer aquí, con cierta tímidez ó desgano todavía, lo que hace el estudiante norteamericano, y no tengo ninguna duda de que lo haría de mejor gana alli si se le pusiese en el elemento adecuado, que quizás pudiera ser la ciudad de La Plata, con su espléndido museo, su observatorio astronómico, su facultad de agronomía, su escuela de artes y oficios y el parque y anexos en que está todo eso contenido, dedicando á oficinas públicas nacionales esos inadecuados edificios de las facultades de la capital federal, con excepción de la de medicina, que quedaría bien donde está." 91.

Tanto Zubiaur como otro conocido educacionista, Ernesto Nelson (1873$1955)^{92}$, después de visitar las universidades norteamericanas coincidían en admirar el establecimiento de esos centros en plena naturaleza, lejos de los lugares poblados, formando verdaderas ciudades donde se vivía un medio "depurado" y noble. En relación con ello, también consideraban que ese ambiente fomentaba entre los jóvenes un estrecho espíritu de camaradería entre ellos y con los profesores. De esa forma, ese tipo de convivencia era visto como el elemento más adecuado para estimular las actitudes de tolerancia, respeto y cooperación. Por otro lado, ambos coincidían en señalar que las diferencias que se observaban entre los resultados alcanzados por esas instituciones y la educación superior en la Argentina no se debían a una cuestión de raza, como sostenían varios autores de la época, sino al tipo de ambiente en el cual se desenvolvían las universidades ${ }^{93}$. De esa forma, mientras el problema no estribaba en

\footnotetext{
${ }^{91}$ Zubiaur 1904: 81. José B. Zubiaur fue compañero de J. V. González en la comisión didáctica del Consejo Nacional de Educación hacia 1899 y también su amigo. Desde diferentes ámbitos fomentó innovaciones educativas como excursiones escolares, instalación de museos, plazas de juegos y la difusión de la enseñanza manual, agrícola e industrial. Tradujo a Pestalozzi y otros trabajos sobre educación, además de ser enviado a observar la organización de la educación primaria en Europa. Entre mayo de 1901 y octubre de 1902, viajó por Estados Unidos y Canadá, publicando sus impresiones en La Nación y Tribuna y en varios libros. En ese viaje se preocupó por observar la organización de la enseñanza agrícola-ganadera y visitar las universidades donde había becados y estudiantes argentinos para realizar un informe a pedido del Ministro de Justicia e Instrucción Pública. Zubiaur destacó especialmente la organización de los estudios de la Universidad de Cornell, institución que también sería bastante citada por Joaquín V. González como uno de los modelos a partir del cual se pensó el proyecto de la Universidad Nacional de La Plata.

${ }^{92}$ Nelson 1914. Ernesto Nelson, realizó estudios en la Universidad de Columbia y posteriormente fue comisionado por el Consejo Nacional de Educación entre 1906 y 1908 para observar la organización de la educación en Estados Unidos. A su regreso fue convocado por González para organizar y dirigir el Internado del Colegio Nacional. Sobre esto último véase: Gentile y Vallejo 1999.

${ }^{93}$ Un cierto debate sobre el origen de la "superioridad anglo-sajona" se había abierto a partir de la popularización de la obra de Demolins, en la que se reducía esa superioridad a la educación y las
} 
condiciones inherentes a una determinada raza, se abrían posibilidades para la Argentina a partir de crear o recrear los ambientes físicos y sociales adecuados para la formación de una nueva clase dirigente. En este sentido, la ciudad de La Plata aparecía como un lugar ideal para experimentar en la constitución de un nuevo tipo de sociabilidad.

La creación de un gran centro intelectual o universidad modelo, en la cual se integrarían los institutos científicos de La Plata fue especialmente promovido desde las páginas del El País, periódico del Partido Autonomista Nacional. Esta campaña sería apoyada por el Centro Universitario platense que desde hacia unos años venía gestionando por la nacionalización de los títulos de la Universidad. Este Centro se había creado en 1898 como una sociedad estudiantil que reunía alumnos de las distintas Facultades platenses, incluida la de Agronomía y Veterinaria, y a los que estudiaban en Buenos Aires. Además, como socios honorarios y protectores se incluían a graduados, profesores $\mathrm{y}$, en general, a todos los que tenían un título universitario, se afiliaran y abonaran una cuota. Inicialmente se organizó de forma similar a otras sociedades como la Unión Universitaria de Buenos Aires o la Asociación General de Estudiantes de París ${ }^{94}$. Al igual que ellas, terminó dividiéndose a partir de grupos más especializados por carreras y que prefirieron organizarse separadamente. De esa forma, los alumnos de agronomía y veterinaria se separaron tempranamente y conformaron su propia asociación en 1900: el Centro de Agrónomos y Veterinarios. Por su parte, el Centro Universitario funcionó hasta aproximadamente 1903, dedicándose a editar una revista de divulgación científica, organizar conferencias y actos patrióticos ${ }^{95}$. Una de sus principales preocupaciones fue lograr el reconocimiento nacional de los títulos y el mantenimiento de la Universidad, para lo cual desplegaron numerosas acciones tanto en el ámbito provincial como nacional. De forma separada, también los alumnos de agronomía y veterinaria ante los rumores de la

características de la raza sajona. Entre las impugnaciones a esa idea se destacaron las de académicos franceses como Charles Seignobos, cuya carta de réplica "Monsieur Desmolins" fue traducida y publicada en la Revista de Derecho, Historia y Letras. Seignobos 1901. En esa Revista también se publicaron otros comentarios críticos como los de Felipe Semillosa, quien concluía que: "no es la raza la que produce el estado de un pueblo, sino el ambiente que predomina en las costumbres ó sea el estado social y político el que determina á la larga, las peculiaridades de la raza ó de los pueblos...." Semillosa 1900b: 107. Véase también Semillosa 1900a.

${ }^{94} \mathrm{La}$ formación de Centros de Estudiantes por Facultad con un carácter más marcadamente gremial es una característica del siglo XX. A fines del siglo XIX, el modelo de organización estudiantil de la Argentina correspondía principalmente al de una asociación general como la de París. Véase al respecto el Capítulo II

${ }^{95}$ Azzarini 1963. 
nacionalización de su Facultad, iniciaron una campaña para que se otorgara validez nacional a los diplomas otorgados por dicho establecimiento. Posteriormente, la movilización de los distintos grupos estudiantiles por la nacionalización de los títulos se desplazaría hacia la nacionalización de las casas de estudio. Por otro lado, la inestabilidad institucional provincial llevó a que varios de los centros educativos y científicos de La Plata buscaran una mayor seguridad bajo el amparo del Gobierno Nacional.

En 1902 se promovieron los primeros acuerdos para la nacionalización del Observatorio, la Facultad de Agronomía y Veterinaria y el Instituto de Santa Catalina. Sin embargo, durante la presidencia de Roca esos traspasos quedarían inconclusos y recién se reactivarían bajo la presidencia del bonaerense Manuel Quintana a fines de $1904^{96}$. Por otro lado, la alineación de ciertas fracciones de las fuerzas políticas provinciales y nacionales generó una coyuntura favorable para concretar esas iniciativas. En esa época, el gobernador Marcelino Ugarte se había consolidado como la principal fuerza política dentro de la provincia y en el ámbito nacional había logrado imponer la candidatura presidencial de Quintana. ${ }^{97}$. Dentro de la nueva gestión, Joaquín V. González fue convocado como Ministro de Justicia e Instrucción Pública y desde ese lugar elaboraría el proyecto de creación de la Universidad Nacional de La Plata. Con fecha del 12 de febrero de 1905, González presenta al gobernador Ugarte, una memoria en donde se reseñaba un proyecto de ley para el establecimiento de una universidad nacional en la ciudad de La Plata ${ }^{98}$. La misma se organizaría sobre la base de una serie de instituciones educativas y científicas dependientes, hasta ese momento, de la administración provincial. Estas abarcaban: la Universidad de La Plata, la Facultad de Agronomía y Veterinaria, el establecimiento de Santa Catalina, el Museo General de La Plata, la Biblioteca Pública, el Observatorio Astronómico, el Colegio Nacional y dos escuelas que finalmente no se incorporarían: y la de Artes y

\footnotetext{
${ }^{96}$ En noviembre de 1902 se acordó con el Ministro de Justicia e Instrucción Pública de la Nación, Juan Fernández, que se cedería la Facultad de Agronomía y Veterinaria, el Observatorio Astronómico y el establecimiento de Santa Catalina, ubicado en Lomas de Zamora. Estos traspasos de la esfera provincial finalmente se concretaron en diciembre de 1904, bajo la gestión ministerial Joaquín V. González. Unos meses después, la Provincia también cedió un terreno para la construcción de un colegio nacional modelo. Castiñeiras 1985. Cabe señalar que como contra partida el Gobierno Nacional se comprometió a saldar una serie de deudas e hipotecas que pesaban sobre algunas de esas propiedades. Por otro lado, varios de los terrenos cedidos por la Provincia para la creación de la Universidad Nacional nunca se lograron recibir, ya que fueron enajenados por el Gobierno provincial antes de la sanción definitiva del convenio-ley o fueron reclamados por particulares.

${ }^{97}$ Barba 2000.

${ }^{98}$ González 1935, XIV; Castiñeiras 1985; Biagini 1999.
} 
Oficios, que fue cerrada en 1905 y la Escuela Normal que se reorganizó en esa época, pero se mantuvo independiente.

Esta iniciativa pareció responder inicialmente a las expectativas de distintos sectores intelectuales y políticos platenses. En efecto, los grupos de estudiantes así como la prensa de distintas orientaciones como El $\mathrm{Dí}^{99}$ o la revista católica el Siglo Ilustrado $^{100}$ celebraron esa propuesta como la culminación de los trámites para la nacionalización de los diplomas que se gestionaba desde hacia años. También otros sectores, como los nucleados en la Cámara de Comercio, festejaron el proyecto pensando que la instalación de una gran universidad podría reactivar el poblamiento y la actividad económica de la ciudad. Otros, en cambio, lo apoyaron con la esperanza de mantener o conseguir un lugar en la nueva institución. Entre ellos, no faltaron figuras destacadas de los grupos católicos platenses como Enrique Plack ${ }^{101}$, quien posteriormente se integraría al heterogéneo grupo que intentó impugnar la nueva Universidad. En relación con ello, si bien el proyecto de González intentó articular los intereses de distintos actores e instituciones, no a todos los sectores se les otorgaría el espacio deseado $\mathrm{y}$ en el funcionamiento de la Universidad también surgirían nuevas redefiniciones.

De esa forma, hacia 1905, momento en que se presentó oficialmente el ambicioso proyecto universitario esbozado por el Ministro de Instrucción Pública

\footnotetext{
${ }^{99}$ Inicialmente el periódico El Día, pese a no ser favorable al grupo de Ugarte, defendió el proyecto de la Universidad Nacional. De hecho, a fines de 1905 promovió una colecta popular para adquirir una casa para que González se instalara en La Plata. Sin embargo, un año después desde este diario comenzaría a impugnar la nueva cada de estudios y en sus páginas se dio lugar a las críticas realizadas por los antiguos miembros de las instituciones provinciales que fueron desplazados con la nacionalización. Durante la década de 1910, este periódico formaría parte del aparato político del radicalismo y desde allí se continuó criticando duramente a la Universidad platense.

${ }^{100}$ Es interesante señalar, mientras en las páginas de esta revista católica local se apoyaba la creación de una universidad que se presentaba como científica, bajo el título de "Fosforescencia científica" se criticaba la tendencia hacia la enseñanza científica que se quería instrumentar en las escuelas primarias. Los católicos habían ganado una batalla en 1903 al lograr que se permitiera la educación religiosa durante la reforma de los planes de estudio primarios de la Provincia. Sin embargo, ello no duró mucho ya que en las transformaciones curriculares de 1905 se volvería a eliminar ese tipo de enseñanza y al mismo tiempo se incorporaría mayor cantidad de asignaturas de ciencias naturales. Sobre los cambios curriculares en las escuelas primarias de Provincia de Buenos Aires, véase: Pineau 1997.

${ }^{101}$ Enrique Plack participó en varias instituciones de orientación católica de la época, tanto de Buenos Aires como de La Plata. Fue redactor en la revista platense El Siglo Ilustrado, presidente de una Sociedad Protectora de la Educación y la Buena Prensa, de la Academia de Sociología de la Congregación de ex-alumnos del Colegio del Salvador de Buenos Aires, la Asociación "La Defensa del Hogar Obrero" creada en 1905. Además, fue profesor de filosofía del derecho en la Universidad provincial y conferencista en los ciclos de lecturas dominicales de la Biblioteca Pública de La Plata. Hacia 1904 comenzaría a competir con los socialistas por el análisis y la resolución de la cuestión social, organizando conferencias y fomentando la creación de círculos de obreros, especialmente en el barrio de Tolosa. En 1907 pasó a integrar un Comité Pro-Universidad, que criticaría duramente a la
} 
existía una serie de condiciones políticas favorables que convergieron con los intereses de distintos grupos locales que buscaban impulsar el desarrollo de la ciudad de La Plata y sus instituciones educativas. En este sentido, es destacar lo rápido que fue aceptado este proyecto en las distintas instancias oficiales, frente a las inconclusas gestiones relacionadas con las reformas universitarias o la nacionalización de títulos de las Facultades provinciales, que en general caducaron en los cajones de las comisiones asesoras del Congreso Nacional.

Los conflictos estudiantiles de la Universidad de Buenos Aires habían agudizado el cuestionamiento hacia el funcionamiento de la institución universitaria. Si bien en las propuestas de esos años se atendió principalmente a la reorganización del régimen de gobierno, aparecieron otros reclamos vinculados a nuevas tareas que debían ser abordadas por la universidad. En esos años se observa que términos como "extensión universitaria", la "universidad en el exterior" o la preocupación por organizar la vida estudiantil aparecieron incorporados en el vocabulario de académicos, legisladores y otros sectores universitarios. En ese contexto, la Universidad Nacional de La Plata se presentaría como la encarnación de los nuevos tiempos y las tendencias modernas en educación superior, como se examina en los siguientes capítulos. En ese proyecto, una cierta redefinición del papel social y nacional de la universidad y los grupos intelectuales ligados a ella sería reforzado a partir de las lecturas de las propuestas sustentadas por reformadores académicos franceses en la Revue International $d^{\prime}$ Enseignement; las tendencias educativas norteamericanas difundidas en la Educacional Review, y posteriormente se sumaría la propaganda de los regeneracionistas españoles de la Universidad de Oviedo y la Institución de Libre de Enseñanza. Como se intenta demostrar en los siguientes capítulos, esas lecturas internacionales acusaban un movimiento hacia la incorporación de nuevas y variadas tareas educativas, científicas y sociales por parte de la Universidad. 
Justicia e Instrucción Pública. 


\title{
Capítulo II
}

\section{La república universitaria platense}

\begin{abstract}
"La misión más alta de las universidades en la época presente es, así, instruir la conciencia en la noción real de las cosas y del medio en que vive, y educar las voluntades y los afectos para hacer posible y habitual la cooperación individual y social, sobre que se funda la existencia pacífica y el bienestar de toda comunidad que aspire a perpetuarse....

"La universidad tradicional reclama urgentemente una reforma fundamental: extender su dominio en el espiritu de la juventud, acrecentar sus responsabilidades en la obra educadora del país."2
\end{abstract}

En el capítulo anterior se examinó el clima de ideas con respecto al funcionamiento de las instituciones universitarias argentinas en la transición del siglo del XIX al XX. Las discusiones giraron inicialmente en torno al régimen de gobierno interno, las formas de financiamiento para lograr una autonomía económica y didáctica y una preocupación por el tipo de formación que se brindaba a las futuras elites dirigentes. A ello se sumarían nuevos reclamos por la incorporación de actividades de investigación, cursos libres y extensión universitaria como forma de promover el mejoramiento de la enseñanza universitaria y una mayor difusión cultural entre distintos sectores sociales. En ese contexto, el proyecto universitario pensado para la ciudad de La Plata se erigía con un carácter renovador frente a los reclamos de reforma universitaria que caracterizaron el inicio del siglo y paralelamente intentaba satisfacer las demandas de los grupos intelectuales de la ciudad.

Por otra parte, la fundación de la Universidad Nacional de La Plata ha sido ubicada dentro de una serie de iniciativas impulsadas por un sector de la élite política e intelectual, caracterizado como "reformista liberal"3. Ese grupo, dentro del cual se ha ubicado la figura de Joaquín V. González, asoció el interés por una reforma social con preocupaciones de regeneración político-institucional ${ }^{4}$. Como parte de esas

\footnotetext{
${ }^{1}$ González 1935 XIV: 239.

2 Nelson 1914: 171.

${ }^{3}$ Zimmermann 1995

${ }^{4}$ Sobre la trayectoria política de Joaquín V. González y su participación en los debates en torno a los problemas sociales y político-institucionales, véase, entre otros, Botana 1985 ; Roldán 1993; Halperin
} 
aspiraciones, la nueva casa de estudios se puso en marcha con amplios objetivos educativos, políticos y científicos. El vasto plan universitario apuntaba a formar un nuevo tipo de intelectual, que sobre la base del saber científico, pudiera gestionar el desarrollo económico del país y la resolución de los problemas sociales ${ }^{5}$. En ese sentido, la propuesta institucional se justificó en la necesidad de crear un establecimiento moderno y de carácter científico que respondiera a los cambios que se estaban operando en el país. Para ello se intentaría adaptar localmente los modelos y las últimas tendencias en educación que se observaban en Europa y Estados Unidos. Desde esa perspectiva, la nueva universidad fue pensada como una institución "multifuncional" adaptada a las necesidades sociales locales y al desarrollo de nuevas tareas: investigación científica, educación en todos los niveles y extensión universitaria $^{6}$. De hecho, el lugar desde donde se impulsó la creación de la Universidad Nacional de La Plata, permitió que la nueva institución contara inicialmente con amplios recursos, planes de estudios propios y una estructura académica particular.

El presente capítulo esta dedicado a examinar la construcción de un discurso sobre la universidad como se manifestó en la casa de estudios platease. Para ello se tomó como eje de análisis el proyecto universitario y los discursos académicos de Joaquín V. González, las opiniones de otros sectores universitarios acerca de la "función" o misiones de la institución universitaria. Más allá del éxito o fracaso en la aplicación de algunas de esas ideas y del funcionamiento real de la institución, el discurso fundacional de esta casa de estudios permite observar la circulación y emergencia de nuevos sentidos sobre la universidad y los grupos ligados a ella. En particular, una fuerte convicción en el papel de la educación y la ciencia para la regeneración social y la construcción de un verdadero régimen democrático, cobraría una cierta difusión entre los estudiantes platenses como se manifestó en las distintas iniciativas de popularización científica y extensión universitaria, como se analiza al final de este capítulo y en el siguiente.

II. 1. El proyecto universitario y educativo de Joaquín V. González

Donghi 2000. Alejandro Crispiani 1999 ha relacionado la actuación política de González y sus propuestas reformistas y educativas con el proyecto de creación de la Universidad Nacional de La Plata.

${ }^{5}$ Graciano 1998.

${ }^{6}$ Podgorny 1995; Caldelari y Funes 1997. 
El proyecto de la Universidad Nacional de La Plata fue elaborado en sus lineamientos generales por Joaquín V. González durante su gestión al frente del Ministerio de Instrucción Pública, entre fines de 1904 y principios de 1906. En esa propuesta se plasmaría gran parte de las preocupaciones que atravesaban los debates educativos de la época y además el interés por fomentar un nuevo tipo de sociabilidad tanto en el intramuros académicos como con la sociedad externa. En relación con ello, Ricardo Nassif ha señalado que este político-intelectual manifestó un profundo optimismo con respecto al poder de la educación como instrumento esencial para el progreso de la sociedad y como condición básica para el desarrollo de la democracia. Al igual que los regeneracionistas españoles ${ }^{7}$ y republicanos franceses ${ }^{8}$, reconocía a la educación una funcionalidad política en un doble aspecto: como elemento estabilizador del régimen republicano y como medio para la conformación de una unidad nacional. Estas ideas se sustentaban en la convicción de que el hombre se desempeñaba en la vida de acuerdo con la educación que había recibido y de la influencia que aquella ejerciera sobre su espíritu. Desde esa perspectiva, las personas actuaban según el grado de cultura intelectual y espiritual que habían alcanzado, y de acuerdo a la orientación que esa cultura asumiera frente a los problemas fundamentales del individuo y la sociedad.

En marco de esas ideas, la nueva Universidad era concebida como una fuerza transformadora capaz de actuar sobre los caracteres étnicos e históricos de la sociedad para "remodelar el pasado, disciplinar el presente y orientar el futuro" ${ }^{9}$. La principal misión que se asignaba a la enseñanza universitaria era forjar la integración social y espiritual de la nación, entendida esta última en términos de una entidad cultural. En particular, los discursos académicos de González sobre la nueva universidad y la educación argentina en general, girarían en torno al "trabajo de unificación social" que debía realizarse sobre el "heterogéneo conjunto étnico" que poblaba el país. Dentro de

\footnotetext{
${ }^{7}$ El movimiento regeneracionista y especialmente el llamado "grupo de Oviedo", entre los que se puede mencionar a Rafael Altamira, Adolfo Posada, Adolfo Alvarez Buylla y Fermín Canella Secádes traía a primer plano la cuestión educativa como artífice prioritario en la solución de los problemas del país, pretendiendo que la educación sea el motor del cambio y de la transformación social. Este grupo estuvo nucleado inicialmente en torno a la Universidad de Oviedo, desde donde se promovió una campaña de afianzamiento de los vínculos hispano-americanos. Muchos de ellos participaron o estuvieron vinculados de alguna forma a importantes instituciones españolas como: la Institución Libre de Enseñanza de Madrid, dirigida por Francisco Giner de los Ríos, el Instituto de Reformas Sociales, el Museo Pedagógico de Madrid, fundado y dirigido por Manuel Cossio y la Junta para la Ampliación de Estudios. También este grupo ha sido vinculado a los postulados krausistas y krausopositivistas. Véase entre otros: Luzuriaga 1957; Palacios Lis 1985; AAVV 1989; Uría 1994.

${ }^{8}$ Weisz 1983.
} 
ese proyecto, se asignaría un papel fundamental a los maestros y educadores: "no sólo deben ser capaces de educar al hombre para la vida civilizada, sino crear y modelar el tipo de ciudadano y miembro de una República culta, honesta y laboriosa"10.

La búsqueda de los mecanismos que aseguraran una cohesión social interna fue un problema que las élites dirigentes comenzaron a percibir como problemático desde la crisis de 1890, especialmente frente la inmigración y la conformación de los partidos políticos "modernos"11. En ese sentido, la integración social que prometía la educación universitaria intentaba solucionar los "males históricos nacionales": la lucha entre distintas facciones políticas; y contrarrestar las "fuerzas disolventes que llegaban del exterior": la población inmigrante y las protestas sociales. En relación con ello, González constantemente resaltaba el ejemplo de Inglaterra, que debía la asimilación de sus diversas colonias y regiones, a la acción de las cincuenta y dos universidades del imperio antes que a la de sus acorazados y ejércitos. Así si Gran Bretaña había utilizado esa fuerza cultural para la tarea política de asimilación y cohesión nacional, no había que dudar de aplicarla en la sociedad argentina para la construcción de la nación y como medio para asegurar el orden social. También otras experiencias internacionales, especialmente la norteamericana, mostraban como la acción de las universidades contribuía a la formación de la "fraternidad democrática de la nación". En este sentido, González señalaba que en la casa de estudios platense se había "emprendido la olvidada misión de la universidad educadora a la vez que instructiva, en la creencia de que los núcleos fraternales del colegio, prolongados en las aulas facultativas y después en los estratos profesionales del mundo externo, se elaboran las uniones más extensas y fecundas de la vida colectiva de la nación, para fundar o consolidar, en su medida, la gran conciliación de los núcleos sociales.... ${ }^{12}$

Al mismo tiempo, la Universidad platense como encarnación de los nuevos tiempos de la República Argentina también debía asumir múltiples funciones. Su creación se justificó en la necesidad de contar con un nuevo modelo de institución "científica" y "moderna". A partir de una lectura histórica de la ley de diferenciación de Spencer, González señalaba que cada momento de la vida del país había engendrado un tipo de institución universitaria. De esa forma, la creación de la Universidad de Córdoba había correspondido a la época colonial, la de Buenos Aires a

\footnotetext{
${ }^{9}$ González 1935, XVI: 69-77.

${ }^{10}$ González 1935, XV: 80.

${ }^{11}$ Botana y Gallo 1993.
} 
la independencia y la de La Plata estaba destinada a acompañar la época moderna basadas en el "espíritu científico" ${ }^{13}$. Una cierta convicción en la capacidad mística de la ciencia para transformar la realidad y alcanzar la verdad corrió paralela a los discursos que enfatizaban los valores morales y sociales que se derivaban de una educación basada en un método científico, como se analiza en el siguiente capítulo. De hecho, el énfasis en la adopción de este método para todas las áreas de conocimiento se volvió la ideología oficial de la Universidad, y lo que además permitía justificar su unidad por encima de las crecientes especializaciones. Por otro lado si la retórica "cientificista" ${ }^{14}$ respondía a las preocupaciones por el mantenimiento del orden social y la unidad nacional, también permitía encuadrar los reclamos profesionales de los científicos y de aquellos que buscaban legitimar sus prácticas y saberes a través del prestigio técnico y simbólico de la ciencia.

En líneas generales, la relevancia del nuevo centro educativo se fundamentó en tres sentidos: a) socioeconómico, definido en términos un adecuado entrenamiento profesional y la aplicabilidad de la ciencia para la resolución de los problemas sociales y el desarrollo económico del país, b) cultural, en relación con la promoción de distintas campos del saber y la construcción de la identidad nacional, c) político, en el sentido de la educación del ciudadano y una selecta clase dirigente, comprometida con los propósitos de renovación de los hábitos politicos-institucionales del país. Paralelamente, el ambicioso programa también pretendía ensayar una reforma de algunos aspectos organizativos y didácticos que hasta entonces habían prevalecido en la educación superior argentina. Según González, ya no había: " en el país mucho ambiente ni espacio bastante para una tercera universidad del tipo de las clásicas de Buenos Aires y Córdoba; pero precisamente, en esa convicción, pienso que una tercera universidad de tipo moderno y experimental, que se aparte de aquellos por su organización, diferente carácter y métodos de sus estudios, sistema de gobierno interior y direcciones especiales y prácticas de sus diversas secciones, no sólo tendría cabida fácil, sino que respondería a una necesidad evidente de todas las clases sociales de la Nación, y en particular, de las que miran más a la prosperidad general, bajo su faz cientifica y económica, que del solo punto de vista literario...... "15

\footnotetext{
12 González 1935, XVI: 17.

${ }^{13}$ Podgorny 1995.

${ }^{14}$ Soler 1968, Terán 1987.

15 González 1935 XVI: 35.
} 
En efecto, las características innovadoras y particulares con las que se quiso distinguir a la nueva casa de estudios abarcaron varios aspectos. Algunos de ellos apuntaron al régimen de gobierno interno y la autonomía económica, la valorización institucional de disciplinas hasta ese momento marginalizadas o no incluidas en el curriculum universitario, la promoción de la actividad científica y los estudios experimentales, una redefinición de la tarea educativa de la universidad, la integración de distintos niveles educativos y la difusión científico-cultural, entre otras propuestas ${ }^{16}$. González apuntaba a generar un nuevo tipo de universidad que se abocaran al desarrollo de nuevas carreras y estudios científicos que pudieran ser aplicados para el estudio de las cuestiones sociales como en el uso de los recursos locales. De esa forma, la universidad era presentada como el ámbito donde se conjugaría el debate científico y con las soluciones a los problemas sociales y económicos del país. Junto con una formación profesional con base científica se pensaba inculcar a los alumnos en la responsabilidad de los universitarios hacia los problemas sociales del país y fomentar entre ellos lazos de solidaridad y confraternidad.

La estructura académica de la nueva universidad se erigió sobre la base de los establecimientos provinciales preexistentes y creando algunas secciones más. En ese sentido, González señalaba que la organización de los estudios superiores respondía a un quadrivium diferente del que existía en las restantes universidades del país ${ }^{17}$. Inicialmente comenzaron a funcionar las siguientes unidades académicas: a) la Facultad de Ciencias Jurídicas y Sociales, que incluiría además: la Sección Pedagógica, la cual se separaría en 1914 para formar la Facultad de Ciencias de la Educación; y una Sección de Filosofía, Historia y Letras creada en 1909, que luego pasaría a formar parte de esta última Facultad; b) el Instituto del Museo y Facultad de Ciencias Naturales, constituida por tres escuelas: la de Ciencias Naturales, la de

\footnotetext{
${ }^{16}$ Esto es mencionado, entre otros, en: Nassif 1967; Biagini 1999; Caldelari y Funes 1999; Podgorny 1995.

${ }^{17}$ En esa época la Universidad de Buenos Aires estaba conformada por cuatro Facultades: la de Medicina (que incluía las carreras de ciencias médicas, odontología y farmacia), la de Derecho y Ciencias Sociales (que otorgaba el título de abogado y doctor), la de Ciencias Exactas, Físicas y Naturales (que principalmente formaba ingenieros y en la que se incluían los estudios de arquitectura, química, ciencias naturales y de ciencias fisico-matemáticas) y la de Filosofía y Letras (con cursos para el doctorado en filosofía y letras y otros especiales para la formación docente). En 1909 se incorporaría como Facultad al Instituto Nacional de Agronomía y Veterinaria creado en 1904, y en 1913 los estudios de ciencias económicas. La Universidad de Córdoba estaba conformada por tres Facultades: de Ciencias Médicas, de Ciencias Jurídicas y Sociales y la de Ciencias Físicas y Naturales (que formaba
} 
Química y Farmacia, una de Geografía con una Escuela anexa de Dibujo, c) Facultad de Agronomía y Veterinaria, con la Escuela Práctica y establecimiento productivo de Santa Catalina, y d) el Instituto del Observatorio y Facultad de Ciencias Físicas, Matemáticas y Astronómicas, conformada inicialmente por una Escuela de Matemáticas y un Instituto de Física. Para la dirección del Observatorio y como decano de esa Facultad se contrató al astrónomo italiano Francisco Porro de Somenzi ${ }^{18}$, cuya actuación en la institución fue cuestionada por los consejeros académicos de esa Facultad y finalmente sería exonerado por una asamblea universitaria en 1910. El funcionamiento inicial de esta institución fue bastante problemático durante los primeros tres años debido a conflictos internos de poder que se hicieron públicos en la prensa diaria, los reclamos de los alumnos por la enseñanza de física en 1906 y luego el de estudiantes propios de esta Facultad por la organización y sanción oficial de los planes de estudio para las distintas orientaciones de ingeniería, arquitectura y el doctorado en física ${ }^{19}$. Finalmente las autoridades universitarias promovieron la reorganización de esta Facultad en 1909 y la contratación de científicos alemanes para estimular los estudios e investigaciones en ciencias físicas. Durante la década de 1910 la Escuela/Instituto de Física se convertiría

principalmente ingenieros civiles y geógrafos, este último título era reconocido como equivalente al de agrimensor).

${ }^{18}$ Sobre la actuación de los científicos italianos en Argentina, véase: Montserrat 1993.

${ }^{19}$ La Facultad de Ciencias Matemáticas y Físicas fue la única unidad académica que comenzó a funcionar en 1906 sin contar con planes de estudios sancionados por el Poder Ejecutivo Nacional, en parte porque se esperaba para ello la llegada de su director y decano Porro de Somenzi. En las otras Facultades se elaboraron los planes de estudios a fines de 1905 y los primeros días de enero de 1906 y en el caso de Agronomía y Veterinaria se mantuvieron los mismos, todos los cuales fueron aprobados por el Gobierno nacional con fecha del 24 de enero de 1906. Asimismo, en las primeras ordenanzas se había establecido que la Facultad de Ciencias Matemáticas y Físicas se encargaría de la enseñanza de las asignaturas de ciencias exactas para los estudiantes de correlación, para las especialidades a crearse de ingeniero geógrafo, doctor en física, ingeniero electricista y astronomía, y también podría ofrecer una preparación para las profesiones prácticas en sus talleres y gabinetes. UNLP 1906. La idea original de las autoridades universitarias era impulsar carreras que no se dictaban u ocupaban un lugar marginal en las otras Facultades del país. En relación con ello, se había excluido la carrera de ingeniería civil y arquitecto y en cambio se procuró fomentar otras especialidades de Ingeniería como mecánica, hidráulica y electrónica, que, sin embargo, contarían con muy pocos alumnos. Finalmente en la década del 1910 se ofrecería también el titulo de ingeniero civil, para los que previamente habían cursado alguna de las otras especialidades. Entre los estudiantes que reclamaban en 1908 y 1909 la reorganización de Facultad se encontraban apellidos conocidos de La Plata y egresados del Colegio Nacional platense. A comienzos de 1909, el Centro de Estudiantes de Ingeniería hizo pública su resolución de no asistir a la colación de grados ni a la inauguración de los cursos hasta que no se organizara definitivamente la Facultad. De hecho, la inscripción en esta Facultad fue la que contó con el número más bajo de alumnos durante los primeros años. Entre los que habían reclamado en 1909, figuraban Teofilo Isnardi, Ramón Loyarte y José Collo, quienes serían los primeros en terminar los estudios del doctorado en física entre 1912-1913. 
en un importante centro de producción científica con un amplio reconocimiento local e internacional, como ha sido analizado en varios trabajos ${ }^{20}$.

La incorporación de institutos científicos como el Museo y el Observatorio a la estructura universitaria, se fundamentó en la idea de constituir escuelas superiores de ciencias dentro de las especialidades que practicaban sus científicos e incorporar las tareas de investigación como una de las funciones de las instituciones universitarias, a lo cual se agregaría posteriormente el Instituto de Física. Como se mencionó en la Introducción, la integración estos institutos científicos a la Universidad ha sido considerada como un indicador del fortalecimiento de esta última como centro organizador y promotor de la investigación científica durante las primeras décadas del siglo XX en la Argentina ${ }^{21}$. Por otro lado, este movimiento puede ser pensado como parte del proceso de institucionalización del entrenamiento formal del científico y la profesionalización de la práctica científica. En esa época, se fueron multiplicando los espacios institucionales que proveerían de ciertas facilidades y posibilidades laborales para desarrollar una incipiente carrera científica y trabajos de investigaciones. Desde el Estado se favoreció la creación de institutos y laboratorios dedicados a estudios de carácter aplicado, mientras que los laboratorios universitarios ofrecieron una mayor libertad para desarrollar otras líneas de trabajo y proyectos científicos. En particular, algunos profesores encontraron en la Universidad Nacional de La Plata la posibilidad de articular un espacio de investigación en torno a la cátedra universitaria. Sin embargo, la articulación entre las tareas de investigación y enseñanza asumió diferentes modalidades según los intereses de los profesores, los estilos de trabajos científicos, las motivaciones de los alumnos y las distintas disposiciones internas de cada unidad académica.

Desde una perspectiva vinculada a la historia de la ciencia, se ha considerado que el proyecto universitario pensado por González respondía en general al modelo alemán de "universidad científica"22. Si bien algunos de los elementos de este tipo de institución se intentaron aplicar, ello respondió más bien a las iniciativas promovidas por los científicos formados en las universidades de habla alemana que a lo proyectado por las autoridades de la casa de estudios platense. Además, como se

\footnotetext{
${ }^{20}$ Véase especialmente los trabajos de Pyenson 1978, 1984; 1985a, 1985b, Ortiz 1995, Ranea 1994.

${ }^{21}$ Podgorny 1995; Myers 1992.

${ }^{22}$ Myers 1992. Esta idea se basa en la incorporación del Museo, el Observatorio, la importancia que alcanzó el Instituto de Física y especialmente debido a la presencia de varios profesores alemanes en las carreras científicas. Sobre esto último véase: Ciappa 1987.
} 
analiza más adelante, las propuestas para acomodar algunos aspectos de aquel modelo encontrarían mucha resistencia y en general no fueron vistas como consistentes con la realidad de los establecimientos argentinos. González, más que inspirarse en el modelo alemán, pareció reunir de forma ecléctica y no demasiado sistemáticamente, algunos de los aspectos educativos de las universidades inglesas y las ideas promovidas por presidentes de las universidades norteamericanas y los académicos reformistas franceses y españoles. En ese sentido, defendió una idea amplia y comprensiva de universidad que en líneas generales pareció guardar mayor similitud con el modelo emergente de las universidades norteamericanas. Estas últimas eran vistas como institución que respondían a múltiples propósitos y abarcaban una diversidad de institutos científicos, actividades extra-aúlicas, educación liberal, escuelas profesionales y técnicas. Entre ello, se destacaba la incorporación de disciplinas como pedagogía, agricultura y veterinaria dentro del curriculum universitario. El diseño de la nueva casa de estudios platense intentaba responder a esos cambios y a una mayor complejidad en los patrones de crecimiento de la educación superior que se observaban internacionalmente. De esa forma, la estructura universitaria platense abarcó varias instituciones y tipos de educación: a) institutos de investigaciones y escuelas científicas, b) carreras profesionales; c) formación de docentes, d) educación secundaria, primaria y especial de carácter técnico-práctico y e) extensión universitaria.

Por otra parte, las referencias a los ejemplos extranjeros antes que funcionar como patrones a imitar parecieron más bien formar parte de una estrategia argumentativa para apoyar las propias versiones de reforma. Desde esta perspectiva, la idea de "trasplante" o "importación" de ideas o la difusión unilateral de modelos de otros países, que tanto auge cobró en cierto momentos de la historia de la ciencia y la educación, debería revisarse teniendo en cuenta la internacionalización de los discursos científicos y pedagógicos que circularon en múltiples direcciones y la dinámica de los procesos de recepción. De hecho, las lecturas de las variadas experiencias internacionales, disponibles por diferentes vías, posibilitaron un horizonte común de donde extraer elementos para conformar propuestas institucionales, que en la transición del siglo XIX al XX parecieron guardar un cierto grado de similitud, por lo menos en el plano retórico. Sin embargo, esas iniciativas asumirían desarrollos particulares como resultado de las elecciones y las prácticas de actores locales situados en contextos socio-políticos e institucionales específicos. 


\section{2. Ideales y modelos universitarios internacionales}

En el cambio de siglo, como ha sugerido Björn Wittrock, los distintos ideales universitarios, como los de educación liberal, formación profesional e investigación científica, se encontraron y confrontaron entre $\mathrm{si}^{23}$. Como resultado de ello, muchas universidades abarcaron, tanto arquitectónica como institucionalmente, diferentes tradiciones y valores educativos. De modo similar, este tipo de superposiciones se presentaría en el diseño de la casa de estudios platense. Por otra parte, es indudable que la relativa generalidad con que González caracterizó ciertos elementos de su proyecto universitario respondía a los esfuerzos por elaborar una propuesta que coordinara y diera unidad a un conjunto de instituciones preexistentes muy diferentes. En cierta forma, el desarrollo inicial de la Universidad pareció estar condicionado por la posibilidad de unir ese mosaico heterogéneo y darle una coherencia desde un marco de centralización universitaria. Paralelamente, para conciliar los intereses de los distintos grupos fue necesario prometer autonomía institucional, influencia social y mayores recursos para cada unidad académica o instituto que se incorporaba. Como se analiza en la siguiente sección, las tensiones por mantener una unidad universitaria frente a la autonomía reclamada por cada facultad no pudieron resolverse a pesar de las distintas medidas que se promovieron.

Al comenzar el siglo XX, Carlos Octavio Bunge en un informe sobre educación comparada propuso una nueva clasificación de las universidades que funcionaban en el "mundo civilizado"24. A diferencia de la caracterización bipartita, basada en el tipo de autonomía con respecto al Estado, prefirió seguir a los autores alemanes y tomar como base el "espíritu" de esas instituciones ${ }^{25}$. Desde esa perspectiva se reconocían tres tipos de modelos: a) el inglés, b) el alemán y c) el

\footnotetext{
${ }^{23}$ Wittrock 1996. Para el caso de Estados Unidos, Roger Geiger (1984) señala que durante la primera década del siglo se produjo un debate interminable entre quienes pensaban que la universidad debía tener un mayor énfasis en la enseñanza y los científicos que demandaban un mayor peso para la investigación.

${ }^{24}$ Bunge 1903.

${ }^{25}$ En particular, Bunge seguía una recopilación de trabajos organizados por el profesor W. Lexis para la Exposición de Chicago en 1893 y que alcanzó una amplia difusión internacional. Esa obra fue una de las primeras que inició la propaganda del sistema universitario alemán fuera de ese contexto realizada por los mismos alemanes. Entre esos trabajos se destacó el del profesor alemán Paulsen, cuyos escritos sirvieron de base a muchas de las obras de propaganda posterior que se escribieron sobre este tipo de universidad.
} 
francés. Dentro de este último se ubicaba a las universidades argentinas y latinoamericanas, $\mathrm{y}$ en general se lo consideraba como un sistema fuertemente controlado por el Estado. A este modelo se le atribuía principalmente una "función profesional", en el sentido de constituir oficinas administrativas destinadas a la de preparación para los exámenes y los títulos habilitantes para el ejercicio profesional. Para ello, la organización de la enseñanza se debía ajustar a reglamentaciones minuciosas y programas de estudio obligatorios. Esto último contrastaba con el modelo de las universidades alemanas, a las que se admiraba por su régimen de libertad de enseñanza y aprendizaje.

Para Bunge, el tipo alemán constituía un término medio entre el inglés y el francés, ya que eran instituciones estatales pero el Gobierno no las modelaba y conservaban una completa autonomía en lo relativo a la enseñanza y la investigación. En general, una idea muy difundida internacionalmente era que una de las bases de la grandeza científica de Alemania se debía a la organización de su profesorado universitario y la amplia libertad que se le otorgaba. Entre ello, Bunge destacaba el sistema del Privatdozent, que presentaba una doble ventaja: "completar la enseñanza del profesor ordinario, y establecer una competencia de estímulo, siempre útil, para el perfeccionamiento de la enseñanza de uno y otro" ${ }^{26}$. Como se señaló en el capítulo anterior, el sistema del "docente privado" alemán aparecía en los debates universitarios argentinos como una de las características más admiradas del sistema alemán. Durante los siguientes años, parte de los reclamos para el mejoramiento de la enseñanza se vinculaba a la vaga idea de la "docencia libre". Algunos sectores estudiantiles, relacionaban esto último con la organización de cursos paralelos a los oficiales y además insistirían en la asistencia libre a las clases. Otros grupos veían en ese sistema un mecanismo para formar y seleccionar el profesorado universitario, un cursus honorum que comenzaría con la habilitación para dictar cursos y series de conferencias a aquellos graduados que querían iniciar una carrera docente. En otros casos, algunos profesores o jóvenes graduados dictarían cursos libres sobre determinada temática con la intención de institucionalizar una nueva cátedra. Por su parte, González respondió a esos debates a través de la creación de una nueva figura docente: el "profesor adjunto", una mezcla entre la categoría del docente privado alemán, el agregé francés y el assistant norteamericano. Se esperaba que el docente

\footnotetext{
${ }^{26}$ Bunge 1903:325.
} 
adjunto profundizara o intensificara la enseñanza de alguno de los temas de la asignatura, ampliara con nuevas experiencias o ilustrara de forma práctica las lecciones expuestas por el profesor titular, quién de esa forma podría disponer de mayor tiempo para estudiar nuevos temas y realizar investigaciones. La preparación de cursos libres o el dictado de ciertas partes de los programas oficiales se consideraban una vía no sólo para evitar la cristalización o estancamiento de la enseñanza sino también como un procedimiento de iniciación a la docencia universitaria. De hecho, para el nombramiento de estos cargos se estableció como requisito la aprobación de un año de estudios en la Sección Pedagógica. Por otra parte, a diferencia de los suplentes, que tenían una posición marginal en la estructura universitaria, los adjuntos se incorporaron como personal permanente de la institución con un sueldo mensual y con las mismas prerrogativas que los titulares para la elección de autoridades, aunque no para integrar los consejos directivos. La creación de esta categoría, junto a la multiplicación de los cargos de auxiliares y jefes de trabajos prácticos estableció las bases de una incipiente carrera académica.

Las universidades alemanas eran vistas como el ideal de instituciones dedicadas a la producción de conocimiento. No sólo aparecían como los "refugios naturales" para la práctica científica "desinteresadas", sino también como las que habían establecido las modalidades de enseñanza y el "medio" más exitosos para el entrenamiento de futuros investigadores. En contraposición, el tipo universitario inglés aparecía como el ideal de una formación educativa integral del hombre, más adecuada para la preparación de la élite dirigente. Este modelo estaba representado por los colegios universitarios de Oxford y Cambridge. Si bien, se las consideraba como "documentos del pasado" ya que mantenían la forma de las universidades medievales, en otros aspectos se las reconocía como "modelos para el presente". Entre sus principales características, Bunge destacaba: su autonomía económica-política y la disponibilidad de rentas propias; su funcionamiento como una confederación de colegios; la integración de la vida intelectual con la social y el régimen tutorial. Se reconocía que en la última parte del siglo XIX se habían producido algunos cambios importantes como: el ingreso de católicos -antes sólo se admitían a los afiliados a la Iglesia Anglicana-, la existencia de estudiantes libres -es decir, externos a los colleges, y la extensión universitaria. Estas transformaciones eran vistas como una redefinición de las relaciones entre la universidad y la sociedad. Especialmente, la extensión universitaria inglesa fue un sistema ampliamente publicitado y que sirvió de 
modelo para las adaptaciones que se promovieron en Bélgica, Francia y otros países. A fines de la década de 1890 se volvió una moda entre profesores y autoridades de las universidades del continente europeo hablar de imitar o adaptar los programas de "university extension" organizados por las universidades inglesas.

La emergencia de la "university extension" en Inglaterra, ha sido relacionada con los debates sobre el papel de las universidades en la sociedad que se dieron en la segunda mitad del siglo. De ello se derivó una serie de reformas importantes como la ampliación de la instrucción elemental y postescolar y las primeras alianzas entre el Partido Liberal y los sindicatos. En ese contexto, los académicos liberales buscarían acercarse al pueblo por medio de conferencias para "externos" 27 . Durante la década de 1870, primero en Cambridge y luego en Oxford, Londres y otras universidades inglesas y escocesas se organizaron series de conferencias y cursos en varios distritos rurales y centros industriales ante los pedidos de distintas instituciones y asociaciones locales. Estas actividades implicaron la organización de una compleja de red de comités locales coordinados desde las secretarias de extensión de las Universidades o por parte de sociedades regionales de extensión de la enseñanza universitaria. Los ciclos de conferencias se complementaban con la difusión de libros a través de bibliotecas ambulantes, las "clases" en las que podía discutir, preguntar y dialogar con el profesor, ediciones de folletos y libros en formatos económicos y la publicación de los programas de los cursos o "syllabus": resúmenes de los contenidos, indicaciones sobre bibliografía complementaria o ejercicios para guiar el trabajo personal de los alumnos y su auto-aprendizaje. En algunos casos también se otorgaron certificados de estudio y se permitió la filiación como "externo" a las universidades de Oxford y Cambridge $^{28}$. El esquema de funcionamiento de la extensión universitaria inglesa se divulgó por otros países produciendo nuevas modalidades e instituciones como los "university settlements" ingleses y norteamericanos; las universidades populares francesas; las conferencias y cursos de perfeccionamiento para maestros; los "summer meeting" o cursos prácticos de verano en laboratorios o de idiomas para extranjeros; clases para trabajadores, intercambios de profesores y estudiantes, entre otros. En la transición del siglo, los autores que escribieron sobre esas experiencias hablaron de un "movimiento de extensión universitaria" o un "movimiento de extensión de la educación superior" para referirse al rápido desarrollo y propagación de esas prácticas

\footnotetext{
${ }^{27}$ Samuel 1984 ; Tiana Ferrer 1991

${ }^{28}$ Leclerc 1892, 1899; Espinas 1892; Sadler s/f.
} 
en distintas partes del mundo ${ }^{29}$. De hecho, también se presentó el problema de la traducción de ese término al francés y al español, aunque en general se tendió a utilizar una traducción literal como finalmente quedaría establecido en el lenguaje universitario $^{30}$.

Otro de los aspectos más admirados del modelo universitario inglés, era la integración de la educación intelectual, física y moral que daba por resultado la formación del carácter y la preparación de una homogénea élite política y administrativa para todo el imperio británico. En ese sentido, autores españoles como Francisco Giner de los Ríos (1839-1915) o Adolfo Posada (1860-1944) caracterizaron a estas instituciones como de "tipo general educativo", cuya finalidad era formar el medio social ideal para la educación integral de las clases gobernantes ${ }^{31}$. Según Bunge esto resultaba de la vida que llevaba el estudiante en una ciudad de escasa población y sin importancia comercial o política, sometidos a la tutoría universitaria y al trato frecuente con los profesores y otros estudiantes. El sistema tutorial permitía que los alumnos tuvieran una cierta libertad de estudios aunque estaba restringida a las indicaciones del tutor, quién marcaba a sus pupilos los programas a seguir y repetía en privado las lecciones para pequeños grupos. En general, los profesores solteros vivían en los mismos Colleges y a los casados se les exigía la residencia en la zona, lo que permitía el trato cotidiano entre estudiantes y tutores. Se consideraba que ese tipo de sociabilidad en la que se conjugaba la formación intelectual con la social ayudaba a que los alumnos se identifican entre sí y con ese estilo de vida. En ese modelo, la forma específica de educar a los miembros de la élite nacional se basaba en la dualidad de un alejamiento del mundo extra-universitario y la integración intraacadémica Precisamente, una formación siguiendo este ejemplo se buscó promover a través del sistema de internados abiertos del Colegio Nacional: " con esto realizamos una doble conquista: una puramente institucional al hacer posible entre nosotros el

\footnotetext{
${ }^{29}$ El rápido crecimiento de las experiencias de extensión universitaria y universidades populares se manifestó en la aparición de una gran cantidad de notas, artículos e informes que publicitaban su organización en diferentes localidades o países. Para un estudio comparativo efectuado en la época, véase: Palacios 1904. De hecho, en la revista de educación superior más difundida de la época, la Revue Internacionale de l'enseignement publicada desde 1881 por la Société de l'Enseignement Supérieur, se creó en 1898 una sección especial para las noticias sobre extensión universitaria y en 1900 otra sobre las universidades populares.

${ }^{30}$ Las distintas posibilidades para traducir el término son mencionadas en las traducciones de los trabajos sobre la extensión universitaria y la educación de adultos en Inglaterra que reunió el educacionista francés Ferdinand Buisson. La traducción al español de esta obra fue dirigida por Adolfo Posada. Véase: Buisson s/f.

${ }^{31}$ Giner de los Ríos s/f.; Posada 1892, 1908, 1911.
} 
colegio americano inglés, y otra al ofrecer a multitud de familias distinguidas de la provincia de Buenos Aires, y aún de otras más, una casa de estudios y educación social a la vez, donde puedan enviar con toda confianza sus niños desde los doce o catorce años, sin la inquietud natural por los peligros a los que los expone la cultura descuidada o insuficiente de los inquilinatos, hospedajes y otros albergues expuestos a las desviaciones tan inesperadas como lamentables en los grandes centros de población" ${ }^{\prime 32}$.

En la transición del siglo XIX al XX, los internados estudiantiles ingleses y norteamericanos se presentaban como algo muy distinto de los recuerdos de Miguel Cané en Juvenilia (1882) ${ }^{33}$. Como han señalado Eduardo Gentile y Gustavo Vallejo, la concepción anglosajona de los internados sedujo a González en los momentos iniciales de la planificación de la Universidad, plasmándose en un ambicioso proyecto tanto edilicio como educativo ${ }^{34}$. El Colegio Nacional anexado a la Universidad en 1907, se justificó en términos de una preocupación social, política y educativa en torno a la formación de las clases dirigentes desde temprana edad. La importancia conferida al ambiente en la conformación del carácter y la personalidad de un selecto grupo de alumnos se manifestó en la construcción de un hogar estudiantil que se intentó aislar de las pasiones políticas y las influencias nocivas de "las calles urbanas". Para otros grupos de alumnos, sin embargo, la relación entre la "calle" y los estudiantes adquiriría distintos valores en los discursos de González $z^{35}$.

Los años posteriores al 1900 fueron testigos de tendencias que enfatizaban en la formación cultural y moral del estudiante así como la extensión de la acción educativa de la universidad. Es de destacar que la idea que la universidad debía cumplir varias misiones y ser rectora del espíritu nacional fue un tema recurrente en las publicaciones de publicistas y académicos de diferentes países, como se manifestó en las proposiciones votadas en el III Congreso Internacional de la Enseñanza Superior realizado en París en 1900. En ese encuentro, que contó con delegados de muchos países europeos y de Estados Unidos, se discutió el papel de las universidades en la vida nacional, concluyendo que la institución universitaria tenía tres "misiones": 1) científica: la investigación "desinteresada" y el progreso de la ciencia, 2) profesional: la educación de profesionales y los cuadros administrativos del Estado y

\footnotetext{
${ }^{32}$ González XIV: 53.

${ }^{33}$ Cané 1950.

${ }^{34}$ Sobre el desarrollo de los internados véase: Gentile y Vallejo 1999.
} 
3) de vulgarización científica y formación de un "espíritu público"36. Asimismo, los organizadores de ese Congreso promovieron la discusión sobre cuestiones como: la organización de la vida estudiantil fuera de las aulas, extensión universitaria y programas de cooperación universitaria internacional a través del intercambio de publicaciones, profesores y estudiantes; uniones o asociaciones nacionales $\mathrm{e}$ internacionales de profesores, métodos de enseñanza, la formación de docentes para los distintos niveles educativos ${ }^{37}$, entre otros temas que formarían parte de la agenda de la Universidad platense.

En el nuevo siglo, el ideal de universidad moderna aparecía como una síntesis entre el "tipo educativo inglés" y "el científico alemán", pero reorientada hacia la atención de una nueva "función social". En el contexto de la Universidad platense, estas ideas encontraron una amplia difusión a partir de los trabajos y la propaganda realizada por los profesores de la Universidad de Oviedo, en especial con la visita de Rafael Altamira en 1909 y Adolfo Posada en 1910. A pedido de González, Adolfo Posada concluyó sus actividades docentes en La Plata, con un discurso acerca de la transformación del ideal universitario. En esa conferencia, el profesor español de ciencias políticas retomó las ideas sustentadas por Francisco Giner de los Ríos en Pedagogía universitaria, un libro muy difundido en el ambiente rioplatense. Según este profesor las crisis del ideal universitario y los cambios que se percibían en la organización de la educación superior se debían a la confluencia de una serie de transformaciones, entre las que destacaba: a) los cambios operados en las ideas pedagógicas, que reclamaban una mayor acción educativa y moral, así como la urgencia de una formación reflexiva para las clases medias y una mejor preparación de las clases dirigentes, b) la creciente importancia otorgada a la investigación científica para la formación de las fuerzas productivas nacionales y también para procurar a los profesionales una sólida base científica, c) el aumento de demandas externas por educación y las necesidades sociales que reclamaban una mayor difusión

\footnotetext{
${ }^{35}$ Podgorny 1994.

${ }^{36}$ Los trabajos y conclusiones de ese Congreso fueron publicados en los números de ese año y el siguiente de la Revue Internacionale de l'enseignement. Las conclusiones sobre las "misiones" de la institución universitaria se mencionan en el volumen XLI, 1901: 160-161. Posteriormente los trabajos presentados en ese evento fueron publicados en tres tomos con el título de Troisième Congrés de l'Enseignement Supérieur, bajo la dirección del profesor François Picavet entre 1902-03.

${ }^{37}$ Véase el folleto de propaganda de ese Congreso: Congrès International d'Enseignemet Supérieur, 1900. Este documento integra una colección de folleto sobre proyectos y observaciones sobre la organización de la enseñanza superior europea, principalmente francesa y también de Bélgica, de la Biblioteca de la Universidad Nacional de La Plata, ubicación FB-1010.
} 
cultural y una nueva actitud de la universidad ante los problemas nacionales. Frente a ello, esta institución “....no podía sustraerse al influjo de los cambios que entraña el vivir moderno; no era posible el advenimiento de la democracia, el surgir de los nuevos ideales políticos y sociales, sin que ello obrase en el proceso de las funciones universitarias." 38 . Para Posada la idea de universidad que se estaba comenzando a bosquejar era “...científica, educativa y, además social, para responder á las ansiedades de la época, que piden cada día con mayor apremio, con la 'socialización' de la ciencia y de la enseñanza, la difusión expansiva de la cultura. "39.

Como misión científica: "la universidad debe realizar la alta función de la investigación científica directamente, en sus laboratorios, archivos y bibliotecas é indirectamente, formando en su 'medio' los grandes y pequeños investigadores cientificos ${ }^{40}$. Para esto último, se señalaba que era necesario intensificar la acción docente del maestro con su discípulo y establecer los ámbitos adecuados para una socialización científica. Con relación a la función "educativa", ese entrenamiento debía ir paralelo a la formación del hombre en un ambiente social de altas condiciones morales. Al mismo tiempo, estas instituciones tenían un doble papel que cumplir en la obra educativa nacional: a) contribuir a formar las clases dirigentes, modelando su carácter y gustos al estilo de los caballeros ingleses, y b) dirigir el sistema educativo nacional a través de la formación de los docentes de los ciclos inferiores de enseñanza. De esa forma, la universidad era presentada como una fuerza intelectual y moral que tenía que ejercer una acción social más amplia, a través de la difusión del saber y un "tutelaje cultural" entre los sectores populares y extraacadémicos. En ese sentido, la universidad era pensada como la institución clave para la construcción de la Nación y la modernización del Estado. Pero para cumplir esa tarea, aparecía como necesario que primero se constituyera como tal, es decir como una comunidad de profesores y alumnos trabajando juntos por los mismos ideales y en un ambiente de amplia autonomía económica, política y docente.

\section{3. La cuestión de la autonomía universitaria}

\footnotetext{
${ }^{38}$ Posada 1911: 116

${ }^{39}$ Posada 1911: 120.

${ }^{40}$ Posada 1908: 268.
} 
El lugar desde donde fue impulsado el proyecto de la Universidad Nacional de La Plata, permitió establecer algunas características particulares en la organización de los estudios y régimen de gobierno. De hecho, la nueva institución no se rigió por la Ley Avellanada de 1885, a la cual estaban sujetas las otras universidades argentinas, sino que gozó hasta 1948 de su propio marco legal: la ley $n^{\circ} 4699^{41}$. Las primeras ordenanzas y reglamentos que se pusieron en vigencia a partir de la misma promovían algunas innovaciones en el sistema de gobierno y la participación docente. Recordemos, como ha sido analizado en el capítulo anterior, que esto fue uno de los temas centrales en los debates universitarios en la transición del siglo. En líneas generales, se reconocieron que las posibilidades para aumentar la capacidad de renovación de la universidad estaban ligadas a la transformación de al menos tres aspectos: a) la organización del gobierno académico, b) la autonomía administrativa y económica y c) la preparación y selección del profesorado superior, entre lo que se incluía la "docencia libre". A ello se agregaría la necesidad de renovar los métodos de enseñanza, crear nuevos estudios y promover las investigaciones científicas.

En el caso de la Universidad platense, una de las principales diferencias con el sistema de gobierno vigente en las otras casas de estudio fue la reivindicación de la figura del profesor en la gestión administrativa y cognitiva. Las prerrogativas que se le confirieron a los docentes en la marcha de la institución se articularon alrededor de varias medidas. Por un lado, los consejos directivos de las Facultades fueron integrados exclusivamente por profesores titulares, con mandato limitado y elegidos en asambleas por el resto de los docentes titulares, interinos y adjuntos. Ello implicó la transferencia de la autoridad y competencia técnica desde las tradicionales academias vitalicias- conformadas por personas de reconocida actuación profesional o intelectual pero no necesariamente vinculadas a la tarea educativa dentro de la institución- hacia el claustro docente. De esa forma, en la nueva universidad se buscó una mayor autonomía con respecto a la intervención de personas ajenas al cuerpo de enseñanza. Asimismo, la capacidad que se confirió al profesorado a través del voto directo para la

\footnotetext{
${ }^{41}$ Esta ley remitía a los cuarenta y seis artículos del convenio entre el Poder Ejecutivo de la Nación y la Provincia. Sobre ella, las autoridades universitarias difundieron la interpretación que la existencia de la institución descansaba en un pacto entre dos partes, por lo cual no se podría eliminar unilateralmente sino sólo con un nuevo acuerdo entre la Nación y la Provincia que autorizara la derogación del anterior. Con ello se intentaba salvaguardar la integridad de la Universidad de los continuos cambios ministeriales y la fragilidad los proyectos educativos, o de la aplicación de alguna ley en contra que pudiera votar el Congreso Nacional.
} 
elección de las autoridades universitarias- tanto de los consejeros como del presidente y el decano- constituyó uno de los rasgos novedosos del sistema platense ${ }^{42}$.

En el informe que Rodolfo Rivarola elevó a las autoridades de la Universidad porteña durante los conflictos de 1904, había reconocido que la constitución de un cuerpo de profesores que pudiera influenciar en los rumbos de la institución, debía ser una aspiración importante en cualquier proyecto de reforma académica. Para ello se consideraba conveniente otorgarle atribuciones electivas y fomentar reuniones anuales donde se establecieran lineamientos didácticos generales. Esto último era pensado como una forma para contrarrestar la falta de vínculos orgánicos y corporativos entre los miembros de la educación superior. Al igual que muchos otros universitarios, Rivarola observaba que: "El sistema actual del profesorado se caracteriza por la absoluta falta de cualquiera vinculación entre los profesores de una misma Facultad. Los Estatutos y ordenanzas no reúnen dos Profesores sino en la mesa de exámenes, y en esta ocasión, el voto secreto de clasificación los separa en el mismo momento en que el examen los reune. Cada Profesor está encargado de su clase con entera despreocupación de lo que se enseña en las demás. La extensión é intensidad de la enseñanza; la coordinación de las diversas materias; la fundación ó supresión de cátedras; los métodos de exposición é investigación; las diversas cuestiones relacionadas con la ética profesional, y tantos otros asuntos darían ocasión á que el profesorado de la Universidad se elevara de un estado que con poca exageración diríase análogo á la servidumbre, para constituir un cuerpo, un órgano de pensamiento, en bien de la enseñanza..."43.

Con la finalidad de revertir esa situación, las autoridades de la Universidad platense fomentaron distintas medidas para la integración de los miembros de la institución y la coordinación de tareas en común. Entre ellas se pueden mencionar los intentos por institucionalizar reuniones anuales de profesores titulares y los adjuntos, suplentes o extraordinarios con más de un año de antigüedad, para tratar asuntos graves de disciplina, cuestiones científicas o didácticas. Según González esas reuniones habían estado destinadas: "no sólo a formar y estrechar el espíritu universitario, sino el progreso efectivo de las ideas orgánicas y docentes del país". Sin

\footnotetext{
${ }^{42}$ En la primera asamblea extraordinaria para la elección de presidente, realizada en 1909, González insinuó la posibilidad de que en el futuro se incorporaran en ese tipo de elecciones a docentes de otras jerarquías y representantes de los estudiantes. Sin embargo, durante la gestión de González ni la de su sucesor, Rodolfo Rivarola, esto último se llevaría a cabo.

${ }^{43}$ Rivarola 1904: 57.
} 
embargo, estas reuniones se llevaron a cabo solamente entre 1907 y 1913 . Muchas de las proposiciones votadas en esas primeras asambleas constituyeron más bien deseos para el futuro que medidas de aplicación concreta. Por otro lado, si bien con ello se intentaba establecer lineamientos comunes para todas las secciones de la Universidad, la disparidad de opiniones con respecto a la aplicabilidad de ciertas medidas para determinadas carreras o Facultades, llevó en general a reafirmar las atribuciones de cada unidad académica para legislar sobre esos temas. Paralelamente, las cuestiones más conflictivas o disputadas entre los miembros de algunas facultades fueron retiradas de los debates. Es de destacar, que a medida que se expande el profesorado y crecen las especializaciones, con la consecuente complejización de la estructura universitaria, fue cada vez más difícil articular espacios para el debate entre todo el claustro docente o imprimir una dirección común sobre las distintas Facultades. De hecho, Rodolfo Rivarola, al poco de asumir como presidente de la Universidad platense en 1918, organizó una Asamblea General de Profesores para tratar el perfil que se debía imprimir a los estudios universitarios. La diversidad de opiniones sobre ese tema y las particularidades que se reconocían a cada Facultad y carrera, impidieron arribar a conclusiones generales consensuadas. La siguiente asamblea reunida en 1919 sería el escenario donde se manifestaría los efectos del movimiento reformista por la que atravesaban las universidades argentinas ${ }^{44}$; la presión de los estudiantes y las luchas de intereses entre los distintos grupos de profesores. Posteriormente, en los inicios de la década de 1930 el presidente de la Universidad platense, el historiador Ricardo Levene, volvería a insistir en la importancia de establecer asambleas periódicas entre los profesores para definir rumbos y líneas de trabajo generales para esta casa de estudios.

En 1906, para agilizar la administración de la nueva Universidad se limitó el número de los miembros de los consejos directivos de cada Facultad a seis - en lugar de quince como en las otras universidades-, y la composición del Consejo Superior, conformado en este caso por todos los decanos o directores y un representante del claustro docente por cada Facultad. Al igual que el anterior Ministro de Instrucción Pública, Juan R. Fernández, González señalaba que los cuerpos académicos numerosos terminaban convirtiéndose en maquinarias administrativas inútiles y lentas para acompañar el progreso de las ciencias y las prácticas educativas. Para atender

\footnotetext{
44 Sobre el movimiento reformista universitario de 1918, véase entre otros: Portantiero 1978; Ciria y Sanguinetti 1983; Caldelari y Funes 1997; Biagini 1987, 1999 b.
} 
esto último, por lo menos en los momentos iniciales de una nueva institución, se estableció un principio de autoridad ejecutiva unitaria complementada con el poder deliberativo y electivo de los profesores reunidos en asambleas o consejos parciales ${ }^{45}$. La nueva institución encarnaba la construcción de una "república de sabios", entendida como una comunidad democrática con un poder ejecutivo fuerte, un poder legislativo y electivo de profesores y una población educada y consciente de sus deberes $^{46}$. Desde esta perspectiva, la universidad se presentaba como un ensayo del sistema político ideal para la Argentina: un sistema federal con una dirección común centralizada y la autonomía administrativa de cada unidad, bajo la dirección de una "aristocracia del talento".

Como se mencionó en el capítulo anterior, la reforma de los estatutos de la Universidad de Buenos Aires a mediados de 1906 también apuntó hacia una mayor participación del claustro docente en la dirección de la institución; mientras que la Universidad de Córdoba continuó con el antiguo sistema de las academias vitalicias que se renovaba por cooptación, hasta los conflictos de 1918. Sin embargo, el sistema de elección periódica de los consejeros por parte de los profesores, ensayado en La Plata, tampoco pudo evitar el problema de la cristalización de un círculo cerrado al frente de ciertas unidades académicas. De hecho, los primeros catedráticos fueron designados por Joaquín V. González, como Ministerio de Justicia e Instrucción Pública ${ }^{47}$. Este grupo se encargaría de la organización y dirección de cada unidad académica, ocupando las posiciones claves en la estructura de gobierno universitario hasta los conflictos de 1919 y 1920. Principalmente esas influencias se manifestaron a través de las recomendaciones para la elección de docentes y empleados de distinta jerarquía, un cierto control sobre los ascensos, la creación de nuevos cargos o cátedras, los planes de estudio y la distribución del presupuesto y recursos especiales.

45 El régimen de gobierno interno de la Universidad platense comprendía: un presidente (renovable cada tres años y elegido en asamblea por todo el cuerpo de profesores), acompañado de un vicepresidente (elegido por el Consejo Superior) y un Consejo Superior, integrado por todos los decanos o directores y un profesor titular por cada Facultad, elegido en asamblea por todos los profesores de cada unidad académica. Además, se estableció una diferencia con respecto a la composición de la Asamblea Universitaria que funcionaba en las otras universidades, que se conformaban por un número igual de representantes por cada Facultad (Academias), por lo que cada unidad académica tenía la misma cantidad de votos para elegir al rector. En cambio, en La Plata la cantidad de votos de cada Facultad dependía del número de profesores titulares que componía cada una. ${ }^{46}$ Roldán 1993; Podgorny 1995.

${ }^{47}$ Para ello se reclutaron profesores de la Universidad de Buenos Aires, especialmente de la Facultad de Filosofía y Letras como Rodolfo Rivarola, Nicolás Matienzo, Samuel Lafone Quevedo, Ernesto Quesada entre otros, se mantuvo parte del personal de las instituciones platenses, se convocó a algunos 
Por otro lado, la relativa autonomía que se le concedió a cada Facultad para establecer los lineamientos de su organización y coordinar la enseñanza generó que se fueran estableciendo diferencias significativas con respecto al proyecto universitario originario $^{48}$. Al mismo tiempo, como se analiza más adelante, las autoridades de la Universidad se preocuparon por reforzar los mecanismos de integración para intentar contrarrestar las tendencias "centrífugas" de la fragmentación institucional.

Si bien González intentaba fomentar un principio de "autonomía universitaria", por lo menos en el plano administrativo y didáctico, era consciente que una verdadera libertad en las decisiones no se lograría plenamente si no se alcanzaba una independencia económica. En relación con ello, se buscó generar los mecanismos necesarios para una mayor autonomía con respecto al Estado y en el plano interno se permitió que cada Facultad dispusiera de un fondo propio ${ }^{49}$. Como se señaló en el capítulo anterior, las aspiraciones por una mayor autonomía para administrar y disponer de recursos económicos, estuvieron presentes en todos los proyectos de reforma universitaria en la transición del siglo. Ello se consideraba como un factor importante para la modernización institucional. Al igual que el principal propagandista de la reforma de las universidades francesas, Louis Liard, se pensaba que una verdadera libertad académica no se conseguiría a menos que las instituciones pudieran emanciparse de las limitaciones impuestas por el financiamiento estatal, el cual estaba supeditado a las crisis económicas y las contingencias políticas.

Desde los últimos años del siglo XIX, se sucedieron varias propuestas para generar una "autonomía universitaria", en las cuales no faltó la preocupación por la independencia económica de estas instituciones a partir de establecer fondos especiales, destinar tierras fiscales para su administración o impuestos sobre ciertos productos, entre algunas de las principales medidas propuestas. Joaquín V. González no estuvo ajeno a esas iniciativas y como senador nacional presentó en 1907 un

normalistas que comenzaban a destacarse como especialistas en pedagogía y desde el exterior llegarían algunos investigadores y profesores europeos.

${ }^{48}$ Esto por ejemplo, fue lo que sucedió con la separación a fines de 1906 del Observatorio de la Facultad de Ciencias Físicas, Matemáticas y Astronómicas debido a problemas personales y administrativos en la dirección de ambas unidades.

${ }^{49}$ Internamente, la Universidad ofreció ciertas condiciones de independencia a las distintas dependencias que la conformaban. Cada unidad académica pudo disponer de un fondo propio proveniente de distintos servicios, venta de productos y principalmente a partir de un porcentaje sobre las matrículas y derechos de exámenes abonados por los alumnos. Inicialmente se estableció que lo recaudado por esta vía se repartiría entre la Facultad y el fondo universitario en un 50 \% para cada parte. En 1909 se entregaba a cada Facultad el 37, 5 \% de los aranceles y matrículas estudiantiles y a mediados de 1914 se redujo a un $10 \%$. 
proyecto de ley sobre reserva de tierras fiscales para el patrimonio de las tres universidades nacionales ${ }^{50}$. Como antecedente se mencionaba la Ley Morill de los Estados Unidos de 1862, por cual se había establecido la donación de tierras físcales a los Estados que querían fundar escuelas de estudios especiales y superiores. La propuesta de González, que coincidía con las ideas sustentadas en los proyectos de reforma universitaria de la época, apuntaba a que el Estado nacional entregara en propiedad cien leguas de tierra fiscal a cada universidad nacional para conformar su patrimonio, de forma que cada institución pudiera administrarlo autónomamente y explotarlo para autofinanciarse, aunque debiendo informar periódicamente al Gobierno sobre el uso y administración de esas tierras. Con ello se intentaba suplir la falta de ayuda privada en el fomento de la instrucción pública. Este proyecto, pese a que fue presentado en varias ocasiones por González, terminaría archivado en una de las comisiones del Congreso al igual que otras propuestas como las que intentaban generar un fondo permanente a través de un gravamen sobre las bebidas alcohólicas o un porcentaje sobre el impuesto interno al tabaco ${ }^{51}$, y posteriormente sobre el juego.

En su proyecto universitario, González había sido partidario que para favorecer el progreso científico, este tipo de instituciones no debían estar sometidas a los vaivenes del presupuesto estatal, las decisiones políticas y las crisis económicas que dificultaban contar con los recursos necesarios para seguir las constantes demandas de la ciencia y la educación universitaria. De hecho, para la universidad platense se había calculado que podría obtener una renta a partir de la explotación de algunas propiedades y servicios, en particular los vinculados a la Facultad de Agronomía y Veterinaria y la Escuela de Santa Catalina ${ }^{52}$. Especialmente se esperaba que fuera esta

\footnotetext{
${ }^{50}$ Véase: "Por la Autonomía Universitaria" en: González 1935, XV: 173-180.

${ }^{51}$ En 1912 frente a varios proyectos presentados sobre autonomía universitaria y otras sobre recursos para estas instituciones, la comisión de instrucción pública de la Cámara de Diputados aconsejó la sanción de una propuesta que apuntaba a conformar el patrimonio de cada universidad nacional a partir de la distribución de un gravamen sobre las bebidas alcohólicas y un porcentaje sobre el impuesto interno al tabaco. En ese proyecto se estipulaba que lo recaudado por esa vía se distribuiría en la siguiente proporción: 50\% para la Universidad de Buenos Aires, 30\% para la de La Plata y 20\% para la de Córdoba. Anónimo 1912a..

${ }^{52}$ Según señalaba González en el proyecto de creación de la Universidad, eso sería factible de lograr en poco tiempo: "es esto tanto más posible cuanto que dos de las instituciones ya cedidas consisten en el cultivo útil de extensas superficies como los terrenos de la Facultad de Agronomía y Veterinaria y de la Escuela de Santa catalina, cuyos productos diversos de la tierra o fabricación, puestos en venta en el mercado público, ofrecen segura renta y creciente desarrollo, igual consideración puede hacerse respecto de los bienes con que se ha dotado a la actual Universidad de La Plata y cuya renta o arrendamiento según los casos, pueden ofrecer recursos extraordinarios de verdadera consideración". González XIV: 106. Cabe destacar que varios de los terrenos y propiedades cedidos por la Provincia para la creación de la Universidad Nacional nunca se lograron recibir, ya que fueron enajenados por el Gobierno provincial antes de la sanción definitiva del convenio-ley. En otros casos, particulares y el
} 
última, "la que por sí sola, una vez dotada convenientemente, deberá costear gran parte del presupuesto universitario". En ese sentido, se había concebido que este establecimiento funcionara como una finca agrícola-ganadera modelo, donde además de ofrecer enseñanza práctica y un campo de experimentación se dedicara a la explotación formal y productiva de sus recursos. Sin embargo, lo producido por esta institución fue muy poco. Al dejar la presidencia de la Universidad en 1918, González reconoció que esto estuvo lejos de alcanzar las esperanzas que se habían depositado en ese establecimiento. De hecho, las sospechas por la mala administración de este establecimiento, llevaron a que una de las primeras medidas del nuevo presidente, Rodolfo Rivarola, fue la separación de su director y comenzar una investigación para intentar reorganizar esta dependencia. Además, Rivarola se preocupó por intensificar el control sobre la inversión de fondos y la administración de los recursos de las distintas dependencias de la Universidad, ya que en esa época se encontraron varias deudas sin saldar y partidas gastadas sin justificar ${ }^{53}$. A los problemas con el Establecimiento de Santa Catalina, se sumaron las críticas que efectuaron los estudiantes hacia las autoridades y algunos profesores de la Facultad de Agronomía y Veterinaria, por el manejo de los recursos y la calidad de la enseñanza. Estos problemas fueron uno de los factores desencadenantes del conflicto universitario y la movilización estudiantil que estalló en $1919^{54}$, en el marco más general del movimiento reformista de aquella época. En los siguientes años, tampoco la reorganización del establecimiento de Santa Catalina y la asignación de fondos especiales para la explotación de sus recursos, pudo hacer viable el proyecto de obtener una renta significativa como para cubrir parte de los gastos universitarios o por lo menos los de esa finca-escuela.

En el convenio-ley de creación de la Universidad se estableció la "personería jurídica" de esta institución, un estatus legal que le daba derecho a percibir y utilizar

\footnotetext{
Banco Hipotecario reclamaron la posesión de fracciones que decían haber adquirido antes de ese convenio. Finalmente se acordó que esos terrenos se cederían ante una compensación con otros bienes que debía efectuar el Gobierno de la Provincia de Buenos Aires. Algunas propiedades estuvieron por varios años en litigio, como la casa de 45 entre 2 y 3. En el caso de la Escuela de Santa Catalina, esta se recibió junto a una importante hipoteca que fue liquidada en 1907, con la ayuda de varios subsidios nacionales extraordinarios.

${ }^{53}$ Rivarola convocó a un contador de la Contaduría General de la Nación para supervisar la contaduría de la Universidad y de las distintas dependencias. Por otra parte, en esa época se encontraron muchas dificultades para reconstruir el movimiento del fondo universitario, por la falta de comprobantes de las inversiones y libros de cuentas. Véase al respecto los comentarios en el Consejo Superior y algunas medidas tomadas por la Presidencia en los primeros tomos del Boletín de la Universidad Nacional de La Plata, publicado a partir de marzo de 1918.
} 
fondos sin la mediación del gobierno, excepto para enajenar los bienes o propiedades de que disponía ${ }^{55}$. Con ello, la Universidad podía disponer libremente de lo recaudado a través de los aranceles estudiantiles, los arrendamientos y explotación de algunas propiedades o los excedentes de los ítems del presupuesto que no se aplicaban, sin tener que depender de una autorización del Poder Ejecutivo o una ley especial del Congreso. Una situación similar había logrado la Universidad de Buenos Aires a partir de 1901. Al mismo tiempo, las nuevas medidas implicaron un cambio en el tipo de financiamiento estatal, ya que se estableció una subvención general anual para cada casa de estudios en la Ley de Presupuesto de la Nación votada por el Congreso, en vez un presupuesto interno detallado y al cual cada institución debía ajustarse. Por esa vía se minimizó la intervención de los legisladores sobre la distribución interna de los fondos y la creación de cátedras, ya que ahora sólo podían mediar sobre las cantidades globales para cada universidad. Con el anterior régimen las sumas que la ley de Presupuesto asignaba para los gastos de cada universidad sólo podían ser invertidos en los ítems que esa ley determinaba y para inversiones del fondo universitario se necesitan leyes especiales. Para varios sectores universitarios el nuevo régimen marcaba una diferencia y otorgaba un estatus diferente al de una repartición pública. Esto se manifestaría ante el caso de la Universidad de Córdoba que continuó hasta 1913 con el antiguo sistema de fijar las partidas para gastos y cátedras de cada Facultad y depender de la autorización del Poder Ejecutivo para la inversión de los fondos como cualquier otra oficina pública. A principio de la década de 1910, esta falta de "autonomía económica" era vista por algunos diputados universitarios como una situación anómala y de estancamiento, ya que parecía que a la Universidad de Córdoba no le interesaba disponer de recursos para llamar profesores de afuera, fomentar los trabajos de investigación y los laboratorios ${ }^{56}$. En esa época, los informes

\footnotetext{
${ }^{54}$ Biagini 1987, $1999 \mathrm{~b}$.

${ }^{55}$ Según el articulo ${ }^{\circ} 4$ del convenio del 12 de Agosto de 1905: "la Universidad de La Plata, como persona jurídica podrá adquirir bienes y administrar los que por ese convenio se le adjudican, pero no podrá enajenarlos ni adquirir otros nuevos á título oneroso, sin especial consentimiento del Poder Ejecutivo de la Nación". Asimismo en el siguiente artículo se agregaba: "podrá establecer y cobrar derechos universitarios, pensiones y otros emolumentos, cuyo producto se destinará á constituir un fondo propio, el cual, agregado á la renta que le den sus bienes y productos agrícolas, ganaderos, manufacturados y los de sus talleres y demás obras que se realicen en sus diversas dependencias, se destinará el sostenimiento de los institutos, facultades y escuelas ó colegios que constituyan la Universidad, comprendidos los gastos de sostenimiento de las oficinas del Presidente y Consejo Superior". UNLP 1910: 9-10.

${ }^{56}$ En esa época las críticas hacia el funcionamiento de la Universidad de Córdoba se multiplicaban y abarcaban varios sectores. Algunos diputados, especialmente los que pertenecían al grupo de los médicos y universitarios, cuestionaron el estancamiento institucional, la falta de trabajos de
} 
de la Comisión de Presupuesto de la Cámara de Diputados pusieron de manifiesto una cierta preocupación por la promoción de los estudios e investigaciones experimentales como se evidenció en los intentos de fijar que los aumentos de las subvenciones se destinaran especialmente para ello ${ }^{57}$. Sin embargo, la situación de los subsidios a las universidades comenzaría a ser cuestionado con la consolidación de un bloque socialista en la Cámara de Diputados a partir de 1913. Si bien los miembros de este grupo asumieron actitudes diferentes con respecto a este tema, en general predominó la postura crítica sostenida por Juan B. Justo hacia el elitismo de estas instituciones. Los datos del censo nacional de 1914 denunciaron nuevamente un alto índice de analfabetismo y abrieron el debate sobre la necesidad de intensificar la educación de los niveles inferiores y concentrar el presupuesto educativo en este sector que alcanzaba a una mayor proporción de la población antes que en la enseñanza superior. De hecho en 1915, en el marco de la crisis económica de esos años, el subsidio estatal a las universidades sería recortado en un diez por ciento y el incipiente sistema de becas de estudio y perfeccionamiento en el exterior sería suspendido, tema que se examina en el capítulo siguiente.

La administración más independiente de los recursos que se confirió a cada casa de estudios, no pudo evitar que el funcionamiento institucional y las orientaciones generales de los estudios fueran evaluados anualmente al discutirse el presupuesto general de la Nación. En algunas oportunidades en el Congreso Nacional - y también desde la prensa diaria - se evaluaría el costo de estos establecimientos en función del gasto anual que demandaba la formación de cada estudiante. Desde esa perspectiva, la universidad platense recibió ciertas impugnaciones por la poca concurrencia de alumnos en los estudios universitarios, sobre todo en las materias científicas, las cuales aparecían como muy costosas y con cargos que no se podían

\footnotetext{
investigación y participación en los congresos científicos de 1910, el rechazo a la visita de Ferri pese al pedido de los alumnos, la falta de un movimiento estudiantil y los escasos recursos que se destinaban para laboratorios. Los socialistas, como el senador Enrique del Valle Iberlucea impugnaban los gastos religiosos y las pocas facilidades que se destinaban para las investigaciones científicas y la Academia Nacional de Ciencias. Véase, por ejemplo, los informes de la Comisión de Presupuesto de la Cámara de Diputados y los debates sobre el presupuesto para los años 1911 y 1912.

${ }^{57}$ En el caso de la Universidad platense, se promovió que el aumento de 500.000 pesos proyectado para 1911 se destinara a los estudios experimentales y en particular a la Facultad de Agronomía y Veterinaria, por "el prestigio demostrado por sus diplomados y la trascendencia de sus fines y enseñanza en relación a la riqueza nacional". Finalmente este aumento se aprobó pero sin esa indicación, aunque no se hizo efectivo hasta el año siguiente.
} 
justificar ni siquiera con el sistema de la correlación de estudios ${ }^{58}$. Por otro lado, las matrículas y otros derechos estudiantiles constituían la principal fuente de ingresos ordinarios de las universidades. Al mismo tiempo, la atracción de alumnos constituía un elemento importante en las evaluaciones institucionales, ya que otorgaba prestigio y paralelamente permitía justificar los cargos docentes y los pedidos de recursos especiales. En relación con ello, se observa que en ciertos momentos, algunas unidades académicas de la Universidad platense establecieron políticas de admisión bastantes amplias como las que permitieron el ingreso de maestros normales como en los profesorados y en la carrera de farmacia, o la matriculación tras una prueba de ingreso de alumnos sin certificado de estudios secundarios, como en el caso de la Facultad de Agronomía y Veterinaria a partir de 1913. Esta Facultad experimentó un descenso en la matriculación de alumnos frente a la competencia con la Facultad similar que se incorporó a la Universidad de Buenos Aires en 1909.

El nuevo régimen de autonomía para el manejo de fondos y el subsidio estatal permitió dirigir y agilizar el uso de los recursos económicos para la contratación de profesores extranjeros, adquisición de material, edificación o publicaciones, entre otras inversiones que se dieron durante la primera década del siglo. Las transformaciones operadas con relación a este aspecto, parecieron tener un efecto positivo para la promoción de la actividad científica y el crecimiento institucional. Sin duda, a ello contribuyó el interés una elite política y universitaria preocupada por impulsar el desarrollo de las ciencias, especialmente las experimentales, y una época de un relativo crecimiento económico. En particular, la estabilidad cambiaria que se mantuvo hasta $1914^{59}$, favoreció la compra de aparatos y materiales costosos en Europa, las becas de estudios y mantener los contratos en pesos oro de los especialistas extranjeros. Recordemos que el contrato de profesores y de técnicos europeos y norteamericanos formó parte de las políticas de modernización cultural y científica del país en distintos momentos. También en el caso de la Universidad platense se recurriría a este tipo de convenios para ofrecer condiciones de trabajo atractivas a los científicos que se convocaron en el exterior, con el objeto de reorganizar algunos centros de investigación, formar estudiantes y fomentar el desarrollo de nuevas disciplinas.

\footnotetext{
${ }^{58}$ Sobre el número de estudiantes universitarios en las universidades nacionales y la distribución de alumnos por Facultad y nivel educativo en la Universidad Nacional de La Plata, véase el Anexo.

${ }^{59}$ Panettieri 1983.
} 
Si bien en el sistema de gobierno se había reforzado el principio de "autonomía" administrativa y didáctica. En varios aspectos se mantuvo la dependencia con respecto a los poderes públicos: nombramiento de profesores, aprobación de estatutos y planes de estudios y el financiamiento. En cuanto al problema de la selección y formación del profesorado, González consideraba que formalmente según el régimen argentino eran posible tres modalidades para la designación de profesores: a) el nombramiento directo del Poder Ejecutivo, como se llevo a cabo para la conformación del primer cuerpo docente de la Universidad, b) la propuesta de una terna por las Facultades, ratificada y elevada por el Consejo Superior al Poder Ejecutivo, como el sistema vigente en las restantes universidades nacionales y c) la votación por un cuerpo electoral universitario y confirmado por el Gobierno. González desconfiaba de este último sistema, ya que este tipo de práctica electoral no era un hábito arraigado dentro del país y podría presentar el peligro de originar los mismos vicios de riñas, fraudes y favoritismo que demostraba el régimen electoral de la República. Además, esto presentaba el problema de determinar quienes serían los votantes, entre los cuales los estudiantes no parecían ser los más capacitados para ello. Finalmente, en este aspecto se decidió no innovar. El Poder Ejecutivo retuvo la prerrogativa de nombrar a los profesores titulares, en el que se mantenía el sistema vigente basado en ternas elaboradas por los Consejo Académico y supervisadas por el Consejo Superior. En cambio, para el nombramiento del resto del personal y otras categorías docentes se dejo autonomía a cada Facultad, aunque posteriormente debía ser ratificado por el Consejo Superior. También este último ámbito, en el que participaban representantes de todas las Facultades, estuvo pensado para coordinar las actividades entre las distintas unidades y fomentar una política universitaria unificada. No obstante, las disputas por el presupuesto y la defensa de las iniciativas individuales por parte de cada unidad académica mostrarían los límites impuestos por la acción de grupos con diferentes intereses y la estructura institucional. Los sueños del presidente de la casa de estudios platense, que había imaginado que la nueva universidad se erigiría como ejemplo de una comunidad de ideales con un nuevo "espíritu" para la administración de los asuntos públicos no parecieron materializarse en la forma prevista al terminar su mandato en marzo de $1918^{60}$.

\footnotetext{
${ }^{60} \mathrm{Al}$ dejar la presidencia, González reconoció que después del período inicial de organización, se probó "ver si las facultades e institutos entregados ya a sí mismos, según su propio reglamento funcionaban con la misma orientación del principio. Es mi deber confesar, agregó, que en su opinión ellas no han
} 


\section{4. La formación de un "espíritu universitario"}

En la transición del siglo XIX al XX, el aumento de la matriculación estudiantil, la diversificación de los estudios y la expansión institucional traerían aparejado una mayor complejidad de los problemas académicos y la fragmentación de los grupos universitarios. Como ocurrió con la reorganización de las universidades francesas en 1896, las autoridades de la casa de estudios platense se tuvieron que enfrentar con la dificultad de hallar los mecanismos necesarios para lograr una unificación y coordinación entre las distintas unidades académicas sin restringir su autonomía. Un punto importante del programa de González fue intentar disminuir las barreras institucionales impuestas por el sistema de facultades y consolidar un sentimiento de confraternidad entre los profesores y alumnos. Uno de los mecanismos pensados para constituir una "comunidad de estudio" fue la correlación de estudios afines o similares entre las diferentes facultades. Con ello se buscaba promover la coordinación y cooperación de las distintas secciones de la Universidad, concentrar los recursos y especialistas, y al mismo tiempo, favorecer la rotación y el acercamiento de los alumnos de una facultad a otra: "nuestra correlación consiste en eso, en reunir a los alumnos que estudian una misma rama de las distintas facultades, realizando así la unión y formando el espiritu de los jóvenes en esto que significa, al fin, la fraternidad política, social y cívica."61. A través de fraternizar en laboratorios, clases, actos oficiales y otras instancias de la vida universitaria, se esperaba que los estudiantes se reconocieran como "hermanos de una sola labor". De esa forma, sostenía González, la correlación de estudios era una fuerza poderosa para suprimir las causas de discordia y disgregación entre los grupos estudiantiles, trasmitidas luego a la vida social y política, donde se generaban "los antagonismos irreductibles y el germen de disolución de la patria.".

respondido a la dirección inicial en varios aspectos de la labor conjunta.....Esta tendencia hacia la separación en nuestras propias facultades, e institutos, y a exagerar la autonomía y acción particular de cada uno, se nota en el seno mismo del Consejo superior. Los señores decanos y directores se creen en el deber de defender a todo trance su propio departamento sin tener en cuenta el conjunto del cuerpo universitario. Este concepto, es general, pues lo mismo ocurre en otros consejos. Así se explica que sea tan dificil la tarea administrativa, en particular la confección del presupuesto universitaria, por el esfuerzo de cada uno en provecho exclusivo de su facultad o instituto." Discurso pronunciado en el Consejo Superior, en la sesión del 16 de marzo de 1918, publicado en: Castiñeiras 1985, I: 66.

${ }^{61}$ González 1935, XV: 360. 
Las autoridades universitarias defendieron el sistema de correlación tanto desde una perspectiva pedagógica como económica, en la medida que evitaba la duplicación de cátedras y permitía concentrar los recursos para una enseñanza adecuada en una misma unidad. Junto a ello se promovía una nueva aproximación en la organización de las unidades básicas de la estructura universitaria. En particular, el químico Enrique Herrero Ducloux (1877-1962) $)^{62}$, quien se desempeñaría como vicedirector del Museo, académico y profesor de la Facultad de Agronomía y Veterinaria, consejero superior y vicepresidente, fue una de las figuras que procuró materializar esa idea en las instancias donde actuó, especialmente en relación con los estudios científicos. Su propuesta tendía a la agrupación de las cátedras afines bajo la dirección común de un especialista, para la coordinación de programas de enseñanza e investigación, el trabajo del personal docente y auxiliar, el uso del material y la distribución de recursos. Estas unidades, llamadas indistintamente "institutos" o "escuelas" concentrarían todas las facilidades y el personal especializados en un área determinada de conocimiento para la atención de los alumnos de distintas carreras y las necesidades de toda la Universidad y no para una sola Facultad. Esta organización, no muy claramente definida, tendía a centrarse en las disciplinas y tomaba como modelo los institutos científicos de las universidades francesas, que se estaban expandiendo en esos años ${ }^{63}$. Por otra parte, la baja cantidad de estudiantes que se inclinaban por las carreras científicas, hacía que fuera muy difícil justificar ciertos cargos o cátedras a menos que esas materias se incluyeran como parte de una formación científica básica o general para las carreras profesionales o la preparación del profesorado secundario.

\footnotetext{
${ }^{62}$ Enrique Herrero Ducloux nació en Navarra, España y llegó a la Argentina de niño junto a su familia que se instaló en la Provincia de Santa Fé, allí se diplomó de maestro normal y ejerció de docente en escuelas de Rosario. Estudió en la Facultad de Ciencias Exactas, Físicas y Naturales de Buenos Aires, donde obtuvo el título de Doctor en Química en 1901. Trabajó en una oficina de química del Ministerio de Agricultura de la Nación, como profesor en el Colegio Nacional Sud de Buenos Aires y en la Facultad donde se graduó. En 1904 fue convocado por González, para los cursos de perfeccionamiento en ciencias para los profesores de enseñanza secundaria organizados por el Ministerio de Instrucción Pública. A partir de 1906, Herrero Ducloux concentraría su actividad en la cátedra universitaria, tanto de La Plata como Buenos Aires y en los laboratorios de la Escuela de Química y Farmacia que se instalaron en los subsuelos del Museo. Se radicó en La Plata, donde formó su familia y participó en distintos ámbitos culturales y de sociabilidad de la ciudad. Sus principales investigaciones se concentraron en química analítica, contribuyendo al conocimiento de las aguas minerales de distintos puntos del país, cenizas volcánicas, la composición de meteoritos, entre otros temas. También se destacó por sus obras y conferencias de divulgación científica y la confección de libros para la enseñanza de química y física.

${ }^{63}$ Herrero Ducloux 1909; Weisz 1983.
} 
Sin embargo, este tipo de organización no se lograría sistematizar adecuadamente ni tampoco algunas secciones lograrían monopolizar una determinada área de conocimiento. En varios casos, el sistema de correlación derivó en la acumulación de dos o más cátedras en distintas Facultades por parte de un sólo individuo ${ }^{64}$, mientras que para otros profesores implicó multiplicar sus cursos o organizar programas especiales para atender a los grupos de alumnos de distintas carreras $^{65}$. Por otra parte, ello trajo aparejado numerosas dificultades y la oposición de diversos sectores universitarios ${ }^{66}$. Los problemas principales se encontraron a la hora de coordinar programas, horarios y regímenes de cursadas entre distintas unidades académicas. Esto principalmente se originaba porque cada Facultad reclamaba su competencia para establecer los planes de estudios para los títulos que otorgaba, incluyéndose en ello los contenidos de las materias que los alumnos cursaban en otra dependencia. Paralelamente, se defendía la atribución de los profesores para elaborar el programa de sus cursos y la de cada consejo académico para establecer la distribución y el contenido la enseñanza que estaba bajo su jurisdicción disciplinar. En particular, estos enfrentamientos se manifestaron en los debates sobre la formación del profesorado secundario, como se analiza con mayor profundidad en el capítulo VI.

Otro de los problemas que se presentaron al aplicarse el sistema de correlación se derivó de la creciente especialización que se reclamaba para los cursos de las distintas carreras. Los debates en este sentido giraban en torno a si la enseñanza de un curso debía responder a un sólo programa o atender a las particularidades de las distintas carreras. Esto último era principalmente reclamado por los estudiantes,

\footnotetext{
${ }^{64}$ Por ejemplo, en el caso de botánica, inicialmente el ingeniero agrónomo italiano Carlos Spegazzini se encargó de la enseñanza general y especial de esa disciplina para los alumnos de distintas carreras a través de la acumulación de tres cátedras, una en el Museo y dos la Facultad de Agronomía y Veterinaria. También el químico y vicedirector del Museo, Enrique Herrero Ducloux, gozó de dos cargos como profesor de química analítica distribuidos uno en cada una de esas dos unidades académicas.

${ }^{65}$ En el caso de algunos docentes de ciencias naturales, como se analiza más adelante, esto último generó una mayor carga de las actividades docentes, ya que ello exigía un cierto grado de especialización de los contenidos según las carreras. Para atender esas demandas, frecuentemente dividieron los cursos y se incorporaban diferentes temas. En algunos casos, se repartió la enseñanza con el docente adjunto o se alternó año por medio el dictado de los cursos especializados.

${ }^{66}$ Al dejar la presidencia de la Universidad en 1918, González reconoció que: "la correlación efectiva de los estudios afines o idénticos entre las diferentes facultades: sistema al cual se le atribuyó una función primordial en los primeros años y que, por diversas causas de orden más práctico u operativo que cientifico y racional, fue degenerando sucesivamente hasta desaparecer casi por completo. Error grande que habrá de desnaturalizar la indole de esta Universidad, si no se reacciona y se procura restablecer la rotación o compenetración de estudiantes de unas facultades o institutos en las aulas de otros, que den enseñanzas comunes dos o a más ellas .... vi también con dolor la falta de verdadero interés en vencer las dificultades materiales para arreglar los horarios, destinados a la realización de una cómoda asistencia simultánea de los cursos de correlación." González 1935, XVI: 345-346.
} 
quienes insistían en la especialización de las materias en torno a la orientación de cada profesión. Por otro lado, desde algunos consejos académicos se formularon críticas en las que se aludía a la "anticientificidad" del sistema, ya que en varios cursos cursaban alumnos de diferentes orientaciones, años de estudio y preparación. Es de destacar que varias de estas quejas tenían como trasfondo gestiones para conseguir un aumento de cargos especiales, la creación de cátedras propias o de materias que habían sido incorporadas en nuevos planes de estudio.

Otras medidas tendientes a promover la unidad entre los miembros de las distintas facultades fueron: la institucionalización de las asambleas anuales de profesores, como ya se mencionó; la extensión universitaria y la organización de distintos eventos sociales como la recepción de profesores, bailes, banquetes y otras ceremonias universitarias donde participaba la sociedad platense. Es interesante señalar, la creación de un distintivo universitario: las dos hojas de roble, como símbolo para reconocer a los "miembros de la gran familia universitaria" y su jerarquía: "de oro para los dignatarios y profesores y de plata dorada para los alumnos y empleados". También se esperaba que funcionara como credencial de entrada para las distintas instalaciones de la Universidad y obtener descuentos en ferrocarriles y actividades recreativas ${ }^{67}$. No obstante, este distintivo no funcionó para afirmar la pertenencia a la "clase" universitaria en la medida en que fue apropiado por otros sectores, según se quejaron algunos grupos estudiantiles ${ }^{68}$. El distintivo universitario,

\footnotetext{
${ }^{67}$ Los profesores y graduados de la Facultad de Agronomía y Veterinaria mandaron confeccionar en oro el distintivo de las dos hojas de roble o encina en 1906 para homenajear a Joaquín V. González como fundador de la Universidad Nacional de La Plata. Su uso se justificaba, ya que: "todas las universidades é institutos del mundo tienen una insignia ó distintivo que se aplica en los escudos, membretes y todo aquello que pertenece á la institución. ...Las ventajas que proporcionan a los miembros colejiados el uso de un distintivo son muchos. Les sirve de credencial para poder entrar libremente á todas las dependencias que formen parte del núcleo principal como ser: bibliotecas, talleres, gabinetes, laboratorios, clases, etc. Las empresas de ferrocarril rebajan el 30 ó $50 \%$ del precio de los pasajes; las de diversiones hacen lo mismo y por último el distintivo sirve para reconocerse entre sí á los miembros de la gran familia universitaria, en cualquier parte que se encuentren, lo que es no poca ventaja. Atendiendo á estas razones y á otras más, la Universidad de La Plata ha adoptado como peculiar distintivo una insignia formada por dos hojas de roble unidas por sus pecíolos, simbolizando el árbol de la ciencia. Este distintivo es de oro para los dignatarios y profesores y de plata dorada para los alumnos y empleados.". Redacción. "El distintivo universitario" en: Revista de la Facultad de Agronomía y Veterinaria, 1906 I: 2-3. Se ha reconocido que la propuesta de este distintivo fue de Enrique Herrero Ducloux. Ringuelet 1997.

${ }^{68}$ Desde el Centro de Estudiantes del Museo se señalaba como causa principal del fracaso de esa iniciativa:"el hecho de que el distintivo haya dejado de serlo por el uso y abuso que de él hace todo aquel que disponiendo de la corta suma que se requiere para adquirirlo en cualquier joyería, lo usa sin ser estudiante ni tener nada que ver con nuestra Universidad. Hoy podemos considerar que el distintivo ha pasado á la categoría de adorno personal y citar el caso de artistas teatrales de la localidad que lo llevan clavado en la solapa sin el menor empacho". El Museo, 1907, II, 21: 4. Los estudiantes no se resignaban al "uso de un símbolo que acredita á su portador como persona dotada de
} 
como símbolo de estatus y exclusividad también era un objeto comercial que se ofrecía en venta en los negocios de la ciudad.

En la Universidad platense los proyectos para conformar una cultura académica buscarían encauzar la socialización desde los primeros niveles de la educación formal, a través del recorrido por la Escuela Graduada y el Colegio Nacional, para los varones, y el Colegio Secundario de Señoritas para las niñas, trayectoria que se completaría en las aulas y laboratorios universitarios. Se esperaba que los jóvenes no asistieran sólo para instruirse y alcanzar una habilitación profesional sino también para "educarse" y convirtiese en parte de esa comunidad de labor intelectual con su propio orden y valores morales, a través de una socialización dirigida por parte de los que ya pertenecían a ella. El presidente de la Universidad platense centraba sus esperanzas en que el trabajo conjunto de alumnos y maestros en un "ambiente social depurado" como los laboratorios y gabinetes universitarios permitiría conformar una verdadera comunidad universitaria e inculcar nuevos valores y pautas de conducta a los sectores medios y la futura clase dirigente. La influencia moral del "profesorado sabio, laborioso, amigo de la ciencia y sus discípulos" era, según el presidente de la Universidad platense, la base para mantener la disciplina académica entre la masa estudiantil y ofrecer ejemplos morales a la juventud.

González promovía una renovación de la relación entre los grupos estudiantiles y el cuerpo docente que era percibida como de recíproca hostilidad, sobre todo a partir de agitación estudiantil que sacudió la Universidad porteña en 1904-1905. Para él era necesario trasformar la concepción tradicional según la cual: "la autoridad universitaria se imagina que los estudiantes son algo así como un pueblo rebelde que hay que sujetar por la fuerza, por leyes duras o de una excesiva severidad; $y$ naturalmente, el gremio estudiantil, por contraposición, ha creado en su espíritu la idea errónea de que los cuerpos docentes son algo así como un gobierno despótico y tiránico al cual hay que combatir en todo tiempo. esta situación de recíproca hostilidad, unas veces tácita y otras veces ostensible, es la que produce y ha producido siempre una situación difícil, de regresión en las evoluciones de nuestras instituciones universitarias. Y es natural, porque esos sistemas han venido a romper la unidad de una persona moral que es indivisible por sí sola, y a la cual se atribuye

cultura científica y que propende al reconocimiento mutuo" de los miembros de la "familia" universitaria y desde el Centro se mandó a confeccionar un nuevo diseño, controlando su producción y distribución a través de tarjetas que acreditaban el derecho a poseer ese distintivo. 
dos cabezas, cuando en realidad no tiene sino una, es decir, la Universidad, que se compone de los que enseñan y de los que aprenden, porque unos no pueden existir sin los otros"69.

En esta idea de universidad aparecía la figura del estudiante como un componente central para consolidar y divulgar las actividades culturales y educativas que se proponían desde el seno de esta institución. Ello, además, se enmarcaba en una idealización de la juventud estudiosa como el sujeto no corrompido por los avatares de la vida y capaz de lograr el advenimiento de un mundo mejor, como se manifestaría en el Ariel (1900) del uruguayo Enrique Rodó ${ }^{70}$. En esa obra se exaltaba la función de la inteligencia y se reafirmaba la aristocracia del espíritu ${ }^{71}$. Optimismo y juvenilismo confluían con cierto tono mesiánico en ese libro, que como señala Carlos Real de Azúa: "condensaba con suma destreza la imagen más benévola, más ennoblecida que el "ethos" prospectivo de la "intelligentsia" juvenil latinoamericana y española podían

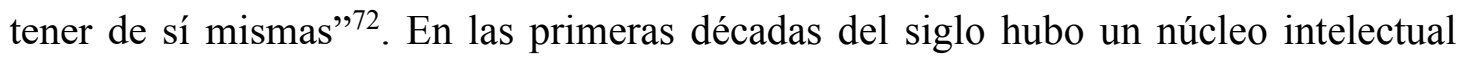
latinoamericano que profesó las proposiciones conceptuales del Ariel como definición ideológica. Principalmente ese núcleo estuvo conformado por la promoción juvenil e ilustrada de las capas altas y medias, entre quienes Rodó se encontró como profeta y evangelista de ese "arielismo" americano, y abriendo la cuenta de los "Maestros de Juventud"73. Precisamente, la imagen de resonancias arielistas del viejo maestro que bajo el imperio de la razón y el sentimiento congrega y guía a la juventud pareció agradar a González, como papel a asumir en la nueva universidad ${ }^{74}$. Los jóvenes estudiantes en La Plata serían estimulados a conformar asociaciones estudiantiles, a desarrollar actividades culturales y deportivas y crear un ambiente para la ciencia y el conocimiento como se observaba entre los estudiantes europeos y norteamericanos.

II. 5. La vida estudiantil fuera de las aulas y la emergencia de los centros de $\underline{\text { estudiantes }}$

\footnotetext{
${ }^{69}$ González 1935 XV:193.

${ }^{70}$ Halperin Donghi 2000.

${ }^{71}$ Romero 1987, Terán 2000.

72 Real de Azúa 1985: XXIII.

${ }^{73}$ La conformación de la figura del "maestro-ciudadano" durante las primeras dos décadas del siglo XX es analizado por Prislei 1992.

${ }^{74}$ Podgorny 1995.
} 
El programa educativo de la Universidad platense también procuraría encauzar la vida estudiantil fuera de las clases organizando por ejemplo, un campo para ejercicios físicos y deportes en los predios del Colegio Nacional, apoyando las asociaciones y las actividades estudiantiles, promoviendo su participación en actividades de divulgación científica y abriendo los laboratorios y gabinetes para los interesados en profundizar sus estudios, entre otras medidas. Como se mencionó anteriormente, en la transición del siglo la "función educativa" asignada a la universidad se vinculaba, en gran parte, con la formación cultural y moral del estudiante. En el Congreso Internacional de Enseñanza Superior realizado en París en 1900, por ejemplo, se discutió la creación de obras a favor de los estudiantes, los medios de evitar su aislamiento y las instituciones que se ocupaban de organizar la vida estudiantil existentes en diferentes países. En Francia, los estudiantes habían sido incentivados a reunirse por las autoridades políticas y universitarias a partir de la consolidación de la Tercera República. Los administradores y políticos no sólo fueron tolerantes con las asociaciones estudiantiles que se comenzaron a expandir en la década de 1880, sino que además elogiaron sus virtudes educativas como escuelas prácticas de tolerancia y sociabilidad. También se había considerado que esas asociaciones podrían ayudar a asentar la unidad universitaria que se fomentaba, en la medida que pudieran disolver la doble distancia que existía entre los estudiantes de distinta procedencia y entre las diferentes facultades ${ }^{75}$. De esa forma, las asociaciones estudiantiles permitirían la cohesión social sobre la heterogeneidad de sus miembros y favorecerían una unidad institucional a través del vínculo estudiantil, como también se pensó en la Universidad platense. Hacia 1900, las asociaciones estudiantiles francesas recibían subsidios de las universidades locales y del Estado, cuando el gobierno radical comenzó sistemáticamente a financiar sociedades mutuales y asociaciones de distinto tipo como medio de promover la solidaridad social. La más importante de ellas la Association Générale des Estudiants de Paris, creada hacia 1891, disponía de un local con biblioteca, sala de lectura y en la que se organizaban conferencias semanales para que los estudiantes se ejercitaran en debatir las cuestiones difíciles,

\footnotetext{
${ }^{75}$ Weisz 1983. A principios del siglo XX se comenzó a reconocer que las asociaciones de estudiantes eran un fracaso en términos de las esperanzas políticas e ideológicas de los sectores académicos y políticos las habían fomentado. En muchos casos, las sociedades estudiantiles representaron una fracción muy pequeña del total de alumnos, para sus lideres constituyó un caso útil para desarrollar una carrera política, muchas de ellas fueron más devotas a organizar actividades recreativas y deportivas, y en otros aspectos también estuvieron lejos de adecuarse a las esperanzas de los reformadores académicos.
} 
muchas veces presididas por los profesores ${ }^{76}$. La Casa del Estudiante al estilo de esta asociación sería una aspiración de los estudiantes argentinos. En la Cámara de Senadores de la Nación, Joaquín V. González defendió reiteradamente el proyecto de creación de la "Casa de los Estudiantes" en la ciudad de Buenos Aires para: "formar un centro común, un hogar colectivo de toda la juventud que estudia en la Universidad y en los institutos de enseñanza del País, para realizar una idea, que es para mi la más querida de todas: que se forme un espíritu nacional en la juventud; que la ciencia misma que se estudia en nuestras universidades sea vivificada por ese calor patriótico que ellos se proponen estimular en esta casa..."77 . Ese proyecto presentado inicialmente en 1909 y luego en 1911, también buscaba resolver las tensiones y conflictos existentes entre el cuerpo de profesores y académicos y los gremios estudiantiles, insistiendo para que el Estado se preocupara en dar soluciones a los problemas que las altas casas de estudios no habían podido resolver en forma eficaz. Si bien este proyecto fue apoyado por las autoridades superiores de la Universidad de Buenos Aires, quienes destinaron un subsidio para ello, y un amplio grupo de profesores y graduados universitarios, entre los cuales se hizo una suscripción pública para recaudar fondos; la casa del estudiante quedó como un sueño a cumplir en el imaginario juvenil ${ }^{78}$, como se manifestaría en la década de 1920 entre sectores del movimiento reformista.

Las fraternidades de las universidades y colleges norteamericanos se veían como una experiencia interesante en la regulación de la vida del estudiante, ofreciendo alojamiento y comida, estableciendo normas de conducta y preocupándose por su bienestar físico así como por el desarrollo intelectual y del carácter ${ }^{79}$. Asimismo, las prestigiosas fraternidades norteamericanas -que adoptaban nombres del alfabeto griego y estaban conformadas por grupos más exclusivos- al igual los colleges residenciales en las viejas universidades inglesas funcionaron como ámbitos de

\footnotetext{
${ }^{76}$ Quesada 1906; Guichard 1911.

${ }^{77}$ González presentó en 1909 como senador nacional un proyecto para crear una "Casa de los estudiantes" en la Capital Federal y destinada a los alumnos de todas las universidades del país. En 1911 lo presentó nuevamente, mencionando las palabras arriba citadas en la sesión del 20 de Julio de 1911. Diario de Sesiones de la Cámara de Senadores, 1911, I.. Parte de ese discurso se reprodujo en la nota: "Casa de los estudiantes" en la Revista del Centro de Estudiantes de Derecho, 1911, V, 22: 200201.

${ }^{78}$ García 2000.

${ }^{79}$ Nelson 1914. Para un análisis de la transformación de las fraternidades en una institución importante en las universidades norteamericanas, como espacio de control y regulación del comportamiento estudiantil así como un canal para trasmitir pautas de conducta y responsabilidad, véase: Finnegan 1989.
} 
sociabilidad de las élites como se promovió en el sistema de Internado del Colegio Nacional de La Plata. Para la dirección del mismo, se convocó a Ernesto Nelson, quién había realizado estudios en la Universidad de Columbia con el educador John Dewey ${ }^{80}$, y divulgaba las ventajas educativas del sistema de las universidades norteamericanas. En los internados se promovió la superación del tiempo habitual de las clases, bajo el ejercicio de un tutelaje permanente y la estrecha vinculación de alumnos y docentes en una convivencia cotidiana, donde el presidente de la Universidad platense confiaría la educación de uno de sus hijos: Julio V. González. Además, el tutelaje del rector se extendía incluso en el periodo de vacaciones: a fines de 1910 se organizó una "gira educacional" por Europa y Estados Unidos para los alumnos del Internado y algunos jóvenes profesores del Colegio Nacional, bajo la dirección de Nelson ${ }^{81}$. El costoso sistema de estos internados destinado a un grupo selecto de estudiantes secundarios, hijos de terratenientes, banqueros, miembros del gobierno nacional o de las provincias y algunos becados ${ }^{82}$, sería sumamente cuestionado por diputados socialistas como Juan B. Justo. En el marco del movimiento de reforma universitaria platense de 1919 se identificaría esta institución como símbolo de la "universidad de privilegio" y al año siguiente sería clausurado, a

\footnotetext{
${ }^{80}$ Biagini 1989.

${ }^{81}$ Gentile y Vallejo 1999.

${ }^{82}$ Christmann, un médico platense nacido en 1898, que realizó todos sus estudios en la Universidad platense, asistiendo al Colegio Nacional como "externo", recordaba varias décadas después: "los alumnos residentes en el internado eran pensionistas en su mayoría y un muy pequeño grupo de becados. Los primeros ostentaban apellidos ilustres, de muy conocidos terratenientes o de banqueros. Otros provenían de dirigentes de los Poderes Ejecutivo, Legislativo y Judicial, tanto del orden nacional como de provincias. En muy reducido número estaban los becados que eran designados simplemente por amistad con las autoridades, sin concursos, ni inscripción de aspirantes. Además lo que costaba la pensión era totalmente prohibitivo para la clase media del país ....El único punto en contacto que teníamos con ellos era en esas horas matutinas de clase. Alli nos conocíamos, nos tratábamos y valorábamos mutuamente la capacidad de aprovechamiento intelectual de casa uno al observar que su nivel era muy aproximadamente el mismo en ambos grupos.....En horas de la tarde, destinadas por lo general a cultura física, mejor dicho: simplemente a jugar al foot-ball o a la pelota, los internos tenían su cancha y su estadio totalmente privados, incluso muy especialmente el pequeño Partenón inaccesible para nosotros, así como una de las canchas de pelota. Al final de la tarde y e las primeras horas de la noche tenían lugar en el internado reuniones culturales y artísticas. A ellas asistian invitados algunos profesores y autoridades universitarias, pero jamás los fuimos ninguno de nosotros... Esta separación en dos clases se documentaba también en el atuendo deportivo y en los distintivos que mostraban, como insignia, el color violeta de fondo y con letras blancas la sigla U.L.P.I (universidad La Plata internado) ....especialmente era un grupo aparte de la universidad, formando en ella una especie de isla o de lugar reservado... .El internado venía a ser como una especie de quiste dentro del colegio Nacional, por supuesto no maligno, sino todo lo contrario, pues el programa integral proyectado por el Dr. González se cumplió siempre muy bien...." Christmann 1992: 34-36. Otros recuerdos sobre la "república ULPI" son mencionados también en: Amaranto 1963.
} 
partir de lo cual comenzaría una disputa por las instalaciones y uso de los edificios como han analizado Eduardo Gentile y Gustavo Vallejo ${ }^{83}$.

A principios del siglo $\mathrm{XX}$, las universidades alemanas eran otra de las referencias importante en cuanto al papel de las corporaciones estudiantiles en la vida académica y en especial, por su preocupación que demostraban los estudiantes universitarios por su auto-formación y el estudio, que no se limitaba a las exigencias requeridas para un diploma o los exámenes. Esto último, como se examina en el siguiente capítulo, aparecía como una gran diferencia con respecto a los alumnos argentinos. Según las observaciones de Ernesto Quesada, el estudiante alemán estaba dedicado plenamente a los estudios, así por ejemplo en la Universidad de Berlín no se admitía empleados de la administración pública, ni a quiénes tuvieran el tiempo ocupado en ocupaciones comerciales o industriales ${ }^{84}$. Los estudiantes alemanes constituían una comunidad aparte de la sociedad general y sobre ellos regían leyes civiles especiales. Tenían sus propias asociaciones, tradiciones y estaban sometidos a una justicia académica; lo que anteriormente también había implicado la excepción a ciertas leyes comunes al resto de la población ${ }^{85}$. Esto estaba relacionado con el alto prestigio social que gozaban los sectores universitarios en la sociedad alemana ${ }^{86}$. Según las descripciones de la época, a los estudiantes matriculados se les confería una especie de título de ciudadano académico, que les otorgaba cierto estatus y les permitía gozar de descuentos en ferrocarriles, teatros y establecimientos del estado. La universidad cuidaba de su conducta y bienestar organizando cursos e instalaciones para la formación física, social y artística de los alumnos, bibliotecas bien equipadas que prestaban libros a domicilio, seguro médico ("caja universitaria de socorro") y procuraba listas de comedores, habitaciones higiénicas y casas de "buena moralidad"87. Las "corporaciones" desempeñaban un papel importante en la vida estudiantil, existían varias por universidad y la mayoría de los estudiantes estaba afiliada a alguna. Eran reconocidas por la universidad y en muchos casos las autoridades académicas no trataban con los alumnos individualmente sino con la corporación. En 1902, Enrique B. Demaría las comparaba con la situación argentina: "es sensible que entre nosotros no hayan sobrevivido las que fueron sus semejantes,

\footnotetext{
${ }^{83}$ Gentile y Vallejo 1999

${ }^{84}$ Quesada 1910.

${ }^{85}$ Hobsbawm 1998.

${ }^{86}$ Ringer 1995.

${ }^{87}$ Demaría 1902.
} 
también que las actuales parezcan más bien "sociedades de defensa o resistencia" análogas á las socialistas de obreros; y finalmente que no comprenden á los estudiantes de las diversas Facultades, con lo cual resulta que no se conocen entre sí ni se hacen las amistades de la juventud que son más durables y desinteresadas; además el intercambio de ideas entre alumnos de diversas Facultades, es favorable para la cultura de todos" 88 .

El comentario de este médico ilustra los desplazamientos que se habían producido en el contexto argentino con respecto a las formas y fines de los agrupamientos estudiantiles. En el último cuarto del siglo se habían creado varias sociedades literarias y científicas por iniciativa de estudiantes que habían sobrevivido poco tiempo o se habían trasformado en otros tipos de instituciones como la Sociedad Científica Argentina o el Círculo Médico Argentino ${ }^{89}$. En la década del 1890, funcionaría por algunos años una agrupación denominada "Unión Universitaria" que reunía a estudiantes de distintas carreras y que tendría un papel destacado en la conformación de la nacionalidad y difusión de "un espíritu patriótico" a través de su participación en diferentes actividades ${ }^{90}$. Entre ello, como señala Bertoni, se puede mencionar la participación en festejos patrios, las peregrinaciones patrióticas a diferentes lugares que se asignaron como "históricos", la intervención en la repatriación de restos de los "héroes" que conformarían el panteón nacional y construcción de ciertos monumentos. También el "Centro Universitario" de La Plata promovería la realización de homenajes a la patria en esta ciudad así como actividades de divulgación como conferencias, concursos literarios y la edición de una revista con extractos de las lecciones de los profesores, notas de interés general y ensayos de los alumnos $^{91}$. Por la misma época, un grupo de estudiantes de ingeniería de Buenos Aires se reunía para organizar la adquisición de bibliografía vinculada a su profesión en Europa, formando la agrupación "Línea Recta" en 1894, que posteriormente se trasformaría en el centro de estudiantes de esa Facultad, publicando también una revista $^{92}$. Paralelamente, el peso creciente de la masa estudiantil comenzó a sentirse de forma variada a través de su participación esporádica en protestas, huelgas y

\footnotetext{
${ }^{88}$ Demaría 1902: 428.

${ }^{89}$ El Círculo Médico Argentino fue creado el 30 de junio de 1875 con el nombre de Biblioteca Popular Médica, reunía en sus inicios a casi la mitad de los alumnos de esa carrera. Después de unos años, esta agrupación dejó de ser de estudiantes, pasando a funcionar como un centro de egresados, aunque hacia principios del siglo XX aparecería ligada al centro de estudiantes de esa Facultad. Bargero 1998.

${ }^{90}$ Bertoni 2001.

91 Azzarini 1963.
} 
movilizaciones, que cada vez cobraban mayor visibilidad pública. En la transición del siglo, surge una nueva modalidad de agrupación estudiantil: el "centro de estudiantes", que se organiza localmente en torno a la defensa de cuestiones específicas de cada facultad y profesión. En 1900 se crea el Centro de Estudiantes de Medicina de Buenos Aires y al poco tiempo se organizaron en las restantes Facultades de la Universidad de Buenos Aires, coincidiendo con los conflictos estudiantiles de 1904-1905. Una de las primeras actividades a la que se abocaron los centros de estudiantes fue la publicación de las clases y las conferencias de los profesores, posibilitando a los alumnos el acceso al material de estudio ${ }^{93}$. Poco a poco se les reconocería personaría jurídica como representantes de los estudiantes para gestionar ante las autoridades universitarias, con lo cual se pensaba poder evitar las peticiones y movilizaciones colectivas que desprestigiaban públicamente a la institución ${ }^{94}$. La emergencia de estas experiencias fue mirada con benevolencia por ciertos sectores de la elite dirigente y universitaria, que veían en ellos la réplica local de las asociaciones estudiantiles anglosajonas y alemanas. Entre 1900 y 1915 quedaron conformados centros de estudiantes en las distintas universidades, colegios nacionales, escuelas industriales, comerciales y normales de las principales ciudades del país. Estos nuevos centros de estudiantes ya no se identificarían con el modelo de las sociedades eruditas del siglo XIX, sino más bien con los que aportaba el mundo del trabajo: los gremios y universidades populares que comenzaban a surgir en el contexto argentino.

A los pocos meses de inaugurada la Universidad Nacional de La Plata se conformaron centros de estudiantes en todas las Facultades. Los alumnos podían ingresar como socios activos de esas sociedades abonando una cuota mensual. Como

\footnotetext{
92 Dalmazzo 1997.

${ }^{93}$ Esto por ejemplo, se manifestó en el programa del Centro de Estudiantes de Derecho de Buenos Aires, según se anunció en la portada de su revista: "la obra principal del centro, aquella que determina en primer término su fundación, que exteriorizó visiblemente su utilidad, dándole un inmediato éxito, ha sido la publicación de los Apuntes, ó sea extractos de las conferencias de los profesores; los cuales han facilitado á todos los estudiantes, socios y no socios, el estudio de varias materias que no cuentan con textos adaptados a los programas respectivos". En: Boletín del Centro de Estudiantes de Derecho 1906, I, 1:2.

${ }^{94}$ El mantenimiento de la disciplina universitaria a través del reconocimiento y control de los centros de estudiantes organizados por Facultad, se manifestó en el proyecto de Rodolfo Rivarola, presentado en el Consejo Superior de la Universidad de Buenos Aires en 1904. Rivarola 1904. Este abogado y decano de la Facultad de Ciencias Jurídicas de La Plata también presentó esa propuesta en la segunda Asamblea General de Profesores de la Universidad platense, la cual fue discutida y aprobada en sus lineamientos generales. Véase: UNLP 1908. Sin embargo, sólo en la Facultad de Ciencias Físicas, Matemáticas y Astronómicas se reglamentó la participación de un delegado estudiantil en las reuniones del Consejo Académico con vos pero sin voto, a partir de un proyecto del decano Nicolás Besio Moreno en 1913. Este profesor también presentó una propuesta similar en el Consejo Superior para hacerlo extensivo a toda la Universidad, pero no fue aprobada.
} 
socios honorarios y protectores figuraban profesores y autoridades universitarias, quienes donaban libros de estudio, sus publicaciones o algún subsidio para el mantenimiento de las actividades estudiantiles. Para la biblioteca del Centro de Estudiantes de Derecho, el presidente de la Universidad ordenó la donación de los duplicados de la Biblioteca y la Secretaria de la Universidad. Este Centro también recibiría ayuda del Ministro de Gobierno de Provincia así como un subsidio de 2.400 pesos anuales, durante varios años, a partir de una ley votada en 1909 por la Legislatura provincial.

Desde la Universidad también se facilitó en 1906 el mobiliario necesario para que el Centro de Estudiantes del Museo pudiera formar una sala de lectura y biblioteca, donde se organizarían todos los días conferencias nocturnas de repaso sobre temas vinculados a las materias que se cursaban y abiertas a todos los alumnos y público en general. Estas conferencias así como las lecturas y discusión de trabajos estuvieran a cargo de los alumnos y en menor medida por los profesores, pese a la convocatoria de los estudiantes. Entre los profesores que participaron en esas actividades se destacó el director de la Escuela de Geografía, el geógrafo suizo Enrique A. S. Delachaux (1864-1908) $)^{95}$, quien también organizaría para sus estudiantes excursiones de estudio y fiestas de fin de año en su casa, respondiendo de esa forma al programa de educación integral de la nueva Universidad. En los primeros años los estudiantes también reconocían el apoyo que recibían del presidente de la Universidad: "en su visita al Centro de Estudiantes del Museo, el Presidente de la Universidad, doctor Joaquín V. González, instaba a los estudiantes á reunirse, á congregarse, y reconocía á esos centros como engranajes de la universidad. ....Los Centros de Estudiantes además de ser una fuerza colectiva con la autoridad que sus propios procederes le aportan, relacionan el Instituto oficial con los populares, porque son alumnos en el aula y participan en la vida del pueblo en la comuna; ejercen por acción refleja su cultura y conocimientos, por medio del trato, las

\footnotetext{
${ }^{95}$ Enrique Delachaux nació en Neuchatel, Suiza. Realizó sus primeros estudios en el Colegio de Pestalozzi, luego en la Escuela Nacional de Matemáticas y después siguió los cursos "geográficos" de la Sorbona y del Museo de Historia Natural de París. Llegó a Argentina en 1888 y se incorporó al Departamento de Ingenieros de La Plata. Poco tiempo después ingresó al Museo de La Plata como cartógrafo. También fue integrante de la Comisión de Límites con Chile entre 1896 y 1903 y luego fue nombrado profesor en la Facultad de Filosofía y Letras de Buenos Aires y Jefe consultor del Instituto Geográfico Militar. Delachaux fue parte del grupo de profesores convocados por González para organizar los estudios de la nueva Universidad, siendo nombrado Jefe de la Escuela/Instituto de Geografía del Museo de La Plata. Publicó varios trabajos cartográficos y geográficos, entre ellos: "Las divisiones geográficos de la Argentina" que sirvió de base para el ordenamiento de la exhibición de la Sección de Antropología del Museo de La Plata. Sobre esto último, véase: Podgorny 1999a.
} 
relaciones, la conferencia, las reuniones que han de caracterizarlos. Un centro de estudiantes es un gobierno en pequeño, con la notable y feliz diferencia de que los electores-alumnos sufragan con conciencia y discernimiento, eligiendo sus delegados entre los más aptos." 96

Las prácticas democráticas de estos centros, sin embargo, no fueron ajenas a los "vicios" que se observaban en la política partidaria. Los periódicos de la época y las revistas estudiantiles publicarían diversas denuncias e impugnaciones hacia la actuación de algunas listas y grupos. Otros de los problemas señalados por la comisión directiva de estos Centros como el del Museo, fue la heterogeneidad de sus miembros, en cuanto a ocupaciones, edades, sexo y estado civil que hacían difícil constituir un centro "a la alemana". También la falta de participación de los estudiantes sería denunciada en los siguientes años. Hacia 1912 desde la Revista del Centro de Estudiantes de Química y Farmacia se llamaba la atención sobre la poca cohesión estudiantil y la falta de un "espíritu universitario" en la casa de estudios platense: "los profesores viven en cierta forma disgregados y muchos no viven en la Universidad sino durante las horas de clase, no hay cohesión entre los alumnos, los centros estudiantiles se desenvuelven con dificultad ó no, pero es indudable que no son núcleos de atracción, no existe todavía el home universitario"97

A pesar de ello, los grupos de estudiantes platenses desarrollaron una gama variada de actividades culturales, deportivas y gremiales. Las acciones de tipo "gremial" estaban vinculadas a la defensa de los derechos estudiantiles ante las autoridades universitarias, que en la mayoría de los casos se referían a cuestiones relacionadas con los exámenes; préstamo de dinero o libros, formación de biblioteca y adquisición de material directamente en Europa para evitar los recargos de las casas consignatarias; obtención de descuentos en librerías y otros comercios, asistencia médica y legal, entre otros. Además, la actividad "gremial" también involucró la defensa del ejercicio profesional por parte de los que disponían de diploma universitario nacional, la contratación de los egresados en los ámbitos públicos y la delimitación o ampliación de la competencia profesional de sus respectivas carreras. Las tareas sociales y deportivas incluían: la organización de torneos atléticos y de ajedrez, partidos de "foot-ball", campamentos en la costa uruguaya, funciones

\footnotetext{
${ }^{96}$ Redacción. "Los centros de estudiantes", El Museo, 1907, I, 15: 36.
} 
teatrales, banquetes, recepción de delegaciones de estudiantes y profesores extranjeros. Entre esas actividades se destacaron los grandes festejos del 21 de Septiembre, después de institucionalizado como Día del Estudiante en 1910, para lo cual contarían con buques facilitados por el gobierno y trenes especiales para el viajes de los estudiantes ${ }^{98}$. Otras actividades incluían concursos literarios y científicos; conferencias sobre temas de actualidad, de repaso o de divulgación. Las conferencias desarrolladas por los alumnos, eran vistas como una práctica que los preparaban para actuar en la vida pública, ejercitándolos en el arte de exponer y en el recurso de la oratoria.

Al igual que los centros de estudiantes de la Capital Federal, una de las primeras tareas a las que se dedicó el Centro de Estudiantes del Museo fue la organización de una publicación quincenal: “...una colección de apuntes de la materias del plan de estudio, de manera de poner al alcance de los estudiantes, los principios que el profesor dicta ..." ${ }^{99}$. La Revista del Centro de Estudiantes del Museo (1906-1908), se editaba con un tiraje de 500 ejemplares y su objetivo era aportar material de estudio de forma "sintética" para que los alumnos no desperdiciaran su tiempo y trabajo consultando las fuentes originales. Coleccionando todos los números a fin de año era posible completar las lecciones dictadas por los profesores como "un libro polictécnico" para preparar los exámenes de fin de año. Para ello, también se organizarían cursos de taquigrafía para registrar las clases de los profesores. Como otras revistas estudiantiles, la publicación de este Centro sirvió como canal para divulgar los contenidos de las clases universitarias, monografías de estudiantes, las conferencias y trabajos de los profesores, comentarios y traducciones de bibliografía nueva. Al mismo tiempo, constituía un medio para ingresar a los circuitos de canjes e intercambios entre otras asociaciones y extender la comunicación entre los estudiantes más allá del ámbito local. Al iniciarse la década de 1910 otros centros de estudiantes publicarían sus propias revistas: Ciencias Sociales (1910-1913), de los estudiantes de Derecho; la Revista de Centro de Estudiantes de Química y Farmacia a partir de 1912; la Revista del Centro de Estudiantes de Ingeniería desde 1913 y la del de Pedagogía (1915), el Colegio Nacional (1915), Inter-Nos de los

\footnotetext{
${ }^{97}$ Redacción. "Nuestro ambiente universitario", Revista del Centro Estudiantes de Química y Farmacia, 1912, I, 3: 1. En el siguiente número, la Redacción de la revista repitió el tema, bajo el título de "La cohesión estudiantil".

98 García 2000.

${ }^{99}$ Redacción. Revista del Centro de Estudiantes del Museo, 1906, I, 1:1.
} 
alumnos del Internado. Para ello, algunas de estas asociaciones contaron con subsidios del Gobierno, tanto nacional como provincial, y apoyo de las autoridades universitarias para su publicación y distribución.

También tuvieron una importante participación en los festejos patrios, procesiones y actos públicos realizados en La Plata así como en la difusión del canto del Himno Nacional. Entre ello, se puede señalar la organización de "conferencias patrióticas" en distintas localidades de la Provincia de Buenos Aires. En Julio de 1908, por ejemplo, se dictaron cuarenta conferencias dadas por los estudiantes y algunos invitados especiales en las principales ciudades de la Provincia, gracias a los pasajes gratis en tren facilitados por el gobierno provincial. Asimismo, como una práctica habitual en la época, participaron en las peregrinaciones patrióticas a Tucumán a partir de 1909, para lo cual también contaron con subsidios del gobierno nacional y del provincial. Es de destacar, que actividades similares también eran promovidas por estudiantes de otros países latinoamericanos ${ }^{100}$. De hecho, en los primeros congresos de estudiantes americanos (Montevideo, 1908; Buenos Aires, 1910; Lima, 1912) se fomentó la intervención de los estudiantes en las campañas de propaganda de "patriotismo" en un sentido americano ${ }^{101}$. La participación de los alumnos platense, al igual que del resto del país, en esos encuentros latinoamericanos fue patrocinada por las autoridades universitarias y el Gobierno nacional como parte de una política de relaciones internacionales. En ese programa los intercambios científicos e intelectuales jugarían un papel importante en la construcción de la paz americana y en las relaciones con Europa. En el marco de esa política, los estudiantes serían considerados como "embajadores intelectuales" y representantes de sus respectivas universidades ${ }^{102}$.

A modo de síntesis no se puede dejar de remarcar el importante papel que se asignó a los estudiantes en la conformación de una cultura científico-académica impulsada desde las autoridades de la Universidad Nacional de La Plata. En el próximo capítulo se examinan las prácticas educativas y de extensión universitaria que se impulsaron en esta institución y la recepción de las mismas por parte de los sectores estudiantiles.

\footnotetext{
${ }^{100}$ Melgar Bao 1999, García y Podgorny 2001.

101 Biagini 1997.

102 García 2000.
} 


\title{
Capítulo III
}

\section{La tarea educativa de la Universidad y la transmisión del "espíritu científico"}

\begin{abstract}
"Las universidades en su sentido tradicional, son oficinas donde expiden títulos de capacidad o habilitantes para las profesiones superiores o que interesan al Estado ... . pero en su significación actual son, además, centros de labor científica donde los más profundos y vastos problemas de la vida son estudiados..."

“...uno de los fines de mayor importancia y trascendencia para la ciencia universal y la cultura nacional en particular, que debe cumplir esta universidad, es la obra de investigación cientifica y su mayor difusión en las clases sociales, por los diferentes medios que la extensión universitaria pone en practica. $" 2$
\end{abstract}

En el mismo discurso fundacional de la Universidad Nacional de La Plata la nueva institución se definía como "científica". Este calificativo aludía, al menos, a dos cosas diferentes aunque interrelacionadas entre sí. Por un lado, se vinculaba con los esfuerzos por renovar las orientaciones y métodos de enseñanza y, por otro -tal vez más importante respecto de las aspiraciones de los sectores científicos-, significaba introducir la investigación como una función central de las actividades académicas. La transformación de la idea de "facultad", que deberían pasar de escuelas profesionales a centros de altos estudios e investigaciones, y las demandas para incorporar un entrenamiento científico más intenso en aras de la formación profesional ayudarían a expandir la base institucional para la práctica científica. A su vez, los propósitos de adicionar "ciencia" a la tradicional tarea académica y los intentos por abrir nuevos "nichos" para la investigación en el espacio universitario involucrarían un conjunto diverso de propuestas acerca de la organización del trabajo docente, la educación de los alumnos, el entrenamiento en actividades de investigación y un discurso sobre el valor educativo de la ciencia.

\footnotetext{
${ }^{1}$ González 1935; XIV: 66.
}

${ }^{2}$ González 1913: 37. 
En algunos estudios sociales de la ciencia se ha enfatizado en el problema de las redes sociales de sustentación necesarios para el mantenimiento de la actividad científica $^{3}$. Hacer que la empresa científica y las instituciones que la sostienen sea considerado como algo legítimo y socialmente "necesario" implica persuadir al público en general y, especialmente, a los sectores influyentes de lo siguiente: que la ciencia puede apoyar o nutrir ciertos ideales políticos, sociales o económicos ampliamente aceptados. En relación con ello, Turner ha introducido el concepto de "ciencia pública" para denominar al conjunto de prácticas discursivas y retóricas en torno al valor social de la ciencia. Según este investigador, el propósito de la "ciencia pública" consiste en buscar apoyo e influencia institucional, argumentando públicamente que la ciencia y las profesiones "científicas" puede mejorar o dar respuesta a cuestiones económicas y sociales, que se definen como importantes en tanto su solución puede asociarse al conocimiento o la pericia que sustentan estos sectores profesionales ${ }^{4}$. A partir de esta perspectiva, en este capítulo se busca analizar el valor educativo y moral asignado a la ciencia y la conformación de un discurso sobre la función pedagógica de la institución universitaria. En particular, se examinan las propuestas de educación y divulgación científica así como algunas de las medidas que se intentaron poner en práctica en la Universidad platense para responder a las ambiciosas promesas de regeneración político-educativa anunciadas en el proyecto fundacional de esta casa de estudios.

La articulación entre las tareas científicas y docentes asumiría diferentes modalidades y estaría condicionada por varios factores: la cantidad y predisposición de los alumnos; los intereses y dedicación de los investigadores/profesores y las distintas disposiciones internas de cada unidad académica, entre otras cuestiones. En relación con ello, Crispiani ha puesto en duda hasta qué punto la relación investigación/enseñanza se hizo efectiva e implicó un verdadero cambio cualitativo en las prácticas educativas, aunque considera que no puede negarse el lugar que se le dio a esa relación en la organización general de la institución ${ }^{5}$. No obstante, es posible detectar una incipiente política científica-educativa como se manifestó en la contratación de especialistas extranjeros, la organización de carreras científicas, becas de estudio y perfeccionamiento, la provisión de instalaciones para clases prácticas y

\footnotetext{
${ }^{3}$ Véase entre otros: Latour 1983; Knorr-Cetina 1996.

${ }^{4}$ Turner 1980.

${ }^{5}$ Crispiani 1999.
} 
actividades de investigación y la divulgación de la ciencia para un público más amplio que los alumnos oficiales. En las siguientes páginas se analiza algunos de estos aspectos en forma general para las distintas unidades académicas, mientras que en la segunda parte de la tesis se examinan en mayor profundidad estos temas en relación a las ciencias naturales y el Museo de La Plata.

\section{$\underline{\text { III. 1. El valor educativo de la ciencia y la acción docente de la Universidad }}$}

En las retóricas sobre las innovaciones en el área educativa a principios del siglo XX aparecían enfrentados dos sistemas de enseñanza: uno basado en el verbalismo y la imaginación, y otro moderno apoyado por la experimentación, la observación y el "método científico". Mientras el primero se asociaba a una transmisión dogmática, teórica y repetitiva de ideas recibidas, se consideraba que el segundo promovía un conocimiento real de las cosas y la difusión de un "espíritu científico", entendido como la capacidad de examinar crítica y racionalmente la realidad concreta. En ese sentido, se esperaba que las modalidades de enseñanza basados en los métodos de observación y experimentación de la ciencia operaran como un sistema de prácticas que otorgaran a los individuos una determinada manera de concebir la realidad y ubicarse frente a ella ${ }^{6}$. A principios del siglo XX, el valor social asignado a la educación científica no descansaba tanto en la importancia de los conocimientos que trasmitía, sino en su "espíritu" y las virtudes morales que ofrecía para modelar la conducta individual y generar una nueva cultura pública ${ }^{7}$. Así, por ejemplo, Joaquín V. González, durante su actuación como Ministro de Instrucción Pública, había reconocido que la piedra angular de un plan general de instrucción pública debía descansar en el estudio de las ciencias, ya que de ello" se desprendía un puro ambiente de moralidad, que purifica las almas, las eleva y fortalece, sin duda porque demuestra al hombre la verdad del dominio que ejerce sobre el planeta. Comunicándole la conciencia y el hábito de la rectitud, de la exactitud, de la

\footnotetext{
${ }^{6}$ Esta idea fue compartida por sectores de distintas tendencias ideológicas y políticas. Para un análisis del pensamiento científico difundido por los socialistas argentinos, véase Barrancos 1996 y para el contexto de la escuela primaria: Gvirtz 2000.

${ }^{7}$ En esta época, fueron frecuentes enunciados de este tipo: "la ciencia no vale tanto por su contenido cuanto por su influencia sobre el "continente" que es el entendimiento, es decir, por la actitud en que ha puesto á las inteligencias frente á las verdades del universo; por el espíritu de investigación, de originalidad, de iniciativa, que ha promovido." Nelson 1914: 123-124.
} 
realidad, de la observación propia y de la investigación personal, se siente más dueño de sí, más libre, más soberano"8

En los discursos académicos de las autoridades de la Universidad platense, el valor otorgado a la ciencia se articuló en varios sentidos. En diferentes oportunidades se enfatizó en los fines prácticos y aplicados al progreso económico e industrial del país o también en relación al bienestar general de la sociedad. Paralelamente, algunos sectores académicos harían hincapié en la importancia de divulgar el "espíritu científico" que proveía de los valores morales y políticos adecuados para la renovación de la elite dirigente y la conformación de los sujetos sociales necesarios para la sustentación de la "república verdadera", a través de un tutelaje pedagógico previo. Por otro lado, si ese discurso "cientificista" ${ }^{9}$ intentaba satisfacer la demanda política de mantenimiento del orden social y la unidad nacional, también permitía encuadrar los reclamos profesionales de académicos y científicos, especialmente entre aquellos que tenían poco que ofrecer en cuanto a las aplicaciones económicas de sus disciplinas. En general, el término "ciencia" sería presentado como un valor universal asociado no sólo a la idea de progreso y la felicidad humana, cuya evidencia se confundía con el propio desarrollo científico, sino también a una serie de virtudes como la tolerancia, la solidaridad, la fraternidad social y el respeto por las leyes y el conocimiento razonado de las cosas, entre otras cualidades necesarias para construir un nuevo orden social ${ }^{10}$. En el marco de esas ideas, la función educativa de la nueva Universidad no debía restringirse a la habilitación profesional de los que pasaban por los exámenes, sino más bien a la divulgación del "espíritu" de la ciencia para crear y educar mejores ciudadanos. Según el presidente de la casa de estudios platense, una enseñanza basada en el método científico permitiría producir: "nuevas formas en la sociabilidad argentina. Sobre las bases de la ciencia, como generadora insuperable de verdad y virtud, y de la labor fraternal e intima como génesis de amor y

\footnotetext{
${ }^{8}$ González 1935, XIX: 172

${ }^{9}$ Soler 1968; Terán 1987.

${ }^{10}$ En relación con ello, Joaquín V. González señalaría en 1914, en uno de sus discursos: “es la ciencia la que descubre en el alma y en la tierra todo lo oculto; enseña el sentido de la verdad y de la justa medida de las cosas; hace comprender el valor real de las cualidades que crean las locas vanidades y transitorias grandezas y ambiciones; suprime las distancias y demuestra con hechos la fraternidad y la unidad de destino de todas las razas; enseña a conocer la razón de amarse y no odiarse los hombres entre sí, porque todos conocen su infinita pequeñez ante la inmensidad de lo desconocido que los envuelve y los enceguece; les indica y alumbra el sendero de la única felicidad posible en la vida, y da la clave para la constitución de los gobiernos fáciles.....y en este problema palpitante de la educación moral de los pueblos; ella tiene la única palabra, porque es la enseñanza de la verdad, y ante ella toda
} 
solidaridad humana, irá echando raíces en la conciencia nacional un concepto más real de la vida y el destino personal y colectivo" ${ }^{11}$

Esto se manifestaría en los intentos por crear un nuevo tipo de relación estudiante-profesor, y paralelamente, otras formas de vinculación entre la universidad y la sociedad ${ }^{12}$. Como se señaló en los capítulos anteriores, los años posteriores a 1900 fueron testigos de tendencias que enfatizaban en la formación cultural y moral del estudiante así como en la extensión de la acción educativa de la universidad fuera de sus aulas. Al iniciarse el nuevo siglo, temas como: las misiones sociales de la universidad, la "extensión universitaria" o la preocupación por organizar la vida estudiantil y renovar los métodos de enseñanza aparecieron incorporados en el vocabulario de profesores, legisladores y distintos miembros de la comunidad universitaria. La emergencia de estas cuestiones en el discurso académico argentino parece remitir a la configuración de un nuevo lenguaje pedagógico sobre la institución universitaria y marcan una diferencia con los debates universitarios del siglo XIX $^{13}$. En el contexto universitario platense, la tarea educativa de la Universidad se asoció a la divulgación del "espíritu científico" en relación a tres circuitos: a) el entrenamiento de las elites dirigentes y las clases medias profesionales; b) la popularización científica en el marco de la extensión de la instrucción popular y la difusión cultural para los sectores populares; y c) la divulgación científica para un público general ilustrado y con cierta base educativa.

El énfasis en el método científico se volvió un componente central de la ideología oficial de la nueva Universidad, en la medida que proveía de un elemento unificador por sobre las distintas especializaciones, el entrenamiento profesional y la investigación científica; y, al mismo tiempo, justificaba la "función social" de esta institución. Mientras que el curriculum universitario reflejaba las diversas funciones asignadas a la educación superior y los compromisos entre varios intereses disciplinares, institucionales y políticos, una segunda tendencia que enfatizaba en el aspecto metodológico de la Ciencia -en singular- pareció ganar mayor popularidad por su "neutralidad". La identificación con un método general y universal para arribar a la verdad proveía de una base para la elaboración de una identidad común a una

construcción de la ignorancia, de la desigualdad y de la discordia se desvanece por sí sola." González 1935, XVI: 97.

${ }^{11}$ González 1935, XV: 400.

12 Podgorny 1995.

${ }^{13}$ Rodríguez Bustamante 1985; Tedesco 1983. 
comunidad separada en grupos especializados y diferentes adscripciones profesionales e institucionales ${ }^{14}$.

Por otro lado, los procedimientos científicos y experimentales prometían un mayor control o dominio sobre la naturaleza y la sociedad, y al mismo tiempo, un discurso atractivo para una valorización social de la formación universitaria como relevante para una administración "científica" o racional del Estado y el desarrollo socio-económico. En este sentido, por ejemplo, las autoridades de la Facultad de Agronomía y Veterinaria señalarían que: "la opinión pública y el juicio de nuestros grandes estadistas comienzan a reconocer como imposible la creación de un estado próspero de estas industrias, si no se las ordena y conduce sobre bases, procedimientos y métodos rigurosamente científicos. $Y$ decir ciencia, es decir categoría y nivel superior en las tareas del espíritu humano, y es enunciar el postulado de que las universidades que orientan este género cultural, tienen en su mano el secreto de la prosperidad de las países naciones cuya base primordial de vida descansa sobre esas dos grandes y fecundas fuentes de riqueza: la agricultura y la ganadería..." 15 .

Los grupos ubicados en la Universidad buscaban consolidar una mayor autoridad y control sobre el ejercicio profesional de sus disciplinas a través de la expedición de los títulos habilitantes, los requisitos de ingreso y principalmente regulando el entrenamiento de los aspirantes. La educación "experimental" o "científica" que se promovía implicaba un mayor énfasis en la dimensión práctica y la transmisión de las habilidades y procedimientos para conocer de forma "positiva y racional". En ese marco, los trabajos prácticos, la disponibilidad de laboratorios, colecciones y bibliotecas, las excursiones, los estudios críticos de documentos y el

\footnotetext{
${ }^{14}$ González citaba las ideas del presidente de la Universidad de Harvard, Charles W. Eliot, para justificar la unidad universitaria sobre la base de un mismo "espíritu científico": "en la verdadera universidad debe cuidarse que el espíritu sea uno, aunque las materias sean diversas. Hoy no existe diferencia entre el método de estudio del filósofo y del naturalista, o entre el del psicólogo y el del fisiologista: los estudiante de historia y de historia natural, de fisica y metafísica, de literatura y bellas artes, deben descubrir que, aunque sus campos de investigación sean diferentes, sus métodos y espíritu son idénticos. Esta unidad de método es lo que caracteriza la verdadera universidad, y en parte justifica su nombre". González XIV: 184-185. Durante su largo mandato al frente de la Universidad de Harvard, Eliot fue hablando cada vez más de "profesiones científicas". A pesar del amplio rango de materias comprendidas en las diferentes Escuelas de esa Universidad, para él todas compartían el mismo espíritu: "the spirit of modern science - candid, fearlees, truth-secking". En general, se utilizaría una definición amplia del término "ciencia", relacionado con toda la enseñanza o saber ofrecido en las distintas secciones universitarias, incluyéndose, entre ello, la teología. Hawkins 1993. González también retomaría otras ideas sostenidas públicamente por Eliot como por ejemplo, en el énfasis en que la universidad debía ser primeramente una institución de enseñanza para producir ciudadanos mejor educados y abierta a distintas clases de estudios.
} 
personal adecuado para atender las clases prácticas aparecían como elementos imprescindibles tanto para una renovación pedagógica como para los que aspiraban transformar las escuelas profesionales en centros productores de saber o por lo menos investirlas con el prestigio técnico y simbólico de la ciencia. El reconocimiento de este tipo de entrenamiento entre profesores de distintas disciplinas, pareció formar parte de lo que Rolf Torstendahl denomina las "exigencias mínimas" de una profesión, es decir, aquellos requisitos que en determinado contexto sociohistórico son considerados indispensables para que una clase particular de actividad basada en determinados conocimientos y procedimientos sea reconocida como "académica" 16 . Precisamente la "necesidad" de una formación "científica" universitaria era lo que permitía justificar los distintos proyectos que se presentaron en esos años para reglamentar el ejercicio libre de ciertas ocupaciones y los esfuerzos por restringir las prácticas profesionales de los "empíricos" -sin título universitario- o de los que disponía de un diploma extranjero sin revalidar ante las universidades nacionales ${ }^{17}$.

La enseñanza práctica y la participación de los alumnos en trabajos científicos se defendían en un triple sentido: a) porque contribuirían a una formación más sólida; b) incentivarían las investigaciones personales y una actitud crítica; y c) por la posibilidad de fomentar sentimientos de compañerismo entre los estudiantes y con los profesores. Con respecto a esto último, como se señaló en el capítulo anterior, se buscaba superar las hostilidades y enfrentamientos entre las dos grandes divisiones de la vida académica: profesores y académicos por un lado, y los estudiantes por otro, lo cual remitía para algunos a la dicotomía del orden político: pueblo y gobierno. Según González, el trabajo conjunto de alumnos y maestros en los laboratorios y gabinetes universitarios permitiría conformar una comunidad intelectual, desde la cual se difundirían nuevos valores y pautas de sociabilidad. Para el presidente de la Universidad platense, la influencia moral del profesorado era la base para mantener la disciplina académica entre la masa estudiantil y ofrecer ejemplos morales a la juventud. En particular, la visita de distinguidos profesores extranjeros y la contratación de investigadores europeos que recrearan el ambiente y hábitos de trabajo

\footnotetext{
${ }^{15}$ Griffin 1917: 262.

16 Torstendahl 1996.

${ }^{17}$ Esto, por ejemplo, se manifestó en dos proyectos que se presentaron casi simultáneamente en la Cámara de Diputados de la Nación en 1912. Uno del Poder Ejecutivo nacional para reglamentar el ejercicio libre de la medicina veterinaria y otro de un grupo de diputados que buscaban delimitar y regular las prácticas profesiones privadas vinculadas a la salud, construcciones y otras áreas.
} 
científico, se defendería en base a esa idea y como parte de un programa de cooperación universitaria internacional.

Los intentos por reorganizar algunas dependencias científicas y actualizar la enseñanza de ciertas disciplinas llevaron a que las autoridades universitarias contrataran como profesores a investigadores extranjeros, para lo cual se les ofrecían condiciones de trabajo especiales. Para ello, la Universidad platense ofrecía cubrir los gastos de viajes del investigador y su familia, alojamiento, dotaciones para investigaciones, altos sueldos y poca carga docente a cambio de una dedicación exclusiva a las actividades académicas. En particular las ciencias astronómicas y físicas serían las más favorecidas con la política de contratos extraordinarios para científicos extranjeros. ${ }^{18}$. En menor medida también se promovieron otras áreas como fisiología, para lo cual se invitó sin éxito al español Santiago Ramón y Cajal en 1907 y luego se contrató al italiano Mario Camis en 1913. La autoridades universitarias fomentaron la visita y contratación de especialistas extranjeros pensando que ello favorecería: a) institucionalizar o promover ciertas disciplinas científicas y técnicas; b) establecer o afianzar contactos con otros centros científicos o instituciones internacionales, y c) presentar "ejemplos" a la juventud. En el banquete de despedida del físico alemán Walter Nernst, quien había sido invitado a dar un curso sobre termodinámica y electroquímica en el Instituto de Física de La Plata a principios de 1914, el Presidente de la Universidad brindó por "el embajador de la alta cultura y poder civilizador de la nación alemana" y por la solidaridad internacional a través de la ciencia, entendida como una corriente universal que contrarrestaba los intereses de la política egoísta o un "patriotismo" mal entendido ${ }^{19}$. Asimismo, González remarcó la importancia de visitas como la de este investigador, ya que generaban un doble impacto sobre la "cultura nativa": a) por un lado, al demostrar el valor educativo y moral de la ciencia en sí misma y b) por otro, como ejemplos de dedicación a la ciencia por la ciencia podrían despertar vocaciones y la pasión por el trabajo del laboratorio entre la juventud estudiosa ${ }^{20}$. La Universidad Nacional de La Plata se presentaría en la época, como en un intento de renovación de la ciencia argentina a través de la presencia de "sabios de las más altas civilizaciones", los cuales aportarían elementos de la ciencia universal para crear el "ambiente" necesario para conformar

\footnotetext{
18 Pyenson 1984, 1985a.

${ }^{19}$ García y Podgorny 2000.

${ }^{20}$ González 1935, XVI: 99-105.
} 
tradiciones científicas locales. La confianza en esta comunidad de sabios que trascendía las fronteras y los intereses nacionales era tanta como la depositada en la misma Universidad de La Plata, una reproducción a escala local de la ciencia universal con sus profesores de diversas nacionalidades y el espíritu protector de Atenea en el escudo.

Para generar nuevos hábitos de estudio se consideró indispensable el trabajo diario de los alumnos junto al profesor y en ese sentido, muchos docentes defendieron la obligatoriedad de la asistencia a clases. Por otra parte, la nueva casa de estudios necesitaba legitimarse tanto a través de una renovación de los métodos y orientaciones de sus estudios como por la presencia regular de los alumnos en sus aulas ${ }^{21}$. Por esa vía, sostenían algunos académicos, se podría ejercer un mayor tutelaje sobre el desempeño académico y la conducta de los estudiantes. En la Universidad platense, a diferencia de las otras casas de estudio superior, no se admitieron "alumnos libres", es decir personas que pudieran rendir exámenes y alcanzar un título universitario sin asistir a los cursos. Cabe señalar, que la categoría de estudiante libre había formado parte del régimen de la antigua Universidad provincial y de la Facultad de Agronomía y Veterinaria y seguía vigente en algunas carreras y cátedras de las otras casas de estudio del país. La nueva reglamentación suscitó las quejas de varios grupos estudiantiles y el reclamo por la libre asistencia a clases estuvo presente en los programas de la mayoría de los centros de estudiantes hasta la modificación de esa ordenanza durante las reformas de 1919-1920. Hasta esa época, las autoridades universitarias mantuvieron firmemente la decisión de que sólo obtuvieran un diploma aquellos que cursaran regularmente y estuvieran sujetos a la disciplina académica, a pesar que con ello se perdía cerca de un 20 o 30 por ciento de alumnos potenciales ${ }^{22}$.

\footnotetext{
${ }^{21}$ En 1919 frente a los reclamos estudiantiles por la asistencia libre, el nuevo presidente de la Universidad platense, Rodolfo Rivarola, recordaba que la ordenanza de prohibición de alumnos libres de 1906, de la cual había sido autor, había tenido por objeto "crear el estudiante universitario para la Universidad que entonces se creó. El efecto de esa resolución está a la vista. La nueva Universidad pudo ser un simple establecimiento de mesas examinadoras para los alumnos de todas las regiones de la República. La ciudad de La Plata es hoy universitaria, porque los alumnos han tenido que ser alumnos regulares." Rivarola 1919a: 6.

${ }^{22}$ En los debates parlamentarios por el presupuesto universitario frecuentemente se criticaba el costo de la Universidad platense en función de la poca cantidad de alumnos que tenía, especialmente con respecto a Buenos Aires. Desde su banca como senador nacional, González defendía la institución en relación con el sistema de enseñanza basado el régimen de asistencia obligatoria, y el cupo máximo de 50 alumnos por curso en la Facultad de Derecho, que reducía el número de alumnos potenciales. Según se observaba en las estadísticas y memorias institucionales, los estudiantes libres alcanzaban entre un 25 o $30 \%$ del total de los estudiantes que tenían las otras casas de estudio del país. De hecho, la Facultad de Agronomía y Veterinaria había contado con cerca de 20 por ciento de alumnos libres en los años previos a su incorporación a la Universidad.
} 
Paralelamente se permitió que los interesados en asistir a algún curso o trabajos de laboratorio o los que no cumplían con los requisitos para inscribiese como alumno regular, pudieran hacerlo en calidad de "oyentes" 23 . Esto último era entendido como una de las formas en que la Universidad podía realizar la "extensión universitaria".

Con la presencia obligatoria de los alumnos en las aulas se intentaba reforzar la tarea educativa por sobre la función "examinadora" de la Universidad, y al mismo tiempo, prestigiar los títulos que se otorgaban. En este sentido, por ejemplo, el decano de la Facultad de Ciencias Físicas, Matemáticas y Astronómicas, Nicolás Besio Moreno, insistía: "dentro de nuestro régimen de estudios debe estudiarse en las aulas ya que la Universidad entre sus funciones tiene la de enseñar antes de la de tomar exámenes. Las puertas de la casa están plenamente abiertas para quien quiera concurrir a ella a estudiar, y son las limitaciones para el que quiere rendir exámenes y obtener diplomas de competencia, que es grave otorgar sin la segura confianza de que se otorga debidamente, y esto principalmente en beneficio de los propios estudiantes que tendrán más fácil camino en la vida profesional, cuanto más prestigioso sea el diploma que exhiban." 24 .

La función docente de la universidad presuponía que el ámbito por excelencia de formación era el espacio universitario, para lo cual se debía ofrecer las instalaciones, equipos, bibliotecas y personal adecuado para el entrenamiento en las distintas carreras. Precisamente sobre esta idea se justificarían los pedidos de recursos y dotaciones para las distintas dependencias. Por otro lado, el establecimiento de un conjunto de prerrequisitos y normas óptimas de entrenamiento, permitía a los académicos cerrar sus filas a los amateurs y mantener sus diferenciaciones con otras profesiones. En ese sentido, por ejemplo, un profesor de abogacía sostenía que la asistencia libre sólo favorecía una formación "autodidacta” y “empírica”, de la cual la

\footnotetext{
${ }^{23}$ Para este tipo de estudiantes se establecieron tarifas de aranceles más baratos y en algunos casos se les otorgaba un certificado de asistencia al curso que habían tomado, pero ello no los habilitaba para alcanzar ningún diploma de competencia profesional. Para esto último se debía cumplir con los requisitos de ingreso, es decir, poseer diploma de estudios secundarios y en el caso de Derecho, además aprobar un examen de ingreso. Durante la década de 1910, algunos oyentes se registraron en la Sección Pedagógica y en materias de ciencias naturales. En 1913 se mencionaba un oyente - Dolores Albarracín, egresada del Colegio Nacional de La Plata- en los cursos de ciencias físicas.

${ }^{24}$ Besio Moreno 1917:185-186. Este comentario contestaba las críticas efectuadas por el Centro de Estudiantes de esa Facultad, que se había opuesto a que la asistencia a los cursos - requisito necesario para rendir examen- valiera sólo por el año en que se había cursado. También los estudiantes reclamaron la reducción de las horas de trabajos prácticos y de la exigencia de la totalidad de los mismos para rendir examen. En 1915, la huelga estudiantil se evitó con algunas concesiones por parte de las autoridades académicas con respecto al primer punto, dejando que la asistencia valiera por dos años después de haber cursado.
} 
universidad no podría dar garantías: "el estudiante libre...no es un universitario: busca su éxito en un trabajo ó en una aptitud, que la Universidad no ha anotado, observado ni dirigido; es una suficiencia individual desniveladora y destructora de la labor cooperativa y metódica; es un espécimen de suficiencia personal, antitético del concepto de miembro del enjambre que elabora, clasifica y acrecienta el hogar de esta familia, ...de esta casa ideal que se llama Universidad, primero, y de ahí al núcleo social y á la humanidad entera. No soy partidario de que las Universidades consagren esta forma parasitaria de competencia que la Universidad se vé obligada á calificar, sin observación constante, sin comunidad ni participación de la labor que debe preceder á todo éxito y que es la verdadera esencia de estas asociaciones. "25

La idea del estudiante libre parecía contradecir por un lado, el papel que reclamaban los profesores como guías del proceso de aprendizaje del estudiante y el fin atribuido a la enseñanza, ${ }^{26}$ y por otro, la idea de universidad como una comunidad de estudiantes y alumnos dedicados al trabajo intelectual con su propio orden y valores morales. Desde esta última perspectiva, se esperaba que los jóvenes no asistieran sólo para instruirse y alcanzar una habilitación profesional sino también para educarse y convertirse en parte de esa comunidad intelectual a través de una socialización dirigida por parte de los que ya pertenecían a ella. No obstante, las aspiraciones de organizar en la ciudad platense "una vida universitaria" al estilo de los colleges anglosajones y otras instituciones europeas encontraría un primer obstáculo en el profesorado "trashumante" y con múltiples ocupaciones en la Capital Federal. El alto porcentaje de profesores que residía en Buenos Aires y sus clases sujetas al horario del tren fueron cuestiones reiteradamente señaladas por los sectores estudiantiles, la prensa periódica y en las cámaras del Congreso Nacional a la hora de discutirse el presupuesto universitario. De hecho, la importante huelga ferroviaria de

\footnotetext{
${ }^{25}$ Comentario del profesor y consejero académico de la Facultad de Ciencias Jurídicas y Sociales, Joaquín Carrillo en la primera Asamblea general de profesores de la Universidad platense. UNLP 1907: 28-28.

${ }^{26}$ En este sentido, por ejemplo, el profesor suplente de procedimientos penales, Alfredo Bozzetti coincidiendo con las ideas del decano de la Facultad de Ciencias Jurídicas y Sociales- Rodolfo Rivarola-, señalaba en la primera Asamblea de profesores de la Universidad que la enseñanza tenía por fin: "la educación mental y desempeñando el profesor la función de conductor del alumno para señalarle el camino que más directamente lleva á ese fin de perfeccionamiento, lógico es que no admitamos que esté habilitado para llegar á la meta, quien, repudiando toda guía, se lanza al azar de la investigación por sendas de las cuales no han sido antes desviados los obstáculos....". UNLP 1907: 30.
} 
1917 y así como las que le siguieron frenaron gran parte de las actividades docentes de la Universidad ${ }^{27}$.

Para los profesores que buscaban la profesionalización de las actividades docentes y de investigación dentro del espacio universitario, la falta de "verdaderos estudiantes" aparecía como un problema ${ }^{28}$. Frente a ello, una de las soluciones propuestas, era, precisamente, la institucionalización de la figura del profesor universitario "al estilo europeo". En ese sentido, por ejemplo, se señalaba en 1909: "luchamos por desgracia con el medio ambiente; contra hábitos invertebrados, contra la falta del elemento ó clase estudiantil que en las ciudades europeas forman una clase especial y que entre nosotros no puede definirse, pues los común es ver á los jóvenes estudiar, mientras desempeñan empleos diversos, siendo para ellos el estudio un complemento, cuando no un adorno, en lugar de ser la ocupación exclusiva de su espíritu....un camino para que tal estado de cosas desaparezca, y un camino para llegar á este resultado es tal vez la formación del profesorado, consagrado á la enseñanza, de un núcleo de hombres dedicados á la investigación en los laboratorios $y$ en los campos de experimentación, que atraigan insensiblemente por la fuerza irresistible de la verdad y el respeto que despierta el trabajo cientifico en los espíritus jóvenes que se vinculan á la Facultad con aficiones que deben fomentarse y con hábitos que convine multiplicar. Para formar este núcleo de profesores...es menester asegurar la estabilidad de las instituciones entre nosotros, favorecer la especialización de los profesionales dedicados á la enseñanza, evitar el recargo de tareas docentes en una misma persona y tratar de reunir bajo una misma dirección las asignaturas afines" 29

\footnotetext{
${ }^{27} \mathrm{El}$ tren era el principal medio de transporte para la movilización de las cosas y las personas para la ciudad de La Plata. Si bien a principios del siglo XX se comienza a importar y difundir el automóvil, especialmente en la ciudad de Buenos Aires, el uso de este tipo de vehículos era principalmente con fines deportivos o dentro de la ciudad, debido a la falta de caminos adecuados y estaciones de nafta y mantenimiento. Las huelgas ferroviarias de esos años pusieron en evidencia la fragilidad del sistema de transporte y aceleró la terminación de un camino consolidado entre La Plata y Buenos Aires, no obstante en los siguientes años seguiría siendo el tren el principal medio para movilizarse.

${ }^{28}$ Herrero Ducloux 1910. En este artículo, este profesor señalaba la falta de "verdaderos estudiantes" y en relación con ello defendía la creación de una Federación Universitaria que uniera al estudiantado y posibilitara un contexto para la ciencia. En esa época, esto último era promovido por los estudiantes universitarios de Buenos Aires y de La Plata, aunque de forma separada.

${ }^{29}$ Informe de la Comisión de revisión del plan de estudios de Agronomía, integrada por Enrique Herrero Ducloux, Carlos G. Girola, Pedro T. Pagés, Moldo Montanari. Redacción. "Proyecto de plan de estudios" en: Revista de la Facultad de Agronomía y Veterinaria, 1908, IV, 1: 8-24, pág. citadas: 1718. Es de destacar, que Herrero Ducloux sostendría ideas similares en distintas oportunidades, y por otra parte era el único de los profesores mencionados que se dedicaba la investigación científica. Sobre el perfil del profesorado y planes de estudios en la Facultad de Agronomía y Veterinaria véase: Graciano 1998.
} 
Así, para algunos académicos como, por ejemplo, el químico Enrique Herrero Ducloux, una de las figuras influyentes en la organización de la Universidad nacional platense, el papel del profesor universitario no era sólo trasmitir conocimientos sino también el de compartir con los estudiantes la producción de nuevos saberes y unirse a ellos en el servicio de la ciencia: "es menester que el profesor haga también vida de laboratorio, despertando entusiasmos, iniciando á sus discípulos en los placeres del trabajo desinteresado, en la investigación cientifica, porque ante los hombres jóvenes más que todos los libros, vale el ejemplo del sabio ó del estudioso en plena labor..."30. Para ello, tanto los docentes como los laboratorios de la Universidad debían adecuarse a esa doble tarea: "el papel del profesor es doble en nuestra institución, si ha de cumplir la misión que el fundador de la misma le ha señalado; los mismos gabinetes y laboratorios se han organizado con el doble fin de la enseñanza y de la investigación; y aún en la primera, no se persigue la producción de profesionales exclusivamente, sino formar para el futuro un núcleo de hombres jóvenes dedicados al cultivo de la ciencia y á su divulgación....,"31

A través de la combinación de investigación, enseñanza y divulgación se debía alentar el "espíritu científico" de la época y prevenir, según este profesor, uno de los mayores peligros que vislumbraba en esa época: la "crisis de indiferencia" que se observaba entre la juventud estudiosa, en la producción intelectual y en el grado de adelanto de la ciencia argentina. Junto a la prosperidad nacional y el crecimiento económico era necesario asegurar: "un núcleo de hombres selectos, ajenos á esas luchas y á esas ambiciones, consagrados á una labor sin tregua, oscura é ignorada muchas veces, noble y elevada siempre, que cultiven la ciencia, atrayendo la gloria para la república, formando hombres jóvenes de nobles ideales, futuros continuadores de esta empresa sin término, divulgando entre las multitudes las conquistas de la inteligencia y elevando el nivel del pueblo con la moral de su enseñanza......" 32 .

Las ideas de este profesor de química y vicedirector del Museo/Facultad de Ciencias Naturales de La Plata, daban cuenta de dos "funciones" asignadas a la institución universitaria moderna: a) la divulgación de las prácticas de investigación científica entre los estudiantes y la formación del "medio" para el trabajo científico de

\footnotetext{
${ }^{30}$ Herrero Ducloux 1909: 311.

${ }^{31}$ Comentario de Enrique Herrero Ducloux en la Segunda Asamblea General de Profesores de la Universidad. UNLP 1908: 23.
} 
nuevas generaciones de investigadores y, b) la divulgación de la ciencia más allá de los muros académicos para contribuir a la educación popular y orientar la opinión pública. En los próximos apartados se analiza algunas de las principales medidas y prácticas que se pusieron en juego para responder a la "misión" científico-pedagógica de la Universidad.

III. 2. Una educación organizada científicamente y la formación de "aptitudes de investigación"

Las prácticas de "enseñanza científica" que se promovían en la Universidad platense prescribían un nuevo papel para cada uno de los sujetos implicados en esa relación y la búsqueda de otras formas y ámbitos para llevar a cabo ese proceso. Esto involucraba una transformación en el concepto de estudiante y el profesor universitario así como un desplazamiento en las modalidades tradicionales de enseñanza. Las nuevas propuestas enfatizaban que la educación no tenía que descansar sólo en la transmisión de los contenidos de la "ciencia hecha" sino principalmente en la experiencia de la "ciencia que se hace" a través de ejercicios prácticos, el uso de instrumentos, investigaciones personales y análisis críticos por parte de los estudiantes, bajo la supervisión de los profesores. El método "eurístico" intentaba "hacer del alumno un elemento activo, un colaborador del profesor actuando individual ó colectivamente" ${ }^{133}$.

En la transición del siglo XIX al XX, el entrenamiento en el trabajo de laboratorio y en otras prácticas de investigación en diferentes disciplinas se consolidó como un elemento central para la formación científica y técnica ofrecida en centros universitarios de diferentes países. Las disertaciones orales en anfiteatros acompañadas de colecciones, ilustraciones o demostraciones fueron complementadas y/o remplazadas por el trabajo de pequeños grupos de estudiantes junto al profesor y sus ayudantes en las "clases" y aulas-laboratorios. Vinculado con la difusión internacional de esas experiencias se produjo una diversificación de los espacios físicos y modalidades de enseñanza, entre las que se reconocían por lo menos tres tipos: a) las conferencias o disertaciones de los profesores en anfiteatros,

\footnotetext{
${ }^{32}$ Palabras de Enrique Herrero Ducloux reproducidas en: Lafone Quevedo 1906: 32.

${ }^{33}$ Herrero Ducloux 1909: 320.
} 
frecuentemente de carácter público. En las materias científicas las exposiciones orales generalmente serían reforzadas con dispositivos visuales como láminas, objetos o demostraciones experimentales; b) las clases y trabajos prácticos en aulas-laboratorio para grupos más reducidos y bajo la supervisión del docente, y c) el entrenamiento especializado en trabajos de investigación para los alumnos avanzados en los espacios más cerrados o semi-autónomos de los laboratorios, institutos y seminarios ${ }^{34}$. En la Universidad platense convivirían estos distintos tipos según el perfil de cada asignatura y la disponibilidad de recursos de las distintas cátedras. En particular, los sectores científicos y especialmente los profesores formados en las universidades de lengua alemana serían los que más promoverían la tercera modalidad que permitía articular un lugar para desarrollar sus propias investigaciones, reclutar colaboradores y formar estudiantes; y al mismo tiempo, responder a las exigencias docentes de la institución universitaria.

Como tendencia moderna se reconocía la disminución de la cantidad de alumnos por clase y el trabajo personal de estos bajo la guía del profesor. Según el presidente de la Universidad platense, el predominio de las conferencias para grandes grupos de alumnos al estilo de una tribuna pública, como se observaba en la educación universitaria argentina traía aparejado una deficiente preparación: "porque es sabido que una enseñanza personal tiene que ser de influencia directa y continua, y ésta no se puede realizar con centenares de alumnos en las clases. Y de éste nace otro mal: el charlatanismo del profesor, que tiene el prurito de los discursos, que desvía el alma de la juventud hablando con el sentimiento de las clases populares, tratando de encausarla en determinadas corrientes, buscando la popularidad; y esa declamación es el veneno más mortal que se puede infiltrar en el alma de los jóvenes, inoculado y difundido por el profesor que va a hacerse aplaudir, buscando efectos de retórica y despreciando la exposición seria y metódica de la ciencia. Y esta enseñanza no puede darse en clases de numerosos alumnos, y muchos menos en ciencias experimentales, en que hay que manejar instrumentos, que, por lo común, el alumno sólo toma por casualidad. El alumnos sale así mal educado, o, lo que es peor, medio educado..."35. En ese sentido, concluía señalando las ventajas que presentaba la universidad platense al no tener "clases desbordantes de alumnos, este es su mayor mérito y la mayor probabilidad de éxito de los profesores, porque pueden ver trabajar junto con ellos,

\footnotetext{
${ }^{34}$ Quesada 1906, 1910; Weisz 1983.

${ }^{35}$ González 1935, XV: 357-358.
} 
conversar con ellos en la clase, que es el gran sistema de educación, y no el de los discursos recitados de memoria o no meditados" ${ }^{\prime 36}$.

Los trabajos prácticos y experimentales tuvieron diferente peso según las asignaturas, pero en general fueron ocupando un lugar cada vez más importante en el entrenamiento de las carreras técnicas y científicas. La instalación de la nueva casa de estudios contó con importantes partidas de dinero que posibilitaron la creación y/o renovación de laboratorios y gabinetes en las distintas facultades, así como la compra en fábricas europeas de aparatos y otros elementos para modernizar la enseñanza ${ }^{37}$. Si bien, los recursos no se distribuyeron de forma similar para cubrir las demandas de las distintas dependencias, durante los primeros años las autoridades universitarias intentaron atender esos pedidos, por lo menos en los casos en que las instalaciones no eran demasiado costosas. La elección de esos materiales fue realizada por el personal que tenía a su cargo la dirección y organización de las distintas secciones, a partir de los catálogos de cada empresa. Según los intereses de los profesores, los recursos se destinaron para adquirir colecciones de enseñanza o también para comprar materiales e instalar laboratorios para investigación. En general, se continuó adquiriendo nuevo instrumental y material didáctico en el extranjero hasta el estallido de la guerra europea en 1914. En esa época, las dificultades en el comercio internacional ${ }^{38}$ sumado a la crisis económica y la devaluación de la moneda argentina ${ }^{39}$ incrementó enormemente el costo de esos materiales así como el de los elementos y sustancias

\footnotetext{
${ }^{36}$ González 1935, XV: 359.

${ }^{37}$ En la ley de creación de la Universidad Nacional de La Plata se estableció para 1906 un presupuesto ordinario de 1.079.201,40 pesos y una partida extraordinaria para gastos de instalación de 337.282,14 pesos. Dentro de esta última, se establecía fondos para adquirir equipos y material de laboratorio y de enseñanza, colecciones para las secciones de ciencias naturales y química (23.500 pesos) y para la Escuela de Geografía (8.000). Para dotación de nuevos instrumentos y reparaciones, biblioteca y publicaciones en el Observatorio (113.968), adquisición de 3130 aparatos de física (74.632,64 pesos) e instalación de aulas, armarios, museos, muebles y útiles de escritorio (7.000 pesos). En la Sección Pedagógica, para gabinetes y laboratorios de: antropología, psicología, psicopedagogía, laboratorio fotográfico y micrográfico, oficinas, útiles de enseñanza (8.491 pesos). Para la Sección de Agronomía: laboratorio de química cualitativa y agrícola, de enología, patología vegetal, zoología agrícola, entomología agrícola, tecnología y agricultura especial (30.000 pesos). Para la sección Veterinaria: laboratorios y gabinetes de embriología, histología, fisiología, terapéutica y toxicología, anfiteatro, museo y laboratorio de anatomía é histología patológica, museo de zootecnia y clínica (40.000). UNLP 1906. En los subsuelos del Museo de La Plata, no se crearon aulas sino laboratorios para las clases, además los profesores utilizarían los espacios de las secciones y gabinetes de trabajo para ello. Allí se instaló un laboratorio de Química analítica cuantitativa con una superficie de más de 212 metros cuadrados, con instalaciones para trabajos analíticos de investigación y de enseñanza. Posteriormente se crearon otros laboratorios de ciencias químicas, para zoología y botánica. Para las clases prácticas de Farmacia y Química también se utilizarían en los primeros años los laboratorios de Farmacología, Farmacia práctica y analítica que existían en el edificio de la Universidad y los laboratorios de química de la Facultad de Agronomía y Veterinaria.

${ }^{38}$ Weinmann 1994.
} 
básicas para el funcionamiento cotidiano de los laboratorios, especialmente alcohol, que se adquirían en el mercado local.

Inicialmente, la baja cantidad de alumnos en la mayoría de las carreras de la Universidad platense posibilitó el desarrollo de clases prácticas y una interacción casi "familiar" entre estudiantes y profesores. No obstante, en pocos años las materias generales de las carreras profesionales y las que recibían alumnos por correlación desbordarían la capacidad de las aulas-laboratorio o los propios gabinetes de trabajo de los investigadores-docentes, donde algunos daban sus clases. Así, por ejemplo, en el caso de las asignaturas de botánica general, farmacia y química del Museo para atender grupos de más de cincuenta alumnos de debió recurrir a la conferencia del profesor en el nuevo espacio del anfiteatro, que se inauguró en 1911 y se equipó con aparatos para proyecciones y ampliación de preparados microscópicos. Paralelamente, las lecciones se completaban con trabajos prácticos en los laboratorios, para los cual se dividían los alumnos en dos o tres grupos y se recurriría al apoyo docente de ayudantes y jefes de trabajo. Al iniciarse la década de 1910, en la Facultad de Ciencias Físicas, Matemáticas y Astronómicas comenzarían a desdoblar las clases prácticas en grupos de no más de veinte alumnos y a incorporar a los primeros doctores y egresados como jefes de trabajos para atender algún grupo. A su vez, en la Facultad de Agronomía y Veterinaria se trasformaría la figura del "repetidor" en puestos de jefes de trabajo y ayudantes para atender y supervisar a los alumnos en los ejercicios prácticos de laboratorio. La generalización de los cargos de auxiliar docente abrió la posibilidad de seleccionar y entrenar personal para las distintas actividades universitarias. Al mismo tiempo, para los alumnos y egresados con altas calificaciones el acceso a esas posiciones constituyó los primeros pasos para desarrollar una carrera académica.

Con la organización de clases prácticas y la intensificación de la enseñanza se intentaba contrarrestar los defectos del "sistema memorístico" basado en las exposiciones orales y los exámenes. Muchos educacionistas denunciaban que esto último sólo privilegiaba la instrucción y la adquisición dogmática de conocimiento en detrimento de la educación del carácter, de la formación de una actitud crítica y del trabajo personal del alumno. El sistema de exámenes a fin de año generaba, según algunos profesores, que los estudiantes se preocuparan más por estudiar a fin del curso

\footnotetext{
39 Panettieri 1983.
} 
con el objeto de aprobar las pruebas que por atender a su preparación personal y autoperfeccionamiento. Por otra parte, la cuestión de los exámenes estuvo en la base de la mayoría de los reclamos estudiantiles de la época. Otros reconocían que los exámenes traían aparejado una gran cantidad de "peligros", tanto fisiológicos, como problemas físicos derivados del "surmenage" intelectual, las fiebres, las tensiones cerebrales y sus efectos sobre la potencia vital del individuo, así como cuestiones pedagógicos y morales ${ }^{40}$. Además, el examen como única prueba de aptitud estaba bastante desacreditado en la medida en que parecían permitir el triunfo de los "mediocres" o "simuladores", quienes sólo necesitaban recurrir a la repetición dogmática y el ejercicio retórico ${ }^{41}$. Como se señaló en el capítulo 1 , el incremento significativo de alumnos y especialmente los que alcanzaban el título de doctor en abogacía en las universidades argentinas, generó preocupación y un cierto malestar entre sectores de la clase dirigente y universitaria. Frente a ello, aparecía como necesario generar mecanismos más efectivos para ejercer una mejor selección basada en el talento y el esfuerzo personal y no a partir de un incremento de los aranceles o restricciones de carácter económico. La intensificación de la acción pedagógica de la universidad; la renovación de métodos de enseñanza y las pruebas de aptitud; el trabajo diario del alumno en el aula bajo la guía del profesor aparecían, entonces, como elementos claves para una selección más "meritocrática".

Para responder a las nuevas tendencias pedagógicas, en la Facultad de Ciencias Jurídicas y Sociales se estableció la asistencia obligatoria de los estudiantes y un ensayo de promociones en 1906, por el cual se reemplazaba el examen por un sistema

\footnotetext{
${ }^{40}$ Estas ideas, por ejemplo, se manifestaron en el Congreso de Estudiantes Americanos reunido en Montevideo en 1908, donde uno de los temas generales de debate fue el sistema de exámenes y el método de exoneraciones. En ese evento, además, los estudiantes de la Universidad de Montevideo comentaron el poco éxito que habían alcanzado las disposiciones tendientes a reemplazar el examen por otro sistema de promociones que se adoptó en esa institución en 1905. Esas medidas habían formado parte de las reformas impulsadas por el nuevo rector desde 1904, con el objeto de incentivar una renovación de los estudios y atraer a lo estudiantes a las aulas. No obstante, esas medidas resultaron poco efectivas para la reforma esperada, como también sucedería en La Plata. En la misma época, los defectos del sistema memorístico y del régimen de exámenes también serían denunciados en la Universidad de San Marcos de Lima. Cueto 1989.

${ }^{41} \mathrm{Al}$ dejar la presidencia de la Universidad platense, González continuaba caracterizando la institución del examen como: "esa escuela de fraude universal, que enseña la simulación, la mentira y el ardid culpable, desde el umbral de la escuela primaria hasta los últimos tramos de la escala universitaria; y si hasta ahora esta Universidad no ha podido extirparlo de su seno, no obstante hallarse en su primitivo programa, es de esperar la reacción que haya de reemplazarlo al fin por un mejor régimen de la clase, o por otro medio de constancia y verificación de la enseñanza". González 1935, XVI: $344-$ 345. Recordemos que la idea de "simulación" y de "mediocridad" eran tópicos recurrentes en los análisis de la cultura de la época, tal como se puede ver en los escritos de José Ingenieros o de José M. Ramos Mejía. Terán 1987.
} 
en el que el alumno debía trabajar y acreditar su preparación diariamente en el aula ante el profesor y presentar una monografía final para aprobar la asignatura. Se anunciaba que en el nuevo sistema se combinarían los métodos más tradicionales de la exposición del profesor y la interrogación a los alumnos sobre temas ya explicados, con los modernos ejercicios prácticos de análisis y discusión de textos y fuentes, tratando de: "fomentar en los alumnos el gusto de investigación personal, el análisis sincero de los hechos, el examen imparcial de las opiniones y la iniciativa intelectual....El profesor debe distribuir su curso en conferencias expositivas y críticas, en el seminario ó laboratorio, en el cual enseñará prácticamente el trabajo monográfico y el ejercicio crítico, de modo que habitúe á los estudiantes á profundizar los temas, encararlos lógicamente, agotar la bibliografía de la materia, tomar las notas que corresponden, clasificarlas, meditar sobre ellas, y redactar su trabajo con la constante comprobación de cada hecho y cada argumento. Lo que el profesor debe enseñar, ante todo, es á saber trabajar." 42

El término "investigación personal" no hacia referencia la producción de conocimiento original sino más bien a ejercicios individuales de búsqueda y análisis de datos, confrontación de fuentes y elaboración de una opinión fundamentada. Los esfuerzos iniciales por modernizar los métodos de enseñanza en la Facultad platense formaban parte de una preocupación más amplia por la renovación de los estudios jurídicos a partir de los aportes de las ciencias políticas y sociales. Los llamados "reformistas liberales" que actuaron como profesores en esta casa de estudios buscaron promover el estudio de la legislación comparada y el análisis de las leyes históricas de formación de las instituciones políticas, económicas y civiles de la Nación ${ }^{43}$. Frente a las profundas transformaciones que se observaban en la sociedad argentina y la emergencia de la cuestión social, era necesario que las aulas universitarias, en tanto "laboratorios clínicos", se abocaran al estudio metódico de los

\footnotetext{
${ }^{42}$ Nota sobre los estudios de la Facultad de Ciencias Jurídicas y Sociales, elevada al Ministro de Justicia e Instrucción Pública, con fecha del 31/7/1907 en: UNLP 1909: 77-78. Unos años después, el decano de esta Facultad, Rodolfo Rivarola, señalaba que el sistema ensayado se basaba en cinco principios: 1) la educación mental del alumno por el ejercicio de la investigación propia, 2) en lo posible esa investigación debía estar dirigida hacia los hechos que se relacionaban más directamente con la vida jurídica y educacional del país, 3) una prueba final de competencia para obtener el título profesional, de carácter práctico: un ejercicio de aplicación del derecho para los futuros abogados, y la práctica pedagógica para los aspirantes al magisterio, 4) relaciones más inmediatas y directas del alumno con el profesor a partir de la asistencia obligatoria a un mínimo de clases, 5) metodización de las pruebas de aprovechamiento del alumno a través de clasificaciones en diversas épocas del año y supresión del sistema de exámenes orales a fin de año. Rivarola 1913.

${ }^{43}$ Zimmermann 1992, 1995.
} 
nuevos fenómenos para brindar una comprensión de los mismos a la sociedad y los sectores dirigentes ${ }^{44}$. Como respuesta a la necesidad de entender la realidad social, pero también pensando en la formación de futuros estadistas y funcionarios estatales, se incluirían nuevos cursos como: historia de las instituciones, legislación comparada o economía política; asignaturas hasta ese momento no comprendidas en las Facultades de Derecho argentinas ${ }^{45}$. Otra de las innovaciones fue la división de los estudios en dos ciclos: uno para preparar profesionales y otro posterior destinado al doctorado, orientado hacia las ciencias sociales y políticas. Con este plan de estudios, se intentaba aplicar algunas de las reformas que se habían estado discutiendo en la Facultad de Buenos Aires. Junto con ello, se destinaron importantes partidas de dinero para cursos especiales de profesores invitados, como por ejemplo, los dictados por los españoles Rafael Altamira en 1909 y Adolfo Posada al año siguiente. El primero dictaría conferencias públicas y un curso sobre Metodología de la Historia, con el cual se inauguraría la Sección de Filosofía, Historia y Letras, mientras que Posada también daría conferencias y un seminario sobre el régimen democrático.

En el espacio denominado de "seminario" se esperaba que los alumnos pudieran desarrollar ejercicios basados en el uso de fuentes, datos estadísticos, análisis de bibliografía secundaria, escritura de monografías, lectura crítica y discusiones sobre el trabajo realizado por cada estudiante. Esto implicaba la presencia de los alumnos en las aulas pero en un número limitado, para lo cual la Facultad de Ciencias Jurídicas fijó un número máximo de cincuenta estudiantes por clase y posteriormente se estableció un examen de ingreso. Es de destacar que la cantidad de estudiantes admitidos por clase era bastante elevada comparada con otras experiencias internacionales similares que recomendaban grupos de no más de quince o veinte personas. Por su parte, las autoridades universitarias reconocían que reducir el número de alumnos por clase implicaría un mayor aumento de la planta docente y la multiplicación de cursos paralelos, situación que el presupuesto universitario de ese momento no podía afrontar.

También los ejercicios monográficos y de exposiciones por parte de los alumnos se aplicaron inicialmente en los cursos de otras carreras como los de pedagogía, donde varios de esos trabajos serían publicados en la revista Archivos de Pedagogía de esa Sección. En la Escuela/Instituto de Geografía dependiente del

\footnotetext{
44 González 1935, XVI: 11-18.
}

${ }^{45}$ Palacios 1957. 
Museo de La Plata, se incentivó los trabajos monográficos, visitas de estudio a las principales reparticiones públicas que se vinculaban con esa disciplina y entre los ayudantes-alumnos la realización de trabajos de aplicación e investigación en los gabinetes de la institución, aunque esto se vería interrumpido con la muerte del director de esa Escuela, Enrique Delachaux, en 1908. En la misma época, el sistema monográfico se intentaba institucionalizar en la Facultad de Filosofía y Letras de Buenos Aires, donde participaban muchos de los docentes de La Plata. Paralelamente, también se discutía en la Facultad de Derecho de la Universidad porteña junto con la reforma de los planes de estudio para abogacía y el doctorado, en el marco de una serie de conflictos estudiantiles. En esta última, algunos académicos como Antonio Dellepiane, impulsaron los cursos intensivos y el trabajo monográfico como forma de trasformar a la Facultad en un centro de altos estudios ${ }^{46}$. Sin embargo, al igual que en La Plata, estos experimentos resultaron un fracaso. A principio de siglo, el sistema monográfico remitía a una lectura particular del "seminario" que había alcanzado una amplia difusión como modelo dominante de interacción pedagógica en las universidades alemanas y que había sido adoptado como modalidad de entrenamiento de alumnos avanzados en ciencias sociales y humanidades entre las instituciones de educación superior de diferentes países. Pero mientras en Alemania, los seminarios se trasformaron en los "laboratorios" de las ciencias sociales para producir investigaciones originales y entrenar discípulos para ello, en la zona rioplatense, se lo adaptó como modalidad de trabajos prácticos para todos para alumnos antes que como efectivas "islas" para articular las tareas de enseñanza e investigación de los profesores a través de la formación en investigación.

Uno de los principales promotores de la modalidad del seminario, las monografías así como de los cursos intensivos y especializados en un tema distinto cada año, fue Ernesto Quesada, quien intentaría aplicar las experiencias observadas en Alemania a su cátedra de sociología tanto en la Facultad de Derecho de La Plata como en la de la Universidad de Buenos Aires ${ }^{47}$. Por su parte, los estudiantes platenses de

\footnotetext{
46 Dellepiane 1910.

${ }^{47}$ Pereyra 1998. Para Quesada el seminario tenía una metodología precisa. Primero, el profesor realizaba una exposición sobre un asunto determinado. Luego, señalaba temas especiales a los estudiantes y aconsejaba las áreas que podían interesarles. Más tarde, se distribuían los temas de las monografías, pero no se indicaban datos ni fuentes de consulta. Esta tarea era dejada para otro momento, cuando, ante la consulta y la inquietud de cada estudiante, el profesor les indicaba las referencias correspondientes. Cada alumno debía escribir un trabajo y además realizar una crítica de la tarea de un compañero, analizando el método, el uso de la bibliografía y fuentes y el enfoque teórico utilizado e incluyendo un comentario personal sobre el mismo. En la clase, cada estudiante leía su
} 
Derecho no se interesaron demasiado por este tipo de experiencia y de hecho desconfiaron del aire "germanófilo" que parecía invadir la Facultad. A fines de 1911, el Centro de Estudiantes elevó a las autoridades académicas un proyecto para la admisión de alumnos libres y la sustitución de la promoción con monografías por exámenes. Los estudiantes criticaban varios defectos del sistema: la superposición horaria, las clases numerosas y las dificultades que se le presentaban al profesor para evaluar el trabajo personal durante el año y la necesidad de contar con estudios extensivos previos al intensivo. Asimismo, insistían en que el sistema monográfico estaba lejos de cumplir con los objetivos previstos y tampoco constituía una tarea estimulante: "se pierde el tiempo buscando libros, datos insignificante á través de las bibliotecas" 48 . Tampoco los profesores de la Facultad parecieron sentirse conformes con los resultados de los miles de trabajos monográficos que se acumularon en los archivos de la institución y hacia 1914 se reemplazaría los trabajos escritos por exámenes finales. De hecho, también en la Universidad de Buenos Aires se discutió en 1910, la idea de suprimir la promoción por monografía en razón de los deficientes resultados que había producido. ${ }^{49}$

Tal vez uno de los problemas iniciales fue que se miraron esas experiencias más bien como una modalidad de trabajos prácticos de carácter obligatorio para todo el alumnado, que como un lugar donde los profesores y asistentes desarrollaban sus investigaciones y entrenaban a los alumnos que estuvieran interesados en formarse en investigación como sucedía en los Seminarios alemanes, Institutos o las Escuelas prácticas de Altos Estudios europeas. Por otra parte, ello pone en evidencia algunos de lo límites para adecuar una educación científica que respondiera al mismo tiempo a la finalidad de formación profesional y aplicación del conocimiento, y por otro, a los intereses científicos e intelectuales de sus profesores. Como ha analizado Diego Pereyra, los esfuerzos de algunos profesores como Ernesto Quesada por incentivar los estudios sociales entre sus alumnos no despertaron demasiadas vocaciones y al mismo tiempo fracasaron en la formación de discípulos, quienes al parecer no tenían los

monografía y el crítico elegido exponía oralmente los méritos y las deficiencias de ese trabajo. Al finalizar el seminario, los alumnos debían entregar el trabajo corregido y confeccionar, de esta manera, "una monografía definitiva lo más perfecta posible". De esa forma, se esperaba que el conocimiento pasaba por un quíntuple tamiz: "exposición oral, monografía preliminar, crítica escrita, crítica oral, monografía definitiva".

${ }^{48}$ En octubre de 1911, el Centro de Estudiante de Derecho elevó al decano de la Facultad, un proyecto para la admisión de alumnos libres y sustitución de monografías por exámenes. Esa nota se publicó en la revista del Centro: Ciencias Sociales, 1912, 11: 392-401.

49 Véase, por ejemplo, Revista de la Universidad de Buenos Aires, 1910, XIV: 31. 
mismos intereses o preocupaciones ${ }^{50}$. En ese sentido, tanto en la Universidad de Buenos Aires como en La Plata el proyecto de investigación social parece no haber sido seductor para los alumnos. Es de destacar que en la década de 1920, los intentos por implementar las clases de seminario o investigación monografía como parte del programa de reforma universitaria impulsado en la Facultad de Humanidades y de Derecho de La Plata, encontrarían bastante resistencia entre los sectores estudiantiles ${ }^{51}$.

La idea del "seminario" también estuvo presente en otras unidades académicas. Así, por ejemplo, en 1914 se estableció en la Facultad de Agronomía y Veterinaria un Seminario de Economía Rural y Contabilidad Agrícola como una actividad complementaria y optativa para los alumnos de cuarto año que siguieran esos cursos. Los objetivos del mismo eran: a) reunir bibliografía sobre el tema, en particular documentación e información nacional, b) realizar investigaciones especiales y aplicadas al país, c) entrenar estudiantes en la preparación de informes orales, escritos, gráficos y síntesis de los estudios realizados, d) organizar una sección especial en el Museo Agrícola de la Facultad, y e) establecer relaciones y canjes con otros seminarios similares. Este Seminario a diferencia de la experiencia que se intentó ensayar en los estudios de ciencias jurídicas, estaba destinado a formar un grupo de trabajo con estudiantes avanzados y conformar un centro de estudios. De hecho, como parte de las actividades de este ámbito, algunos estudiantes publicarían trabajos en la revista de la Facultad. En la misma época, también se organizaron otros espacios destinados especialmente a la formación en investigación en esta Facultad, especialmente vinculadas con las ciencias veterinarias. En 1912 se sancionó una ordenanza creando un curso superior de bacteriología que tendría un carácter de curso experimental de perfeccionamiento y facultativo para los estudiantes que hubieran terminado de cursar la carrera o para graduados. Para ello se pensaba recurrir a la contratación de especialistas extranjeros que darían cursos temporarios, como los que había dado el francés Henry Vallée en 1910. Este proyecto se justificó en la falta de este tipo de estudios en el país, y de hecho, en esa época se estaba intentando organizar en Buenos Aires un Instituto Bacteriológico. El curso propuesto en la Facultad platense se estructuró como una especialización de postgrado para médicos veterinarios, médicos, doctores en ciencias naturales o química e ingenieros

\footnotetext{
${ }^{50}$ Pereyra 1998.

${ }^{51}$ Con respecto a la Facultad de Derecho, véase: Palacios 1957, Caldelari y Funes 1997
} 
agrónomos y alumnos de la Facultad que habían terminado los estudios. El mismo comprendería 16 meses de clases dividido en dos ciclos, con un mínimo de cien horas de trabajo mensual y una cuota de cien pesos, de lo cual el $50 \%$ se destinaría al desarrollo del curso ${ }^{52}$. Para la aprobación se exigía una monografía original resultado de trabajos experimentales y de investigación y su defensa oral. Si bien, no se ha podido encontrar registros que permitan conocer como funcionó este curso y si contó con interesados, pone de manifiesto como en esta Facultad, orientada principalmente a la formación de profesionales, se pensó en formar en investigación como una especialización de postgrado. En esta época, la idea de estudios de perfeccionamiento y postgrado también se manifestaría en las becas para que los graduados completaran su entrenamiento en instituciones extranjeras. Al mismo tiempo, se fomentó la investigación en otras áreas como físiología, para lo cual se contrató al italiano Mario Camis en 1913. Para ello, además, se destinaría un local especial para instalar el Laboratorio de Fisiología y se otorgaron a este investigador amplios recursos para adquirir en Europa instrumental actualizado para investigación y enseñanza ${ }^{53}$. Este instituto se terminaría de instalar a fines de 1914 y unos meses después su director lo abandonaría para ir a participar en uno de los frentes de combate de su país.

Uno de los esfuerzos iniciales por renovar la estructura y el perfil de la institución universitaria se manifestó en la incorporación de institutos de investigación, como el Observatorio y el Museo con el objeto de que participaran en la "misión pedagógica" de la Universidad. Las autoridades de la casa de estudios platense se preocuparon por crear nuevas carreras científicas o darles mayor espacio en la estructura universitaria con el objetivo de incentivar la formación de cuadros

\footnotetext{
52 Véase al respecto: "Programa y Reglamento del curso experimental de perfeccionamiento en Bacteriología" en: UNLP 1913b: 93-98.

${ }^{53}$ Este Laboratorio estaba conformado por varios salones. En el medio estaba ubicada una sala central que funcionaba como aula con una mesa central para las demostraciones experimentales. Esta estaba conectada con las salas colaterales donde se preparaba los materiales y los animales, lo que facilitaba el transporte de los elementos demostrativos para las lecciones. A los costados se ubicaban: una sala para servicios generales, que incluía la limpieza y preparación preliminar de los animales y otra estaba destinada a los trabajos de vivisección, con grandes aparatos y un motor eléctrico. También había un gabinete destinado al jefe de trabajo prácticos y otro como habitación y biblioteca para el profesor; un taller para trabajar el vidrio, corcho y otros elementos necesarios; un gabinete de química; otro pequeño salón para guardar los instrumentos más delicados o de uso poco frecuentes; una sección para experimentación en física y un sótano para guardar material, conservar las ranas - que se utilizaban en la mayoría de los experimentos- y para realizar "experimentos que requerían un ambiente tranquilo". A poca distancia de este edificio habían un local amplio y aireado destinado a guardar los animales de experimentación. Este Laboratorio había sido dotado para la actividad científica en dos sentidos: la enseñanza y la investigación. Asimismo, se señalaba que uno de los elementos más necesarios era "la cooperación de los jóvenes que deben contribuir a la obra con entusiasmo por la ciencia y el amor al trabajo". Camis 1915.
} 
científicos nacionales. Inicialmente esto último se promovería por medio de dos formas: la enseñanza formal en materias científicas y la contratación de los pocos alumnos interesados en este tipo de estudios como ayudantes y preparadores en las distintas secciones del Museo, como se analiza en la segunda parte de la tesis, o como calculistas y personal técnico en las dependencias del Observatorio. De esta manera, por ejemplo se formaron los dos primeros alumnos que se interesaron por los estudios de astronomía: el sanjuanino Felix Aguilar y Raúl Gómez ${ }^{54}$. Ambos habían estudiado en la Escuela de Minas de San Juan y en 1910 se diplomaron de ingenieros geógrafos, ya que en esa época el título de doctor en astronomía no se había establecido ${ }^{55}$. En los siguientes años no hubo prácticamente estudiantes interesados en estos estudios. Por otro lado, el funcionamiento de Observatorio fue bastante problemático durante los primeros años hasta su reorganización en 1911, cuando se contrató al astrónomo norteamericano William Hussey ${ }^{56}$. En 1913 el decano de la Facultad de Ciencias Físicas, Matemáticas y Astronómicas se lamentaba que pese a que la Escuela superior de Ciencias Astronómicas contaba con personal, equipos y todas las condiciones necesarias para la enseñanza adecuada de esas disciplinas: "desgraciadamente, la afluencia de estudiantes ha sido nula, no habiéndose logrado atraer alumnos ni formarlos dentro de la casa, a pesar del empeño manifiesto de las autoridades para ir preparando personal argentino en rama tan especial de estudios, lo que habría sido de interés, si se recuerda que en el país existen dos observatorios astronómicos

\footnotetext{
${ }^{54}$ Raúl Gómez practicaba en el Observatorio de San Juan desde 1904, bajo la dirección de Virgilio Rafinetti, quien entre 1904 y 1905 dirigió el Observatorio de La Plata y luego fue incorporado a la Universidad como vicedirector del Observatorio, profesor y académico de la Facultad de Ciencias Físicas, Matemáticas y Astronómicas. La tesis de Gómez consistió en un trabajo de fotometría: un relevamiento foto-teodolítico de un ventisquero del Aconcagua. Aguilar se formó bajo la dirección del Dr. Cornera en la estación astronómica de Oncatio, Córdoba, instalada por la Asociación Geodésica Internacional. Cuando el Gobierno Nacional adquirió esta estación, la misma pasó a depender de la dirección del Observatorio de La Plata en 1908. Al renunciar Cornera, esta pasó a ser dirigida por Aguilar, quien se encargaba de remitir mensualmente datos a la Asociación Geodésica Internacional. Después de graduarse realizó un viaje por Europa durante más de un año para completar su formación. Al regresar se instalaría en La Plata y se incorporaría a la Facultad de Ciencias Físicas, Matemáticas y Astronómicas.

${ }^{55}$ Es de destacar que el diploma de ingeniero geógrafo se otorgaba también en la Universidad de Córdoba, pero mientras en La Plata se lo equiparaba con los estudios superiores en astronomía en la primera era equivalente al título de agrimensor, un carrera más corta y de menor estatus en la jerarquía de los estudios universitarios. Las autoridades de la Facultad platense consideraban que esa diferencia podía ser uno de los factores que hacían poco atractiva esta carrera en La Plata.

${ }^{56}$ Este investigador, que permaneció hasta 1915, se dedicó a la reorganización de los servicios del Observatorio y estuvo más interesado en atender sus propias investigaciones -que desarrollaba un semestre en La Plata y otro en Estados Unidos- antes que en promover la enseñanza en esta disciplina.
} 
ricamente montados y que deberán alguna vez hallarse en manos de personal nacional." 57

En 1915 se organizó el doctorado en astronomía y en matemática, que junto al doctorado en física establecido en 1909, constituyeron el núcleo de estudios científicos de esa Facultad. No obstante, estas carreras prácticamente no atraerían casi estudiantes, a fines de esa década la primera contaba con un par de alumnos propios que habían sido incorporados como personal auxiliar en el Observatorio. La falta de estudiantes también se sentiría en las otras carreras científicas y sería un problema para los proyectos de formar escuelas de investigación como en el caso del Instituto de Física $^{58}$. A partir de 1909, las autoridades universitarias habían impulsado la completa reorganización de este último, para lo cual se contrataron investigadores en Alemania con el objeto de que promovieran esos estudios y entrenaran discípulos. El nuevo director de la Escuela de Física, Emil Bose (1874-1911), consiguió que le cedieran un edificio destinado inicialmente para los laboratorios del Colegio Nacional, donde se ubicó el Instituto de Física inaugurado en 1911. Este contaría con: a) un auditorio con equipos para demostraciones experimentales que se utilizaría en clases y conferencias de extensión universitaria, b) salones y laboratorios equipados para los trabajos prácticos de los alumnos e investigaciones de los profesores y colaboradores. En estos espacios de investigación no sólo los pocos estudiantes de física realizaran sus tesis doctorales, sino también algunos alumnos del doctorado de química bajo la dirección

\footnotetext{
${ }^{57}$ Memoria correspondiente a 1913 de la Facultad de Ciencias Físicas, Matemáticas y Astronómicas, 1913:108.

${ }^{58}$ En la Memoria de la Facultad de Ciencias Físicas, Matemáticas y Astronómicas elevada a las autoridades universitarias se señalaba: "las investigaciones efectuadas en la Escuela superior de ciencias físicas, se han referido a cuestiones de valor cientifico y doctrinario, realizadas por el personal docente, con poco concurso de estudiantes por la falta de alumnos en la carrera especial del doctorado en física, falta tanto más importante, por cuanto ella puede hacer fracasar el pensamiento de esta Facultad de crear una escuela de investigaciones físicas dentro del organismo del instituto y con la cual puede movilizarse de un modo más propicio que para la enseñanza sola, el material valioso que se dispone para esos fines; el personal didáctico que puede aplicarse a esos trabajos, forzosamente reducido, ni puede realizar, sin su auxilio, una labor considerable, ni será su obra de gran valor si no aparece vinculada a la función de formar una escuela de investigación; resulta pues, indispensable atraer estudiantes a esta carrera, desviándolos de las profesiones que ya comienzan a tenerlos en exceso, pero para ello sería indispensable utilizar al doctorado obteniendo, por ejemplo, del respectivo ministerio nacional una resolución que diera preferencia para las designaciones de profesores de física y matemáticas de los colegios y escuelas de la Nación, a los doctores de esta Facultad, de otro modo el propósito de fundar la ciencia física y matemáticas nacional estará por mucho tiempo contrarrestado por el éxito utilitario de las carreras profesionales ......En la Escuela Superior de Ciencias Matemáticas se ha tropezado con las mismas dificultades que en la de Física, sobre la falta de estudiantes que ha dificultado la aplicación del seminario y la discusión en los estudios superiores de matemáticas. Los trabajos se han limitado, pues, a los estudios personales de los profesores, de modo que no pueden considerarse propiamente como de la escuela en su carácter propio de instituto". Besio Moreno 1917: 158-159.
} 
del físico alemán Ricardo Gans (1880-1954), el nuevo director de ese Instituto entre 1912 y 1925. En los planes de estudios del doctorado en física, se establecieron dos cursos de "Trabajos prácticos en física" como una asignatura independiente de otras materias para los alumnos de segundo y tercer año, que también se consideró como una instancia necesaria para la formación del profesorado en física como se analiza en el último capítulo. En el cuarto y el quinto año se incluía un curso de "Trabajos de investigación en Física", inicialmente de seis horas semanales, que luego se planificó que fueran de nueve horas semanales para cuarto año y quince para el último año. No obstante, la poca concurrencia de alumnos haría que estos dos cursos se dieran de forma conjunta, los cuales estarían dedicados a realizar trabajos especiales e investigaciones que servirían para confeccionar las tesis doctorales. Este tipo de curso "práctico" especial -diferente de los ejercicios prácticos de las otras asignaturas de los planes de estudios- $\mathrm{y}$ destinados al entrenamiento en el trabajo de laboratorio e investigación también se organizarían en los estudios de zoología del doctorado en ciencias naturales que se ofrecía en el Museo/Facultad, como se analiza en la segunda parte de esta tesis. En este último ámbito, el zoólogo Miguel Fernández, formado en la Universidad de Zürich, promovió una modalidad de enseñanza -investigación denominada "Trabajos de laboratorio", que pareció tener un cierto éxito en fomentar trabajos científicos entre sus alumnos y en reunir un pequeño grupo en torno a su laboratorio.

El "laboratorio" fue otro de los ámbitos establecidos para la socialización de la práctica científica, que al mismo tiempo ofrecía un lugar de trabajo para los profesores-investigadores, pero también abierto a los estudiantes y otras personas que solicitaran permiso para realizar o participar en ese tipo de actividades. En varias Escuelas se preocuparon para que los gabinetes y laboratorios fueran dotados para responder tanto la "función profesional" como a la "función científica" de la universidad. En algunos casos, como por ejemplo los laboratorios de química instalados en el subsuelo del Museo, estos espacios estuvieron conformados por varios salones: aula-laboratorio para las clases prácticas, depósitos de instrumentos y colecciones; un lugar de trabajo específico para los profesores y colaboradores con instrumentos de precisión, oficina para el profesor, entre otras instalaciones. Sin embargo, la "función científica" de los laboratorios estaría lejos de alcanzarse en todas 
las dependencias en parte por las dificultades para conformar un grupo de trabajo en torno al mismo. Como se ha señalado en otros casos, las vocaciones frustradas por falta de espacios y el fracaso de los espacios por falta de vocaciones u oportunidades laborales sería una situación que se repetiría a lo largo de la historia ${ }^{59}$. En parte, ello se debía a los pocos profesores que hacían de esos laboratorios su principal lugar de trabajo, la falta de posibilidades laborales para los que se interesaban por las actividades científicas dentro de la universidad, y en otras ocasiones por los pocos interesados en los trabajos de investigación más allá de los requisitos para alcanzar el diploma. En este sentido, por ejemplo, en el informe de la Escuela de Química y Farmacia se reconoció en 1913 que: "El funcionamiento de los laboratorios tiene dos fases que merecen comentarios muy diferentes. En lo que a la enseñanza se refiere, considerándolos como medio de observar y practicar después de las conferencias en el anfiteatro, nada hay que observar: su función se cumple activa e incesantemente, despertando entusiasmos en los alumnos y destruyendo los horarios, pues las secciones de trabajo empiezan a la hora fija terminando más allá de lo calculado y exigido. Pero no puede decirse lo mismo, si se piensa en todo lo que podría realizar los jóvenes en los últimos años de su carrera y en los primeros de su vida como exalumnos. Los gabinetes y laboratorios se hallan bien dotados como para que en ellos puedan realizarse trabajos de investigación científica en las distintas ramas de la Química, y sus fines no se cumplirán mientras no se complementen las tareas del estudiante como tal en los estudios que el futuro hombre de ciencia debe emprender. Todo lo que hasta hoy se ha podido conseguir de los estudiantes, es que se dediquen por algunos meses a una investigación, a un trabajo original bajo la dirección de un profesor, pero con el interés de que sus resultados fuesen la base de la tesis inaugural, la prueba última de su carrera... Pasado ese término, salvado el puente, las condiciones del medio ambiente conspiran contra los mejores deseos, y solicitados, arrastrados, empujados en rumbos diferentes, la vida los aleja del laboratorio.... "60

Como solución indirecta para comenzar a formar un futuro núcleo de profesores dedicados a las investigaciones científicas, Enrique Herrero Ducloux consideraba necesario: "enviar nuestros ex alumnos sobresalientes a perfeccionar sus estudios en los Institutos especiales europeos”. Para ello promovía la organización de

\footnotetext{
${ }^{59}$ Buch 2000.

${ }^{60}$ Lafone Quevedo 1913: 78-79.
} 
un sistema de becas de perfeccionamiento y su regulación por parte de las universidades, para que estas últimas pudieran dirigir el desarrollo de nuevas áreas científicas. En Argentina, la institución de becas estatales para estudiar en el exterior venía implementándose desde hacia varias décadas atrás, aunque la obtención de las mismas había estado supeditada a contactos personales y recomendaciones políticas. Inicialmente gran parte de esas becas se otorgaron para estudiar bellas artes o música en Europa y en menor medida para completar la formación profesional en medicina, ingeniaría o ciencias agronómicas. A principios del siglo XX, el Estado comenzó preocuparse por la actuación de los becados en el exterior, su desempeño académico y la imagen de país que podían trasmitir. Con el objeto de supervisar más de cerca de los estudiantes en el exterior se crearía en 1909 una nueva institución denominada: Patronato de Becados en el extranjero, con sede en Estados Unidos y otra en Europa. Junto con ello se comenzaron a establecer reglamentaciones más detalladas sobre los becados. También las Universidades nacionales fueron consiguiendo que se destinaran algunas becas para sus egresados. En La Plata, las becas de perfeccionamiento en el exterior se aplicaron para los ex-alumnos de Facultad de Agronomía y Veterinaria y luego para los primeros doctores de las carreras científicas de química, física y ciencias naturales, aunque en este último caso no llegó concretarse por el inicio de la guerra europea. Hacia 1913 las distintas unidades académicas comenzaron a reglamentar este sistema, estableciéndose un año de duración de las becas y una selección en base a las calificaciones, los proyectos de estudios y actividades a realizar y/o las aptitudes para el trabajo científico demostrado por los estudiantes en los laboratorios. Con ello se procuraba estimular a un grupo selecto de alumnos interesados en las actividades científicas, promoviendo el ideal de estudios de postgrado en los mejores centros científicos europeos y la organización de un sistema incipiente para la formación de científicos jóvenes en el exterior. No obstante, esto duró poco. Al estallar la guerra europea en agosto de 1914 se frenaron los viajes programados. Con la crisis económica argentina de esa época se suprimirían las becas de perfeccionamiento en el exterior así como las de estudio, que se habían conseguido en 1911 para estimular la carrera de ciencias naturales. Finalmente en 1915, en el marco de los recortes al presupuesto nacional, en el Congreso Nacional se decidió eliminar del mismo la partida del Patronato de Becados en el exterior.

La "Gran Guerra" y la situación económica de esos años, tendría un efecto mucho más amplio sobre diversos aspectos de la organización de la práctica científica 
en la universidad de lo que generalmente se ha considerado. Por un lado, se interrumpieron los intercambios científicos internacionales, los contratos de profesores extranjeros, la adquisición en Europa de nuevo material para la renovación de los laboratorios y las bibliotecas; y por otro, se incrementaron los costos de los productos que se adquirían en el mercado local para el funcionamiento cotidiano de los mismos. Paralelamente, se produjeron recortes en el presupuesto universitario y se comenzó a ejercer un mayor control sobre la actividad docente de los profesores. La falta de estudiantes en las materias científicas, sobre todo en las específicas de los doctorados de física y ciencias naturales, fue una situación problemática para los profesores que articulaban un espacio laboral en torno a la cátedra. Según las ordenanzas del presupuesto universitario, los sueldos docentes de asignaturas que no se dictaran durante el año o que contaran con menos de tres alumnos matriculados no se abonarían. Si bien esta disposición se estableció en 1909, recién hacia fines de 1914 se comenzó a ejercer un mayor control. En el caso del Museo/Facultad de ciencias naturales, como se examina en el siguiente capítulo, se buscó legitimar algunas cátedras como destinadas a investigaciones y tareas museísticas. Otros profesores se dedicarían a dictar cursos libres o conferencias de extensión universitaria como parte de sus obligaciones docentes. En el caso de la Facultad de Ciencias Físicas, Matemáticas y Astronómicas, se sancionó una ordenanza en 1915, por la cual se le otorgó a ciertas cátedras, especialmente las de los años superiores de las carreras científicas, el carácter de "especiales" y destinadas a trabajos de investigación. No obstante, la falta de estudiantes en estos estudios continuaría siendo una cuestión crítica.

Otra consecuencia del conflicto bélico europeo sería que algunos investigadores extranjeros abandonarían sus cargos para ir al frente de batalla o colaborar con sus respectivos países. El impacto de la guerra también se haría sentir en el seno de la comunidad académica argentina, tal como se manifestó en algunos conflictos suscitados en los institutos de la Universidad platense en torno al desempeño de varios científicos de origen alemán y las divisiones entre quienes defendían uno u otro bando ${ }^{61}$. Si bien las tensiones entre los objetivos internacionales y las adscripciones locales/ nacionales de la ciencia existían con anterioridad a 1914, con la guerra europea se trasformaron en conflictos concretos que tendieron a

\footnotetext{
${ }^{61}$ García y Podgorny 2000.
} 
resolverse colocando los intereses nacionales por encima del ideal de una república de sabios. La primera Guerra Mundial socavó los sueños de paz y amistad internacional promovidos por la ciencia $\mathrm{y}$, si bien en la posguerra las relaciones académicas se restablecieron, el principio de lealtad a la patria ya no regía sólo sobre los científicos como individuos sino sobre la ciencia organizada en cada país. Al mismo tiempo, algunos de los conflictos que asumieron la forma de un enfrentamiento nacionalista tenían su raíz en una disputa concreta por puestos de trabajo y espacios de poder dentro de la Universidad ${ }^{62}$. Las acusaciones por los privilegios que se concedían a los investigadores extranjeros fueron elementos que recurrentemente emergieron en diferentes momentos, especialmente cuando se consideraba que se contaba localmente con el personal adecuado para atender esas actividades. La existencia de cargos de profesores que no estaban al frente de alumnos, la acumulación de cátedras, las prerrogativas que tenían los "sabios" extranjeros y lo costoso de las instalaciones científicas fueron parte de las críticas que recibió la Universidad platense durante su etapa fundacional ${ }^{63}$.

Durante la década del 1910 se fue haciendo evidente que los ejemplos de "sabios" trabajando en los laboratorios no era un estímulo suficiente para atraer estudiantes en la labor "desinteresada" de la investigación científica. En particular, la falta de alumnos en los doctorados en física y ciencias naturales fue una cuestión crítica para los que aspiraban formar escuelas de investigación y difundir sus disciplinas. El entrenamiento de estudiantes en la producción de conocimientos y la formación de un grupo de discípulos provistos con posiciones para dedicarse y continuar estas actividades jugaría un rol importante en ese proceso ${ }^{64}$. En ese sentido, la disponibilidad de importantes facilidades y profesores dedicados a investigación ayudaron a sentar las bases de una cultura científica-académica, pero esto no sería garantía suficiente para consolidar una tradición en investigación o una escuela científica. Esto último, también pone en evidencia la importancia del reclutamiento,

\footnotetext{
${ }^{62}$ Podgorny 1996.

${ }^{63}$ Muchas de las críticas provinieron de algunos miembros de las antiguas instituciones provinciales que se sintieron desplazados al crearse la Universidad Nacional de La Plata, que formaron un "Comité Pro-Universidad de La Plata" dirigido por el químico Pedro Pando. Ese grupo, en varias oportunidades, solicitó al Ministro de Justicia e Instrucción Pública que interviniera y reorganizara esta casa de estudios. De hecho, entre 1907 y 1910 la Universidad platense tuvo que efectuar varias campañas de difusión y defensa ante los rumores de recorte del subsidio nacional y la propaganda en contra de ese grupo. Para contrarrestar esto último, se formó otra comisión también llamada "Comité Pro-

Universidad de La Plata", apoyada por estudiantes, profesores y distintas asociaciones como la de maestros de la Provincia de Buenos Aires.

${ }^{64}$ Pyenson 1978.
} 
preparación y posterior ubicación de los estudiantes de ciencias cuando se promueve la institucionalización de una disciplina o un nuevo programa de investigación.

Por otro lado, como se examina en el último capítulo, otro de los elementos importantes para el soporte de las disciplinas científicas "desinteresadas" estuvo relacionado con el sistema de educación pública. En particular, esto se buscaría a través de la preparación y acreditación del profesorado secundario, lo cual era visto tanto como un canal para una mayor difusión de la práctica científica como para ampliar el campo laboral para los jóvenes científicos e interesados en las ciencias. La formación de maestros y profesores; los programas de conferencias y cursos, exhibiciones y publicaciones para un público general aparecieron como diferentes modalidades a través de las cuales los sectores universitarios buscaron extender la influencia de sus disciplinas y crear una contexto de recepción social para las mismas más allá de los grupos que participaban habitualmente en el ámbito académico. Al mismo tiempo, la divulgación científica jugaría un papel importante como estrategia para legitimar una universidad que se definía como científica y solicitaba grandes recursos para su mantenimiento.

\section{3. La extensión universitaria y la divulgación de la ciencia}

En el programa fundacional de la Universidad Nacional de La Plata, la "socialización" de la ciencia y la extensión de la educación a un público más amplio que el conformado por los alumnos universitarios se presentarían como parte de la "función social” de las universidades modernas. En efecto, Joaquín V. González, dedicó a la "extensión universitaria" un capítulo especial en el proyecto de esta institución: "faltaría al concepto informativo y generador de la Universidad nueva, el de la extensión, incorporada desde no hace mucho tiempo á las de más renombre de Europa y América, como expresión de la influencia directa de esos grandes focos científicos sobre la masa social externa, que no frecuenta las aulas: en una palabra la participación popular en los beneficios de las enseñanzas que aquéllos cultivan y pueden serles trasmitidos..." 65

Como se señaló en el capítulo anterior, en la transición del siglo XIX al XX se expandió un "movimiento de extensión de la educación superior" vinculado a la 
ampliación de la base social de los sistemas educativos y la popularización científica para sectores trabajadores ${ }^{66}$. Si bien las actividades de divulgación científico-cultural por medio de conferencias, demostraciones científicas y obras de popularización, ya sea por iniciativas particulares, de sectores universitarios o sociedades eruditas se había producido en siglos anteriores ${ }^{67}$, lo novedoso de este proceso fue que varias universidades lo asumieron como parte de sus funciones docentes, creando instituciones especiales y programas sistemáticos para el desarrollo de la extensión de sus enseñanzas a amplios sectores sociales y generalmente en interacción con otras instituciones educativas, sociedades culturales o centros populares. En ese época, las propuestas internacionales de extensión universitaria y educación popular de adultos se insertaron en un marco de preocupaciones cuyos temas centrales giraban en torno a: 1) la educación de la democracia, 2) la cuestión social y 3) la cuestión nacional. En general, estos problemas se reflejaron de diferentes maneras y su contenido varió de acuerdo a los grupos que la organizaban, los sistemas educativos y a los malestares sociales de cada país. En algunos casos, los programas universitarios de educación popular o extensión universitaria reforzaban el papel de universidad y los grupos ligados a ella como sujetos privilegiados para liderar el proceso de regeneración nacional o en los intentos de afianzar una unidad lingüística, cultural y política ${ }^{68}$. Estos esfuerzos se basaban en la convicción de la capacidad integrativa y disciplinar de la educación, que además, aparecía como el principal canal para difundir los componentes ideológicos más importantes para generar una identidad colectiva, afianzar los lazos sociales y un sentimiento de filiación hacia el territorio ocupado por la moderna unidad Estado-Nación ${ }^{69}$. Por otra parte, como ha señalado Hobsbawm hacia el último tercio del siglo XIX se hizo cada vez más evidente que la democratización de la política, o al menos la electoralización cada vez más ilimitada, eran inevitables ${ }^{70}$. En ese proceso, las clases dirigentes se encontraron frente a grupos rivales que competían por la lealtad y las actitudes políticas de las clases populares, especialmente ante el auge de los movimientos obreros y sindicales. A ello se agregaría la ampliación de un público alfabetizado por las campañas de instrucción pública, el desarrollo de la industria editorial y las bibliotecas populares como también

\footnotetext{
${ }^{65}$ González 1935, XIV: 83.

${ }^{66}$ Hobsbawm 1998; Tiana Ferrer 1991.

${ }^{67}$ Ordoñez. y Elena 1990.

${ }^{68}$ Kantasalmi 1999.

${ }^{69}$ Gellner 1988; Hobsbawm 1991, 1998; Hobsbawm y Ranger 1983.
} 
ocurriría en la Argentina $^{71}$. A fines del siglo XIX, se produce la inserción activa y en masa de un público obrero en un nuevo tipo de prensa comercial y popular, que implicó una reorganización importante de la base y estructura de la industria cultural así como el aprovechamiento de nuevas formas de tecnología, procedimientos de trabajo y mecanismos de distribución que funcionasen a través de los nuevos mercados culturales. Como ha sugerido Stuart Hall, uno de los efectos de estas trasformaciones fue la reconstitución de las relaciones políticas y culturales de la clase dominante y la dominada, un cambio íntimamente relacionado con la contención de la democracia popular ${ }^{72}$. En ese proceso, sectores de la elite ilustrada proyectaron ejercer un "tutelaje cultural" sobre los sectores populares, elaborando programas culturales, publicaciones económicas y colecciones de libros seleccionados cuidadosamente. Al mismo tiempo, las experiencias de extensión universitaria y universidades populares también remiten a una nueva sensibilidad social por parte de algunos sectores universitarios, y especialmente en relación con la conformación de la figura del "intelectual" "73.

En el contexto argentino las primeras lecturas acerca del movimiento de extensión universitaria fueron en relación con la educación popular de adultos impulsada por los socialistas, las propuestas de fomentar la participación activa de la sociedad civil en el sostenimiento de la educación ${ }^{74}$ y ciclos de conferencias en las bibliotecas o salones universitarios. En la primera década del siglo XX, también aparecería vinculado a la extensión de la acción educativa de los colegios secundarios y escuelas normales; la capacitación o perfeccionamiento docente; la divulgación de principios científicos útiles para la vida social y ciclos de conferencias. En general bajo el término de "extensión universitaria" se colocaron una diversidad de experiencias educativas y de divulgación para un público adulto. Las mismas serían organizadas tanto desde sectores universitarios como por distintas asociaciones de

\footnotetext{
${ }^{70}$ Hobsbawm 1991.

${ }^{71}$ Prieto 1988.

${ }^{72}$ Hall 1984.

73 Tiana Ferrer 1991; Barrancos 1995.

${ }^{74}$ Esto, por ejemplo, se registró en una circular destinada a los consejos escolares de la Capital Federal y el Territorio Nacional, escrita por Joaquín V. González en 1899 como vocal del Consejo Nacional de Educación. En ella se mencionaba el tema utilizando el término en inglés- "university extension"-, en referencia a la participación de universitarios y el fomento de la educación realizada a partir de la sociedad civil como se daba en Estado Unidos e Inglaterra. González 1935, XIII. Asimismo, en el Reglamento de las Escuelas Comunes de 1900, se estableció como necesario estimular la acción pública a favor de la educación y como modo de retribución se postuló que los establecimientos
} 
educación popular y las bibliotecas populares que se fueron expandiendo durante las primeras décadas del siglo.

Entre esas instituciones, como ha sido analizado por Dora Barrancos, se destacaron las actividades organizadas por la Sociedad Luz desde 1899 y el Ateneo Popular en la primera mitad de la década de 1910, ambas vinculadas a los socialistas; el Colegio Nacional Oeste y la Universidad Popular de Buenos Aires ${ }^{75}$. En esta última participarían también varios profesores de la Universidad platense, al igual que en el Ateneo Popular, donde además se sumaron varios alumnos de La Plata como conferencistas y divulgadores científicos. Entre estos últimos sobresaldrían las figuras de los estudiantes de derecho: Saúl Taborda y Fernando de Andreis así como el de ciencias químicas y naturales, Ricardo Calatroni. Los tres participaron en la formación de la Universidad Obrera en 1909 y los dos últimos en la sucursal local del Ateneo Popular en 1912. Calatroni tuvo un importante papel en las iniciativas de popularización científica en La Plata desarrolladas durante la década de $1910^{76}$. Había estudiado el profesorado en ciencias naturales, farmacia y se doctoró con una tesis en físico-química, formó parte del Centro de Estudiantes de Química y Farmacia y de la creación de la Federación Universitaria de La Plata en 1911. Además pertenecía al grupo de egresados y docentes del Colegio Nacional de La Plata y los sectores anticlericales que organizaron diferentes iniciativas de popularización científico-cultural. En los periódicos de la época, Calatroni aparece como uno de los divulgadores más importantes de las ideas ameghinistas y el guía de las excursiones al Museo de La Plata organizadas por el Ateneo Popular, la Sociedad Luz o la Biblioteca Ameghino de Tolosa. Durante la década de 1910, esas sociedades culturales, sobre todo las de Buenos Aires, organizaban anualmente visitas a las instituciones científicas de La Plata como parte del plan de "elevar el nivel moral e intelectual del pueblo". Estas excursiones movilizaban entre cien y doscientas personas y el itinerario incluía el recorrido por los laboratorios del Colegio Nacional, demostraciones experimentales en el Instituto de Física, una conferencia y/o explicaciones durante el recorrido por las salas de exhibición del Museo y la visita a las instalaciones del Observatorio, guiados por sus directores o profesores. Un programa similar pero reducido a estas dos últimas

educativos debían abrir sus puertas para realizar "la extensión de la enseñanza a la sociedad", por medio de conferencias y el uso público de las bibliotecas y museos escolares.

${ }^{75}$ Barrancos 1995, 1996. 
instituciones también formaría parte de las excursiones escolares de establecimientos educativos de la Capital Federal y otras localidades cercanas. El Museo y Observatorio, además, estaban abiertos al público los jueves y domingos por la tarde, aunque para las visitas escolares se permitía el acceso en otros días y horarios especiales. En el Observatorio también se estableció un servicio de observaciones nocturnas públicas un día por semana. En ambos casos, los excursionistas eran atendidos por el personal técnico y científico de la institución y el acceso era gratuito.

Esto respondía al programa de extensión universitaria anunciado por el presidente de la Universidad platense. En efecto, González había previsto que la extensión social de la enseñanzas y conocimientos producidos en esta casa de estudios se podría llevar a cabo a través de: a) conferencias periódicas "en forma elemental, experimental y empírica" a cargo de los profesores de las distintas asignaturas y en salones abiertos a la concurrencia pública; b) el acceso público a la Biblioteca, museos, exhibiciones, gabinetes y los distintos materiales de estudio que disponía la Universidad, para la lectura, realizar observaciones o una "enseñanza intuitiva" bajo la guía de los "expertos". A ello agregaría: c) una forma de extensión universitaria interna o "intercomunicación de las ciencias" entre sí y que consistía en una serie de conferencias comunes para todos los alumnos y docentes de la Universidad como forma de afianzar el vínculo universitario a través de la unidad de la ciencia; y d) una difusión más amplia por medio de las publicaciones, entre las que se incluirían revistas científicas, series de divulgación científica, los actos académicos y la propaganda de las distintas dependencias para promocionar los estudios; las conferencias y trabajos de los profesores así como también la adquisición y reimpresión de obras antiguas o históricas. Tanto las publicaciones científicas y de series de difusión como la conservación y edición de un patrimonio escrito sobre la historia antigua del país formarían parte del programa de divulgación promovido por las autoridades del Museo de La Plata, como se analiza en el siguiente capítulo.

Inicialmente se había proyectado que la Biblioteca de la Universidad - la antigua Biblioteca provincial ubicada en el piso alto de la Legislatura y dirigida por el catalán republicano Luis Ricardo Fors desde 1898 y hasta fines de $1907^{77}$ mantendría su carácter público, funcionando como lugar de estudios y Centro de

\footnotetext{
${ }^{76}$ Durante los conflictos y distintos acontecimientos que se sucedieron en el marco de la "reforma universitaria" en La Plata entre 1919-1921, Calatroni quedó cesante del Colegio Nacional al igual que Saúl Taborda. Calatroni se mudó y se insertó a trabajar en la Universidad de Santa Fe.
} 
Extensión Universitaria, donde se organizarían conferencias especiales de divulgación, lecturas dominicales sobre temas científicos, artísticos o literarios y cursos libres, bajo la supervisión del director de la Biblioteca. Asimismo, Fors había propuesto que los trabajos se vulgarización y propaganda científica, literaria y artística se publicaran por cuenta de la Universidad como un medio más eficaz y de mayor alcance para exteriorizar las actividades institucionales. Una de las formas previstas para ello, era a través del Boletín de la Biblioteca Pública de la Provincia de Buenos Aires, que se había publicado regularmente entre 1899 y 1905 . No obstante, si bien en 1906 se retomó su edición, sólo aparecieron unos pocos números durante ese año. En cuanto al programa de extensión universitaria, este era una ampliación de los ciclos anuales de "lecturas dominicales" que se habían desarrollado entre 1901 y 1905. Esas conferencias habían estado a cargo de distintas personas vinculadas a las letras, los problemas educacionales, la política y las ciencias jurídicas tanto de La Plata como de Buenos Aires. Es de destacar que en 1904, sectores socialistas y católicos se disputaron el uso de esa tribuna pública para difundir sus posturas con respecto a la cuestión social, competencia que también se manifestaría en la creación de centros y asociaciones culturales para obreros en el barrio ferroviario de Tolosa. Como se menciona más adelante, varios alumnos de la Universidad platense organizarían conferencias y cursos en ese barrio, en varios casos en centros vinculados al socialismo. De hecho, en años iniciales de la nueva Universidad desde el periódico local El Día se criticaría la difusión del socialismo a través de la cátedra y los espacios de extensión universitaria, especialmente en relación con la actuación del socialista Enrique del Valle Iberlucea (1872-1921), secretario general de la Universidad platense y profesor suplente de la cátedra de J. V. González. En efecto, en el ciclo de "Lecturas Dominicales" que se organizó en 1907 en la Biblioteca Pública de la Universidad, la conferencia de este profesor se tituló: "Teoría materialista de la historia". También en esos días se denunciaría que se efectuaba propaganda socialista en las conferencias pedagógicas para los docentes de las escuelas locales, organizadas por la Dirección General de Escuelas. Periódicamente durante varios años, la Sección Pedagógica de la Universidad en combinación con esta institución organizaría cursos y conferencias de capacitación para maestros y estudiantes del magisterio a cargo de los docentes y alumnos avanzados de la Sección.

${ }^{77}$ Palcos 1934. 
Con respecto al programa oficial de Lecturas dominicales en la Biblioteca, estas actividades recién se iniciaron en 1907, comprendiendo un ciclo de 15 conferencias entre los meses de mayo y agosto a cargo de profesores de la casa y dos invitados especiales: Alicia Moreau y David Peña, quiénes luego se incorporarían al cuerpo docente de la institución. Las conferencias fueron ampliamente publicitadas a través de la prensa local y diarios de la Capital Federal, donde se remarcaba que eran de libre entrada y no se necesitaría invitación especial para asistir como era la costumbre en las conferencias de la Universidad de Buenos Aires y otros actos universitarios. Asimismo, los diarios de La Plata publicaron los trabajos expuestos o extractos de ello, una práctica que se mantendría en relación con otras conferencias y los cursos dictados por los profesores extranjeros visitantes. La difusión de las "lecturas dominicales" se reforzó con la publicación de algunas de ellas en la revista del Centro de Estudiantes del Museo y posteriormente en un libro editado por la Universidad con el título: Extensión Universitaria en $1909^{78}$, donde también se incluyeron la mayoría de las conferencias del segundo ciclo realizado en 1908. Este último, sería bastante irregular y sólo comprendió ocho conferencias de las veinticinco que inicialmente se habían proyectado, y al año siguiente ya no se volvería a organizar. En los siguientes años se organizarían diferentes ciclos de conferencias y cursos libres en los nuevos espacios de los anfiteatros y salones de distintas unidades académicas como el Museo, el Instituto de Física, el Colegio Nacional. También se organizarían conferencias públicas y cursos de libre entrada a cargo de los profesores extranjeros visitantes, graduados y algunos profesores.

Para González la esencia del sistema de "extensión universitaria" consistía en convertir a la Universidad en el centro abierto a todos los que se interesaran por profundizar sus conocimientos, ofreciendo una "igualación" de las oportunidades para el desenvolvimiento intelectual. En relación con ello, era partidario que la instrucción extensiva se diera en los mismos edificios y locales universitarios para hacer uso de los materiales de experimentación y observación que disponía la Universidad, y por ese medio ofrecer una enseñanza "objetiva" de acuerdo al método de la ciencia. El presidente de la Universidad platense defendía la extensión universitaria retomado los

\footnotetext{
${ }^{78}$ En esa recopilación se publicaron las conferencias que habían sido escritas, muchas de las cuales también se publicaron en los periódicos locales. Significativamente llama la atención que en ese libro no se incluyó la conferencia del entonces director del Instituto de Física, el ingeniero Teobaldo Ricaldoni, titulada: "Las Tres Unidades"- Dios, materia y energía-, según se publicó en el diario El Día.
} 
argumentos del educacionista Michel Sadler, secretario de la Oficina de Extensión Universitaria de Oxford, quien señalaba: "...su enseñanza lleva á comprender qué servicios los tan lejanos sabios prestan al mundo. las oposiciones se atenúan, se suspenden las hostilidades y, en su lugar, nace una más justa estimación de lo que la ciencia hace por la humanidad, por la sociedad, no solo por el rico y el ocioso, sino también por el pobre y el trabajador y ese cambio de sentimientos beneficia la paz social"79.

De esa forma, la "extensión" de la educación superior se veía como un medio para superar las distancias entre la ciencia y el pueblo, poniendo al alcance de todas las personas: "los medios de aprender la significación histórica del país, de hacerle conocer los modelos de la literatura nacional, de comprender el sentido del método científico." ${ }^{80}$. Esto último sería el eje central de los programas de extensión universitaria que se promovieron en Argentina, en momentos en que se discutía la organización de la república verdadera durante los primeros años del siglo XX. En ese marco, la relación entre la Universidad y el pueblo también se inscribía en un "móvil político" y la educación del ciudadano. Esto se manifestaría especialmente entre los alumnos de pedagogía y derecho de la Universidad platense. Así, por ejemplo, el estudiante Julio C. Moreno retomaba en 1909 las ideas de Adolfo Posada, Sadler y otros autores, señalando: "si el movimiento democrático, que no es hoy ya un puro movimiento igualitario como podría desprenderse de las premisas del Contrato Social de Rousseau, resulta positivo, inexcusable; si por virtud de mil causas complejas, todas las clases sociales entran en la vida pública, y se convierten poco á poco en factores influyentes en la opinión, en instrumentos de acción social, económica y política ... el egoísmo más elemental aconseja el mejoramiento total de las condiciones propias de cuantos de alguna manera habrán de tener que intervernir en las relaciones sociales. Y siendo una de esas condiciones la cultura, la expansión de la cultura tenía que ser una de las preocupaciones sociales más apremiantes y atractivas. Aparte de esta socialización del saber, de este amor ideal á la masa que tan bien responde á las exigencias de la fraternidad humana....quiero referirme al móvil politico. Sobre el particular, dice Sadler: 'El patriotismo y el civismo deben

\footnotetext{
Esta conferencia fue la última del ciclo de 1907 y suscitó varias críticas por su contenido y sus alusiones religiosas.

${ }^{79}$ Sadler s/f.:103. Este comentario tuvo una amplia circulación y fue reproducida casi textualmente en muchos discursos académicos.

${ }^{80}$ Sadler s/f: 127.
} 
estar fundados en el entusiasmo inspirado en el saber ... las naciones más grandes corren el peligro de arruinarse por la falta de conocimientos en aquellos cuyos votos determina su política y cuya moralidad afecta la moralidad pública'.....En tal sentido se reclama para cada ciudadano la igualación de las condiciones en el desenvolvimiento intelectual, lo que se busca es una educación liberal que despierte, en quien la quiera, una nueva manera de ver la vida, un nuevo ideal en los gustos, y, de rechazo una mayor fuerza de juicio para apreciar todo el engranaje y la marcha del gobierno social." 81

Este alumno terminaba su monografía reconociendo que si bien la Universidad platense se esforzaba en contribuir a esta obra, los ciclos de conferencias en la Biblioteca Pública, como los realizados en 1907 y 1908, no parecían ser los medios más efectivos para "hacer sentir su acción en las masas populares", ya que su auditorio se conformó por un "público ilustrado que tiene oportunidad de completar, de intensificar su instrucción por medio de la lectura de las grandes obras". En ese sentido, la Universidad no debía preocuparse tanto por la "extensión" sino de una "verdadera expansión en el sentido regenerador y tutelar de la acción social" sobre los sectores populares. Para este futuro pedagogo: "la Extensión trata de difundir, no solo conocimientos, sino mucho más: hábitos de estudio, gusto por la ciencia, respeto y amor hacia cosas elevadas, consideración por lo que el ignorante le parece inútil, cultura y educación, despertando de paso, corrientes de solidaridad social" 82

Si bien se reconocía que se habían hecho algunas actividades al respecto, como: el "ejemplo de civismo" dado por la juventud universitaria por medio de las conferencias "patrióticas" en distintos pueblos de la Provincia de Buenos Aires; y la Universidad había enviado profesores a dictar conferencias a Córdoba, Entre Ríos ${ }^{83}$ y

\footnotetext{
${ }^{81}$ Moreno 1909: 13-14

${ }^{82}$ Moreno 1909: 32.

${ }^{83}$ En el Colegio Nacional de Concepción del Uruguay, dirigido entre 1902 y 1909 por Dermidio Carreño, quien había sido designado por Joaquín V. González como Ministro interino y con el que mantenía una cierta amistad; se organizó un comité popular extensionista para la "obra de difusión científica", presidida por el vicerrector Juan José Millán y el apoyo de la Universidad platense. Para ello se envió en 1908 a Enrique Herrero Ducloux y Víctor Mercante, inicialmente en vez de este último iba a ir E. Delachaux pero falleció en esos días. Estos profesores dictaron clases de química, ciencias naturales, sociología, psicología y fisiología del sistema nervioso. A su vez, los profesores del Colegio dictaron cursos de matemáticas, castellano, francés, dibujo, geografía, historia, derecho penal, régimen municipal, primeros auxilios, higiene obrera, antroposociología, materiales de construcción, arquitectura, entre otros temas. En la Memoria de ese Colegio, estas actividades de divulgación del "espíritu moderno" se presentaron como una "propaganda higienizadora y de profilaxis moral", que había tenido que vencer las resistencias y prejuicios de las clases populares "del mismo modo y por idénticas razones que el niño y el salvaje rechazan el agua higienizadora". Véase el informe de este
} 
otras provincias, el problema estaba en la instrucción de los sectores populares y obreros que no se acercaban a la Universidad. La "extensión universitaria" a la que se referían los estudiantes se vinculaba más con los modelos de las universidades populares y la educación de los trabajadores promovida por los sectores socialistas y el movimiento de libre-pensamiento, de gran influencia en La Plata y la localidad vecina de Ensenada. Como señala Daniel De Lucía, entre este grupo se encontrarían profesionales relacionados con el surgimiento de la ciudad, alumnos, feministas, miembros de la colectividad italiana, profesores y autoridades universitarias ${ }^{84}$ como el secretario general de la Universidad, el socialista Enrique del Valle Iberlucea y el vicepresidente Agustín Alvarez (1857-1914) ${ }^{85}$, quien tendría una notable influencia sobre algunos sectores estudiantiles.

En La Plata, la creación de la Universidad Nacional de La Plata y el aumento de profesores y estudiantes universitarios que se instalaron o trabajaron en la ciudad tuvieron un efecto positivo sobre las actividades culturales y de divulgación científica local. Estas se organizarían tanto desde el ámbito oficial de la Universidad como a partir de las acciones de profesores, estudiantes, técnicos del Observatorio y otros sectores intelectuales de la ciudad. Durante los primeros años de funcionamiento de la Universidad se realizó una importante campaña de difusión en la prensa diaria de las tareas llevadas a cabo por el personal de sus institutos, especialmente el Museo y Observatorio. En particular, el director de este último, el italiano Porro de Somenzi desarrolló series de conferencias populares con proyecciones luminosas sobre astronomía en la Escuela Normal, en salones de la Facultad de Ciencias Jurídicas y sobre otros temas en los círculos italianos platenses. Por medio de estas actividades, este astrónomo alcanzó una cierta popularidad local frente a las impugnaciones por su actuación científica y la administración del Observatorio, aunque finalmente ello no sería suficiente para que en 1910 fuera destituido de su cargo. En los primeros años, también se ofrecieron en el Observatorio cursos libres de manejo de instrumentos, óptica, nociones de matemáticas, entre otros temas. Inicialmente estos cursos habían sido proyectados para capacitar personal técnico para los trabajos de ese instituto, pero luego fueron abiertos a todos los interesados según se anunciaba en los periódicos.

Colegio sobre esas actividades en: Memoria presentada al Congreso Nacional de 1910 por el Ministro de Justicia e Instrucción Pública, 1909, II: 254-255.

${ }^{84}$ De Lucía 1999. 
Paralelamente, entre 1907-1908 se organizaron clases dominicales de dibujo industrial para obreros a cargo de docentes y alumnos de la Escuela de Dibujo que funcionaba en el Museo, posteriormente esta actividad se retomaría cuando esa Escuela fue trasladada al centro de la ciudad en 1921. También en los primeros años del Instituto de Física, bajo la dirección del ingeniero Teobaldo Ricaldoni hasta $1908^{86}$, se organizó una escuela industrial para hijos de obreros, en la que se ofrecieron cursos de electricidad, mecánica y carpintería en los talleres de ese establecimiento. Este tipo de actividad no sería continuada por los profesores alemanes que lo reemplazaron en la dirección del Instituto, quienes en cambio, se preocuparon por reorganizar ese Instituto y elevar el nivel de la enseñanza científica de las ciencias físicas, aunque igualmente participarían en la extensión universitaria promovida por la Universidad.

En 1906, de forma paralela a la creación de la Universidad, un grupo de vecinos de la ciudad propuso la organización de una universidad popular sobre el modelo de las francesas, para lo cual se convocó públicamente a todos los que estuvieran interesados en dar conferencias y cursos. Desde las páginas de la prensa se apoyó con entusiasmo esta iniciativa y se publicitó ampliamente las actividades educativas propuestas, las cuales comprendieron una amplia diversidad de temas y niveles de enseñanza para un público adulto. Este emprendimiento se denominó "Universidad Libre" y se propuso como objetivo la difusión de la ciencia y sus aplicaciones de manera sencilla, concisa y práctica $^{87}$. Se inauguró en julio de 1906 con un curso de electricidad a cargo de un alumno del último año de preparatorio del Colegio Nacional, Rafael Sanromá, en el local de la Sociedad Tipográfica. Esa iniciativa fue apoyada por las autoridades de la Universidad oficial que veían en ello una ampliación de la acción de Universidad Nacional y para ello se ofrecieron materiales para las clases prácticas. También varios profesores de agronomía y veterinaria organizaron cursos destinados a formar administradores técnicos para establecimientos ganaderos o agrícolas, y técnicos criaderos de aves, abejas, plantas y

\footnotetext{
${ }^{85}$ Sobre el pensamiento de Agustín Alvarez véase entre otros: Terán 1987. Las conferencias sobre instituciones libres de este profesor así otros textos como Adonde Vamos? (1902), La Creación del Mundo Moral (1913) tuvieron un amplia recepción entre los estudiantes platenses.

${ }^{86}$ von Reichenbach et al. 2002.

${ }^{87}$ Como presidentes honorarios figuraban: Dardo Rocha, Florentino Ameghino, Carlos Spegazzini y Francisco P. Moreno, aunque las funciones reales estuvieron a cargo de: Agustín Lantera, presidente; el empresario Esteban Pucciarelli, vicepresidente, y Campos Otamendi como secretario general. Entre los vocales se encontraba Enrique de Madrid y Manuel Meyer González. También participaron profesores como Víctor Mercante y Rodolfo Senet y varios estudiantes como: Alfredo Capurro, A. Rivas, Enrique Gil, Gabriel Garachico (h) y Ramón Loyarte, entre otros.
} 
flores. Numerosas personas se anotaron para dictar cursos de electricidad, idiomas, química, dibujo, teneduría de libros, odontología, prehistoria americana, carpintería, tipografía, caligrafía, entre otros temas. Entre ellos, participaron varios alumnos de la Escuela de Química y Farmacia, ofreciendo cursos populares vinculados a sus disciplinas. Varios centros sociales ofrecieron un local para las actividades, aunque los cursos se desarrollaron principalmente en los salones del diario Buenos Aires, que dirigía la familia Della Croce, en la Sociedad Tipográfica, en el Centro Republicano Español y en el salón Rossini. Todas las actividades se ofrecieron de forma gratuita y abarcaron tanto cursos de enseñanza primaria como superior. No obstante, al poco tiempo comenzaron a surgir varias dificultades: la división de la comisión directiva, renuncias, la asistencia irregular de profesores y alumnos, mala organización de los cursos que terminaban suspendidos, heterogeneidad del público y de los programas, falta de recursos, entre otros factores que se atribuyeron al fracaso de esta iniciativa que no sobrevivió más de dos años. Entre 1907 y 1908 la prensa siguió publicando noticias sobre esta institución, invitaciones a participar para impulsar nuevos rumbos y renovar su consejo directivo. La falta de continuidad y la perdida de interés de los participantes sería un problema presente en gran parte de este tipo de experiencias.

Un tiempo después, un grupo de estudiantes de distintas carreras, que tenían en común haber tomado los cursos de la Sección Pedagógica, buscaron establecer una universidad popular. En 1909 se inauguró la Universidad Obrera, cuya comisión directiva estuvo conformada por los estudiantes: Saúl Taborda, Fernando de Andreis, Jorge Ferri (los tres de Derecho); Ricardo Calatroni, Francisco Legarra y Marcelino Mattaloni, (estos dos eran también docentes en la Escuela Graduada Anexa); Víctor Etcheverry, Ponce de León, entre otros ${ }^{88}$. Como parte de la misma se organizaron conferencias y cursos en distintos centros obreros de La Plata, Tolosa y Ensenada. La visita del español Rafael Altamira en 1909 ayudó a dar un nuevo impulso a las actividades extensionistas ${ }^{89}$. Una de las características que introdujo este profesor fue la de organizar los temas y actividades de extensión conjuntamente con las sociedades obreras y a partir de los intereses de este sector. Estas ideas fueran aplicadas en la reorganización de los trabajos en el Colegio Nacional Oeste y en las universidades

\footnotetext{
${ }^{88}$ Véase la crónica: "La Universidad Obrera de La Plata" en: Humanidad Nueva, 1909, II, 2: 108-109, y otras noticias de la misma en los siguientes números de esta revista vinculada al Ateneo Popular y grupos socialistas.

${ }^{89}$ Sobre la actuación de este profesor durante su estadía en la Argentina y otros países de América Latina, véase la crónica que realizó de su viaje: Altamira 1911.
} 
populares que habían comenzado a organizar grupos de estudiantes de varios países latinoamericanos. A ello se sumó un nuevo estímulo con la visita de Adolfo Posada al año siguiente, quien también daría varias conferencias promocionando la importancia de la extensión universitaria y la educación general para conformar un verdadero régimen democrático.

En el II Congreso Internacional de Estudiantes Americanos, reunido en Buenos Aires en 1910, hubo una mesa especialmente dedicada a debatir sobre la "necesidad de elevar el nivel intelectual y moral del pueblo, por la extensión universitaria.". En ese evento, los estudiantes de distintos países reseñaron las experiencias de extensión universitaria y universidades populares que se fomentaban y las dificultades por las que atravesaron muchas de esas iniciativas. Los estudiantes de la Universidad platense presentaron la experiencia de la Universidad Obrera y defendieron la idea de extender la ilustración a todo el pueblo. Asimismo, Saúl Taborda reconoció que la extensión universitaria así como las conferencias para las clases obreras no serían suficientes para evitar las rivalidades y conflictos entre el capital y el trabajo. Para él: "el principal objetivo de la extensión universitaria, tanto de las repúblicas americanas, como de las naciones europeas es, la consecución de la democracia; es, como dice Posada, una consecuencia lógica de la exigencia de la democracia misma......Entiéndese ahora por democracia, una de las formas más adelantadas en la adaptación social de los seres; esa forma última á que hemos llegado después del largo trabajo de siglos, después del largo trabajo de la humanidad en busca de la felicidad. Supone al individuo apto, en condiciones de poder vivir la forma política más adelantada. Los pueblos americanos, en general, no tenemos al individuo, apto para la democracia; por esta razón, la tendencia de esta extensión universitaria no debe ser otra cosa que la de formar al ciudadano para que tengamos, en realidad, una democracia verdadera" ${ }^{\prime 90}$.

Los estudiantes como "diputados de la democracia" asumían la tarea de extender la acción educativa de la Universidad, concurriendo a los locales obreros para disipar el prejuicio de estos hacia la institución universitaria. Como parte del programa de la Universidad Obrera se organizarían conferencias y cursos en: el Centro Martín Iraola de Tolosa, el Salón Unión de Ensenada, la Federación obrera, la Unione Operari Italiani, la Sociedad Tipográfica y la Biblioteca de la Universidad,

\footnotetext{
${ }^{90}$ Este comentario de Saúl Taborda se encuentra en las actas de ese Congreso: Federación Universitaria
} de Buenos Aires 1912, I: 231. 
entre otras instituciones. Entre los temas de esas actividades que se desarrollaron entre 1909 y 1910 predominaron cuestiones como: la importancia de la educación, cómo el obrero debe criar a sus hijos, el alcoholismo, trabajo de mujeres y niños, causas que determinan la formación de un delincuente y cursos de aritmética elemental, geometría, ciencias físico-naturales, geografía económica, gramática, sociología, higiene, anatomía y fisiología, entre otros. La divulgación promovía a través de esta experiencia al igual que las similares que le siguieron en los años sucesivos guardan una gran similitud con los programas destinados tanto a conformar una cultura urbana basada en una racionalidad laica y científica, como a moralizar los hábitos de higiene y pautas de vida de los sectores obreros que organizaron distintas asociaciones en la ciudad de Buenos Aires; como ha sido estudiado por Dora Barranco y Héctor Recalde $^{91}$. En los programas de "extensión" de la época del centenario, la divulgación de la ciencia y del "espíritu científico" ocupó un lugar central para la formación de los ciudadanos y en la conformación de una "cultura pública". Para algunos, la "religión científica" se presentaba como la más apta para enseñar una "verdad comprobada" y universal que permitiría remplazar las "supersticiones" y la "verdad dogmática" ofrecida por la Iglesia. Por otra parte, la Iglesia Católica, desde fines del siglo XIX y en el marco de la política impulsada por el papa León XIII, también desplegó una intensa campaña de educación y creación de espacios de sociabilidad para los trabajadores a través de los círculos de obreros ${ }^{92}$. En el marco de esa competencia, se puede ubicar la construcción del culto público a la figura de Florentino Ameghino como el "sabio argentino" y la santidad laica del científico, promovida especialmente por los sectores socialistas, pero también apropiada por sectores nacionalista como Ricardo Rojas, como ha sido analizado por Irina Podgorny ${ }^{93}$. Según demuestra esta investigadora, la creación de la figura de Ameghino como la de un arquetipo moralizador para niños y maestros formó parte tanto de un proceso de laicización progresiva del país, que incluyó la divulgación de la palabra científica y de una liturgia escolar, como de la configuración del campo de las ciencias naturales. En los círculos científicos argentinos la discusión de su obra se enfrentó al culto al sabio en un contexto de amplia difusión popular de la antropología y la paleontología, donde los gliptodontes "argentinos", los fósiles y los restos arqueológicos se trasformaron en

\footnotetext{
${ }^{91}$ Barrancos 1991, 1995, 1996; Recalde 1994.

92 Recalde 1985.

93 Podgorny 1997, Farro y Podgorny 1998.
} 
los "monumentos" materiales de la ciencia y la historia natural del territorio, así como en un motivo para solicitar al Estado la protección de las instituciones encargadas de velar por ese patrimonio ${ }^{94}$.

En la época del centenario, la experiencias educativas que se denominaron "extensión universitaria" se multiplicaron abarcando tanto las modalidades de cursos elementales y de alfabetización para obreros como clases más específicas para distintos gremios sobre temas científico-técnicos. En los siguientes años, varios de los participantes de la Universidad Obrera junto a otros estudiantes y profesores del Colegio Nacional continuarían organizando este tipo de actividades en distintos centros obreros y especialmente en las bibliotecas populares que se comenzaron a crear en La Plata y las localidades vecinas en la segunda parte de la década de 1910. Un centro importante donde estudiantes universitarios desarrollaron actividades de divulgación científica y cultural durante esos años fue la Biblioteca "Florentino Ameghino" de Tolosa, ubicada en la calle 31 entre 1y 2, donde antes había funcionado el Centro Martín Iraola. En 1912 el mismo grupo de estudiantes participó en la creación de una sucursal local del Ateneo Popular y otros en la de la Sociedad Luz en 1915. Asimismo, en esos años se promovió la creación de una Escuela Popular a cargo de estudiantes universitarios, coordinada por la Federación Universitaria de La Plata. También a partir de 1914 se desarrollaron cursos nocturnos para obreros en el Colegio Nacional a cargo de los estudiantes avanzados de ese establecimiento y de los cursos universitarios. Estas actividades fueron impulsadas por el centro de ex-alumnos de ese Colegio, que paralelamente organizó ciclos de conferencias de divulgación cultural para un público más selecto.

En el contexto universitario platense, la "extensión" implicó por lo menos dos circuitos: a) las actividades organizadas por los estudiantes para los obreros y sectores populares en bibliotecas y asociaciones de distintos barrios y b) las que se organizaban en la misma Universidad y que en general implicaron un nivel más elevado de divulgación. Las principales modalidades para ello abarcaron conferencias, demostraciones experimentales, visitas guiadas, publicaciones y cursos para docentes. En muchas de las conferencias se tendió a presentar las investigaciones que se llevaban a cabo en la institución, así como a mostrar los equipos y materiales de los

\footnotetext{
${ }^{94}$ Endere y Podgorny 1997; Podgorny 2000. Sobre el uso de esos materiales en la enseñanza escolar, véase: García y Podgorny 2001. De hecho, a partir de 1910 se sucedieron algunas propuestas para crear
} 
institutos científicos. Como ejemplo de esto último, se puede mencionar la demostración experimental que organizó el físico alemán Emil Bose en marzo de 1911, en momentos en que se discutía una asignación de 500.000 para el presupuesto de la Universidad platense, que afectaba principalmente a la Facultad de Agronomía y Veterinaria y los estudios experimentales. Bose organizó una conferencia para mostrar por medio de experimentos las nuevas instalaciones del Instituto/Escuela Superior de Física y las fuentes de energía eléctrica y su aplicación industrial. Para la observación se recomendó al público que llevaran los gemelos de teatro y además que retirara las entradas anticipadamente por el espacio limitado. La ciencia como "espectáculo" resultó un éxito, la conferencia debió repetirse, la prensa de distintas tendencias alabaron la organización del Instituto de Física y el desempeño de su director y finalmente el recorte del presupuesto no se efectuó ${ }^{95}$. Poco tiempo después, este investigador fallecía. El nuevo director desde 1912, el alemán Ricardo Gans también se destacaría como un gran experimentador y daría conferencias con demostraciones experimentales a los excursionistas del Ateneo Popular y la Sociedad Luz.

Unos meses después del éxito de las conferencias de Bose, el vicedirector del Museo, Enrique Herrero Ducloux convocó a los ex-alumnos del doctorado química y farmacia y estudiantes avanzados para organizar "lecturas dominicales" de vulgarización científica en el nuevo espacio del anfiteatro del Museo, con el objeto de mostrar los aparatos que disponía la institución y la formación alcanzada por sus alumnos. Varios estudiantes se ofrecieron y en agosto comenzó un ciclo de "Lecturas Científicas en el Museo", los jueves a las 15 hs., uno de los días de visita pública ${ }^{96}$. Estas conferencias se acompañaron con experiencias de laboratorio, proyecciones luminosas y observación de colecciones y preparados microscópicos y estuvieron destinadas especialmente para los alumnos de los colegios secundarios y del último año de la Escuela Graduada de la Universidad, como una forma de "extensión universitaria interna" y para estimular los estudios en ciencias químicas. Sin embargo, esto último no se logró realizar de la forma prevista frente a la poca participación de

\footnotetext{
un parque paleontológico en La Plata, fomentado por distintos vecinos y también por los sectores científicos del Museo de La Plata, como se menciona en el capítulo siguiente.

${ }^{95}$ Ranea 1994.

${ }^{96}$ Las conferencias estuvieron a cargo de los siguientes alumnos: María Luisa Cobanera: "Aluminio térmico y sus aplicaciones", Ricardo Calatroni: "Historia de la teoría de la evolución", Vicente Isnardi: "Radiación solar", Carlos A. Sagastume: "La química en la alimentación", Carlos Quiroga: "Industria del gas acetileno", Edelmiro Calvo (h): "El gas del alumbrado", J. Bragadín y F. Zelada "Vulcanismo", Alberto Solari: "Venenos y Sortilegios", Alfredo O. Rafaelli "La vida de las abejas", Nazario Alvarez "La materia".
} 
esos alumnos, aunque igualmente las conferencias contaron con una cierta concurrencia. El ciclo fue inaugurado por una presentación de Herrero Ducloux y la conferencia de María Luisa Cobanera sobre los procedimientos de obtención del aluminio. En última, que fue la única alumna que dio una conferencia pública en esos años, enfatizó en el carácter democrático de la ciencia y su aplicación en el trabajo de los obreros así como en la importancia de su divulgación ${ }^{97}$. La segunda conferencia a cargo de Calatroni, trató sobre la teoría de la evolución y la obra de Ameghino y reunió un auditorio de más de cien personas. Las siguientes se centraron en temas vinculados a la historia de los descubrimientos de las ciencias químicas, sus aplicaciones industriales y en la vida cotidiana, asociando el progreso material y moral de los pueblos con la ciencia. Es de destacar que en los mismos meses, el Centro de Estudiantes de Física y Matemáticas en su local de la calle 45 también ofrecía conferencias de divulgación científica popular los martes a la noche sobre temas como las aplicaciones de la electricidad y del vapor a las máquinas. Esta actividad sería continuada en los siguientes años. También hacia 1917, los periódicos anunciaban las conferencias públicas organizadas por el Centro de Estudiantes de Derecho sobre reformas legales y otras cuestiones vinculadas a los estudios de esa carrera.

Como se señaló en el capítulo anterior, los centros de estudiantes tuvieron un papel destacado en la difusión de las lecciones y trabajos científicos de profesores y alumnos, noticias sobre descubrimientos o nuevas teorías entre otros temas que se incluían en las revistas estudiantiles. Durante estos años y las siguientes décadas, las dos publicaciones que tendría mayor continuidad serían la Revista del Centro de Estudiantes de Química y Farmacia, creada en 1912 y la del Centro de Ingeniería en 1913. Asimismo, la publicidad de los trabajos de investigación producidos en la Institución se reforzaría con la edición de memorias, revistas u otras series científicas destinadas al canje y la circulación entre especialistas, como se analiza en el capítulo siguiente con respecto a las publicaciones del Museo.

Otra vía de divulgación para un público especializado serían los cursos libres y artículos en revistas científicas destinadas a difundir nuevas teorías entre la

\footnotetext{
${ }^{97}$ Según la trascripción de la conferencia que se publicó en el periódico El Día, 11/8/1911, Cobanera señaló: "en los pueblos jóvenes y nuevos como el nuestro, en que los trabajos de investigación están aún en la infancia donde quiera que ello reciban un pequeño apoyo y alli la antorcha de la civilización recibe también un rayo de luz que la vivifica y fortalece. Es por este medio de las conversaciones cientificas que tratamos de fomentar la luz más pura y bienhechora, que puede llegar hasta la conciencia de un pueblo. Es el mejor bruñidor de las malas costumbres y de los hábitos viciosos de una
} 
comunidad científica local. En esto participarían los científicos así como los pocos graduados de las carreras científicas. En los siguientes años la divulgación científica en la Universidad se ampliaría con la actividad de los graduados y la organización "curso libres"98, aunque en muchos casos esto tropezaría con la falta de un público para ello. Esto por ejemplo, se manifestó en un curso libre organizado por Ricardo Gans en 1913, sobre capítulos especiales de la física que contó un auditorio poco numeroso. En la memoria de la Facultad, esto aparecía como un obstáculo para continuar con este programa de cursos especiales y ajenos a los planes de estudios: "la población de La Plata no se halla aún en condiciones de proveer al público necesario para este tipo de conferencias y dentro de la población universitaria las obligaciones de asistencia a clase y las extrañas a la Universidad de los estudiantes, hacen que no tengan en general el tiempo disponible para concurrir a conferencias de esta índole, en la forma en que sería de desear, para elevar el nivel cientifico de las facultades y propender de este otro modo al desarrollo de la cultura pública"99.

No obstante, este tipo de actividades se continuó promoviendo en los siguientes años, participando también los primeros doctores en física. El problema de la falta de un público con cierta base científica también se reconoció como un problema en algunos de los cursos libres y ciclos de conferencias que se ofrecieron en el Museo de La Plata, como se menciona en el siguiente capítulo. A mediados de la década de 1910 estas actividades se fomentarían especialmente en las Facultades de Ciencias Físicas, Matemáticas y Astronómicas y en la de Ciencias Naturales, y en algunos casos se buscaría conformar un auditorio entre los sectores científicos de Buenos Aires. Finalmente, a través de la formación de los docentes del sistema de instrucción pública se exploraría otra vía para la divulgación de la ciencia, tema que se examina en el capítulo VI.

Como se intentó demostrar en estas páginas y se procura ampliar en los siguientes capítulos, la institucionalización de la ciencia en el contexto universitario implicó la construcción de un discurso sobre la ciencia y, al mismo tiempo, un público para el mismo. En este último proceso, los estudiantes y graduados tendrían un papel

sociedad; combaten las preocupaciones absurdas que vician y adulteran la sana moral y despertando el alma adormecida....".

${ }^{98}$ Antes del movimiento reformista de 1918, estos "cursos libres" tenían un carácter de actualización científica para todos los estudiantes universitarios, profesores y cualquier persona interesada. Estos eran más bien complementarios de los oficiales, pero en general no eran paralelos ni tenían un carácter de optativos con respecto a los oficiales como se les dio después de la Reforma Universitaria. 
importante en la reproducción ampliada de una cultura científica así como en las prácticas de popularización de la ciencia más allá del ámbito académico. Los estudiantes como "fuerza de trabajo intelectual en proceso de formación" también fueron incentivados a entrenarse en las prácticas de divulgación científico-cultural y a asumir un papel activo en el programa de regeneración social de la época. De hecho, la "extensión universitaria" reclamada por los estudiantes y otros sectores reformistas se vincularía precisamente con la idea de extender la acción educativa-cultural sobre "el pueblo", donde la "nueva generación" terminaría por postularse como dirigentes de los trabajadores ${ }^{100}$ y la "extensión universitaria" se convertiría en parte de la militancia o la carrera política de algunos jóvenes universitarios. Sin embargo, la divulgación de la ciencia no sólo implicaría los canales propuestos desde ese tipo de "extensión" sino un conjunto más amplio de interacciones y prácticas culturales destinadas a diversos públicos.

\footnotetext{
${ }^{99}$ Memoria correspondiente a 1913 de la Facultad de Ciencias Físicas, Matemáticas y Astronómicas, 1913:61-62.

${ }^{100}$ Portantiero 1978; Vázquez 2000.
} 
Parte 2:

El Museo de La Plata, la divulgación y la educación científica 


\title{
Capítulo IV
}

\section{El Museo en el contexto universitario}

\begin{abstract}
"No perderá el Museo su destino de centro de estudio y exploración del territorio y conservación de sus tesoros acumulados, sino que esas cualidades se harán mucho más notables poniéndose al servicio de la instrucción científica de la Nación entera, bajo el plan metódico y coordinado de una Universidad"l
\end{abstract}

"La noción de museo no es perfecta sino se considera á una institución de este género como un organismo donde alienta como espiritu ó fuerza directora el espiritu cientifico de la época....... un museo es un centro de investigaciones y de enseñanza, comprendiendo en ésta la más alta cultura científica de cursos universitarios y la difusión de las verdades adquiridas entre los humildes, entre los que por factores múltiples y complejos se ven alejados de esos goces del espiritu que subliman el alma humana." ${ }^{2}$

En la primera parte de esta tesis se examinó el proyecto de creación de la Universidad Nacional de La Plata y los intentos por renovar las orientaciones de los estudios y el perfil de la institución universitaria. Como parte de la propuesta científico-educativa pensada para la nueva casa de estudios se destacaría la incorporación del Museo de La Plata y el Observatorio Astronómico. La integración de estos institutos científicos a la estructura universitaria tenía por objeto ampliar su función pública participando de la "misión educativa" de la Universidad. Como se mencionó en el capítulo anterior, esto era pensado en un doble aspecto: la cátedra universitaria y la extensión de los favores de la ciencia a un público más amplio. El Museo con sus diversas colecciones y un amplio espacio físico se presentaba como el ámbito ideal para la articulación de la investigación y enseñanza. Para ello se fomentó la organización de escuelas superiores de ciencias dentro de las especialidades que practicaban sus científicos, con el objeto de entrenar nuevas generaciones de investigadores y personal técnico, y al mismo tiempo, completar la educación científica de los futuros profesionales y profesores de enseñanza secundaria. Junto a

\footnotetext{
${ }^{1}$ Mensaje del Ministro de Justicia e Instrucción Pública, Joaquín V. González defendiendo el proyecto de la Universidad Nacional de La Plata en la Cámara de Senadores, Diario Sesiones de la Cámara de Senadores de la Nación, 1905, I: 853.

${ }^{2}$ Herrero Ducloux 1907a: 17.
} 
ello, además, sus publicaciones y salas de exhibición aparecían como un escenario público para mostrar y difundir el trabajo de los científicos.

En esta segunda parte de la tesis se examina como se integró el Museo dentro del proyecto universitario platense, atendiendo principalmente a la articulación entre las actividades científicas, docentes y de divulgación y tomando como eje analítico el concepto de "ámbito de socialización" definido en la Introducción. Principalmente en esta parte se procura analizar esas cuestiones a través de la organización del profesorado y la enseñanza en ciencias naturales así como los proyectos institucionales y modelos de ciencia que se promovieron. En particular, en este capítulo se focaliza en el funcionamiento institucional del Museo de La Plata como Instituto/Facultad de Ciencias Naturales en relación con tres aspectos principales: a) la concepción de museo y las prácticas que se asociaron a ese espacio institucional; b) las condiciones laborales del profesorado, la organización cotidiana del trabajo y la articulación de las actividades museísticas, docentes y de investigación y c) la divulgación de la ciencia y la participación en las prácticas sociales de difusión cultural de la época.

\section{1. De Museo a Facultad}

El Museo General de La Plata fue fundado en 1884, por decreto del poder ejecutivo de la Provincia de Buenos Aires a partir de la iniciativa de Francisco P. Moreno, quien además ejercería su dirección hasta $1905^{3}$. Sus primeros elementos los constituyen las colecciones paleontológicas, antropológicas y arqueológicas del Museo Antropológico y Arqueológico de Buenos Aires, establecido en 1877 sobre la base de las colecciones particulares de Moreno. El museo platense, a diferencia de este último, fue pensado como un museo general para la Provincia, que comprendería la producción artística e industrial del hombre así como todas las áreas del conocimiento relacionadas con la historia natural. La imponente construcción levantada en las márgenes de la ciudad de La Plata intentaba representar en su interior "el anillo biológico que principia en el misterio y termina en el hombre". En la

\footnotetext{
${ }^{3}$ Sobre la creación y primer etapa del Museo de La Plata, véase especialmente los trabajos de Teruggi 1988 y Podgorny 1995, 2000. Para un estudio comparado del funcionamiento de esta institución y otros museos similares a fines del siglo XIX, véase el trabajo de Sheets-Pyenson 1988; Pérez Gollán 1995, Lopes y Podgorny 2000.
} 
concepción de Moreno el Museo de La Plata debía ser, al mismo tiempo, un "museo de exposición" y un centro de estudio ${ }^{4}$. El Museo platense, al igual que otros establecimientos latinoamericanos similares, jugaría un papel importante en la conservación, exhibición y estudio de objetos representativos de la historia de la naturaleza local y de los grupos indígenas; así como en el proceso de institucionalización de las prácticas de la historia natural y las ciencias antropológicas como una actividad profesional. En su interior, comenzaron a ubicarse naturalistas que trabajaban de forma exclusiva o semi- exclusiva en torno a una serie de prácticas y saberes organizados en base a un conjunto de objetos. Adaptados a los cambios científicos y culturales, los museos no sólo se constituyeron en lugares para las investigaciones sistemáticas sino también se volvieron monumentos científicos y símbolos de la identidad nacional ${ }^{5}$.

Durante la década de 1890, el Museo de La Plata se consolidó como un centro científico gracias a lo organización de exploraciones sistemáticas del territorio, el levantamiento de mapas y su participación en la cuestión de límites con Chile. A partir de esas tareas ampliamente difundidas a través de la prensa periódica, se buscaría construir una nueva identidad institucional y legitimidad como centro organizador de exploraciones. En esa época, la actividad científica se buscó reforzar por medio de la contratación de especialistas extranjeros, las publicaciones y los intercambios con instituciones similares de otras partes del mundo ${ }^{6}$. Asimismo, Moreno proyectó que el Museo ampliara su función educativa con el desarrollo de cursos y conferencias de divulgación a cargo del personal científico de la Institución y la confección y venta de colecciones para la enseñanza escolar. No obstante, de ese plan sólo se organizaron tres conferencias públicas a fines de 1896, que fueron dadas por los distintos jefes de sección, fueron impresas en los talleres de publicaciones del Museo y distribuidas gratuitamente entre el público ${ }^{7}$.

\footnotetext{
${ }^{4}$ Moreno 1890.

5 Lopes y Podgorny 2000.

${ }^{6}$ Teruggi 1988.

${ }^{7}$ García 2001. Las conferencias fueron dadas por: el botánico ruso Nicolás Alboff sobre "La Naturaleza de Tierra del Fuego", la siguiente por el zoólogo francés Fernando Lahille titulada "La aplicación de las ciencias naturales á la colonización de las costas del sud" y la última por el paleontólogo suizo Santiago Roth, "La Paleontología y el origen del mundo orgánico". Estas conferencias fueron anunciadas en la prensa local, donde posteriormente se publicaron comentarios muy positivos de las dos primeras, especialmente de la propuesta de Lahille. De la tercera no hubo ningún comentario, por lo que quedan abierto el interrogante si efectivamente se realizó, ya que ese día hubo un temporal que dificultó el tránsito por el paseo del Bosque. De esas conferencias se editaron bastantes ejemplares que parecieron no haber tenido demasiada circulación. En 1973, el inventario de las publicaciones de la institución, registraba la existencia de 140 ejemplares de la de Alboff, 499 de la de Lahille y 545 de la de Roth.
} 
Hacia mediados de la década 1890, se concedió al Museo, al igual que a otras instituciones provinciales que dependían de fondos provinciales, una mayor autonomía para administrar sus propios recursos y crear un fondo propio a partir de sus publicaciones y otros productos o servicios. Asimismo, gracias a la influencia del senador Bartolomé Mitre, el Congreso Nacional aprobó un subsidio mensual de 400 pesos para esta institución, destinado especialmente a investigaciones arqueológicas y lingüísticas americanas que estarían a cargo de Samuel Lafone Quevedo (18351920) ${ }^{8}$, quien en 1906 asumiría la dirección del Museo de La Plata. Hasta 1899 el Museo también recibió una subvención nacional para mantener los talleres de publicaciones, aunque entre 1897 y 1902 se interrumpiría la edición de la Revista y los Anales $^{9}$. En esos años, las actividades se concentraron principalmente en la comisión de exploraciones nacionales y de límites con Chile, financiada por el Gobierno nacional entre 1896 y hasta 1902, cuando se resuelve el conflicto internacional entre Argentina y Chile. A partir de ese momento, el subsidio nacional sería suprimido, provocando una reducción importante de los recursos con los que contaba este establecimiento. Por otra parte, como se señaló en el capítulo I, el Museo de La Plata, al igual que otros establecimientos provinciales, experimentaría las consecuencias de la inestabilidad económica y política de la Provincia. Frente a ello, las soluciones pensadas girarían en torno a la nacionalización de estas instituciones aunque existirían diferentes ideas en cuanto a la función y el perfil pensado para cada una de ellas. Finalmente en 1905 se concretaría el proyecto oficial sustentado por el gobierno provincial y el Ministro de Instrucción Pública de crear un centro universitario al estilo norteamericano con institutos científicos como museos y observatorios.

En general, la incorporación del Museo de La Plata a la Universidad y su transformación en Instituto/Facultad de Ciencias Naturales ha sido caracterizada como un suceso traumático y desnaturalizador del designio que guiaba el futuro del primero.

\footnotetext{
${ }^{8}$ Lafone Quevedo nació en Montevideo, mientras sus padres estaban exiliados durante el gobierno de Rosas. Entre 1848 y 1857 realizó estudios en Inglaterra, graduándose de Magister Artium en la Universidad de Cambridge. De regreso a la Argentina, se instaló cerca de Andalgalá, Catamarca, donde su padre era propietario de unas minas de cobre. Allí permaneció entre 1860 y 1894, dirigiendo un establecimiento de fundición de cobre en esa zona y participando como vocal del Consejo Escolar de esa Provincia. En la década de 1880 comienza a difundir algunos estudios sobre alfarería calchaquí y trabajos de lingüística y folklore a través de artículos en La Nación. A mitad de los años 1890 es designado encargado de la Sección Lingüística del Museo de La Plata y en 1898 fue nombrado profesor de Arqueología Americana en la Facultad de Filosofía y Letras, cargo que mantuvo durante las siguientes dos décadas. Sus principales trabajos se relacionaron con estudios lingüísticas, etnográficos, arqueológicos y de folklore, fomentando al mismo tiempo la recopilación de fuentes históricas sobre los grupos indígenas.

${ }^{9}$ Barrio 1927.
} 
Como ha sostenido Irina Podgorny, el énfasis puesto en esa ruptura no se acompañó de un análisis de las continuidades y transformaciones en las ideas, políticas institucionales y líneas de investigación que la misma habría producido o con las que estaría relacionada. Si en la última parte del siglo XIX, el Museo provincial había sido concebido como un centro rector y conductor de la ciencia y la evolución del país, al iniciarse el nuevo siglo y en el marco de las ideas de González, se le asignaría ese papel a la universidad nacional ${ }^{10}$. Al mismo tiempo, en la transición del siglo se produjo una renovación de las instituciones encargadas de organizar el estudio científico del país y una mayor división y especialización en las tareas de investigación. Además de las actividades organizadas desde el Museo Nacional de Buenos Aires y la Academia de Ciencias de Córdoba, es importante señalar la creación de varias oficinas especializadas en la identificación de recursos naturales y sus aplicaciones dentro del Ministerio de Agricultura creado en 1898, como la Sección de Zoología aplicada, la de Biología vegetal o Botánica, o la División de Minas, Geología e Hidrología establecida en $1905^{11}$. A ello se sumaron las distintas dependencias provinciales destinadas al levantamiento de mapas geológicos e hidrográficos, como el de la Provincia de Buenos Aires. Esta última fue creada en 1904 y dirigida por Francisco P. Moreno hasta 1910, y luego por el suizo Santiago Roth, quien también trabajaba en el Museo, hasta 1917 cuando es suprimida. En el campo de los estudios arqueológicos, la Facultad de Filosofía y Letras de Buenos Aires asumió las tareas de investigaciones y exploraciones a través de las actividades del Museo Etnográfico, creado en 1904 bajo la dirección de Juan Ambrosetti. Con la mayoría de estas instituciones o con parte de su personal se organizaron actividades conjuntas con el Museo de La Plata.

En el proyecto universitario de Joaquín V. González se le asignó un lugar muy importante al Museo de La Plata, como institución para combinar el entrenamiento científico de estudiantes con el desarrollo de investigaciones sobre la naturaleza nacional y el estudio del hombre en relación con su medio físico antiguo y actual ${ }^{12}$. Al mismo tiempo, se esperaba que este instituto atendiera a los numerosos problemas

\footnotetext{
${ }^{10}$ Podgorny 1995.

${ }^{11}$ Babini 1949, 1963; Myers 1992, Camacho 2001.

12 Según señalaba González como Ministro de Justicia e Instrucción Pública en la Cámara de Senadores: "su carácter dominante será el estudio de las ciencias de la naturaleza, con sus más directos derivados, y los que tienen por objeto principal el estudio del hombre en su medio físico antiguo y actual. Las ciencias antropológicas, serán allí las generadoras de las más fecundas
} 
prácticos que interesan a la vida y al porvenir económico del país y participara en los programas de extensión universitaria fomentados por las autoridades de la Universidad platense. En la memoria que González presentó al Gobernador de la Provincia de Buenos Aires a principio de 1905 se proyectaba que el Museo de La Plata comprendería dos grandes divisiones: 1) las ciencias naturales y antropológicas, entre lo que se incluían los estudios de geografía, geología, paleontología, botánica, zoología, antropología y lingüística, y b) química y farmacia. El primer grupo constituiría el núcleo principal, como de hecho se manifestó inicialmente en la distribución de los cargos docentes y el presupuesto. Asimismo, como parte del trabajo que abarcaría el Museo se señalaban las siguientes las aplicaciones y secciones: 1) topografía, 2) cartografía y relieve, 3) exploraciones, 4) investigaciones del suelo, al estilo de los trabajos realizados por los "geological survey", 5) mineralogía y minería, 6) análisis de laboratorio, bacteriológico y microbiológico, 7) modelado y preparaciones de piezas, 8) colecciones escolares, 9) talleres gráficos y tipográficos, 10) la Revista del Museo y los Anales, 11) una sala de Bellas Artes ${ }^{13}$. De los ítems comprendidos en este programa, gran parte se cumplirían, excepto por los talleres para publicaciones que fueron retenidos por la Provincia y se trasladaron a otro lugar. Otros trabajos como los topográficos y cartográficos se interrumpirían al poco tiempo, mientras que los estudios bacteriológicos y microbiológicos se concentrarían en los laboratorios de la Facultad de Agronomía y Veterinaria.

Dentro del espacio del Museo, ahora trasformado en Instituto/Facultad de Ciencias Naturales además de las disciplinas vinculadas al estudio de la naturaleza y los grupos indígenas, se ubicaron otras dos dependencias: la Escuela de Química y Farmacia y un Instituto/Escuela de Geografía con una Escuela anexa de Dibujo. La segunda fue dirigida por el geógrafo suizo Enrique A. S. Delachaux hasta su muerte en 1908, y luego sólo funcionaría un año más para que los estudiantes terminaran sus estudios. Los estudios de geografía física pasarían a depender del área de Ciencias Naturales y las otras cátedras, de la Escuela de Dibujo. Esta última, dirigida por el dibujante francés Emilio Coutaret constituyó una escuela profesional anexa sin representación en el Consejo Académico hasta que separa del Museo en 1921. La Escuela de Química y Farmacia correspondía a la antigua Facultad de Química y

relaciones con las demás de índole filosófica ó jurídica...".Diario de Sesiones de la Cámara de Senadores de la Nación, 1905, I: 854.

${ }^{13}$ González 1935, XIV: 58. 
Farmacia de la Universidad Provincial, pero a partir de su nacionalización fue totalmente reorganizada bajo la dirección del químico Enrique Herrero Ducloux. Este profesor también se desempeñaría como vicedirector del Museo, teniendo un papel destacado en la administración de esta institución hasta su renuncia a fines de 1918, en el marco de una serie de conflictos con los estudiantes de farmacia. Esta Escuela contó con amplias instalaciones y laboratorios para la enseñanza práctica e investigación, que se instalaron en uno de los hemiciclos del subsuelo del Museo ${ }^{14}$, donde anteriormente habían estado los talleres de impresiones oficiales de la Provincia. Asimismo, para las clases y conferencias de divulgación se construyó un anfiteatro ${ }^{15}$ con capacidad para 500 personas, que se inauguró en 1911 y fue equipado con aparatos para proyecciones luminosas y ampliaciones de preparados microscópicos.

Las autoridades académicas así como el primer grupo de profesores fue nombrado por Joaquín V. González, como Ministro de Instrucción Pública. Samuel Lafone Quevedo ocuparía el puesto de director del Museo y decano de la Facultad de Ciencias Naturales hasta su muerte en 1920, junto con otro cargo como profesor de lingüística. Asimismo, la dirección de la institución fue compartida con el vicedirector y un Consejo Académico. Hasta la reforma de los estatutos universitarios en 1920, este último se conformó por seis profesores titulares renovables periódicamente y elegidos en asamblea entre todo el claustro docente. Durante los primeros tres años, se integró con dos representantes de ciencias naturales, dos de química y farmacia y dos de la Escuela de geografía y dibujo, pero desde 1910 sólo estarían representadas las dos primeras con tres consejeros cada una. Mientras que la dirección del Museo no se renovó y su elección o destitución dependía del Consejo Superior - ya que esta institución fue definida como un instituto científico-, el espacio del Consejo Académico favoreció la participación del personal científico-docente en la marcha de la institución, la distribución de los recursos y el presupuesto, el nombramiento del

\footnotetext{
${ }^{14}$ Los laboratorios instalados en uno de los hemiciclos del subsuelo comprendían: a) el de química analítica cuantitativa general y aplicada con una superficie de $350 \mathrm{~m} 2$ y varios salones para trabajos prácticos con numerosos aparatos, una parte especial para estudios especiales de los profesores y depósitos de balanzas e instrumental, b) el de química orgánica con un espacio de $200 \mathrm{~m} 2$ y dos salones, uno para el trabajo práctico de 30 alumnos y otro para el profesor de la materia y sus ayudantes, c) el de química inorgánica y d) uno de toxicología. Además, esta Escuela disponía de un laboratorio de química analítica cualitativa en la Facultad de Agronomía y Veterinaria, un gabinete de farmacología y el laboratorio de farmacia práctica en el primer piso del edificio de la Universidad, que ocupaban una superficie de más de 200 m2. Herrero Ducloux 1909.

${ }^{15}$ El espacio del anfiteatro esta ocupado actualmente por la Biblioteca, trasladada allí en los inicios de la década de 1920 bajo la gestión de Luis María Torres.
} 
personal y especialmente en todo lo referido a la actividad docente de las distintas escuelas.

Como se señaló en capítulos anteriores, Herrero Ducloux tendría un papel destacado en la definición de varios aspectos de política científica de la Universidad Nacional de La Plata y en la gestión universitaria, llegando a ocupar la vicepresidencia de la Universidad entre fines de 1913 y 1917. Entre 1906 y 1918 fue reelecto sucesivamente consejero superior por el Instituto del Museo, gestionando desde ese espacio recursos para esta institución. Asimismo, desempañaría un papel clave en la coordinación de las distintas actividades del Museo de la Plata, tanto en lo relativo a la organización de los estudios como en la programación de los viajes de exploración del personal científico y la actualización de las exhibiciones públicas. En varias notas periodísticas, así como en la primera memoria institucional, Herrero Ducloux definió el programa futuro y la definición de lo que debía ser el Museo de La Plata de acuerdo a las ideas propuestas por George Brown Goode (1851-1896), director del Museo Nacional de Washington. De acuerdo a este último, en el trabajo "The principles of Museum administration" de amplia difusión, un museo público moderno debía abarcar tres funciones: 1) constituir un lugar para la conservación de objetos de estudios y de muestras de la naturaleza y las obras del hombre, 2) ser un centro de investigaciones científicas y 3) funcionar como un espacio para la instrucción pública, a través de la exhibición de colecciones y sus explicaciones ${ }^{16}$. Para Herrero Ducloux, esta última tarea debía contemplar no sólo la educación popular sino la difusión de una cultura científica superior a través de cursos libres y la cátedra universitaria. La función del Museo de La Plata, sería albergar colecciones pero también "un núcleo de hombres selectos que cultive la ciencia por la ciencia" y que pudiera "ser legión antes de 20 años y entonces se podrán contar con sabios de gabinete haciendo de su profesión un sacerdocio...y sabios divulgadores de la ciencia ..."17

A través de la combinación de investigación y enseñanza, este tipo de institución debía alentar el "espíritu científico" de la época. Para ello, el antiguo personal científico extranjero, que estaba encargado de algunas de las secciones del Museo, fue incorporado a la estructura universitaria en la doble función de profesores titulares y jefes de sección, ocupando esos cargos durante las siguientes dos décadas. Paralelamente, se incorporarían otros investigadores y algunos jóvenes como

\footnotetext{
${ }^{16}$ Kohlstedt 1991

${ }^{17}$ Herrero Ducloux 1907b. Véase también: Herrero Ducloux 1907a, Podgorny 1995.
} 
profesores adjuntos de las secciones. El primer grupo estuvo conformado por los alemanes: a) Roberto Lehmann- Nitsche (1872-1938), doctor de las Universidades de München y Berlín, dirigiría la Sección de Antropología desde 1897 hasta su jubilación en 1930, también fue profesor de antropología en la Universidad de Buenos Aires y miembro activo de las sociedades alemanas en las provincias del Plata; b) Walter Schiller (1879-1944), doctorado en la Universidad de Freiburg, llegó al país a mediados de 1905 convocado para trabajar como geólogo y encargado de la Sección de Mineralogía y continuaría vinculado al Museo hasta su muerte, con excepción del período de 1915-1919 en que viaja a Alemania a participar por su país en la guerra europea; también hasta ese momento fue profesor del Instituto Nacional del Profesorado Secundario y geólogo ad-honorem de la División de Minas, Geología e Hidrología ; c) Carlos Bruch (1869-1943), nacido en Munich llegó a la Argentina en 1887 y pocos meses después ingreso al Museo junto con su padre para trabajar como fotógrafo en los talleres de la imprenta, luego participaría de exploraciones y se dedicaría a la entomología, hacia 1901 fue nombrado encargado de la sección de zoología, cargo que desempeñaría hasta su jubilación en 1920 y luego de forma honoraria durante la siguiente década ${ }^{18}$; y d) el suizo Santiago Roth (1850-1924), nacido en Herisan, Suiza, llegó a la Argentina en 1866 y durante un tiempo trabajó reuniendo colecciones para museos europeos y explorando el país, fue incorporado a la Sección de Paleontología en 1895 y estaría vinculado al Museo hasta su muerte. Posteriormente, en el área de geología y geografía física también se incorporarían otros profesores extranjeros, especialmente alemanes ${ }^{19}$. En 1906, González también nombró a Florentino Ameghino como jefe de sección y profesor en geología, consejero académico y superior, quien aceptó más bien como compromiso hacia el Ministro y sólo participó en algunas reuniones iniciales, renunciando al poco tiempo. En el área de botánica se designó como profesor titular al italiano Carlos Spegazzini (1858-1926), quien también se desempeñaba como docente en la Facultad de Agronomía y Veterinaria y como director del laboratorio de Biología vegetal del Ministerio de Agricultura; y ocuparía la cátedra del Museo hasta su jubilación en 1912. En 1907 se incorporó como profesor auxiliar, el italiano naturalizado Augusto Scala (1880-1933), un egresado de la carrera de farmacia en la Universidad de Buenos Aires y que se dedicaría a los estudios de histología vegetal y las actividades docentes.

\footnotetext{
18 Birabén 1961.

${ }^{19}$ Sobre la historia de la geología en el Museo de La Plata, véase: Teruggi 1977.
} 
En los primeros años, no existía una sección de botánica ni un local especial para esta disciplina, cuestión que sería reiteradamente reclamada por sus profesores.

Las ciencias antropológicas contaron inicialmente con la mayor cantidad de cargos y como profesores adjuntos fueron incorporados varios argentinos: Luis María Torres (1878-1937) ${ }^{20}$, Félix Outes (1878- 1938) y el sanjuanino Desiderio Aguiar $(1865-1909)^{21}$. Asimismo, en 1906 se incorporó como profesor adjunto un joven zoólogo nacido en Alemania pero con nacionalidad argentina: Miguel Fernández $(1882-1950)^{22}$, con veintitrés años, una sólida formación científica y una tesis defendida en la Universidad de Zürich bajo la dirección del especialista Arnold Lang, discípulo de Haeckel $^{23}$. En el Museo de La Plata, Fernández junto a su esposa, Kati Marcinowski también doctorada en la Universidad Zürich, se dedicaría a los estudios de laboratorio en embriología y posteriormente genética, un estilo de trabajo muy diferente a lo que habitualmente se venía realizando en el espacio de los museos $\operatorname{argentinos}^{24}$. En 1906 fue nombrado profesor adjunto encargado de los cursos de zoología - cargo que en el primer presupuesto se había destinado a un profesor de química y fue cedido por la Escuela de Química y Farmacia- y al año siguiente acumuló otro puesto similar en anatomía comparada. Además, obtuvo el apoyo de las autoridades universitarias para instalar un laboratorio de zoología en los subsuelos del Museo, equipado con los instrumentos y otros elementos para desarrollar sus investigaciones y también con los materiales necesarios para que funcionara como aula-laboratorio para la enseñanza práctica. Inicialmente en este lugar también se dictaron algunas clases prácticas de asignaturas de química y farmacia, pero a

\footnotetext{
${ }^{20}$ Torres se graduó de abogado en la Universidad de Buenos Aires, ingresó en 1901 al Museo Nacional como adscripto ad-honorem de la Sección Arqueología, en 1903 a la Junta de Historia y Numismática Americana y luego en 1905 como encargado de la Sección de Arqueología del Museo de La Plata. Intervino además en los estudios históricos de la Facultad de Filosofía y Letras y se desempeñaría como profesor de historia colonial y prehistoria en la Sección de Historia, Filosofía y Letras de la Universidad de la Plata creada en 1909. Podgorny 2002a.

${ }^{21}$ También por unos meses se mantuvo un puesto de adjunto de lingüística, pero esto fue muy criticado en la prensa y en 1907 se eliminó del presupuesto.

${ }^{22}$ En los documentos del Archivo del Museo, Fernández figura como de nacionalidad argentina nativa. No obstante, había nacido en Essen, Alemania, de padre argentino y madre alemana, pasó su infancia en un campo de la Provincia de Buenos Aires y luego en Montevideo, donde estudió .en el prestigioso Colegio Alemán de esa ciudad. Sus estudios superiores los realizó en Zürich, en el famoso Instituto Politécnico y luego se dedicó a anatomía comparada en la Universidad de esa ciudad. Asistió a la Universidad de Heidelberg y al igual que otros zoólogos de la época, completo su entrenamiento con tres estadías en un laboratorio marino. En su caso, eligió la estación, por entonces rusa, de Villefranche sur-le mer, en la costa mediterránea francesa y especializada en estudios embriológicos. En el Museo de La Plata, continuaría dedicándose a este tipo de estudios, primero completando sus investigaciones sobre Ascidias y luego sobre mamíferos y otros vertebrados en el laboratorio de zoología.

${ }^{23}$ Sobre el desarrollo de la "zoología científica" en las universidades alemanas, véase: Nyhart 1995.

${ }^{24}$ Podgorny 2000.
} 
mediados de la década de 1910 al contar con alumnos propios del doctorado en ciencias naturales, Fernández logró monopolizar el uso de este laboratorio para entrenar estudiantes avanzados en las técnicas de investigación y facilitar la preparación de sus tesis doctorales. En esa época, este profesor pasaría a ser reconocido en la práctica como el Jefe de la Escuela de Zoología y Botánica o también llamada de Biología.

Para la atención de las actividades especializadas de las distintas secciones y laboratorios se contrató personal auxiliar conformado por estudiantes. Las reglamentaciones de los cargos de ayudantes-alumnos fueron muy estrictas con respecto a las altas calificaciones que debían poseer los candidatos y el mantenimiento de los mismos estaba supeditado a la aprobación regular de materias sin aplazos. En cierta forma, esto conformó un mecanismo de selección de personal auxiliar para los trabajos científicos, técnicos y docentes, ya que posteriormente algunos de los exalumnos destacados fueron nombrados jefes de laboratorio y luego profesores suplentes o adjuntos. Esto último remite al problema señalado por Carlos Prego acerca del "ciclo de reproducción ampliada" de la ciencia ${ }^{25}$, en tanto esas posiciones abrían oportunidades de entrenamiento y de entrelazar los primeros pasos para desarrollar una carrera académica. Según las disciplinas, los cargos de ayudantes fueron destinados para ayudar en el desarrollo de las clases, colaborar en la preparación de material didáctico, o para que los alumnos se entrenaran junto a los profesores en las actividades de investigación. En 1906 los alumnos inscriptos en ciencias naturales no llegaron a cubrir las doce ayudantías que se establecieron en el presupuesto y en los siguientes años ante la falta de estudiantes y los recortes presupuestarios estos cargos se fueron reduciendo. En cambio, la Escuela de Química y Farmacia, que contó con una cantidad creciente de alumnos pudo justificar un aumento de esos cargos, así como los de jefe de trabajo de laboratorio y profesor, para los que disponían de un título universitario.

La reorganización interna del Museo de La Plata al incorporarse a la universidad fue decidida en el seno del Consejo Académico durante los primeros días de $1906^{26}$, donde se dio inicialmente participación a todos los profesores titulares. En

\footnotetext{
${ }^{25}$ Prego 1998.

${ }^{26}$ La primera sesión se realizó el 8 de enero de 1906 para intercambiar ideas entre los profesores sobre el plan general de estudios que regirían en la futura Facultad. En esa reunión participaron varios profesores y jefes de sección y se distribuyó la organización en la siguiente forma: geología, mineralogía y paleontología: F. Ameghino, Roth y Schiller; botánica: Spegazzini; zoología: Bruch;
} 
las primeras reuniones, Herrero Ducloux propuso agrupar las materias afines en varios Institutos - o Escuelas - para una mejor organización de los trabajos y concentración de los recursos para investigación y enseñanza en cada área. Cada unidad contaría con un director, encargado de coordinar la enseñanza y los trabajos del resto del personal científico-técnico. Para las ciencias naturales se proyectaron tres escuelas: a) de ciencias geológicas bajo la dirección de Florentino Ameghino, y que comprendería las secciones y cátedras de mineralogía, geología y paleontología, b) de ciencias biológicas, dirigida por Carlos Spegazzini e integrada por las dependencias de botánica y zoología; y c) la de ciencias antropológicas, bajo la jefatura de Lafone Quevedo y que comprendería antropología, etnografía, arqueología y lingüística. Esta estructura fue resistida por los antiguos investigadores extranjeros que no habían sido designados para dirigir ninguna de ellas. Estos prefirieron mantener la vieja organización basada en secciones científicas y anexar como complemento las tareas docentes. De esa forma, la unidad de investigación basada en la sección les permitiría disponer de mayor independencia para organizar sus trabajos, dirigir el personal auxiliar y el uso de los recursos. Finalmente, con la renuncia de Florentino Ameghino y los problemas con Carlos Spegazzini, las tres Escuelas de Ciencias Naturales se reunificaron en una sola al año siguiente, bajo la dirección de director del Museo de La Plata.

En el reglamento de $1907^{27}$ se estableció que el Museo conservaría su carácter como tal y al mismo tiempo funcionaría como una Facultad de Ciencias Naturales con una estructura interna compuesta por dos tipos de unidades: a) Secciones dedicadas a investigaciones científicas, de las cuales se reconocieron siete: antropología, etnología, arqueología, lingüística, botánica, zoología, anatomía general y comparada, geología y paleontología y mineralogía; aunque no todas contaron con cargos, espacios o recursos propios. A ello, además, se agregaba una sección administrativa; y b) Escuelas de enseñanza en: ciencias naturales, ciencias químicas y ciencias geográficas, con cargos de profesores titulares y adjuntos cuyas tareas fueron inicialmente independientes de las actividades museísticas. Cada Escuela contó con gabinetes y laboratorios para la enseñanza práctica y las investigaciones de los docentes, colaboradores y para que alumnos realizaran sus tesis doctorales. De esa

antropología: Lafone Quevedo, Lehmann-Nitsche y Torres. En cuanto a los estudios relacionados con química, física y geografía quedarían a cargo de Herrero Ducloux y Delachaux.

27 "Reglamento del Museo" en: UNLP 1910: 198-225. 
forma, las actividades científicas se organizaron por dos vías: la antigua estructura del Museo y los laboratorios de las cátedras, donde se desarrollarían nuevas líneas de investigación no necesariamente vinculadas con el uso de colecciones, como algunos estudios químicos, de histología vegetal y las investigaciones promovidas en el laboratorio de zoología.

Por otra parte, el Museo de La Plata al incorporarse al contexto universitario no perdió su dimensión museológica, hecho que se vio reflejado por el mantenimiento de su organización interna en secciones y por la preocupación en la conservación, estudio y exhibición de colecciones. Como cualquier otro museo continuó disfrutando de ese nombre por su prioridad en la adquisición y conservación de un conjunto particular de objetos. Sin embargo, la convivencia de las tareas docentes, museísticas y de investigación, así como el funcionamiento de las distintas Escuelas en el interior de esta Institución tendría repercusiones en la distribución de recursos, espacios físicos y la organización del trabajo. En los siguientes apartados se examina esto último en relación con la organización del profesorado en ciencias naturales y las actividades de divulgación.

\section{2. Cuidar colecciones, investigar, enseñar}

Se ha señalado que uno de los aspectos a tener en cuenta para examinar las condiciones de posibilidad para la investigación universitaria, debería ubicarse en torno a la organización del profesorado y las oportunidades para acomodar estas actividades como parte de algún rol reconocido social e institucionalmente ${ }^{28}$. En el caso del Museo de La Plata, esto oscilaría entre el cargo docente y el de empleado técnico, con algunos arreglos institucionales ad-hoc para determinados individuos. La estructura científica previa sobre la cual se estableció la Facultad promovió la identidad del docente-investigador entre los profesores de ciencias naturales, donde los antecedentes y trabajos científicos fueron uno de los elementos que primó en la selección y evaluación académica. Como ya se señaló, los investigadores extranjeros que venían trabajaban en el Museo pasaron a ejercer una doble función de profesores titulares y jefes de sección. También a la mayoría de los profesores adjuntos se le asignó responsabilidades vinculadas a un puesto como encargados de sección. Las

\footnotetext{
${ }^{28}$ Véase entre otros: Ben-David 1971; Geiger 1984; Schwartzman 1985; Prego 1998.
} 
obligaciones principales relacionadas con la dirección de una sección giraban en torno al enriquecimiento, el estudio y la clasificación de un conjunto particular de colecciones así como atender la organización y el cuidado de las exhibiciones públicas de esos materiales. Esto incluía un conjunto variado de actividades desde viajes de estudio, recolección de material, coordinación del trabajo de los preparadores y ayudantes, el inventario y catalogación de las piezas, la atención de los canjes y pedidos de información u objetos, hasta el diseño y mantenimiento de las exposiciones dependiente de la sección respectiva. Asimismo, la dirección de la institución esperaba que escribieran guías populares y catálogos para difundir públicamente el patrimonio de la institución, y que periódicamente elevaran informes y trabajos científicos para publicar en la Revista del Museo.

En el reglamento que se estableció en 1907, se mantuvo gran parte de las disposiciones que habían regido en la organización del trabajo del Museo durante la dirección de Moreno $^{29}$, aunque en la práctica se concedió mayor autonomía al personal técnico superior. Esas ordenanzas establecían que todos los materiales, fotografías, mapas e informes obtenidos a través de expediciones financiadas por la institución eran propiedad de esta última, al igual que todos los trabajos que editaba. Si bien en ambos casos se reconocía la autoría del investigador, para la reproducción de parte de esas publicaciones, imágenes u otros registros se debía solicitar autorización a la dirección del Museo. Como empleados de la institución estaban supeditados a las ordenes de la dirección en cuanto a la organización de exploraciones y trabajos a realizar en las secciones, debían cumplir un horario y asistencia $\operatorname{diaria}^{30}$, atender visitas escolares o de otros investigadores y a partir de 1914 debían alternarse en la guardia de los días feriados y de descanso. Estas obligaciones implicaban una dedicación casi exclusiva a la institución, sólo compatible con el ejercicio docente. Además, legalmente no tenían vacaciones ni podían ausentarse sin permiso por más de tres días. Muchas actividades -como los viajes, exploraciones de estudio, la asistencia a congresos internacionales o el estudio de colecciones en otras instituciones-,

\footnotetext{
${ }^{29}$ Algunas de las pautas de trabajo impuestas por Moreno para el Museo de La Plata son analizadas en: Podgorny 2002.

${ }^{30}$ En 1906 el horario diario de los jefes de sección y profesores adjuntos era el siguiente: el secretario, Outes: de 13 a 16 hs.; el Jefe de Antropología, Lehmann-Nitsche: lunes, miércoles y viernes: 8.30 a 11 y de 13 a 16.30 hrs.; el adjunto de Arqueología, Torres: de 11.30 a 16.30 hs; el adjunto de Antropología, Aguiar: 13 a 16 hs. (este profesor remarcó que el cargo de adjunto sólo implicaba 6 horas semanales obligatorias, las demás voluntarias); el Jefe de la Sección Zoología, Bruch: de 8 a 11 hs y de 13 a 17 hs; el adjunto de Zoología, Fernández: 8 a 11 hs y de 13 a 17 hs; el
} 
dependían de la licencia y permisos especiales acordados por las autoridades académicas y estaban supeditados al calendario escolar. Durante los primeros años, la falta en el cumplimiento de los tiempos estipulado en las licencias para expediciones o viajes a Europa, donde los científicos extranjeros tenían su familia y colegas, fue motivo de algunos problemas entre el personal científico y la dirección de la institución. En el caso de los viajes a Europa, además de justificarse por la asistencia a congresos internacionales también se relacionaron con la posibilidad de actualización en lo relativo a materiales de investigación y enseñanza, contacto con otros científicos y establecimiento de intercambios institucionales de colecciones y publicaciones.

Generalmente, los distintos investigadores enfatizaban en la intención de reunir colecciones para el Museo como una de las estrategias para gestionar permisos y licencia con goce de sueldo, pasajes en tren o algún pequeño subsidio para participar en exploraciones organizadas por otras instituciones o sus propios viajes durante el período de vacaciones. En muchos casos, el tiempo de ocio se combinaban con las prácticas de observación y recolección de especimenes in situ en las sierras cordobesas, Sierra de la Ventana o la cordillera mendocina. Esto, por otra parte, respondía a una de las funciones asignadas a los jefes o encargados de sección: aumentar los ejemplares y el patrimonio de la institución. De ahí que en los informes de los viajes, los investigadores señalaban especialmente los objetos recolectados para el Museo, que no sólo implicaban los de su especialidad sino también, siguiendo las prácticas de los naturalistas de la época, las de otras áreas de las ciencias naturales. Por otra parte, la importancia de relación expedición-colección-museo también se pondría de manifiesto en la publicidad que la Institución realizaba a través de la prensa. En efecto, las noticias periodísticas de la época que daban cuenta de las actividades científicas del Museo se referían principalmente a las expediciones y las colecciones reunidas por su personal.

Ciertas tensiones y problemas de "indisciplina" se suscitaron entre la libertad y privilegios que otorgaba el cargo de profesor con respecto a las disposiciones que regían para el personal "técnico", el cual era considerado dentro de la categoría de empleado administrativo. Frente a ello, la figura del profesor universitario gozaba de mayor consideración social e independencia para llevar a cabo actividades de investigación, tenía vacaciones y sus obligaciones con respecto a la Institución eran 
mucho menores a pesar de cobrar casi el mismo sueldo ${ }^{31}$. En ese sentido, por ejemplo, el zoólogo Miguel Fernández, cuyas investigaciones no se basaban en colecciones o trabajo en el campo sino en el laboratorio, prefirió articular su lugar de trabajo en torno a la cátedra y el laboratorio de la Escuela de Ciencias Naturales, acumulando dos cargos docentes, en vez de encargarse de alguna sección de la estructura museística. También en 1910, Santiago Roth trasformó su puesto de jefe de sección y profesor (con un sueldo de 400 pesos) en un cargo de profesor (300 pesos), aunque manteniendo ad-honoren la jefatura de la sección de paleontología, ya que esto último resultaba incompatible con la dirección del Mapa Topográfico y Geológico de la Provincia de Buenos Aires. Es de destacar, que por medio de esta repartición, Roth ofreció la infraestructura necesaria para la realización de algunas expediciones del personal del Museo.

Las diferencias entre la figura del profesor universitario y el jefe de sección también se hicieron evidentes en el caso de la contratación de profesores en el exterior como se manifestó con León Collet, convocado para fomentar los estudios de geografía física. Este joven investigador se había formado con John Murray, un reconocido especialista en estudios oceanográficos en aquella época; y en 1910 trabajaba en el Laboratorio de Paleontología y Geología de Facultad de Ciencias la Universidad de Ginebra. Allí fue entrevistado por Herrero Ducloux durante su viaje por Europa en 1909-10, gracias a las recomendaciones del rector de la Universidad de Ginebra y otros profesores. Durante ese viaje, el vicedirector del Museo de La Plata se interesó por los estudios oceanográficos ${ }^{32}$ y en el presupuesto para el año siguiente se proyectó crear una sección de geografía y la cátedra de geografía física y oceanografía con la idea de contratar a este investigador ${ }^{33}$. Después de algunos ofrecimientos extraoficiales, la Universidad de la Plata destinó 5.000 francos para cubrir los gastos

\footnotetext{
${ }^{31}$ En 1906 el sueldo de jefe de sección y profesor era de 400 pesos moneda nacional, igual que el sueldo de los otros profesores titulares de la Universidad. En 1907 se redujeron los sueldos de estos últimos a 300, al igual que el de jefe de sección, aunque a este se le adicionaban 100 pesos más por sus actividades docentes. A su vez, los profesores adjuntos cobraban 250 pesos, ya sea que dictaran clases y/o estuvieran a cargo de una sección. Este monto se mantuvo igual hasta 1912, cuando se aumentó el subsidio nacional y se elevaron los sueldos en 50 pesos.

${ }^{32}$ Durante su recorrido por Europa, Herrero Ducloux se entrevistó en España con el director del laboratorio marino de las islas Baleares, el naturalista catalán Odeón De Buen, quien señaló la participación que podría tener la República Argentina en los trabajos oceanográficos que se estaban organizando a escala internacional. En esa época, se habían comenzado a organizar comisiones por océanos y mares para la coordinación de los trabajos entre los distintos países y para homogeneizar los procedimientos de trabajo. De Buen 1910. La importancia de estos estudios en Argentina venía siendo señalada por algunos zoólogos desde fines del siglo XIX, como se menciona en el capítulo siguiente.

${ }^{33}$ AHMLP, Actas del Consejo Académico, Libro I, sesión del 8/11/1910.
} 
de traslado de ese profesor, además de ofrecerle un nombramiento como docente en el Colegio Nacional para complementar sus ingresos y alojamiento en el Internado de ese establecimiento. Tras un retraso en la partida, Collet comenzó sus actividades en La Plata en mayo de 1911. Al poco tiempo comenzó a reclamar por su situación como profesor, señalando que no se estaban cumpliendo las condiciones prometidas y solicitando la equiparación de su sueldo con el de los profesores alemanes contratados en el Instituto de Física ${ }^{34}$. A esto se opuso Herrero Ducloux, argumentando que la situación de este profesor era inferior a la de estos últimos, que habían sido convocados para constituir escuela de investigación y organizar nuevos estudios, y no como Collet, que si bien era un joven competente se había llamado para la enseñanza de una materia. Asimismo, el vicedirector señaló que en Ginebra este profesor tenía un puesto modesto y peor retribuido. Con respecto a las condiciones de trabajo en el Museo, Collet se quejó, entre otras cosas, de que se le había dado la responsabilidad por la sección y enseñanza de geología y no la de geografía física como se le había prometido y en la cual estaba especializado; la falta de vacaciones oficiales y las obligaciones docentes no le permitían realizar excursiones científicas ${ }^{35}$. Su propuesta era que lo nombraran director de la enseñanza de geografía en el Colegio Nacional y cambiar el cargo de jefe de sección de geología por el de profesor, quedando como jefe ad-honorem de la sección. Esto último fue interpretado por las autoridades académicas como un medio de rehuir a las obligaciones de "empleado técnico" para alcanzar las ventajas de "profesor". Finalmente, ante la imposibilidad de obtener un

\footnotetext{
${ }^{34}$ En AHMLP, caja $n^{\circ} 4$, se conservan varios telegramas, cartas de este profesor así como copia de las notas que le enviaron las autoridades del Museo.

${ }^{35}$ Las quejas de Collet por su situación laboral abarcaron varios puntos: a) un reclamo por sus ingresos, ya que el montepelio le retuvo el $50 \%$ de su primer sueldo y el 5\% de los restantes, y que le otorgaran una suma mayor por sus gastos de traslado; b) la responsabilidad por la jefatura de la sección de geología y la enseñanza de esa asignatura y no de geografía como se le había prometido en las cartas. Según Herrero Ducloux, las relaciones intimas entre las dos ciencias permitían que un hombre preparado en ciencias geográficas pudiera desempeñar fácilmente ese cargo, c) el dictado de las clases de geología le habían impedido realizar excursiones de estudio por el país. Según indicaba se le había prometido que el primer año de su estadía iba a estar dedicado a esto último, antes que a dar clases. Mientras que Herrero Ducloux criticó que a ocho o nueve lecciones se le pudiera llamar "curso" y que hubo proyectos para que viajara al sur con Roth por cuenta del Mapa Hidrográfico, y a Salta y Tucumán, los cuales si se suspendieron no fueron por culpa del Instituto o la Universidad. Cabe destacar que igualmente durante el año lectivo, Collet realizó una expedición por la Provincia de Córdoba junto al personal de la División de Minas, Geología e Hidrografía. Por otro lado, su curso abarcó sólo 11 clases de una hora; d) la falta de vacaciones oficiales como jefe de sección, e) falta material de enseñanza, bibliografía actualizada y luz adecuada en su lugar de trabajo. Con respecto a ello, Roth indicó lo contrario, y f) que no le habían comprado las diapositivas que había traído de Europa. El Consejo Académico contestó que no se contaba con recursos para ello y además todavía se adeudaban las diapositivas compradas a Carlos Bruch el año anterior. AHMLP, Actas del Consejo Académico, Libro I, sesión del 13/10/1911.
} 
cambio en su situación, Collet presentó su renuncia y regreso a su país a fin de año. Es interesante señalar, que al poco tiempo el rector de la Universidad de Ginebra manifestó su sorpresa porque este joven investigador no se hubiera podido adaptar a las condiciones locales, como los otros profesores que se había enviado a distintas partes del mundo no europeo.

Las cartas guardadas en el Archivo del Museo y los debates en el Consejo Académico sobre este caso constituyen una fuente interesante para analizar la situación laboral de los jefes de sección y profesores de esta institución, en el momento en que se intentaban articular las funciones de enseñanza superior con las actividades de investigación, exploración del territorio y las tareas propias de un museo. Estos documentos permiten observar que el Museo/Facultad no contó con las mismas facilidades para ofrecer condiciones de trabajo, sueldos extraordinarios o arreglos especiales para contratar investigadores extranjeros ${ }^{36}$, como otras unidades académicas, especialmente la Escuela de Física o el Observatorio ${ }^{37}$. En relación a ello, la política científica de la Universidad platense para dotaciones, recursos y contratos pareció concentrarse en la promoción de disciplinas vinculadas a las ciencias experimentales o a las que no contaban con una tradición reconocida en el país.

Otro aspecto que es interesante destacar de este caso, es el complejo entramado de relaciones diplomáticas que involucraba la contratación de un profesor en el extranjero. En efecto, las autoridades del Museo debieron presentar un informe justificando el problema de la renuncia de Collet ante el rectorado de la Universidad de La Plata y el de Ginebra. Asimismo, cuando este profesor retornó a Europa dictaría unas algunas conferencias sobre la Argentina que fueron seguidas de cerca por el representante diplomático argentino, quien posteriormente enviaría un informe de las mismas al Ministro de Relaciones Exteriores y a la Universidad platense. Durante esta época, la contratación de profesores extranjeros, al igual que la participación en congresos internacionales, las pensiones o becas en el exterior y los intercambios de publicaciones y colecciones formaban parte de las políticas de cooperación universitaria y relaciones exteriores ligados a la defensa o aumento del prestigio nacional en el contexto internacional. En relación con ello, desde la Universidad platense se apoyaría y en varios casos se patrocinaría la participación de sus

\footnotetext{
${ }^{36}$ Esto se manifestaría también en el fracaso de las gestiones de Herrero Ducloux para contratar especialista en química en la misma época.

${ }^{37}$ Pyenson 1984, 1985a.
} 
profesores en congresos científicos internacionales y también en los nacionales que se comenzaron a organizar a partir de la guerra mundial de 1914.

Para la mayoría de los jefes o encargados de sección del Museo, la enseñanza ocupó un rango subordinado a la investigación en cuanto a dedicación y remuneración. Si bien no se había fijado una cantidad determinada de horas semanales o clases anuales, el reglamento de 1907 establecía el dictado de materias anuales, participar en mesas examinadoras y en todos los actos oficiales universitarios y la obligación de dar por los menos dos conferencias anuales de "vulgarización científica" como parte del programa de extensión universitaria. Sin embargo, no todos cumplirían con estas obligaciones. En el caso de los profesores de ciencias geológicas fueron solicitados frecuentemente por dependencias oficiales y empresas particulares para la exploración de ciertas regiones y la determinación de recursos de posible explotación económica. La atención de esas demandas y el desarrollo de sus propias investigaciones en el campo hacían que las tareas docentes y el desarrollo de los cursos quedaran supeditados a los tiempos de las expediciones. En otros casos, ello se debió a la falta de estudiantes como las cátedras de arqueología, lingüística y paleontología que no recibían alumnos de correlación. Por otra parte, algunos investigadores estuvieron más interesados en definir el trabajo en el Museo en relación con sus propias investigaciones e intereses cognitivos antes que en brindar una enseñanza de forma sistemática o formar alumnos. Al igual que en la Universidad de Buenos Aires, la carrera de ciencias naturales ofrecida en La Plata contó con un número muy bajo de estudiantes ${ }^{38}$, llegando a ser una docena recién a fines de la década del 1910 y manteniéndose esa cantidad durante los siguientes quince años. La distribución de la enseñanza se realizó a partir de un modelo de cátedra-disciplina hasta la década de 1930, momento en que se produjo una renovación y ampliación de la planta científico- docente. En general, el profesor de una materia se encargaba del dictado de todos los cursos relacionados con ella, ya sea para alumnos propios o de otras Facultades que asistían por el sistema de correlación. La atención de los alumnos de otras carreras, especialmente de farmacia e ingeniería que fueron aumentando considerablemente durante la década de 1910, generaría una mayor carga de las actividades docentes, ya que ello exigía un cierto grado de especialización de los contenidos según las carreras. Las cátedras que recibirían más estudiantes y que

\footnotetext{
${ }^{38}$ Para una referencia de la cantidad de estudiantes de ciencias naturales en las universidades nacionales en las primeras dos décadas del siglo XX, véase el Anexo.
} 
debieron adecuarse a este último requisito fueron las de ciencias geológicas, botánica y zoología general. Como se menciona en el siguiente capítulo, para atender esas demandas, frecuentemente se subdividían los cursos y se incorporaban diferentes temas. En otros casos, se alternó año por medio el dictado de algunas asignaturas.

En distintas oportunidades, los científicos formados en las universidades alemanas, fomentarían la institucionalización de algunos elementos de ese tipo de universidad, especialmente aquellos que proveían de una mayor libertad académica. En ese sentido, por ejemplo, el antropólogo Lehmann-Nitsche promovió la institucionalización de la división del año en semestres como en Alemania. Este sistema permitió a los profesores atender varios cursos durante el año, distribuir en semestres las partes o contenidos especiales para los alumnos de distintas carreras y disponer de mayor tiempo libre para trabajos científicos y viajes de estudio. Otra de las cuestiones reiteradamente promovida fue la libertad de aprendizaje y enseñanza. La existencia de planes de estudios y programas oficiales que fijaban los contenidos a enseñar en cada asignatura, parecía contradecir tanto el principio de libertad reclamado para la ciencia, como también el estatus del profesor universitario según el "modelo alemán" difundido por estos profesores. En ese sentido, por ejemplo, el Santiago Roth en la primera Asamblea General de Profesores de la Universidad platense, recomendó adoptar el sistema alemán de la libertad de aprendizaje por parte de los alumnos ${ }^{39}$. Las mismas ideas fueron sustentadas por el zoólogo Miguel Fernández, quien además agregó que era necesario eliminar los "programas" oficiales y el sistema de "pasar lista" a los profesores y estudiantes, que daba a las universidades el carácter de escuelas de segunda enseñanza: "es universalmente conocido que la ciencia solo puede prosperar únicamente en un ambiente de completa libertad. Por lo tanto, nunca se llegará á formar hombres capaces del verdadero trabajo científico, sinó únicamente rutinarios en universidades donde se estudia y enseña según planes de estudios obligatorios y se explican programas oficiales compuestos por los consejos y se pasa lista á los estudiantes y profesores......también

\footnotetext{
${ }^{39}$ En esa reunión Roth propuso: "se debe adoptar el sistema universitario de Alemania, dejando á los estudiantes la libertad de elegir las materias y el orden en que quieran cursarlos...las facultades deben exigir solamente de los estudiantes la justificación de haber cursado cierta cantidad de materias durante los años que prescriban los reglamentos, para ser admitidos en los exámenes finales". UNLP 1907: 20 .
} 
se producirá por la enseñanza y los estudios libres una selección natural tanto entre el cuerpo de profesores como de estudiantes" 40.

De esa forma, el principio de la libertad intelectual aparecía como un prerrequisito para el trabajo científico original. Por otra parte, como ha observado Weisz en el caso de los universitarios franceses, los requerimientos de la ciencia también podían ser usados para justificar las demandas por una mayor libertad académica, recursos y autonomía institucional. De hecho, Fernández insistiría en diferentes oportunidades en este tema. En la Asamblea General de Profesores 1910, por ejemplo, señalaba que: "para "levantar el nivel de los estudios universitarios y crear la aptitud de investigación independiente", me parece que medios mas eficaces, serían: nombrar en lo sucesivo únicamente profesores que ya hayan publicado trabajos científicos, remunerar á éstos de tal manera que puedan dedicarse exclusivamente á su cátedra y sus estudios, darles una intervención más amplia y directa en la marcha de la Universidad, introducir para los estudiantes la "libertad de estudios", á la manera de las universidades de lengua alemana, dotar a los laboratorios no solamente de instalaciones, sino también de las bibliotecas necesarias, hacer reglamentos más liberales para el uso de las bibliotecas de las Facultades é Institutos y de la Universidad"41

Los reclamos de este investigador en cuanto a la dotación de las bibliotecas, nombramiento de profesores que acreditasen antecedentes científicos y una remuneración que permitiera la dedicación exclusiva serían temas presentes en las demandas de los sectores científicos a lo largo de varios años. A principios del siglo $\mathrm{XX}$, la acumulación de dos cátedras o en combinación con un cargo directivo dentro de la Universidad, fue una de las medidas que se aplicaría frecuentemente para mantener especialistas que dedicaran todo su tiempo a las actividades académicas y ofrecerles una remuneración que les permitiera vivir según un estilo de vida asociado con el estatus del profesor universitario ${ }^{42}$. Especialmente ello formó parte de arreglos ad hoc para brindar a los profesores-investigadores, y en particular a los que se llamaban del exterior, una situación económica adecuada a sus expectativas, a cambio de que se dedicaran de forma exclusiva a las tareas docentes, de investigación y

\footnotetext{
${ }^{40}$ UNLP 1908: 26.

${ }^{41}$ UNLP 1911: 10.

${ }^{42}$ Mientras que el sueldo mensual básico de un profesor titular por una cátedra, no llegaba a trescientos pesos (por los descuentos por jubilación), el alquiler de una casa en La Plata, como las que tenían los profesores de física era de aproximadamente 150 pesos por mes.
} 
entrenamiento de estudiantes. La mayoría de los profesores de ciencias naturales del Museo acumularon como mínimo dos o tres cátedras distribuidos entre la Universidad platense y la de Buenos Aires, y en ciertos casos también ejercerían de profesor en algún otro establecimiento educativo. En el caso de los investigadores en ciencias geológicas también mantuvieron vínculos con algunas reparticiones públicas de investigación. Si bien este sistema permitía obtener una mayor remuneración, no siempre remitía a una motivación económica, ya que en varios casos algunos de los puestos se ejercían de forma honoraria. En ese sentido, como ha señalado Camille Limoges en el caso de los profesores del Museo de Historia Natural de París, ello parecería estar relacionado con proveer a los científicos de una mayor visibilidad social y aumentar su prestigio y autoridad intelectual, sobre todo en la medida de que se ubican en los espacios centrales de producción y reproducción de una determinada área de conocimiento ${ }^{43}$.

Otro mecanismo para mantener un personal de investigación fue permitir que ciertas cátedras o cargos docentes que no contaban con alumnos regularmente, se justificaran en base a actividades de investigación o de extensión universitaria. Hacia 1909 la situación de los profesores que no tenían alumnos se complicó ante una nueva ordenanza del presupuesto universitario, en el que se establecía que no se abonaría el sueldo de cátedras que no se dictaran durante el año ${ }^{44}$. Para los profesores adjuntos de ciencias naturales que no tenían cursos a su cargo o no dictaban clases por falta de alumnos, el Consejo Académico consideró que realizaban una tarea de investigación científica continua en las secciones del Instituto, dentro y fuera del año universitario como empleados técnicos dependientes de los jefes de sección respectivos y resolvió considerarlos como adjuntos de sección, mientras no dictaran clases de su asignatura dentro del Instituto ${ }^{45}$. Una situación similar se generó en torno al carácter de la cátedra

\footnotetext{
${ }^{43}$ Limoges 1980.

${ }^{44}$ En el Presupuesto Universitario para 1909 se incluyó un artículo que se establecía que no sería abonado el sueldo que correspondían a cátedras que no se dictaran durante el año universitario. Con lo que se recaudara por ese concepto y con las demás economías que se realizaran se destinaría al fomento de gabinetes, laboratorios, publicaciones y bibliotecas de las Facultades e Institutos. Asimismo, en el artículo 4 se indicaba que todas las unidades académicas debían informar a la presidencia de la Universidad sobre las cátedras que quedasen comprendidas en la ordenanza anterior. Estos artículos se mantuvieron en los siguientes años, aunque no se efectuó un control muy estricto hasta la crisis económica de 1914.

45 A principios de 1909, el Consejo Académico trató el tema de las condiciones en que se hallan los profesores de la Escuela de Ciencias Naturales con el objeto de establecer sus obligaciones y atribuciones. Se reconoció que "los profesores adjuntos de la Escuela de Ciencias Naturales realizan una tarea de investigación cientifica continua en las secciones del Instituto, dentro y fuera del año universitarios como empleados técnicos dependientes de los jefes de sección respectivos", por lo que se
} 
de lingüística a cargo del director del Museo, que en esa época se eliminó del presupuesto universitario. A principios de 1909, en una discusión en el Consejo Académico, Lafone Quevedo indicó que esa cátedra era una continuación de la asignación especial votada por el Congreso Nacional en la década de 1890, destinada a la conservación de materiales y el estudio de las lenguas americanas ${ }^{46}$, y en función de ese argumento se solicitó a la presidencia de la Universidad que gestionara ante el Gobierno Nacional el restablecimiento de esa partida. La cátedra de lingüística fue restituida, aunque su existencia continuó siendo cuestionada por la falta de actividad docente desde la prensa diaria. La situación de esos cargos pone de manifiesto, por un lado, la tensión entre las exigencias docentes ligados al trabajo en la Universidad y los intereses científicos de los investigadores; y por otro, las posibilidades de hacer arreglos especiales e individuales. En el contexto inicial de funcionamiento de la Universidad, fue factible trasformar la "función docente" del cargo de profesor en tareas de extensión universitaria, actividades científicas o de curador de museo.

En 1915, ante la difícil situación económica por la que atravesaba la Universidad se volvió a plantear el problema de las cátedras sin alumnos matriculados oficialmente o las que tenían menos de tres. Si bien la disposición que establecía que los profesores que no dictaran clases no cobrarían se había establecido en 1909, fue a partir de la crisis de esos años cuando se comenzó a aplicar y a ejercerse un mayor control sobre el dictado de las clases. En esa época, el Consejo Académico reconoció que los profesores de paleontología y de etnografía realizaban trabajos que podían ser considerados equivalentes al dictado de un curso. También Lafone Quevedo volvió a proponer que se considerara su cargo de profesor de lingüística como medio de ayudar y sostener el estudio de las lenguas nacionales indígenas a través de publicaciones, antes que para instrucción de alumnos. Al año siguiente, el Consejo Superior resolvió que esta cátedra quedara excluida de la aplicación de las ordenanzas del presupuesto

estableció que: "los profesores adjuntos de la Escuela de Ciencias Naturales del Museo se consideran como adjuntos de los Jefes de las Secciones respectivas, mientras no dicten clases de su asignatura dentro del Instituto" . AHMLP, Actas del Consejo Académico, Libro I, sesión del 6/3/1909.

${ }^{46}$ Lafone Quevedo señaló que: "la cátedra de lingüística fue fundada por el Congreso Nacional á moción del señor general Mitre para la conservación y estudio de las lenguas indígenas americanas y que me fué adjudicada. Al fundarse el Instituto del Museo en la nueva Universidad de La Plata, fue continuada dicha asignatura en el mismo carácter por cuya razón no se cobró la asignación que tenía por sanción del Congreso en el año 1906, considerando que la presente cátedra no es sino continuación de la anterior. Por lo tanto, considero que esta cátedra se encuentra en las mismas condiciones de las adjuntas que se ha resuelto por este consejo que son de investigación, sin perjuicio de poder dedicarse, también, á la enseñanza......". AHMLP, Actas del Consejo Académico, Libro I, folio 140 . 
y se destinara a publicaciones e investigaciones de lingüística y arqueología americana, debiendo rendirse cuenta de las inversiones ${ }^{47}$. En los siguientes años también se mantendría la cátedra de lingüística con esa función.

Paralelamente, Herrero Ducloux propuso que los profesores que no tuvieran alumnos reglamentarios y fueran además jefes de sección, dictaran cursos libres o conferencias de su especialidad como una forma de cumplir con sus obligaciones docentes. Inicialmente, se consideró la posibilidad de organizarlas en los días de visita pública para alcanzar un mayor auditorio, aunque ello fue objetado a partir del poco éxito obtenido por las conferencias dominicales dadas por alumnos de la Escuela de Química y Farmacia en años anteriores y las que se intentaron organizar en esa época. Frente al poco éxito de esas actividades se concluía que para el aprovechamiento de las mismas era necesario un auditorio con una cierta base científica. En los siguientes años se insistió en que los profesores sin alumnos dictaran conferencias semanales o quincenales y extensivas a los alumnos de las diferentes carreras a través de una selección apropiada de los temas y en horarios que no se superpusieran con los cursos oficiales. También se establecería como una obligación de los profesores suplentes el dictado de conferencias y cursos libres. En esos años, varios profesores de distintas categorías realizaron alguna de esas actividades de difusión. Así, por ejemplo, los profesores suplentes y adjuntos de química dictaron series de conferencias y cursos libres sobre temas de su especialidad, el profesor adjunto de paleontología ofreció clases libres de paleobotánica y paleozoología; el de zoología uno de herencia abierto a todos los estudiantes y docentes de la Universidad en 1915; Lehmann-Nitsche atendería a grupos de excursionistas de escuelas y sociedades culturales, y Luis María Torres organizó una serie de charlas sobre la arqueología del delta del Paraná los sábados a la mañana en 1915, que si bien fueron bastante promocionadas en la prensa local, el ciclo se suspendió por falta de auditorio y enfermedad del profesor. Como se señaló en el capítulo anterior, la falta de público para actividades difusión de este tipo fue un problema presente en varias de las iniciativas de extensión universitaria y difusión científica de la época. En el siguiente apartado, se examinan otras modalidades de divulgación de la ciencia organizadas en el Museo de La Plata.

\footnotetext{
${ }^{47}$ AHMLP, Actas del Consejo Académico, Libro II, folio 36.
} 


\section{3. Difundir: publicaciones y colecciones}

Al Museo de La Plata se le había concedido un lugar importante en el programa de extensión universitaria y difusión de la ciencia que se esbozó para la Universidad Nacional de La Plata. Como se mencionó en el capítulo anterior, la "extensión" de los favores de la ciencia a un público más amplio que el conformado por la comunidad académica se había proyectado a través de conferencias periódicas, el acceso público a las exhibiciones y el material de estudio y las publicaciones. Los profesores y estudiantes vinculados a las distintas Escuelas que conformaban el Museo/Facultad de Ciencias Naturales participaron de varias iniciativas de popularización científica y divulgación de las actividades que se desarrollaban en el "intramuros", como se señaló en la primera parte de esta tesis. En este apartado se atiende específicamente a los emprendimientos de difusión científica vinculados con la palabra escrita y los objetos, en sus diferentes modalidades, circuitos de circulación y lectores.

Las publicaciones han sido consideradas como indicadores significativos para el análisis de los procesos de institucionalización y difusión de las ciencias así como para la consolidación de centros de estudios como los museos, en la medida que permitían exteriorizar las actividades institucionales, las investigaciones de su personal y dialogar dentro del mundo científico ${ }^{48}$. Las observaciones de campo, los estudios de laboratorio así como colecciones catalogadas, descriptas, dibujadas o fotografiadas al ser inscriptas en un sustrato público como la revista o el libro pasan a formar parte de un conocimiento con posibilidad de ser compartido "universalmente"49. La institucionalización de la práctica científica tendría efectos sobre ese trabajo de difusión a través de lo impreso. Por un lado, las instituciones se legitimarían como centros científicos a través de la publicación oficial de los estudios que patrocinaba, ya sea facilitando sus colecciones u otros recursos, o de los de su personal, del cual se esperaba que presentaran monografías, catálogos o informes para su edición. Al mismo tiempo, una publicación institucional situaba el trabajo del científico en otro marco de legitimidad y circulación.

La edición y distribución de publicaciones permitía a las instituciones, pero también a su personal, ingresar en los circuitos institucionales de canje de bibliografía

\footnotetext{
${ }^{48}$ Pyenson y Sheets-Pyenson 1999; Lopes 1999.

${ }^{49}$ Podgorny 2002.
} 
y a distintas redes de intercambio en el ámbito local pero sobre todo entre instituciones internacionales. Esto facilitaba la adquisición de revistas y otro tipo de obras, así como mantener una actualización en las líneas de investigación y discusiones que se estaban llevando a cabo en otros centros científicos. Al mismo tiempo, permitía acceder al circuito comercial de bibliografía científica extranjera controlado por libreros particulares y empresas editoriales, en la medida en que se trabajara con casas que operaran simultáneamente como consignatarias y proveedoras. De esa forma, esas librerías acumulaban un saldo a partir de la venta de las publicaciones del Museo de La Plata, que permitía a este último adquirir obras y mantener la suscripción de revistas extranjeras. Esto, por ejemplo, se evidenció en las relaciones que mantuvieron por varios años con la librería de K. W. Hiersemann de Leipzig, la cual también se encargó de la distribución de las publicaciones en el continente europeo.

Por otro lado, las publicaciones del Museo de La Plata también participaron en los circuitos de canjes entre instituciones universitarias, patrocinados por las autoridades de la Universidad platense, como parte de una política de relaciones internacionales de cooperación y reciprocidad. Los trabajos editados por este Instituto fueron utilizados para retribuir los obsequios y donaciones que había recibido la Universidad Nacional de La Plata de otras instituciones similares, especialmente de las americanas como las de Chile, Perú y Estados Unidos. La política de cooperación científica no sólo se llevó a cabo a través del canje de publicaciones sino también mediante intercambios y donaciones de colecciones mineralógicas, zoológicas, moldes de yeso de objetos arqueológicos y restos paleontológicos. Entre ello se destacaría la donación de una copia del dinosaurio Diplodocus Carnegii, un regalo del multimillonario norteamericano Andrew Carnegie le hizo al entonces presidente de la Argentina, Roque Sáenz Peña, como parte de la misión de paz y relaciones internacionales que las instituciones patrocinadas por la Fundación Carnegie impulsaban en los años anteriores a la guerra mundial ${ }^{50}$. La exhibición en 1912 del Diplodocus Cargenii o también llamado "Pacificus" por el presidente de la Universidad platense, sería presentada como una evidencia más de los vínculos de solidaridad internacional establecidos por la práctica de la ciencia ${ }^{51}$.

\footnotetext{
50 Teruggi 1963; Podgorny y Plöger 1999.

${ }^{51}$ González 1935, XVI: 109-133; Podgorny 1995.
} 
Cabe destacar que la presentación del Museo de La Plata a través de sus publicaciones no sólo apuntaba a dialogar con el mundo científico sino también a difundir su importancia dentro del contexto político nacional, donde se decidía la supervivencia económica de las instituciones estatales o los subsidios para el financiamiento de algún proyecto de investigación. En este sentido, se observa que dentro de las listas de distribución nacional de la Revista se incluían a ministros, diputados y senadores de distintos partidos políticos, miembros de la elite dirigente y figuras importantes en la vida social y política del país, así como a los principales periódicos nacionales como La Nación, La Prensa y El Diario ${ }^{52}$. La presentación y legitimación ante los sectores políticos muestra, por un lado, los límites difusos de un campo científico aún débil e incapaz de funcionar con sus propias reglas autónomas de reconocimiento y consagración, y al mismo tiempo, la importancia de la empresa de difusión científica entre otros interlocutores. En relación con ello, también se puede mencionar las numerosas noticias periodísticas sobre viajes de exploración, trabajos de campo y las colecciones reunidas por el personal del Museo, gran parte de las cuales eran producidas y enviadas por la misma institución a los diarios, revistas semanales así como a las específicas del ámbito científico y educativo. Se ha señalado que la gran expansión de la prensa periódica a fines del siglo XIX tuvo un papel destacado en la conformación tanto de "campos de lectura"53 como de una "esfera pública". En ese sentido, los diarios no sólo funcionaron como los principales canales de comunicación e información sino también como instrumentos formadores de opinión y de ampliación del debate público ${ }^{54}$, que en este caso se observa con respecto a las discusiones científicas como, por ejemplo, los debates sobre "el hombre fósil americano" y su antigüedad en el Plata durante la década de $1910^{55}$. Por otro lado, según observó el director del Museo de La Plata en esos años, tras la aparición de alguna noticia periodística que anunciaba el hallazgo de restos fósiles se incrementa la concurrencia de visitantes al Museo ${ }^{56}$. La visita a esta institución, además, se

\footnotetext{
52 Véase las listas de distribución nacional de algunos tomos de la Revista del Museo de La Plata en el Anexo.

${ }^{53}$ Prieto 1988.

${ }^{54}$ Esto ha sido analizado en Argentina especialmente en relación a la prensa política y la formación de una opinión pública. Véase entre otros: Zimmermann 1998, Alonso 1997.

55 Podgorny y Politis 2000. Este tema, además, se entrelazó con la construcción del culto Florentino Ameghino fallecido en 1911. Podgorny 1997.

${ }^{56}$ En la Memoria del Instituto del Museo de 1913-1915, por ejemplo, se señaló: "un dato sugerente obsérvase en el público que visita el Museo, y es que la concurrencia aumenta siempre considerablemente cuando la prensa anuncia que en cualquier parte de la provincia se han encontrado restos fósiles que se destinan a nuestras colecciones. Esto puede ser efecto de simple curiosidad, pero
} 
incorporó al circuito turístico de los extranjeros ilustres que llegaban a la Argentina, con lo cual se reforzó aún más su publicidad.

Las distintas funciones que cumplían las publicaciones ayudan a entender la importancia que durante la primera parte del siglo XX, tuvo el emprendimiento editorial en la organización del trabajo y la distribución de recursos del Museo de La Plata. A partir de 1906, estas tareas al igual que algunas publicaciones especiales de la Universidad fueron supervisadas por un director de publicaciones. Este cargo fue desempeñado por Félix Outes, quien además se ocuparía de la administración de la Secretaria y Biblioteca del Museo y de la Sección de Etnografía como profesor adjunto hasta su renuncia a fines de 1911. Luego la organización de las publicaciones quedaría como parte de las actividades de la secretaria y dirección del Museo. Durante los primeros años, también continuó trabajando el contador suizo Rafael Cattani, quien se había desempeñado como secretario durante la dirección de Francisco P. Moreno, y por su intermedio se mantuvo una cierta continuidad en la administración de los canjes y los acuerdos con los libreros y las casas consignatarias. Durante la primera etapa del Museo, bajo la dirección de Moreno, las publicaciones se habían realizado en los talleres de fotograbado, impresión y encuadernación del subsuelo de la institución, que habían permitido obtener imágenes de muy buena calidad. Cuando el Museo fue nacionalizado, la Provincia retuvo los talleres de impresiones oficiales y a partir de ese momento, se recurrió a la empresa de los Hermanos Coni para la impresión de los textos, compaginación final y distribución, mientras que para la confección de clisés y edición de láminas se utilizaron diferentes talleres gráficos, entre los cuales se destacarían los de los libreros-editores Werner y Winter de Frankfurt por la calidad y precisión de las imágenes fotográficas. Por su parte, la casa Coni estaba especializada en la confección de obras científicas y las publicaciones periódicas de instituciones como el Museo Público de Buenos Aires, la Sociedad Científica Argentina y la Sociedad Physis, entre otras. De esa forma, el trabajo de impresión encargado a esta casa se veía facilitado porque esos editores estaban familiarizados con las normas y estilos vigentes en las publicaciones científicas, conocían los circuitos de distribución internacional y tenían listas con las direcciones de las principales instituciones científicas vinculadas a estas disciplinas.

también puede denotar, y nos es muy grato consignarlo, que el gusto del público se va depurando en beneficio de la cultura general a la que contribuye el Museo de una manera tan eficaz y visible". Lafone Quevedo 1917: 108. 
En cuanto a las publicaciones científicas se continuó la edición de la Revista del Museo y de los Anales, cuyos primeros números habían aparecido en 1890. Los Anales tenían un formato de gran tamaño ( $4^{\circ}$ mayor) con ilustraciones de la misma dimensión y estaba destinada a difundir las monografías finales del personal científico de la institución, aunque de estos últimos sólo se organizaron dos entregas entre 1906 y 1908, con un tiraje de 1000 ejemplares cada una. Posteriormente se retomaría la edición de algunos tomos más de esta serie durante la gestión de Luis María Torres en la década de 1920. Los mayores esfuerzos y preocupaciones con relación a las publicaciones de carácter científico se concentraron en la Revista del Museo de la Plata. A partir de 1906 se inició una segunda serie, cuyos tomos incluyeron: investigaciones del personal de la institución, catálogos de especimenes o de las colecciones de la institución, estudios patrocinados por el Museo y en menor medida, contribuciones de otros investigadores y algunas tesis $u$ otros trabajos realizados por los primeros graduados en ciencias naturales y química ${ }^{57}$. Algunos tomos estuvieron conformados exclusivamente por una monografía - trabajo final- de los profesores, reemplazando de esa forma la función de los antiguos Anales, y otros estuvieron dedicados especialmente a trabajos lingüísticos, como los inventarios de lenguas indígenas de la región chaqueña reunido por los misioneros Richard J. Hunt ${ }^{58} \mathrm{o}$ Zacarías Ducci. Ambos formaban parte de las redes de corresponsales que había establecido Lafone Quevedo para el relevamiento de los vocabularios de grupos indígenas sudamericanas. También los intereses intelectuales del Director del Museo de La Plata por fomentar los estudios lingüísticos y etnohistóricos se manifestarían en

\footnotetext{
${ }^{57}$ En esta época se publicaron algunos trabajos que correspondían al texto presentado como tesis de doctorado por algunos alumnos, para lo cual se aprovechaba la composición realizada por la imprenta Coni para la Revista y se le encargaban de forma privada unos tirajes aparte con una tapa y primera hoja en el que se indicaba el carácter de tesis. Una de ellas fue la de Carlos Marelli: "La complicación y sinostosis de las suturas del cráneo cerebral de los primitivos habitantes de la República Argentina" presentado para obtener el grado de doctor en ciencias naturales en la Universidad de Buenos Aires en 1909 y dirigida por Félix Outes, y para la cual había utilizado las colecciones del Museo de La Plata. Otra correspondió a la de María Luisa Cobanera: "Datos sobre las sales de alúmina en la vegetación", presentada en el Museo en 1912 para doctorarse en química y farmacia, bajo la dirección de Enrique Herrero Ducloux. Asimismo, en la Revista del Museo se incluiría otras notas de investigación de Cobanera, una junto a Carolina Spegazzini y otra con su director. También Max Birabén publicaría su trabajo de tesis sobre los cladóceros.

58 Richard Hunt era un misionero anglicano inglés y traductor de evangelios a la lengua indígena "Macoy". Formaba parte de una misión instalada en Concepción del Paraguay, dependiente de la Sociedad Misionera Sudamericana de Londres a los Indígenas del Chaco y durante muchos años mantuvo correspondencia mensual con Lafone Quevedo, enviándole periódicamente registros y vocabularios de distintos grupos indígenas de acuerdo a las instrucciones del director del Museo. En el Archivo Histórico del Museo, se conservan varias cartas de este misionero desde 1909 y durante la siguiente década.
} 
otras series de publicaciones, las cuales, por otra parte, serían bastante solicitadas por misioneros y otros interesados en estos temas.

La Revista del Museo se editó en general con una frecuencia anual o bianual y con un tiraje de 800 ejemplares $^{59}$, que luego se elevó a 900, y cerca de 200 separatas de algunos de los trabajos. Su distribución implicó: a) un circuito nacional restringido especialmente a Buenos Aires y algunos centros del interior del país: Córdoba, Tucumán y Catamarca, y b) una circulación internacional entre instituciones científicas e investigadores de diferentes países europeos y americanos. En 1906 se reactivó la distribución de estas publicaciones, estableciéndose un canje con 248 revistas, principalmente extranjeras. Asimismo, la adquisición de bibliografía se completó con la suscripción a 17 revistas y la compra de obras especiales para investigación y otras para enseñanza según los pedidos de los distintos profesores. Unos años después, al regularizar el reparto de las publicaciones el canje llegó a 395, reduciéndose a 289 en 1912. Cabe señalar, que en 1911 se enviaron al exterior cerca de 280 ejemplares de la Revista ${ }^{60}$. En esa época, se elevó la suscripción a revistas de 17 a 27, gracias al aumento del subsidio nacional y el presupuesto del Museo en 1912. En 1914 se recibieron por canje 345 revistas y 390 en $1915^{61}$. En los siguientes años, en cambio, se redujo considerablemente la adquisición de bibliografía, que se restringió a la obtenida por canje debido a la falta de fondos para compras o suscripciones. Por otro lado, ello además se vería afectado por los problemas en el comercio internacional y la guerra mundial. Esto último también afectaría a los trabajos que se habían mandado editar a Europa. En esa época, se había enviado imprimir a Inglaterra, el tomo XXIII de la Revista, dedicado a estudios lingüísticos recopilados por el misionero inglés, Hunt, y organizado por Lafone Quevedo. Además en esa época, la casa alemana de Werner y Winter estaba encargada de la confección de las ilustraciones y fotografías para la Revista, así como de la impresión del tomo XXI, dedicado íntegramente a la investigación de Miguel Fernández sobre la poliembrionía específica de la mulita y que se había decidido editar en lengua alemana. Este trabajo estaba destinado a dialogar con científicos europeos ${ }^{62}$ y norteamericanos dedicados a esos estudios y para su difusión, Fernández había

\footnotetext{
${ }^{59}$ Salas 1908.

${ }^{60}$ AHMLP, Copiador $n^{\circ} 6$, folio 211.

${ }^{61}$ UNLP 1913, 1917.

${ }^{62}$ Especialmente en las universidades e institutos de habla alemana, las investigaciones embriológicas habían alcanzado un gran desarrollo, véase entre otros: Nyhart 1995; Hopwood 1999.
} 
solicitado en 1913 al Consejo Académico su publicación en inglés o alemán, eligiendo este último porque era el que mejor manejaba ${ }^{63}$. Por otra parte, el editor Winter era autor de trabajos de investigación en zoología y se había ofrecido a leer y corregir personalmente la última prueba ${ }^{64}$. En octubre de 1914, los editores de Frankfurt comunicaban a la dirección del Museo que tenía todo preparado para comenzar la impresión de ese trabajo e intentaban tranquilizar con respecto a la situación de la guerra $^{65}$. También las operaciones con la casa alemana Karl Hiersemann sufrieron algunas modificaciones en la forma de realizar los pagos, por las prohibiciones que existían con respecto al funcionamiento los bancos alemanes en los años de la guerra, y la disminución de las ventas de la Revista ${ }^{66}$. Durante esos años, se presentaron problemas para la llegada de publicaciones extranjeras y las cajas remitidas desde Alemania con los trabajos para el Museo de La Plata, que peregrinaron por Europa, llegaron a Inglaterra y demandaron la intervención de varias instituciones y diplomáticos para que pudiera llegar a la Argentina, lo que retrasó en algunos años su circulación. Especialmente, el caso del trabajo de Miguel Fernández permite observar el efecto de la "Gran Guerra" sobre otro aspecto de la práctica científica de la época, y abre el interrogante acerca de los tiempos de las publicaciones y su distribución en función de las cuestiones de prioridad y reconocimiento internacional. Asimismo, en la década de 1920, este zoólogo sería cuestionado por su falta de "patriotismo" al haber publicado su investigación más importante en idioma alemán.

Durante los años que duró el conflicto bélico europeo se interrumpió gran parte del reparto de las publicaciones del Museo para no someterlas a los peligros de

\footnotetext{
${ }^{63}$ El Consejo Académico aprobó la propuesta de Fernández de enviar los originales para su edición en Alemania y en lengua alemana, aunque indicó que se debía incluir un resumen en castellano y las referencias de las ilustraciones debían estar escritas en ambos idiomas.

${ }^{64}$ Carta fechada el 20/1/1914. Además, se señalaba que esa casa contaban con el personal necesario para la composición y corrección de trabajos de esa índole y se comprometía a imprimir el texto sin faltas de imprenta. AHMLP, caja $\mathrm{n}^{\circ} 16$, doc. $\mathrm{n}^{\circ} 31$.

${ }^{65}$ En este sentido, en una carta fechada el 7/10/1914, indicaban que "si la parte de las comunicaciones con el extranjero que va por ultramar no estara casi por completo paralizada, aquí sabríamos apenas que hay guerra. Aqui todos los negocios son completamente normales, aunque no tan rápidos como de ordinario. Dificultades de pago no existen, solamente el extranjero teme de hacer pagos. En estos dias recibímos un cheque de América. Con América expedimos nuestra correspondencia por la Estación Zoológica de Nápoles y ruego á Ud. de escribir en lo sucesivo al profesor D. J. Grohs, Estación Zoológica, Nápoles, quien se ha encargado de la correspondencia con el exterior...... En el extranjero cursan aún, debido á la censura inglesa, las noticias la más contrahechas é increibles respecto á nosotros; cuando la verdad sea sabida también en América se juzgará muy distintamente....." AHMLP, caja $\mathrm{n}^{\circ} 14$.

${ }^{66}$ En una carta fechada el 5/11/1915 se le pidió al Museo que girara los pagos a través de un Banco en Nueva York, agregando que: "como es natural la guerra mundial dificulta mucho á la venta, pero á pesar de las circunstancias poco favorables voy continuar mis esfuerzos y contribuiré en todo cuanto este á mi alcance, al despacho de sus publicaciones." AHMLP, caja $\mathrm{n}^{\circ} 16$, doc. $\mathrm{n}^{\circ} 57$.
} 
la navegación. En algunos casos, se recurrió a embajadores y diplomáticos para la distribución internacional de la Revista del $\mathrm{Museo}^{67}$, que implicó, además, un menor costo, rapidez y seguridad en los envíos. Por otra parte, hacia 1919 cuando se normalizaron las comunicaciones, la circulación de los tomos acumulados de la Revista del Museo demandaba una importante suma de dinero. También había cuentas pendientes con librerías europeas y la casa consignataria Hiersemann tenía publicaciones del Museo para vender, las cuales adquirieron un precio muy elevado por la devaluación de la moneda alemana. De hecho, la dirección del Museo recomendó esperar a que se acomodaran los precios, para que sus publicaciones no se vendieran a menor valor. Al iniciarse la década de 1920, se saldaron las deudas con ese librero y se propuso la adquisición de nueva bibliografía y materiales para los laboratorios aprovechando el cambio favorable para la moneda argentina. Esto último, también permite observar como la infraestructura necesaria para la práctica científica cotidiana fluctuó de forma paralela a los períodos cíclicos de crisis y recomposición de la economía argentina y con respecto a la situación internacional.

Las publicaciones del Museo fueron principalmente financiadas con los fondos asignados en el presupuesto universitario, ya que no se aceptaron suscriptores ni se ofrecieron espacios de publicidad y por otro lado, los costos de edición no se recuperaban, ya que gran parte de los números se destinaban al canje o se enviaban gratuitamente a investigadores e instituciones que lo solicitaban. En los años en que se eliminó del presupuestario universitario las partidas destinadas a exploraciones y publicaciones de este instituto, estos gastos se financiaron inicialmente con el fondo propio del Museo. Parte de este fondo se obtenía a partir de lo producido con la venta de publicaciones, colecciones escolares y réplicas de yeso de fósiles pampeanos $\mathrm{u}$ objetos arqueológicos. No obstante, por este medio no se logró acumular una gran suma, ya que se presentaron muchas dificultades para el cobro de esos productos, como se evidencia en los documentos del Archivo de la institución. En cuanto a la venta de las publicaciones servían para acumular un fondo en las casas consignatarias extranjeras que se destinaba a pagar los gastos de distribución internacional de la Revista, de compra de bibliografía y las suscripciones a revistas científicas extranjeras. También se obtenía una pequeña entrada a partir de un cierto porcentaje

${ }^{67}$ Así por ejemplo en 1916 se enviaron varios tomos de la Revista a Suecia para ser distribuidas a las instituciones con las que el Museo mantenía canjes, por intermedio del Encargado de Negocios en Suecia, A. Paulin. En 1917 se gestiona ante la Legación de Bolivia para enviar las publicaciones del Museo por intermedio de una vía diplomática para ser distribuidas entre instituciones de ese país. 
sobre las matrículas y aranceles que abonaban los estudiantes, aunque este tipo de ingreso se fue reduciendo a lo largo de los años. Como se mencionó en el capítulo II, inicialmente desde la Universidad se había establecido que sobre lo recaudado por cada unidad académica, esta última retendría un 50\% y la Universidad el resto, pero para 1914 el porcentaje asignado a las Facultades se redujo al $10 \%$. Otra estrategia empleada para pagar los gastos de traducciones e impresiones fue la utilización de las partidas de sueldos de ayudantes y cargos de profesores que estaban vacantes, habían sido suspendidos o tenían licencias sin goce de sueldo. Para cubrir el déficit de los gastos de las publicaciones, se debió gestionar frecuentemente alguna partida especial del fondo de la Universidad. Es de destacar que el costo de edición y distribución de las publicaciones eran uno de los gastos ordinarios más caros del Instituto del Museo. Durante de la década de 1910, se fue acumulando una cierta cantidad de deudas con las casas de libreros, imprentas y talleres gráficos nacionales. Las dificultades para la edición de la Revista, se complicaron aún más a fin de esa década por el aumento del precio de impresión y especialmente del papel que se importaba. En la Memoria institucional de 1918, esta situación junto a la interrupción de algunas publicaciones aparecía como un problema importante del funcionamiento institucional.

A partir de 1906, también se habían comenzado a producir otras clases de publicaciones destinadas a la divulgación y la enseñanza. Entre esto último se pueden mencionar: los planes y programas de estudio, folletos con reglamentos y de propaganda de las carreras que se estudiaban en el Museo, para enviar a los colegios nacionales del interior del país y a las personas que lo solicitaran. Asimismo, se proyectó la edición de otro tipo de obras habituales en museos, como eran las guías populares para el recorrido de las salas y los catálogos de las colecciones de cada sección. De esto último sólo apareció el Catálogo de la Sección Antropológica en 1910, confeccionado por Roberto Lehmann- Nitsche ${ }^{68}$ y que se distribuiría junto a la Revista por el circuito nacional e internacional de las publicaciones científicas. De las otras secciones, se publicarían catálogos parciales en la Revista del Museo. Con respecto a las guías, estas estuvieron supeditadas a la terminación y arreglo de las exposiciones públicas de los materiales así como a la definición de un criterio para el

${ }^{68}$ Lehmann-Nitsche 1910a. 
ordenamiento de las piezas ${ }^{69}$. Al iniciarse la década de 1910 se confeccionaran algunas guías populares relacionadas con las secciones de mineralogía ${ }^{70}$; geología ${ }^{71} \mathrm{y}$ antropología $^{72}$, que aparentemente nunca llegaron a imprimirse. La única guía popular que se editó y circuló en esos años fue la Guía Sumaria para la visita de la Sala XIX (1912), confeccionada por Félix Outes ${ }^{73}$. En esta sala se exponían calcos de piezas arqueológicas de Estados Unidos, México, Guatemala, Honduras, Perú y Bolivia, obtenidas por canje del Museo Nacional de los Estados Unidos, compradas al Museo Etnográfico de Berlín y otras donadas, en gran parte por Lehmann-Nitsche, cuyo ordenamiento seguía un criterio geográfico-político y luego tipológico. En la guía se ofrecía una breve explicación de la procedencia de los objetos y de los grupos indígenas relacionados a los mismos y se acompañaba con algunas fotografías de esculturas y grabados expuestos. La mayoría de los calcos eran reproducciones que mantenían el tamaño del original, con la excepción de la puerta de Tiahuanaco reducida a un décimo, y además gran parte de las piezas se habían pintado tratando de imitar el color natural de las rocas y otras de amarillo claro para destacar el modelado. También otros jefes de sección se preocuparían por el diseño de las exposiciones y los

\footnotetext{
${ }^{69}$ En la Sección de Paleontología la falta de inventario, determinación y ordenamiento de la gran cantidad de piezas hizo que algunas de las salas no estuvieran inicialmente abiertas al público ni se confeccionara una guía para ello. Hacia 1913 fue nombrado profesor adjunto en paleontología, el exalumno Eduardo Carette, a quien se le encomendó la tarea de catalogar y ordenar las piezas y tratar de reunir los datos que pudiera sobre la procedencia y edad geológica de las piezas, ya que hasta ese momento se carecía un catálogo y el registro de esa información. En un informe sobre esa Sección correspondiente a los años 1914-1915, se indicaba que: "no respondiendo la colocación del material paleontológico depositado en las vitrinas laterales de la sección a ningún orden científico y no siendo posible adoptar el criterio geológico por lo exiguo de los salones, se ha principiado con el arreglo de los restos de vertebrados siguiendo la sistemática zoológica en uso... a este nuevo ordenamiento responde la 'Guía de la sección de Paleontología del Museo', la cual junto con los letreros explicativos que se imprimirán, permitirán al público recorrer con todo provecho esta sección tan importante, hasta ahora cerrada a los visitante ". Lafone Quevedo 1917:104. En 1915 se había terminado de acomodar el material del salón de los desdentados y para dar una idea más completa de esa fauna fósil al público visitante se había encargado al dibujante y modelador de la Escuela de Dibujo, Dalmiro Navarro, esculpir y modelar las restauraciones de diversas especies.

${ }^{70}$ Entre los manuscritos de Walter Schiller se encuentra una guía popular para las colecciones de la Sección de Mineralogía con fecha de 1910, en la que se indica que fue corregida y traducida en 1912. Uno de los cambios se debido al traslado de plantas y animales petrificados de una de las salas por el montaje del calco del Diplodocus. Biblioteca del Museo de La Plata, Doc. Manuscrito ${ }^{\circ} 120$. Aparentemente esta guía se había enviado a la imprenta para su publicación según se informaba en la Memorias del Museo, aunque no se encuentran registros de que se hubiera editado.

${ }^{71}$ La guía-catálogo de esta Sección fue confeccionada por el profesor suizo León Collet. Los problemas con este profesor tal vez provocaron que no se informara sobre este trabajo ni se enviara a publicar. Unos años después se encargó al profesor adjunto de paleontología, el Eduardo Carette, la traducción de esta guía del francés al castellano, tal vez con la intención de publicarla. La traducción manuscrita de esta guía se conserva en el AHMLP.

${ }^{72}$ En diciembre de 1912, Lehmann-Nitsche entregó los manuscritos de una guía popular de su Sección, la cual debía haber aparecido publicada hacia mediados de 1914. AHMLP, caja $\mathrm{n}^{\circ} 14$. No se ha podido encontrar más indicios que permitan conocer el destino de ese material.

${ }^{73}$ Outes 1912.
} 
objetos exhibidos, atendiendo a la distribución de las piezas, la elección de los colores, los soportes visuales como fotografías, mapas o etiquetas, la disposición de los armarios y vitrinas, entre otros dispositivos para facilitar la mirada del público. Aunque no todos los proyectos para renovar las salas se pudieron materializar por los altos costos que implicaban, ponen de manifiesto la importancia atribuida a las mismas como escenarios para mostrar la organización del conocimiento en las respectivas disciplinas y el trabajo de cada sección. Por otro lado, los ejemplares armados, las reconstrucciones en yeso de la apariencia externa, las recreaciones del ambiente natural de los animales y las fotografías de paisajes formaban parte de los dispositivos visuales para captar un público no instruido a través de las impresiones sensoriales y favorecer una enseñanza "objetiva"74. Pero a diferencia de la primera etapa del Museo de La Plata, ahora el poder educativo de la imagen se intentaba reforzar con la palabra oral o escrita de los "expertos". De la guía de la sala XIX se confeccionaron 2000 ejemplares en formato pequeño y económico, que se vendía a treinta centavos. Para las excursiones organizadas por instituciones educativas y culturales, el recorrido por las salas era acompañado con las explicaciones del personal técnico o algunos estudiantes de la institución ${ }^{75}$.

Como parte del programa de extensión universitaria fomentado por el presidente de la Universidad platense, también se proyectó otro conjunto de publicaciones como la Biblioteca de Difusión Científica. Esta colección había sido pensada para difundir traducciones en español de dos tipos de obras: a) relatos de viajeros que habían recorrido el país, y b) trabajos editados en el extranjero relacionados con las disciplinas practicadas en la institución. Además, en esta serie se incluirían manuales y trabajos de vulgarización científica. De esta colección solamente aparecieron cuatro tomos y su circulación estuvo restringida al ámbito nacional, principalmente entre establecimientos educativos y las bibliotecas populares que se fueron creando por esos años. El primer tomo se editó en 1907 y en él se incluía la traducción del primer manual inglés de arqueología publicado tres años antes por el egiptólogo inglés W. M. Flinders Petrie: "Métodos y propósitos de la arqueología", cuya traducción se encargó al traductor profesional A. Costa Alvarez. Este tomo se completaba con otro artículo del mismo autor: "Las sucesiones en los restos prehistóricos", y un artículo del antropólogo norteamericano G. E. Holmes

\footnotetext{
${ }^{74}$ Podgorny 1995.

${ }^{75}$ García y Podgorny 1999; García 2001.
} 
sobre "Clasificación y arreglo de las exhibiciones de un museo antropológico", ambos traducidos por el director del Museo. Este primer volumen estuvo dedicado a difundir procedimientos vinculados al trabajo de campo en arqueología, la conservación de las piezas y la manera de ordenarlos en los museos. Del mismo se imprimieron 400 ejemplares y en poco tiempo se agotó.

El segundo tomo, aparecido al año siguiente, se denomino: La ciencia y sus grandes problemas y contenía una recopilación de conferencias y artículos de popularización sobre la historia de la ciencia, descubrimientos y el desarrollo de las ciencias químicas, escritos por Enrique Herrero Ducloux. De esta obra, el Consejo Nacional de Educación adquirió 200 ejemplares y también se envió a varias escuelas y bibliotecas públicas que solicitaron publicaciones al Museo. El tercer tomo apareció en 1912 con el título de Manual de manipulaciones de botánica, y del mismo se confeccionaron 900 ejemplares. Fue escrito por el profesor adjunto de botánica, Augusto Scala, quien en 1910 ofreció esa obra al Consejo Académico del Museo, renunciando a sus derechos de autor y cediendo los beneficios a la institución. Este manual era una síntesis de técnicas de: preparación de colorantes, cortes delgados, uso de aparatos y microscopía, aplicados a los estudios de morfología interna e histología vegetal. Principalmente estaba destinado a difundir entre estudiantes, profesores de enseñanza media y un público general, los procedimientos más efectivos y los recursos accesibles en el mercado local, según las recomendaciones y ensayos efectuados por este profesor. Posteriormente, Scala confeccionaría otros manuales destinadas a la enseñanza de la botánica para distintos niveles educativos ${ }^{76}$. También en la década de 1910, otros profesores del Museo como Outes y Bruch, Torres o Herrero Ducloux confeccionarían obras para la enseñanza elemental, aunque en estos casos se vincularían con los emprendimientos de libreros-editores como Angel Estrada y la producción nacional de textos de enseñanza ${ }^{77}$.

El cuarto y último tomo de la Biblioteca de Difusión Científica se publicó en 1918 y llevaba por título: Disertaciones Químicas. Ese libro reunía una serie de conferencias sobre temas de ciencias químicas y sus aplicaciones industriales escritas por Herrero Ducloux. Si bien hacia 1917 se había encargado a la casa Coni la impresión de este texto, las cuentas adeudas con esta casa y la falta de fondos retrasaron la publicación que se redujo a una primera parte y de la cual se editaron

\footnotetext{
76 Scala $1915,1929$.

77 Podgorny 1999b.
} 
cerca de 900 ejemplares. Las huelgas ferroviarias y los conflictos estudiantiles de 1918 retasaron aún más la distribución de este último tomo.

Desde el Museo de La Plata también se participó en la conformación de otra "biblioteca" proyectada por las autoridades universitarias. En 1910, la Universidad Nacional de La Plata recibió un subsidio nacional especial de 50.000 pesos moneda nacional para publicaciones en conmemoración del centenario de vida independiente de la Nación, que se editaron bajo el nombre de Biblioteca Centenaria y comprendió principalmente obras de carácter histórico, entre las que se incluirían investigaciones arqueológicas y folklóricas. Uno de los encargados de esa serie fue el profesor adjunto de arqueología Luis María Torres, quien recurrió a la casa Coni para la impresión de los textos. El Museo colaboró con los gastos de traducción e ilustraciones de algunos tomos, en los que se publicaron documentos históricos y lingüísticos inéditos como los Tomo I y II de El Paraguay Católico del Padre Sánchez Labrador, organizado por Lafone Quevedo; y diarios de viajeros como los de Muster y Falkner, que inicialmente se había proyectado como parte de la Biblioteca de Divulgación del Museo. Además, se incluyeron monografías y trabajos de investigación del personal científico de este Instituto como: Estudios sobre el folklore argentino: adivinanzas rioplatenses, por Lehmann- Nitsche; Investigaciones arqueológicas en las provincias de Catamarca y Tucumán, por Carlos Bruch; y Los primitivos habitantes del delta del Paraná, por Luis María Torres. Asimismo, también se aprovechó la composición de pliegos efectuada en la casa Coni de algunos de estos últimos trabajos, para incluirlos en los tirajes de la Revista del Museo, de forma que alcanzaran una difusión más amplia entre instituciones científicas y centros internacionales. Hacia 1917, mientras se suspendía la publicación de esta última por falta de fondos, el director del Museo consiguió la autorización de la Universidad para invertir 2000 pesos y se editó el tomo III de El Paraguay Católico, conteniendo: "Arte de la lengua mbayá", también preparado por Lafone Quevedo ${ }^{78}$. De esta obra se imprimieron 600 ejemplares, de los cuales se enviaron 50 ejemplares al Colegio del Salvador. Este trabajo, al igual que los anteriores y los otros inventarios de vocabulario indígenas, fue bastante solicitado por aficionados y eclesiásticos dedicados a los estudios lingüísticos. Al año siguiente, se comenzaron a preparar las pruebas de imprenta del tomo IV, que contenía un diccionario castellano-mbayú, aunque esta obra quedaría inconclusa al morir Lafone Quevedo en 1920. 
Los textos que conformaron las colecciones de divulgación, a diferencia de Revista del Museo, estuvieron diseñados para su circulación en el contexto nacional, en una época que podría caracterizarse como "el tiempo de las bibliotecas", en un doble sentido del término: por un lado, por la creación y multiplicación de las bibliotecas populares, y por otro, por la empresa cultural de libros baratos y las colecciones dirigidas por los sectores intelectuales, vinculado a la extensión cuantitativa del público lector ${ }^{79}$. Estas "bibliotecas" al igual que la producción nacional de libros escolares se proponían educar y sensibilizar gradualmente a los lectores en determinados marcos de ideas y, al mismo tiempo, se inscribían en un proyecto más amplio de conformación de la nacionalidad ${ }^{80}$. Los sectores universitarios y científicos no permanecerían ajenos a esos emprendimientos y participarían en la circulación de imágenes e información en el sistema de instrucción pública. Junto a la confección de textos y manuales para la enseñanza, es interesante señalar la confección de colecciones, láminas y positivos para proyecciones como parte de los materiales visuales para promover la enseñanza de una naturaleza e historia argentina. Entre las ilustraciones producidas para el uso en las aulas, se puede mencionar los seis cuadros murales (láminas de gran formato que incluían varias imágenes) sobre "Las viejas razas argentinas" confeccionados por Feliz Outes y Carlos Bruch en 1910. Cada cuadro correspondía a una región del país y contenía un mapa, vistas del medio físico, figuras y fotografías que ilustraban distintos aspectos de la vida de los diferentes grupos indígenas y sus objetos materiales. Además, ello se acompañaba de un texto explicativo de cada imagen y una descripción general de cada grupo para que el docente pudiera guiar la lección ${ }^{81}$. La mayoría de las imágenes eran fotografías de colecciones o del registro fotográfico del Museo de la Plata, con lo que se procuraba reforzar una enseñanza "objetiva" ante las dificultades de que todas las escuelas contaran con colecciones para la enseñanza de estos temas. En el caso de la enseñanza escolar de las ciencias naturales se recurriría preferentemente a colecciones de objetos o sus reproducciones tridimensionales.

\footnotetext{
${ }^{78} \mathrm{El}$ costo de impresión, encuadernación y embalaje de esta obra fue de: 1842,88 pesos.

${ }^{79}$ Gutiérrez y Romero 1995. Entre las empresas culturales dirigidas a orientar la lectura de los sectores populares y un público general se puede mencionar: la Biblioteca de La Nación; la Biblioteca Argentina organizada por Ricardo Rojas; La Cultura Argentina de José Ingenieros; la Cooperativa de Buenos Aires de Manuel Gálvez o las colecciones de textos y folletos editados por la Sociedad Luz. Sobre esta última véase Barrancos 1996.

${ }^{80}$ Rojas 1909.

${ }^{81}$ Outes y Bruch 1910.
} 
Desde fines del siglo XIX, funcionarios escolares y docentes de algunas escuelas normales comenzaron a fomentar la modernización de la enseñanza a partir del uso de colecciones con ejemplares del territorio nacional, formación de museos en las escuelas, excursiones a la naturaleza y visitas a los museos públicos y distintas exposiciones $^{82}$. Las iniciativas denominadas "museos escolares" se dirigieron inicialmente hacia la promoción de los estudios de la naturaleza local y los recursos productivos con los que contaba el territorio argentino, tratando de divulgar una imagen de país integrado y próspero, donde las colecciones mineralógicas, botánicas o de productos manufacturados testificarían los amplios recursos con los que contaba la República Argentina. En las escuelas de las Provincias de Buenos Aires y de Entre Ríos así como otras de la zona del litoral, también los restos de fauna fósil entrarían a formar parte de objetos coleccionables y que servirían para intercambiar con los productos "regionales" reunidos en las escuelas de otras partes del país. Asimismo, a principio del siglo XX la idea de reproducción de piezas y formación de colecciones para la educación general también fue promovida por los sectores científicos. En efecto, al asumir Florentino Ameghino como director del Museo Nacional de Buenos Aires en 1902, una de las propuestas que elevó al Ministro interino, Joaquín V. González, fue la idea de confeccionar reproducciones en yeso de fauna fósil para lo que solicitaría la instalación de un taller especial, el cual finalmente se destinaría a producir piezas para el canje con otros Museos. Esta propuesta sería retomada por el inspector escolar Leopoldo Lugones durante la gestión de González al frente del Ministerio de Instrucción Pública (1904-1906). Uno de los objetivos era imprimir a la educación un carácter nacional y a la vez regional, ampliando al mismo tiempo, el espacio destinado a la enseñanza de las ciencias. Para ello, Lugones propuso en 1905 dos proyectos: uno destinado a formar colecciones mineralógicas argentinas, encargándoselas a la Escuela de Minas de San Juan y a la Facultad de Ciencias de Córdoba; y el segundo consistía en modelar en yeso fósiles típicos argentinos ${ }^{83}$. Para esto último se contó con el asesoramiento de Ameghino, quien le había indicado cien ejemplares "típicos" y fáciles de reproducir, que formaban parte de la colección del Museo Nacional, de la del de La Plata y de la particular de Ameghino. La lista incluía partes de corazas y esqueletos, cráneos y dientes de ochenta y cinco mamíferos, siete aves, tres reptiles y cinco peces. De ninguno de los ejemplares se preveía realizar el

\footnotetext{
${ }^{82}$ Rajschmir 2000; García 2001.

${ }^{83}$ García y Podgorny 2001.
} 
calco completo de todo el esqueleto. Gran parte de las especies indicadas habían sido descriptas en una serie de conferencias que Ameghino había dado a docentes de enseñanza secundaria y que se había editado en un folleto para distribuir entre los $\operatorname{mismos}^{84}$. A principio de 1906, el Poder Ejecutivo nacional autorizó la adquisición de los ejemplares referidos y su reproducción en los talleres del Museo Nacional. Sin embargo, en el Consejo Académico del Museo de La Plata, la entrega de esos materiales, que eran piezas únicas, fue resistida aludiendo varias razones: por un lado, Herrero Ducloux señaló que era de temer que un "egoísmo injustificado" utilizara esas réplicas para futuros canjes con instituciones extranjeras $\mathrm{y}$ en provecho del establecimiento de la Capital Federal; y por otro lado, el Jefe de la Sección de Paleontología, Santiago Roth, consideró que los numerosos fósiles de la lista no parecían ser los más apropiados para la enseñanza secundaria. Por su parte, Ameghino, que en esos días todavía participaba en las reuniones de este Consejo, defendió esa lista y la discusión se prolongó en varias sesiones, hasta que se resolvió elevar este asunto al Consejo Superior. Finalmente, aunque este proyecto ni la otra propuesta de Lugones se concretaron, marcan un rasgo interesante en el sentido de la importancia que asumían los fósiles como símbolos de lo regional y lo local, y también como objetos de disputa y prestigio entre naturalistas e instituciones científicas. Las escuelas, por su parte, solicitarían al Museo de La Plata: "fósiles pampeanos" para ilustrar las clases.

Paralelamente a la propuesta de Lugones, desde la División de Minas del Ministerio de Agricultura de la Nación, se comenzaron a confeccionar colecciones escolares y se procuró centralizar bajo un "criterio científico" la clasificación de los ejemplares recolectados en las escuelas ${ }^{85}$. El Museo de La Plata, al igual que esta última institución, colaboró con la formación de los museos en las escuelas primarias y secundarias enviando principalmente colecciones mineralógicas y geológicas, preparadas por Walter Schiller, y en menor medida: animales embalsamados, herbarios, reproducciones de restos fósiles y publicaciones, por varios años. Igual

\footnotetext{
${ }^{84}$ Ameghino 1904.

${ }^{85}$ En 1905, por ejemplo, el director de esa División elevó una nota al Ministerio de Agricultura, que luego se envió al de Instrucción Pública, en la cual se presentaba un modelo de mueble para guardar las colecciones escolares que confeccionaba esa dependencia para los colegios secundarios. Asimismo, señalaba: "aprovecho también la oportunidad para significar la conveniencia que habia en que el Excelentisimo Sr. Ministro de Instrucción Pública si lo tuviese á bien, ordenara á los Establecimientos de Instrucción Secundaria que tuviesen minerales los enviaran á esta División para su clasificación y formación de colecciones típicas que respondan al criterio científico de la enseñanza de la materia".
} 
ayuda se prestó a varios museos pedagógicos, educativos y regionales, que se fueron creando a partir de la década de 1910 en distintas localidades y provincias. A estos, además, se enviarían también objetos arqueológicos. En el caso de las colecciones zoológicas, cada vez que se renovaban las exhibiciones y se retiraban los especimenes deteriorados, estos se ponían a disposición de las escuelas que los solicitaran. En este sentido, los jefes de sección consideraban que si bien esos materiales no eran aptos para estudios científicos y tampoco reunían las condiciones adecuadas para una presentación pública, podían aún ser útiles para ilustrar las lecciones escolares. De hecho, muchas escuelas se interesaron por estos materiales y cada vez que se renovaban las vitrinas pedían los ejemplares que se habían enviado al depósito o de los que hubiese duplicado.

En la década de 1910, los gliptodontes "argentinos" y otros mamíferos fósiles se convirtieron en símbolos de la ciencia nacional, reforzado por las campañas de popularización de la paleontología y los homenajes por la muerte de Florentino Ameghino en 1911. En relación a este aspecto se puede señalar que algunos colegios secundarios solicitaron al Museo de La Plata esqueletos o sus réplicas enteras para armar en esos establecimientos, por más que en algunos casos se presentaron ciertas dificultades para el armado y el montaje de las piezas. En la época del centenario de vida independiente de la Argentina, los mamíferos fósiles aparecían como "monumentos" materiales de la ciencia y la historia natural del territorio nacional, capaces de competir con los "héroes de la patria" en el espacio de las paseos públicos. En efecto, en 1910 se publicó en el diario platense El Día un extenso artículo sosteniendo la necesidad de crear un parque paleontológico en La Plata y esculpir en piedra la apariencia externa de esos antiguos animales para adornar las plazas y paseos y dar una idea de los paisajes de los tiempos lejanos. En esa nota, atribuida a un vecino de la ciudad, se sostenía que esto, además, contribuiría a dar trabajos a los escultores y mayor impulso a la paleontología: "los fósiles que restauran los paleontólogos en los museos son una prueba admirable de su ciencia y paciencia, más poco dicen al pueblo que no hace distinción entre los fósiles y las osamentas en el campo. Pero si se esculpe en la piedra un fósil, cuya forma, tamaño y color se conocen por los esqueletos que posee el museo, los más ignorantes tendrán al verlos una idea exacta del monstruo que la que tienen los mismos sabios que lo 
armaron..."86. Dos días después, el antropólogo Lehmann-Nitsche publicó en el mismo periódico una nota apoyando también la idea de crear un parque paleontológico ${ }^{87}$. Señalaba como ejemplo el que se estaba organizando en el parque Hagenberk de Hamburgo, donde se había comenzado a modelar en cemento reptiles del jurásico y se había proyectado agregar una "pampa argentina", para lo cual se había enviado a la Argentina al escultor Pallemberg con el objeto de realizar reconstrucciones de la apariencia externa de los ejemplares de mamíferos fósiles de los Museos de Buenos Aires y La Plata. En este último se exigió a ese escultor que realizara dos ejemplares de cada escultura, una para la institución platense. La idea del parque paleontológico, continuó presente en los siguientes años y difundiéndose en periódicos y revistas educativas, pero no se lograría concretar. En esa época, el auge que cobró la paleontología y las frecuentes visitas a las salas destinadas a la exhibición de la fauna fósil, llevaron a las autoridades del Museo de La Plata a encargar al dibujante y escultor Navarro, la confección de reconstrucciones y modelos en miniatura de la apariencia externa de los mamíferos fósiles sudamericanos para una mejor comprensión popular de las exhibiciones. En ese sentido, si la palabra escrita apuntó a difundir la ciencia entre un público letrado; los objetos exhibidos, las reconstrucciones de las apariencias externas, las colecciones y otros dispositivos visuales buscaron reforzar una iconografía de la ciencia entre los sectores populares y el público infantil.

\section{4. De Facultad a Museo}

En 1918 se comenzarían a producir importantes redefiniciones la Universidad platense debido a la confluencia de varios factores. Por un lado, se produce un cambio de gestión en la casa de estudios platense, asumiendo como presidente Rodolfo Rivarola; tras una elección bastante disputada. Uno de los ítems del programa de reformas propuesto por Rivarola era brindar un mayor apoyo a las carreras científicas y recursos para las Facultades científicas, redistribuyendo el presupuesto universitario en favor de estas últimas y en detrimento de la Facultad de Agronomía y Veterinaria, a

\footnotetext{
86 "Proyecto de Parque Paleontológico en La Plata", EL Día, 23/9/1910.

${ }^{87}$ Lehmann- Nitsche 1910b.
} 
la cual se intentó reducir. En ese marco, el presupuesto para el Museo se aumentó significativamente en la segunda parte del año. Al mismo tiempo, se comenzarían a bosquejar proyectos alternativos en relación con el Museo/Facultad, entre los que se pueden identificar dos tendencias: a) quienes intentarían reforzar la tarea docente de las cátedras de ciencias naturales y, b) los que buscaban independizar la actividad científica-museológica de las obligaciones docentes y concentrar los recursos en las tareas propias del Museo. Entre los primeros, se puede citar las propuestas de Miguel Fernández para reforzar la influencia de la Escuela de Ciencias Naturales en torno al profesorado secundario en ciencias naturales como se analiza en los siguientes capítulos. Paralelamente, el nuevo presidente de la Universidad impulsaba la creación de una Escuela preparatoria de Medicina bajo la dirección del Consejo Académico, y en la cual se dictarían las materias básicas de los primeros tres años de la carrera de medicina de Buenos Aires, aprovechando las cátedras de ciencias naturales y otras afines. Esto había sido promovido en varias ocasiones por el antropólogo Roberto Lehmann- Nitsche, y también Herrero Ducloux lo apoyaría inicialmente pensando que ello favorecería a la institución. Sin embargo, no todos los profesores estaban interesados en ese plan, que por otra parte aumentaría considerablemente las actividades administrativas como señaló el director del Museo en el Consejo Superior, por lo que finalmente se fijó que esa Escuela dependiera directamente de las autoridades universitarias. Otros estaban más interesados en independizar las actividades científicas de las docentes, especialmente por el peso que habían cobrado la enseñanza para alumnos de correlación y las actividades de la Escuela de Química y Farmacia, que era la que más alumnos y profesores tenía. A todo ello, se sumaría el conflicto con los estudiantes de farmacia a fines de 1918, quienes cuestionaban la actuación de algunos docentes y pedían reformas de los planes de estudios.

Por otra parte, la existencia de cargos de profesores adjuntos y titulares que no estaban destinados a la enseñanza sino a investigaciones y la atención de las tareas de las secciones del Museo se presentaría como otro tema problemático en el nuevo contexto universitario. En 1919, el Instituto del Museo elevó al Consejo Superior de la Universidad varias ternas de profesores titulares, tanto de ciencias naturales como de química y farmacia. La consideración de las ternas de botánica y arqueología, especialmente esta última que no estaba comprendida en el plan de estudios de ninguna carrera, generó un debate importante acerca del carácter de esas cargos y las funciones de esos profesores en relación con la cantidad de alumnos que atendían y el 
lugar de esas cátedras en los planes de estudio ${ }^{88}$. Por su parte, el director del Museo defendió esos cargos en función de las tareas propias de un departamento de investigación, como hasta ese entonces se habían podido justificar. En los mismos días, el presidente de la Universidad recibió anteproyectos y opiniones de varios profesores del Instituto $^{89}$, y una nota del Director y jefes de Sección, en la que insistían en la separación definitiva de la Escuela de Química y Farmacia. Para no demorar más la "situación confusa del Instituto", a mediados de 1919 Rivarola elevó al Consejo Superior un proyecto que establecía la separación de la Escuela de Química y Farmacia del Museo, señalando la conveniencia de separar "el departamento de investigación, que no debe depender del número de alumnos, de lo simplemente enseñante". En la defensa de ese proyecto se indicaba la necesidad de autonomía del Museo para reforzar su actividad científica vinculada a las exploraciones en el terreno y la conformación de colecciones por los propios investigadores y no por coleccionistas, para lo cual además, se necesitaría de todos los locales del edificio para guardarlas y utilizarlas adecuadamente. Asimismo, se señalaba: "la tarea docente de los profesores ha ido decreciendo en cuanto a las ciencias naturales, pero no así la correlación, y, debido a la correlación, la actividad de los profesores y empleados, el espacio y los recursos del Museo ha sido menester ofrecerlos a los institutos que cobija y aún a otros institutos hermanos..."90. En ese marco, los problemas de articulación entre investigación y enseñanza se referían a la distribución de recursos y al peso que había cobrado las actividades de Escuela de Química y Farmacia y la atención de los alumnos de correlación. Por su parte, los académicos de esa Escuela buscaban también la independencia de la misma y nuevos locales para su ampliación y trasformación en Instituto/Facultad. Finalmente este proyecto de separación fue aprobado por el Consejo Superior y luego confirmado por un decreto del Poder Ejecutivo en octubre de ese año ${ }^{91}$.

Las reformas proyectadas quedaron paradas al estallar una importante huelga estudiantil poco tiempo después y un conflicto universitario que se extiende por más de diez meses, que la historiografía ha analizado como la "Huelga Grande" y la

\footnotetext{
${ }^{88}$ Los debates sobre este tema en el Consejo Superior se pueden seguir a través de las actas publicadas en BUNLP, 1919, II, 13.

${ }^{89}$ Entre ellos de Luis María Torres, Miguel Fernández y Salvador Debenedetti, E. Herrero Ducloux,

${ }^{90}$ Rivarola 1919b: 102.

${ }^{91}$ Castiñeiras 1985.
} 
Reforma Universitaria ${ }^{92}$. Uno de los efectos del movimiento reformista de esos años fueron las discusiones en torno a la reforma de los estatutos de la Universidad platense y una revisión de los reglamentos y ordenanzas vigentes en cada unidad académica. Esto generaría importantes luchas de poder entre distintos grupos, especialmente en lo relativo a la organización del régimen interno del gobierno académico. En los siguientes años se producirán otros conflictos y profundas divisiones entre los distintos sectores universitarios. Por otra parte, como parte de las transformaciones operadas en el ámbito universitario platense y el crecimiento institucional, se generó una mayor autonomía de acción de cada unidad académica con respecto a las líneas o programas promovidos desde la presidencia de la Universidad, lo que marca una diferencia con la primera etapa de la Universidad Nacional de La Plata.

En 1920 se aprobaron nuevos estatutos en la Universidad platense, en los cuales se reafirmaba el carácter de instituto científico del Museo, dentro del cual se mantendría una Escuela Superior de Ciencias Naturales. La dirección del instituto estaría a cargo de un director- renovable cada tres años solamente por un período más y elegido por el Consejo Superior- y un Consejo Académico, compuesto por todos los jefes de departamentos y profesores mientras no excediesen de doce ${ }^{93}$. Además se incluirían dos representantes de alumnos y otros dos de los egresados, entre los que se incluyeron también los de la antigua Escuela de Geografía. Ese año también se produjeron dos acontecimientos importantes en el Museo de la Plata: el cambio de director y la separación de las otras Escuelas que funcionaban en este ámbito. Tras la muerte de Samuel Lafone Quevedo, quien había ejercido el cargo de director por catorce años, y el Consejo Superior designó en su reemplazo a Luis María Torres. Este arqueólogo dirigiría la institución durante los siguientes doce años, gracias al cambio de los estatutos universitarios en 1926, que fijaban un término de seis años y reelecciones para ese cargo.

En los espacios del subsuelo que antes ocupaba la Escuela de Química y Farmacia se establecieron laboratorios para geología y mineralogía y se ampliaron las instalaciones de los de zoología y botánica así como los depósitos para guardar colecciones. El mejoramiento general de la situación económica del país, el restablecimiento de los circuitos comerciales internacionales junto con la devaluación

\footnotetext{
92 Biagini 1987, 1999b; Caldelari y Funes 1997.

${ }^{93} \mathrm{Si}$ excedían de doce profesores y no llegaban a veinte, el Consejo Superior designaba seis consejeros académicos, si se superaban los veinte serían elegidos por ellos mismos a propuesta de la respectiva asamblea.
} 
de la moneda alemana permitió adquirir nuevos materiales y equipos, especialmente fotográfico, de vidrio y microscopia; restablecer los canjes de bibliografía y de colecciones y saldar las deudas con lo libreros extranjeros. Paralelamente, se realizarían importantes reformas y ampliaciones en la estructura del edificio, gracias a los contactos políticos y gestiones del nuevo director y el apoyo del presidente de la Universidad platense, Benito Nazar Anchorena, entre 1921-1927. Torres también gestionaría donaciones de particulares y subsidios ante el gobierno nacional y provincial para la remodelación del edificio, adquisiciones de nuevos materiales y organizar un programa sistemático de exploraciones regionales. Inicialmente esto último se bosquejó para llevarse a cabo de forma interdisciplinaria y con la participación de todo el personal bajo un plan coordinado por la dirección de la institución, aunque no se descartó en los primeros momentos la idea de que se continuaran los estudios embriológicos y genéticos como los desarrollados en el laboratorio de zoología. No obstante, el nuevo proyecto para el Museo buscaba reafirmar un perfil científico vinculado principalmente con los estudios de historia natural. Según el nuevo director, la organización institucional: "más adecuada para nuestros medios y teniendo muy presente que se trata de un museo de historia natural, es aquella que puede darle una gran actividad a las exploraciones del territorio argentino y países limitrofes, el estudio en los aspectos o puntos de vista, puede decirse clásicos en estas materias, y aun en los nuevos que constituyen el plan general de las ciencias biológicas, e incluyendo el estudio del hombre indígena de nuestro continente. Como complemento de este programa puede desenvolverse paralelamente el de la difusión de la ciencia para los jóvenes que por vocación quieran proseguirla, y aun la divulgación de los resultados, fácilmente apreciables, para el público en general que se proponga comprender el significado de estas instituciones." 94

Al asumir la dirección, Torres enunció entre sus principales objetivos el reordenamiento de las exhibiciones y el trabajo de la institución. Su propuesta se presentaría como una restauración del programa asignado por el fundador del Museo pero atendiendo a las nuevas orientaciones de las prácticas científicas. Torres citaría como autoridad en organización de un museo de historia natural a G. Gilson, director del Museo Real de Historia Natural de Bélgica. En 1914, Gilson publicó una memoria sobre las misiones y actividades de un museo de historia natural moderno que tuvo

\footnotetext{
94 Torres 1924: 8 .
} 
una amplia difusión ${ }^{95}$, como se manifestaría también en las referencias del entonces director del Museo de Buenos Aires, Angel Gallardo (1867-1934) ${ }^{96}$. En ese libro, Gilson reconocía una cierta crisis por la que atravesaban los museos nacionales de historia natural en relación con sus finalidades de educación pública y ciencia frente a la multiplicación de otra clase de instituciones que atendían esos objetivos de forma más especializada: escuelas, bibliotecas, laboratorios, institutos, facultades de ciencias, jardines zoológicos y botánicos, museos escolares, locales o universitarios. Frente a ello, sugería que un museo nacional de historia natural moderno debía: a) definir su carácter de institución destinada al avance del conocimiento, precisando un programa de trabajo que comprendiera la exploración, estudio y conservación de colecciones, b) eximirse de todo servicio pedagógico de orden superior, es decir de enseñanza universitaria metódica, como también sería defendido por el director del Museo de Buenos Aires; y c) organizar y centralizar las exploraciones regionales, seguidas de su publicación y la exhibición de las colecciones reunidas. En ese marco, las funciones del museo comprendían: la exploración, el estudio de los materiales reunidos y su conservación, y la exposición. Asimismo, Torres retomaba el argumento de Gilson, al indicar que las investigaciones científicas del Museo no debían repartirse en compartimientos fijos o secciones administrativas para sus funcionarios, sino en misiones de exploraciones y ejecutadas por los naturalistas, bajo un plan sistemático y coordinado por la dirección de la institución. De esa forma, el director del Museo de La Plata reconocía: "lo que concibo como división de tareas en el Museo son variaciones en las exploraciones y estudios -mediante procedimientos particularespara los cuales no deben crearse dispendiosamente servicios separados, y que no se puedan asociar o utilizar cuando las necesidades lo requieran; ni intereses teóricos, ni elementos técnicos en provecho personal" ${ }^{97}$.

De esa forma, los científicos como empleados de la institución estaban al servicio del programa de exploraciones esbozado por la dirección y supeditados en cuanto a las actividades científicas a la autoridad de este. En 1923, Torres junto con el director del Observatorio lograron que el Consejo Superior aprobara una ordenanza

\footnotetext{
95 Gilson 1914.

${ }^{96}$ Gallardo 1918-19

97 Torres 1932: 9. En este comentario retomaba las ideas que había señalado en el programa esbozado en la Memoria del Museo de 1922-23, donde había señalado la necesidad de que todos los departamentos y dependencias estuvieran al servicio de un mismo plan de trabajo y de forma correlacionada: para los cuales no deben crearse dispendiosamente servicios separados, y que no se
} 
para dichos institutos, sancionada poco tiempo después por el Poder Ejecutivo. Esto implicó un nuevo reglamento para el Museo, en el cual se enfatizaba el carácter científico de la institución por sobre el docente. Se establecían nueve departamentos de investigación científica: 1) antropología; 2) arqueología y etnografía; 3) botánica; 4) zoología; 5) geología y geografía física; 6) petrografía y mineralogía; 7) paleontología (invertebrados); 8) paleontología (vertebrados) y 9) biología. Asimismo, se indicaba que la Escuela de Ciencias Naturales permanecería mientras el número de alumnos no impidiera la función de investigación y se regiría por las disposiciones de los estatutos de 1920. Sin embargo, el reglamento del Museo indicaba que para ser profesor se debía ser jefe de departamento y, perdida esta condición, el Director podía solicitar al Consejo Superior su separación. De esa forma, el nombramiento y destitución de profesores titulares no seguía las pautas establecidas para las Facultades, donde se había establecido el concurso público y la confección de una terna por parte de los Consejos Académico que era elevada al Consejo Superior y luego al Poder Ejecutivo. En el Museo, en cambio, la selección de los jefes de departamento, al que se le adicionaba el carácter de profesor, quedó como una atribución del director, quien luego debía elevar su propuesta al Consejo Superior o la presidencia de la Universidad. De esa forma, las atribuciones sobre el nombramiento del personal tanto superior como de las jerarquías inferiores así como la autoridad para decidir sobre las actividades y responsabilidades de los mismos se concentraron en la figura del director, mientras que las atribuciones del Consejo Académico, compuesto de todos los profesores, se restringieron a la administración y docencia de la Escuela de Ciencias Naturales. La concentración de la autoridad del director por sobre el Consejo Académico - donde participaban todos los profesores y jefes de departamento- fue resistida por algunos profesores, que deseaban conservar el espacio de poder y decisión de este último ámbito. Entre ellos, Miguel Fernández buscaría mantener su lugar de trabajo en torno a cátedra y el laboratorio, donde había logrado formar un grupo de estudiantes y colaboradores; antes que ser jefe de un departamento científico. Esto último era asociado a un cargo técnico, con tareas y responsabilidades vinculadas a exploraciones, recolección y atención de colecciones y su exhibición; y sujeto a las decisiones de la dirección del Museo. Esto contrastaba con la posición defendida por el profesor de zoología, en dos aspectos: por un lado, en relación con el

puedan asociar o utilizar cuando las necesidades lo requieran; ni intereses teóricos, ni elementos técnicos en provecho personal". Torres 1924: 15. 
principio de libertad académica que reclamaba para la ciencia; y por otro, con el estilo de práctica científica que promovía. En esa época, Fernández intentaba consolidar un espacio para las investigaciones biológicas de laboratorio, vinculadas a estudios embriológicos y genéticos, y para lo cual había logrado formar algunos discípulos y un pequeño grupo de trabajo. Es de destacar, que el desarrollo de ciencias experimentales y de laboratorio en el ámbito de los museos se había operado en otros lugares y en algunos casos esto había sido visto como una amenaza para el programa sostenido por los naturalistas y la definición de las funciones institucionales ${ }^{98}$.

En el Museo de La Plata, la definición del perfil de la institución y la organización del trabajo se inscribió en una lucha por los espacios de poder, que a su vez tenía por trasfondo las divisiones que se habían operado en el profesorado de la Universidad durante el movimiento de reforma universitaria y el crecimiento del número de graduados que buscaban un lugar de trabajo. También estos conflictos se manifestarían en los debates sobre el plan de estudios y el perfil del egresado en ciencias naturales, como se analiza en el siguiente capitulo. A fines de la década de 1920, a ello se sumarían las presiones de los graduados por el carácter de los cargos de profesores y su sistema de nombramiento que no seguía las pautas de las otras facultades con lo cual se restringía el acceso a los mismos. Torres recurrió a la contratación de especialistas para determinados estudios, o investigadores europeos para cubrir las jefaturas vacantes de algunos departamentos como fue el caso del español Angel Cabrera (1879-1960), en 1925 para el de Paleontología; y en 1928, el joven alemán Erich Dautert, doctorado un año antes, para el Biología o Zoología. Esto último originaría un nuevo cuestionamiento hacia la dirección del Museo, por parte de los egresados de la institución, respaldados por la Sociedad Argentina de Ciencias Naturales, quines denunciaron que ese zoólogo alemán iba a ocupar un puesto para el que las universidades argentinas ya contaban con personal formado, y al mismo

\footnotetext{
${ }^{98}$ Para el caso del Museo de Zoología comparada de Harvard véase: Winsor 1991. En el caso del Museo de Historia Natural de París, Camille Limoges señala que el avance de estas disciplinas generó que la función museológica se volviera una actividad más de la institución pero no su principal propósito y el cambio de orientación fue visto como una amenaza por los naturalistas. Esta investigadora señala que frente a la marginalización de esta institución frente al crecimiento de otros centros científicos y las Facultades de ciencias, se buscó redefinir el plan del Museo como una autoridad central en la actividad científica vinculada con la exploración en relación con los intereses económicos y político de la nación mientras se enfatizaba en la importancia del clásico programa de historia natural. A fines del siglo XIX se habían creado más cargos relacionadas con las ciencias experimentales que con las ciencias naturales descriptivas. En el nuevos siglo los intentos de algunos sectores por darle otra orientación ha las actividades del Museo tuvieron éxito y para 1934 de 19 cargos sólo tres se relacionaban con las ciencias experimentales de laboratorio. Limoges 1980.
} 
tiempo, solicitarían que se concursara ese $\operatorname{cargo}^{99}$. A su vez, el conflicto por el carácter de los puestos de profesor y los concursos se mantendría en los siguientes años ${ }^{100}$. Hasta ese momento, el director del Museo había utilizado el sistema de contratación para reforzar el programa científico-institucional de un museo de historia natural e incorporar personal que se especializara en el estudio de un conjunto de colecciones o atendiera una parte de aquel programa. Además para responder al plan de exploraciones y reunir colecciones para el Museo se enviarían a trabajar al campo preparadores y algunos alumnos y se mantendrían recolectores semiprofesionales reuniendo colecciones arqueológicas en Patagonia y otros colectando especimenes botánicos en el noreste del país. Esto se apartaba de la idea de que fuera el mismo investigador que efectuara el trabajo de campo y estudio de gabinete de los objetos recolectados, un criterio que dominaba en la organización de la práctica científica de la época como había sido enunciado varias veces por el director del Museo de La Plata y a partir del cual se fundamentó la imposibilidad de que las egresadas pudieran acceder al cargo de jefe de departamento y profesor ${ }^{101}$. Por otro lado, ello también muestra que un programa institucional esbozado para todo el personal científico sería difícil de sostener a menos que los propios investigadores pudieran articular en él sus propios intereses, como se evidenció especialmente en las numerosas exploraciones realizadas por los geólogos.

\footnotetext{
${ }^{99}$ Podgorny 1996. Torres fundamentó la contratación de este joven zoólogo, aludiendo a la necesidad de impulsar los estudios de fauna acuática, cuyas colecciones estaban escasamente representadas en el Museo de La Plata. Como antecedentes para su contratación se destacaba su entrenamiento en las estaciones marinas europeas. Finalmente, este investigador sólo permaneció unos meses en Argentina, reuniendo colecciones en Mar del Plata y en la región antártica.

${ }^{100}$ Los conflictos por el carácter de los cargos de profesor y jefe de departamento se mantuvieron hasta la intervención del presidente de la Universidad, Ricardo Levene en los inicios de la década de 1930, cuando se establece un nuevo reglamento para el Museo. Levene, además, promovió una mayor participación de los egresados en las actividades de la institución y la creación del Centro de Estudios de Ciencias Naturales, creado en 1933 sobre la base de la "Sociedad Platense de Ciencias Naturales" creada un año antes, e integrada con investigadores, egresados y alumnos del Museo; alumnos y egresados del profesorado de ciencias naturales y otros naturalistas que residían en la ciudad. Este Centro se dedicaría a organizar conferencias, cursos y a promocionar los estudios del doctorado en ciencias naturales.

${ }^{101}$ En una reunión extraordinaria del Consejo Académico, efectuada el 27 de mayo de 1929 para discutir el nombramiento de un profesor y jefe del Departamento de Biología, cargo vacante por la renuncia de Miguel Fernández dos años antes, se analizaron los antecedentes científicos y docentes de varios candidatos. Con respecto a las egresadas, Luis María Torres señaló: "no pueden ser incluidas en esta lista porque su condición de mujeres no les permite cumplir con todas las obligaciones inherentes al cargo, tales como salir a expedicionar en los diferentes Territorios de la República". El resto de los consejeros acordaron con esa opinión y se eliminaron a las egresadas como candidatas para ese cargo. AHMLP, Libro de Actas de Reuniones extraordinarias del Consejo Académico y Asambleas de Profesores, folio 55-56.
} 
Como parte de las actividades vinculadas al trabajo propio de un museo de historia natural, Torres también se preocupó por renovar las exhibiciones públicas, la relación con el público y una mayor publicidad del Museo de La Plata. Con respecto a las publicaciones científicas, se continuó la edición la Revista en la casa Coni, de la cual se inició una nueva serie con un tiraje reducido a 500 ejemplares, aunque se aumentaron las tiradas aparte de cada trabajo para satisfacer los pedidos y canjes de cada especialidad. También se procuró retomar la edición de los Anales, de los cual se editarían tres tomos dedicados a las monografías finales de investigaciones patrocinadas por el Museo, como el trabajo sobre dinosaurios del norte de Patagonia y sus relaciones extracontinentales realizadas por el investigador alemán contratado, F. von Huene o los estudios sobre la estratigrafía y tectónica de las sierras meridionales de la provincia de Buenos Aires, realizados por Walter Schiller y J. Keidel. A fin de la década de 1920 se crearía una nueva serie: Notas Preliminares del Museo de La Plata, conformada con contribuciones cortas y resultados preliminares de investigación del personal de la Institución; con una mayor frecuencia de edición para agilizar su difusión entre especialistas. La Biblioteca de Difusión Científica, los trabajos lingüísticos e etnohistóricos, así como los manuales y traducciones para la enseñanza no se incluyeron en el programa institucional del Museo en la década de 1920, aunque se consideró la necesidad de establecer otras series de divulgación como guías y la publicación de lecturas o conferencias públicas. La edición del primer grupo de obras pasaría a formar parte del plan de trabajo de la Facultad de Humanidades y Ciencias de la Educación, desde donde se organizarían manuales y conferencias para la enseñanza primaria que contarían con la participación del personal científico del Museo. Sin embargo, esa división en las organización de estas tareas pone de manifiesto una mayor especialización y delimitación del campo de intervención de cada unidad académica, proceso que también se puede observar en el caso de la formación del profesorado secundario como se analiza en el último capítulo.

A principios de la década de 1920, el Museo de La Plata fue abierto públicamente todos los días por la tarde y se mantendría la entrada de forma gratuita hasta $1968^{102}$. Durante todo el período estudiado se continuó incrementando el número de visitantes y las excursiones organizadas por instituciones educativas de la ciudad, de Capital Federal y otras localidades de la Provincia de Buenos Aires. De la cifra de 36.396 visitantes que se mencionaba en la memoria de 1906 , un cuarto de 
siglo después se indicaba la circulación de cerca de 90.000 personas durante el año. La concurrencia de alumnos de colegios y universidades excedía los 15.000 en el mismo período de tiempo. La visita de las escuelas se había promovido desde la dirección del Museo, gestionando para ello rebajas en los pasajes en el Ferrocarril del Sud ${ }^{103}$. Los gerentes de esta empresa también se interesaron por las actividades científicas del Museo, facilitando un $50 \%$ de descuento en el trasporte de materiales y colecciones, informando del hallazgo de restos paleontológicos y poniendo a disposición personal e instalaciones para los trabajos de campo organizados por el Museo. Además, esta empresa donó un subsidio para la renovación de las exhibiciones y se encargó de editar afiches y avisos en los periódicos promocionando la visita turística a La Plata y su Museo. Para ello se ofrecerían boletos con descuentos para las excursiones dominicales a esta ciudad ${ }^{104} \mathrm{o}$ en el tren Buenos Aires-La Plata de los sábados a las 13: $30 \mathrm{hs}$. para asistir a las conferencias de las 15 hs. organizadas en el Museo ${ }^{105}$. Esta institución, al igual que el Museo Etnográfico de Buenos Aires, también fue incorporado a los tour turísticos organizados en esos años por las compañías norteamericanas como la American Express Company de Nueva York.

Para acompañar el recorrido de los visitantes se confeccionó una guía general de todos los departamentos y salas comprendidos en el Museo de más de trescientas páginas, que se editó en 1927, con un tiraje de 10.000 ejemplares y que se ofrecía a la venta a 2 pesos el ejemplar rústico y a 3 pesos el encuadernado. Con lo recaudado por esta vía se procuraba generar recursos para las exploraciones. La Guía para visitar el Museo de La Plata, estaba dedicada a la memoria del fundador del Museo e incluía

\footnotetext{
102 Teruggi 1988.

103 Torres 1934.

${ }^{104}$ En los avisos de esta empresa publicados en los diarios de Buenos Aires, se anunciaba: "un día en La Plata. Excursión económica. Visita al Museo y exposición de avicultura. Boletos especiales de ida y vuelta....". Para la excursión dominical se ofrecían boletos de primera clase a precios reducidos o los pasajes más económicos de segunda clase. AHMLP, caja $n^{\circ} 21$. Véase también: García y Podgorny 2001.

${ }^{105}$ AHMLP, caja 30-Doc. $\mathrm{n}^{\circ} 7$. Esto, por ejemplo, se organizó para el ciclo de conferencias mensuales de 1926. Como parte de las actividades de extensión universitaria de ese año se anunciaron las siguientes conferencias, a cargo de Torres: "Resultado de las últimas exploraciones realizadas por el Museo de La Plata"; Angel Cabrera: "La Argentina como centro de dispersión"; Augusto Scala: "La yerba mate de cultivo en Misiones" (con proyecciones luminosas); Salvador Debenedetti: "Viaje arqueológico por las lagunas de Guanacache, en las provincias de Mendoza y San Juan" (con proyecciones luminosas); Horacio Arditi )profesor suplente de zoología): "Ranas y sapos"; Roberto Lehmann-Nitsche: " El altar mayor de Coricancha, templo del sol en el Cuzco" (con proyecciones luminosas); Miguel Fernández: "Influencia genética sobre problemas de la descendencia"; Walter Schiller: "Los yacimientos de minerales en la Argentina" (con proyecciones luminosas). En los años siguientes también se organizarían algunas conferencias y se publicarían en forma de folleto como parte de las actividades del Departamento de Extensión Universitaria de la Universidad platense que se creó a
} fines de la década de 1920. 
una reseña histórica de la institución y una descripción de las salas públicas y las reservadas a la investigación. Esto último fue escrito por los distintos jefes de departamento, bajo la coordinación del director del Museo y en general se tendió más a presentar las disciplinas científicas antes que los objetos exhibidos ${ }^{106}$. Asimismo, la iconografía de la institución se reforzó con la producción de tarjetas postales para los que visitaban las salas como para los que estaban distantes. Tanto la guía como las tarjetas se incluyeron en los canjes internacionales, se enviaron a las personas del interior del país que lo solicitaban, especialmente a las escuelas de la provincia de Buenos Aires, donde se había incorporado una referencia a la actividad del Museo de La Plata en sus programas de enseñanza. Además, al igual que la gestión anterior, se mantuvo la práctica de remitir colecciones de rocas y minerales, fragmentos de fósiles, aves y mamíferos embalsamados y reconstrucciones en yeso de la fauna fósil cuaternaria, a los museos escolares y locales de distintas partes del país. Esto, por otra parte, se vinculaba con el papel asignado al Museo de La Plata, como una centro nacional recopilador de información y colecciones desde donde luego se redistribuirían hacia las otras instituciones provinciales y regionales ${ }^{107}$. Asimismo, se promovió que la institución escolar se constituyera en un colaborador del Museo, remitiendo información sobre el descubrimiento de yacimientos de fósiles o restos arqueológicos y controlando que el "patrimonio nacional" no fuera expropiado por agentes no autorizados por los museos nacionales, a los cuales el Estado, por la ley 9080 y su reglamentación en 1921, les había encomendado la función de legislar sobre esos restos ${ }^{108}$.

Como ha señalado Irina Podgorny, el "regreso" al ideal del Museo como centro explorador y organizador de los estudios de historia natural se unió al culto de la

\footnotetext{
${ }^{106}$ Podgorny 2002.

107 García y Podgorny 2001.

${ }^{108}$ En 1927, por ejemplo, Torres agradecía a la Dirección General de Escuelas y a una docente por la información sobre restos fósiles. Además, desde la dirección del Museo se promovía la idea de generar una red de corresponsales a través de los inspectores escolares y maestros para recibir información sobre hallazgos y que se generara un cuerpo de "guardianes" o cuidadores locales de los yacimientos descubiertos, hasta que interviniera el personal autorizado del Museo. Para ello se repartió a los funcionarios escolares la reglamentación de la ley 9080 y se señaló a las autoridades de la Dirección de Escuelas de la Provincia de Buenos Aires: "este Museo quedará muy reconocido al Sr. Secretario si tiene a bien recomendar a los señores Inspectores, Maestros y Maestras que tan pronto tengan noticia de un hallazgo de esta índole, se sirvan comunicarlo/a este Museo, tomando las medidas necesarias para que nadie toque el yacimiento descubierto hasta que no haya intervenido el personal autorizado de este Instituto, de acuerdo a la ley 9080 y su Reglamentación, de la que me es grato adjuntar un ejemplar.....El Magisterio de la Provincia puede ser un auxiliar eficacísimo del Museo facilitando a la vez la labor que el Gobierno provincial le ha encomendado de verificar investigaciones en el territorio de la provincia de Buenos Aires....." AHMLP, Copiador 1926-1928, folio 239.
} 
figura de Francisco P. Moreno a través de la ambientación de una sala que remitía a una habitación privada y la instalación de un busto del fundador en la rotonda central que inauguraba la entrada al Museo. En el marco de los conflictos que atravesó su gestión, Torres buscó legitimar su propia posición como director del Museo, presentándose como el heredero y restaurador del designio original esbozado por Moreno. Con la ayuda del secretario del Museo, el periodista español Maximino de Barrio, se construyó un relato de las "tres épocas" del Museo, en la que la biografía del fundador se entrelazaba con la del Museo y tras una etapa de retroceso por haberse roto ese lazo, volvía a unirse espiritualmente en la nueva etapa inaugurada por Luis María Torres ${ }^{109}$.

La relativa autonomía que alcanzó el Museo de La Plata a partir de 1920 para trazar su propio programa institucional habla de la acción de su director pero también de la disolución de un proyecto universitario que coordinara y diera unidad a las distintas dependencias de la estructura universitaria. Torres logró configurar una amplia red de difusión del Museo, trasformándolo en un icono científico con una autoridad independiente de la Universidad, aunque no pudo evitar que los conflictos y vaivenes de la política universitaria se entremezclaran en la práctica de la ciencia. La cual, por otra parte, también estaría atravesada por los problemas propios del mundo del trabajo y del científico como asalariado. Como se intentó mostrar en este capítulo, la práctica científica implica una organización social del trabajo y la articulación con las prácticas culturales y de difusión vigentes en la época. A ello se sumaría la construcción de un pasado y una tradición que legitimara los proyectos del presente. Algunos investigadores, también buscarían legitimar sus prácticas científicas y extender la influencia de sus disciplinas a través los programas de enseñanza de nuevas generaciones de científicos y docentes para el sistema educativo, como se analiza en los siguientes capítulos.

${ }^{109}$ Barrio 1923. 


\title{
Capítulo V
}

\section{La formación universitaria en ciencias naturales}

\begin{abstract}
"en ciencias naturales, por ejemplo, aún esperan sucesores y continuadores los hombres eminentes que fundaron entre nosotros esa clase de estudios, porque sólo son excepciones los hombres jóvenes que se han consagrado á perpetuar sus tradiciones."1
\end{abstract}

La institucionalización de las ciencias se ha definido como la construcción de una serie de prácticas y discursos, cuyos elementos de mayor visibilidad son las instituciones científicas. En un sentido amplio, estas no sólo comprenden los institutos de investigación sino también un conjunto de dispositivos que posibilitan la reproducción ampliada de la práctica científica y su divulgación. De esa forma, tanto un museo, un laboratorio, una revista científica, comisiones de exploración o planes de estudio pueden ser considerados espacios institucionales, dentro de los cuales se manifiestan ciertos estilos de trabajo ${ }^{2}$. Asimismo, la consolidación de una determinada disciplina u orientación comporta tres aspectos interrelacionados: a) la articulación de ideas acerca de un campo de estudios; b) los espacios institucionales para la instrumentación material de dicho campo, y c) el entrenamiento de discípulos que desarrollen y difundan esa orientación ${ }^{3}$. A su vez, los conflictos que se suscitan alrededor de la instauración de determinado modelo de ciencia constituyen una de las formas en que se manifiesta la lucha por los espacios institucionales y la autoridad dentro del campo ${ }^{4}$.

En relación con ello, el objetivo de este capítulo es examinar las distintas propuestas y disputas en torno a la formación en ciencias naturales que se ofreció en el contexto del Museo de La Plata a partir de su incorporación a la Universidad Nacional de La Plata en 1906. Para ello se relevaron las modificaciones y continuidades presentes en los distintos planes de estudio de la carrera de ciencias naturales durante las primeras décadas del siglo XX, así como los programas y los

\footnotetext{
${ }^{1}$ Comentario del vicedirector del Museo de La Plata, Enrique Herrero Ducloux, en la segunda Asamblea General de Profesores de la Universidad platense. UNLP 1908: 23.

${ }^{2}$ Lopes 1999.

${ }^{3}$ Nyhart 1995, Winsor 1991, Clark 1991.
} 
informes sobre la enseñanza de las distintas cátedras. En general, la reforma de estos planes surgió por iniciativa de las autoridades académicas y de los mismos profesores, quienes consideraron que una renovación de la oferta educativa podría atraer una mayor cantidad de estudiantes interesados por estos estudios "desinteresados". Los proyectos para modificar los planes de estudios y las orientaciones generales de esta carrera generaron importantes discusiones en torno al perfil de los egresados en ciencias naturales que se consideraba "viable" y "útil" para la Argentina. En ese marco, hubo enfrentamientos entre lo que se percibía como un "modelo extranjero", dentro del cual se promovía la especialización y un entrenamiento en el trabajo de laboratorio, frente a las "necesidades nacionales" de naturalistas con una preparación general en las distintas áreas de las ciencias naturales. A partir de esos debates, se procuró identificar los procesos de selección, organización y jerarquización de conocimientos presentes en las ofertas educativas de ciencias naturales y en las distintas orientaciones que se insinuaron durante las primeras dos décadas de funcionamiento de la Facultad de Ciencias Naturales, luego Escuela Superior de Ciencias Naturales.

Si bien un plan de estudios o un programa analítico puede reflejar la organización institucional de una disciplina en un momento dado, durante su aplicación se generan continuas negociaciones y resignificaciones a partir de las acciones concretas de los sujetos que intervienen en ese proceso. En los últimos años, el estudio del "curriculum" ha atravesado una serie de discusiones importantes en torno a su objeto. Como producto de estos debates, se amplió el sentido que se asignaba históricamente al término y se han revisado los paradigmas de comprensión de las prácticas educativas. Una cuestión relevante que se desprende de los nuevos análisis, es la diferenciación entre el "documento curricular" o plan de estudios y el proceso de desarrollo del curriculum ${ }^{5}$. El primero se asocia a un momento inicial en el cual se define un conjunto de reglas y normas, mediante las cuales se delimitan los requisitos de formación y acreditación de los sujetos, y al mismo tiempo, se propone un modo de organizar un conjunto de contenidos y prácticas para enseñar. En la determinación de los contenidos mínimos y las "normas óptimas" de formación se producen enfrentamientos y procesos de negociación entre distintos actores que

\footnotetext{
${ }^{4}$ Bourdieu 1984, 1994,1999.

${ }^{5}$ La reflexión sobre el curriculum ha generado numerosos trabajos en los últimos años, entre otros se pueden mencionar: Kemmis 1980; Goodson 1991, 1995; Alba 1995; Argumedo 1999.
} 
luchan por imponer una definición válida de saber científico. A su vez, este "curriculum propuesto" no se mantiene como algo inmutable, sino que se actualiza en las prácticas concretas de los sujetos y da lugar a lo que se denomina el "curriculum real". A ello, se suma el llamado "curriculum oculto" en referencia a un conjunto de actitudes, valores, disposiciones y prácticas que se trasmiten implícitamente mediante los vínculos institucionales, las identidades profesionales, las relaciones docentealumno, entre otros factores que interactuan en el proceso de enseñanza-aprendizaje.

En particular, en este capítulo se procura examinar la organización de la enseñanza de las ciencias naturales a partir de los siguientes problemas: a) el reclutamiento de estudiantes y las posibilidades laborales para los diplomados en ciencias naturales, b) los distintos estilos y orientaciones de trabajo científico que se promovieron a través de las clases prácticas, c) los lugares considerados centrales para transmitir los procedimientos y técnicas de investigación; d) las tensiones entre procurar una formación general o especializada, e) los debates en torno a la definición del perfil del egresado en ciencias naturales y la propuesta formativa en el marco de las luchas de poder y espacios institucionales.

\section{1. La carrera de ciencias naturales en la Argentina}

Durante el siglo XIX, algunas asignaturas de historia natural formaron parte de la preparación científica de médicos y farmacéuticos, pero sería con la creación del Departamento de Ciencias Exactas en la Universidad de Buenos Aires en 1865, cuando la enseñanza de las ciencias naturales y exactas comenzaría a adquirir un mayor impulso ${ }^{6}$. Diez años después, se estableció el primer plan de estudios para el doctorado en ciencias físico- naturales. Sin embargo, estos estudios no contarían con una inscripción regular de alumnos hasta principios del siglo XX. Según Jorge Myers, entre 1870 y 1902 se diplomaron 307 ingenieros frente a cinco doctores en ciencias fisico-matemáticas, tres en ciencias naturales y dos en química, que obtuvieron el título de doctor más por sus actividades extracurriculares que como culminación de un

\footnotetext{
${ }^{6}$ Sobre la creación del Departamento de Ciencias Exactas de la Universidad de Buenos Aires, véase entre otros: Besio Moreno 1915, Babini 1963; 1949; Halperin Donghi, 1962; Myers 1994; Montserrat 1993 Para la historia de las enseñanza de las ciencias naturales, véase especialmente Camacho 1971.
} 
entrenamiento regular y una tesis doctoral de investigación ${ }^{7}$. Durante esos años se continuaron renovando los programas de estudio en ciencias naturales pese a la baja o casi nula atracción de estudiantes, que preferían seguir carreras con mayor prestigio social o que ofrecieran perspectivas laborales más amplias, como se señaló en el primer capítulo. Por otra parte, hasta el siglo XX, las alternativas en el campo científico estuvieron enmarcadas entre un vacilante y esporádico apoyo a las instituciones estatales y una cierta condición de "gentleman-scientist", que debía contar con sus propios recursos y/o algún tipo de patronazgo o relaciones políticas ${ }^{8}$.

En la década de 1870, también en la Universidad de Córdoba se organizaron planes de estudio para los títulos de doctor en varias disciplinas científicas y para formar profesores en ciencia en el marco de la modernización institucional y organización de la actividad científica impulsada desde el gobierno nacional. Para establecer la Facultad de Ciencias Físicas y Matemáticas, que debía tener agregada una Academia de Ciencias Exactas, se contrataron investigadores alemanes y se procuró la organización de varios museos con colecciones para la ilustración de las clases y como espacio de trabajo para los profesores $^{9}$. En sus inicios, esta Facultad centró sus actividades en torno a las materias de ciencias naturales y exactas, pero frente a los pocos alumnos que se inclinaron por estos estudios, se generó una situación que hizo peligrar la supervivencia de la institución, ya que la afluencia de estudiantes no se correspondía con la cantidad de locales, cátedras y personal que se disponía. De hecho, el título académico de doctor en ciencias naturales se entregó a un sólo estudiante como certificación de estudios ${ }^{10}$. Al mismo tiempo, al igual que las facultades o escuelas de ciencias de otros países ${ }^{11}$, también se incluyó la formación de

\footnotetext{
${ }^{7}$ Myers 1992.

${ }^{8}$ Myers 1992; Podgorny 2000.

${ }^{9}$ Después de varios conflictos en la organización de estas instituciones, la Academia quedó como una corporación científica con una cierta autonomía con respecto a la Universidad, aunque compartiendo el mismo personal. Besio Moreno 1915; Tognetti 2000.

${ }^{10} \mathrm{El}$ primero en obtener el título de doctor en ciencias naturales fue el sanjuanino Saile Echegaray, discípulo del botánico Hieronymus, pero que al parecer dejó la ciencia para dedicarse a la política. Hicken 1923, Tognetti 2000.

${ }^{11}$ En la misma época, en Francia se procuraron distintas medidas para fortalecer la actividad de las Facultades de ciencias. Entre ello se suprimieron las cátedras de química e historia natural de las Escuelas preparatorias de Medicina y se estableció que los alumnos de estas últimas debían cursar previamente esas materias en las Facultades de ciencias. En el caso de algunas Facultades de provincia hacia el final del siglo, diversificaron sus enseñanzas y se reorientaron hacia la investigación aplicada a las industrias locales y la agricultura. Weisz 1983. En Colombia, por ejemplo, en la Escuela de Ciencias Naturales de Bogotá la carrera de ciencias naturales, orientada hacia la explotación minera y agrícola, contó con muy pocos alumnos y varias cátedras se mantuvieron por la asistencia de los estudiantes de medicina e ingeniería. La situación de la Escuela de Ciencias Físicas y Naturales de Antioquía no fue muy diferente. Bencerra Ardilla y Restrepo Forero 1993.
} 
los aspirantes al profesorado, la preparación científica básica para los alumnos de la Facultad de Medicina creada 1878, y los estudios de agrimensura e ingeniería ${ }^{12}$. Paulatinamente, las cátedras para el entrenamiento profesional fueron adquiriendo cada vez más peso en el desenvolvimiento de la institución ${ }^{13}$. Unos años después, al igual que la Facultad de Ciencias Exactas de Buenos Aires, la enseñanza universitaria de la Facultad cordobesa giro en torno a la formación de ingenieros. De hecho, hacia 1900, y en los años siguientes, los planes de estudios que se organizaron sólo hacían referencia a distintas orientaciones de ingeniería ${ }^{14}$. Si bien en los siguientes años las memorias oficiales de esta Universidad mencionaban la inscripción de alumnos libres en cursos de ciencias naturales no hay registros de egresados o diplomados en estas disciplinas, hasta que se reorganiza nuevamente la carrera en la década de 1920.

A fines del siglo XIX, se comenzó ampliar considerablemente el nivel medio y especial de educación, favoreciendo la difusión de las ciencias y la apertura de nuevos espacios laborales. No sólo se crearon nuevos establecimientos secundarios sino también se aumentaron las horas y materias de enseñanza científica, posibilitando un mayor campo laboral para los que se interesaban por el estudio de la naturaleza. En esa época, el ejercicio docente en los colegios secundarios gozaba de prestigio y los cargos de profesor en ciencias naturales en esos establecimientos fueron ocupados preferentemente por universitarios con formación en medicina o ingeniería ${ }^{15}$. En el interior, algunos naturalistas amateurs encontraron un espacio de inserción institucional en las escuelas normales y otras instituciones provinciales. En la Capital Federal, las cátedras del Colegio Nacional central y la Escuela Normal de Profesores serían desempeñadas por los mismos que enseñaban en la Universidad. Desde esos establecimientos, profesores como Eduardo L. Holmberg (1852-1937) comenzaron a renovar los métodos de enseñanza y a incentivar entre los estudiantes el interés por las ciencias naturales y la observación de la naturaleza ${ }^{16}$.

Hasta las primeras décadas del siglo $\mathrm{XX}$, los estudios y diplomas que acreditaban competencia en ciencias naturales atrajeron muy pocos estudiantes, los

\footnotetext{
12 Véase al respecto el folleto con los estudios ofrecidos en esa Facultad: Facultad de Ciencias FísicoMatemáticas 1883.

${ }^{13}$ En la década de 1890 también se pensó en ofrecer la orientación en Ingeniería en Minas, pero esto estaba supeditado a la creación de algunas cátedras. En 1894 se incorporó Metalurgia y explotación de minas y se elevó un proyecto de creación de un Departamento Nacional de Industrias y Minería. Véase: Castellanos 1892, 1894.

${ }^{14}$ Besio Moreno 1915.

15 Tedesco 1986, Pinkasz 1992

${ }^{16}$ Hicken, 1923.
} 
cuales generalmente disponían de otra profesión. En 1902, se doctoró el ingeniero Angel Gallardo (1867-1934), constituyendo el primer diplomado de la Escuela de Ciencias Naturales de la Universidad de Buenos Aires, y un año después, el agrimensor Carlos Hicken (1875-1933). Ambos se desempeñarían posteriormente como profesores en colegios nacionales y en la Universidad. Paralelamente, en 1903 se renovó el plan de esa carrera otorgando mayor peso a las disciplinas comprendidas dentro del campo de las ciencias naturales en detrimento las asignaturas de matemáticas y física, a las que se les dio un carácter introductorio. Asimismo, se introdujeron nuevos cursos como microbiología y petrografía ${ }^{17}$. En esa época, Gallardo comenzó a participar como profesor, promoviendo un cambio en la enseñanza de la zoología con la introducción de "trabajo prácticos", que comprendieron observación, disecciones de especimenes o preparados microscópicos y dibujos de lo observado por parte de los alumnos. Según este profesor, la modalidad de enseñanza predominante hasta esa época había consistido en el dictado de cuadros y claves de clasificación con la indicación de las especies principales, con un bosquejo de la anatomía, fisiología y "costumbres" de algunos representantes de cada grupo y una mención de las principales fuentes bibliográficas. Todo ello era presentado en forma oral por el profesor, quien a veces recurría a colecciones para ilustrar la lección, sin que los alumnos realizaran ejercicios prácticos ${ }^{18}$. También para renovar la enseñanza de esta disciplina, obtener ejemplares frescos para los ejercicios prácticos y fomentar los estudios marinos, Gallardo apoyó los planes de creación de una Estación Marina en Mar del Plata, bajo la administración de la Universidad porteña, como las que existían en Europa, Estados Unidos y Japón ${ }^{19}$. En la Argentina, esto había comenzado a ser promovido por el zoólogo francés Fernando Lahille (1861-1940) desde 1894, quien también realizaría una importante campaña de difusión de los estudios zoológicos ${ }^{20}$. En las siguientes décadas, varios naturalistas y zoólogos

\footnotetext{
${ }^{17}$ Besio Moreno 1915; Camacho 1971.

${ }^{18}$ Gallardo 1907. Véase también: Camacho 1971.

${ }^{19}$ Gallardo 1906.

${ }^{20}$ Fernando Lahille nació en Toulouse y en 1891 se doctoró en ciencias naturales en París y un año después en medicina. Desde 1884 y por varios años trabajó en las estaciones marinas de Bayuls y Roscoff. Su primer trabajo fue sobre fisiología experimental con tunicados y luego estudio otros aspectos de ese grupo. Fue preparador y luego profesor en la Facultad de Ciencias de Toulouse hasta que se traslada a la Argentina en 1893. Trabajó seis años en el Museo de La Plata como encargado de la Sección Zoología, dejando establecidas las bases de una estación marítima en Punta Mogotes. En 1899 se incorpora al recién creado Ministerio de Agricultura, como Jefe de la División Caza y Pesca y posteriormente en la de Zoología Aplicada hasta su retiro en 1930. Fue profesor en la Escuela Normal de Profesores de la Capital desde 1904 y en la Facultad de Agronomía y Veterinaria en la Universidad
} 
continuaron insistiendo en la creación de una estación biológica en las costas argentinas.

En la transición del siglo XIX al XX, una estadía en un laboratorio o estación marina como las francesas, la de Nápoles o Woods Hole en Estados Unidos, constituía un paso casi obligado en la trayectoria formativa de zoólogos y biólogos, tanto por motivos intelectuales como profesionales y sociales ${ }^{21}$. Como señala Pamela Henson, estas instituciones funcionaron como clubes científicos o campamentos de verano, permitiendo la articulación de relaciones informales importantes para el progreso de una carrera y el ingreso en el pequeño grupo de especialistas de distintos países ${ }^{22}$. Además, esos establecimientos contaban con todos los instrumentos, materiales y bibliotecas especializadas para el entrenamiento y desarrollo de investigaciones en las formas de vida marina. Por otro lado, a partir del estudio de invertebrados marinos se articularon importantes líneas de investigación biológica en embriología, anatomía microscópica y ciclos de vida, entre otros temas cuyo lugar de construcción de conocimiento se ubicaría en torno al laboratorio. Con la expansión internacional de estas disciplinas en el contexto universitario, aparecería, entonces, el laboratorio como el lugar central para la enseñanza y entrenamiento práctico, y junto a ello, otras formas de organización social de la práctica científica, que difería de las disciplinas museológicas $^{23}$ o de los estudios del "campo"24. Como se examina más adelante, en la formación ofrecida en ciencias naturales en el Museo/Facultad de Ciencias Naturales de La Plata coexistirían estas distintas orientaciones. En particular, el entrenamiento en el trabajo de laboratorio predominaría principalmente en los estudios zoológicos durante las décadas de 1910 y 1920. En esa época, la mayoría de los estudiantes de ciencias naturales de esta institución se orientarían hacia esta disciplina.

La carrera de ciencias naturales en La Plata, al igual que en la Universidad de Buenos Aires, contó con un número muy bajo de estudiantes durante las primeras dos décadas del $\operatorname{siglo}^{25}$. En el primer caso, la inscripción anual total fluctuó entre uno y

\footnotetext{
de Buenos Aires. Lahille dictó conferencias y escribió varios artículos en La Nación y en publicaciones científicas promocionando los estudios marinos y su aplicabilidad para la industria pesquera y la colonización de los territorios costeros del sur. Véase entre otros, Lahille 1898, 1907. Si bien hubo un decreto del Gobierno de la Provincia de Buenos Aires favorable a ese proyecto y una donación particular de un terreno para una Estación Marítima provincial en Punta Mogotes, como dependencia del Museo de La Plata, esto quedaría abandonado.

${ }^{21}$ Véase, entre otros: Benson 1988; Maienschen 1989 y Winsor 1991.

${ }^{22}$ Henson, 2000.

${ }^{23}$ Pickstone 1993, 1994.

${ }^{24}$ Podgorny 2002b.

${ }^{25}$ Véase tabla en el Anexo.
} 
diez alumnos hasta 1920 y en la siguiente década se mantendría entre once o doce estudiantes matriculados. Además, fue frecuente la presencia de uno o dos "oyentes" en algunos cursos y en trabajos de laboratorio de zoología ${ }^{26}$. Es interesante destacar, el alto porcentaje de alumnas que se interesaron por las distintas carreras que dependían del Museo/Facultad ${ }^{27}$. De hecho, en 1917, la matriculación femenina alcanzaba el 38 $\%$ del total de estudiantes en las distintas carreras de dibujo, ciencias naturales, farmacia y química de esta Facultad ${ }^{28}$. En el caso de ciencias naturales, el porcentaje era aún más elevado y, además, se destacaron por obtener las mejores calificaciones. Entre 1906 y 1930, la inscripción de mujeres alcanzó el 48 \% de los 46 estudiantes regulares y una proporción similar se mantuvo entre los que alcanzaron el doctorado entre 1912 y $1932^{29}$. De hecho, el primer alumno en terminar la licenciatura en ciencias naturales, junto con el profesorado, fue Carolina E. Spegazzini en 1910, quien además estudiaría farmacia y completaría el doctorado en química en 1918. Hija del profesor de botánica, Carlos Spegazzini, fue nombrada ayudante en 1907, publicaría algunos trabajos de investigación en laboratorio y de química analítica, y luego de doctorarse sería ascendida a jefe de trabajos en la Facultad de Química y Farmacia. También en la Escuela de Ciencias Naturales de Buenos Aires, un cierto aumento en la matriculación general se debió a la concurrencia femenina, doctorándose las primeras en 1912: Juana Dieckmann, Axa y Lía Acevedo. La primera se dedicaría a la

\footnotetext{
${ }^{26}$ Como se señaló en capítulos anteriores, en la Universidad Nacional de La Plata se aceptaron alumnos en calidad de oyentes como una forma de realizar la extensión universitaria. En el Museo, se permitió que asistieran tanto a clases teóricas como a trabajos prácticos y de laboratorio. Algunos de los alumnos oyentes que se ha podido identificar eran maestros, personal técnico inferior del Museo u estudiantes universitarios.

${ }^{27}$ Como se mencionó en el primer capítulo, la concurrencia femenina en los estudios de farmacia se manifestaba desde la época de la Universidad Provincial. Entre ellas, María Luisa Gutiérrez, continuó los estudios de ciencias naturales y del doctorado en la Escuela de Química y Farmacia. En otros casos, la matriculación en las carreras científicas fue posible para aquellas que contaban con el título de bachiller del Colegio Nacional de La Plata. Cuando este Colegio se incorporó a la Universidad se separó la enseñanza de las mujeres, creándose para ellas el Colegio Secundario de Señoritas, que otorgaba el diploma de bachiller. Otras ingresaron al Museo tras haber realizado estudios en la Sección Pedagógica, que aceptaba a las egresadas de las escuelas normales. En 1907, se permitió la inscripción de maestras normales en la Escuela de Geografía y posteriormente en la carrera de Farmacia. Una tercera vía de acceso a los estudios universitarios, se abrió en 1913 cuando la Facultad de Agronomía y Veterinaria aceptó, previó examen de ingreso, el ingreso de personas que no tenían certificado de estudios secundarios. En dos casos, por lo menos, alumnas que habían sido admitidas como regulares en aquella Facultad, pidieron el traspaso y reconocimiento como tal al Museo y paralelamente una beca de estudio.

${ }^{28}$ Lafone Quevedo: 1918.

${ }^{29}$ De los 46 alumnos registrados hasta 1930, 18 se doctoraron en esos años. El porcentaje de mujeres que obtuvo ese título en el Museo fue del 44, $4 \%$. Si se tiene en cuenta, que además dos alumnas presentaron sus tesis en Córdoba, el porcentaje de las doctoradas alcanza una cifra similar que la registrada entre los estudiantes. Véase cuadro con los primeros alumnos de ciencias naturales en el Museo de La Plata en el Anexo
} 
docencia en establecimientos de educación media y a escribir artículos de divulgación científica $^{30}$.

En el Museo de La Plata, varios alumnos cursaron de forma simultánea o posteriormente los estudios de ciencias naturales, farmacia o el doctorado en química, ya que esas carreras tenían varias materias en común. En algunos casos, asistieron a cursos de ciencias naturales para completar la formación exigida para el diploma de profesor de enseñanza secundaria que otorgaba la Sección Pedagógica de la Universidad platense, tema que se analiza en el siguiente capítulo. En esos años, el título de doctor en ciencias naturales no aportaba ninguna prerrogativa especial para ocupar un empleo ni ofrecía demasiadas perspectivas laborales ${ }^{31}$. En ciertas reparticiones públicas e instituciones educativas debieron competir con egresados de la Facultad de Agronomía y Veterinaria o Medicina. Por otra parte, los cargos docentes o de auxiliares de trabajo en la universidad tampoco aumentaron en la medida en que la cantidad de estudiantes era sumamente baja con relación a otras carreras. En 1907, frente a ciertas críticas por el perfil profesional de la Universidad de Buenos Aires, Angel Gallardo argumentaba que esta institución se había preocupado por contratar profesores extranjeros y organizar la enseñanza científica, sin que los estudiantes se interesaran en ello ${ }^{32}$. Una década después, Miguel Fernández, profesor de zoología en La Plata, indicaba que el problema principal no estribaba en las instituciones universitarias sino en las condiciones sociales desfavorables para la inserción profesional de los doctores en ciencias naturales y los pocos medios de vida que ofrecía esa carrera. Como se analiza en el siguiente capítulo, este profesor intentaría promover que los diplomas de doctor en ciencias gozaran de las mismas prerrogativas que los de profesor para acceder a cargos docentes en establecimientos secundarios y al mismo tiempo, otorgar competencia técnica a las Facultades científicas en la formación del magisterio secundario.

\footnotetext{
${ }^{30}$ Hicken 1923.

${ }^{31}$ En 1961, Juan José Nágera, doctorado en la Universidad de Buenos Aires en 1916, recordaba en el cincuentenario de la fundación de la Asociación Argentina de Ciencias Naturales, el poco reconocimiento que tenía la carrera de ciencias naturales en la década de 1910 y que muchos aconsejaban seguir carreras liberales, mientras otros mencionaban la falta de libertad que tendrían en sus investigaciones científicas si trabajaban en alguna repartición publica, al tener de jueces a personas ajenas a la Historia Natural. Nágera 1962. También Angel Bianchi Lischetti, en esa celebración, rememoraba que después de recibirse de farmacéutico y comenzar a estudiar ciencias naturales: "el maestro Hicken al iniciar mis estudios, me preguntó si estaba enterado que la carrera de Ciencias Naturales no era de porvenir material y si contaba con otros medios de vida. Al responderle, que ya contaba con una carrera universitaria práctica, exclamó: ¡Ah, bueno ahora me quedo más tranquilo!". Bianchi Lischetti 1962: 118.
} 
En 1911 un grupo de estudiantes y doctores en ciencias naturales principalmente de Buenos Aires y algunos de La Plata, formaron una asociación dedicada al fomento de las ciencias naturales llamada Sociedad Physis, posteriormente Sociedad Argentina de Ciencias Naturales. Entre los primeros objetivos, figuraba la defensa y valoración del título académico, aunque el mismo no se requirió para ser miembro de esa asociación. Asimismo, hubo una preocupación por promover la enseñanza universitaria de ciencias naturales, aunque sólo en el ámbito de la Facultad de Ciencias Exactas de Buenos Aires, gestionando para ello premios y becas de estudio. Esta Sociedad se dedicó principalmente a organizar secciones de discusión y la publicación de notas científicas para un público conformado por especialistas en las distintas áreas que se reconocían como parte de las ciencias naturales: geología, mineralogía, paleontología, zoología, botánica, antropología y arqueología. En ese sentido, se definió un perfil netamente científico antes que profesional o gremial. Colectivamente no hubo una preocupación por monopolizar una determinada área de aplicación de las ciencias naturales o delimitar incumbencias para un despeño profesional como realizaron los centros de estudiantes o asociaciones similares de otras disciplinas.

En esa época, el campo laboral para los graduados en ciencias naturales comenzaba a ofrecer nuevas posibilidades tanto en el ámbito docente al crearse nuevas instituciones de enseñanza, como en distintos dependencias públicas de ciencias aplicadas. Entre ellos se destacaron los distintos laboratorios y secciones del Ministerio de Agricultura creado en 1898. En varias de esas dependencias se establecieron cargos de ayudantes y naturalistas viajeros, cuyo acceso hacia fines de la década de 1910 se comenzó a restringir a los que poseían una acreditación universitaria. En el campo de las ciencias geológicas, Horacio Camacho ha enfatizado en la importancia que tuvo la División de Minas, Geología e Hidrología, creada en 1905, y especialmente bajo dirección de Enrique Hermitte desde 1907 ${ }^{33}$. Este ingeniero en minas también se desempeñó como profesor en la Facultad de Ciencias Exactas, Físicas y Naturales de Buenos Aires y desde allí fomentaría la incorporación de algunos estudiantes en la repartición que él dirigía, para especializarlos en petrografía y geología junto a los investigadores extranjeros que trabajaban en esa

\footnotetext{
32 Gallardo 1907.
}

${ }^{33}$ Camacho 2001. 
División $^{34}$. Esta política generó que en la Universidad de Buenos Aires se formaran los primeros doctores en ciencias naturales dedicados a las ciencias geológicas durante la década de $1910^{35}$. En cambio en el Museo de La Plata, si bien hubo algunos interesados por esas disciplinas y varios estudiantes solicitaron su inscripción en la especialización en geología y mineralogía, ninguno terminó el doctorado en ciencias naturales hasta la década de $1930^{36}$. No obstante, algunos estudiantes de química eligieron a profesores de geología para que los dirigieran en tesis sobre análisis químicos y petrográficos. Entre 1912 y 1932 se registraron dieciocho tesis doctorales en ciencias naturales en La Plata, entre las que predominado las dedicadas a las investigaciones zoológicas, incluyéndose en ellas a los estudios de fauna fósil. En ese primer período, también se registraron dos tesis en antropología y tres en botánica y en 1932 la primera en geología y mineralogía. En los siguientes apartados, se analiza la organización de la enseñanza, los distintos planes de estudios y los perfiles de ciencia que se promovieron en el área de ciencias naturales dentro del Museo de La Plata.

$\underline{\text { V. 2. La organización de la enseñanza de las ciencias naturales en el Museo de La }}$ Plata

El plan de estudios de ciencias naturales fue una de las primeras cuestiones debatidas en las secciones preliminares del Consejo Académico del Instituto del Museo. Para organizar el plan general de estudios que regiría en la futura Facultad se dividieron las tareas entre los profesores y jefes de secciones. Para los estudios de ciencias naturales, el antropólogo alemán Roberto Lehmann-Nitsche propuso los títulos de licenciado y doctor, y presentó un plan de estudios elaborado conjuntamente con los geólogos Santiago Roth y Walter Schiller, que dividía el año en semestres

\footnotetext{
${ }^{34}$ En 1910 se contrataron a los estudiantes Elías Pelosi y Franco Pastore como Geólogos de Segunda. Posteriormente ingresaron: Juan José Nágera en 1912, y José María Sobral en 1914, quien hasta ese momento había estado becado por el Gobierno argentino para estudiar en la Universidad de Uppsala. Camacho 2001.

${ }^{35}$ Los primeros graduados en ciencias naturales con tesis vinculadas a las ciencias geológicas fueron: Franco Pastore doctorado en 1914, Juan José Nágera, en 1916 y Edelmira Mórtola en 1921, quien realizó un estudio sobre rocas alcalinas básicas de Chubut recolectadas por el geólogo alemán Juan Keidel en 1917. Camacho 2001.

${ }^{36}$ En estos años, Yacimientos Petrolíferos Fiscales realizó una importante campaña de promoción de las ciencias geológicas, y, junto a otras compañías norteamericanas, patrocinó becas de estudio y aseguró la contratación de graduados. A partir de esa época, como ha señalado, Mario Teruggi, la formación de geólogos experimentó un "período de eclosión". En los siguientes veinte años, entre 1935 y 1958, se aprobaron 159 tesis doctorales en la orientación de ciencias geológicas. Teruggi 1977.
} 
como en las universidades alemanas ${ }^{37}$. Por su parte, Florentino Ameghino criticó este proyecto e insistió en una ordenación de materias por año y un plan que no excediera los cinco años ${ }^{38}$. Su propuesta contemplaba una primera etapa de estudios complementarios, introductorios y generales, equivalente a un ciclo preparatorio, promovido también por el director del Museo, Samuel Lafone Quevedo. El segundo y tercer año, comprenderían cursos especiales y avanzados, mientras que en el cuarto año, se dictarían las mismas materias pero referidas a la República Argentina. El último año estaría dedicado a cursos prácticos. Según las actas del Consejo Académico, el arqueólogo Luis María Torres también presentó un plan de estudios, pero finalmente se tomó como base la propuesta de los profesores alemanes. Sobre esta última se realizaron varias modificaciones siguiendo las indicaciones de Ameghino. Entre ellas, se incluyeron las materias de complementos de física, química y matemáticas en primer año, a pesar del voto en contra de Lehmann-Nitsche. Por unanimidad se establecieron cinco años de estudios divididos en dos ciclos. El primero comprendía veinte materias distribuidas en tres años y permitía obtener el título de licenciado. El segundo ciclo estaba proyectado para el doctorado y abarcaba un cuarto año con seis materias dedicadas al estudio de la Argentina y un quinto año, en el cual, los alumnos vigilados directamente por sus respectivos profesores, debían realizar estudios especiales y excursiones ${ }^{39}$.

Este plan fue rápidamente aprobado por todas las instancias oficiales sin sufrir modificaciones. En total, la formación exigida para el doctorado en ciencias naturales comprendía veintiséis materias. Las asignaturas específicas de dictadas por los profesores de la Escuela de Ciencias Naturales, incluían varios cursos cada una: cuatro de botánica, dos de paleontología, cuatro de zoología, tres de geología, dos de petrografía y mineralogía, dos de antropología, dos de etnología, uno de los cuales incluía un complemento de lingüística. Además, en los primeros años del plan se exigían otras materias que se cursaban por correlación: dos correspondían a

\footnotetext{
${ }^{37}$ Lehmann-Nitsche 1906. En esa nota señalaba que sólo él y Schiller habían cursado sistemáticamente estudios regulares en las universidades alemanas hasta terminarlos con el título de doctor, y junto con Santiago Roth, que había realizado estudios como "alumno libre" en Suiza, eran los únicos que conocían a fondo la organización y métodos de enseñanza de las mejores universidades del mundo. La propuesta era dividir el año lectivo en semestres con vacaciones en el medio. La misma idea también sería presentada en la Universidad de Buenos Aires, en donde fue aceptada en noviembre de 1906. En la Universidad platense, esta propuesta no fue oficializada, aunque los cursos dependientes de estos profesores se organizaron de forma semestral como se señaló en el capítulo anterior.

${ }^{38}$ Las discusiones sobre la organización de los planes de estudio se pueden seguir en: AHMLP, Actas del Consejo Académico, Libro I, folios 5-7.

${ }^{39}$ Véase: Planes de estudio en el Anexo.
} 
asignaturas dictadas la Facultad de Ciencias Físicas y Matemáticas (complementos de física y de matemáticas) y cuatro a otras Escuelas del Museo: complementos de química (aunque también se exigió química analítica), geografía física y dos cursos de dibujo. Si bien se había establecido dibujo natural, un conocimiento muy apreciado en la práctica de naturalista, no se organizó un curso especial para los alumnos de ciencias naturales, quienes durante los primeros años asistieron a los cursos de dibujo geométrico y topográfico que se organizaron para los estudiantes de otras carreras.

Tanto en La Plata como en Buenos Aires, se proyectó para el egresado en ciencias naturales un perfil científico vinculado a la práctica del naturalista, en tanto persona que dominaba las distintas áreas de conocimiento de la naturaleza y de la historia natural del hombre ${ }^{40}$. Sin embargo, en la formación exigida en Buenos Aires se incluyó una asignatura de microbiología y muchas más horas y cursos dedicados a ciencias exactas. En cambio, las materias relacionadas con el estudio del hombre constituyeron una peculiaridad de la formación del naturalista propuesta en La Plata. En el plan vigente hasta 1906 en Buenos Aires no incluía estos temas, aunque al año siguiente se reemplazó el cuarto curso de zoología por uno de geografía y otro de antropología, que por falta de fondos para nuevas cátedras se derivó a los alumnos a las asignaturas correspondientes de la Facultad de Filosofía y Letras de la Universidad de Buenos Aires. En esa Facultad, se habían establecido las primeras cátedras de ciencias antropológicas en la Argentina, que estaban a cargo de los mismos profesores que trabajan en el Museo de La Plata. En efecto, en 1898 se creó la cátedra de Arqueología Argentina y como profesor se nombró a Lafone Quevedo. En 1903, Lehmann-Nitsche organizó un curso libre de antropología y al año siguiente uno de paleoantropología, que sentaron las bases para la fundación de la cátedra de antropología en 1905, la cual sería ocupada por este profesor ${ }^{41}$.

En la Facultad de Ciencias Naturales de La Plata, Lehmann Nitsche asumiría como profesor titular de Antropología, y al igual que en Buenos Aires, dictaría esta asignatura "desde el punto de vista del naturalista". Esto, según la clasificación seguida de Emil Schmidt de 1897, implicaba el estudio descriptivo y comparativo,

\footnotetext{
40 Teruggi 1988.

${ }^{41}$ Para la selección del profesor titular, la Facultad elevó una terna al Ministro de Instrucción Pública, quine nombró Florentino Ameghino, aunque este renuncio inmediatamente. A partir de una segunda terna fue elegido Lehmann-Nitsche.
} 
tanto físico como psíquico, del género humano ${ }^{42}$. En relación con ello, señalaba dos tendencias: a) la comparación de la posición de hombre en el mundo orgánico con respecto a los animales, y b) la comparación de los individuos del género humano entre sí. Un programa que también se intentaría reflejar en las salas de exposición del Museo. La asignatura de Antropología se dictó por primera vez en el Museo en 1907, dividida en dos cursos semestrales. En el primero los estudiantes de ciencias naturales fueron invitados a asistir a las clases de Anatomía Artística, dictadas también por este profesor, para los alumnos de dibujo ${ }^{43}$. Estas clases estuvieron destinadas al estudio de la osteología y en el segundo semestre se orientaron hacia la miología. Además, para alumnos de la materia de Antropología, en el segundo semestre dictó un curso de antropología zoofísica, estudiando el cuerpo humano de forma comparativa entre las distintas razas y con respecto a otros vertebrados. Se había proyecto dividir los cursos entre el profesor titular y el adjunto, el sanjuanino Desiderio Aguiar, encargado de la parte de antropología psiquíca $^{44}$, pero este profesor pidió licencia en 1908 y finalmente su cargo fue suprimido del presupuesto universitario. El dictado esta materia quedó enteramente a cargo de Lehmann-Nitsche hasta su jubilación en 1930, cuando retornó a Alemania. A partir de 1922, la cátedra de antropología también se

\footnotetext{
${ }^{42}$ Lehmann- Nitsche 1899, 1921. Este investigador seguía la clasificación E. Schmidt de 1897, según la cual el estudio del género humano se dividía en dos procedimientos: a) naturalista: que abarcaba las manifestaciones físicas del género humano (antropología física o somática), el hombre como especie y las diferencias con los animales (antropología zoológica), el estudio descriptivo y comparativo de las razas (phylografía y phylología), las manifestaciones intelectuales y sociales del género humano, el estudio de los pueblos, (antropología étnica) con el estudio descriptivo (etnografía) y de las leyes de la vida intelectual (etnología); y b) el histórico: que estudiaba las etapas anteriores e inferiores del género humano (antropología histórica o prehistoria). En un programa de 1906, Lehmann Nitsche definió la antropología como: "el estudio fisico y psíquico de género humano bajo el punto de vista comparativo (comparación de los demás vertebrados, comparación de las diferentes razas humanas entre si). Resultan por consiguiente cuatro grandes divisiones: Ia Antropología zoofísica, IIa Antropología phylofísica, Ib Antropología zoopsíquica, IIb Antropología phylopsíquica. Lehmann- Nitsche 1921: 8. ${ }^{43}$ En su informe sobre la enseñanza, Lehmann-Nitsche señaló que al curso de anatomía artística concurrieron 28 alumnos de dibujo, que demostraron gran interés por la materia, y cuatro de ciencias naturales. Asimismo, indicó que en general se sintió conforme por el interés demostrado por los alumnos y el nivel de los exámenes rendidos. AHMLP, caja 4, doc. n 146 . Nota con fecha de $10 / 04 / 1908$.

${ }^{44}$ En 1906 Aguiar solicitó libros vinculados: "al estudio y desarrollo de la cultura americana; el de su prosperidad ó retrocesos; el de los fenómenos y causas que han conducido y nos conducen aún a los fines generales antropológicos". Como obras necesarias para la consulta diaria pidió libros sobre fisiología, histología, anatomía, psicología, diccionarios, obras de Virchow, Lombroso y Haeckel, entre otros. El secretario del Museo y profesor suplente de antropología, Felix Outes contestó que se podrían adquirir Psicología celular y Morfología de los organismos de Haeckel, y además Psicología experimental de Hoffding. En cuanto a las otras obras, indicó que las obras de Virchow en castellano no eran fácil de conseguir aunque se intentaría adquirir alguna, y Estudios de antropología y psiquiatría de Lombroso estaba agotada. AHMLP, caja 34, doc. n 35-36.
} 
dictó para los alumnos de algunos profesorados de la Facultad de Humanidades y Ciencias de la Educación ${ }^{45}$.

En 1906, las ciencias antropológicas contaron con la mayor cantidad de personal docente con respecto las otras áreas de las ciencias naturales que funcionaban en el Museo de La Plata. Entre ello, se incluirían cargos de profesores de materias que no estaban comprendidas en el plan de estudios como arqueología o lingüística, que sólo abarcaba la mitad de un curso en cuarto año. En parte, esto demuestra el interés inicial de las autoridades universitarias en fomentar tanto la enseñanza como las investigaciones en las distintas disciplinas vinculadas al estudio del hombre dentro de la organización de esta institución, reflejado también en la elección de Samuel Lafone Quevedo como director del Museo. Sin embargo, estas materias atrajeron pocos estudiantes y en algunos años ni siquiera llegaron a dictarse. En ciertas ocasiones, la enseñanza de etnografía o arqueología consistió en la preparación para los exámenes y asesoramiento bibliográfico de uno o dos alumnos que necesitaban aprobar esas $\operatorname{asignaturas}^{46}$. A partir de la década de 1910, cuando se crean las especializaciones dentro de las ciencias naturales, el curso de etnografía dejó de tener alumnos propios, aunque comenzó a recibir por correlación a los aspirantes al doctorado y profesorado en historia de la Facultad de Ciencias de la Educación. Para reemplazar el dictado de la cátedra por falta de estudiantes se articularon diferentes estrategias como desarrollar cursos libres, conferencias de extensión universitaria, reivindicar los trabajos de investigación o redefinir el perfil de los cargos docentes como empleos científicotécnicos del Museo. En cambio, las cátedras de geología, mineralogía, botánica y zoología recibieron regularmente estudiantes, sobre todo en los cursos generales que también formaban parte de los planes de estudio de geografía, ingeniería, química y farmacia, y posteriormente de los profesorados. En muchos casos para atender las necesidades de los distintos grupos de estudiantes se organizaron clases especiales o

\footnotetext{
${ }^{45}$ Como se analiza en el capítulo siguiente, la materia Antropología formó parte de los planes de estudios de los distintos profesorados organizados por la Sección Pedagógica desde 1906, posteriormente trasformada en la Facultad de Humanidades y Ciencias de la Educación. Allí, la enseñanza de esa materia estuvo a cargo de Rodolfo Senet hasta su jubilación en 1920. Para una caracterización de la enseñanza de la Antropología y las diferencias en los enfoques entre ambas cátedras, véase: Podgorny e.p., 2001.

${ }^{46}$ En 1908 se organizó la enseñanza de etnografía para la única alumna regular de esa época: Carolina Spegazzini. A fines de 1909, Luis María Torres dictó un curso de etnografía comprimido de dos meses para que los estudiantes del último año del profesorado de geografía terminaran sus estudios.
} 
se incluyeron algunos temas particulares, lo que recargó el trabajo docente de esas cátedras ${ }^{47}$.

La enseñanza de las ciencias naturales, al igual que otras materias del Museo, tendió a incluir trabajos prácticos y excursiones. Durante los primeros años la baja cantidad de alumnos posibilitó que las clases se dieran en las secciones y gabinetes de estudio de los profesores, quienes también aprovecharon las colecciones de las secciones y las exhibiciones para ilustrar sus lecciones. Hacia 1911 se inauguraría un anfiteatro, donde se instaló un aparato de proyecciones para apoyar visualmente las clases y conferencias de extensión universitaria. A partir de mediados de la década de 1910 este lugar fue utilizado para el dictado de las materias generales y de primer año que comenzaban a contar con más de cincuenta alumnos, sobre todo en los cursos incluidos en la carrera de farmacia. En algunas materias como antropología y zoología se encargó a los ayudantes alumnos que confeccionaran "mapas murales" (láminas de gran formato), a partir de copiar en forma ampliada figuras esquemáticas de diversas obras. Asimismo, se recurrió a la compra de distintos tipos de materiales y colecciones didácticos producidas por preparadores y casas especializadas de Alemania. Especialmente, los profesores de mineralogía y geología adquirieron en varias oportunidades colecciones de rocas y minerales para enseñanza, modelos cristalográficos y ópticos, cuadros demostrativos, microscopio de polarización y otros elementos de trabajo a la casa Kranz en Bonn ${ }^{48}$. Para atender el curso de zoología general, que comprendía lecciones teóricas sobre distintos grupos de invertebrados y

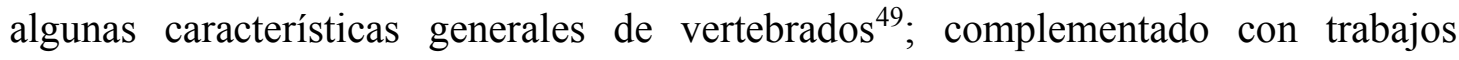

\footnotetext{
47 Así, por ejemplo, en 1909, la cátedra de botánica organizó los siguientes cursos: a) fisiología y biología para los alumnos de 4to. año de ciencias naturales, b) ecología y fitogeografía para alumnos de segundo año del doctorado en Química y Farmacia , c) Histología práctica, para el doctorado en Química y Farmacia. Todos estos a cargo de Spegazzini. A su vez, Scala dictó: a) Botánica económica, para el doctorado en Química, b) Taxonomía vegetal (en el primer semestre), para segundo año del profesorado en geografía y ciencias naturales, c) fitogeografía para el tercer año del profesorado de geografía y ciencias naturales (aunque no hubo alumnos de esta última área) d) botánica farmacéutica para los alumnos de primer año de Farmacia.

${ }^{48}$ Para ilustrar sus clases de mineralogía Schiller encargó la compra de modelos de cristales, mapas murales y colecciones en Alemania y además armó colecciones para ser usadas en la enseñanza. Principalmente su curso de mineralogía estuvo dedicado a morfología, cristalografía y claves para la clasificación de los cristales. Extractos de sus clases de 1907 se publicaron en El Museo, la revista del Centro de Estudiantes del Museo.

${ }^{49}$ El primer programa de Zoología General puede consultarse en: UNLP 1906: 135-136 y las primeras clases se publicaron en la Revista del Centro de Estudiantes del Museo. En los primeros años, para responder a los requerimientos de los estudiantes de Farmacia se trató más detenidamente parasitología y los grupos que contenían agentes patógenos importantes y su biología (reproducción, ciclos de vida, costumbres), especialmente en relación con sus aplicaciones para el tratamiento de enfermedades. Un programa similar sería desarrollado durante varios años. De hecho, por ejemplo, la misma distribución de contenidos se observa en las clases de zoología general de 1912 y 1913 que se publicaron en la
} 
prácticos de observación y disecciones de ejemplares, se compraron en 1906 dos colecciones de invertebrados marinos a la Estación Zoológica de Nápoles, una para servir de material de estudio y otra para exhibición ${ }^{50}$. Para Antropología y Anatomía Artística se armó un gabinete con moldes de yeso, con reproducciones de cuerpos enteros y máscaras faciales de indígenas de diferentes continentes, producidos en los talleres del Museo Real de Berlín ${ }^{51}$. En este caso, Lehmann Nitsche seleccionó las colecciones a partir del catálogo de ese establecimiento y luego se adquirieron por intermedio de Enrique Herrero Ducloux durante su viaje por Europa en 1910.

Los profesores se mantenían al tanto de las últimas novedades en materiales de enseñanza y elementos de trabajo por medio de la circulación de los catálogos de las fábricas, noticias en revistas científicas y sobre todo a través de los frecuentes viajes a Europa. En general, hasta la guerra mundial de 1914 y luego desde 1922, los investigadores del Museo de La Plata viajaron cada dos o tres años para visitar familiares o asistir a congresos internacionales. Asimismo, recorrían centros científicos, librerías y casas proveedoras de varias ciudades, estableciendo relaciones y canjes o adquiriendo nuevos materiales y aparatos. Varios trabajos de historia de la ciencia, especialmente en el campo de las ciencias físicas, han analizado como la ciencia adquiere una dimensión "universal" a través de la producción, circulación y uso de instrumentos que generan una cierta "homogeneización" del trabajo científico. Si bien la circulación de catálogos, instrumentos, colecciones e individuos facilitó la difusión internacional de ciertas prácticas y saberes, no se debe olvidar que la aplicación de las mismas se realiza en contextos específicos y como reglas de sociabilidad tales prácticas requieren un considerable grado de improvisación o adecuación a las exigencias locales ${ }^{52}$.

Revista del Centro de Estudiantes de Química y Farmacia. Por otra parte, el esquema de zoología general fue similar, en cuanto a la organización temática y contenidos, al de la materia que dictaba Angel Gallardo para los alumnos de Farmacia en la Universidad de Buenos Aires. En este sentido, más allá de la incorporación en cada ítem de nueva información o algunas diferencias en cuanto a clasificaciones, pareció existir un alto grado de "estandarización" de los contenidos de los cursos de Zoología general que se registra en esos años. De hecho, el manual de Zoología escrito por Angel Gallardo y editado por la casa Angel Estrada en 1907, inicialmente para los estudiantes de farmacia y también para los de los colegios nacionales, se continuaría reeditando medio siglo después.

${ }^{50}$ En 1906 se adquirió una colección de exposición, conformada por 225 especies con 471 ejemplares de Protozoarios, Poríferos, Celenterados, Moluscos y Tunicados. La de estudio comprendía menos especies y más ejemplares de cada una: 24 especies con 815 ejemplares. Esta colección llegó hacia octubre de 1906.

${ }^{51}$ Catálogo de la Sección Antropología desde 1910, documento manuscrito del Departamento de Antropología. Sobre la producción y circulación de modelos de yeso y su uso pedagógico, véase: García y Podgorny 2001.

${ }^{52}$ Lopes 2001. 
En 1906, comenzaron seis alumnos la carrera de ciencias naturales. Las autoridades académicas habían previsto más del doble de estudiantes, ya que en el presupuesto de ese año se establecieron doce ayudantías-alumno rentadas, seis para colaborar en tareas de las secciones y otras seis para ayudantes-preparadores. Como se ha mencionado en capítulos anteriores, para incentivar un entrenamiento en las tareas científicas y ayudar económicamente a los estudiantes se instituyeron ayudantías en todas las secciones de la Universidad que disponían de laboratorios y gabinetes. En 1906, se repartieron esos cargos entre todos los alumnos matriculados en ciencias naturales y en geografía que solicitaron los puestos, ya que en ninguno de los dos casos sobrepasaron el número de las ayudantías establecidas en el presupuesto ${ }^{53}$. Posteriormente, la cantidad de esos cargos se iría reduciendo frente a los recortes presupuestarios y a la falta de estudiantes. Estos empleos y especialmente las becas de estudios que se consiguieron a partir de 1910 constituyeron un incentivo para reclutar los pocos alumnos que se interesaron por los estudios de ciencias naturales. Por otra parte, las reglamentaciones de estos cargos fueron muy estrictas con respecto a las altas calificaciones que debían poseer los candidatos y el mantenimiento de los mismos estuvo supeditado a la aprobación regular de materias sin aplazos. En cierta forma, esto conformó un mecanismo de selección de personal auxiliar para los trabajos científicos, técnicos y docentes, ya que posteriormente algunos de los alumnos destacados fueron nombrados jefes de laboratorio o de trabajos prácticos. Para las egresadas, estas últimas posiciones serían las más altas de la jerarquía académica a las que tendrían acceso hasta la década de $1930^{54}$.

Para completar el aprendizaje desde el Centro de Estudiantes del Museo, entre otras actividades, se organizaron conferencias de repaso sobre las materias que se cursaban, se publicaron los apuntes de clase de los profesores para disponer de material de estudio, se armó una biblioteca, se consiguieron descuentos para la adquisición de textos, se organizaron algunos viajes de estudios y cursos de

\footnotetext{
${ }^{53}$ La asignación mensual de esos puestos era de 75 pesos moneda nacional, la mitad del sueldo de un jefe de trabajos prácticos y un tercio del de un profesor titular. A su vez, con la asignación de cerca de dos o tres meses se cubría el costo de las matrículas, los aranceles por trabajo de laboratorio y exámenes de un año. En el caso de la Escuela de Química y Farmacia, frente a la gran demanda estudiantil por esos cargos se estableció un sistema de selección (concurso) basado en las calificaciones.

${ }^{54}$ La primera mujer en acceder a un cargo de profesora en el Museo de La Plata sería Juana Cortelezzi, nombrada profesora de mineralogía en 1933. Esta doctora en química había comenzado a estudiar ciencias naturales en 1906, pero sólo completó el profesorado en ciencias naturales. En 1928 se incorporó al Museo como jefe de trabajos prácticos en el Departamento de Mineralogía y Geología. Véase el cuadro con los primeros alumnos de la Escuela de Ciencias Naturales de La Plata en el Anexo.
} 
taquigrafía para que los alumnos pudieran tomar notas durante las conferencias de los profesores, como se señaló en el Capítulo II. Disponer de estas lecciones, se consideraba un elemento imprescindible para seguir el desarrollo de la materia y preparar los exámenes, ya que se reconocía que los profesores realizaban una síntesis de muchos textos extranjeros y de artículos de revistas científicas que no estaban al alcance de los alumnos. Por otra parte, se reconocía que muchas veces los docentes introducían comentarios o conclusiones de sus propias investigaciones antes de publicarlas. Paralelamente, como un complemento necesario de la formación científica, los estudiantes solicitaron a la Facultad que organizara un curso libre de alemán. Recordemos que este idioma era la lengua materna de la mayoría de los profesores de ciencias naturales y de gran parte de las publicaciones que estos investigadores y otros docentes utilizaban para sus trabajos científicos y para apoyar sus clases. En sucesivas oportunidades, los alumnos reconocieron la necesidad de contar con conocimientos de alemán y en algunas ocasiones se recurrió a la contratación privada de un profesor para ello.

En general, la mayoría de los profesores se sintieron conformes por las primeras experiencias docentes en 1906 y 1907. En cambio, el profesor adjunto de zoología, Miguel Fernández, que en esa época acababa de arribar a la Argentina luego de un entrenamiento en las universidades alemanas, manifestó su preocupación por la falta de interés científico de los alumnos: "me ha parecido que empero, que con pocas excepciones, los estudiantes no persiguen en sus estudios un ideal cientifico, sino que asisten á los cursos tan sólo porque así lo exigen los programas. Los estudiantes no asisten al trabajo estimulados por un intenso amor al saber, sino que á cada paso se preguntan si el punto que piensan estudiar puede ser pedido en los exámenes ó no. Á mi entender esta pobre interpretación del estudio, es debida en gran parte, al régimen de los estudios reglamentados, que con demasiada facilidad hace crecer al estudiante, que el fin primordial y único de su trabajo es obtener buenas clasificaciones á fin de año." 55

Para este profesor los programas oficiales y los estudios reglamentados eran prácticas escolarizadas que no se correspondían con el nivel superior que debía tener la enseñanza universitaria. Esta última, además, debía basarse en la libertad de estudio

\footnotetext{
${ }^{55}$ El comentario de este profesor fue extraído del informe sobre las clases que presentó a la dirección del Museo, parte del cual fue publicado en la Memoria de la Institución. Memoria del Museo de La Plata correspondiente a 1906: 49.
} 
y el interés de los alumnos por completar su formación científica como en las universidades alemanas. Según se mencionó en la Memoria de la Institución, los esfuerzos de este profesor por despertar "el amor a la ciencia" generaron el interés de treinta y cinco alumnos que asintieron como oyentes a sus lecciones prácticas sobre vertebrados en el curso de 1906. Cabe indicar que a las clases obligatorias de zoología concurrieron cuarenta alumnos: seis de ciencias naturales y treinta y cuatro de farmacia. Sin embargo, durante todo el año hubo reiterados pedidos por parte de los estudiantes de farmacia y geografía para que se suprimiera esta materia de los planes de estudios. Estos últimos también pedían que se eliminara de su plan de estudios el curso de Botánica de Spegazzini, o por lo menos todo lo que no implicara las clasificaciones de fauna y flora regional, ya que sino no habría diferencias entre la formación de un profesor de geografía y un egresado en ciencias naturales ${ }^{56}$. Posteriormente, para geografía se organizaría un curso de zoogeografía y otro de fitogeografía. En general, en los pedidos estudiantiles se criticó la formación "enciclopedista" o general y se enfatizó en la necesidad de una especialización profesional.

La solicitud de los alumnos de farmacia de eliminar Zoología del plan de estudios, al igual que en otras ocasiones no fue aceptada por las autoridades académicas. También los estudiantes de ciencias naturales pidieron eximirse del examen de Geografía Física, y junto con el resto de los del Museo se quejaron por las materias de ciencias exactas ${ }^{57}$. Si bien la mayoría de estos pedidos no fueron atendidos, pusieron de manifiesto algunos de los problemas que se suscitaron con respecto al sistema de correlación. Por este sistema, los alumnos de la Universidad platense debían cursar materias en distintas Escuelas y Facultades, que tenían regímenes diferentes de cursada, promoción y exigencias. Uno de los principales reclamos de los estudiantes fue por la materia de Física y hacía referencia a dos cuestiones: los exámenes parciales distribuidos a lo largo del año,- que no existían en el régimen del Museo, donde sólo se tomaban una prueba final en cada materia-, y la

\footnotetext{
${ }^{56}$ Nota editorial:"La Zoología en el plan de estudios de Farmacia y en el de Geografía". Revista del Centro de Estudiantes del Museo, 1906, I, 4: 49-50.

${ }^{57}$ En la Nota editorial "El concepto de disciplina" se cuestionaba que: "en razón de que los directores de Institutos formulan los programas, horarios y exámenes de las materias correspondientes á los suyos, los alumnos tienen que estudiar más matemáticas y fisica que las otras de su especialidad; los de química, dibujo de aparatos para cuando tengan que inventar alguno, los programas de Geografía Física, Cosmografía, Topografía y Meteorología con varios temas y tópicos iguales; el dibujo geométrico para las ciencias naturales; el título de profesor en lugar de geógrafos....". Revista del Centro de Estudiantes del Museo, 1906, I, 12: 202.
} 
modalidad de enseñanza ${ }^{58}$. Pese a los pedidos, los exámenes parciales no se derogaron y los alumnos del Museo pasaron las pruebas con buena preparación, para demostrar que esa solicitud no se basaba en un "facilismo" sino en una crítica hacia el sistema de exámenes y la enseñanza desarrollada en esa cátedra. Con respecto a esto último, se insistía en que: "...no se dicta la materia con criterio profesional. Los estudiantes piden una física más experimental: que ellos vean, palpen y manejen los aparatos. La física teórica no coincide con los estudios materialistas del naturalista, porque como dice el Dr. Porro es una manía esto de querer sujetar á la exactitud matemática los fenómenos naturales..." 59

La enseñanza "profesional" de la Física se asociaba con la "experimentación". En el lenguaje pedagógico de la época, esto último aludía a la experiencia que se adquiría en presencia de los objetos a estudiar y a través del uso de los sentidos. De esa forma, los alumnos demandaban que los enunciados teóricos pudieran ser constatados por medio de la observación, los experimentos y la manipulación de instrumentos, y no como derivación de cálculos matemáticos o la exposición oral del profesor. Si bien en esa época el Instituto de Física disponía de algunos aparatos, según los alumnos estos no funcionaban y los que se habían encargado a Alemania no llegaron hasta fines de 1906. En ese sentido, en una carta publicada en el periódico local El Día se mencionaba que las clases eran: "desarrollos interminables de formulas que se sucedian en el pizarrón, no era la fórmula aplicable, el conocimiento práctico el que nos enseñaba y se nos viene enseñando. Se nos dice sencillamente: el aparato lo encontraran Uds. en el libro y alli lo veran, los pocos que se traen a clase no funcionan, en su mayor parte se hallan descompuestos y los se han pedido a Europa no llegan, tal vez corran la misma suerte de los que se hallan en el gabinete....." ${ }^{60}$.

A su vez, el carácter práctico y experimental que se pedía para las clases, coincidía con una representación de las ciencias naturales vinculada a la figura del

\footnotetext{
${ }^{58}$ Los estudiantes reconocían que la solución de este problema no dependía solo de la Academia del Museo sino de la Facultad de Física y Matemáticas. Especialmente las críticas se dirigían hacia la Escuela de Física, dirigida en esa época por Teobaldo Ricaldoni, que según los alumnos era la única que tomaba exámenes parciales. Por otra parte, en esa época existía un gran conflicto entre algunos profesores y académicos de esa Facultad y el director del Observatorio, el italiano Francisco Porro de Somenzi, quien inicialmente estaba encargado de la dirección de la Facultad. Para las clases de física, Ricaldoni, había encargado varios aparatos e instrumentos de demostración según el catálogo de la fábrica alemana Max Kohl, a partir de un subsidio especial girado por el Poder Ejecutivo. No obstante, esos materiales se recibieron a fines de 1906. Ranea 1994, von Reichenbach et. al. 2002.

${ }^{59}$ Nota editorial: "Planteo de un problema", Revista del Centro de Estudiantes del Museo, I, 7: 105-106.

60 "Situación molesta: carta de un estudiante" en: El Día, 4/9/1906.
} 
naturalista y a los fenómenos naturales no sujetos a mediciones precisas y las leyes exactas y abstractas de las matemáticas. Según los estudios de Jean-Marc Drouin y Bernadette Bensaude- Vincent, en el imaginario popular la historia natural era asociada a descripciones pintorescas sobre flores o el comportamiento de las aves o insectos $^{61}$. Estos investigadores señalan que esta visión bucólica fue muy difundida en los trabajos de popularización, fomentando la creencia que los estudios de la naturaleza constituían una actividad placentera y útil, al mismo tiempo que la figura del naturalista se representaba como un aventurero o explorador de las bellezas vírgenes de la naturaleza. En Argentina, esas imágenes sobre la práctica de las ciencias naturales, basadas en la figura del "field naturalist", las excursiones y la observación de la naturaleza fueron difundidas en conferencias y trabajos de popularización y especialmente en la enseñanza escolar, donde se incorporaron las excursiones a la naturaleza, la recolección de especímenes y la formación de museos escolares.

Por otra parte, los estudiantes mencionaban que no disponían de los conocimientos matemáticos suficientes para entender la materia, pese a que dichas nociones se dictaban en los colegios nacionales, reconocían que no habían sido muy buenos alumnos en esa área y que además no todos eran bachilleres. Pero el principal problema parecía girar en la intervención de diferentes Institutos sobre la formación de una determinada carrera. El conflicto que percibían los estudiantes, y que se mantendría por varios años, estaba relacionado a las materias que se cursaban por correlación, cuyo programa, horarios y régimen de cursada dependía de la Facultad en donde se dictaba la materia y no de la que establecía el plan de estudios. Los alumnos solicitaban que la unidad académica a la que pertenecían, fuera la que estableciera todas las condiciones y programas para todas las materias del plan de estudios, para dar, de esa manera, una dirección común y unidad a los estudios. Según los estudiantes, la falta de esto último así como una jerarquización de las asignaturas no ayudaba a distinguir entre las materias principales y las accesorias de una determinada carrera, generando una formación enciclopedista: "una erudición viviente $y$ molesta....una enciclopedia andante..., lo que vale decir que la especialización será un mito...". ${ }^{62}$

\footnotetext{
${ }^{61}$ Drouin y Bensaude- Vincent 1996.

${ }^{62}$ Nota editorial: "El recargo de los horarios", Revista del Centro de Estudiantes del Museo, 1906, I, 9: 138-139. Asimismo, los alumnos se quejaron del "horario de clases sumamente recargado de cuatro
} 
La unidad de la ciencia proclamada por González para su proyecto de Universidad, y materializada en el sistema de correlación, en la práctica creaba una situación sumamente paradójica y conflictiva. Para los estudiantes de la Facultad del Instituto del Museo, la forma en que se aplicaba ese sistema provocaba un "enciclopedismo", entendido como una acumulación de conocimientos en los cuales la especialización en ciertas disciplinas y la distinción en la formación de las distintas carreras no se percibían. A partir de ese argumento, los estudiantes de geografía reclamaban la supresión de algunas materias o la reducción y especialización del contenido de las mismas, ya que la formación no se diferencia demasiado de la de ciencias naturales $^{63}$. Después de la muerte del director de la Escuela de Geografía en 1908, algunas de esas materias pasarían a depender de la Escuela de Ciencias Naturales. En esta última Escuela, precisamente una incipiente especialización dentro de cada disciplina comprendida en esta última y la concentración de los cursos en las distintas áreas de las ciencias naturales sería una de las transformaciones principales que aparecerá en la modificación del plan de estudios llevado a cabo en 1909.

\section{$\underline{\text { V. 3. La transmisión de la aptitud técnica }}$}

Como había anunciado el presidente de la Universidad platense, la modalidad de enseñanza que se fomentó en el Museo trató de separarse del "modelo verbalista" para acercarse a un aprendizaje apoyado en la experiencia y el trabajo personal del alumno. De esa forma, no sólo se buscaron diferentes soportes materias para representar visualmente lo que exponía el profesor sino que se organizaron trabajos prácticos. En las materias generales, sobre todo durante los primeros años, los ejercicios prácticos giraron principalmente en torno a observaciones macroscópicas, determinaciones de ejemplares y excursiones. Así, por ejemplo a fines de 1906 los

\footnotetext{
horas y media termino medio, con el inconveniente que tres dias por semana hay clases por la tarde además de las correspondientes a la mañana... esto es sin duda para recuperar el tiempo trascurrido en los primeros meses del año, por un lado; por otro, que varios profesores viven en Buenos Aires y tienen que combinar el horario del tren de acá y sus ocupaciones en la Capital Federal, con el horario del ferrocarril. Pero creemos que todo se allanará después de este primer año de ensayos".

${ }^{63}$ Ambas carreras parecían estar diseñadas para producir exploradores y personas que se dedicaran a mapear e inventariar los recursos naturales del país. Sin embargo, la situación de los alumnos de geografía era todavía más conflictiva ya que el único título que se ofrecía era de profesor y pese a las promesas de J. V. González y el proyecto del director de la Escuela, Enrique Delachaux, no se había logrado que se estableciera el grado de doctor dentro de esta disciplina
} 
alumnos mencionaban las excursiones organizadas por el agrónomo italiano Carlos Spegazzini por los alrededores de la ciudad: "se hacen actualmente más provechosas porque empezando á las 6 de la mañana permiten alejarse de los alrededores de la ciudad ensanchando así el campo de observación y estudio práctico de la botánica" 64 Este profesor era partidario de que la recolección de especímenes y el estudio de las colecciones fuera realizada por el mismo investigador y en general había tendido a elaborar catálogos sobre plantas coleccionadas y estudiadas por el mismo. A sus clases concurrieron estudiantes de ciencias naturales, farmacia y del doctorado de química. La enseñanza del primer curso de botánica, según se desprende de los apuntes registrados y publicados por los alumnos, abarcó nociones generales sobre la historia de la disciplina, sistemas taxonómicos, descripción de familias botánicas, deteniéndose sobre todo en la sistemática de hongos, tema de especial interés para este profesor. Los trabajos prácticos se destinaron a la preparación de herbarios, reconocimiento de ejemplares, preparación de órganos vegetales, análisis macroscópicos y manejo de diferentes clasificaciones y monografías para las determinaciones de ejemplares recolectados ${ }^{65}$. Para presentarse a examen final, los alumnos debían presentar un herbario con un tipo de cada familia estudiada en el curso y con una descripción adjunta de cada uno. Durante el examen se requería que cada alumno determinara tres plantas diferentes con indicación de familia, género y especie $^{66}$. Es interesante señalar que las excursiones, trabajos de herborización y clasificación de ejemplares botánicos parecieron ser rápidamente incorporados por los alumnos, quienes los aplicaron en distintos ámbitos. Así, por ejemplo, en 1907 la alumna Juana Cortelezzi, docente en el recién creado Colegio de Señoritas de la Universidad, promovía este tipo de prácticas como una forma de renovar los métodos de enseñanza de las ciencias naturales en esa institución ${ }^{67}$. Asimismo, en excursiones

\footnotetext{
64 "Excursiones de botánica". Revista del Centro de Estudiantes del Museo, I, 9:140.

${ }^{65}$ El primer programa de Botánica general (para alumnos de primer año de ciencias naturales) comprendía historia y definición de la disciplina, la botánica en la República Argentina, caracterización de diferentes grupos botánicos, taxonomía, sistemas de clasificación y generalidades de las distintas ramas de la botánica que luego se ampliaría en los cursos especiales. Asimismo, como trabajos prácticos se establecía: "los alumnos en las horas de trabajos prácticos prepararan órganos vegetales, debiendo efectuar su análisis macroscópico. Para ser admitido á examen deberán presentar un herbario que posea por lo menos un tipo de cada familia estudiada, con el análisis completo redactado al pié. Los alumnos deberán aprender á manejar los autores populares, clásicos y monográficos, para poder al fin del año llegar á determinar con seguridad á lo menos el género de cualquier vegetal indigena que la mesa examinadora le presente." UNLP 1906: 138.

${ }^{66}$ Memoria del Museo de La Plata correspondiente al año de 1906.

${ }^{67}$ Juana Cortelezzi indicaba que para el nuevo Colegio Secundario de Señoritas de la Universidad platense, organizado bajo la dirección de Víctor Mercante, se renovarían los métodos de enseñanza de
} 
y viajes estudiantiles se llevaron a cabo herborizaciones e identificación de ejemplares como durante la Semana Santa de 1907. En esa época, un grupo de alumnos organizó una excursión a Tandil con la colaboración del Gobierno de la Provincia, que facilitó los pasajes. En ese viaje, los estudiantes de las diferentes carreras trataron de aplicar los conocimientos aprendidos y en el caso de los dos de ciencias naturales, María Luisa Gutiérrez y Franco Pastore, se dedicaron a recolectar e identificar ejemplares de la flora local, llegando a determinar cerca de cincuenta especies ${ }^{68}$.

En sus clases, Spegazzini recomendó a sus alumnos dedicarse a la catalogación de los especímenes botánicos del territorio argentino, ya que era un campo donde había mucho por hacer y estaba siendo disputado por comisiones científicas extranjeras. En este sentido, indicaba que: "la botánica sistemática debe preceder á la botánica física en todo país donde se inician estas investigaciones; antes de entrar en los estudios en detalle hay que levantar el inventario de los materiales de que disponemos y aprender á conocerlos esmeradamente en sus formas externas para despues entrar en los estudios minuciosos y no correr peligro de presentar hipótesis y fundar teorías basadas en el vacio. La República Argentina es precisamente uno de aquellos países en los cuales queda aún ámplio campo para los fitógrafos, y vemos á diario sus diferentes regiones recorridas por comisiones de botánicos de lejanas tierras, los cuales hallando en su país agotado el material vienen á buscarlo en esta tierra; creo pues que los jóvenes naturalistas argentinos deben ante todo enderezar sus estudios en el sentido taxonómico, que como hemos dicho presenta un ámplio campo para cosechar laureles...." ${ }^{69}$.

Si bien los estudios taxonómicos ocuparon un lugar importante en la enseñanza de la botánica, Spegazzini también dictó otros cursos que incluyeron temas de ecología, fisiología, patología vegetal, los debates sobre la teoría evolutiva, la adaptación al medio y los experimentos en genética vegetal como los de Mendel, de Vries, y Nilson desarrollados en la Estación Agronómica de Slavot, Suecia durante

\footnotetext{
las ciencias naturales: de la observación de "fenómenos en las líneas impresas de los libros ó folletos, mal expresados algunos y peor interpretados otros" se pasaría al estudio de los ejemplares mismos "de manera de poder comprobar los que en la teoría decimos, será un medio de distracción al mismo tiempo que podrá admirarse á la naturaleza que tantas bellezas encierra ella misma....". Cortelezzi 1907: 95. Frente a la imposibilidad de llevar todo el material al aula, se proponía complementar la enseñanza con excursiones a los alrededores de la ciudad para conocer la flora local y despertar en los alumnos el "espíritu de observación".

${ }^{68}$ Varias noticias sobre ese viaje se publicaron en la revista del Centro de Estudiantes, El Museo, durante 1907.

69 "Los apuntes de clase de Botánica. Divisiones de la Botánica". Revista del Centro de Estudiantes del Museo, I, 1: 11-12. pág. 12.
} 
1905. Especialmente, para los alumnos de ciencias naturales y geografía se incluyeron: taxonomía y fitogeografía. Mientras que para los de la Escuela de Química y Farmacia se organizaron clases de botánica farmacéutica, económica e histología vegetal. Estos últimos estuvieron a cargo del profesor adjunto, el farmacéutico italiano Augusto Scala. Este docente se dedicó especialmente a las investigaciones en histología vegetal interna, así como a ensayos en técnicas de fijación y estudios de morfología interna, basados en el trabajo de laboratorio con microscopio, micrótomo y numerosos reactivos. Inicialmente, en el espacio del Museo no se había destinado una sección o gabinete especial para botánica. En 1908, después de sucesivos reclamos de ambos profesores, la Universidad autorizó la inversión de algunos fondos para ello. Particularmente, Scala se interesó por la creación de un laboratorio de botánica para desarrollar sus investigaciones y realizar una enseñanza práctica. De hecho, en 1910 propuso como tema para debatir en la Asamblea General de Profesores de la Universidad, la creación de un Instituto Fitohistológico. Por varios años el espacio y materiales que se disponían para botánica parecieron no responder a las expectativas de este profesor, quien elevó numerosas reclamos a la dirección del Museo. Especialmente a partir de la década de 1910 solicitaría la ampliación del laboratorio para las clases prácticas, ya que sólo tenía capacidad para el trabajo de cerca de 20 alumnos y el número de estudiantes farmacia y el doctorado en química era más del triple.

Como se mencionó en el capítulo anterior, para fomentar la enseñanza y divulgación de los estudios fitohistológicos y las técnicas para la preparación de cortes y observación microscópica, Scala escribió el Manual de Manipulaciones de Botánica, publicado en 1912 como parte de las series de divulgación del Museo de La Plata. En ese año, Scala fue nombrado profesor titular al jubilarse Spegazzini y a partir de ese momento concentraría la enseñanza de todos los cursos de botánica que se dictaron en el Museo hasta su muerte en $1933^{70}$. En general, esto no implicó un cambio en el perfil y la forma de organizar la enseñanza de la botánica, por lo menos para los alumnos de ciencias naturales, ya que se siguió fomentando la formación de naturalistas "en sentido taxonómico"71. Las primeras tesis doctorales de ciencias

\footnotetext{
${ }^{70}$ Sobre la historia de la Botánica en el Museo de La Plata, véase: Guarrera 1977.

${ }^{71}$ Los apuntes de las clases del primer curso de botánica publicados en 1912 y 1913 en la Revista del centro de Estudiantes de Química y Farmacia guardan mucha similitud con las lecciones dadas por Spegazzini. En la década de 1910, la enseñanza de la botánica para los alumnos de química y farmacia abarcaba: un primer curso, donde se realizaban excursiones por los alrededores de la ciudad,
} 
naturales, en la especialidad de botánica se dedicaron a estudios taxonómicos, descriptivos y efectuar catálogos de la flora de la Provincia de Buenos Aires ${ }^{72}$. En cambio, los estudios experimentales con plantas o que exploraban la línea de trabajo de Scala fueron temas de tesis y trabajos de estudiantes de ciencias químicas ${ }^{73}$.

Los primeros cursos de geología estuvieron a cargo de Santiago Roth por renuncia de Ameghino. En sus clases, Roth señaló reiteradamente que la geología era una ciencia que se basaba en hechos empíricos y en la observación en el terreno que excluía las especulaciones filosóficas: "el objeto de la geología consiste en averiguar el origen y cambios que ha sufrido la masa sólida de la tierra lo mismo que las transformaciones y el desarrollo de la vida orgánica durante la existencia del globo, es decir averiguar la historia de la tierra .....La historia primitiva de la tierra está ligada á la cosmogenía y si bien algunos geólogos tratan de ella no es la geología sino la astronomía y aún más la filosofía especulativa que se proponen de resolver este problema.....La geología excluye en sus afirmaciones las especulaciones filosóficas. Muy distinta es la geología si explica el origen de una cadena de montañas ó volcanes. Esto se basa en observaciones de hechos concretos..." 74

Junto a ello también enfatizaría en la necesidad de un conocimiento local para contrastar las interpretaciones de la ciencia europea, sobre todo en relación con la determinación de ciertas rocas y estratos. En su curso de 1908, se detuvo en la clasificación de las rocas, señalando que desde el punto de vista geológico no

\footnotetext{
observaciones y recolecciones para confeccionar herbarios y en el se promovía la confección de preparados microscópicos sobre los ejemplares recogidos, que ilustraran las principales estructuras histológicas de las distintas partes de la planta. Además, para rendir examen los alumnos debían presentar esquemas de sus observaciones. Los cursos específicos para ciencias naturales comprendieron: botánica general e histología; botánica sistemática e histología, botánica sistemática argentina y fisiología; taxonomía y fitogeografía. Estos se dieron de forma alternada a partir de la segunda mitad de la década de 1910 para uno o dos alumnos.

${ }^{72}$ La primera tesis doctoral de ciencias naturales, en la especialidad de Botánica fue la de Ana Manganaro sobre leguminosas bonaerenses, publicada en 1919. Inicialmente se había propuesto realizar una parte taxonómica y descriptiva y una segunda dedicada al estudio histológico; pero finalmente, sólo presentó la primera parte, en donde describió ejemplares de 56 géneros y 119 especies de la flora leguminosa silvestre de la Provincia, presentando su clasificación sistemática e información sobre distribución geográfica. Para ello realizó observaciones y recolecciones por los alrededores de La Plata y Buenos Aires y comparaciones con las observaciones registradas en el pasado por viajeros y otros botánicos. Asimismo, agregó algunos datos sobre propiedades, usos, distribución geográfica de algunas de esas especies. Manganaro 1919.

${ }^{73}$ Como ejemplo, se puede citar la tesis de Enrique Ramírez (farmacéutico e Inspector de Farmacias de la Provincia de Buenos Aires), para optar al grado de doctor en química y farmacia, presentada en 1913 y publicada al año siguiente. Su trabajo de tesis, denominado "Datos para el estudio del vanadio y acción de algunos vanadatos en los vegetales", se basó principalmente en trabajo de laboratorio, en análisis químicos y experimentación con algunas plantas facilitadas por Spegazzini. En los trabajos de la alumna de química y farmacia María Luisa Cobanera sobre la acción de sales de alúmina y otros minerales sobre vegetales, se utilizaron las técnicas histológicas difundidas por el profesor Scala.
} 
importaba tanto la composición mineralógica o química, sino el origen y el modo en que se presentan en la naturaleza. Al mismo tiempo indicaba que las teorías sobre ciertas rocas (como las "masosas" o primarias) estaban establecidas sobre fenómenos locales europeos y los estudios químicos o mineralógicos no bastaban para explicar su origen. Para ello, se necesitaban investigaciones amplias en el terreno sobre las condiciones en que se habían formado esas rocas y se presentan en distintas regiones del mundo. En la clasificación de rocas y ubicación cronológica de las formaciones, Roth constantemente comparaba las secuencias establecidas en Europa con las que aparecían en distintas regiones de la Argentina, especialmente en Patagonia, donde había efectuado sus propias observaciones y estudios. Al igual que otros investigadores del Museo, sostuvo una posición polémica con respecto a las interpretaciones y secuencias elaboradas por la ciencia europea, principalmente por el carácter fragmentario y eurocéntrico de las observaciones, que además se restringían a ciertas localidades del viejo continente. En este sentido, esas impugnaciones pretendían legitimar una autoridad apoyada en el valor del "estar aquí" y las particularidades de la geografía local. De ahí, que las exploraciones y observaciones in situ efectuadas por el mismo investigador se presentaban como un elemento imprescindible de la actividad del geólogo. Como ha indicado Martín Guntau, el trabajo de campo constituyó una parte esencial de la práctica científica en las ciencias de la tierra, cuya importancia no descansaba en la recolección de ejemplares para el estudio en los gabinetes sino en la intención de ver con los propios ojos como se presentaban los minerales y rocas, se relacionaban entre sí y con la topografía física en la que se encontraban ${ }^{75}$.

Este tipo de actividad también se incluyó inicialmente como complemento en los cursos de geología y mineralogía. Para brindar una enseñanza práctica, los profesores de estas materias realizaron algunas excursiones de estudio con los alumnos a localidades cercanas. Así, por ejemplo, a fines de 1907, los estudiantes del curso de geología visitaron la isla Paulino, un lugar de paseo cerca del puerto de Ensenada, acompañados por Roth y Spegazzini, y realizaron otras observaciones con esos profesores y Schiller en los alrededores del pueblo de Magdalena a $40 \mathrm{Km}$ de La Plata $^{76}$. En varias oportunidades los profesores de geología y también los alumnos de

\footnotetext{
74“Geología (apuntes de las clases del profesor Dr. Rooth)” [sic]. El Museo, 1907, II, 21: 5-8.

75. Guntau 1996; Rudwick 1996; Second 1986.

76 "Excursión de estudio" El Día, 19/9/07 y 7/10/07.
} 
sus cursos elevaron proyectos de viajes y excursiones didácticas pero en general esas propuestas no prosperaron o fueron atendidas tardíamente por las autoridades universitarias $^{77}$. Cabe señalar que si bien estos investigadores, realizaron frecuentes exploraciones y estudios en el campo no llevaron a ningún alumno durante estos primeros años. En ese sentido, pareció existir una demarcación entre una expedición científica y otra para brindar lecciones prácticas y un entrenamiento en el terreno a los alumnos.

Los profesores de geología fueron muy demandados por dependencias oficiales y empresas particulares para la exploración de ciertas regiones y determinación de recursos de posible explotación económica. La atención de esas demandas y el desarrollo de sus propias investigaciones generaba que estos investigadores realizaran continuamente expediciones y permanecieran cierto tiempo en el campo, por lo que las tareas docentes se tuvieron que adecuar a esos ritmos y ocuparan un lugar marginal. En el caso de Walter Schiller sus actividades en el Museo se interrumpieron durante los años que participó por su país en la Primera Guerra Mundial. Para la enseñanza de Geografía Física durante estos años se contrataron varios profesores extranjeros: el investigador suizo León Collet en 1911, a quien se le asignó la cátedra de geología; luego Pablo Merian entre 1912-1916, cuando pide licencia por enfermedad y posteriormente viaja a Suiza; el alemán Armin Reinmann en 1917, quien muere hacia 1919. Interinamente ejerció como docente, el profesor de geografía Esteban Menéndez, un graduado de la Escuela de Geografía del Museo de La Plata, quien también había seguido los cursos para la licenciatura en ciencias naturales, en la especialidad de geología y mineralogía. A partir de 1921 la enseñanza de esta materia sería asignada a Walter Schiller.

En 1912 se nombró interinamente al ruso-alemán Moises Kantor como profesor y jefe de la Sección de Geología, quien le imprimió un mayor impulso a la enseñanza de esta materia y también dictó cursos de petrografía y mineralogía para los

\footnotetext{
${ }^{77}$ En 1907 Schiller elevó al consejo Académico una propuesta para organizar expediciones de estudio con los alumnos que cursaban geología y mineralogía, que no fue aprobada seguramente debido a los gastos que demandaba. Al año siguiente, Roth presentó un plan de excursiones hasta la frontera de Bolivia, de carácter geológico y geográfico con el objeto de dar lecciones prácticas a los alumnos. Si bien, el Consejo Académico nombró una comisión para que preparara un plan minucioso, esa propuesta no prosperó. A fines de 1909, para complementar el aprendizaje de esta materia, los alumnos presentaron al Consejo Académico una solicitud de fondos para organizar un viaje de estudio. Las autoridades académicas atendieron el pedido y lo elevaron al Consejo Superior para solicitar los fondos necesarios. Finalmente, cuando llegó a este Consejo, como la fecha en la que se iba a llevar a cabo el viaje había pasado se decidió archivar la solicitud.
} 
alumnos de ciencias naturales, otros cursos para los de ingeniería y los del doctorado en química. Este ingeniero en minas, formado en la Academia de Minas de Freiberg (Sajonia), se interesó por divulgar las aplicaciones económicas de los minerales y de los estudios geológicos ${ }^{78}$. En sus clases prácticas de geología general se detuvo en la determinación macroscópica de rocas, sirviéndose de las colecciones del Museo y de otras compradas especialmente para ello en Alemania. Kantor dirigió e incentivó el trabajo de los dos estudiantes que eligieron la especialidad de geología y mineralogía por esa época: Sarah Cortelezzi y María Amelía Osacar ${ }^{79}$. Para completar la formación de estas alumnas con trabajo de campo y además recolectar material que les sirviera para su trabajo de tesis, Kantor organizó en 1918 un viaje con ellas a Montevideo para hacer estudios geológicos y mineralógicos en los alrededores de esa ciudad. Este profesor consideraba que el trabajo de campo con los alumnos era un medio que facilitaba la tarea de enseñanza ${ }^{80}$. Otros profesores también consideraron que las excursiones y un entrenamiento en la práctica de campo eran importantes para las aplicaciones económicas de la geología. Con relación a ello, la incorporación de las excursiones al programa de enseñanza universitaria de las ciencias naturales marca la importancia que adquirió el trabajo de campo como parte de las habilidades que el naturalista debía reunir en su formación profesional, especialmente en las áreas de botánica y geología.

En zoología, en cambio, el profesor Miguel Fernández, fomentaría el entrenamiento en el trabajo de laboratorio de los futuros naturalistas. Como ya se mencionó, este profesor se había formado en el sistema de las universidades alemanas y estaba dedicado a investigaciones embriológicas vinculado al programa de la "zoología científica" y el estudio de la génesis de la forma animal difundido en aquellas instituciones ${ }^{81}$ y cuyo loci de trabajo era el laboratorio. Para las prácticas de laboratorio, el microscopio y en segundo lugar el micrótomo para confeccionar cortes delgados y preparados, constituyeron elementos imprescindibles en los estudios morfológicos, histológicos y embriológicos, junto a la disponibilidad de especimenes

\footnotetext{
${ }^{78}$ Kantor 1913a, 1913b, 1913c.

${ }^{79}$ En esa época, estas dos alumnas terminaron de cursar pero ninguna presentó su tesis. Sólo Sarah Cortelezzi, después de casarse, completaría su doctorado en 1932 bajo la dirección de Schiller.

${ }^{80}$ En el informe de la Sección de geología y Mineralogía incluido en la Memoria del Instituto del Museo de 1917, se señaló: "sería muy conveniente organizar excursiones geológicas, sobretodo con los alumnos del doctorado en ciencias naturales, las que en alto grado facilitarían las tareas de la enseñanza". Lafone Quevedo 1918: 109.

${ }^{81}$ Sobre el desarrollo de la "zoología científica" en las universidades alemanas y los programas de investigación derivados de la teoría de Haeckel, véase: Nyhart 1995.
} 
frescos o vivos. Como ha señalado Nick Hopwood, el micrótomo simbolizó una transformación en la práctica de la microscopia, un cambio en la experiencia del trabajo de laboratorio en las ciencias de la vida y una reorientación del objeto de investigación que no se basaba en la observación de colecciones u los organismos vivos en su ambiente sino que se concentraba en la topografía interna de especímenes fijos y seccionados ${ }^{82}$. Un entrenamiento en este tipo de trabajo sería promovido por Fernández en el laboratorio de zoología instalado en los subsuelos del edificio del Museo de La Plata. También, como ya se mencionó, el farmacéutico Augusto Scala se interesó por un tipo de trabajo similar vinculado a la histología vegetal, aunque para los futuros naturalistas seguiría insistiendo en la importancia del trabajo de recolección, clasificación y confección de herbarios.

Fernández estaba dedicado a sus trabajos de investigación en el laboratorio y se encargaba de la enseñanza de zoología general y los curso especiales para los alumnos avanzados de ciencias naturales. Para ello, al igual que en las universidades europeas combinó un sistema de cátedra y laboratorio. Para los alumnos de ciencias naturales estableció una modalidad de trabajos prácticos denominada "Trabajos de Laboratorio" que durante la década de 1910 adquirió un lugar importante en el entrenamiento científico para los estudiantes de segundo año en adelante. En esa época, los trabajos de laboratorio se constituyeron en cursos anuales, en los cuales los alumnos realizaban trabajos prácticos en anatomía, histología y embriología, participaban de alguna investigación o desarrollaban sus propios trabajos científicos bajo la dirección de Fernández. Este profesor, promovió que no se tomara examen a los alumnos de anatomía comparada si antes no exhibían la boleta de asistencia a su laboratorio. De esa manera, esta actividad se consideró como obligatoria hacia 1910 y para la formación en zoología se exigió como mínimo haber asistido a dos de estos cursos. Para ello, el laboratorio de zoología se mantenía abierto diariamente de 8 a 11 hs. por la mañana y de 13 a 17 hs. por la tarde. Este lugar tenía capacidad para el trabajo individual de diecisiete alumnos, aunque sólo disponía de trece microscopios. Para los ejercicios prácticos de zoología general, a los que asistían alumnos de química y farmacia, se dividían los alumnos en dos o tres grupos por vez y en algunos casos se recurría al préstamo de microscopios de los profesores ${ }^{83}$. Para la atención de

\footnotetext{
${ }^{82}$ Hopwood 1999.

${ }^{83}$ Hasta mediados de la década de 1910, el laboratorio de zoología se usaba para la enseñanza de los cursos de zoología general y especiales dictados por Fernández; el de zoogeografía de Carlos Bruch y
} 
estas tareas, Fernández consiguió un cargo de jefe de trabajos para su discípula: María Isabel Hylton Scott. Este profesor prestó una gran dedicación a las actividades docentes, preocupándose por entrenar a algunos alumnos dentro de su línea de trabajo y fomentar la organización de los estudios como en las universidades de tipo germánico con una mayor especialización y entrenamiento en los trabajos de laboratorio, como se analiza a continuación.

\section{4. Especialización y formación de los primeros egresados}

La necesidad de revisar el primer plan de estudios, sobre todo ante la falta de alumnos fue planteada en el Consejo Académico por el químico y vicedirector del Museo, Enrique Herrero Ducloux, en Abril de $1909^{84}$. Ese año no se había inscripto ningún nuevo estudiante y en total sólo se contaba con una alumna regular que había ingresado en 1906. De hecho, con el primer plan de estudios de ciencias naturales cursaron algunos alumnos, que poco tiempo después abandonaron o continuaron estudiando en Buenos Aires u otra carrera. Sólo Carolina Spegazzini completó la licenciatura ${ }^{85}$ y Teodoro de Urquiza el doctorado en 1912, pero con el plan de estudios vigente a partir de 1910 y algunas concesiones en cuanto a la duración de los cursos y exámenes.

En 1909, se consideró que la falta de interesados en esta carrera y la continuidad de los que habían ingresado se debía a deficiencias en el plan de estudios ofrecido por la institución y se propuso una revisión del mismo. Para el tratamiento del tema se nombró una comisión especial formada por el Herrero Ducloux, Miguel Fernández y Santiago Roth. Como se mencionó en el capítulo anterior, en diferentes

\footnotetext{
algunas materias prácticas de química y farmacia. A partir de 1914, la enseñanza de estas últimas se trasladó a los laboratorios de esa Escuela que funcionaban en la Facultad de Agronomía y Veterinaria, por un lado, debido a la cantidad de alumnos, y por otro, porque Fernández reclamó el uso del laboratorio de zoología para el entrenamiento de sus estudiantes y la realización de los trabajos de investigación para las tesis doctorales.

${ }^{84}$ En las Actas del Consejo Académico se menciona que hubo debates con respecto a la modificación del plan de estudios, pero ellos no quedaron registrados ni tampoco hay indicios que permitan conocer cuales fueron las cuestiones en disidencia.

${ }^{85}$ En Abril de 1909, el Consejo Académico autorizó a los profesores para que pusieran a Carolina Spegazzini, única alumna de ciencias naturales en condiciones de dar examen, debiendo dejar constancia de su asistencia al Museo y los laboratorios. Cuando se presentó el nuevo plan de estudios en 1909, esta alumna solicitó cambiar de plan en la orientación botánica, pero el Consejo Académico no aprobó el cambio, porque en esos meses todavía el plan no había sido aprobado oficialmente por el Poder Ejecutivo. Posteriormente continúo el doctorado en ciencias químicas.
} 
ocasiones como, por ejemplo, las Asambleas Generales de Profesores de la Universidad, estos dos últimos profesores manifestaron la necesidad de organizar los estudios sobre la base de la libertad de aprender por parte de los alumnos y libertad de enseñar para los docentes, como se realizaba en las universidades de tipo germánico. Ambos sostenían que había que indicarles a los alumnos un mínimo de materias y darles la libertad de completar su formación eligiendo cualquier asignatura de las ofrecidas por la Universidad. Precisamente, una organización de este tipo se bosquejó en el diseño del nuevo plan de estudios.

En octubre de 1909 fue aprobado por el Consejo Académico un nuevo plan para ciencias naturales y la reorganización de estos estudios en una Escuela por cada disciplina practicada en la institución ${ }^{86}$. En cierta forma, esto retomaba la idea inicial de 1906, que no se había logrado consolidar. Por otra parte, la agrupación de materias afines en una misma unidad fue apoyada por el presidente de la Universidad y en esa misma época, también se aplicó a la reorganización de los estudios en la Facultad de Ciencias Físicas, Matemáticas y Astronómicas. En el caso de las ciencias naturales, la división en Escuelas se vinculó con la organización y dirección de las cuestiones relacionadas con la enseñanza, pero no introdujo cambios en las unidades de investigación de las secciones del Museo. Las tareas docentes se repartieron en cuatro Escuelas: a) Ciencias geológicas, que ofrecía cuatro especializaciones: Geología, Mineralogía, Geografía y Paleontología; b) Botánica; c) Zoología, con Anatomía Comparada; d) Ciencias Antropológicas, que comprendía las materias de antropología, etnografía, arqueología y lingüística, y dos especializaciones: Antropología y Etnología, que compartían dos materias complementarias en común: arqueología y geografía.

En el nuevo plan de estudios que entró en vigencia en 1910, se tendió a sentar las bases para una formación especializada en una de las disciplinas ofrecida por alguna de estas Escuelas, tanto para la licenciatura (tres años) como para el doctorado (cuatro años) ${ }^{87}$. Los estudios de cada especialidad comprendían los diversos cursos de la materia principal que había elegido el alumno y de las materias complementarias establecidas para cada orientación. Aunque no se determinaba la cantidad mínima de cursos que se debía aprobar, los alumnos que terminaron con este plan cursaron trece o más materias. Además, para acceder a cualquiera de los dos títulos era necesario

\footnotetext{
86 UNLP 1910.

${ }^{87}$ Véase Planes de estudios en el Anexo.
} 
rendir un examen general sobre la materia principal (especialidad) y además, presentar una tesis para el doctorado. En este sistema no se estableció ningún ciclo general o introductorio ni una secuencia de materias por año de estudio o complejidad como en el primer plan y como era frecuente en la organización de otras carreras en las universidades argentinas. Como se señaló en el Capítulo I, en Argentina la Universidad se había constituido en el ámbito oficial que regulaba la habilitación para el ejercicio de las profesiones. A falta de la institución europea del Examen de Estado, generalmente se sostenía que las Facultades argentinas debían supervisar y sistematizar el ordenamiento de los estudios debido a que eran las responsables por la emisión de los títulos de habilitación profesional. En ese sentido, se reconocía que las autoridades académicas tenían la obligación de establecer un curriculum reglamentado y exigir el cumplimiento del mismo. La existencia de planes de estudios oficiales y programas que fijaban los contenidos de cada asignatura, parecía contradecir el principio de libertad de la ciencia y el estatuto del profesor universitario, según reclamaban los científicos alemanes o formados en esas universidades. En ese sentido, el nuevo plan de estudios para ciencias naturales parecía basarse en este último modelo, organizado sobre la libertad de aprendizaje de los alumnos y de enseñanza por parte de los docentes, y en donde la Facultad sólo exigía que los alumnos cursaran una cantidad mínima de cursos antes de presentarse a los exámenes finales y una tesis de investigación para obtener el diploma de doctor.

Entre las exigencias mínimas del nuevo plan, no se incluyeron materias de física, asignatura sumamente criticada por los alumnos durante 1906, ni de matemáticas, que sólo se fijó como materia complementaria de geografía. Tampoco los conocimientos de dibujo que se vinculaba con la práctica del naturalista tanto de campo y gabinete, estuvieron comprendidos en este plan. Sólo se mantuvo la asignatura de Topografía como requisito para la especialidad en Geología y Geografía. Hacia la mitad de la década del 1910 se ofrecería otro saber para el registro e ilustración de la información: la fotografía. La organización de un curso práctico de fotografía estuvo a cargo de Carlos Bruch, quien fue nombrado profesor auxiliar de fotografía. Esto no se incorporó de forma oficial sino que se ofreció como curso libre, abierto a cualquier estudiante o interesado. Por otra parte, este cargo estuvo más orientado hacia actividades técnicas que docentes, incluyéndose la preparación de material para las clases y fotografías para los trabajos científicos. Es de destacar, que las tesis doctorales que se presentaron a partir de esta época, incorporaron 
ilustraciones fotográficas de los materiales estudiados como un apoyo visual y una representación de lo expuesto verbalmente ${ }^{88}$.

Con el nuevo plan de estudios en ciencias naturales se comenzaron a inscribirse algunos alumnos a partir de 1911. La mayoría provenían de otras carreras de La Plata o Buenos Aires, y al mismo tiempo, solicitaban una de las becas de estudio que se habían incorporado en el presupuesto universitario para incentivar estos estudios. En general, a esos estudiantes se les reconocieron como aprobadas y equivalentes varias asignaturas, por lo que sólo cursaron algunas materias que le faltaban. Paralelamente, la Facultad reforzó la propaganda de las distintas carreras que ofrecía, a través de la edición de folletos y notas periodísticas, y también concedió algunas facilidades a los alumnos, como inscripciones condicionales a los que adeudaban el título secundario o los que pagaban fuera de término. En la práctica, el nuevo plan implicó una importante reducción en la cantidad de materias que debían aprobar los estudiantes y una disminución de los años necesarios para completar los estudios. De esa forma, hacia 1912 la carrera de ciencias naturales pudo contar con cinco alumnos regulares y los primeros estudiantes en completar el doctorado: Teodoro de Urquiza (en antropología) y el francés Eduardo Carette (en zoología). Ese año, el vicedirector Herrero Ducloux presentó en el Consejo Académico una propuesta para tratar de vincular al Museo a los ex-alumnos que se distinguieron por su concentración y competencia. En el marco de esa propuesta, se resolvió nombrar a Carette profesor adjunto de paleontología y solicitar oportunamente al Consejo Superior la creación de dicho puesto, que se concretó al año siguiente. Posteriormente, Carette se encargó de las actividades de la sección de paleontología y de la organización de cursos libres sobre paleobotánica y paleozoología. Este alumno fue el único que por esos años que se interesó por los estudios paleontológicos y las autoridades de la Facultad gestionaron una beca de perfeccionamiento para que pudiera profundizar su formación en Suiza y Alemania. Su viaje se vio frenado al comenzar guerra europea en agosto de 1914. Al año siguiente, aunque se había conseguido disponer del fondo para esa beca, las autoridades académicas decidieron comunicarle a Carette la imposibilidad de que realice ese viaje, ya que era necesaria su presencia en la Sección donde prestaba servicios, especialmente para que confeccionara el catálogo de la misma. En los siguientes años, frente a los ajustes

\footnotetext{
${ }^{88}$ En la mayoría de los casos, los alumnos agradecieron la ayuda prestada por Carlos Bruch en el trabajo fotográfico.
} 
económicos y los recortes presupuestarios estas becas desaparecieron hasta la década de 1920, cuando se comenzaron a otorgar nuevamente algunas a estudiantes de áreas como ciencias exactas, químicas y literatura, aunque desde la dirección del Museo no se gestionó ninguna beca para sus estudiantes.

El primer doctor en ciencias naturales del Museo, Teodoro de Urquiza no se vincularía a la Institución después de terminar sus estudios. Había ingresado en 1906 y luego de desaprobar varias materias decidió continuar sus estudios en la Facultad de Ciencias Exactas, Físicas y Naturales de Buenos Aires. Al establecerse el nuevo plan en el Museo, solicito su inscripción en la especialidad de Antropología. Su tesis doctoral, dirigida por Lehmann-Nitsche, fue la primera en antropología que se dedicó al problema del hombre fósil, tema muy controvertido en los primeros años del siglo XX. Como ha indicado Irina Podgorny, en esa tesis se analizó el problema de la edad de la Formación Pampeana y el "atlas" hallado por los hermanos Ameghino en el yacimiento de Monte Hermoso, que se había dado a conocer como restos de un precursor del hombre. Teodoro de Urquiza, como su director, combinó aparatos y técnicas que se adaptaran a su objeto de estudio, elaborando una serie de medidas y correlaciones que le ayudaron a concluir que el atlas era de un individuo de un género Homo pero no sapiens, opinión divergente de la de Ameghino ${ }^{89}$. Después de presentar la tesis, este doctor y profesor de ciencias naturales no siguió estudiando este tema ni dedicándose a investigaciones científicas, sino a la enseñanza y dirección de una Escuela de Criminología. Lehmann-Nitsche tampoco continuaría con el tema del hombre fósil y abandonaría las investigaciones somatológicas y antropométricos para dedicarse a estudios de folklore popular, lenguas y mitologías indígenas. Esto no implicó un cambio en la orientación de sus clases de antropología que continuaron girando en torno al estudio físico del hombre. Por otra parte, esta materia se dictó principalmente como asignatura complementaria para los alumnos de zoología, ya que las especializaciones en antropología y etnografía no atrajeron estudiantes. En cuanto a la materia de Etnografía, esta estuvo a cargo de Luis María Torres y sólo funcionó para los alumnos del profesorado de geografía y posteriormente para estudiantes de correlación de la Facultad de Ciencias de la Educación.

El tercer alumno en completar el doctorado en ciencias naturales fue María Isabel Hylton Scott en 1916, con una tesis sobre el desarrollo embrionario de una

\footnotetext{
${ }^{89}$ Podgorny e.p.
} 
especie de peces vivíparos y la formación de su sistema respiratorio, realizada en el laboratorio de zoología bajo dirección de Miguel Fernández ${ }^{90}$. Unos meses después terminaría su tesis en zoología el futuro esposo de esta alumna: Max Birabén, con un trabajo sobre determinación y clasificación de especies de un grupo de invertebrados acuáticos, reunidos por él en algunos viajes y principalmente en las inmediaciones de la ciudad. Durante la década de 1910 la especialidad en zoología atrajo a la mayoría de los estudiantes que se inscribían en la carrera de ciencias naturales ${ }^{91}$. Después de la jubilación del botánico Carlos Spegazzini en 1912, la jefatura de la Escuela de Botánica se fusionó con la de Zoología, formado la Escuela de Botánica y Zoología, también llamada indistintamente de Ciencias Naturales o Biología, bajo la dirección de Miguel Fernández.

A principios de 1914 este profesor presentó un proyectó para modificar el plan de estudios de ciencias naturales y la reglamentación del mismo. Si bien en líneas generales, la propuesta del Jefe de la Escuela de Botánica y Zoología mantenía la misma estructura de especialización que el anterior, no obstante ello generaría un importante debate durante todo el año ${ }^{92}$. Para estudiar el asunto se nombró una comisión compuesta por este zoólogo y dos consejeros académicos, que no eran profesores de ciencias naturales sino de química y farmacia: Guillermo F. Schaefer y Pedro T. Vignau. Fernández, en minoría, defendió su proyecto y argumentó en pro del sistema de especialización, sobre todo teniendo en cuenta que los que ingresaban en ciencias naturales provenían de otras carreras universitarias por lo que disponían de una cierta formación. Los profesores de química manifestaron su desacuerdo tanto con relación al plan de estudios como a la reforma del sistema de evaluación de la tesis doctoral y presentaron un dictamen en disidencia. Principalmente criticaron el alto grado de especialización propuesto para las ciencias naturales, que según los profesores de química no era viable y útil para el contexto nacional. En este sentido, indicaron que en la Argentina todavía no estaban dadas las condiciones para ello, debido a la falta de: a) una tradición científico-cultural como en el viejo continente y b) una instrucción preparatoria intensiva, que permitiera a las Universidades brindar

\footnotetext{
${ }^{90}$ Hylton Scott 1928. Su tesis no se publicó en la Revista del Museo de La Plata como había recomendado su director y el jurado de tesis. Se publicó doce años después en los Anales del Museo de Buenos Aires, en el marco de las discusiones por la contratación del zoólogo alemán E. Dautert.

${ }^{91}$ Véase en el Anexo un cuadro con las orientaciones elegidas así como las inserciones y trayectoria profesional inicial de los primeros alumnos de ciencias naturales.

${ }^{92}$ Las discusiones sobre el plan de estudios se dieron en varias reuniones del Consejo Académico durante 1914 y se pueden seguir en: AHMLP, Actas del Consejo Académico, Libros I y II.
} 
una especialización en alguna carrera como sucedía en algunos países europeos. Al mismo tiempo, se desconfiaba que la especialización propuesta por Fernández se pudiera alcanzar en los tres años de estudio proyectados o en más años. Por otra parte, según se registró en las Actas del Consejo Académico, los profesores de química se sintieron molestos por las críticas que presentó ese profesor en su informe sobre la organización de los estudios en las facultades argentinas.

El vicedirector del Museo, Herrero Ducloux, también participó en la discusión y en líneas generales coincidió con lo manifestado por los profesores de química, señalando que tanto la generalización y como la especialización eran buenos si se aplicaban en el ambiente adecuado. Para conciliar las opiniones dispares, propuso que se confeccionara un plan intermedio, sujeto a modificaciones pero que respondiera a las condiciones nacionales de ese momento. Fernández continuo insistiendo en que por lo menos en una materia, el alumno debía poseer conocimientos especiales y se decidió que el proyecto fuera analizado por todos los profesores de ciencias naturales. En noviembre de ese año, se volvió a discutir el plan de estudios. Después de algunas discusiones, Herrero Ducloux señaló que en ese tema estaban involucrados dos cuestiones: a) el plan de estudios propiamente dicho y b) el sistema de exámenes parciales y finales, que implicaba una modificación en las ordenanzas vigentes para toda la Facultad. Se resolvió tratar por separado esos dos asuntos, comenzando por el primero. Este tema reanudó los debates en torno a dos propuestas de formación: a) una de carácter general en ciencias naturales y con una especialización tardía, b) una especializada en una disciplina.

El consejero Pedro Vignau insistió nuevamente en que se estableciera un plan general mínimo de tres o cuatro años y luego una especialización de uno o dos años, en una materia elegida por el alumno. Este profesor consideraba conveniente una formación general en función de la inserción laboral del futuro diplomado y de la falta de un ambiente para el trabajo especializado. En este sentido, señalaba como necesario que el estudiante de ciencias naturales dispusiera de: "...una serie de conocimientos generales que lo habiliten para el desempeño completo de su profesión, sobre todo por tratarse de un país en formación como este, donde un diplomado en Ciencias Naturales se ve obligado a intervenir constantemente en las diversas ramas de la carrera a causa de la falta de especialistas..."93. Enrique Herrero Ducloux opinó en el

\footnotetext{
${ }^{93}$ AHMLP, Actas del Consejo Académico, Libro II, reunión del 6/11/1914, folio 4.
} 
mismo sentido, "por no ser posible entre nosotros constituir de improviso plan y proyectos análogos a los que se sigue en Europa, que posee naciones con una civilización resultante de largas evoluciones"94. Es interesante señalar, que en relación con la organización de los estudios químicos, este profesor también se había opuesto a la creación de especializaciones, como la de ingeniería química o químico industrial que se promovía en Buenos Aires y posteriormente en otras universidades. Herrero Ducloux había defendido una formación general para el doctorado de química, de forma de que los graduados contaran con las herramientas tanto para insertarse en los distintos ámbitos profesionales como para los que deseaban dedicarse a las investigaciones científicas ${ }^{95}$. Al igual que otros profesores, era partidario de que la creación de estudios especializados debían dejarse para después de contar con un grupo importante de profesionales.

En la discusión por el plan de ciencias naturales, el vicedirector del Museo promovería elaborar un plan intermedio que conciliara ambas tendencias. En el Consejo Académico, el profesor de zoología continuó defendiendo la formación especializada desde el primer año, el cual había sido examinado por todos los profesores de ciencias naturales. Finalmente se aprobó este proyecto en sus aspectos generales $^{96}$, aunque no se trató la reforma de los exámenes y las tesis doctorales, ya que ello afectaba a todas las Escuelas de la Facultad. Posteriormente se estableció que para obtener el título de doctor se debía presentar una tesis y aprobar un examen escrito de cuatro horas sobre un tema elegido por el candidato entre tres propuestos por la Mesa Examinadora, y un examen oral de una hora sobre la totalidad de los cursos de la materia principal, dentro del cual se incluirían preguntas sobre el trabajo de tesis ${ }^{97}$.

\footnotetext{
${ }^{94}$ Ibid.

${ }^{95}$ Herrero Ducloux manifestó estas ideas en varias conferencias y artículos, así como en alguno de los debates en el Consejo Académico y en diferentes congresos. Véase entre otros: Herrero Ducloux 1923.

96 El tratamiento de los aspectos particulares del proyecto de plan de estudios también suscitó discusiones. Vignau opinó que entre las materias elegibles había algunas que no eran apropiadas al conjunto del plan, como por ejemplo: Anatomía de los animales domésticos, que correspondía a la formación de un veterinario; o Matemáticas superiores, ya que sostenía que no podría ser cursada por alumnos que seguían un plan que carecía de materias previas y elementos de matemáticas, que le permitieran el estudio complicado de las matemáticas superiores. Fernández explicó que esa materia era elegible y que el alumno que la seleccionara se prepararía especialmente para ponerse en condiciones de rendirla. Después de un cambio de ideas entre los consejeros se aprobaron las materias optativas propuestas. Es de destacar que las dos asignaturas optativas en discusión no fueron elegidas por ninguno de los alumnos.

${ }^{97}$ UNLP: 1915.
} 
El nuevo plan de estudios fue sancionado por el Poder Ejecutivo el 30 de enero de 1915 y estuvo en vigencia hasta 1925. En él se reconocía un sólo título académico: el de doctor en ciencias naturales, explicitándose en el diploma la especialidad elegida, según los cursos que el alumno hubiera realizado como parte de la formación en la materia principal. Se reconocieron las siguientes especialidades (materias principales): a) Geología y Mineralogía, b) Zoología, c) Botánica, d) Antropología y Etnología. En la materia principal el estudiante debería seguir todos los cursos que sobre ella se dictaran en el Instituto, o por lo menos cuatro, cuya duración no sería menor de dos horas semanales cada uno durante un año, y dos cursos como mínimo de trabajos de laboratorio, sin incluir en estos el trabajo de preparación de la tesis ${ }^{98}$. A cada materia principal le correspondían cuatro materias accesorias, de las cuales tres eran obligatorias y una podía ser elegida por el candidato de entre una lista preestablecida. Entre estas últimas se incluyeron asignaturas no comprendidas entre las que se dictaban en el Museo, como: Física general, Matemáticas superiores, Metalogenia. Microbiología, Fisiología y Anatomía de los animales domésticos. Sin embargo, la mayoría de los estudiantes se inclinaron por las materias que ofrecían los profesores de ciencias naturales ${ }^{99}$.

Al igual que con el plan anterior, los alumnos completaban su formación con un mínimo de trece materias aprobadas. En el caso de los que siguieron la especialidad en zoología, nueve de esas asignaturas correspondían a cursos dictados por los profesores de esa disciplina, entre las que se incluía el curso de Trabajos de Laboratorio. Si bien en esa época, en botánica se disponía de un laboratorio y se dictaban clases prácticas de reconocimiento de ejemplares, preparación de herbarios y preparados microscópicos, esto no se consideró como un espacio formativo separado de los cursos ordinarios. En cambio, en zoología, el entrenamiento en el trabajo en el laboratorio se constituyó como un curso independiente, que implicó, además, una instancia de evaluación y aranceles especiales. Para los estudiantes de la especialidad eran obligatorios a partir del segundo año y se exigían por lo menos dos cursos anuales como mínimo. Fernández supervisaba estos trabajos y calculaba que los alumnos en promedio trabajaban en el laboratorio no menos de 300 horas anuales y más del doble para los que realizaban sus propias investigaciones. Según este

\footnotetext{
${ }^{98}$ UNLP 1915. Véase este plan de estudios en el Anexo.
} 
profesor, de esta forma se brindaba una formación científica tan intensa como en las universidades europeas, aunque en varias oportunidades reconoció como una deficiencia la falta de las más importante revistas de "zoología científica" (anatomía, histología, embriología y biología experimental): "en cualquier ciencia, los trabajos ya publicados constituyen la base de toda investigación posterior; son un "instrumento de trabajo", para nosotros tanto o más necesario que el microscopio o el micrótomo" 100 .

Para dar a los alumnos una preparación sólida en la especialidad de zoología se alternaban todos los años los cursos superiores especiales. De esa forma se esperaba que los alumnos, además de Zoología general pudieran cursar: anatomía comparada, invertebrados, vertebrados, embriología, herencia; biología y sistemática de insectos y zoogeografía. Estas dos últimas materias estaban a cargo de Carlos Bruch mientras que el resto de los cursos fueron dictados por Fernández. En 1915, este profesor dictó por primera vez un curso libre sobre herencia, que comprendió una introducción a los métodos de la estadística de la variación y una exposición de las investigaciones más importantes sobre herencia experimental ${ }^{101}$. A estas clases se invitó al personal docente y estudiantes de las demás Facultades de la Universidad, pero sólo asistieron los alumnos propios, algunos jóvenes graduados de la Facultad de Ciencias Naturales y profesores del Colegio Nacional. Posteriormente se dictaría en otros años, alternándose con los otros cursos especiales.

También a mediados de la década de 1910 se establecieron acuarios en el laboratorio de zoología y a principios de 1916 se realizó un viaje con los alumnos a Puerto Madryn para incentivar la enseñanza de la biología marina, el estudio de ejemplares vivos de fauna acuática y recolectar especimenes. El material reunido se utilizaría para trabajos científicos de los estudiantes, apoyar la enseñanza y otros ejemplares se destinaron a las salas de exhibición. Por otra parte, algunos de los alumnos que comenzaban a trabajar en sus tesis doctorales o realizar otros trabajos de

\footnotetext{
${ }^{99}$ AHMLP, Libro de Registro de Alumnos. En este registro, las materias aprobadas por los alumnos correspondían a los cursos dictados principalmente por los profesores de ciencias naturales y algunos de las otras Escuelas de la Facultad.

${ }^{100}$ En ese sentido agregó: "Sólo un dominio completo de la literatura permite al investigador formular, a la vez, problemas que puedan servir de punto de partida para nuevos estudios, y el que comience un trabajo sin orientarse con el mayor esmero sobre todo lo ya existente al respecto, siempre correrá el peligro de dedicar sus energías a la solución de asuntos ya puestos en claro desde hace tiempo." Fernández 1918a: 117. Este profesor en varias oportunidades había pedido obras especiales y revistas para los trabajos de investigación que estaban efectuando los alumnos, además insistiría en que el laboratorio de zoología contara con su propia biblioteca.

101 "Escuela de Zoología y Botánica" en: Lafone Quevedo1917.
} 
investigación, se inclinaron por investigar sobre peces, ranas y microorganismos acuáticos, que presentaban la ventaja de ser fácilmente manipulables en el laboratorio y se podían conservar frescos o vivos para realizar diferentes estudios. También en la Escuela de Ciencias Naturales de Buenos Aires, algunas tesis doctorales - como la de J. M. de la Rúa en 1911- se dedicaron al estudio de microfauna. Asimismo, en 1914 Martín Doello Jurado desde el Museo Nacional de Historia Natural de Buenos Aires, también comenzó a realizar expediciones a la costa atlántica sur para estudiar y recolectar ejemplares de invertebrados marinos. Esas expediciones fueron fomentadas por invitación del comandante Pedro Casal del buque "Patria", que tenía la misión de realizar estudios hidrográficos en la costa sur de la provincia de Buenos Aires, a la cual también invitaría al geólogo del Museo de la Plata, Moises Kantor, para realizar estudios sobre el fondo marino. Paralelamente desde Córdoba, el profesor alemán Hans Seckt promovía las investigaciones limnológicas y la necesidad de articular estudios químicos, bacteriológicos, botánicos y zoológicos en lagos, ríos y otros depósitos de agua $^{102}$. Los estudios de organismos acuáticos y los estudios oceanográficos cobraron mucha importancia durante la década de 1920, constituyendo un nuevo campo de estudio al que se dedicarían varios naturalistas ${ }^{103}$.

A principios de 1918, el presidente de la Universidad platense, Rodolfo Rivarola, convocó a una Asamblea General de Profesores para analizar el perfil de los estudios universitarios y evaluar la necesidad de reformas en la organización de la enseñanza. Para ello se realizó una encuesta previa a todos los docentes, consultándoles acerca de los fines a los que debía responder la enseñanza universitaria, si los planes de estudios y métodos de enseñanza eran adecuados y cuales serían las reformas necesarias ${ }^{104}$. Con respecto de la formación en el área de ciencias geológicas, sus profesores consideraron que si bien los programas eran adecuados para una preparación científica, en cambio, resultaban insuficientes para la aplicación profesional de los estudios geológicos, donde el futuro egresado estaba

\footnotetext{
102 López y Mariazzi 1994.

${ }^{103}$ En 1923, Doello Jurado promovería en la Universidad de Buenos Aires la creación una estación hidrobiológica de agua dulce, aunque ese proyecto no llegó a concretarse. Doello Jurado 1924. Hacia 1928, a través de las gestiones de este investigador se consiguió que el Estado financiara la creación de la primera estación marítima en Quequén, bajo la dirección del Museo de Historia Nacional de Buenos Aires. Camacho 1971. En esa época, también funcionaba una Comisión Nacional de Estudios Oceanográficos que trabajaba principalmente en Mar del Plata. Desde el Museo de La Plata se enviaría a algunos ayudantes alumnos y preparadores para estudiar y reunir colecciones en las instalaciones de esta última.

${ }^{104}$ Las respuestas de los profesores y los debates en esa reunión se pueden examinar en: "Octava Asamblea General de Profesores". BUNLP, 1918, I, 5.
} 
llamado a dar informes y practicar estudios de orden económico. Moises Kantor y Eduardo Carette proponían intensificar los estudios prácticos sobre el terreno, a través de excursiones obligatorias de los estudiantes e introducir algunas materias relacionadas con la explotación de la minería. Estos estudios eran los únicos que se consideraron de aplicación económica inmediata y con un campo profesional más amplio que las otras ramas de las ciencias naturales. En cambio, para los graduados en las especialidades de botánica y zoología se consideraba que su campo profesional se ubicaba principalmente en torno a la educación secundaria y universitaria. Por otra parte, esto también se relaciona con las inserciones profesionales de los profesores universitarios en estas áreas. Con excepción de los docentes de geología, el resto de los profesores de ciencias naturales del Museo de La Plata se desempeñaba en la docencia universitaria y algunos también trabajaban en establecimientos de educación media. Por su parte, Carlos Bruch estimó que en la formación en ciencias naturales había que otorgar mayor importancia a los estudios sistemáticos y biológicos, los cuales permitirían el aprovechamiento económico de la fauna y flora local y una forma de desarrollar una ciencia aplicada. Otros profesores como Santiago Roth, Eduardo Carette y Miguel Fernández consideraron que los programas y planes de estudio vigentes eran adecuados para atender tanto a una preparación científica como para el ejercicio de la docencia secundaria, ya que daban a los alumnos un amplio margen de libertad para elegir las materias complementarias y se adaptaban a las distintas necesidades e inclinaciones individuales. Según el Jefe de la Escuela de Zoología y Botánica: "las escuelas de ciencias naturales no tienen por objeto preparar a profesiones netamente prácticas, sino formar para sus especialidades: $1^{\circ}$ investigadores; $2^{\circ}$ profesores secundarios. Para ambos una preparación científica amplia e intensa a la vez es indispensable y los planes de estudio respectivos deberán coincidir en todo lo posible. No otorgando el Museo hasta ahora títulos de profesorado secundario en sus respectivas especialidades, es necesario crearlos.... Sería quizás útil que existieran cursos sobre capítulos especiales, así como biología aplicada (para aspirantes a puestos de investigación económica en la administración pública) y de sistemática y biología de animales y plantas argentinas (para los aspirantes al profesorado argentino)..."105.

${ }^{105}$ Respuesta de Miguel Fernández a la encuesta de la Presidencia de la Universidad platense. Ibíd: 215. 
Como se analiza en el siguiente capítulo, este zoólogo promovería algunas iniciativas tendientes a articular la formación del científico con la del profesor de enseñanza secundaria. Asimismo, con la ampliación del presupuesto a fines de 1918 se había acordado la necesidad de crear un cargo de profesor en zoología sistemática. Sin embargo, ninguna de estas propuestas se lograría concretar. Como se señaló en el capítulo anterior, las transformaciones operadas en el ámbito universitario platense como efecto del movimiento reformista, provocaron la reforma de los estatutos de la Universidad platense en 1920 y una revisión de los reglamentos y ordenanzas vigentes en cada unidad académica. A ello se sumarían los cambios en las autoridades universitarias y en el Museo de La Plata. Después de la reforma de los estatutos universitarios se incorporaron representantes alumnos y diplomados al Consejo Académico del Museo de La Plata. Los graduados insistieron en una revisión de los planes de estudios y de las ordenanzas de esta institución para reglamentar el uso del edificio, las adscripciones y su incorporación a los trabajos de laboratorios y excursiones. En esa época, en distintas secciones se había comenzado a contar con algunos ayudantes-alumnos y colaboradores. Las secciones de geología y mineralogía a cargo de Kantor y la de botánica, bajo la dirección de Scala, contaban con un ayudante alumno cada una. Especialmente en torno al Laboratorio de Zoología se había formado un grupo de alumnos y graduados y se había comenzando a institucionalizar un espacio de "seminario" para actualización y debate sobre temas de zoología y paleontología. En ese ámbito se organizarían conferencias, charlas y lecturas de trabajos. La vinculación de los graduados a la institución a través de conferencias de extensión universitaria, participación en seminarios y trabajos de investigación, fue apoyada en el Consejo Académico por los profesores Kantor, Fernández y Carette. Inicialmente también Schiller había firmado un proyecto de ordenanzas sobre estos aspectos, pero luego retiró su firma. Por su parte, Santiago Roth presentó un contra-proyecto que no llegó a tratarse y en el que reclamaba la autoridad de los jefes de departamento para decidir sobre ello.

Con respecto al plan de estudio, el principal punto de preocupación de los egresados y alumnos giraba en torno a la supresión de los exámenes generales y la tesis que se exigían en el Museo para obtener el doctorado, ya que estos requisitos restaban competencia frente a los graduados de Buenos Aires ${ }^{106}$. En esa época, en la

\footnotetext{
${ }^{106}$ En la misma época, el Centro de Estudiantes de la nueva Facultad de Ciencias Químicas de la Universidad platense, manifestó su preocuparon por esa situación y en función de ello se solicitó a las
} 
Facultad de Ciencias Exactas, Físicas y Naturales de Buenos Aires se había eliminado los exámenes generales y la presentación de una tesis para la obtención de los distintos títulos. Esto había posibilitado que los alumnos de la carrera de ciencias naturales de Buenos Aires que habían terminado de cursar pero no habían elaborado la tesis ni rendido los exámenes correspondientes se doctoraran. Los ex-alumnos y licenciados del Museo se preocuparon por esta situación "desventajosa", ya que el diploma de doctor era cada vez más requerido para ejercer en distintas dependencias y acceder a un nombramiento como profesor suplente en las universidades. Finalmente, las discusiones sobre este tema se aplazaron, para atender primero a la reglamentación de la participación de los graduados en la institución. Si bien, el Consejo Académico aprobó un proyecto con respecto a este último asunto, ello no llegó a concretarse frente a las nuevas ordenanzas para los institutos científicos que voto el Consejo Superior de la Universidad a fines de 1922. En el caso del Museo de La Plata, como se mencionó en el capítulo anterior, ello generaría ciertas discusiones en torno a la organización institucional, la autoridad del director frente a la del Consejo Académico, la definición como instituto de investigación y el espacio asignado a la enseñanza. Como parte de esos debates surgiría una nueva propuesta formativa para la carrera de ciencias naturales, como se examina a continuación.

\section{5. Naturalistas para el inventario del territorio nacional}

Las tensiones y los cuestionamientos hacia la autoridad del director del Museo que se desarrollaron durante 1923, llevaron el conflicto al Consejo Superior. Luis María Torres acusó a Miguel Fernández por sus actitudes irrespetuosas hacia las autoridades del Museo y pidió el cese de actividades de ese profesor, Eduardo Carette y Moisés Kantor, por indisciplina y no cumplir con sus tareas ni sus horarios como jefes de departamento y profesores. Recordemos que con el nuevo reglamento del Museo, el cargo de profesor estaba supeditado al del jefe de departamento y su nombramiento o destitución se efectuaba en el Consejo Superior a propuesta del director del Museo. En esa ocasión, el profesor de zoología no fue removido de su

autoridades académicas la eliminación de las tesis doctorales, proposición que no fue aceptada. El pedido de estudiantes se fundamentó en la desigualdad que se establecía con los que cursaban en la Universidad de Buenos Aires y en el desprestigio y la poca importancia científica que se le asignaba al trabajo de tesis, como se ponía de manifiesto en la falta de laboratorios, recursos y el asesoramiento de profesores para esas tareas. 
cargo, ya que no se le pudo cuestionar ni su producción científica ni su dedicación a la docencia, aunque se cuestionó su falta de "patriotismo" por haber publicado su principal investigación en idioma alemán. Las medidas disciplinarias recayeron en los otros dos profesores. Carette fue separado de su cargo y sin posibilidad de vincularse de ninguna forma al Museo. Mientras que en el caso de Kantor, se aceptó que no faltaba a sus obligaciones docentes, pero se cuestionó sus actividades como jefe de sección por lo que fue dejado cesante en ese cargo y su cátedra trasladada a otra Facultad, hasta que en 1925 se terminaría alejando ${ }^{107}$. A principios de 1924, el conflicto también se extendió hacia la jefa de trabajos de zoología, María Isabel Hylton Scott, que fue dejada cesante por no acceder a que su cargo fuera trasladado a otra dependencia de la Universidad, como propusieron algunos consejeros superiores que reconocían la competencia científica y dedicación de esta egresada del Museo. Finalmente, la organización de la enseñanza en el doctorado en ciencias naturales fue el último de los espacios de poder disputados, ya que la especialización en zoología y el entrenamiento en el trabajo de laboratorio conformaban uno de los elementos principales para la instrumentación material de los proyectos científicos e institucionales del profesor Fernández. En esa época, el Laboratorio de Zoología era el más frecuentado por los estudiantes, ya sea por los cursos de trabajo de laboratorio como por los se ocupaban de alguna investigación ${ }^{108}$. Alternativamente ante los problemas con la dirección del Museo, Fernández junto al médico alemán Christofredo Jakob (1866-1956), presentaron un proyecto para crear un Instituto de Biología animal y Neurobiología fuera del espacio del Museo ${ }^{109}$. En este instituto se pensaba combinar el entrenamiento especializado de estudiantes con el desarrollo de

\footnotetext{
${ }^{107}$ Cabe señalar que este profesor había participado activamente en las asambleas vinculadas al conflicto universitario y desde 1918 había estado escribiendo algunas obras literarias difundiendo la acción de la revolución rusa y la figura de Lenin. En 1925 pediría licencia y se ausentaría del país, por lo que las autoridades universitarias consideraron abandono de sus funciones y decretaron vacante sus cargos.

${ }^{108}$ En la Memoria de 1924 se señalaba que en el curso de Laboratorio de Zoología, ese año dedicado a vertebrados y con una duración de 160 días, se habían inscripto cinco estudiantes de ciencias naturales y uno de correlación del profesorado, además de cinco alumnos que desarrollaban sus propios trabajos de investigación. También ese año había terminado sus tesis en zoología América del Pilar Rodrigo, jefe de trabajos prácticos en el Departamento de Botánica. Torres 1925.

${ }^{109}$ En 1924 Fernández elevó un informe al director del Museo, argumentando la necesidad de crear un Instituto independiente del Museo, ya que: "los fines de un instituto como el proyectado no podrán realizarse dentro del Museo. Necesita aquel ante todo de locales suficientes y apropiados a sus fines, así como de una cierta extensión de terreno para la cría de animales de experiencia, aparte de que las necesidades de los estudios que en el que se llevarán a cabo no siempre podrían conciliarse con el cuidado y seguridad que el Museo debe ofrecer a sus valiosas colecciones..." AHMLP, Copiador Departamento de Biología, folio 3. A su vez, Torres había comenzado a gestionar un lugar para ello en la Facultad de Agronomía o Veterinaria.
} 
investigaciones científicas, principalmente a nivel experimental y genético. Pese a las reiteradas presentaciones, esto no sería atendido en el Consejo Superior de la Universidad.

A fines de 1924, el director del Museo propuso revisar el plan de estudios vigente para examinar si era necesaria alguna reforma, sobre todo por las alteraciones que había sufrido la composición del profesorado en el Instituto. Para ello, se nombró una comisión especial integrada por Roberto Lehmann-Nitsche, el profesor suplente de zoología Horacio Arditi, Augusto Scala y Miguel Fernández, que no funcionó regularmente por falta de quorum. El profesor de botánica fue el principal promotor del cambio de plan de estudio, sobre todo en lo referente a la eliminación de las especialidades. Su propuesta era volver a un plan menos especializado que brindara a los alumnos una formación general después de cuatro o cinco años de estudio, dejando en claro que: "no lo hace para atraer alumnos, porque a los jefes de departamento eso no les interesa. Todos los alumnos deben seguir el mismo plan. El actual es bueno en cuanto tiende a producir especialistas bien preparados, pero esta especialización debe venir después de que el alumno haya terminado sus estudios generales."110

El cambio del plan de estudios fue tratado durante varias reuniones del Consejo Académico lo largo de 1925. De la Comisión de Enseñanza surgió un proyecto por mayoría, firmado por Scala y Arditi, y otro, en minoría, elaborado por Fernández. El proyecto de plan de estudio presentado por la mayoría apuntaba a generar "naturalistas" para el inventario de los recursos nacionales y para lo cual se propuso un plan único de cuatro años de estudios. Para justificar esta propuesta se argumentaba que la organización de los estudios vigente desde 1914, exhibía una desconexión con respecto a las necesidades del país y a la ciencia nacional. En este sentido, Scala indicaba que: " la experiencia adquirida durante mas de diez años del actual plan de estudios del Doctorado en Ciencias Naturales, ha demostrado, por los escazos resultados obtenidos en la práctica, que tal plan, aparentemente viable, no ha respondido a las necesidades de nuestro ambiente científico, ni a las menos imperiosas de nuestro territorio biológico, pese al enorme esfuerzo realizado por numerosos naturalistas, y a la inmensa como dispersa bibliografia reunida en todos los capitulos de la vasta obra de las ciencias naturales; baste decir que su inventario razonado y metódico esta aún por hacer. Esta obra primordial debe realizarse, sin

110 "39a . Sesión ordinaria del Consejo Académico del Instituto del Museo" (29/11/1924) en: BUNLP, 1924, VIII: 692. 
embargo, en primer término, y ella exige naturalistas habilitados, no en determinadas especialidades, sino con una preparación general que abarque mayor superficie aunque menos profundidad. Ahora bien, el número de alumnos que ingresan a nuestra Escuela es reducidísimo, y si este total se subdivide aun por el número de "especialidades" que hoy tenemos, resulta una escasez realmente alarmante del tipo medio de naturalista, que es el que hoy por hoy y aun por muchos años deberemos fomentar y estimular...."111

Mientras se enfatizaba en que había que formar naturalistas con una formación general en todas las disciplinas de las ciencias naturales, desde la dirección del Museo se contrataban "especialistas" para que estudiaran determinados temas o clasificaran un conjunto particular de colecciones. También las actividades que desplegaban los profesores e investigadores del Museo, así como otros profesionales de las ciencias naturales se circunscribían a un determinado campo disciplinar. Por su parte, los alumnos consideraban que era más ventajoso una formación especializada y solicitaron a las autoridades académicas que reconsideran la aprobación de un plan generalizado, ya que: "el nuevo plan de estudios aprobado por el Consejo Académico tiene una orientación tan diferente del actual, en el que nos estamos formado y cuyo propósito de especialización juzgamos acertado, que tememos no aliente a los futuros alumnos...". 112

Alternativamente, Fernández presentó un plan de estudios que abarcaba un año general y especializaciones desde el segundo año, con materias específicas para cada disciplina $^{113}$. Al igual que lo ocurrido en 1914, las propuestas formativas giraban en torno a dos perfiles curriculares diferentes: a) naturalistas con una preparación general y que pudieran abarcar por igual los distintos ramas de las ciencias naturales para el estudio de los recursos nacionales, $\mathrm{y}, \mathrm{b}$ ) científicos especializados en una orientación y con un gran entrenamiento en el trabajo de laboratorio, dedicados a investigar problemas para el avance del conocimiento, lo que Fernández defendía como "ciencia pura", y cuyo contexto de discusión era la ciencia internacional.

Una de las dificultades que encontraba Scala, para la aplicación de la especialización, era la deficiente preparación media del alumno "que no pasa de ser

\footnotetext{
${ }^{111}$ AHMLP, Actas del Consejo Académico, Libro III, folio 242, sesión del 16/4/1925.

112 Nota con fecha del 22/6/1925, dirigida al Director del Museo y firmada por los siguientes alumnos:

Albina Bonjour, Zelmira D'Ovidio, Ernestina Lagmann, Oreste Giacobbe, María M. Job, Anita

Cortelezzi, Emiliano Mac Donagh. AHMLP, caja 34.

${ }^{113}$ Véase Plan de estudios alternativo en el Anexo.
} 
mediocre en el bachiller como en los demás profesorados oficiales"114. Frente a esa situación se consideraba que había que proveer de conocimientos informativos con una enseñanza apropiada en las aulas de la Facultad de forma que al cabo de cuatro o cinco años se pudieran obtener "jóvenes naturalistas con una preparación sólida y listos para emprender cualquier trabajo general o de especialización". Al igual que en las discusiones de 1914 se criticaba que se quisieran adoptar modelos europeos que no eran adecuados al contexto nacional: "...pretender calcar servilmente los moldes europeos que, en la inmensa mayoría de los casos, son completamente inadaptables a nuestro ambiente, y lo serán por muchos años todavía, es querer torturar inultilmente jóvenes cerebros que, aun provistos de un entusiasmo muy respetable, fracasan desde el momento que quieren poner en práctica sus aptitudes." 115

Sin embargo, a diferencia de 1914, ahora se aludía a un nuevo elemento de comparación: el grupo de doctores en ciencias naturales que se había formado en Buenos Aires con un plan de estudio generalizados y que, según Scala, constituían: "una apreciable legión de naturalistas capaces de abordar los problemas más urgentes de nuestro ambiente biológico, pues se hallan habilitados para emprender estudios generales zoológicos, botánicos, geológicos y antropológicos y en cualquier momento son capaces de dedicar su atención a una de estas ciencias, después de que una experiencia poco prolongada ha despertado en ellos una vocación, que no les ha sido impuesta ni sugerida a priori, ni escogida al acaso, como aqui ocurre debido a la poca experiencia que tiene el alumno al ingresar a nuestra Escuela de Ciencias Naturales, en donde desde el primer día, debe elegir y seguir una "especialidad"..."116.

En la propuesta de la mayoría no se negaba la especialización, pero se consideraba más adecuado que los estudiantes se dedicaran a entrenarse en una determinada orientación después de que una formación de grado general hubiese puesto al alumno en condiciones de poder elegir una especialización por "su propia voluntad". Con relación a esto último, Scala señalaba que la mayoría de los alumnos no tenía la posibilidad de elegir libremente la orientación de sus estudios: "...a la inmensa mayoría de los candidatos se los obliga por sugestiones que ignoramos, a seguir la especialidad Zoología y desde ese momento fatal el alumno polariza su

\footnotetext{
${ }^{114}$ AHMLP, Actas del Consejo Académico, Libro III, folio 243.

115 Ibid.: 243.

116 Ibid.:243.
} 
atención a dicha materia, se cristaliza en ella, se vuelve una obsesión y todas sus horas y actividad mental están pura y exclusivamente al servicio, no de una zoología nacional o integral, sino de determinados capitulos de esta ciencia y, por tanto, en perjuicio de la misma zoología, que el alumno solo conoce en mínima parte....y este acaparamiento llega a tal extremo en la actualidad que esos mismos alumnos no encuentran suficientes horas disponibles para dedicar al estudio de la materia principal accesoria, la botánica, habiendose obligado al profesor a reducir considerablemente sus horarios ..."117

$\mathrm{Si}$ bien se indicaba que a los alumnos se los "obligaba" a seguir una determinada orientación durante toda su carrera, los documentos del Archivo muestran que los estudiantes tenían la posibilidad de cambiarse de una especialidad a otra. El problema era que la mayoría de los estudiantes elegían zoología. En relación con ello, una de las principales críticas era hacia la unilateralidad que tenía el plan de estudios vigentes, aun dentro de esa disciplina. En ese sentido, una formación general era vista como una forma de contrarrestar esa tendencia y posibilitar que los alumnos se vincularan con todos los profesores del Instituto. En sus estudios comparados sobre el sistema de enseñanza superior, Burton Clark señala que la capacitación especializada genera efectos de alta fragmentación institucional, jerarquización disciplinar, concentración de autoridad así como la creación de monopolios locales. Frente a ello, la educación general pareciera proveer cierta integración simbólica en la medida en que requiere de la participación de las diversas cátedras y Escuelas para la elaboración de un "producto integrado" como el egresado con formación general ${ }^{118}$.

La propuesta de especializaciones del profesor de zoología, fue rechazada en el Consejo Académico, argumentándose: a) la falta de una buena formación científica en los estudios secundarios como para permitir las especializaciones de los estudios universitarios; b) la unilateralidad que exhibía el plan de estudios vigente, ya que provocaba que la mayoría de los estudiantes optara por zoología, y c) el exceso de horas que se proponía para el entrenamiento en el laboratorio. En cambio, para Fernández esas horas resultaban escasas y pretendía que se aumentaran el tiempo obligatorio que los alumnos debían trabajar en el laboratorio. De hecho, en su plan alternativo, se proponía que el alumno a partir del segundo año debía realizar durante su carrera dos cursos de trabajos de laboratorio en la especialidad elegida, con una

\footnotetext{
117 Ibíd.: 244.

${ }^{118}$ Clark 1991.
} 
frecuencia diaria de actividad. Para este profesor de zoología, el locus del trabajo científico se localizaba en el laboratorio, donde era posible depurar y confrontar una "verdadera vocación" por los estudios de la naturaleza. Mientras que para la formación de naturalistas y la aplicación profesional de los estudios, se consideraba necesario fomentar el trabajo de campo, las observaciones in situ, la recolección de material y su posterior determinación.

Finalmente, con la ausencia de Fernández en las discusiones del Consejo Académico, se aprobó la propuesta de formar naturalistas con una formación general. El nuevo plan, que entró en vigencia en 1926, estipulaba que las materias de primer año debían tener un carácter general e introductorio. Esto fue motivo de un nuevo conflicto con el profesor de zoología, quien dictó el primer curso de zoología en forma especializada, dedicándose a invertebrados, pese a las advertencias de las autoridades del Museo. Finalmente, este profesor presentó su renuncia en marzo de 1927 y se trasladó a la Universidad de Córdoba, donde había ganado por concurso un cargo como profesor y se insertó a trabajar junto a un grupo de investigadores alemanes. Es interesante señalar que dos de sus alumnas que estudiaban en La Plata presentaron sus tesis doctorales en Córdoba en 1928 y $1929^{119}$. En esa época, para regularizar la situación de los estudiantes del Instituto del Museo que cursaban con el antiguo plan se concedió dos años para presentar sus tesis doctorales. En 1928 se estableció un nuevo reglamento para las tesis doctorales, en el cual se determina que esos trabajos debían ser dirigidos por un docente de la Institución.

Para completar el entrenamiento de los que debían llevar a cabo el inventario de los recursos del país y la identificación de nuevas especies, se incorporó en el nuevo plan de estudios un curso de latín con un programa especial de nomenclatura científica, a cargo del secretario del Museo, Maximiliano de Barrios. También se estableció que los alumnos debían realizar como mínimo dos excursiones anuales y se incorporó un curso de cartografía. Esto último, así como la asignatura de geografía física que se incorporó dos años después, fue defendido por el naturalista español Angel Cabrera, quien comenzó a trabajar como profesor y jefe del departamento de paleontología en 1926. Ese año, en una conferencia que dictó en la Facultad de

119 Ernestina Rosa Langmann, presentó en 1928 su tesis doctoral, en la se dedicó a estudios biométricos sobre la variabilidad de la coraza en desdentados con y sin poliembrionía especifica, una línea de investigación como las promovidas por Fernández. Al año siguiente, también la uruguaya Albina Bonjour defendió su tesis allá. Ambos trabajos se publicaron en el Boletín de la Academia Nacional de Ciencias de Córdoba. 
Humanidades, este investigador indicó que: " nadie puede llamarse honradamente naturalista si no tiene algo de geógrafo, y creo igualmente que, si los conocimientos cartográficos son indispensables para el geólogo, no es menos necesario al biólogo saber interpretar un mapa o levantar un plano, entendiendo por biólogo, no sólo al que investiga a través del microscopio, sino a todo aquel que cultiva alguna de las ciencias biológicas...... en el caso de la paleontología, la acción depende del escenario: su desarrollo responde a la influencia directa del lugar en que se realiza. El factor geográfico tiene en la historia de la naturaleza viva tanta importancia, por los menos, como en la historia de la humanidad. Un pueblo tienen las condiciones que tienen, no porque sí, sino porque obedece al imperativo de sus condiciones geográficas.....del mismo modo, los animales y plantas evolucionan y llegan a ser lo que son, no por un impulso especial que los haga variar, sino porque su organismo ha de acomodarse a las condiciones del medio en que vive, y las variaciones en el medio tienen como consecuencia la variación de los organismos"

Este naturalista se refería a la biología, en un sentido amplio como todos los estudios vinculados a los seres vivos, tanto los relacionados con el microscopio como con las observaciones y trabajos de campo. Al mismo tiempo, introdujo un nuevo enfoque en el estudio de los vertebrados fósiles más relacionado con la zoología que con los problemas geológicos con los cuales se había vinculado la paleontología a fines del siglo XIX y principios del $\mathrm{XX}^{121}$. Bajo el asesoramiento de Cabrera, varios alumnos de la orientación de zoología presentaron sus tesis doctorales a partir de investigaciones sobre fauna fósil ${ }^{122}$.

En la segunda mitad de la década de 1920, el perfil propuesto para el egresado en ciencias naturales parecía coincidir con lo que desde la dirección del Museo de La Plata se había definido como las funciones primordiales que debía desarrollar esta institución: un plan de exploraciones nacionales e investigaciones regionales interdiciplinarias, que abarcaran la descripción física del presente y el pasado del territorio. Enfrentada a ese modelo, la propuesta para desarrollar una formación especializada y un entrenamiento en los trabajos de laboratorio en disciplinas como

\footnotetext{
${ }^{120}$ Cabrera 1926: 103-4.

${ }^{121}$ Pascual 1961.

${ }^{122}$ Cabrera asesoró el trabajo de tesis de Mathilde Dolgopol de Sáez sobre las aves corredoras fósiles del Santacrucense (1927), la de Dolores López Aranguren sobre camélidos fósiles argentinos (1928), la de Adolfo Gil Rosas sobre clasificación de algunos amonites supra-jurásicos e infra-cretácicos provenientes de los alrededores de la laguna del Diamante, Provincia de Mendoza (1929), la de Ana Cortelezzi y posteriormente otros alumnos.
} 
embriología y genética encontró una gran resistencia y perdió, entonces, su espacio, paralelamente a la consolidación de la gestión de Luis María Torres, quien logró movilizar un importante capital social para consolidar su autoridad y eliminar a sus posibles competidores. Desde ese lugar, Torres definió un proyecto institucional para el Museo, que se presentaba como una continuación de las exploraciones e investigaciones iniciadas durante la gestión de Francisco P. Moreno. La tradición naturalista del Museo parecía restaurada, pero como toda restauración no era un retorno al pasado sino una reinvención de la historia y una construcción del presente. 


\title{
Capítulo VI
}

\section{La formación del profesorado secundario y superior: Facultades científicas vs. Facultad de Ciencias de la Educación}

\begin{abstract}
"...es una deficiencia reconocida en nuestra institución docente que ella forma al hombre de ciencia y especialista en determinadas materias, pero no les da los medios de trasmitir estos conocimientos, en forma de lección. El profesor simplemente universitario pierde mucho tiempo en obtener los resultados de su enseñanza, resultados cuantitativos y aun cualitativos, mientras no tenga la preparación pedagógica necesaria para ser un verdadero profesor en la materia que sabe,.... no se necesita solamente saber, sino saber enseñar lo que se sabe". ${ }^{1}$
\end{abstract}

"...en los círculos cientificos en general y fuera de los círculos correspondientes a los institutos pedagógicos la opinión corriente es contraría a los cursos pedagógicos...en algunos momentos, la actitud de estos círculos científicos ha sido de verdadero combate contra esas ramas de conocimiento....."2

Las propuestas de capacitación docente y los títulos necesarios para ocupar puestos en establecimientos educativos fueron temas muy discutidos durante las primeras décadas del siglo XX. En esa época, la estructuración del sistema educativo nacional traería aparejado redefiniciones en torno a la figura del profesor y la "necesidad" de una formación especifica para las prácticas de enseñanza. En ese marco, se desarrollaron una serie de debates alrededor de los diplomas y certificaciones exigidos para el ejercicio docente y la intervención estatal para regular la actividad laboral. En esas discusiones varios grupos e instituciones intentaron ampliar o establecer su autoridad para formar el personal de los establecimientos secundarios, establecer los programas de enseñanza o asegurar un campo laboral para sus graduados. Algunos trabajos recientes sobre la conformación del sistema educativo argentino, han examinado esos enfrentamientos en relación con la distribución específica de un "capital cultural" y la consolidación de la profesión docente $^{3}$. Desde esa perspectiva, la formación del profesorado puede ser analizado

\footnotetext{
${ }^{1}$ Discurso de Joaquín V. González en defensa de la creación de la Universidad Nacional de La Plata en la Cámara de Senadores de la Nación, sesión del 19/9/1905, reproducido en Castiñeiras 1985, I: 233.

${ }^{2}$ Besio Moreno 1921: 421

${ }^{3}$ Véase entre otros: Birgin 1999; Pinkasz 1992 ; Dussel 1997.
} 
como un espacio de lucha institucional, en el cual diferentes sectores disputaron los modos de legitimación así como el lugar atribuido a determinados saberes. En esa lucha, la habilidad para monopolizar el acceso a ciertas ocupaciones específicas y la distribución de las credenciales profesionales constituirían una de las claves para la consolidación institucional, en la medida en que eso permitía asegurar el reclutamiento de alumnos y extender su influencia a través de la formación e inserción de los graduados.

Las controversias sobre la preparación necesaria que debía tener el docente secundario se presentaron en el interior de la Universidad platense, institución que había asumido la "misión educativa" de formar el profesorado nacional. Para esto último, se estableció una instancia específica dedicada a la preparación pedagógica de los alumnos de las distintas carreras de la Universidad, que aspiraban a dedicarse a la docencia secundaria o universitaria. De esa forma, la Sección Pedagogía debía encargarse de lo primero, mientras las distintas Facultades brindarían la formación científica para cada especialidad. No obstante, durante el desenvolvimiento de esta propuesta se operaron varios cambios con respecto al plan original y el sistema de correlación, que estuvieron lejos de satisfacer las expectativas de algunos sectores. En relación con ello, se presentarían varios conflictos por la autoridad en el diseño de los planes de estudio de los profesorados y en torno a la concepción del perfil del profesor de enseñanza secundaria y superior.

El objetivo de este capítulo es analizar los enfrentamientos que se dieron en torno a la preparación científica de los aspirantes al profesorado, en particular en relación con las ciencias naturales y físicas. Diferentes posturas emergieron con respecto a la formación del docente durante la década del diez cuando en el ámbito nacional circulaban varios proyectos de reforma educativa y en el contexto platense se creó en 1914 la Facultad de Ciencias de la Educación, sobre la base de la Sección Pedagógica y los estudios históricos, literarios y filosóficos. En esa época, las Facultades de ciencias reclamaron su competencia científica en la formación docente, insistiendo en que los futuros profesores debían tener un sólido entrenamiento en las prácticas de investigación y en los métodos experimentales. Como hipótesis de trabajo, se considera que estas disputas pueden ser entendidas en relación con el problema específico de la baja cantidad de estudiantes en las carreras científicas. Esto sería particularmente crítico para aquellos investigadores-profesores, que estaban dedicados exclusivamente a las actividades académicas y cuyo espacio de 
investigación se articulaba en relación a la cátedra universitaria. En esa época, la supervivencia de esos espacios o la ampliación de los equipos de trabajo dependían de la cantidad de estudiantes que se reclutaran. De esa forma, los reclamos por legitimar ciertos saberes y prácticas en la formación de profesores así como asegurar el privilegio de doctores en ciencias para ocupar cargos docentes en los colegios secundarios, constituyó una estrategia para mejorar la posición y la influencia institucional de ciertas disciplinas científicas, que parecían no ofrecer demasiadas perspectivas laborales más allá del ámbito educativo. Por otro lado, estas propuestas fueron principalmente defendidas por profesores formados en el sistema de las universidades alemanas, quienes buscaron reproducir la organización de los estudios y el prestigio social de los universitarios como en el contexto social e institucional en el que se habían formado. Esas polémicas se dieron de forma paralela, y en cierta forma estuvieron correlacionadas, con lo que sucedía en la Capital Federal con respecto a los proyectos de anexión del Instituto Nacional del Profesorado a la Facultad de Filosofía y Letras de Buenos Aires y en el marco de un contexto social atravesado por una aguda crisis económica y los comienzos de la guerra europea. Posteriormente, a ello se sumarían las presiones ejercidas por los centros de estudiantes del profesorado y asociaciones de profesores diplomados para restringir el acceso al ejercicio de la docencia secundaria.

\section{1. Educar al educador}

En el diseño de la Universidad Nacional de La Plata, González se preocupó por la creación de una sección pedagógica para la formación de profesores: "esta universidad nueva...lleva consigo una facultad, en embrión o desarrollada (esto depende de los recursos), destinada a formar el profesorado científico especial, que después ha de mejorar sucesivamente, en orden descendente todas las demás instituciones que se van agregando, como por ejemplo la instrucción primaria y secundaria. El resultado específico y cuantitativo de la instrucción secundaria y primaria será tanto mayor cuanto más perfectos sean los profesores superiores que van a difundir las ciencias."4

\footnotetext{
${ }^{4}$ Discurso de González en: Castiñeiras 1985, I: 234.
} 
Según los planes de este Ministro de Instrucción Pública, esto constituiría el primer paso para establecer una facultad de pedagogía, según el modelo de algunas universidades norteamericanas o los seminarios pedagógicos de Alemania. Esta unidad fue pensada inicialmente para que brindara una preparación pedagógica a los estudiantes de las distintas carreras científicas y profesionales de la Universidad, que aspiraban a ocupar algún cargo docente o directivo en la enseñanza secundaria o como profesor adjunto en la Universidad platense. En la defensa de su proyecto universitario, González señaló la importancia de constituir "un cuerpo docente instruido en la ciencia y en el arte de enseñar". Para él no bastaba saber para enseñar, era necesario también saber trasmitir: "la libre e ilimitada investigación de un sabio no puede llegar en su forma originaria a la conciencia social. El descubrimiento desarrollado en larga gestación, ha de reducirse a una fórmula sintética y tangible por parte del maestro...Esa admirable aptitud para desentrañar de los grandes tratados las verdades elementales y trasmitirlas al discípulo, no se obtiene sin el cultivo de la ciencia de la educación, que es teoría y práctica, historia y experiencia actual" 5 .

En ese sentido, la relación entre los conocimientos producidos por el sabio y su recepción social demandaba la mediación de un nuevo conjunto de saberes técnicos vinculados al "arte" de enseñar. Para ser docente, ahora ya no era suficiente el dominio de los conocimientos de las disciplinas a enseñar, sino que se requería "el estudio metódico y experimental de la ciencia de la educación". Estas ideas, se inscribían en una preocupación más general por la creación de instancias específicas para la formación del profesor y la consolidación de la actividad docente como profesión. En relación con ese movimiento, como observó Rodolfo Rivarola, se produjo una literatura y una organización técnica y administrativa para educar a los educadores $^{6}$. La ciencia de la educación emergente a fines del siglo XIX situaría a docentes y alumnos en un contexto de nuevas prácticas discursivas ${ }^{7}$. En un primer momento, el discurso pedagógico se concibió como ciencia en relación con la

\footnotetext{
${ }^{5}$ González 1935, XIII: 346.

${ }^{6}$ Rivarola 1906. En general, indicaba que toda pedagogía comprendía: 1) las bases psicológicas de la educación, y b) los métodos para la mejor enseñanza. Para él, la ciencia de la educación también debía comprender la determinación del fin social de la educación y la organización general de la enseñanza ${ }^{7}$ Popkewitz 1997.
} 
educación del niño. Posteriormente se agregaría la construcción del adolescente como otro sujeto pedagógico particular ${ }^{8}$.

Hasta principios del siglo XX, los lugares específicos donde se formaban los docentes para la enseñanza primaria y secundaria eran las escuelas normales, instaladas a partir de la década de 1870. Por esta vía, el Estado argentino intentó constituir un cuerpo homogéneo y especializado para dirigir y sostener la expansión escolar. La intervención estatal provocó una unificación y ampliación de las instancias de formación docente, y al mismo tiempo generó una "jerarquización" del trabajo de enseñar, que se constituyó como una profesión estatal ${ }^{9}$. En algunas de las escuelas normales se establecieron cursos de profesores que habilitaban para la enseñanza secundaria en esas instituciones y para actuar como inspectores o funcionarios escolares. En particular, la Escuela Normal de Paraná creada en 1871, cuyos discípulos ocuparon altos cargos y articularon amplias redes sociales e institucionales, ejercería una notable influencia sobre la educación y la cultura argentina ${ }^{10}$. Por esa vía, el "normalismo" se constituyó como el discurso pedagógico dominante en las tres últimas décadas del siglo y de la formación de varias generaciones de educadores y $\operatorname{pedagogos}^{11}$.

Al terminar el siglo XIX, las universidades argentinas no habían consolidado un papel específico con respecto a la emergente profesión docente como podría haber sido a través de la imposición de un período obligatorio de estudio o la certificación de los aspirantes al profesorado secundario como sucedía en los sistemas educativos europeos. En relación con esto último, cabe recordar que las facultades francesas de letras y ciencias o la de filosofía alemana proveían de la formación y los diplomas necesarios para acceder a los cargos de profesores en los liceos, gimnasios y colegios secundarios. Esto había constituido una de las principales vías por la que se aseguró el reclutamiento de alumnos en los estudios científicos "desinteresados" y parte del poder de los "mandarines" académicos ${ }^{12}$. En Argentina, en cambio, esto sería más difícil de consolidar. En 1865, al crearse el Departamento de Ciencias Exactas en la

\footnotetext{
${ }^{8}$ Puiggrós 1990; Carli 2002.

${ }^{9}$ Birgin 1999.

${ }^{10}$ Para una idea de la difusión del normalismo de la Escuela Normal de Paraná y las localizaciones institucionales de sus discípulos, véase: Bosch 1993. En 1920, los cursos del profesorado de esta Escuela fueron reemplazados por los de la nueva Facultad de Ciencias de la Educación de la Universidad del Litoral. En 1931, esta Facultad fue trasformada en la Escuela Normal Superior y dos años después, en el Instituto Nacional del Profesorado Secundario de Paraná.

${ }^{11}$ Dussel 1997; Puiggros 1990.

12 Weisz 1983; Ringer 1995.
} 
Universidad de Buenos Aires se había contemplado la idea de preparar ingenieros y profesores en materias científicas ${ }^{13}$. También la Facultad de Ciencias FísicoMatemáticas en la Universidad de Córdoba establecida en la década de 1870, había sido concebida con el objeto de fomentar y divulgar las ciencias físico-químicas y naturales, a través de la formación de investigadores locales y docentes para la enseñanza secundaria de esas disciplinas ${ }^{14}$. Como se señaló en el capítulo anterior, en general los estudios científicos casi no atrajeron estudiantes, y por otro lado, para las cátedras en los colegios secundarios no se requería una formación o certificación especial sino más bien contactos personales. En 1896 se creó la Facultad de Filosofía y Letras en la Universidad de Buenos Aires como un centro de "alta cultura", destinada a promover las investigaciones y estudios "desinteresados" y también para preparar profesores a través de cursos especiales. Según Pablo Buchbinder estas dos funciones generarían por varios años una tensión difícil de resolver ${ }^{15}$. Por otra parte, esta Facultad se enfrentó al problema de la falta de alumnos regulares, lo cual se atribuía a la escasa perspectiva laboral que representaban las disciplinas practicadas en esta institución. Para incentivar estos estudios, una de las disposiciones adoptadas fue eximir de matrículas y otros aranceles a los alumnos regulares, lo que posteriormente sólo se mantendría en vigencia para los estudiantes del doctorado. Otra de las soluciones bosquejadas fue tratar de asegurar ante las instancias oficiales, que los graduados de esta institución fueran preferidos para cubrir los empleos docentes en los colegios nacionales y escuelas normales. Esta última medida, por otra parte, sería reiteradamente solicitada por estudiantes y egresados en sucesivas oportunidades ${ }^{16}$.

Al comenzar el nuevo siglo, la enseñanza en las instituciones de educación media podía ser ejercida tanto por profesores normales, graduados universitarios o individuos sin título, pero que tenían cierto prestigio científico o social. En general, el acceso a un cargo en estos establecimientos estaba supeditado a los vínculos personales de los aspirantes y a un sistema basado en la recomendación y clientelismo político, según reconocían los actores de aquella época. En los colegios nacionales predominaron los docentes con formación universitaria como médicos y abogados, mientras que los profesores y maestros normales eran mayoría en las escuelas normales. Estas diferencias han sido interpretadas en el marco de la existencia de dos

\footnotetext{
${ }^{13}$ Babini 1949, 1963, Camacho 1971; Myers 1994.

14 Tognetti 2000.

15 Buchbinder 1997.
} 
circuitos de formación y reclutamiento docente: a) un circuito escuela primarianormal, conformado por sectores de menores recursos y mujeres; y b) educación secundaria (bachillerato)-universidad ${ }^{17}$. Dentro de este último, tanto los profesores como los alumnos generalmente pertenecían al mismo estrato social, vinculados a las elites intelectuales gobernantes y los grupos políticos provinciales. Es interesante señalar, que en cierta forma, también la producción de textos, ilustraciones y materiales para la enseñanza científica parecieron dar cuenta de esa segmentación y de las diferencias en las modalidades de enseñanza y contenidos que se dieron entre ambos circuitos educativos en la transición del siglo, pese a que en general los planes de estudios oficiales fueron similares ${ }^{18}$. En esa época, los colegios nacionales se mantenían como instituciones radicalmente separadas de la escolarización primaria y constituían la vía de acceso para los diplomas universitarios. De hecho, la mayoría de las Facultades, sobre todo en las carreras que gozaban de mayor prestigio como medicina y abogacía, exigían como requisito de ingreso el título de bachiller o certificado de estudio de esos colegios. En ese sentido, varios sectores universitarios consideraban a estas instituciones como una instancia preparatoria para los estudios universitarios. Para otros grupos, en cambio, estaba destinado a completar la cultura general de la clase media. Los normalistas, por su parte, promovieron la escolarización de la educación secundaria como una prolongación de las escuelas primarias. Las numerosas reformas ministeriales para regularizar la instrucción secundaria que se sucedieron en aquellos años, ponen en evidencia las diferentes

\footnotetext{
${ }^{16}$ Buchbinder 1997.

${ }^{17}$ Pinkasz 1992.

${ }^{18}$ Con respecto a ello, se observa que los textos científicos producidos para los cursos universitarios generales eran también destinados a los colegios nacionales, en parte ello respondía a que en general los profesores de esos dos ámbitos eran los mismos. En este sentido, entre las obras producidas a principios del siglo XX se puede señalar el manual Zoología de Angel Gallardo, publicada en 1907 para la enseñanza de zoología general de la carrera de Farmacia de la Universidad Nacional de Buenos Aires y los colegios secundarios. Este texto fue editado por la casa Angel Estrada, la cual lo continuaría reeditando por varias décadas, aunque sólo se destinaba a los colegios secundarios. Paralelamente, la editorial Cabaut editó Zoología de Víctor Mercante, un manual para la enseñanza secundaria y las escuelas normales. En esa época, también existieron diferencias en los espacios y las orientaciones de las ciencias naturales entre las escuelas normales y los colegios secundarios, según se desprende de las memorias institucionales. En las primeras fue frecuente la formación de museos y las prácticas del naturalista de campo basadas en las excursiones a la naturaleza, la observación de especímenes y en general, un conocimiento de tipo analítico-sistemático. Mientras que en los colegios nacionales, especialmente en los de Capital Federal, se establecieron laboratorios para realizar experimentaciones en fisiología, estudios microscópicos y disecciones, es decir, una orientación más biológica y experimental.
} 
visiones que se enfrentaron con respecto al papel que cumplía ese espacio formal de educación y la orientación de esos estudios ${ }^{19}$.

En los primeros años del siglo XX, se establecieron algunos reglamentos para ser docente en los colegios nacionales que tendían a excluir a los normalistas. Paralelamente se fijaron ciertas instancias específicas para la formación del profesor secundario diplomado. En enero de 1903, el Ministro de Justicia e Instrucción Pública, Juan R. Fernández, determinó que para ocupar un cargo en los colegios secundarios nacionales se necesitaba: a) estudios secundarios completos y para la mayoría de las asignaturas un diploma universitario, b) certificado de aprobación de la asignatura Ciencias de la Educación en la Facultad de Filosofía y Letras, y c) un curso práctico de pedagogía, que comprendería: un primer año de pedagogía general en la Escuela Normal de Profesores de la Capital, y un segundo año de pedagogía especial en un seminario pedagógico próximo a fundarse ${ }^{20}$. Además, para los profesores de materias de instrucción nacional se exigía la aprobación de historia argentina y arqueología americana. En esos días, por otro decreto se agregó a los estudios normales un curso de tres años para obtener el título de profesor. Otra de las iniciativas tendía a la reorganización de la Inspección General de Enseñanza, para lo cual se consideró conveniente que los inspectores tuvieran un título universitario y dictaran conferencias de "extensión universitaria", durante su recorrido por las provincias como una forma de capacitación docente para los profesores del interior del país ${ }^{21}$.

En el marco de esas reformas, se promovió la creación del Seminario Pedagógico, inspirado en el modelo prusiano. Esta institución fue pensada como un espacio de preparación en las prácticas de enseñanza para los graduados universitarios que deseaban dedicarse a la docencia secundaria. Para su organización se recurrió a la contratación de varios profesores alemanes, incluyéndose a su director, quienes

\footnotetext{
${ }^{19}$ Véase entre otros: Tedesco 1986; Dussel 1997.

20 Memoria presentada al Congreso nacional de 1902 por el Ministro de Justicia e Instrucción Pública, 1903, tomo III.

${ }^{21}$ Asimismo, al igual que todos los Ministros de Instrucción Pública de esa época, propuso una modificación de los planes de estudio de los colegios secundarios y escuelas normales. Otra de las reformas apuntaba a que el salario de los profesores se pagaría por horas cátedras y no por mes, como se venía realizando. Además, se procuraba establecer una jerarquía de sueldos según las materias y el nombramiento de los profesores de marzo a diciembre, con lo cual se pretendía ahorrar en las vacaciones. Las medidas del Ministro Fernández fueron muy criticadas por algunos inspectores escolares vinculados a la corriente normalista como Pablo Pizzurno y Leopoldo Lugones. Véase por ejemplo: Lugones 1903, y Pizzurno 1903; y para contextualizar las discusiones: Dussel 1997.
} 
llegaron a principios de $1904^{22}$. Las negociaciones para ello se realizaron por medio del Ministro de Relaciones Exteriores y Culto argentino y el Ministerio de Cultura prusiano. Según Lewis Pyenson, la presencia de profesores e investigadores alemanes en la Argentina, al igual que en otras partes del mundo, fue apoyada por los intereses imperialistas que sustentaron las autoridades políticas y culturales de Berlín ${ }^{23}$. Es de destacar, que estos profesores alemanes realizaron una importante campaña de difusión de la organización del magisterio y la enseñanza en Alemania a través de la publicación de folletos $\mathrm{y}$ artículos en algunas revistas educativas argentinas ${ }^{24}$. Asimismo, formaron parte de las redes de científicos alemanes en el cono sur y actuaron como nexos para la contratación de profesores universitarios en Alemania.

Durante el ministerio de Joaquín V. González, algunas de las reformas promovidas por Juan R. Fernández, como las que requerían una formación universitaria para ser profesor secundario o inspector, o las relativas al sueldo docente, se dejaron sin efecto. No obstante, González coincidió con el anterior Ministro en que el problema de la enseñanza secundaria dependía principalmente de la formación de los profesores. Para ello, por ejemplo, se organizaron en 1904 cursos de capacitación científica para docentes a cargo de los "sabios locales" 25 . Al mismo tiempo, a pedido de los profesores alemanes, el Seminario fue trasformado en el Instituto Nacional del Profesorado Secundario, dedicado inicialmente a la preparación pedagógica y filosófica de los futuros docentes ${ }^{26}$. Bajo la dirección del alemán Wilhelm Keiper, este establecimiento recibió del gobierno importantes recursos y locales para la instalación de varios departamentos y laboratorios dedicados a la enseñanza e investigación ${ }^{27}$. A fines de 1906, por gestiones iniciadas por las autoridades de la Facultad de Filosofía y Letras de la Universidad de Buenos Aires se anexo este Instituto, fundamentándose en la analogía de estudios y los fines comunes de ambas instituciones. Esa disposición generó varios conflictos y dos años después, el Instituto volvió a funcionar independientemente. A partir de ese momento, esta institución consolidó una posición

\footnotetext{
${ }^{22}$ En el decreto ministerial de 1903 se establecía la contratación de: un profesor de filosofía con conocimientos en psicología experimental, dos de lenguas clásicas, uno de ciencias matemáticas, uno de física y uno de química.

${ }^{23}$ Pyenson 1984, 1985a, 1985 b.

${ }^{24}$ Véase entre otros: Keiper 1919; Sorkau 1912, 1915; Gans 1918.

${ }^{25}$ Se organizaron cursos de ciencias naturales, químicas y físicas a cargo de: Florentino Ameghino, Eduardo Holmberg, Carlos Spegazzini, Enrique Herrero Ducloux y Samuel de Madrid. Para promover la asistencia de los profesores del interior, el Ministerio facilitó los pasajes y cinco pesos diarios como viáticos a cada docente.

${ }^{26}$ El decreto de organización de esta institución se pueden consultar en González 1935, XIV: 432-439.

27 Babini 1954.
} 
autónoma y contó con amplios recursos estatales para la reorganización de los estudios, la creación nuevas secciones y la ampliación de la planta docente. Esto le permitió ofrecer una formación completa e independiente de la Universidad en la mayoría de las disciplinas que se enseñaban en la educación secundaria ${ }^{28}$. La competencia por la formación del profesor de enseñanza secundaria entre la Facultad de Filosofía y Letras y el Instituto volvería a discutirse a fines de 1914 y nuevamente algunos sectores de la primera fomentarían la incorporación de los laboratorios, bibliotecas y personal de Instituto a la Facultad ${ }^{29}$. Si bien esto no se concretó, la disputa por los privilegios de sus egresados para ocupar los cargos en la educación media se mantendría por varios años ${ }^{30}$. A ello se sumaría, los intentos por legitimar la preparación pedagógica que tenían los profesores normales.

En las discusiones sobre la formación de los docentes para los establecimientos secundarios, los representantes de la tradición normalista defendieron una autoridad en el campo educativo a partir de la revalorización de su competencia técnicodidáctica en los procesos de enseñanza. Según Inés Dussel, los sectores que asumieron esta postura, en su pretensión hegemónica sobre el campo educativo, elaboraron un discurso hacia la escuela media y trataron de mantener el monopolio de la formación de profesores. Dicho movimiento se articuló en varios planos simultáneos: por un lado, se constituyeron como un grupo de opinión importante en las Conferencias Anuales de Profesores que se realizaron entre 1901 y 1905 y en la Encuesta al Profesorado Secundario de 1910; en segundo lugar a través de la lucha por la

\footnotetext{
${ }^{28}$ Después de diez años el Instituto Nacional del Profesorado comprendía los siguientes departamentos: 1) Pedagogía, con dos cátedras; 2) Filosofía, con cuatro cátedras, 3) Francés, con cuatro cátedras, 4) Inglés con seis cátedras, 5) Historia y Ciencias Sociales, con siete cátedras, 6) Geografía y Geología, con seis cátedras, 7) Matemáticas, con siete cátedras, 8) Física con seis cátedras, 9) Química y Mineralogía, con ocho cátedras y 10) Ciencias Biológicas con ocho cátedras. Además tenían laboratorios, gabinetes, y bibliotecas. Instituto Nacional del Profesorado Secundario en la primera década de su existencia, 1905 a 1915, 1916.

${ }^{29}$ En el ámbito de la Asociación Nacional del Profesorado se debatió esta cuestión y en ese marco Rodolfo Rivarola, por entonces decano de la Facultad de Filosofía y Letras de Buenos Aires, presentó un bosquejo de una ley de profesorado, en donde se señalaba por un lado, la necesidad de nombrar para la enseñanza secundaria a profesores diplomados por las universidades nacionales y por otro, la incorporación del Instituto Nacional del Profesorado como parte de la Facultad de Filosofía y Letras. Rivarola 1915. Asimismo, Ernesto Quesada promovía la reorganización de esta última con la anexión de los laboratorios, bibliotecas y personal de ese Instituto y su trasformación en una Facultad de Filosofía al estilo europeo o como una "pequeña Sorbona". Quesada 1915. Durante los años de la guerra mundial, la situación del Instituto se complicó, ya que no se renovaron los contratos de los profesores alemanes que vencían en esa época, y posteriormente fue perdiendo el prestigio científico que había alcanzado en los inicios de la década de 1910. Su director, W. Keiper, después de la Reforma Universitaria en La Plata se incorporaría como docente de la Facultad de Humanidades y Ciencias de la Educación de la Universidad platense.

${ }^{30}$ Buchbinder 1997.
} 
legitimidad del título de maestro o profesor normal para ejercer en la escuela media; y en tercer lugar, por la confección de obras de didáctica y libros de textos que proveyeron las bases para un discurso pedagógico que hasta el momento no había sido estructurado como tal, unificando los debates intra-disciplinarios ${ }^{31}$. Como ha señalado esta investigadora, si bien el normalismo perdió la batalla por el monopolio de los títulos, su influencia en el sistema educativo no fue menor, como se evidenció en las inserciones de sus egresados y la aplicación de sus propuestas de reglamentaciones, disciplina y rituales en la educación secundaria. Precisamente, parte del discurso normalista alcanzaría una importante difusión desde el nuevo espacio que abrió la Universidad Nacional de La Plata, con la creación de la Sección Pedagógica.

\section{2. La organización de la Sección Pedagógica}

Al establecerse la Universidad Nacional de La Plata, se creó una Sección Pedagógica en la Facultad de Ciencias Jurídicas y Sociales, destinada a "formar de cada especialista un maestro". La idea original era que junto con una formación profesional o científica, los alumnos pudieran capacitarse en los métodos y las prácticas educativas, como una forma de preparar un personal docente idóneo y especializado para la enseñanza secundaria y universitaria. El sistema propuesto inicialmente descansaba en el principio de la correlación de estudios. Recordemos que una de las bases de la organización de la nueva universidad era la coordinación de estudios similares o materias afines, comprendidos en los planes de las distintas facultades, para concentrar recursos y articular la enseñanza e investigación en cada disciplina bajo la dirección de un especialista. De esa forma, los estudiantes debían cursar en distintas dependencias de la Universidad y relacionarse con los alumnos y profesores de otras carreras. Como se señaló en el Capítulo II, con ello se buscaba generar una mayor integración entre los sectores universitarios y en las orientaciones de los estudios y, al mismo tiempo, contrarrestar la fragmentación institucional derivada de la estructura académica tradicional de las Facultades.

En el proyecto de creación de la Universidad se establecía que la Sección Pedagógica se encargaría de la enseñanza de cuatro materias: 1) filosofía de la

\footnotetext{
${ }^{31}$ Dussel 1997.
} 
educación, 2) historia de los sistemas pedagógicos, 3) legislación escolar comparada, y 4) metodología de las ciencias naturales, jurídicas y sociales; y de la dirección de las prácticas pedagógicas en el Colegio Nacional y la Escuela Normal. Sus alumnos provendría de las diversas facultades e institutos de la Universidad, que se interesaran por acceder al diploma de profesor de enseñanza secundaría y superior o seguir una carrera docente en la Universidad. En relación con esto último se estipulaba que para ser nombrado profesor adjunto era necesario haber realizado un año de estudios pedagógicos. En esa época, se consideraba que para ser profesor eran necesarias dos condiciones: a) conocimiento de la materia; b) método para comunicarla. Mientras que la preparación científica estaría a cargo de los distintas Facultades e Institutos, el entrenamiento en el segundo aspecto sería dirigido por los profesores de pedagogía. Se esperaba, que de esa forma, los futuros docentes del magisterio secundario dispondrían de la misma formación que el científico o el profesional, y para estos últimos se ampliarían las posibilidades laborales al poder acceder a otro título, con sólo completar la formación pedagógica.

La organización de la Sección Pedagógica estuvo a cargo de Víctor Mercante (1872-1934) ${ }^{32}$, quien dispuso de una amplia autonomía con respecto a las autoridades de la Facultad de Ciencias Jurídicas. En esa época, este profesor, egresado de la Escuela Normal de Paraná, tenía varios trabajos publicados sobre metodología de la enseñanza para las escuelas primarias y normales y algunas investigaciones en psicopedagogía. Mercante se trasladó de la Escuela Normal de Mercedes, que dirigía desde 1894, a La Plata, junto con un grupo de colaboradores. Entre ellos, se destacó:

\footnotetext{
${ }^{32}$ Víctor Mercante, era descendiente de inmigrantes italianos, nació en la Argentina y pasó parte de su infancia en Italia. Ingresó en la Escuela Normal de Paraná, donde obtuvo una beca que le permitió terminar el profesorado. Esta escuela era un importante centro de sociabilidad entre sectores vinculados a las elites políticas y educativas del interior del país, lo que le permitió participar en una amplia red de contactos. Como otros egresados de esa Escuela llegó rápidamente a ejercer funciones directivas en los establecimientos educativos. Primero ingresó en 1891 como regente en la Escuela Normal de Varones de San Juan, donde comenzó sus primeros estudios en psicopedagogía y a publicar trabajos sobre métodos de enseñanza. En esa Provincia se vinculó con la élite política local, llegando a ser diputado provincial. En 1894 pasó a dirigir la Escuela Normal de Mercedes en la Provincia de Buenos Aires hasta que fue llamado por González para organizar y dirigir los estudios pedagógicos en la Universidad platense. Mercante 1944. Las ideas pedagógicas y "positivistas" de Mercante han sido objeto de numerosos trabajos y análisis desde distintos puntos de vista. Adriana Puiggrós (1990) lo caracteriza como uno de los referentes principales de la corriente "normalizadora", que promovió una creciente ritualización y rigidez del sistema escolar argentino. Sandra Carli (2002), agrega que tanto la trayectoria profesional como la obra escrita de Mercante, remite a la configuración de un discurso acerca de la infancia, cuyo eje articulador fue la concepción del niño como salvaje y la creación de un dispositivo pedagógico capaz de disolver ese estado primitivo. La tesis del estado primitivo de la infancia en el campo educativo era el correlato de la ideas sobre el paralelismo entre la evolución filogenética y la ontogenética que se discutían en el ámbito científico.
} 
Rodolfo Senet (1872-1938), formado en la Escuela Normal de Profesores de Buenos Aires y nombrado profesor de Antropología y jefe de laboratorio de la Sección. Desde este nuevo espacio abierto por la Universidad platense, ambos profesores, estructurarían una pedagogía basada en el estudio psico-biológico del niño y del adolescente, que buscaba trasformar la escuela en un laboratorio y la construcción del que mira: el sujeto educador ${ }^{33}$. Para ello contaron con importantes recursos para publicaciones, instrumental y la instalación de varios laboratorios: antropología; psicología experimental y psicopedagogía; fotografía y otro de micrografía y museo de cerebrología, destinado a las clases prácticas y el estudio del sistema nervioso. A su vez, bajo la supervisión de esta Sección se crearon dos escuelas de aplicación y observación: la Escuela Graduada Anexa y el Colegio Secundario de Señoritas en $1907^{34}$. En cambio, el Colegio Nacional mantuvo una dirección independiente de esta Sección.

Las materias de capacitación pedagógica propuestas por esta Sección difirieron de las insinuadas en el proyecto de la Universidad. En efecto, en vez de Filosofía de la Educación se crearon las cátedras de: Psicología ${ }^{35}$, Antropología, Anatomía y Fisiología del sistema nervioso ${ }^{36}$, e Higiene Escolar. Mientras que se mantuvieron las asignaturas convencionales en la formación docente de otras instituciones: Metodología general y especial, Legislación Escolar e Historia y Ciencia de la educación. La organización de la enseñanza de Antropología en esta Sección desafiaba el sistema de correlación defendido por el presidente de la Universidad, en

\footnotetext{
${ }^{33}$ Carli 2002.

${ }^{34}$ En los proyectos iniciales de la Universidad, se hablaba de la incorporación de la Escuela Normal de La Plata, como uno de los espacios para los estudios experimentales y las prácticas de enseñanza de la Sección Pedagógica. Si bien la incorporación formal de esta Escuela no se llevó a cabo, igualmente se establecieron estrechos vínculos y colaboración entre estas instituciones. De hecho, en 1906 parte de los equipos e instrumental de la Sección Pedagógica se instalaron en la Escuela Normal, donde además se realizaron numerosas observaciones y mediciones de alumnos. Para la práctica pedagógica y la renovación de los métodos de enseñanza se recurrió al Colegio Secundario de Señoritas, creado en 1907 para separar la enseñanza de las mujeres en el Colegio Nacional, ya que en esa época se había incrementado significativamente el número de alumnas que solicitan la inscripción en ese establecimiento.

${ }^{35}$ En Francia la pedagogía en las universidades se mantuvo firmemente en manos de los filósofos y estaba relacionada con un contenido moral. Allí, una orientación científica vinculada a la psicología como por ejemplo la de Alfred Binet, no tendría acceso a una cátedra en la Sorbona. Weisz 1983. González tal vez pensaba en la primera orientación cuando incluyó Filosofía de la Educación en el diseño de los estudios pedagógicos, aunque en la elección del director y el nombramiento de su personal consolido la segunda línea.

${ }^{36}$ Las clases de sistema nervioso fueron dictadas inicialmente por el profesor auxiliar, el doctor Manuel Beatti, luego por el médico veterinario Nicolás Roveda y desde fines de la década de 1910, esta materia quedaría a cargo del médico neurobiólogo Christofredo Jakob. Los primeros dos profesores
} 
la medida en que esa disciplina formaba parte del grupo de asignaturas del Museo de La Plata. En la Sección Pedagógica, Rodolfo Senet dictaría esa materia hasta su jubilación en 1921 y luego los estudiantes de esta Facultad pasarían a cursar en la cátedra dependiente del Museo, a cargo de Lehmann-Nitsche. El programa del curso de Senet, incluía filogenia y evolución del "filum humano", craneología, antropometría, el tema de la degeneración y en cada capítulo consideraba la aplicación escolar y la experimentación de los alumnos ${ }^{37}$. Entre los trabajos prácticos se incluía la determinación de antropomorfos y homo, observaciones y mediciones de caracteres esqueléticos y somatológicos, manejo de instrumentos de medición y fichas antropométricas, entre otras actividades. Esto no era muy diferente de la propuesta de incluir Antropología en el curriculum de las escuelas normales para capacitar a los futuros docentes en las técnicas de medición, registro y armado de fichas antropológicas de los alumnos, como se venía promoviendo desde fines del siglo XIX. De esa forma, como ha indicado Irina Podgorny, se buscaría combinar la antropometría con la pedagogía para intervenir científicamente en la conformación de una "raza argentina moral y físicamente elevada" ${ }^{38}$. La definición de la pedagogía del director de la Sección se aproximaba a una ciencia soberana que abarcaba : a) el estudio del hombre o "conocimiento del objeto educable", dentro del cual se incluía desde el estudio de las evidencias anatómicas de su evolución, la somatología, fisiología del sistema nervioso y órgano de los sentidos, morfología comparada del cerebro de mamíferos superiores hasta los procesos psicológicos, entre otros temas que compartía con disciplinas como antropología, anatomía comparada, fisiología y psicología; b) el estudio de las leyes educativas en relación con los antecedentes biológicos e históricos y en función de las características ambientales; y c) las metodologías y los procedimientos particulares utilizados en la enseñanza: "el arte de cultivar las aptitudes, fijar los conocimientos y formar el carácter según la naturaleza del grupo escolar y las necesidades del Estado" ${ }^{13}$.

En la "preparación didáctica o método para trasmitir el conocimiento" promovida desde la Sección Pedagógica, se asignó un papel fundamental al estudio del sistema nervioso y la biología humana como parte fundamental de los procesos

promovieron, en sus clases y en algunos artículos, las técnicas y métodos de trabajo de Ramón y Cajal, a quien, por otra parte, se le ofreció un contrato como profesor de la Universidad platense en 1907.

${ }^{37}$ El primer programa de Antropología de la Sección Pedagógica se puede consultar en UNLP 1906: 599-603.

${ }^{38}$ Podgorny e.p. 
educativos ${ }^{40}$. La pedagogía promovida desde La Plata seguía el programa de orientar la enseñanza a partir de un conocimiento basado científicamente en el estudio psicobiológico del niño con la ilusión de formar individuos aptos para afrontar el problema del conocimiento y la reforma moral. Según Irina Podgorny, este proyecto de reunir en la figura del pedagogo- científico todo el conocimiento del hombre sería impugnado desde los científicos especializados en medicina o psicología. Las críticas por parte de los médicos constituían una defensa profesional y por otro, un límite pragmático a los proyectos abarcativos de la pedagogía positivista ${ }^{41}$. También otros sectores científicos, buscando defender la especificidad y entrenamiento necesario para ejercer en sus disciplinas, impugnarían la formación del profesor secundario y superior promovida por la Sección Pedagógica.

En esta Sección se establecieron inicialmente dos planes de estudios para obtener un diploma de profesor de enseñanza secundaria, destinados a dos grupos de alumnos distintos; uno propio y otro de correlación ${ }^{42}$. Estos últimos podían acceder al título de profesor en la disciplina o grupo de materias que el estudiante cursaba como parte de los estudios de otra Facultad. Para ello, la Sección exigía la aprobación de cinco materias: psicología, metodología general, especial, historia y ciencia de la educación y legislación escolar; y además, una práctica pedagógica en los colegios de la Universidad. Es de destacar que estas asignaturas eran las mismas que se requerían para ser profesor adjunto según el Estatuto de la Universidad. En cuanto a la formación científica, no se establecían requisitos, ya que se esperaba que los alumnos completaran el grado académico o profesional de la Facultad en la que estaban matriculados. Asimismo, inicialmente se había insinuado que para los que alcanzaran el título de doctor o ingeniero podrían recibir el título "profesor de enseñanza superior". En 1906, se inscribieron 62 alumnos de distintas carreras de la Universidad $^{43}$, con excepción de los estudiantes de la Escuela de Geografía y Dibujo, en la cual también se habían organizado planes de estudio para el título de profesor,

\footnotetext{
${ }^{39}$ Mercante 1911: 1.

${ }^{40}$ Finocchio 2001.

${ }^{41}$ Podgorny e.p.

${ }^{42}$ Mercante 1907.

${ }^{43}$ Véase la distribución de los alumnos de correlación según las Escuelas o Facultades en el Anexo. De esos 62 estudiantes más de la mitad perdería la regularidad, debido a la ordenanza sobre asistencia obligatoria al $70 \%$ de las clases que se sancionó a mitad de año.
} 
pero que no contemplaban una preparación pedagógica ${ }^{44}$. Con la Escuela de Geografía, no llegó a suscitarse ningún conflicto debido al poco tiempo que funcionó esta última, que desapareció tras la muerte de su director en 1908. Posteriormente, en la Sección Pedagógica se organizaría un plan de estudios para el título de profesor en geografía. En la Escuela de Dibujo se organizaron planes de estudios para el profesorado en la enseñanza primaria y secundaria en dibujo, aunque en ellos se incluía desde el principio un curso de pedagogía. Posteriormente, esta Escuela logró que se reconociera la especificidad de esas materias y sólo se estableció que los alumnos debían cursar metodología y práctica de la enseñanza. Desde la Facultad de Ciencias Físicas, Matemáticas y Astronómicas también se intentaría establecer sus propios planes de estudio para el profesorado en física y matemáticas, como se examina más adelante.

El segundo título que ofreció inicialmente la Sección Pedagógica, fue el de "profesor de enseñanza secundaria" para los alumnos se inscribiera directamente en esta Sección, sin necesidad de matricularse en otra Facultad. Para este diploma de carácter general, se establecía un plan de estudios de doce materias que se cursaba íntegramente en esta dependencia y en cierta forma parecía reproducir la tendencia "enciclopedista" que prevalecía en la formación del profesorado normal y habilitaba para la enseñanza de cualquier asignatura sin que pareciera necesario una preparación especializada en una materia. En ese sentido, la creación de este título por parte de la Sección Pedagógica contradecía la idea de una formación científica intensa como se establecía para los profesorados por correlación, especializados en un conjunto de asignaturas y cuyo diploma restringía su competencia a un conjunto limitado de disciplinas escolares. Por otro lado, también existieron diferencias en cuanto a los requisitos de ingreso y los sectores sociales que podían acceder a esos títulos. Mientras que en la mayoría de las Facultades se exigía diploma de bachiller, universitario y en algunos casos de profesor normal o certificados de estudios secundarios; en la Sección Pedagógica se permitió además la admisión de maestros normales con clasificación sobresaliente en el último año de estudios y la aprobación de algunas materias del quinto año del colegio secundario, exigencia que al poco tiempo se suprimiría. En esa época, la matriculación de los egresados de las escuelas

\footnotetext{
${ }^{44}$ En la Escuela de Geografía del Museo, el único título que se reglamentó inicialmente fue el profesor de geografía que se obtenía después de cursar 28 materias de ciencias naturales, exactas, y de dibujo y geografía. En ese plan no se incluía ninguna materia pedagógica.
} 
normales no se aceptaba en los reglamentos de la mayoría de las carreras universitarias. En este sentido, los estudios pedagógicos constituyeron una de las vía de acceso a la Universidad para los sectores de orígenes sociales más modestos, de los pueblos del interior y especialmente de las mujeres, que en general completaban su educación en las escuelas normales. De hecho, la mayor cantidad de alumnos propios de la Sección fueron maestros normales, prevaleciendo además las mujeres ${ }^{45}$. Una situación similar, con respecto a la matrícula femenina en los profesorados se dio en la Facultad de Filosofía y Letras de Buenos Aires. Para algunas eso podía constituir el primer paso para alcanzar el grado académico de doctor o por lo menos, para una formación superior. En el caso de la Sección Pedagógica, las mujeres constituyeron el 97\% de los 29 profesores de enseñanza secundaria, sin ninguna especialización, que terminaron los estudios hasta $1911^{46}$. La gran mayoría de ellas, ejercieron la docencia en el Colegio Secundario de Señoritas y en la Escuela Normal de La Plata, los únicos dos establecimientos públicos de enseñanza secundaria para mujeres que existían en esa época en La Plata.

La Sección Pedagógica, a diferencia de otras unidades académicas, contó con un número considerable de alumnos, tanto de correlación como propios, que aumentaba todos los años. Ello se puede atribuir a varios factores, entre los que se puede mencionar: la admisión de egresados de las escuelas normales, la propaganda que realizaron los profesores de la Sección (varios alumnos habían sido estudiantes o maestros en las escuelas normales donde antes ellos trabajaban), las becas del gobierno provincial que se establecieron a partir de $1909^{47}$ y las ofertas de cargos docentes en distintos establecimientos educativos de la Provincia de Buenos Aires y

\footnotetext{
${ }^{45}$ En 1906, por ejemplo, solicitaron la inscripción como alumnos propios de la Sección: 4 bachilleres; 3 profesores normales; 6 con título universitario y 20 maestros normales. De estos sólo 14 -todas mujeres- aprobaron los exámenes de ingreso. De los 23 alumnos que terminaron ese primer año, el $78 \%$ eran mujeres. Un cuadro con la distribución de los alumnos de la Sección Pedagógica según los estudios previos se adjunta en el Anexo.

${ }^{46}$ Este porcentaje se calculó sobre la lista de egresados se consignan en la Memoria de la Sección. Mercante 1913. Después de siete años, habían terminado 103 alumnos el profesorado secundario, entre ellos, se incluían ocho que habían alcanzado el titulo de profesor secundario y superior. La proporción de mujeres alcanzó más del 61 \% y principalmente se concentraba en los estudios ofrecido por la Sección.

${ }^{47}$ En febrero de 1909, el Gobierno de la Provincia de Buenos Aires estableció doscientas becas para los aspirantes a maestro, destinándose cuarenta de ellas con un valor de cuarenta pesos mensuales para los alumnos de la Sección Pedagógica. Cada estudiante podría mantener esa beca por un término máximo de tres años, previo informe de la Sección. UNLP 1910. Entre 1909 y 1912, 82 alumnos fueron becados en esta Sección, de los cuales 36 se recibieron, 17 continuaban estudiando y 29 gozaron de la beca por tres años sin recibirse o abandonaron los estudios. Mercante 1913. Cabe señalar que en los periódicos de la época hay numerosas quejas por los problemas que se presentaban para cobrar esas becas.
} 
de la Universidad ${ }^{48}$. Con respecto a ello, es interesante señalar que Víctor Mercante y Rodolfo Senet, junto con algunos otros profesores y estudiantes, desplegaron una intensa campaña de difusión y promoción de los estudios pedagógicos entre los docentes y funcionarios escolares de la Provincia. En este sentido, por ejemplo, se organizaron cursos especiales de metodología y se participó en las conferencias pedagógicas para los docentes de las escuelas locales, organizadas por la Dirección General de Escuelas. También las conferencias de extensión universitaria de Mercante, Senet y Alejandro Carbó, entre otros, alcanzaron un considerable éxito entre los maestros y estudiantes del magisterio de La Plata. De esa forma, los programas de extensión universitaria que se promovieron desde la Sección Pedagógica, ayudaron a consolidar una autoridad en materia educativa entre los funcionarios de la Provincia de Buenos Aires, y por esa vía se buscaría legitimar el derecho de los egresados de esa Institución para ocupar cargos en el sistema de educación provincial. Asimismo, a fines de 1911 el Poder Ejecutivo Nacional decretó que entre los requisitos para el nombramiento de personal docente y directivo de los establecimientos de segunda enseñanza, se necesitaba un diploma de idoneidad de la Sección Pedagógica, el Instituto Nacional del Profesorado y otras instituciones especiales, entre las cuales, paradójicamente, no figuraba la Facultad de Filosofía y Letras de Buenos Aires ${ }^{49}$. La incorporación de la Sección en este decreto, muestra el reconocimiento que había alcanzado como ámbito de transmisión de un saber especifico entre las autoridades nacionales. Paralelamente, los profesores de esta Sección se incorporaron como asesores, funcionarios escolares y directores de algunos departamentos del Ministerio de Instrucción Pública.

Hacia 1911 se reestructuraron los planes de estudio de la Sección Pedagógica, estableciéndose varios títulos de profesor. Por un lado, los estudiantes de correlación podrían obtener el diploma de "Profesor de Enseñanza Secundaria y Superior", si se graduaban de Ingeniero o Doctor y aprobaran en la Sección siete materias: 1) anatomía y fisiología del sistema nervioso, 2) psicología, 3 ) metodología general, 4) ciencia de la educación, 5) historia de la enseñanza, 6) metodología especial, 7)

\footnotetext{
${ }^{48}$ El cuerpo docente de la Escuela Graduada anexa a la Sección así como el Colegio Secundario de Señoritas se conformó por estudiantes y egresados de esa Sección. También algunos de los jóvenes profesores del Colegio Nacional asistieron a los cursos del profesorado. Asimismo, muchos egresados fueron incorporados al cuerpo docente de escuelas normales y otros establecimientos educativos de la Provincia de Buenos Aires. En la Memoria de 1912, Mercante reclamaba que en las escuelas y colegios de la Capital Federal y en los dependientes del Gobierno Nacional no se privilegiaban a los diplomados de esa Sección. Mercante 1913.
} 
legislación escolar; y la práctica de enseñanza. Paralelamente se indicaba que los egresados de las carreras universitarias que cursaran esas siete materias, pero que no obtuvieran el título de Doctor o Ingeniero, podrían alcanzar el título de "profesor de enseñanza secundaria" en el grupo de materias de su especialidad. En relación con esto último, se indicaba que profesionales estaban capacitados para enseñar las distintas asignaturas de la educación secundaria. En ese sentido, se establecía que los abogados podrían dictar: Historia Argentina e Instituciones Jurídicas; los farmacéuticos y peritos químicos: Química; los licenciados en ciencias naturales: Historia Natural; los médicos veterinarios: Anatomía y Fisiología y los ingenieros agrónomos: Botánica, Química, Agricultura y Zoología.

A su vez, los alumnos propios de la Sección podían también obtener un título de "Profesor de Enseñanza Secundaria" en distintas especialidades y según los planes establecidos por la misma. Los estudiantes que siguieran todas las materias de la Sección: doce cursos distribuidos en dos años y un tercer año dedicado a la práctica pedagógica, se diplomarían como profesores de pedagogía y ciencias afines ${ }^{50}$. Al mismo tiempo se establecieron profesorados en otras disciplinas: matemáticas, historia natural, física y química, letras, historia, geografía y filosofía. Para todos se exigían las mismas materias que para ser profesor de pedagogía más algunas específicas de las otras Facultades o carreras ${ }^{51}$. Esto último implicaba una formación científica mucho menor, aunque mayor en "pedagogía", que los diplomas similares que se establecían por el sistema de correlación, los cuales, además, requerían cursar más materias y años de estudio ${ }^{52}$. La mayoría de los estudiantes se concentró en el profesorado secundario de pedagogía y ciencias afines que abarcaba menos materias que los otros planes de

\footnotetext{
${ }^{49}$ Buchbinder 1997.

${ }^{50}$ El plan de estudios de este profesorado abarcaba las siguientes materias: 1) antropología; 2) sistema nervioso; 3) psicología; 4) psicopedagogía; 5) higiene escolar; 6) composición y estilo; 7) metodología general; 8) ciencia de la educación; 9) historia de la enseñanza; 10) metodología especial; 11) legislación escolar; y práctica de enseñanza en el tercer año.

${ }^{51}$ Para el profesorado en matemáticas se sumaban cinco materias científicas; en el de historia natural, siete; en física y química: cinco, en letras: cinco, en historia: cuatro, en geografía: ocho, en filosofía: seis. UNLP 1913 b.

${ }^{52}$ Así por ejemplo, un estudiante que deseaba ser profesor de historia natural tenía dos posibilidades: a) inscribirse en el Museo, cursar los tres años de la licenciatura, (en una especialidad) y paralelamente aprobar las ocho asignaturas de la Sección Pedagógica, incluida la práctica de enseñanza; o b) matricularse en la Sección Pedagógica y cursar las doce materias del profesorado en Pedagogía (dos años), más la práctica de enseñanza, y siete materias científicas, que comprendían cursos introductorios y de primer año: zoología ( $1^{\circ}$ año), botánica ( $1^{\circ}$ año), mineralogía, geología, complementos de química, geografía astronómica y física y complementos de física.
} 
estudio $^{53}$. Además, en la práctica estos estudios permitieron el acceso a la enseñanza de diferentes materias en los colegios de la universidad y en otros establecimientos, pese a que con estas reformas, según indicó Mercante, se habían eliminado los diplomas generales y se tendía a la especialización del profesorado ${ }^{54}$. Por otra parte, los planes de estudio organizados por la Sección para obtener un diploma de profesor en otras disciplinas, entraron en competencia con los que se cursaban por el sistema de correlación como alumno de otra Facultad, y en los cuales se exigía un mayor entrenamiento científico. Esto, como se examina más adelante sería parte de los reclamos de los sectores científicos que cuestionaron la organización de la formación del profesor de enseñanza secundaria al igual que el título de "profesor de enseñanza superior".

\section{3. El título de "profesor de enseñanza superior"}

En el programa universitario inicial, González también había proyectado que la Sección Pedagógica contribuiría a la preparación de los docentes universitarios, a partir de los egresados de las distintas carreras, a quienes se "les iniciará en la ciencia metodológica, que nunca ha sido estudiada en nuestros institutos universitarios, los cuales no obstante, otorgan títulos de profesor en todas las ciencias. Ningún aspirante a cátedra suplente, libre o auxiliar podrá tener entrada en ella, sin haber hecho el año de pedagogía superior. La misma universidad elabora así su propio profesorado, dotándolo de la ciencia y del arte de trasmitirla a los demás"55

Recordemos, que el problema de la formación del profesorado universitario había sido una cuestión presente en los debates universitarios en la transición del siglo y continuaría presente en los programas de los congresos estudiantiles y en las propuestas de varios sectores universitarios. Principalmente, las discusiones sobre este tema se desarrollarían en tono a varias cuestiones: la posibilidad de aplicar el sistema alemán del Privatdozent, el aumento de los sueldos docentes para incentivar una mayor dedicación a las actividades académicas, los requisitos y la forma de realizar la

\footnotetext{
${ }^{53}$ Entre 1906 y1917, 46 \% de los egresados de los distintos profesorados se concentró en el de enseñanza secundaria, normal y especial en Pedagogía y ciencias afines. A ello se agregaba un $8 \%$ de egresados, quienes se inclinaron por el profesorado en pedagogía y una especialidad, según los planes de estudio de la Sección Pedagógica. Véase cuadro en el Anexo.

54 Tras la reforma universitaria en 1919-1920, se eliminó el profesorado en pedagogía y ciencias afines.
} 
selección de los profesores en el marco de las presiones de los egresados para acceder a la docencia universitaria. Es de destacar, que en ningún caso se discutió la necesidad de un entrenamiento pedagógico para los profesores universitarios ni la creación de una instancia específica que regulara la distribución de certificados y la capacitación necesaria para el ejercicio docente en la Universidad. En ese sentido, los sectores universitarios defendieron la autoridad de cada Facultad para regular la selección de sus miembros. Por otro lado, tampoco la Escuela Normal Superior creada en Buenos Aires por decreto ministerial a fines de $1909^{56}$, según el modelo de la de París y destinada a formar un profesorado normal superior bajo la dirección de profesores de la Universidad de Buenos Aires, podría sobrevivir a la gestión del Ministro Rómulo Naón, que fue reemplazado al año siguiente.

No obstante, uno de los títulos proyectados por la Sección Pedagógica era el de "profesor de enseñanza superior", aunque nunca se especificó el alcance del mismo. Como se mencionó anteriormente, este diploma constituiría un agregado al de profesor de enseñanza secundaria en alguna especialidad y se otorgaría a los egresados que hubieran alcanzado el grado académico de doctor o ingeniero. Hacia 1912, cerca de nueve alumnos habían completado los requisitos para obtener el diploma de profesor de enseñanza secundaria y superior. Entre los ocho a los que se les concedió ese título, siete eran egresados de la Facultad de Agronomía y Veterinaria. En cambio, el Consejo Académico de la Facultad de Ciencias Jurídicas se negó a otorgar ese título a un ex-alumno que lo había solicitado ${ }^{57}$. Tampoco, este título pareció encontrar apoyo en otras Facultades, y de hecho no llegó a reglamentarse.

En momentos de establecerse la Facultad de Ciencias de la Educación se consultó a la Facultad de Ciencias Naturales sobre la formación del profesorado superior. El 3 de septiembre de 1913, Víctor Mercante envió al director del Museo,

\footnotetext{
${ }^{55}$ González 1935, XVI: 103.

${ }^{56}$ Para la de esta Escuela Normal Superior se destinaron importantes partidas de dinero, se compró un edificio e importante colecciones para la enseñanza y además se instalaron gabinetes y laboratorios. Se planificó que esta institución estuviera conformada por varios departamentos científicos, de forma similar al Instituto Nacional del Profesorado. Como jefes de esos departamentos y docentes figuraban varios profesores-investigadores de la Universidad de Buenos Aires, a los cuales se le abonaría un sueldo mensual de 800 pesos, es decir más del doble que una cátedra universitaria. No obstante, esta Escuela fue suprimida a fin del año siguiente por decreto de un nuevo Ministro de Instrucción Pública.

${ }^{57}$ Mercante 1913. En la Memoria institucional se mencionaba que ocho alumnos que habían terminado los estudios del profesorado secundario y superior, cuatro eran doctores en medicina veterinaria y tres, ingenieros agrónomos. También se señalaba que un alumno de derecho había completado los requisitos para este diploma, pero el Consejo Académico de esa Facultad se opuso a que se otorgara ese título.
} 
Lafone Quevedo, una nota confidencial para conocer su opinión acerca de la reglamentación del diploma de "profesor superior", que se pensaba gestionar desde la Sección Pedagógica ${ }^{58}$. Especialmente, se solicitaba que indicara los profesorados a los que podían aspirar los alumnos de esa Facultad, en cuanto a preparación y títulos, teniendo en cuenta que, además, debían realizar materias pedagógicas, entre las cuales se encontraba la práctica pedagógica. En la propuesta del director de la Sección Pedagógica, los alumnos podrían cumplir con este último requisito después de haber terminado todos sus estudios. Antes de realizar las prácticas docentes, los alumnos tendrían que presentar un programa de la materia a enseñar con un bosquejo de cada lección, lo cual sería primero supervisado por el profesor de pedagogía y luego elevado al decano de la Facultad respectiva, donde se habrían de realizar las prácticas. Se establecía que la aprobación de esta instancia dependería de la Facultad en la que se había especializado el alumno y de la clasificación otorgada por una comisión que hubiese observado sus lecciones, compuesta de tres profesores: el de la materia, el de práctica pedagógica y otro nombrado ad hoc. La propuesta de Mercante era que la evaluación de los aspirantes al profesorado superior se realizara bajo la dirección científica del Consejo Académico del Museo, o con profesores nombrados para tal fin, y el control didáctico de los docentes de la Sección Pedagógica.

Lafone Quevedo consultó a algunos profesores y los directores de las distintas Escuelas que funcionaban en el Museo. El zoólogo Miguel Fernández como Jefe de la Escuela de Zoología y Botánica, contestó rápidamente una semana después. También respondieron: el vicedirector del Museo, Enrique Herrero Ducloux como Jefe de la Escuela de Química y Farmacia, y el antropólogo alemán Roberto Lehmann-Nitsche. Los tres coincidieron en impugnar la propuesta de la Sección Pedagógica. Principalmente, las críticas se articularon alrededor de dos puntos: a) la categoría de profesor superior y su ámbito de incumbencia, y b) la autonomía de cada Facultad para controlar la enseñanza de las materias que se dictaban en su interior. Esto último se relacionaba con la intervención de la Sección Pedagógica para establecer los criterios y la evaluación de la enseñanza de un egresado universitario, en este caso, de la Facultad de Ciencias Naturales.

Otro graduado que entre los títulos alcanzados, indicaba el de profesor de enseñanza secundaria y superior fue Teodoro de Urquiza, doctorado en ciencias naturales en 1912.

${ }^{58}$ AHMLP, Caja 8, doc. $\mathrm{n}^{\circ}$ 202. Este documento corresponde a un expediente que comprende las notas y propuestas firmadas por los profesores que a continuación se citan en el texto. 
La nota de Fernández era la más extensa y a ella remitían las respuestas de los otros profesores. En primer lugar, se señalaba que el título de "profesor superior" no existía en ninguna universidad del mundo ni tampoco se contemplaba en los documentos orgánicos de la institución platense. Si bien reconocía que por el decreto del 24 de enero de 1906, se había establecido el título de "profesor de enseñanza secundaria y superior", sostenía que seguramente el Poder Ejecutivo lo había entendido como equivalente al de profesor de liceo o colegio secundario, como existía en Alemania donde a los profesores de los gimnasios y escuelas reales se denominaban "höheres Lehramt"(profesorado superior). Por otra parte, indicaba que la celebre Escuela Normal Superior de París había sido creada para formar profesores de liceo y no universitarios. Cabe recordar, que en la práctica, los estudios en esta última institución se habían constituido en un paso casi obligado en las trayectorias de las élites académicas y gran parte del profesorado de las facultades de ciencias ${ }^{59}$. Pero la impugnación de Fernández, al igual que el resto de los profesores del Instituto del Museo, se dirigía hacia la institucionalización de un título de profesor superior, en el sentido de un plan de estudios y otros requisitos formales que habilitaran para la docencia universitaria. Para este zoólogo formado en la Universidad de Zürich, la competencia para ejercer como profesor universitario, no se basaba en una formación pedagógica especial sino en los trabajos de investigación original que el postulante hubiera realizado en la disciplina que aspiraba enseñar. Según indicó: "la primera y esencial condición del profesor universitario, la competencia profesional no se obtiene por práctica pedagógica de ninguna clase, sino únicamente por investigaciones dentro de la especialidad elegida"60.

Fernández defendía el ideal de profesor-investigador como en las universidades de idioma alemán, donde las publicaciones especializadas y los trabajos de investigación eran elementos imprescindibles para desarrollar una carrera

\footnotetext{
${ }^{59}$ La Escuela Normal Superior de París en sus inicios estuvo destinada a la formación de los profesores de los liceos estatales e incidentalmente de las facultades de letras y ciencias. Durante el siglo XIX experimentó una considerable expansión, trasformándose en una institución de enseñanza universitaria con programas y estudios que habilitaban para el ejercicio del profesorado en facultades de ciencias y letras. A través de un rígido sistema de preselección de los ingresantes, las becas otorgadas por el Estado, los seminarios y laboratorios y la identidad colectiva que se establecieron entre sus ex-alumnos, esta Escuela gozó de un amplio prestigio académico. Los normalistas se convirtieron en un segmento sumamente privilegiado y sobre protegido dentro del cuerpo académico francés y también alcanzaron altas posiciones entre los miembros del gobierno. En la transición del siglo, dominaban en la mayoría de las cátedras universitarias de enseñanza científica, especialmente en matemáticas, astronomía, física y química. Hacia 1903 esta Escuela sería integrada a la estructura de la Sorbona. Véase entre otros: Karady 1990; Zwerling 1980; Weisz 1983, Charle 1990.
} 
académica. En ese sentido, consideraba adecuado el procedimiento de habilitación para el ejercicio docente seguido por la mayoría de las universidades europeas, en las cuales se exigían para poder dar clase en alguna Facultad, además del título de doctor, una investigación propia hecha después de la tesis doctoral. Ese trabajo postdoctoral no confería ningún otro grado académico, sino la habilitación para dar clases como Privatdozent (docente libre), o como profesor agregado en el caso de Francia. Finalmente, concluía este primer punto, mencionando el descrédito que tendría la Universidad platense si decidía a conferir ese título de "profesor superior", que se entendía como sinónimo de profesor universitario, ya que ello: "llevaría a las personas entendidas en materia de organización universitaria á creer que nuestras autoridades no distinguen con la nitidez necesaria entre las funciones del profesor universitario y del de enseñanza secundaria, lo que podia dañar al honroso concepto que hasta ahora se tiene de esta Institución." 61 Por su parte, Lehmann-Nitsche realizaría un comentario similar sobre el carácter de este título: el adjetivo 'superior'....puede llevar al público á interpretaciones erróneas sobre el carácter universitario de este" 62 .

La misma opinión sería sostenida por el vicedirector del Museo y consejero superior, Enrique Herrero Ducloux: "....si nos fuese dado evitar la creación del título de Profesor de Enseñanza Superior deberíamos hacerlo en salvaguardias del prestigio del título mismo que no puede adquirirse debidamente siguiendo tales ó cuales cursos y rindiendo pruebas más ó menos rigurosas, sino que representa la consagración de toda una vida, la posesión de facultades especiales y el dominio de una ciencia ó de una rama de ella cultivada con amor y contando en ella con investigaciones originales...". 63

En segunda instancia y ante la posibilidad de que la universidad igualmente resolviera crear ese título, Fernández indicaba un grupo de materias por la que los egresados podrían optar, tomándose como base las especialidades de las carreras científicas del Museo. Consideraba que la práctica de enseñanza se debía realizar en este ámbito y bajo el control exclusivo de este instituto. Paralelamente, criticaba la propuesta de exigir a los practicantes, la presentación anticipada de un programa analítico con la distribución de los contenidos de la materia y un esquema de cada

\footnotetext{
${ }^{60}$ AHMLP, Caja 8, doc. $n^{\circ}$ 202. Informe de M. Fernández

${ }^{61}$ Ibid.

${ }^{62}$ Ibid. Nota de R. Lehmann-Nitsche.
} 
lección. Especialmente esto último era asociado a las prácticas escolarizadas de la enseñanza primaria, algo muy diferente a lo que debía ser la organización de los estudios universitarios, donde el profesor debía gozar de una amplia libertad académica. Como alternativa, proponía que el candidato dictara una serie de conferencias o un curso libre para los estudiantes de la Facultad, cuyo programa sintético sería presentado previamente al Consejo Académico del Museo para su aprobación. Asimismo, la evaluación del desempeño del practicante dependería de esta Facultad, desde la cual se remitiría un informe final a la Sección Pedagógica.

Un punto importante al que se oponían los profesores de la Facultad de Ciencias Naturales, se dirigía hacia la intervención de docentes de la Sección Pedagógica en la evaluación de la práctica de enseñanza de una materia perteneciente al Museo. En este sentido, por ejemplo, Fernández señalaba que: "bajo ningún concepto puede admitirse un 'control didáctico por parte del profesor de Práctica Pedagógica' como lo propone el Sr. Mercante, por no permitir la dignidad de nuestro instituto el ser controlado por otra facultad y mucho menos por esa sección, que no es sino una dependencia de una de ellas" ${ }^{64}$. Otro de los argumentos se basaba en la falta de conocimiento científicos que tenían los profesores de pedagogía sobre la materia a evaluar, por lo que no podrían juzgar adecuadamente el valor del candidato como profesor universitario. Finalmente, Fernández aconsejaba comunicarle a la Sección de Pedagogía que el título propuesto no crearía ninguna prerrogativa para la previsión de cátedras en esa Facultad. De hecho, lo mismo ocurrió con el nombramiento de profesores adjuntos, ya que en varios casos los que accedieron a estos cargos en la Facultad de Ciencias Naturales no cumplieron con el requisito de un año de estudios pedagógicos, según lo establecido en los documentos de fundación de la Universidad Nacional de La Plata ${ }^{65}$.

Por su parte, Herrero Ducloux coincidía con Fernández en considerar innecesario la intervención del profesor de práctica pedagógica, ya que ello suponía "la intromisión en el Museo de un profesor extraño á la institución y de carácter secundario". Además, sostenía que "...a mi entender la pedagogía tiene mucho que

\footnotetext{
${ }^{63}$ Ibid. Informe de E. Herrero Ducloux.

${ }^{64}$ Ibid. Informe de M. Fernández

${ }^{65}$ En la ley-convenio de fundación de la Universidad, el art. 15 establecía: "podrá haber, mediante el permiso de los cuerpos académicos, profesores adjuntos a las cátedras de los titulares, quienes darán clase libremente sobre las mismas lecciones ó materias que se traten en la primera y con el propósito de ampliarlas ó comentarlas, pero ninguna facultad ó instituto permitirá dar estos cursos á quien no
} 
hacer en la enseñanza primaria, poco en la secundaria y nada en la superior."66. Pero como había que aceptar lo establecido por las ordenanzas por sobre "nuestras convicciones y nuestros intereses como universitarios", lo que había que tratar era de suavizar las consecuencias de esa medida, que finalmente no se llegaría a implementar.

La impugnación sobre la reglamentación de un diploma de profesor superior, por parte de los científicos del Museo/Facultad, se enmarcaba dentro de una disputa por los modos de legitimación y definición del perfil del docente y el lugar asignado a los saberes científicos y los pedagógicos. Se enfrentaban, entonces, dos puntos de vista con respecto al profesorado en general: si era necesario saber enseñar o sólo era suficiente saber hacer ciencia. La importancia que se le daba a cada uno de estos tipos de saberes variaba según el nivel de enseñanza de que se tratase. Para varios profesores universitarios, la pedagogía, entendida como el arte de saber trasmitir conocimientos, era útil en la escuela primaria y en la normal; poco provechosa en la secundaria e inútil en la universitaria, en donde lo más importante era la "vocación" y dedicación a la investigación. Para los investigadores del Museo, el derecho a ocupar una cátedra universitaria se debía alcanzar sólo después de recorrer una carrera científica y demostrar la capacidad de producir investigaciones científicas originales. Con respecto este punto, había consenso en que la categoría de profesor universitario no era un título que se pudiera obtener después de haber aprobado determinada cantidad de materias y realizado una práctica pedagógica, sino que implicaba una posición de prestigio científico. Como se analiza a continuación, algunos sectores científicos también reclamarían un mayor entrenamiento en la práctica de la ciencia para el profesorado de enseñanza secundaria.

\section{4. La preparación científica del profesorado de enseñanza secundaria}

La formación científica que debía tener el profesor secundario en la especialidad a enseñar así como la autoridad para diseñar los planes de estudio fueron cuestiones disputadas entre la Sección Pedagógica y las Facultades de Ciencias

haya hecho el año de estudio pedagógico en la Sección de la Facultad de Ciencias Jurídicas y Sociales". UNLP 1910: 12.

${ }^{66}$ Ibid. Informe de E. Herrero Ducloux. 
Naturales y de Ciencias Físicas, Matemáticas y Astronómicas. En 1909, las autoridades universitarias procuraron la reorganización de esta última Facultad, para lo cual se contrataron a varios científicos alemanes. A partir de la llegada del físico Emil Bose, se creó el doctorado en física y se estableció un plan de estudios para el profesorado en física de tres años con una formación idéntica a los primeros tres años del doctorado, excepto por el curso de geofísica que era reemplazada por los de pedagogía ${ }^{67}$. Esta organización tendía a reproducir el sistema alemán de formación del profesor secundario, en donde la preparación científica se adquiría en las Facultades de forma similar al doctorado y se completaba con una materia pedagógica que se cursaba en los Seminarios Pedagógicos. En los reglamentos de 1911 se propuso que esta Facultad otorgaría los títulos de profesor de física y de matemáticas, según los planes de estudio fijados por esta institución; y por correlación, los alumnos deberían aprobar las ocho materias requeridas para todos los profesorados por la Sección Pedagógica $^{68}$. Al año siguiente, esto fue dejado sin efecto por el Consejo Superior.

Para la carrera del profesorado en ciencias naturales también hubo acuerdo entre los docentes de la Facultad de Ciencias Naturales del Museo, en que se necesitaba una formación equivalente a la del doctorado para poder aspirar al título de profesor. Esto, por ejemplo se manifestó en 1910 cuando la Presidencia consultó a las autoridades de esta institución sobre el diploma que se debía otorgar a los alumnos que habían obtenido un título profesional y habían cursado materias en la Sección Pedagógica. El Consejo Académico, después de algunos debates, decidió comunicar que no estaba de acuerdo en que se otorgara el título de profesor a quien no hubiese alcanzado el de doctor; pero viendo que no podía ser de otro modo, indicó que se podía conceder el título de profesor de química a los egresados de la Escuela de Química y Farmacia, y de historia natural, a los licenciados en ciencias naturales ${ }^{69}$.

La rivalidad entre las Facultades de ciencias y la Sección Pedagógica se acentuó cuando esta última estableció sus propios planes de estudio para la preparación de profesores secundarios en distintas especialidades a partir de 1911. Esto implicó un cambio en la matriculación estudiantil, ya que ahora muchos alumnos optaban por ingresar y seguir los planes de la Sección que eran más cortos. A partir de ese momento, la Sección centralizaba la inscripción de los alumnos de los distintos

\footnotetext{
${ }^{67}$ UNLP 1910.

${ }^{68}$ UNLP 1913b.

${ }^{69}$ AHMLP, Actas del Consejo Académico, Libro I, folios 170-173.
} 
profesorados que ofrecía, y desde allí se enviaban a las distintas Facultades las listas de los alumnos que debían cursar algunas materias en ellas. Esto generó situaciones de inscripciones tardías, reclamos por cursos especiales y problemas por los diferentes regímenes de cursada que existían en cada unidad académica. Además, los planes de estudio de la Sección abarcaban en general menos materias y una preparación científica no tan intensa como los profesorados que se habían establecido por el sistema de correlación, tras la consulta a cada Facultad. En esa época, el Consejo Superior derogó la ordenanza referente a los títulos de profesor establecidos por la Facultad de Ciencias Físicas y Matemáticas ${ }^{70}$. Según el decano de esta Facultad, el ingeniero Nicolás Besio Moreno, la existencia dos planes alternativos para los profesorados en ciencias era una "anomalía" que le había restado competencia a esta última institución: "La sección pedagógica de la Facultad de ciencias jurídica y sociales expide estos títulos de profesor a los que hayan cursado planes de estudio propios de la sección muy distintos por cierto de los que tenía en vigencia esta Facultad y con un número considerablemente menor de asignaturas técnicas de la especialidad matemáticas o física; esta anomalía daba lugar a que ningún alumno cursase por los planes de la Facultad, que eran más extensos, sino por los de la sección y careciendo de recursos para obtener la supresión de este estado particular de cosas, pensó el decanato que era indispensable desligar a la facultad de una tarea que representaba para ella mucha responsabilidad. Sin darle a la vez los medios necesarios para desarrollar sus ideas..."71

Desde esa Facultad se cuestionó la preparación técnica y científica de los planes de estudios de los profesorado en ciencias exactas elaborados por la Sección Pedagógica, concluyéndose que era defectuosa e insuficiente, debido a la pocas materias específicas que cursaban los aspirantes. En el caso del profesorado en física y química se sostenía que era el más inadecuado, ya que se establecía que los alumnos cursaran sólo Complementos de Física, materia general e introductoria de primer año de distintas carreras; y no otras asignaturas de los años superiores como Física

\footnotetext{
${ }^{70}$ Los planes de profesor : a) de Física, abarcaban 16 materias de la especialidad, y los 8 cursos de la Sección Pedagógica.; b) de Matemáticas: 14 materias de la especialidad y los 8 cursos pedagógicos. En la misma época la Sección de Pedagogía ofrecía los títulos de Profesor de Enseñanza Secundaria en: a) matemáticas y b) química y física , con la aprobación de 19 materias, de las cuales 5 eran "científicas" y el resto cursos de la Sección.

${ }^{71}$ Besio Moreno 1913: 98.
} 
Experimental $^{72}$. Se consideraba que esa situación provocaba que los futuros profesores no conocieran los métodos experimentales y "...no podrán ellos mismos realizar experimentos, ni estarán en condiciones de enseñar la física más elemental que apenas conocerán..."73 Asimismo, se proponía la separación de los estudios para profesor de física del de química, defendiéndose especificidad de cada una de esas disciplinas; y que se modificaran los planes de estudios. Por otra parte, se insistía en la importancia que los futuros docentes de enseñanza secundaria se entrenaran en las prácticas científicas para una mayor difusión de las ciencias, buscando hacer que los modelos y técnicas de las ciencias enseñadas en la universidad aparecieran como apropiados para el sistema de instrucción pública. Para concluir, se señalaba que: "la instrucción secundaria necesita de ciencias matemáticas, físico y naturales, no solo por los conocimientos que dan, sino por las disciplinas que representan; y estas no sabrán aprovecharse ni trasmitirse, si el profesor no las posee por entero, lo que es tanto más lamentable, cuanto que los que optan por esos títulos, por su preparación pedagógica, se encuentran en mejores condiciones para obtener rápidamente tales disciplinas y trasmitirlas. ¿Cómo podrá trasplantarse a la instrucción secundaria, la enseñanza experimental, si los profesores diplomados no saben experimentar en matemáticas, o en física?. Cuestión es esta que la facultad ha planteado varias veces en la asamblea general de profesores y en el consejo superior, y que es hora de que tenga su solución."74

Efectivamente, la preocupación por la preparación técnica y científica del profesorado fue una cuestión que sucesivamente se discutió en las Asambleas Generales de Profesores de la Universidad platense. En la primera de estas reuniones se generó una discusión en torno a la asignatura de Metodología especial que debían cursar los aspirantes al profesorado: si se debía organizar específicamente para cada disciplina y en la Facultad correspondiente, o si los alumnos debían concurrir al curso especial de la Sección Pedagógica. La mayoría de los profesores apoyaron la segunda opción, mientras que algunos docentes de ciencias naturales emitieron su opinión en contra. Para Santiago Roth, la metodología especial sólo podía ser enseñada por el profesor de la especialidad. Una idea parecida expresó el Miguel Fernández indicando

\footnotetext{
${ }^{72}$ Las materias científicas exigidas por la Sección Pedagógica para el profesorado en Física y Química eran: Física (dos cursos); Química general; Química analítica cualitativa y Química orgánica. Las tres últimas asignaturas eran dictadas por la Escuela de Química y Farmacia del Museo y estaban incluidos en los planes de estudio de las carreras de farmacia y en los doctorados en ciencias químicas.

${ }^{73}$ Besio Moreno 1913: 99.
} 
que la única metodología posible para las diversas materias era el ejemplo de una buena enseñanza por parte del docente de esa disciplina. Asimismo, este profesor cuestionó el saber de los profesores de pedagogía para juzgar los diversos métodos de trabajo e investigación en las distintas disciplinas científicas ${ }^{75}$. Recordemos que la asignatura de Metodología especial estaba a cargo del profesor normal Víctor Mercante, quien dividía parte del curso para atender los métodos de la enseñanza de tres grupos de disciplinas: a) historia, instrucción cívica y letras, b) matemáticas y ciencias físico-naturales y c) pedagogía y psicología aplicada. El cuestionamiento por parte de los científicos a la competencia de los docentes de pedagogía, no se dirigía hacia las credenciales académicas, sino hacia la posibilidad de apreciar la especificidad de las prácticas de cada ciencia. Las especializaciones y la defensa de las particularidades de cada disciplina impugnaban la idea de unicidad de la ciencia, basada en un mismo método para conocer y enseñar, así como la intervención de personas ajenas a la práctica de la ciencia.

En las siguientes Asambleas, los profesores de ciencias defendieron la competencia de cada Facultad, dentro de sus especialidades, para formular los planes de estudio del magisterio de enseñanza secundaria y dirigir el rumbo de la enseñanza de las disciplinas que practicaban. El decano Nicolás Besio Moreno, en representación de la opinión del Consejo Académico de su Facultad, defendió esta idea en la Asamblea de 1910, ya que por: "en el sistema de correlación se deja á cada organismo en la institución, el cuidado de velar de inmediato, el mecanismo de la enseñanza de las ciencias que lo constituyen, lo cual permite una concentración más aguda que es una verdadera especialización....cada facultad preocupada de un modo exclusivo, por asi decir, de la ciencia que enseña, dispone de un bagaje de fuerzas y de un criterio más sistemático y concreto para concurrir con ellas á la determinación del plan de que se trate....habría un verdadero error...en no dar á cada facultad la intervención correspondiente para que, como la más alta autoridad en la materia, formule la parte técnica de los planes para el profesorado secundario y superior."76

\footnotetext{
${ }^{74}$ Ibid.: 99.

${ }^{75}$ En esa reunión, Miguel Fernández manifestó que: "...todo cursos de 'metodología especial'... sea ésta general ó especial, dictado por profesores de la 'Sección pedagógica', por personas de cuya ilustración no dudo, pero que no poséen conocimientos especiales bastantes extensos para juzgar del alcance de los diversos métodos de investigación en las distintas ramas del saber, es de un valor puramente problemático. UNLP 1907: 44.

${ }^{76}$ UNLP 1911: 16-17.
} 
Por su parte, el director de la Sección Pedagógica, también sostuvo que era competencia de cada Facultad dictar los planes de estudio para sus especialidades y en este sentido, los profesorados eran parte de las incumbencias de esa Sección. En última instancia, observaba Mercante, le correspondía al Consejo Superior, donde participaban dos representantes por cada Facultad, supervisar los planes de estudios y las correlaciones elaborados por esta Sección. Paralelamente insistiría en que era peligroso dejar la formación del profesor secundario en manos de las Escuelas de especialización científica y profesional, ya que tendían a establecer un exceso de preparación científica: "...en lo referente a la enseñanza secundaria, considerase que ésta es general y educativa, por consiguiente, no conviene que una facultad cuyo ambiente es de especialización científica orientada según un espíritu eminentemente unilateral, establezca por si el plan de estudios por el que ha de prepararse el profesor de un colegio. Un exceso de preparación tal vez conveniente, no es necesario. El especialista tenderá siempre á considerar insuficiente la preparación de un profesor mientras éste no llegue á diplomarse en la facultad. Hay, pues, posibilidad de confundir las exigencias de la profesión con las de una enseñanza reducida." 77

En esa reunión, la mayoría de los profesores, veintinueve de los cuarenta y tres presentes, apoyó lo sostenido por el decano de la Facultad de Ciencias Físicas, Matemáticas y Astronómicas, mientras que tres opinaron que les correspondía a las Facultades pero dando intervención a la Sección de Pedagogía. Finalmente, el profesor de abogacía Joaquín Carrillo indicó que el tema ya estaba establecido en los Estatutos de la Universidad, por lo que el vicepresidente de la Universidad retiró el tema de la orden del día ${ }^{78}$. En la última Asamblea general que se realizó, en 1913, la Sección Pedagógica propuso que los aspirantes a ejercer la docencia secundaria y normal debían formarse en los institutos pedagógicos, en los cuales por lo menos debían cursar: psicología, metodología general y especial, ciencia e historia de la enseñanza y práctica de la materia de especialización. En cuanto a la preparación científica se indicaba que "con preferencia" debía ser hecha en las facultades

\footnotetext{
${ }^{77}$ UNLP 1911: 18.

${ }^{78}$ Es de destacar, que ante otras cuestiones que generaban demasiados debates o propuestas alternativas que se apartaban de las ideas establecidas por la Presidencia, se tendía a retirar el tema de este ámbito de discusión abierto a todo el claustro docente. Por otro lado, las proposiciones de esta Asamblea no tenían carácter resolutivo ni legislativo y sólo se las consideraban reflexiones sobre el rumbo de la enseñanza universitaria. De hecho, la concurrencia a esas reuniones anuales fue disminuyendo y en 1914 se suspendieron.
} 
especiales y con un programa mínimo de cinco materias. Varios profesores acordaron con esto, mientras que otros indicaron que la preparación científica debía darse exclusivamente en los institutos y facultades respectivas. Algunos, como el director de la Escuela Superior de Física, Ricardo Gans, consideraban que no se necesitaran tantas "materias pedagógicas". Finalmente, la proposición de la Sección Pedagógica ganó con veintiún votos a favor sobre cuarenta y uno. En los siguientes años, los profesores de ciencias físicas y naturales, continuarían fomentando la discusión acerca de competencia de las distintas Facultades para formular los planes de estudio para la carrera de profesor de enseñanza secundaria, en las especialidades de su incumbencia ${ }^{79}$.

El predominio de la Sección Pedagógica en el diseño de la formación de los profesorados de enseñanza secundaria se acentuó aún más con su transformación en Facultad de Ciencias de la Educación en 1914, bajo la dirección de Víctor Mercante. Esta nueva unidad académica se estructuraría sobre tres núcleos de materias: a) pedagógicas; b) históricas y geográficas; y c) filosóficas y literarias, predominado las primeras hasta el movimiento de Reforma Universitaria en 1919, cuando se produjo un importante recambio del personal docente y directivo de esta Facultad. Los primeros planes de estudios de la nueva Facultad comprendieron: el doctorado en ciencias de la educación; los de profesor de enseñanza secundaria, normal y especial en distintas especialidades; los de enseñanza especial en música y dibujo; y en 1916 la preparación del profesorado primario. La formación del docente de enseñanza secundaria se dividió en las siguientes especializaciones: 1) pedagogía y ciencias afines, que comprendía las mismas materias que antes y además se podía agregar una especialidad más, cursando algunas materias extras, 2) filosofía y letras, con quince materias, 3) historia y geografía, con trece, 4) historia argentina e Instituciones jurídicas y sociales, con nueve, 5) matemáticas; con doce, 6) física, con doce, 7) química, con doce; 8) ciencias naturales, con quince; 9) ciencias agrarias, con diez, 10) anatomía, fisiología e higiene, con diez, 11) dibujo.

En el nuevo curriculum propuesto para la formación del profesor secundario se manifestó una serie de desplazamientos con respecto al que había predominado

\footnotetext{
${ }^{79}$ Especialmente, Miguel Fernández elevaría este tema al Consejo Académico del Museo, para que se incluyera entre los asuntos a ser discutidos en las Asamblea General de Profesores. El Consejo Académico optó por presentar otros temas en 1912, aunque dos años después acordó en defender ese tema. No obstante, la Asamblea programada para 1914 y luego aplazada para el año siguiente, nunca se realizaría.
} 
durante la década anterior. El nuevo perfil docente que se promovía, ahora no sólo abarcaba materias "científicas" y "pedagógicas" sino también un tercer núcleo de asignaturas destinadas a proveer de una preparación en "cultura general y nacional". Como formación básica para todos los profesorados, además de las materias pedagógicas -metodología general y especial y ciencias de la educación- se exigían ahora: a) historia argentina, b) teoría y práctica de la composición, c) psicología y d) historia de la filosofía. Hasta esa época, las materias "culturales" no habían constituido un punto importante en la preparación del profesorado secundario que se institucionalizó en el contexto platense, a pesar de que entre los planes del fundador de la Universidad Nacional se había contemplado una instancia para que todos los universitarios adquirieran una misma base de "cultura general". En efecto, en la ordenanza de creación de la Sección de Filosofía, Historia y Letras en 1909 se estableció que no se otorgarían diplomas profesionales o científicos a quien no acreditara la asistencia a dos cursos de esa Sección. No obstante, esto no llegó a aplicarse de forma general, por la solicitud de derogación de las otras Facultades a pedido de los sectores estudiantiles. A fines de la década de 1910, también varios alumnos de los profesorados de ciencias físicas, matemáticas, naturales y químicas solicitarían, sin éxito, que se los eximiera de cursar historia argentina. Con la formación que ahora exigía la Facultad de Ciencias de la Educación se aumentaban las materias que tenían que cursar en esa unidad los alumnos de los distintos profesorados. Particularmente, para el de ciencias naturales, se debían curar aún más materias en esta Facultad: higiene, anatomía y fisiología del sistema nervioso y antropología. A partir de los planes de estudio establecidos por la Facultad de Ciencias de la Educación, cada vez más la formación del profesor tendía a separarse del entrenamiento científico o profesional ofrecido en las otras Facultades. En particular, esto generaría el reclamo de los profesores de las asignaturas propias de los doctorados en ciencias "desinteresadas".

\section{5. El reclamo de los sectores científicos}

La poca concurrencia de alumnos en las materias especificas de ciencias físicas y naturales que sólo se dictaban para el doctorado fue una situación problemática para los profesores de esas cátedras que estaban dedicados exclusivamente a la enseñanza y 
la investigación en la Universidad y también para los proyectos de conformar escuelas de investigación. Por otra parte, la baja matriculación estudiantil también dificultaba la ampliación de los cargos de auxiliar docente para los egresados en estas disciplinas, así como la posibilidad de reclutar colaboradores y conformar equipos de trabajo en torno a los laboratorios e institutos. En la Memoria de la Universidad de La Plata, publicada en 1917, se analizaba el problema de los pocos estudiantes en la Escuela de Zoología y Botánica: "la inscripción de siete alumnos propios con los que contó la Escuela de Zoología y Botánica en este año demuestra claramente que el interés por el estudio de las ciencias puras despierta en nuestro país es mayor de lo que se cree a primera vista. Sin embargo el número de alumnos nunca llegaría a proporciones considerables, si como sucede en la actualidad el título de doctor en Ciencias Naturales no habré al diplomado ningún campo de acción en la vida práctica. Una de las maneras más seguras de dar un fuerte impulso a nuestras facultades de ciencias naturales, dotándolas de vida propia, consistiría en conseguir que las cátedras respectivas de los colegios nacionales, escuelas normales y otros establecimientos de segunda enseñanza fueran reservados a los doctores de ciencias naturales y convendría que las autoridades de nuestras facultades hicieran gestiones en este sentido ante el ministerio de Instrucción Pública ${ }^{" 80}$.

De esa forma, para revertir el problema de la falta de estudiantes en las carreras científicas y fortalecer la situación de las facultades de ciencias naturales, se consideraba necesario asegurar un campo laboral para los egresados, reservando para los doctores las cátedras de enseñanza secundaria en estas disciplinas. Al mismo tiempo, se reclamaba el derecho del Museo/Facultad de Ciencias Naturales para conferir el grado de profesor en ciencias naturales y establecer los planes adecuados para esa carrera. Esto, a su vez, debía estar acompañado por una reglamentación que asegurara a los egresados de estas disciplinas, las mismas prerrogativas para ocupar cátedras en colegios y escuelas que tenían los profesores diplomados de otras carreras e instituciones. Con ello se buscaba el reconocimiento del Museo/Facultad como el espacio privilegiado de las ciencias naturales y centralizar la enseñanza de esas disciplinas. Vinculado a ello, se sugería que la Universidad platense no confiriera ningún título de profesor secundario a quien no hubiera aprobado un curso de biología

\footnotetext{
${ }^{80}$ Informe de la Escuela de Zoología y Botánica en: Lafone Quevedo 1917: 113-114.
} 
$\mathrm{u}$ otro de ciencias naturales en esta unidad académica ${ }^{81}$. La asistencia de los futuros docentes en las materias científicas se presentaba como una forma para la divulgación de la ciencia: "el número de estudiantes es ante todo importante para una facultad cuyos estudios no tienen fines utilitarios, pues cuantos más alumnos pasan anualmente por sus aulas, tanto más se hará sentir su influencia sobre la cultura general del país, y esto es quizás la función más importante del punto de vista social de estas facultades" 82 .

En ese sentido, se enfatizaba en los ejemplos europeos: "las facultades de ciencias europeas no podrían desarrollarse si contaran tan sólo con sus estudiantes de doctorado. En realidad la mayoría abrumadora de estudiantes de estas facultades está constituida por los aspirantes al profesorado secundario. Quitar a una facultad de ciencias estos alumnos equivale a quitar a una facultad de derecho, por ejemplo, los estudiantes de abogacía, dejándole sólo aquellos pocos que piensan dedicarse más tarde al profesorado en una facultad idéntica: nadie dudará que esto sería un absurdo. Además asisten en Europa a los cursos fundamentales de la facultad de ciencias los alumnos de la de medicina y de veterinaria en el primer año, y de allí que en una universidad alemana o suiza de unos mil estudiantes los cursos de zoología general y anatomía comparada cuenten siempre con unos ciento cincuenta a

\footnotetext{
${ }^{81}$ Como se mencionó anteriormente, en esa época en la Facultad de Ciencias de la Educación se dictaban para los estudiantes de los distintos profesorados, materias como Antropología y Anatomía y Fisiología del sistema nervioso, que contaban con laboratorios e instrumental para clases prácticas. La segunda de esas asignaturas estaban destinadas principalmente a proveer a los alumnos de conocimientos teórico-prácticos relacionados a las técnicas y métodos de estudio histológico, especialmente el uso de instrumentos y los procedimientos para la preparación y observaciones de cortes de tejidos del sistema nervioso humano y de distintos animales. Es de destacar, que algunos de esos temas estaban incluidos en las clases de anatomía comparada y otras materias que se dictaban en el Instituto del Museo. Por otra parte, en la Facultad de Filosofía y Letras de Buenos Aires a propuesta de Carlos O. Bunge se organizó en 1913 un curso de Biología a cargo del médico alemán Christofredo Jakob, que posteriormente se institucionalizó como cátedra bajo la dirección del mismo profesor y el Miguel Fernández, como profesor suplente. Esta materia estaría dedicada a analizar las distintas teorías biológicas modernas y sus relaciones con la filosofía y las ciencias naturales. En la Universidad de La Plata, después de la Reforma Universitaria la asignatura de Anatomía y Fisiología del sistema nervioso se dividiría en dos semestres, abarcando uno de ellos un curso de Biología, ambos bajo la dirección de Jakob.

${ }^{82}$ Informe de la Escuela de Zoología y Botánica en: Lafone Quevedo 1917: 117. Cabe señalar que en esa época, los alumnos de la Sección Pedagógica que seguían el profesorado en ciencias naturales no eran mucho más que los que estudiaban del doctorado en el Museo. En cambio el profesorado en biología del Instituto del Profesorado Secundario de Buenos Aires, era el que más estudiantes atraía de esa institución, con cerca de veintiséis alumnos matriculados; mientras que el doctorado de ciencias naturales tanto en la Universidad de Buenos Aires como en La Plata contaban como máximo con una decena de alumnos.
} 
doscientos inscriptos, mientras que nosotros no conseguimos reunir más de seis alumnos" 83 .

Paralelamente el profesor de antropología, Roberto Lehmann-Nitsche, insistía en la creación de una Escuela Preparatoria de Medicina en la Universidad platense, de acuerdo al modelo francés y los planes de estudio de la Facultad de Medicina de Buenos Aires. Según este antropólogo alemán esta nueva oferta educativa ayudaría a atraer mayor cantidad de estudiantes, especialmente en las materias científicas ${ }^{84}$. Para ello, proponía organizar los primeros tres años de la carrera de medicina, que abarcaría materias científicas como botánica médica, zoología, anatomía descriptiva, histología, química, entre otras; y cuyas cátedras se cubrirían con profesores de ciencias naturales y agronomía y veterinaria. Al mismo tiempo, un grupo importante de alumnos platenses que estudiaban medicina en Buenos Aires impulsaba lo mismo desde principio de siglo y a fines de la década de 1910 se conformó un comité especial para impulsar este proyecto, que se concretaría en la gestión de Rodolfo Rivarola al frente de la Universidad platense entre 1918-1919.

Ideas parecidas con respecto a la necesidad de reclutar a los aspirantes al profesorado y asegurar un campo laboral para los doctores y egresados de las carreras científicas, circularon en la Facultad de Ciencias Físicas, Matemáticas y Astronómicas. Como se mencionó en el Capítulo III, la falta de estudiantes en las ciencias exactas ponía en peligro el proyecto de crear escuelas de investigación y la conformación de una "ciencia nacional": "resulta, pues, indispensable, atraer estudiantes a esta carrera, desviándolos de las profesionales que ya comienzan a tenerlos en exceso, pero para ello sería indispensable utilizar al doctorado obteniendo, por ejemplo, del respectivo ministerio nacional una resolución que diera preferencia para la designación de profesores de fisica y matemáticas de los colegios y escuelas de la Nación; de otro modo el propósito de fundar una ciencia física y matemática nacional estará por mucho tiempo contrarrestado por el éxito utilitario de las carreras profesionales" ${ }^{185}$.

\footnotetext{
${ }^{83}$ Ibid: 116.

${ }^{84}$ Lehmann-Nitsche 1915. Lehmann-Nitsche venía proponiendo la creación de esta escuela o liceo de medicina desde varios años antes. En 1908 había presentado un proyecto similar al Consejo Superior y, si bien el presidente de la Universidad platense se había comprometido a gestionar ante las autoridades de las otras universidades nacionales, la admisión de los alumnos de esta futura escuela, esto no llegaría a prosperar durante la gestión de González.

${ }^{85}$ Besio Moreno 1917: 158.
} 
Por su parte, los primeros egresados de esas disciplinas científicas insistirían en la necesidad de una mayor difusión de las mismas. Entre ellos, Teofilo Isnardi no creía que era necesario adosar privilegios oficiales al título ofrecido por la Escuela de Física, pero en cambio consideraba más importante el mejoramiento de la enseñanza en la institución y su difusión: "la Escuela tiene la imperiosa obligación de modificar nuestro ambiente y de atraer alumnos por la propia vitalidad de la obra." ${ }^{86}$. Isnardi sostenía que entre las tareas docentes era apremiante realizar una campaña de difusión de la física sobre todo en el ámbito de la enseñanza primaria y secundaria, de forma que esa ciencia resultara atractiva para los jóvenes que se iniciaban en ella. Esos comentarios fueron escritos simultáneamente a la presentación de un proyecto de cursos de perfeccionamiento en vacaciones destinado a profesores de enseñanza secundaria en física y matemáticas, elaborado por Ricardo Gans. Estas actividades comenzaron a realizarse en 1917 y se continuaron en los siguientes dos años, interrumpiéndose en el marco de los conflictos universitarios de 1920. Como docentes participaron varios egresados de la Facultad y para la asistencia de los profesores de los colegios nacionales del interior del país se ofreció alojamiento en el Internado del Colegio Nacional de la Universidad y pasajes gratis otorgados por el Ministerio de Instrucción Pública. La finalidad de estos cursos de vacaciones era vincular a los profesores de la Escuela de Física con los de los establecimientos secundarios del interior del país y brindarles a estos últimos la posibilidad de repasar sus conocimientos en ciencias físicas, matemáticas y astronómicas, familiarizarlos con las teorías modernas e indicarles experimentos sencillos que podrían realizar aunque no contaran con instrumentos sofisticados ${ }^{87}$. Para los docentes y exalumnos de la Escuela de Física, la capacitación docente ayudaría a mejorar la enseñanza de las ciencias exactas en los colegios nacionales y por esa vía se haría más atractiva a los

\footnotetext{
${ }^{86}$ Informe especial del profesor Teófilo Isnardi en: Memoria correspondiente a 1916 de la Facultad de Ciencias Físicas, Matemáticas y Astronómicas, 1918: 53-57. En relación con este aspecto indicaba que en esa época la misión más importante de esa institución no debía ser la investigación sino la formación de un considerable número de investigadores y profesores. Cabe señalar que sus comentarios críticos hacia la marcha de la Escuela de Física, estaban relacionado con una campaña de desprestigio hacia el director de la misma, Ricardo Gans, que llevaron a cabo los primeros graduados de la Escuela en momentos en que se discutía la renovación del contrato de este profesor alemán. Si bien esto último no se renovó, igualmente se le brindaron a Gans arreglos especiales para que tuviera un sueldo equivalente y una partida para el alquiler de su casa, aunque en el presupuesto universitario esto último no se especificó con esa leyenda como había figurado anteriormente.

${ }^{87}$ Los informes sobre estos "cursos feriales", así como la opiniones de los distintos profesores a cargo se pueden consultar en las Memorias institucionales anuales publicadas por la Facultad de Ciencias Físicas, Matemáticas y Astronómicas durante esos años.
} 
estudiantes, entre los cuales podrían despertarse "vocaciones" por el estudio de la ciencia pura o "desinteresada".

En el caso de la Facultad de Ciencias Naturales no se apostó a la difusión científica entre docentes sino que se continuo insistiendo en que para mejorar la educación científica era necesario que los profesores se formaran en las facultades especiales, tras un intenso entrenamiento científico y el desarrollo de trabajos de investigación. Esto principalmente fue defendido por el zoólogo Miguel Fernández, quien pareció contar inicialmente con el apoyo de la nueva gestión al frente de la presidencia de la Universidad platense. Por otra parte, Rodolfo Rivarola, el nuevo presidente a partir de 1918, no era ajeno a los debates en torno a la preparación del profesorado secundario y de hecho, había propuesto una ley para la regulación de la profesión docente en 1914 cuando ocupó el decanato de la Facultad de Filosofía y Letras de Buenos Aires ${ }^{88}$. Entre los planes para la casa de estudios platense figuraba la creación de la Escuela preparatoria de Medicina y la promesa de incentivar las disciplinas científicas, como las ciencias biológicas y físicas, que contaban con pocos alumnos. Si bien Rivarola reconocía que la finalidad de estos estudios, no era la enseñanza secundaria sino las investigaciones científicas, tal aplicación tendría la "doble utilidad de llamar la atención del mayor número de personas hacia la investigación cientifica $y$ de preparar un profesorado más idóneo en las especialidades respectivas" 89 .

Para la colación de grados de 1918, el Presidente de la Universidad platense eligió como orador a Fernández, quien desarrolló un discurso titulado: "Las facultades de ciencias naturales y el profesorado secundario"90. Según este zoólogo, estas instituciones tenían dos funciones principales: a) "crear una ciencia verdaderamente nacional", y b) "una función educadora general, de efectos más inmediatos con respecto al pueblo". Con relación a esto último, se destacaba la importancia del

\footnotetext{
${ }^{88}$ Rivarola 1915.

${ }^{89}$ Rivarola 1918: 102.

${ }^{90}$ Fernández 1918. La designación directa de este profesor, así como el contenido de su discurso, fue criticada en el seno del Consejo Superior, por algunos consejeros como Nicolás Matienzo, el adversario de Rivarola en la disputa por la presidencia de la Universidad, y Víctor Mercante, quien remarcó que ese discurso constituyó un agravio hacia la Facultad de Ciencias de la Educación. Al mismo tiempo, Mercante señaló que era la segunda vez que un profesor criticaba públicamente a esta Facultad, desde un espacio oficial de la Universidad. Esto último aludía al discurso de apertura de los cursos de vacaciones en 1917, a cargo de Ricardo Gans, y que nunca llegó a publicarse. Rodolfo Rivarola, en cambio, defendió las palabras de Fernández considerando que no era una ofensa para la Facultad de Ciencias de la Educación, sino sólo un llamado por una mayor preparación científica de los
} 
"profesor universitario como agente de difusión de aquella filosofía que por sí sola fluye de cada una de las ciencias". El alcance de esa difusión dependía de la cantidad de estudiante que pasaran anualmente por sus aulas. Especialmente, las disciplinas que él enseñaba tenían un rol fundamental para la conformación de una cultura pública moderna: 'la mente de cada uno de los cientos de jóvenes que en las universidades de Europa asisten todos los años a clases de zoología, será impresionada en algo por las grandes teorías biológicas, será modificada su manera de encarar los problemas de la vida: sus conceptos religiosos, sus ideales de matrimonio, de la familia, de la sociedad y del Estado; y estos jóvenes, que todos ocuparán más tarde posiciones de mayor o menor responsabilidad en el organismo social, representarán un fermento nada despreciable para trasformar en algo la mente del pueblo. Pero si, como entre nosotros, el número de personas que asisten a las clases es muy pequeño, estos pocos granos prácticamente no bastarán para iniciar la fermentación"91.

Desde esa perspectiva, la baja cantidad de alumnos que se dedicaba a estudiar ciencias naturales o que tomaban alguno de estos cursos era el principal obstáculo para que estas Facultades cumplieran sus funciones. Para Fernández, este problema no se debía a la organización interna de estas instituciones, ni a los profesores, ni a la falta de interés de la juventud por esos estudios, sino a las pocas perspectivas laborales para los graduados, que se restringían aún más frente a la competencia con otros grupos profesionales. En ese sentido, señalaba: "la realidad es que el doctorado en ciencias no habré por ahora entre nosotros perspectivas de ninguna especie. En rigor, el único medio de vida que actualmente se ofrece a estos graduados, son las tres o cuatro cátedras de su especialidad en las universidades nacionales; y como los profesores universitarios no suelen tener una vida del todo efimera...! Existen además algunos puestos de ciencia aplicada en la administración nacional y en las provinciales - muy contados por cierto- pero...es corriente que sean llenados con agrónomos, veterinarios $u$ otros profesionales." ${ }^{92}$

Frente al problema de la falta de estudiantes, Fernández volvía a insistir en las soluciones adoptadas por las facultades de ciencias europeas, en donde los cursos de ciencias naturales tampoco podían sobrevivir sólo con los estudiantes interesados en la investigación científica o en completar su cultura general; y por ello se recurría a los

futuros profesores de ciencias, en las materias en que se les confiere un título para enseñar. Sesión ordinaria del Consejo Superior, 8/6/1918 en: BUNLP, I, 6: 251-252.

${ }^{91}$ Fernández 1918: 89. 
alumnos del ciclo introductorio de medicina y a los aspirantes al magisterio. En este sentido, celebraba la fundación de la Escuela Preparatoria de Medicina en La Plata, la cual podría proveer estudiantes para los cursos especiales de biología. Con respecto a los alumnos del profesorado, Fernández apoyó su propuesta retomando la postura de Ernesto Quesada y Rodolfo Rivarola en las discusiones sobre la incorporación del Instituto Nacional de Profesorado a la Facultad de Filosofía y Letras que se había dado a fines de $1914^{93}$. A partir de esas ideas, defendía que las facultades de filosofía, o sus equivalentes de ciencias y letras, además de la función de investigación científica tenían la tarea de formar al profesorado secundario y por eso "otros organismos para los mismos fines no tienen razón de ser; serían una competencia ilícita para aquellas facultades". Como en otras ocasiones, nuevamente impugnaba los privilegios de la Facultad de Ciencias de la Educación para establecer los planes de estudio y supervisar la formación de los alumnos del profesorado en ciencias naturales. Para él: "siempre deberán establecer los planes de estudio y expedir los diplomas aquellas facultades que puedan tomar sobre sí la responsabilidad con respecto a la instrucción cientifica de una profesión..."94. Sumado a ello, estaba el problema de las pocas horas destinadas a la materia principal que los futuros docentes debían enseñar. Esto no sólo provocaba una deficiente preparación científica del profesorado en ciencias naturales, sino que, además, no generaba ninguna ventaja frente a la competencia con los egresados de otras disciplinas. Dado que las asignaturas científicas específicas eran escasas y además correspondían a los cursos generales, eso permitía que los egresados de las carreras profesionales con sólo rendir algunas pocas materias pudieran diplomarse como profesores de ciencias naturales. En poco tiempo, sostenía este zoólogo, por cada cátedra vacante en los colegios secundarios habría numerosos candidatos que procedían de las "profesiones prácticas".

La solución, entonces, era exigir una preparación científica para el profesorado casi equivalente al doctorado, como se daba, por ejemplo, en la Universidad de Zürich. Allí según indicó, para obtener el título de doctor se debía rendir examen en cuatro materias, una que constituía la especialidad, en la que se requerían conocimientos profundos que permitieran realizar investigaciones científicas; y tres accesorias. Además, la tesis debía consistir en una investigación

\footnotetext{
92 Ibid.: 89

${ }^{93}$ Quesada 1915, Rivarola 1915.

${ }^{94}$ Fernández 1918: 92.
} 
original que luego se publicaría como trabajo científico. Para el profesorado se exigía la misma formación pero una materia accesoria más y en lugar de la tesis se exigía una monografía, basada en algún estudio de laboratorio, pero juzgada con menor severidad y la cual, generalmente, servía como base para la futura tesis doctoral. Asimismo, Fernández agregó que habitualmente los alumnos además de las materias reglamentarias seguían los cursos que les interesaban y en general, primero cumplían con los requisitos para el profesorado y luego presentaban la tesis doctoral, obteniendo el doctorado sin ningún requisito ni examen complementario. Como se examinó en el capítulo anterior, en esta época el plan de estudios para el doctorado en ciencias naturales que se ofrecía en el Instituto del Museo estaba organizado sobre la base de ese modelo, centrado en una materia principal elegida por el alumno y tres accesorias obligatorias, con trabajos de laboratorio y una tesis producto de una investigación científica original. Además, en este plan se dejaba un amplio margen para la elección de las materias complementarias, lo que permitía adaptar la formación a las distintas necesidades e inclinaciones individuales. Sobre la base de este plan, Fernández insistía en que el aspirante a profesor de enseñanza secundaria se educara de manera similar al investigador en la asignatura a enseñar. De esa forma, los docentes podrían conocer los detalles difíciles y la estructura teórico-conceptual que formaba el edificio de cada ciencia moderna, para seleccionar los contenidos a enseñar según un "criterio científico": "deseamos que el profesor secundario sea hombre de ciencia, hombre cuya característica no consiste en ser una enciclopedia de todo lo que en su materia se haya escrito, sino que posea lo que suele llamarse 'criterio científico; que haya adquirido la aptitud de aplicar a cada dato una crítica severa antes de usarlo para formar ideas generales...este criterio científico lo adquiere sólo el que haya investigado en una ciencia y nunca lo tendrá aquel que haya aprobado sólo uno o dos cursos de cada materia..." 95

La exigencia de una sólida formación científica y un gran entrenamiento en las prácticas de investigación, según este profesor, podría dar respuesta a dos problemas en torno a las ciencias naturales. Por un lado, evitaría la competencia con los "profesionales científicos-prácticos", como agrónomos, veterinarios, ingenieros o médicos, que ya no entrarían en la carrera del profesorado secundario al no contar con la preparación previa requerida y necesitar cursar una gran cantidad de materias. En

\footnotetext{
95 Ibid.: 90-91.
} 
segundo lugar, con este tipo de entrenamiento se podría obtener un grupo de docentes, capacitados para realizar "investigaciones originales de todo lo que es argentino". De esa forma, el desarrollo de una "ciencia nacional" parecía descansar entre la posibilidad de ofrecer un sólido entrenamiento científico al magisterio y brindar una inserción laboral -institucional a los egresados de las carreras científicas. Entre las distintas opciones, las cátedras de los colegios nacionales parecían gozar de un cierto prestigio y además eran vistas como espacios que ofrecían ciertas facilidades y disponibilidad de tiempo para el desarrollo de estudios científicos.

Este investigador volvería a insistir con estas ideas en la Octava Asamblea General de Profesores que convocó Rodolfo Rivarola para discutir la orientación y fines de los estudios universitarios, como se mencionó en el capítulo anterior. En ese encuentro, la mayoría de los profesores acordaron que la institución universitaria debía ofrecer tanto una preparación para la ciencia como para su aplicación económica o profesional, aunque las opiniones difirieron en cuanto a las relaciones entre ambas orientaciones y las aplicaciones en las distintas carreras y Facultades. Algunos profesores de ciencias físicas como Ricardo Gans y Teófilo Isnardi retomaron las ideas expuestas unos meses antes por Miguel Fernández, para fundamentar la necesidad de que el profesorado de ciencias físicas y matemáticas dependiera de su Facultad. Isnardi, a partir de su experiencia como alumno de los cursos de la Sección Pedagógica y como profesor del Colegio Nacional, remarcó: "en la enseñanza secundaria importa mucho más la preparación científica del profesor, que su dominio de las aplicaciones prácticas. El 'tecnicismo' de la enseñanza, vale decir, el método, es por otra parte apenas un complemento de aquella preparación científica del maestro. Y ese tecnicismo, como toda aptitud práctica, se adquiere mejor practicando que estudiando cursos de pedagogía....El profesorado de enseñanza secundaria es una carrera cientifica que debe estudiarse en la Facultad correspondiente a cada especialidad, y comprendería como mínimo tres años de estudios especiales, una o dos materias pedagógicas y un año de práctica de enseñanza, bajo la dirección de los jefes de Sección. Los doctores de cada ciencia adquirirían el título de profesor, si llenaran las dos últimas condiciones. Debiera negarse título de profesor a quienes sólo poseyeran un título técnico (abogado, ingeniero, etc.), aun cuando cursaran varios años de pedagogía"96.

\footnotetext{
${ }^{96}$ Respuesta de Teofilo Isnardi a la encuesta de la Presidencia de la Universidad platense en: "Octava Asamblea General de Profesores". BUNLP, 1918, I, 5: 218.
} 
Por su parte, el decano de la Facultad de Ciencias de la Educación señaló que no había que confundir "al hombre que investiga con el que trasmite y el que aprende..."97. Para Mercante era necesario diferenciar los ámbitos de investigación de los de enseñanza dentro de la universidad, al igual que el investigador del profesor y el estudiante, principalmente por se trataban de: "situaciones y realizaciones diferentes que no deben confundirse, porque la ciencia que se investiga es una porción muy pequeña de la que se trasmite, no obstante las proporciones extraordinarias que dicha porción puede alcanzar y el tiempo que absorbe. No puede ni debe esa porción en trance de ser interesar sino muy poco a los alumnos, quienes estudian una materia y deben en ella disciplinar sus sentidos, su lógica, su voluntad y sus manos...la cultura universitaria debe ser impersonal y didáctica...no es concebible que pueda a la vez prepararse para la investigación y ser investigador. El investigador, educado ya, se unilateriza en razón de una tendencia y una voluntad..."98 Asimismo, señalaba que junto al problema de la especialización que implicaba toda investigación frente a la preparación general que necesitaban los alumnos, se presentaba el número elevado de estudiantes, como en las materias de ciencias de la educación, que hacían impracticable la articulación entre investigación y enseñanza.

Después de esa Asamblea general, se esperaba la revisión de los planes de estudio y orientaciones de cada carrera fuera analizado en cada unidad académica. Por su parte, Fernández presentó en el Consejo Académico del Museo un proyecto para crear en esa Facultad el profesorado en química, en ciencias biológicas y en geología, que debería cursarse simultáneamente con las carreras científicas afines a ellos. Para el tratamiento del tema se nombró una comisión especial, aunque los conflictos con los estudiantes de farmacia que se desataron esos días, aplazaron el estudio de esta propuesta. Paralelamente, en el ámbito de la Universidad se formó una comisión para discutir este tema. Esas reuniones estuvieron compuestas por el entonces vicepresidente: Nicolás Besio Moreno; el rector del Colegio Nacional y secretario de la Universidad: Donato González Litardo; el decano de la Facultad de Ciencias de la Educación: Víctor Mercante; los primeros egresados de los doctorados de la Facultad de Ciencias Matemáticas, Físicas y Astronómicas y también docentes en esa unidad: Felix Aguilar, José Collo, Héctor Isnardi, Teófilo Isnardi y Ramón Loyarte; y dos profesores de ciencias naturales: Miguel Fernández y Santiago Roth.

\footnotetext{
${ }^{97}$ Respuesta de Víctor Mercante. Ibíd: 203.

${ }^{98}$ Ibid.: 204.
} 
A fines de 1918 se elevó un informe al presidente de la Universidad con una nueva propuesta para la formación del profesorado por el sistema de correlación ${ }^{99}$. Después de varios debates, se acordó que los planes de estudios se conformarían de dos ciclos: a) uno general que comprendería tres asignaturas de cultura general y nacional y una preparación pedagogía: metodología general y la práctica de enseñanza, que se cursarían en Ciencias de la Educación, y la materia de Metodología e Historia de la Ciencia de la especialidad, que se dictaría en la Facultad científica respectiva; y b) uno especial, en la Facultad de la especialidad, que correspondería a la licenciatura o los primeros tres años del doctorado. El primer año de estudios se destinaría casi exclusivamente a las materias del ciclo especial, para que los estudiantes se familiarizaran con la ciencia o materia que habrían de enseñar, antes de saber como enseñarla. Las condiciones de ingreso serían fijadas por la Facultad donde se cursaran los estudios especiales, pero los títulos de profesor serían expedidos conjuntamente con la de Ciencias de la Educación. Ambas instituciones tendrían a esos alumnos como propios en el ciclo correspondiente y sujetos a las reglas de disciplina de cada unidad académica. Se pensaba que con ello se evitaría la situación muy común de que los estudiantes consideraran de menor importancia a las materias de correlación, y de esa forma, todas las disciplinas adquirirían la misma relevancia. La tarea de coordinar y ajustar la correlación y planes de estudio estaría a cargo del Consejo Superior. Asimismo, se postuló la necesidad de revisar los planes de estudio, tratando de reducir al mínimo posible los estudios generales para ofrecer una carrera relativamente corta que atrajera a un gran número de estudiantes, para resolver la "tarea urgente" de preparar un profesorado nacional idóneo. Por otra parte, se consideró que los títulos científicos de doctor otorgados por la Universidad platense, y cuyos estudios fueran completamente "desinteresados", debían comprender la habilitación como profesor de esa disciplina. Se estimaban como carreras "totalmente desinteresadas" -"ciencia pura"- a los doctorados en: ciencias matemáticas, físicas, naturales, astronómicas, químicas, filosofía, literatura, historia y geografía. Para obtener el diploma de profesor, los alumnos de esas carreras debían completar su formación con las siguientes materias: metodología e historia de la ciencia y la práctica pedagógica. Este sistema era defendido sobre la base de una doble utilidad:

99 "Opiniones acerca de los planes de estudio del profesorado secundario". BUNLP, 1918, I, 8: 380384. 
para dar a los doctores una ocupación más provechosa para el país y al mismo tiempo, facilitarles a los mismos una remuneración económica.

Los conflictos universitarios que se desataron en la Universidad Nacional de La Plata en 1919 aplazaron el tratamiento de esta propuesta. En el marco de ese movimiento, se promovería la reorganización de la Facultad de Ciencias de la Educación, que pasó a llamarse de Humanidades y Ciencias de la Educación, bajo el decanato del historiador Ricardo Levene. Entre esas medidas se procuró dar un mayor impulso a los estudios humanísticos y las investigaciones en esta áreas, la renovación de los planes de estudio del profesorado, entre lo que se eliminó el plan del de pedagogía y ciencias afines ${ }^{100}$, y la creación de varios doctorados especializados. Los nuevos planes de estudios para los profesorados en distintas especialidades, contemplaban una misma formación básica que se cursaba en esta Facultad e incluía las siguientes materias: 1) biología y anatomía del sistema nervioso; 2) psicología; 3) composición: teoría y práctica; 4) historia argentina; 5) lógica; 6) didáctica general; 7) historia de la educación; 8) introducción a la filosofía o historia de la filosofía, y 9) metodología especial y práctica pedagógica.

Paralelamente los sectores científicos volverían a insistir en las ideas expuestas anteriormente y reflejadas en gran parte en el proyecto de 1918. En 1921, el Consejo Académico del Museo elevó al Consejo Superior un proyecto de reforma de la organización de los profesorados, que en líneas generales seguía la propuesta del Jefe de la Escuela de Biología, Miguel Fernández ${ }^{101}$. Paralelamente también la Facultad de Ciencias Físicas y Matemáticas presentó una propuesta similar, promovida por los

\footnotetext{
${ }^{100}$ Según los reformistas lo único que proveía ese título era una formación enciclopédica sin profundización en ninguna materia, y además, hasta esa época la mayor cantidad de alumnos se había concentrado en esa carrera en detrimento de las otras disciplinas que se enseñaban en esa Facultad, por lo que las cátedras de los otros profesorados y de los estudios humanísticos no habían sido convenientemente dotadas. Asimismo, cuando se reorganizó el Colegio Nacional y se nombran nuevos profesores a principios de la década de 1920, ese título fue desprestigiado y corrió en desventaja frente a estudiantes y graduados de otras carreras. Véase al respecto los debates en el Consejo Superior y en el Académico de esa Facultad en: BUNLP, 1920, IV.

${ }^{101}$ En la reunión del 30/5/1921, el Consejo Académico del Museo aprobó el proyecto sobre reforma de los planes de estudios para el profesorado en ciencias naturales, presentado por la comisión de enseñanza y decidió elevarlo al Consejo Superior. En esa propuesta se acordaron los siguientes puntos: a) los estudiantes de los profesorados secundarios se matricularían en la facultad científica como alumnos propios, b) los planes de estudio para las materias científicas serían fijados por la facultad científica, c) los diplomas serían firmados por los decanos de ambas facultades, d) los candidatos deberían aprobar un año de práctica en el Colegio Nacional, e) en la facultad científica se dictaría un curso de metodología especial de las ciencias respectivas, f) los doctores en ciencias, con sólo aprobar el año de práctica podrían obtener el título de profesor. En esa reunión, Fernández agregó en la Facultad de Ciencias Físicas, Matemáticas y Astronómicas se preparaba una propuesta similar, confeccionada por el director de la Escuela de Física, para ser presentada en el Consejo Superior. AHMLP, Actas del Consejo Académico, Libro III, folio 78.
} 
profesores de física. El Consejo Superior derivó estos expedientes a la Facultad de Humanidades y Ciencias de la Educación, en donde se contestó que según la ley de fundación de la Universidad, esa unidad académica era la única autorizada para expedir el título de profesor de enseñanza secundaria en cualquier especialidad. Asimismo, se insistía en que, según el principio de autonomía, era atribución de cada Consejo Académico establecer los planes de estudio y las condiciones de ingreso para las carreras que ofrecía. Finalmente, esta Facultad retuvo el monopolio para otorgar los diplomas de profesor, aunque se acordó que se solicitaría a la Facultad respectiva, su colaboración para el curso de metodología especial y su opinión con respecto a las asignaturas científicas. En los siguientes años, en el caso del profesorado en biología, esta Facultad pediría al Museo que acortaran los programas de algunas asignaturas o elaborara algunos especiales para los estudiantes de esta carrera. Si bien el Consejo Académico del Museo atendió a estos pedidos, los cursos más cortos para los aspirantes al profesorado secundario llevó a que las materias científicas que se cursaran para esta carrera ya no pudieron ser reconocidas como equivalentes a las del plan de estudios del doctorado, aunque si al revés ${ }^{102}$.

Los intentos de instituir la autoridad y el derecho de las facultades de ciencias a formar el profesorado secundario, se basaron en algunas estrategias similares a las que se pusieron en juego en la profesionalización de la historia en la Argentina. Según Alejandro Eujanian, la configuración de un campo profesional para el historiador se asentó en la conformación de espacios académicos emisores de títulos habitantes para el ejercicio de la docencia secundaria y superior, y en segundo lugar para la investigación científica ${ }^{103}$. En el caso de las propuestas de los profesoresinvestigadores de ciencias naturales y exactas parecieron perder fuerza en el nuevo contexto universitario de los años veinte. Los docentes de la Escuela de Física, en particular Gans hasta su retorno a Alemania en 1925, continuaron manifestando en diferentes oportunidades su preocupación por los planes de estudio del profesorado en

\footnotetext{
102 En la década de 1930, el Centro de Estudios de Ciencias Naturales de La Plata, conformado por egresados del doctorado, editaba folletos promocionando estos estudios y recomendaba a los estudiantes secundarios que se inscribieran en el doctorado junto al profesorado, ya que de esa forma podrían hacer dos carreras abonando sólo la mitad de las matrículas; y si cursaban las materias de acuerdo a los programas para el doctorado también les servirían para el profesorado. Véase, por ejemplo, el folleto: "Guía para el estudio de las ciencias naturales y especialidades afines", AHMLP Carpetas de Expedientes 1933-1935, letra C.

103. Eujanian s/f
} 
física y matemáticas, la baja cantidad de alumnos que seguían los doctorados en estas disciplinas así como el problema de los egresados ${ }^{104}$.

En la década de 1920, las impugnaciones a la formación propuesta por los "pedagogos", no lograron revertir la situación con respecto al profesorado secundario, que ya estaba plenamente consolidada en instituciones como la Facultad de Humanidades y Ciencias de la Educación, las Facultades similares que se crearon en las universidades del interior y los institutos pedagógicos que se multiplicarían por esa época. Por otra parte, la retórica científica utilizada en los primeros años del siglo XX, para fundamentar un gran entrenamiento en los métodos experimentales y en las prácticas de investigación; pareció perder su fuerza frente al peso de los nuevos sectores intelectuales que fomentaba una "cultura integral", sobre la base de una formación humanística y filosófica durante los años viente. Paralelamente, los estudiantes del magisterio y los profesores diplomados conformaron grupos $\mathrm{y}$ asociaciones que presionarían cada vez más por la especificidad de su trabajo y la regulación del ejercicio de la docencia. En esa lucha, la definición de la formación del profesorado de enseñanza secundaria quedaría cada vez más en manos de los miembros del campo educativo. El sistema de correlación pensado por Joaquín V. González no podría superar las barreras institucionales y las luchas de poder entre los distintos sectores, ni tampoco mantener un fluido canal de comunicación entre la socialización del científico y la del profesor en ciencias, que se conformaron como dos carreras diferentes.

\footnotetext{
${ }^{104}$ Véase, por ejemplo, la exposición sobre los planes de estudio del profesorado en ciencias físicas y matemáticas de Ricardo Gans en el Primer Congreso Universitario Anual realizado en 1923. BUNLP, 1923, VII, 5: 414-417. En ese evento, Gans retomó las ideas de Miguel Fernández presentadas cinco años atrás sobre la necesidad de que los candidatos al profesorado tuvieran una sólida y seria preparación en las materias a enseñar, organizando el profesorado como el primer ciclo del doctorado. Asimismo, descalificó la tendencia instaurada por los "pedagogos argentinos" sobre la formación del magisterio secundario, que subordinaban el dominio de la disciplina a enseñar mientras enfatizaban en las capacidades "retóricas" y pedagógicas.
} 


\section{Consideraciones generales}

Resumiendo los contenidos de esta tesis, en ella se han tratado los siguientes temas. En el primer capítulo se analizó el clima de ideas con respecto al funcionamiento de las universidades argentinas en la transición del siglo XIX al XX. Para ello se analizaron los debates parlamentarios sobre la nacionalización de los diplomas de las universidades provinciales y las propuestas de reforma universitaria surgidos en esa época. En particular se examinó el funcionamiento de la Universidad Provincial de La Plata y los problemas derivados de la falta de reconocimiento nacional de los estudios que esta certificaba, situación que también afectaría a la Facultad de Agronomía y Veterinaria de La Plata. Ambos casos generarían la movilización de sectores intelectuales locales en pro de la nacionalización de los títulos y, luego, apoyando la nacionalización de esas instituciones, una propuesta avalada por el gobierno de la Provincia de Buenos Aires.

Los debates parlamentarios y los distintos comentarios que circularon en las revistas y la literatura de la época aludían al fenómeno de la "doctormanía", en relación con el incremento significativo de los alumnos universitarios y de los que alcanzaban el título de "doctor", sobre todo en los estudios jurídicos. Junto con ello se asociaba también el fenómeno de la "empleomanía" y el crecimiento de la burocracia estatal. Esas "preocupaciones" remiten a las trasformaciones que se estaban operando en el sistema universitario en un doble movimiento: por un lado, como canal de ascenso social de nuevos sectores sociales que disputaban los símbolos de prestigio y distinción de las elites políticas y universitarias tradicionales; $y$, por otro, como el centro de acreditación y el control "cognitivo" de los cuadros profesionales que acompañaban e impulsaban el crecimiento del aparato administrativo del Estado. Como parte de ese proceso, los "expertos" fueron reclamando cada vez más por la especificidad de su actividad y la autoridad "científica" para el diseño de las políticas públicas. En ese movimiento, la universidad estatal pasaría a ocupar un papel central en el control de los procedimientos educacionales y la legitimación de los "saberes científicos" de las profesiones, así como en la distribución de las acreditaciones para el ejercicio profesional, especialmente para el ámbito estatal. Precisamente, el caso de la Universidad Provincial de La Plata y las gestiones para que sus diplomas y certificados de estudios fueran legítimos ante el Estado Nacional, muestra, por un 
lado, la importancia que tenía la función "profesional" de administrar oficialmente la distribución de los diplomas de competencia y habilitación para el ejercicio de ciertas ocupaciones, y, por otro, el crecimiento y la centralización de funciones que había alcanzado el aparato burocrático del Estado Nacional. De forma paralela a ese crecimiento, los sectores universitarios buscarían una mayor autonomía administrativa con respecto al Gobierno, tal como se manifestó en los distintos proyectos de reforma universitaria que se presentaron en esos años. En 1898, dos cuestiones recorrerían las distintas propuestas: a) el régimen financiero, b) la organización del gobierno interno, especialmente en lo referente al cuerpo académico. Pocos años después se insinuaba que las posibilidades para aumentar la capacidad de renovación de la universidad estaban ligadas a las siguientes cuestiones: a) la organización del gobierno académico, b) la autonomía administrativa y económica; c) la preparación y selección del profesorado superior, entre lo que se incluía la docencia libre. A ello se agregaría un mayor énfasis en la necesidad de renovar los métodos de enseñanza, crear nuevos estudios y promover la producción intelectual y científica. Las lecturas de las experiencias internacionales acusaban un movimiento hacia la incorporación de nuevas y variadas tareas educativas, científicas y sociales por parte de la universidad, la cual, además, sería definida como una institución central para la consolidación de los Estados nacionales.

En el contexto argentino, vinculado a la percepción de una crisis de valores culturales y al carácter cosmopolita de la población, aparecía la pregunta por el tipo de educación más adecuada para formar las futuras clases dirigentes y profesionales y por el papel que debía asumir la universidad en la conformación de la cultura nacional. Esto generó una serie de discusiones acerca de los métodos y propósitos de la educación superior, tema que se mantendría en los años posteriores. Para ciertos sectores universitarios, reforzar la función educativa de la Universidad aparecía como una forma de ejercer un mayor tutelaje sobre la formación de las nuevas generaciones, y, al mismo tiempo, una selección más cuidadosa basada en el esfuerzo personal y un principio "meritocrático". Paralelamente, se fueron multiplicando las voces que insistían en que desde la Universidad también se debía promover y organizar las investigaciones científicas y difundir un "espíritu crítico" o "científico" entre las nuevas generaciones. Varios académicos insistirían en que la Universidad debía asumir un papel central para resolver los problemas sociales y el desarrollo económico del país a partir de estudios de carácter científico. Vinculado a ello se manifestaría una 
preocupación por la formación de una clase dirigente ilustrada y educada para la vida pública como parte de las aspiraciones de regeneración espiritual y trasformación de las instituciones y hábitos políticos del país.

El proyecto de creación de la Universidad Nacional de La Plata remitía a ese clima de ideas, pero también, como hemos señalado en el Capítulo II, a un horizonte más amplio de posibilidades discursivas sobre la universidad, vinculado a una mayor internalización de las distintas experiencias y modelos universitarios. La idea que la institución universitaria debía cumplir varias misiones y ser rectora del espíritu nacional fue un tema recurrente en las publicaciones de publicistas y académicos de diferentes países. Al iniciarse el nuevo siglo, el ideal de universidad moderna aparecía como una síntesis entre el "tipo educativo inglés" y "el científico alemán", pero reorientada hacia la atención de una nueva "función social". Los años posteriores al 1900 fueron testigos de tendencias que enfatizaban en la formación cultural y moral del estudiante así como la extensión de la acción educativa de la universidad. Como se ha argumentado a lo largo de esta tesis, un conjunto variado de actividades culturales y la redefinición de la figura del estudiante y del profesor universitario aparecían vinculados a la tarea educativa de la Universidad. Con respecto al papel de este último, se observa que en el régimen de gobierno interno de la Universidad platense se transfirió la autoridad y competencia técnica desde las tradicionales academias vitalicias -conformadas por personas de reconocida actuación profesional o intelectual pero no necesariamente vinculadas a la tarea educativa dentro de la institución- hacia el cuerpo de profesores. Esta medida tendía a consolidar una mayor autonomía con respecto a la intervención de personas ajenas al cuerpo de enseñanza y le daba un estatus diferente al profesor. Posteriormente, ese espacio de poder y privilegios se tendría que compartir con los sectores estudiantiles y los egresados.

La creciente autonomía universitaria que se procuró en el plano del régimen de gobierno también se evidenciaría en la búsqueda de los mecanismos que aseguraran una fuente de ingresos independiente del control de Estado o, por lo menos, el manejo de los propios recursos y la distribución interna del subsidio nacional. Si bien los mecanismos para un auto-financiamiento no se encontrarían, la segunda solución se consolidaría en la primera década del siglo XX. De forma paralela a la búsqueda de una mayor independencia con respecto a los poderes del Estado, las autoridades de la Universidad Nacional de La Plata intentaron consolidar una unidad e identidad común entre los miembros de las distintas dependencias que la conformaban. Sin embargo, no 
sería fácil hallar los mecanismos necesarios para lograr una unificación y coordinación entre las distintas unidades académicas sin restringir la autonomía que todos los sectores reclamaban, como se evidenciaría, por ejemplo, en las dificultades para establecer el sistema de correlación o las disputas por la formación del profesorado secundario. La idea de conformar una comunidad intelectual entre estudiantes y docentes fue un tema presente en gran parte de los discursos académicos durante los primeros años. Vinculado a ello, aparecía la figura del "estudiante" como un componente central para consolidar y divulgar las actividades culturales y científicas que se promovían desde el seno de esta institución. En la transición del siglo, el peso creciente de la población estudiantil cobró mayor visibilidad pública que se sintió de forma variada. Entre ellas, la participación en las movilizaciones políticas, en huelgas y protestas académicas de la época, y en los programas de difusión científico-cultural y conformación de la nacionalidad promovidos por entonces. En el capítulo II, se ha argumentado que en la transición del siglo se observan desplazamientos con respecto a la forma y fines de los agrupamientos estudiantiles, como se evidencia en la emergencia de los "centros de estudiantes", organizados en torno a la defensa de cuestiones específicas de cada Facultad y profesión. Estos grupos ya no se identificaran tanto con las sociedades eruditas del siglo XIX sino con los modelos que aportaba el mundo del trabajo en el nuevo siglo. Las tareas que asumirían estos centros abarcarían múltiples actividades gremiales, sociales y deportivas. Asimismo, los estudiantes como "fuerza de trabajo intelectual en formación" fueron incentivados a asumir un papel activo en los programas de regeneración social de la época y entrenarse en actividades de divulgación como parte de su futura práctica profesional y su participación en la vida pública.

Las autoridades de la Universidad platense promovieron este tipo de prácticas entre los estudiantes así como la conformación de los centros de estudiantes como espacios de sociabilidad y ejercicio de las prácticas democráticas que se impulsaban para el régimen político del país. En el marco de esto último, se puede ubicar la multiplicación de los programas educativos para adultos y de divulgación científicocultural que se denominaron "extensión universitaria". Estas prácticas culturales se inscribieron en un contexto de preocupaciones cuyos temas generales giraron en torno a la educación de los sujetos para la "república verdadera", la cuestión social y la búsqueda de los mecanismos para afianzar una identidad nacional y mantener el orden social. Como se procuró demostrar en el Capítulo III, la relación entre la universidad y 
el "pueblo" a través de los canales de la extensión universitaria promovidos por los sectores estudiantiles en la década de 1910, se inscribía en un "móvil político": la educación del ciudadano y el papel de los universitarios e intelectuales como los sujetos más capaces de dirigir la regeneración cultural de la sociedad. En el contexto platense, los estudiantes como "diputados de la democracia" asumirían la tarea de extender la acción educativa de la Universidad concurriendo a los locales obreros y organizando ciclos de conferencias y cursos de popularización científica, como los programas promovidos por los socialistas y el movimiento de libre-pensamiento.

Las experiencias llevadas a cabo por los estudiantes durante las primeras dos décadas del siglo se inscribieron en los esfuerzos por conformar una cultura urbana, basada en una racionalidad laica y científica y en la moralización de pautas de vida de los sectores populares. En los programas de "extensión universitaria" de la década de 1910, la divulgación de la ciencia y del "espíritu científico" ocuparon un lugar central en la educación del ciudadano y en la conformación de una "cultura pública", en el marco de una estrecha competencia con la "visión de mundo" ofrecida por los sectores católicos. En ese contexto, se ubicaría la construcción del culto público a la figura de Florentino Ameghino y la amplia difusión popular de la antropología y paleontología. En ese movimiento, las gliptodontes "argentinos", los fósiles y objetos arqueológicos se trasformaron tanto en los "monumentos" materiales de la ciencia y la historia natural del territorio como en un motivo para solicitar al Estado la protección y los recursos necesarios para las instituciones encargadas de velar por ese patrimonio.

El Museo de La Plata y su personal participó en el programa de extensión universitaria y difusión de la ciencia promovido por las autoridades universitarias a través de diferentes formas: conferencias públicas, cursos libres, el acceso público y gratuito a las exhibiciones, visitas guiadas por la palabra de los "expertos", publicaciones y materiales didácticos. En particular en el capítulo IV, se examinó específicamente la organización de prácticas de difusión vinculados a la palabra escrita y a los objetos, en sus diferentes modalidades, circuitos de distribución y destinatarios. Como se procuró demostrar en ese capítulo, el emprendimiento editorial ocupó un espacio importante en la organización del trabajo y la distribución de recursos de esta institución. Como se ha argumentado, las instituciones científicas buscarían legitimarse como centros de producción y promoción del conocimiento a través de la publicación oficial de los estudios realizados por el propio personal o de otras investigaciones patrocinadas por dichas instituciones. Al mismo tiempo, la 
publicación institucional situaría el trabajo del científico en un amplio marco de circulación a través de las redes de intercambio institucional en el contexto local e internacional. La distribución de la Revista del Museo entre los políticos nacionales y la publicidad de las actividades institucionales y debates científicos en los periódicos de circulación nacional, permiten observar los límites difusos de un campo científicoacadémico aún débil e incapaz de funcionar con sus propias reglas autónomas de reconocimiento. Al mismo tiempo, ambos rasgos señalan la importancia de la empresa de difusión científica entre otros interlocutores. Paralelamente, puede destacarse un considerable esfuerzo dirigido a la difusión escrita de los procedimientos y prácticas de trabajo científico, como las conferencias de divulgación y la conservación y edición de un patrimonio escrito sobre la historia antigua del país. Los textos que conformaron las series de divulgación, a diferencia de las publicaciones científicas, estuvieron diseñadas para una circulación nacional, en una época de expansión de las "bibliotecas" en un doble sentido del término: a) las bibliotecas populares que se fueron multiplicando en el período estudiado, y b) la empresa cultural de libros baratos, textos escolares nacionales y las colecciones dirigidas por los sectores intelectuales. Esos emprendimientos proponían educar y sensibilizar a un público lector en determinado marcos de ideas y, al mismo tiempo, en un proyecto más amplio de conformación de la nacionalidad. Los sectores universitarios y científicos no permanecerían ajenos a esas campañas y participarían en la producción y circulación de textos y dispositivos visuales para promover la enseñanza de una naturaleza e historia argentinas. Recordemos las colecciones escolares y el diseño de las exhibiciones en el Museo de La Plata. En relación con ello, en el capítulo IV se argumentó que si la palabra escrita apuntó a difundir la ciencia entre un público letrado, el diseño de las exposiciones, las reconstrucciones y el montaje de la apariencia externa de los especímenes, la disposición de los objetos exhibidos -entre otros dispositivos visuales- buscaron reforzar una iconografía de la naturaleza y la ciencia entre los sectores populares.

En el contexto universitario platense, la divulgación del "espíritu científico" se puede asociar a tres circuitos de difusión: a) el entrenamiento de los grupos profesionales y la formación de nuevas generaciones de investigadores, b) la divulgación científica para un público general ilustrado y con cierta base educativa, como se ejemplificó en las series de publicaciones de divulgación c) la popularización científica en el marco de la instrucción popular y difusión cultural 
para los sectores populares. Las actividades de extensión universitaria que se organizaron en la misma Universidad implicaron un nivel más elevado de divulgación y abarcaron diversas modalidades: conferencias, demostraciones experimentales, exposiciones, visitas guiadas por las instalaciones científicas, publicaciones y cursos para docentes. La divulgación de la ciencia se inscribió en los canales propuestos por la "extensión universitaria" y en un conjunto más amplio de interacciones y prácticas culturales destinadas a diversos públicos. Algunas de las vías de divulgación para un público especializado serían las publicaciones científicas, los cursos libres de profesores invitados y los organizados por los investigadores y graduados de la institución. En el periodo estudiado, esto último tropezaría con la falta de un público local que se interesara en estas actividades y se buscaría conformar un auditorio para ello entre los sectores científicos de Buenos Aires. Asimismo, los cursos de capacitación y la formación de los docentes del sistema de instrucción pública fue otra de las formas que asumió la difusión de la ciencia y las disciplinas académicas.

Los intentos de reforzar la tarea educativa de la universidad por sobre la "función examinadora" implicaría la asistencia diaria de los alumnos y la posesión de las instalaciones y el personal adecuado para atender la enseñanza. Esto, a su vez, se daría de forma paralela a la profesionalización de la actividad docente en la Universidad, con la multiplicación de cargos auxiliares y la conformación de una carrera académica. Para los profesores que buscaban la profesionalización de las actividades docentes y de investigación dentro del espacio universitario, la falta de "verdaderos estudiantes" que se interesaran por estudiar y frecuentar los laboratorios o participar en las actividades científicas aparecía como uno de los problemas para consolidar un "ambiente" para la ciencia. Para algunos científicos, el papel del profesor universitario consistía en trasmitir conocimientos, compartir con los estudiantes la producción de nuevos saberes y unirse a ellos en el servicio de la ciencia. De esa forma, se insistiría en que tanto el trabajo docente como los laboratorios debían adecuarse a esa doble tarea. En varias secciones se preocuparon para que los gabinetes y laboratorios fueran dotados para responder a la "función profesional" como a la "función científica" de la universidad. Sin embargo, esto último estaría lejos de alcanzarse en todas las dependencias: en parte por la falta de interesados en los trabajos de investigación más allá de los requisitos para alcanzar el diploma; en parte por la falta de posibilidades laborales por los que se interesaban por las actividades científicas dentro de la universidad y los pocos profesores- 
investigadores que hacían de esos laboratorios su principal lugar de trabajo. La acumulación de diferentes cargos o cátedras dentro de la Universidad, en ciertas ocasiones constituyó uno de los arreglos ad hoc para mantener docentesinvestigadores que dedicaran todo su tiempo a las actividades académicas. Otro mecanismo para mantener un personal de investigación fue permitir que ciertas cátedras o cargos docentes que no contaban con alumnos regularmente, se justificaran por las actividades de investigación o de extensión universitaria, como se demostró en el caso del Museo de la Plata y la organización del profesorado en ciencias naturales. Asimismo, como se analizó en el capítulo IV, la actividad científica en este ámbito estaría atravesada por los problemas propios del mundo del trabajo y del científico como asalariado, a lo que se sumarían los conflictos y vaivenes de la política universitaria. En esta tesis se ha procurado examinar la práctica científica en la universidad y su divulgación como parte de la organización social del trabajo académico y en la articulación con las prácticas culturales y de difusión vigentes en la época. A ello se sumaría la construcción de un pasado y una tradición que legitimara los proyectos del presente. Algunos investigadores, también buscarían legitimar sus prácticas científicas y extender la influencia de sus disciplinas a través los programas de enseñanza de nuevas generaciones de científicos y docentes para el sistema educativo, como se analizó en los Capítulos V y VI.

Los propósitos de adicionar "ciencia" a la tradicional tarea académica y los intentos por abrir nuevos "nichos" para la investigación en el ámbito universitario involucrarían un conjunto diverso de propuestas acerca de la organización del trabajo del profesor universitario, la educación de los alumnos y las actividades estudiantiles así como los espacios físicos donde llevar a cabo la enseñanza y el entrenamiento en actividades de investigación. La educación "experimental" o "científica" que se promovía implicaba un mayor énfasis en la dimensión práctica y la transmisión de las habilidades y destrezas para conocer de forma "positiva y racional". Precisamente la "necesidad" de una formación "científica" universitaria era lo que permitiría justificar los distintos proyectos que se presentaron en esos años para reglamentar el ejercicio libre de ciertas ocupaciones y los esfuerzos por delimitar las prácticas profesionales a los "empíricos" -sin título universitario- o a los que disponían de un diploma extranjero sin revalidar. De esa forma, el establecimiento de un conjunto de prerrequisitos y normas óptimas de entrenamiento, permitía a los académicos cerrar sus filas a los amateurs y mantener sus diferenciaciones con otras profesiones. 
Si bien la "cientificización" de las profesiones abriría inicialmente posibilidades para expandir la base institucional para la práctica científica en el contexto universitario, no sería fácil adecuar una educación científica que respondiera al mismo tiempo a la formación profesional y por otro, a los intereses científicos e intelectuales de los docentes-investigadores. Esto último podría articularse a través de la consolidación de pautas de educación formal y entrenamiento sistemático del científico y la "profesionalización" de la ciencia. Los sectores científicos, especialmente los profesores formados en las universidades de lengua alemana promoverían el entrenamiento especializado en trabajos de investigación para los alumnos avanzados en ámbitos como el laboratorio o el seminario, donde se podía articular un lugar para desarrollar sus propias investigaciones, reclutar colaboradores y formar estudiantes, con lo cual respondían a las exigencias docentes de la institución universitaria. Durante la década de 1910 se fue haciendo más evidente que los ejemplos de "sabios" trabajando en los laboratorios no constituían un estímulo suficiente para atraer estudiantes en la labor "desinteresada" de la investigación científica y esto ponía en peligro los planes de formar escuelas de investigación.

En esta tesis se ha demostrado que uno de los elementos importantes para el soporte de las disciplinas científicas se relacionó con el sistema de educación pública y en particular con la preparación y acreditación del profesorado secundario, lo cual permitía una mayor difusión y la ampliación del campo laboral para los sectores científicos e interesados en las ciencias. En la segunda parte de esta tesis, se procuró demostrar cómo la formación del científico y la del profesor de enseñanza secundaria se constituyeron en un espacio de lucha institucional, donde diferentes sectores se disputaron los modos de legitimación y el lugar atribuido a determinados saberes. En esa lucha, la habilidad para monopolizar el acceso a determinadas ocupaciones específicas y la distribución de las credenciales profesionales constituirían una de las claves para la consolidación institucional: con esto se creía asegurar el reclutamiento de alumnos y extender su influencia a través de la formación e inserción de los graduados. En particular, se analizó cómo los sectores científicos, especialmente los de ciencias naturales y físicas, insistían en que los futuros docentes del sistema educativo se entrenaran en las prácticas científicas para promover una mayor y adecuada difusión de las ciencias. Para ello se buscaría hacer que los estándares y técnicas de las ciencias enseñadas en la universidad fueran apropiados para los establecimientos secundarios. La enseñanza científica en el nivel medio promovía la 
consolidación de un campo científico mediante su difusión intelectual, creando puestos de trabajo y la demanda por un entrenamiento específico. Para los jóvenes graduados, esto podía entenderse como un paso hacia la creación de un ambiente de trabajo que parcialmente reconciliara la distancia resultante entre su entrenamiento universitario y su inserción laboral en la educación escolar. De esa forma, los reclamos por legitimar ciertos saberes y prácticas en la formación de profesores y por asegurar el privilegio de los doctores en ciencias para ocupar los cargos docentes en los colegios secundarios, constituyó una estrategia para mejorar la posición y la influencia institucional de ciertas disciplinas científicas, que parecían no ofrecer demasiadas perspectivas laborales más allá del ámbito educativo. La formación de maestros y profesores, los programas de conferencias y cursos, las exhibiciones y publicaciones estudiantiles y populares constituyeron diferentes canales de comunicación. A través de ellas, los sectores universitarios buscaron extender la influencia de sus disciplinas y crear una mayor sustentación social para la actividad científica más allá de los grupos que participaban habitualmente en el ámbito académico. Como se intentó demostrar en esta tesis, la institucionalización de la ciencia en el contexto universitario implicó la construcción de un discurso sobre la ciencia, y al mismo tiempo, un público para el mismo tanto en el "intramuros" como entre los sectores extraacadémicos. En este proceso, los estudiantes y graduados tendrían un papel importante en la reproducción ampliada de una cultura científica así como en las prácticas de popularización de la misma. 
Anexo 
Estudiantes en los cursos universitarios de las Universidades Nacionales 1906-1920

\begin{tabular}{|c|c|c|c|}
\hline Año & UBA & UNLP & UCO \\
\hline 1906 & 1.942 & 584 & 425 \\
\hline 1907 & 4.062 & 771 & \\
\hline 1908 & 4.364 & 749 & 473 \\
\hline 1909 & 4.530 & 919 & \\
\hline 1910 & 4.730 & 776 & \\
\hline 1911 & 5.054 & 744 & 543 \\
\hline 1912 & 5.476 & 805 & 741 \\
\hline 1913 & & 866 & 770 \\
\hline 1914 & 5.547 & 889 & 868 \\
\hline 1915 & 6.308 & 1.061 & 827 \\
\hline 1916 & 6.983 & 1.188 & 985 \\
\hline 1917 & 7.482 & 1.241 & 840 \\
\hline 1918 & 7.530 & $1.041\left(^{*}\right)$ & 1.084 \\
\hline 1919 & 7.763 & 1.324 & 1.337 \\
\hline 1920 & 9.352 & 1.638 & 1.603 \\
\hline
\end{tabular}

(*) No se incluyen los estudiantes de la Escuela de Dibujo, que desde ese momento se consignan como alumnos de enseñanza especial .

Fuentes: Memorias del Ministerio de Justicia e Instrucción Pública

\section{Estudiantes de Ciencias Naturales en las Universidades Nacionales en las primeras dos décadas del siglo $\mathrm{XX}$}

\begin{tabular}{|c|c|c|c|}
\hline Año & $\begin{array}{l}\text { Univ. de Buenos Aires } \\
\text { Alumnos del doctorado } \\
\text { de Cs. Nat. }\end{array}$ & $\begin{array}{l}\text { Univ. de La Plata } \\
\text { Alumnos propios de la } \\
\text { carrera de Cs. Nat. }\end{array}$ & $\begin{array}{c}\text { Univ. de Córdoba } \\
\text { Alumnos de la Academia de } \\
\text { Ciencias } \\
\text { (incluye alumnos libres) }\end{array}$ \\
\hline 1903 & 4 & -- & \\
\hline 1905 & 7 & --- & \\
\hline 1906 & & 6 & 20 \\
\hline 1907 & 3 & 10 & 20 \\
\hline 1908 & 8 oficiales y 1 libre & $\mathrm{s} / \mathrm{d}$ & 17 \\
\hline 1909 & 8 & 1 & \\
\hline 1910 & & 1 & \\
\hline 1911 & 5 & 3 & 10 \\
\hline 1912 & 7 & 5 & 12 \\
\hline 1913 & & 6 & \\
\hline 1914 & & 5 & 10 (7 regulares y3 libres) \\
\hline 1915 & 7 & 10 & 18 \\
\hline 1916 & 7 & 7 & 22 (alumnos libres y reg.) \\
\hline 1917 & & 9 & \\
\hline 1918 & & 7 & \\
\hline 1919 & & 5 & \\
\hline 1920 & & 10 & \\
\hline 1921 & 9 & $\begin{array}{c}11 \text { (regulares, } \\
\text { condicionales, oyentes) }\end{array}$ & 12 (alumnos de $1^{\circ}$ y $2^{\circ}$ año) \\
\hline
\end{tabular}

Fuentes: Memorias del Ministerio de Justicia e Instrucción Pública

AHMLP, Copiadores de Secretaria 


\section{Distribución de alumnos por nivel educativo y unidad académica en la Universidad Nacional de La Plata 1906-1917}

\begin{tabular}{|c|c|c|c|c|c|c|c|c|c|c|c|c|}
\hline & 1906 & 1907 & 1908 & 1909 & 1910 & 1911 & 1912 & 1913 & 1914 & 1915 & 1916 & 1917 \\
\hline $\begin{array}{c}\text { Instituto del } \\
\text { Museo }\end{array}$ & 152 & 197 & 191 & 194 & $\begin{array}{c}212 \\
(159)\end{array}$ & 183 & $\begin{array}{c}236 \\
(239) \\
\end{array}$ & 208 & 237 & 256 & 280 & 261 \\
\hline $\begin{array}{c}\text { Fac. de Cs. } \\
\text { Físicas, Mat. } \\
\text { y } \\
\text { Astronómicas }\end{array}$ & 16 & 53 & 18 & $\begin{array}{l}46 \\
(55)\end{array}$ & 53 & 67 & 83 & 95 & 126 & 123 & 143 & 142 \\
\hline $\begin{array}{l}\text { Fac. de Cs. } \\
\text { Jurídicas }\end{array}$ & & 147 & 192 & 210 & 231 & 223 & $\begin{array}{l}205 \\
(523)\end{array}$ & 229 & 217 & 220 & 258 & 258 \\
\hline $\begin{array}{c}\text { Sección } \\
\text { Pedagógica- } \\
\text { Fac. en } 1914\end{array}$ & $\begin{array}{l}--- \\
(185) \\
\end{array}$ & 90 & 73 & 238 & 130 & 136 & 159 & 202 & 186 & 334 & 303 & 333 \\
\hline $\begin{array}{c}\text { Fac. de } \\
\text { Agronomía y } \\
\text { Veterinaria }\end{array}$ & 301 & 284 & 275 & 231 & 150 & 135 & 122 & 132 & 123 & 127 & 204 & 247 \\
\hline $\begin{array}{l}\text { Esc. de Santa } \\
\text { Catalina }\end{array}$ & 80 & 100 & 110 & 114 & 112 & 113 & 107 & 106 & 112 & 100 & 107 & 112 \\
\hline $\begin{array}{l}\text { Colegio } \\
\text { Nacional }\end{array}$ & --- & $\begin{array}{c}495 \\
(425)\end{array}$ & 545 & 557 & 630 & 533 & 618 & 713 & 715 & 750 & 821 & 776 \\
\hline $\begin{array}{l}\text { Colegio de } \\
\text { Señoritas }\end{array}$ & --- & $\begin{array}{c}59 \\
(56) \\
\end{array}$ & $\begin{array}{c}134 \\
(130)\end{array}$ & $\begin{array}{c}221 \\
(216) \\
\end{array}$ & $\begin{array}{c}247 \\
(246)\end{array}$ & 283 & 280 & 244 & 280 & 279 & 297 & 338 \\
\hline $\begin{array}{c}\text { Escuela } \\
\text { Graduada }\end{array}$ & $\begin{array}{c}321 \\
(278) \\
\end{array}$ & $\begin{array}{c}299 \\
(295) \\
\end{array}$ & $\begin{array}{c}307 \\
(295) \\
\end{array}$ & $\begin{array}{c}380 \\
(378) \\
\end{array}$ & $\begin{array}{c}400 \\
(385) \\
\end{array}$ & 471 & 472 & 478 & 523 & 520 & 516 & 443 \\
\hline Total & $\begin{array}{c}\mathbf{9 8 5} \\
(1012)\end{array}$ & $\begin{array}{c}\mathbf{1 7 2 4} \\
(1732)\end{array}$ & $\begin{array}{c}\mathbf{1 8 4 5} \\
(1908)\end{array}$ & $\begin{array}{c}\mathbf{2 1 9 1} \\
(2184)\end{array}$ & $\begin{array}{c}\mathbf{2 1 6 5} \\
(2106)\end{array}$ & 2144 & $\begin{array}{c}\mathbf{2 2 8 2} \\
(2496)\end{array}$ & 2407 & 2519 & 2709 & 2929 & 2910 \\
\hline
\end{tabular}

Fuente: Cuadro extraído de Rivarola 1918: 105.

Fuente de los datos en bastardilla: UNLP 1910, 1913a.

NOTA: los datos en presentados en bastardilla corresponden a las cifras que se presentaron en las primeras memorias de la Universidad, que diferían principalmente en los datos de la enseñanza secundaria y primaria y también al incluirse a los alumnos de la Escuela Industrial de anexa a la Facultad de Ciencias Físicas y Matemáticas (1908: 25 alumnos y en 1909: 51), y los de la Sección de Filosofía, Historia y Letras (1909: 121, 1910: 29). Esta Sección al igual que la Sección Pedagógica incluían en sus estadísticas a los alumnos de correlación. De ahí, que en realidad el número total de individuos que cursaban regularmente estudios universitarios eran mucho menor.

A su vez, los datos sobre la cantidad de alumnos en la Facultad de Ciencias Físicas, Matemáticas y Astronómicas presentados por las autoridades de esta unidad académica también difieren en las cifras de los años 1906-1909 (1906: 21 alumnos propios; 1907: 23; 1908: 32; 1909: 39). Besio Moreno 1917. 
Alumnos propios de la Sección Pedagógica entre 1906 y 1913

\begin{tabular}{|c|c|c|c|c|c|}
\hline Año & $\begin{array}{c}\text { Profesores } \\
\text { normales }\end{array}$ & $\begin{array}{c}\text { Maestros } \\
\text { normales }\end{array}$ & Bachilleres & $\begin{array}{c}\text { Con título } \\
\text { universitario }\end{array}$ & Total \\
\hline 1906 & 3 & 20 & 4 & 6 & 27 \\
\hline 1907 & - & 19 & 4 & 5 & 23 \\
\hline 1908 & 1 & 24 & 5 & 1 & 30 \\
\hline 1909 & 1 & 25 & 3 & 1 & 36 \\
\hline 1910 & 2 & 44 & 4 & 2 & 50 \\
\hline 1911 & - & 16 & 7 & 1 & 53 \\
\hline 1912 & - & 32 & 14 & - & 46 \\
\hline 1913 & - & 41 & 23 & 4 & 61 \\
\hline
\end{tabular}

\section{Alumnos de correlación de la Sección Pedagógica 1906-1913}

\begin{tabular}{|l|l|l|l|l|l|l|l|}
\hline Año & $\begin{array}{l}\text { Ciencias } \\
\text { jurídicas }\end{array}$ & $\begin{array}{l}\text { Cs. } \\
\text { Físicas y } \\
\text { Mat. }\end{array}$ & $\begin{array}{l}\text { Ciencias } \\
\text { naturales }\end{array}$ & $\begin{array}{l}\text { Química y } \\
\text { Farmacia }\end{array}$ & $\begin{array}{l}\text { Agronomía } \\
\text { Veterinaria }\end{array}$ & $\begin{array}{l}\text { Otras } \\
\text { Instituciones } \\
\text { nacionales }\end{array}$ & Dibujo \\
\hline 1906 & 23 & 1 & 4 & 5 & 29 & 2 & -- \\
\hline 1907 & 10 & 1 & 2 & 21 & 25 & 3 & 30 \\
\hline 1908 & 13 & - & 1 & 16 & 14 & - & 30 \\
\hline 1909 & 22 & 8 & 1 & 21 & 10 & - & 23 \\
\hline 1910 & 19 & 7 & 1 & 25 & 6 & - & 20 \\
\hline 1911 & 18 & 6 & 2 & 26 & 8 & 7 & 14 \\
\hline 1912 & 27 & 11 & - & 29 & 8 & 2 & 17 \\
\hline 1913 & 44 & 10 & - & 42 & 16 & 4 & - \\
\hline
\end{tabular}

Fuente: Mercante 1913.

Profesores egresados de la Facultad de Ciencias de la Educación 1906-1917

\begin{tabular}{|c|c|}
\hline \multicolumn{1}{|c|}{ Títulos } & Egresados \\
\hline Profesor de enseñanza superior & 8 \\
Profesor de enseñanza secundaria & 17 \\
Prof. de enseñanza secundaria, normal y especial en: & 108 \\
a) Pedagogía y ciencias afines & 2 \\
b) Pedagogía y cs. afines y geografía & 4 \\
c) Pedagogía y cs. afines y matemáticas & 2 \\
d) Pedagogía y cs. afines y castellano & 4 \\
e) Pedagogía y cs. afines e historia & 5 \\
f) Pedagogía y cs. afines y historia argentina & 1 \\
g) Pedagogía y cs. afines y literatura europea & 1 \\
h) Pedagogía y cs. afines y física & 47 \\
i) Química & 18 \\
j) Historia argentina e instituciones jurídicas y sociales & 7 \\
k) Matemáticas & 5 \\
l) Anatomía, fisiología e higiene & 5 \\
m) Ciencias agrarias & 2 \\
n) Ciencias naturales & $\mathbf{2 3 6}$ \\
\hline
\end{tabular}

Fuente: Mercante 1918. 
ALUMNOS MATRICULADOS EN CIENCIAS NATURALES EN EL MUSEO DE LA PLATA ENTRE 1906 Y 1930

\begin{tabular}{|c|c|c|c|c|c|}
\hline $\begin{array}{l}\text { Ingre } \\
\text { so }\end{array}$ & Alumno & Estudios anteriores & $\begin{array}{l}\text { Exámenes rendidos - especialidad } \\
\text { Títulos y estudios posteriores }\end{array}$ & $\begin{array}{l}\text { Beca o Cargos } \\
\text { desempeñados en el Museo }\end{array}$ & \begin{tabular}{|c} 
Actuación profesional inicial \\
(se consignan los principales cargos y trabajos \\
en la primera mitad del siglo XX)
\end{tabular} \\
\hline 1906 & $\begin{array}{l}\text { María Luisa } \\
\text { Gutiérrez }\end{array}$ & $\begin{array}{l}\text { Farmacéutica (1902) } \\
\text { Fac. de Química y } \\
\text { Farmacia Provincial }\end{array}$ & 1906-1908 (6 materias rendidas) & & \\
\hline 1906 & $\begin{array}{l}\text { Teodoro de } \\
\text { Urquiza } \\
\text { (argentino, } \\
\text { tenía } 20 \\
\text { años al } \\
\text { ingresar) }\end{array}$ & $\begin{array}{l}\text { Colegio Nacional } \\
\text { Central, Bs. As. } \\
\text { (certificado } 5^{\circ} \text { año) }\end{array}$ & $\begin{array}{l}1906-1910 \\
(30 \text { materias y algunas } \\
\text { desaprobadas) } \\
\text { Prof. de enseñanza secundaria } \\
\text { (Sección Pedagógica) } \\
\text { Dr. en ciencias naturales, } \\
\text { especialidad Antropología (1912) }\end{array}$ & $\begin{array}{l}\text { Ayudante-alumno de Sección } \\
\text { en 1906, fue dejado cesante } \\
\text { por desaprobar materias. }\end{array}$ & $\begin{array}{l}\text { Profesor de antropología en una Escuela para } \\
\text { oficiales (aprox. desde 1911) } \\
\text { Jefe de la Oficina de Estudio Criminal y director } \\
\text { de la Revista de Criminología y ciencias afines } \\
\text { (desde 1913). En esos años también presentó al } \\
\text { Ministro de Gobierno provincial un proyecto para } \\
\text { la creación de un Instituto de Criminología. }\end{array}$ \\
\hline 1906 & $\begin{array}{l}\text { Juan F. } \\
\text { Norrié } \\
\text { (argentino, } \\
\text { al ingresar } \\
\text { tenía } 18 \\
\text { años) }\end{array}$ & $\begin{array}{l}\text { Colegio Nacional Sud, } \\
\text { Bs. As. }\end{array}$ & & $\begin{array}{l}\text { Ayudante-alumno } \text { (1906- } \\
\text { 1907), quedó cesante r tras } \\
\text { haber sido aplazado en } \\
\text { exámenes. Entre julio } y \\
\text { diciembre de } 1907 \text { fue } \\
\text { reincorporado. }\end{array}$ & \\
\hline 1906 & $\begin{array}{l}\text { Franco } \\
\text { Pastore }\end{array}$ & $\begin{array}{l}\text { Esc. Normal de } \\
\text { Profesores, Bs. As. } \\
\text { (certificado } 5^{\circ} \text { y } 6^{\circ} \text { año) }\end{array}$ & $\begin{array}{l}\text { 1906-1908 (8 materias) } \\
\text { Terminó sus estudios en la Facultad } \\
\text { de Cs. Exactas, Físicas y Naturales } \\
\text { de la Universidad de Buenos Aires. } \\
\text { Dr. en ciencias naturales (1914) }\end{array}$ & \begin{tabular}{|l|} 
Ayudante de Sección (1906) \\
quedó cesante por disposición \\
del Consejo Académico (fue \\
aplazado en varios exámenes)
\end{tabular} & $\begin{array}{l}\text { Fue uno de los socios fundadores de la Sociedad } \\
\text { Physis. } \\
\text { En } 1910 \text { se incorporó como Geólogo de } 2^{\circ} \text { en la } \\
\text { División de Minas, Geología e Hidrología del } \\
\text { Ministerio de Agronomía y Veterinaria de la } \\
\text { Nación. } \\
\text { Se dedicó a investigaciones en ciencias } \\
\text { geológicas y a la enseñanza universitaria en la } \\
\text { Universidad de Buenos Aires. }\end{array}$ \\
\hline
\end{tabular}




\begin{tabular}{|c|c|c|c|c|c|}
\hline 1906 & $\begin{array}{l}\text { Carolina E. } \\
\text { Spegazzini }\end{array}$ & $\begin{array}{l}\text { Colegio Nacional de La } \\
\text { Plata }\end{array}$ & $\begin{array}{l}\text { 1906-1909 (24 materias rendidas) } \\
\text { Profesora de enseñanza secundaria, } \\
\text { Sección Pedagógica (1909) } \\
\text { Licenciada en ciencias naturales } \\
\text { (1910) } \\
\text { Dr. en química (1918) }\end{array}$ & $\begin{array}{l}\text { Ayudante de Sección (1907- } \\
\text { 1910). } \\
\text { Por gestiones de la } \\
\text { Universidad, el Ministerio de } \\
\text { Instrucción Pública le otorgó } \\
\text { una beca para perfeccionar } \\
\text { sus estudios, pero renunció } \\
\text { por no coincidir con algunas } \\
\text { de las disposiciones de esa } \\
\text { beca. } \\
\text { En } 1911 \text { fue reincorporada } \\
\text { como ayudante y continuó } \\
\text { hasta } 1914 . \\
\text { Jefa de trabajos prácticos en la } \\
\text { Escuela de Química y } \\
\text { Farmacia. Posteriormente } \\
\text { continuó trabajando en la } \\
\text { Facultad de Ciencias } \\
\text { Químicas }\end{array}$ & \\
\hline 1907 & $\begin{array}{l}\text { Juana } \\
\text { Cortelezzi } \\
\text { (n. 1887) }\end{array}$ & $\begin{array}{l}\text { Colegio Nacional de } \\
\text { La Plata }\end{array}$ & $\begin{array}{l}\text { 1907-1908 (3 materias aprobadas) } \\
\text { Profesora de enseñanza secundaria, } \\
\text { Sección Pedagógica, UNLP (1909). } \\
\text { Farmacéutica (1909) } \\
\text { Completó su formación en la } \\
\text { Universidad de Heidelberg. } \\
\text { Dr. en química (1927), Tesis: } \\
\text { "Estudio sobre la resina fósil" . }\end{array}$ & $\begin{array}{l}\text { Jefe de Trabajos Prácticos en } \\
\text { Mineralogía y Geología } \\
(1928-1933) \\
\text { Profesora Titular de } \\
\text { Mineralogía desde } 1933 \text { hasta } \\
\text { su jubilación en } 1939 .\end{array}$ & $\begin{array}{l}\text { Prof. de ciencias naturales en el Colegio de } \\
\text { Señoritas de la UNLP (1908-1933) y luego } \\
\text { directora de ese establecimiento. } \\
\text { Prof. de Práctica Pedagógica de Mineralogía y } \\
\text { Geología, Fac. de Humanidades y Cs. de la Ed., } \\
\text { UNLP (1920-1933) } \\
\text { Jefe de Trabajos Prácticos ad-honrem del curso } \\
\text { libre dictado por W. Schiller, Fac. de Cs. Exactas, } \\
\text { UBA (1926) } \\
\text { Jefe de trabajos prácticos y asistente del Instituto } \\
\text { de Investigaciones Químicas, UNLP (1927-1929). } \\
\text { Publicó trabajos de investigación en revistas } \\
\text { nacionales e internacionales, y obras de } \\
\text { divulgación como "El reino Mineral" de la serie } \\
\text { La Escuela Moderna de la Editorial Cabaut y Cía. }\end{array}$ \\
\hline 1908 & $\begin{array}{l}\text { Ricardo } \\
\text { Calatroni }\end{array}$ & $\begin{array}{l}\text { Colegio Nacional de La } \\
\text { Plata. }\end{array}$ & 1908 (1 matreia) & $\begin{array}{l}\text { Ayudante de Sección (1908- } \\
\text { 1912), quedó cesante al }\end{array}$ & $\begin{array}{l}\text { Prof. de cs. naturales y ayudante del Gabinete de } \\
\text { Historia Natural en el Colegio Nacional, UNLP. }\end{array}$ \\
\hline
\end{tabular}




\begin{tabular}{|c|c|c|c|c|c|}
\hline & & & $\begin{array}{l}\text { Estudiaba Farmacia y el prof. en } \\
\text { ciencias naturales } \\
\text { Prof. de enseñanza secundaria en } \\
\text { ciencias naturales, Sección } \\
\text { Pedagógica } \\
\text { Farmacéutico } \\
\text { Dr. en química y farmacia (1917) }\end{array}$ & finalizar sus estudios & $\begin{array}{l}\text { Participante activo del Centro de Estudiantes de } \\
\text { Química y Farmacia, de la formación de la } \\
\text { Federación universitaria platense en 1911, y del } \\
\text { Centro de Ex alumnos del Colegio Nacional } \\
\text { También participó en asociaciones de divulgación } \\
\text { científicas como la Universidad Obrera de La } \\
\text { Plata, el Ateneo Popular de Buenos Aires, la } \\
\text { Biblioteca Florentino Ameghino de Tolosa, etc., } \\
\text { donde dictó cursos populares de ciencias naturales } \\
\text { y divulgó los trabajos de Florentino Ameghino. } \\
\text { Durante la Reforma Universitaria de 1919-1920 } \\
\text { quedó cesante en el Colegio Nacional de la Plata. } \\
\text { Luego se trasladó a Rosario y comenzó a trabajar } \\
\text { en la Universidad del Litoral }\end{array}$ \\
\hline 1911 & $\begin{array}{l}\text { Eduardo } \\
\text { Carette } \\
\text { (francés, n. } \\
1886 \text { ) }\end{array}$ & $\begin{array}{l}\text { Fac. de Agronomía y } \\
\text { Veterinaria, y Fac. de } \\
\text { Ciencias Exactas, } \\
\text { Físicas y Naturales de } \\
\text { Buenos Aires }\end{array}$ & $\begin{array}{l}\text { 1911-1912 (4 materias rendidas) } \\
\text { Dr en ciencias naturales, } \\
\text { especialidad zoología (hacia 1912- } \\
\text { 1913) } \\
\text { No publicó su tesis. }\end{array}$ & $\begin{array}{l}\text {-Beca de estudios } \\
\text {-Profesor adjunto de } \\
\text { paleontología, desde } 1913 . \\
\text {-En 1914, el Consejo } \\
\text { Académico le otorgó una beca } \\
\text { de perfeccionamiento en el } \\
\text { extranjero que no llegó a } \\
\text { implementarse. } \\
\text {-Prof. y sub-jefe de la sección } \\
\text { paleontología. (1918-1920) } \\
\text {-Jefe del departamento de } \\
\text { Paleontología Invertebrado y } \\
\text { Prof. (1920-1923), fue dejado } \\
\text { cesante por conflictos con el } \\
\text { director del Museo. }\end{array}$ & $\begin{array}{l}\text { Profesor en un colegio nacional de Buenos Aires. } \\
\text { En la década de } 1930 \text { fue director del Museo } \\
\text { "Juan Cornelio Moyano" de Mendoza. }\end{array}$ \\
\hline 1911 & $\begin{array}{l}\text { Max } \\
\text { Birabén } \\
\text { (Bs. As., } \\
\text { 1893) }\end{array}$ & $\begin{array}{l}\text { Inscripto condicional } \\
\text { porque no tenía } \\
\text { certificados de estudios } \\
\text { secundarios. Regularizó } \\
\text { su situación }\end{array}$ & $\begin{array}{l}\text { 1911-1916 (12 materias y algunos } \\
\text { aplazos) } \\
\text { Especialidad zoología }\end{array}$ & $\begin{array}{l}\text { Se le otorgó una beca de } \\
\text { estudios, por las } \\
\text { recomendaciones de F. } \\
\text { Lahille y E. Herrero Ducloux, } \\
\text { que luego perdió al }\end{array}$ & $\begin{array}{l}\text {-Prof. de biología en el Colegio Nacional de la } \\
\text { UNLP (1918-1920), } \\
\text {-Prof. sup. de biología en la Fac. de Filosofía y } \\
\text { Letras ,UBA (1919). } \\
\text { - Prof. libre de zoología y parasitología en la }\end{array}$ \\
\hline
\end{tabular}




\begin{tabular}{|c|c|c|c|c|c|}
\hline & & $\begin{array}{l}\text { presentando un } \\
\text { certificado de ingreso } \\
\text { de la Fac. de } \\
\text { Agronomía y } \\
\text { Veterinaria de la } \\
\text { UNLP, donde sólo se } \\
\text { exigía la aprobación de } \\
\text { un examen de ingreso. }\end{array}$ & Dr. en ciencias naturales (1917) & $\begin{array}{l}\text { desaprobar materias. } \\
\text {-Ayudante de Sección (1914- } \\
1917 \\
\text {-Jefe interino de laboratorio } \\
(1917,1918,1919) \\
\text {-Profesor titular de zoología } \\
\text { especial desde 1930. } \\
\text {-Jefe del Depto. de Zoología } \\
\text { Invertebrados, 1933- 1946, } \\
\text { fue dejado cesante durante la } \\
\text { intervención de la } \\
\text { Universidad } \\
\text { Fue reincorporado en } 1955 .\end{array}$ & $\begin{array}{l}\text { Facultad de Química y Farmacia, UNLP (1922- } \\
\text { 23). } \\
\text { En la Escuela de Ciencias Médicas, UNLP, fue: - } \\
\text { jefe de gabinete de parasitología (1919), -jefe de } \\
\text { trabajos prácticos de Embriología e Histología } \\
\text { Normal (1920-1929), luego Prof. sup. y titular de } \\
\text { esa cátedra (1930-1946). Fue reincorporado en } \\
\text { 1955; - Decano interventor (1956-57) y prof. } \\
\text { honorario desde 1965. } \\
\text {-Dir. del Museo Argentino de Ciencias Naturales } \\
\text { (1959-1971) } \\
\text { - Dir. Gral. de Institutos de Investigación (1965). } \\
\text { - Dir. y editor de Neotrópica desde 1954 }\end{array}$ \\
\hline 1911 & $\begin{array}{l}\text { Celia Silva } \\
\text { Lynch }\end{array}$ & $\begin{array}{l}\text { Fac. de Agro. y Vet. de } \\
\text { La Plata } \\
\text { (Ingeniera Agrónoma) }\end{array}$ & $\begin{array}{l}\text { 1912-14 (11 materias) } \\
\text {-Lic. en ciencias naturales } \\
\text {-Prof. de enseñanza sec. y superior } \\
\text { Hacia } 1916 \text { había elegido como } \\
\text { tema de tesis un trabajo sobre la } \\
\text { embriología del escuerzo. }\end{array}$ & & \\
\hline 1912 & $\begin{array}{l}\text { María Luisa } \\
\text { Cobanera }\end{array}$ & $\begin{array}{l}\text { Colegio Nacional de La } \\
\text { Plata }\end{array}$ & $\begin{array}{l}1912 \text { (1 materia) } \\
\text { Dr. en química (1912) }\end{array}$ & $\begin{array}{l}\text {-Ayudante de Laboratorio de } \\
\text { la Esc. de Química y } \\
\text { Farmacia (1909-1910) } \\
\text {-Beca de Estudio }\end{array}$ & $\begin{array}{l}\text { Realizó algunos trabajos de investigación, que se } \\
\text { publicaron en la Revista del Museo }\end{array}$ \\
\hline 1914 & $\begin{array}{l}\text { Ana } \\
\text { Manganaro } \\
\text { (platense, } \\
1891-1921 \text { ) }\end{array}$ & $\begin{array}{l}\text { Farmacéutica, Escuela } \\
\text { de Química y Farmacia } \\
\text { del Museo. } \\
\text { Facultad de Agronomía } \\
\text { y Veterinaria, UNLP. }\end{array}$ & $\begin{array}{l}\text { 1912-17 (8 asignaturas) } \\
\text { Especialidad botánica } \\
\text { Dr. en ciencias naturales (1919) }\end{array}$ & $\begin{array}{l}\text { Recibió una de las becas de } \\
\text { estudio, a la que renunció en } \\
1914 \text { por ausentarse del país. }\end{array}$ & \\
\hline 1913 & $\begin{array}{l}\text { María I. } \\
\text { Hylton Scott } \\
\text { (Córdoba } \\
1889)\end{array}$ & $\begin{array}{l}\text { Maestra normal } \\
\text { recibida en la Escuela } \\
\text { Normal de Córdoba } \\
(1908) \\
\text { Prof. de enseñanza }\end{array}$ & $\begin{array}{l}\text { 1913-15 (9) } \\
\text { Especialidad zoología } \\
\text { Dr. ciencias naturales (1916). }\end{array}$ & $\begin{array}{l}\text {-Beca de estudios } \\
\text {-Ayudante de laboratorio a } \\
\text { partir de } 1914 . \\
\text {-Jefe de laboratorio, } 1917 \text { - } \\
1924 \text { (fue dejada cesante por } \\
\text { conflictos con el Director del }\end{array}$ & $\begin{array}{l}\text {-Maestra en la Escuela Normal de Córdoba (un } \\
\text { año). } \\
\text {-Maestra en la Escuela No } 37 \text { de La Plata (1911) y } \\
\text { en la Escuela Graduada Anexa, UNLP (1912- } \\
\text { 1914). } \\
\text { - Prosecretaria interina del Colegio Secundario de }\end{array}$ \\
\hline
\end{tabular}




\begin{tabular}{|c|c|c|c|c|c|}
\hline & & $\begin{array}{l}\text { secundaria en } \\
\text { pedagogía y cs. afines, } \\
\text { Sección Pedagógica, } \\
\text { UNLP (1911) }\end{array}$ & $\begin{array}{l}\text { Tesis: "Sobre desarrollo intraovarial } \\
\text { de Fitzroyia lineata" (no se publicó } \\
\text { en la Revista del Museo como había } \\
\text { recomendado su director Miguel } \\
\text { Fernández. Se publicó diez años } \\
\text { después en los Anales del Museo de } \\
\text { Historia Natural de Buenos Aires) }\end{array}$ & $\begin{array}{l}\text { Museo) } \\
\text { - Profesora suplente de } \\
\text { zoología especial (ad } \\
\text { honorem) 1933- } 1946 \\
\text {-Jefe de sección ad honorem, } \\
\text { sección malacológica en } \\
\text { 1942-46. Renunció en el } \\
\text { marco de la intervención a la } \\
\text { Universidad. } \\
\text { A fines de } 1955 \text { fue } \\
\text { reincorporada como Prof. } \\
\text { adjunta de zoología } \\
\text { invertebrados (55-65) y Jefa } \\
\text { de la División Zoología } \\
\text { Invertebrados. } \\
\text { En 1957 ganó por concurso el } \\
\text { cargo de Profesora titular de } \\
\text { Anatomía comparada, que } \\
\text { desempeñó hasta 1967. }\end{array}$ & $\begin{array}{l}\text { Señoritas en } 1911 \\
\text { - Prof. de ciencias naturales en la Escuela Normal } \\
\text { Popular de La Plata en } 1915 . \\
\text { - Encargada técnica del laboratorio de la } \\
\text { Asistencia Pública de La Plata, dependiente de la } \\
\text { Dirección General de Higiene en } 1933 \\
\text {-Adscripta honoraria al Departamento de Ciencias } \\
\text { Zoológicas del Instituto Nacional de Investigación } \\
\text { de las ciencias naturales } \\
\text { Numerosos trabajos científicos. Dirigió tesistas. } \\
\text { Se destacó como especialista en malacología. } \\
\text { Miembro del comité redactor de Neotrópica, } \\
\text { desde } 1954 .\end{array}$ \\
\hline 1914 & $\begin{array}{l}\text { Nicolas } \\
\text { Ceppi } \\
\text { (Corrientes, } \\
1888 \text { ) }\end{array}$ & $\begin{array}{l}\text { Col. Nac. de La Plata, } \\
\text { Esc. Química y } \\
\text { Farmacia del Museo. }\end{array}$ & $\begin{array}{l}\text { 1913-1917 (6 materias aprobadas) } \\
\text { Luego retomó entre 1926-1928 } \\
\text { Especialidad botánica } \\
\text { Profesor de enseñanza secundaria en } \\
\text { química, Facultad de Ciencias de la } \\
\text { Educación, UNLP (1917) }\end{array}$ & $\begin{array}{l}\text { Ayudante de laboratorio entre } \\
1910 \text { y } 1912 \\
\text { Ayudante de la Sección de } \\
\text { Botánica entre 1914-1917 }\end{array}$ & $\begin{array}{l}\text { En la década de } 1930 \text { era profesor del Colegio } \\
\text { Nacional de La Plata }\end{array}$ \\
\hline 1912 & $\begin{array}{l}\text { Carlos Lizer } \\
\text { (Bs. As., } \\
\text { 1887) }\end{array}$ & $\begin{array}{l}\text { Ingeniero agrónomo } \\
\text { (1911), Facultad de } \\
\text { Agronomía y } \\
\text { Veterinaria, UBA. }\end{array}$ & $\begin{array}{l}\text { 1913-17 (9 materias aprobadas) } \\
\text { Especialidad zoología } \\
\text {-En } 1928 \text { solicitó la aprobación del } \\
\text { tema de tesis, indicado por el } \\
\text { profesor Horacio Arditi: estudio } \\
\text { monográfico sobre los "Psilidos } \\
\text { argentinos". }\end{array}$ & & $\begin{array}{l}\text { Participó en la fundación de la Sociedad Physis y } \\
\text { de la Sociedad de Entomología Argentina en } \\
1925 . \\
\text { Se dedicó a la entomología agrícola. } \\
\text { Entre } 1912 \text { y su jubilación en } 1942 \text { trabajó en el } \\
\text { Ministerio de Agricultura, llegando a } \\
\text { desempeñarse como Jefe de la División de } \\
\text { Zoología Agrícola y Subdirector de Sanidad } \\
\text { Vegetal. } \\
\text {-Prof. en la Facultad de Agro. y Vet. de la UBA } \\
\text { (1921-46 y luego reincorporado en 1955); y de la } \\
\text { UNLP (1928-1937). }\end{array}$ \\
\hline
\end{tabular}




\begin{tabular}{|c|c|c|c|c|c|}
\hline 1914 & $\begin{array}{l}\text { María Luisa } \\
\text { Petetin } \\
\text { (Rosario, } \\
\text { 1895) }\end{array}$ & Sección Pedagógica & $\begin{array}{l}\text { 1914-17 (13 materias rendidas ) } \\
\text { Especialidad: Zoología }\end{array}$ & $\begin{array}{l}\text { Obtuvo una beca de estudio, } \\
\text { pero el Poder Ejecutivo la } \\
\text { suspendió a fines de 1914 } \\
\text { como parte de los recortes en } \\
\text { el presupuesto nacional. } \\
\end{array}$ & $\begin{array}{l}\text { Retornó a Rosario donde se dedicó a la enseñanza } \\
\text { y a escribir trabajos educativos, políticos y } \\
\text { literarios. }\end{array}$ \\
\hline 1913 & $\begin{array}{l}\text { Abelardo } \\
\text { Gallo } \\
\text { (Cap. Fed., } \\
\text { 1887) }\end{array}$ & $\begin{array}{l}\text { Fac. de Filosofía y } \\
\text { Letras, UBA }\end{array}$ & $\begin{array}{l}\text { 1914-1916 (7 materias) } \\
\text { Especialidad: Antropología } \\
\text {-Lic. en cs. nat. (1916) } \\
\text { Tras los cambios en los reglamentos } \\
\text { y varias solicitudes, el Consejo } \\
\text { Superior lo eximió de los exámenes } \\
\text { generales y de tesis. Pero se le } \\
\text { exigió una tesis escrita. En 1924, } \\
\text { presentó una tesis sobre las ruinas de } \\
\text { Tiahuanaco, que fue aprobada pero } \\
\text { no fue publicada. } \\
\text { - Se le concedió el título de doctor } \\
\text { hacia 1928, pero el Consejo } \\
\text { Académico estableció que no sería } \\
\text { recomendado para ningún puesto } \\
\text { técnico, porque no había completado } \\
\text { todos los requisitos del plan de } \\
\text { estudios. }\end{array}$ & & $\begin{array}{l}\text { Adscripto a la Sección de Antropología del Museo } \\
\text { Nacional de Historia Nacional de Buenos Aires, } \\
\text { desde } 1916 \text {. } \\
\text { Fue profesor en ciencias y letras en el Colegio } \\
\text { Nacional Mariano Moreno y Prosecretario } \\
\text { General de la UBA. } \\
\text { Miembro correspondiente de la Sociedad } \\
\text { Geográfica de Lima y de Chile y titular de la } \\
\text { Americanistas de Paris. }\end{array}$ \\
\hline 1914 & $\begin{array}{l}\text { Víctor } \\
\text { Delfino } \\
\text { (n. Bs. As., } \\
\text { 1883) }\end{array}$ & $\begin{array}{l}\text { Instituto Nacional del } \\
\text { Profesorado, Bs. As. }\end{array}$ & $\begin{array}{l}\text { 1915-17 (7 materias) } \\
\text { Especialidad: Zoología } \\
\text { En } 1928 \text { solicitó tema de tesis. }\end{array}$ & & \\
\hline 1915 & $\begin{array}{l}\text { María } \\
\text { Amelia } \\
\text { Osácar } \\
\text { (.La } \\
\text { Plata,1897) } \\
\end{array}$ & $\begin{array}{l}\text { Liceo de Señoritas de } \\
\text { La Plata }\end{array}$ & $\begin{array}{l}\text { 1915-18 (14 materias) } \\
\text { Especialidad: Geología } \\
\text { Completó sus estudios, pero no hay } \\
\text { registros que haya presentado su } \\
\text { tesis doctoral }\end{array}$ & & \\
\hline 1915 & $\begin{array}{l}\text { Sarah } \\
\text { Cortelezzi } \\
\text { (La Plata, } \\
1897)\end{array}$ & $\begin{array}{l}\text { Liceo de Señoritas de } \\
\text { La Plata }\end{array}$ & $\begin{array}{l}\text { 1915-18 (12 materias) } \\
\text { Especialidad: Geología } \\
\text { Dr. en cs. nat., especialidad }\end{array}$ & $\begin{array}{l}\text { Ayudante de laboratorio } \\
\text { interino (1915) } \\
\text { Ayudante de Sección: } 1917- \\
1918 \\
\text { Ayudante Preparador: } 1918-\end{array}$ & \\
\hline
\end{tabular}




\begin{tabular}{|c|c|c|c|c|c|}
\hline & & & $\begin{array}{l}\text { mineralogía (1932), bajo la } \\
\text { dirección de W. Schiller }\end{array}$ & $\begin{array}{l}1919 \\
\text { Desde 1920, ejerció (sin } \\
\text { nombramiento) como JTP en } \\
\text { la Sección de Mineralogía, } \\
\text { Geología, Geografía física y } \\
\text { Petrografía. Fue nombrada en } \\
\text { ese cargo en 1924. }\end{array}$ & \\
\hline 1915 & \begin{tabular}{|l} 
Carlos \\
Lloveras \\
(Bs. As., \\
1893 ) \\
\end{tabular} & $\begin{array}{l}\text { Fac. de Cs. Exactas, } \\
\text { Físicas y Naturales de } \\
\text { Buenos Aires }\end{array}$ & $\begin{array}{l}\text { 1916-1918 (6 materias) } \\
\text { Especialidad: Zoología }\end{array}$ & & \\
\hline 1917 & $\begin{array}{l}\text { Emiliano } \\
\text { Mac } \\
\text { Donagh }\end{array}$ & & $\begin{array}{l}1917 \text { (4 materias), } \\
\text { 1924-28 (12 materias) } \\
\text { Especialidad: Zoología } \\
\text { Dr. en cs. nat. en 1928, } \\
\text { Tesis: "La helmintiasis de la } \\
\text { pescadilla por un cesto } \\
\text { tetrarrinquido, como tipo de } \\
\text { invasión parasitaria y de reacción } \\
\text { del huésped, principalmente por el } \\
\text { sistema vascular" }\end{array}$ & $\begin{array}{l}\text { Jefe del Dto. y prof. de } \\
\text { zoología (vertebrados) desde } \\
1933 . \\
\text { Director Interventor del } \\
\text { Museo en 1946-1949. }\end{array}$ & $\begin{array}{l}\text {-Ayudante del Instituto Bacteriológico de la Dir. } \\
\text { Gral. de Higiene de la Pcia. de Bs. As. (1915- } \\
\text { 1925) y luego Jefe de la Sección Parasitología del } \\
\text { mismo } \\
(1925-28) \\
\text {-Prof. de Geografía en la Esc. Sup. de Comercio } \\
\text { de La Plata hasta 1949. } \\
\text {-Prof. tit. de zoología y entomología en la Fac. de } \\
\text { Agronomía, UNLP (1937-1947) } \\
\text {-Dir. Gral. de Escuelas de la Pcia. de Bs. As. } \\
\text { (1944) } \\
\text {-Presidente de la Soc. Arg. de Cs. Nat. } \\
\text { (1938-1940) } \\
\text { Se dedicó especialmente y fomentó los estudios } \\
\text { ictiológicos. Dirigió numerosos tesistas y } \\
\text { alumnos. }\end{array}$ \\
\hline $\begin{array}{l}\text { c. } 191 \\
8\end{array}$ & \begin{tabular}{|l} 
Matilde \\
Dolgopol \\
(de Saez)
\end{tabular} & & $\begin{array}{l}\text { 18-24 (13 materias ) } \\
\text { Especialidad: Zoología y } \\
\text { Mineralogía y Geología } \\
\text { - Prof. de enseñanza secundaria en } \\
\text { cs. nat. (1921) } \\
\text {-Dr en ciencias naturales, esp. } \\
\text { Zoología (c. 1927). Tesis dirigida } \\
\text { por A. Cabrera }\end{array}$ & $\begin{array}{l}\text { Ayudante de la Sección de } \\
\text { Mineralogía y Geología, } 1919 \\
\\
\text { Jefe de Trabajos Prácticos del } \\
\text { Dto. de Paleontología desde } \\
1928\end{array}$ & $\begin{array}{l}\text { Prof. sup. de Mineralogía y Geología en el } \\
\text { Colegio Secundario de Señoritas de la UNLP, } \\
1924 \\
\text { Estudios sobre aves y otros animales fósiles. } \\
\text { Trabajos publicados en la Revista del Museo y } \\
\text { otras revistas científicas. }\end{array}$ \\
\hline
\end{tabular}




\begin{tabular}{|c|c|c|c|c|c|}
\hline $\begin{array}{l}\text { c. } \\
1918\end{array}$ & $\begin{array}{l}\text { América del } \\
\text { Pilar } \\
\text { Rodrigo }\end{array}$ & & $\begin{array}{l}\text { 18-22 (12 materias) } \\
\text { Especialidad: Zoología } \\
\text { Dr. en cs. nat., (c. 1924) }\end{array}$ & $\begin{array}{l}\text { Ayudante y luego Jefe de } \\
\text { trabajos prácticos en botánica. } \\
\text { En } 1947 \text { era encargada de } \\
\text { Sección }\end{array}$ & Se dedicó a los estudios botánicos. \\
\hline 1921 & $\begin{array}{l}\text { Pablo } \\
\text { Gaggero } \\
\text { argentino, } \\
1901\end{array}$ & $\begin{array}{l}\text { Bachiller del Colegio } \\
\text { Nacional de La Plata }\end{array}$ & $\begin{array}{l}\text { 21-25 (14 materias) } \\
\text { Especialidad zoología } \\
\text { Dr. en cs. nat. }\end{array}$ & $\begin{array}{l}\text {-Ayudante desde } 1920 \\
\text { JTP en zoología desde } 1924, \\
\text { - Ayudante del Dto. de } \\
\text { biología desde } 1926 \\
\text { - Participó en varias } \\
\text { expediciones arqueológicas, } \\
\text { geológicas y de zoología } \\
\text { organizadas por el Museo } \\
\text { - Encargado adhonorem de la } \\
\text { sección Herpetología desde } \\
\text { 1935 y JTP en zoología }\end{array}$ & $\begin{array}{l}\text { Coleccionista adhonorem de la Comisión nacional } \\
\text { Honoraria para el estudio y captación de las } \\
\text { mareas patagónica de la Academia de Cs. Exactas, } \\
\text { Físicas y Naturales. } \\
\text { Publicaciones científicas en Anales de la Sociedad } \\
\text { Científica Argentina, Memorias del Jardín } \\
\text { Zoológico, varias publicaciones docentes y de } \\
\text { divulgación, en defensa de los estudios } \\
\text { zoológicos, en el diario El Argentino, Archivos } \\
\text { Nacionales de Biología y Medicina. }\end{array}$ \\
\hline 1921 & $\begin{array}{l}\text { Dolores } \\
\text { López } \\
\text { Aranguren } \\
\text { (Caruhe, } \\
\text { 1904) }\end{array}$ & & $\begin{array}{l}\text { 21-26 (13 materias) } \\
\text { Especialidad: zoología } \\
\\
\text { Prof. en Pedagogía y Cs. Afines, en } \\
\text { Ciencias Naturales, y en Filosofía y } \\
\text { Cs. de la Ed., Fac. de Cs. de la } \\
\text { Educación, UNLP. } \\
\text { Dr. en cs. nat. }\end{array}$ & Ayudante de Botánica & $\begin{array}{l}\text {-Bibliotecaria del Colegio Secundario de } \\
\text { Señoritas, UNLP (más de diez años) } \\
\text { - Docente de la Esc. Normal Mary O' Graham y } \\
\text { en el Colegio de Señoritas, UNLP. } \\
\text { - Bibliotecaria y vicedirectora de la Biblioteca } \\
\text { Pública de la UNLP (1933-1947) } \\
\text {-Prof. de Pedagogía y Cs. afines de la Fac. de } \\
\text { Humanidades y Cs. de la Ed., UNLP } \\
\text { Varias obras literarias y de poesía. }\end{array}$ \\
\hline 1921 & $\begin{array}{l}\text { Leonor } \\
\text { López } \\
\text { Aranguren } \\
\text { (Cap. Fed, } \\
\text { 1903) } \\
\end{array}$ & & $\begin{array}{l}\text { 21-27 (16 materias) } \\
\text { Especialidad: Zoología } \\
\text { Pof. de enseñaza sec., en cs. nat, } \\
\text { Fac. de Humanidades. }\end{array}$ & & \\
\hline 1921 & $\begin{array}{l}\text { Adolfo C. } \\
\text { Gil Rosas } \\
\text { (Tres } \\
\text { Arroyos, } \\
\text { 1901) }\end{array}$ & & $\begin{array}{l}\text { 21-25 (13 materias) } \\
\text { Especialidad: Zoología } \\
\text { Dr. en cs, nat., con una tesis en } \\
\text { paleontología }\end{array}$ & & \\
\hline
\end{tabular}




\begin{tabular}{|c|c|c|c|c|c|}
\hline 1921 & $\begin{array}{l}\text { Francisco } \\
\text { Alberto } \\
\text { Sáez } \\
\text { (Montevide } \\
\text { o, 1898 - } \\
\text { 1976). }\end{array}$ & $\begin{array}{l}\text { No tenía certificado de } \\
\text { estudios secundarios } \\
\text { Estudiante del } \\
\text { Profesorado en } \\
\text { Facultad de } \\
\text { Humanidades y } \\
\text { Ciencias de la } \\
\text { Educación }\end{array}$ & $\begin{array}{l}\text { 21-24 ( } 3 \text { materias) } \\
\text { Estudiante condicional y oyente de } \\
\text { varias materias } \\
\text { Especialidad en zoología } \\
\text { Profesor de Ciencias Biológicas, } \\
\text { Facultad de Humanidades y } \\
\text { Ciencias de la Educación } 1927 .\end{array}$ & $\begin{array}{l}\text { Ayudante (1924-33) } \\
\text { Adscrito al Dto. de Biología } \\
\text { (1930) y luego asistente del } \\
\text { Depto de zoología } \\
\text { (vertebrados), donde se } \\
\text { dedicó a investigaciones } \\
\text { citológicas. }\end{array}$ & $\begin{array}{l}\text {-Asistente del Laboratorio de Ciencias Biológicas, } \\
\text { a cargo de la Sección Citología y Genética (1927) } \\
\text { y profesor de Historia Natural en la Universidad } \\
\text { de Montevideo. } \\
\text {-Profesor del Curso magisterial de vacaciones del } \\
\text { Consejo Nacional de Enseñanza del Uruguay } \\
\text { (1929) } \\
\text {-Ayudante del Instituto de Anatomía General y } \\
\text { Embriología en la Fac. de Medicina, UBA (1934- } \\
\text { 43) } \\
\text {-Jefe de Laboratorio de Citología de la Fac. de } \\
\text { Agronomía y Veterinaria, UNLP (1938-1947) } \\
\text {-Becado por la Comisión Nacional de Cultura } \\
\text { para desarrollar investigaciones en citología } \\
\text { (1936) y la American Philosophical Society y } \\
\text { Universidad de Pensilvania, para estudios en el } \\
\text { norte argentino sobre citología de insectos. } \\
\text { - Profesor secundario en la Escuela Normal } \\
\text { Nacional No } 1 \text { de La Plata (1938-47) y en el } \\
\text { Colegio Nacional, UNLP (1941-47). } \\
\text { Tras la intervención de la Universidades } \\
\text { argentinas, regresó al Uruguay, donde se } \\
\text { incorporó al instituto de Investigación de Ciencias } \\
\text { Biológicas de Montevideo, donde organizó desde } \\
\text { 1950 hasta su muerte el Departamento de } \\
\text { Citogenética. } \\
\text { Recibió distintas distinciones, becas y fue } \\
\text { profesor visitante de varias universidades. } \\
\text { Fue miembro de numerosas asociaciones, formó } \\
\text { numerosos estudiantes y discípulos en Argentina y } \\
\text { Uruguay. Se destacó como especialista en } \\
\text { citogenética. }\end{array}$ \\
\hline & $\begin{array}{l}\text { Oreste } \\
\text { Giacobbe }\end{array}$ & & $\begin{array}{l}\text { 1922-27 (14 materias) } \\
\text { Dr. en } 1931 . \\
\text { Tesis sobre la estructura } \\
\text { tegumentaria de los armadillos. }\end{array}$ & $\begin{array}{l}\text { Jefe de Trabajos Prácticos en } \\
\text { Zoología desde } 1933\end{array}$ & $\begin{array}{l}\text { Encargado de la Sección de Parasitología de la } \\
\text { Dir. Gral. de Higiene de la Provincia de Bs. As. } \\
\text { desde } 1933 .\end{array}$ \\
\hline
\end{tabular}




\begin{tabular}{|c|c|c|c|c|c|}
\hline & $\begin{array}{l}\text { Zelmira } \\
\text { d'Ovidio }\end{array}$ & & $\begin{array}{l}\text { 1923-26 (13 materias) } \\
\text { Especialidad: Zoología }\end{array}$ & & \\
\hline & $\begin{array}{l}\text { Susana } \\
\text { María } \\
\text { d'Ovidio }\end{array}$ & & $\begin{array}{l}\text { 1923-24 (7 materias) } \\
\text { Especialidad: Geología y } \\
\text { Mineralogía }\end{array}$ & & \\
\hline & $\begin{array}{l}\text { Ana } \\
\text { Cortelezzi }\end{array}$ & & $\begin{array}{l}\text { 1923-26 (13 materias) } \\
\text { Dr. en cs. nat.. } \\
\text { Tesis en paleontología, bajo la } \\
\text { dirección de Angel Cabrera }\end{array}$ & & \\
\hline & $\begin{array}{l}\text { Ernestina } \\
\text { Langmann } \\
\text { (n.La Plata, } \\
1901 \text { ) }\end{array}$ & $\begin{array}{l}\text { Maestra normal } \\
\text { egresada de la Escuela } \\
\text { Normal Nacional de } \\
\text { profesoras de La Plata, } \\
1921 . \\
\text { Bachiller del Colegio } \\
\text { Secundario de } \\
\text { Señoritas, UNLP, } 1923 .\end{array}$ & $\begin{array}{l}\text { 1924-26 (14) } \\
\text { Especialidad: Zoología } \\
\\
\text { Dr. en cs. nat, Universidad de } \\
\text { Córdoba (1928) } \\
\text { Tesis sobre estudios biométricos } \\
\text { sobre la variabilidad de la coraza en } \\
\text { desdentados con y sin poliembrionía } \\
\text { especifica, publicada en el Boletín } \\
\text { de la Academia de Ciencias de } \\
\text { Córdoba. } \\
\text { Trabajo dirigido por Miguel } \\
\text { Fernández }\end{array}$ & $\begin{array}{l}\text { Jefe de trabajos prácticos en } \\
\text { Zoología especial (1934 - } \\
\text { 1946), renunció ante la } \\
\text { intervención a la Universidad. } \\
\text { Se presentó en los concursos } \\
\text { de normalización de } 1956 .\end{array}$ & $\begin{array}{l}\text { En } 1933 \text { dictó un seminario sobre el estudio de la } \\
\text { herencia mendeliana en Drosophila melanogaster, } \\
\text { en los ciclos de cursos organizados por el Centro } \\
\text { de Estudios de las Ciencias Naturales de La Plata. }\end{array}$ \\
\hline 1924 & $\begin{array}{l}\text { Albina } \\
\text { Bonjour } \\
\text { (uruguaya, } \\
\text { 1905-1930) }\end{array}$ & $\begin{array}{l}\text { Bachillerato en la } \\
\text { Universidad de } \\
\text { Montevideo. }\end{array}$ & $\begin{array}{l}\text { 1921, 1925-26 (13 materias) } \\
\text { Especialidad: Zoología } \\
\text { Dr. en cs. nat, Universidad de } \\
\text { Córdoba (1928) } \\
\text { Su tesis, publicada póstumamente en } \\
\text { el Boletín de la Academia de } \\
\text { Ciencias de Córdoba, trató del } \\
\text { desarrollo embrionario de la forma } \\
\text { externa de algunos batracios } \\
\text { argentinos. } \\
\text { Trabajo dirigido por Miguel } \\
\text { Fernández }\end{array}$ & & $\begin{array}{l}\text { Su actuación profesional se concentró en } \\
\text { Montevideo. Fue "asistente honoraria" y realizó } \\
\text { trabajos de investigación en el Laboratorio de } \\
\text { Ciencias Biológicas del Consejo de Enseñanza. } \\
\text { Además dictó zoología y embriología en los } \\
\text { Cursos de Vacaciones de ese Instituto y clases de } \\
\text { historia natural en la Universidad de Mujeres. }\end{array}$ \\
\hline
\end{tabular}




\begin{tabular}{|c|c|c|c|c|c|}
\hline 1924 & $\begin{array}{l}\text { Julio } \\
\text { Schechtman } \\
n\end{array}$ & $\begin{array}{l}\text { Había realizado } \\
\text { estudios universitarios, } \\
\text { por lo que se } \\
\text { reconocieron varias } \\
\text { materias. }\end{array}$ & $\begin{array}{l}1925 \text { ( } 2 \text { materias). } \\
\text { Se inscribió en zoología y luego se } \\
\text { pasó a mineralogía y geología }\end{array}$ & & \\
\hline 1925 & $\begin{array}{l}\text { María } \\
\text { Manuela Job } \\
\text { (Buenos } \\
\text { Aires, 1897- } \\
1971 \text { ) }\end{array}$ & Farmacéutica & $\begin{array}{l}\text { 1925-28 (7 materias) } \\
\text { Especialidad: botánica } \\
\text { Dr. en cs. nat (1929). } \\
\text { Tesis: "Estudio morfológico, } \\
\text { histólogo y fitogeográfico de las } \\
\text { Umbelíferas Argentinas" }\end{array}$ & \begin{tabular}{|l} 
Se mantuvo vinculada al \\
Museo realizando trabajos de \\
botánica y a partir de 1935 \\
realizó varias excursiones \\
botánicas por el país. En esa \\
época se desempeñaba como \\
Jefe de Trabajos Prácticos en \\
la cátedra de Botánica
\end{tabular} & $\begin{array}{l}\text { Prof. de cs. biológicas en: la Escuela Normal, el } \\
\text { Colegio Nacional de Quilmes y el Instituto } \\
\text { Bernasconi de Buenos Aires. } \\
\text { Inspectora de economía en las escuelas del } \\
\text { Consejo Nacional de Educación. También dictó } \\
\text { cursos sobre nutrición y dietética y organizó } \\
\text { exposiciones sobre aplicación de los vegetales en } \\
\text { la alimentación y la medicina. } \\
\text { En el Instituto Fitotécnico de Santa Catalina se } \\
\text { especializó en fitotecnia y genética vegetal. } \\
\text { Publicó varios trabajos científicos, de divulgación } \\
\text { y manuales didácticos. Sus principales trabajos } \\
\text { científicos giraron en torno a la genética de la } \\
\text { inmunidad del trigo creando variedades resistentes } \\
\text { a las plagas y de mayor rendimiento. Obtuvo } \\
\text { reconocimiento internacional, especialmente en } \\
\text { Holanda y Brasil. }\end{array}$ \\
\hline 1925 & $\begin{array}{l}\text { José } \\
\text { Liebermann } \\
\text { (Villaguay- } \\
\text { Pcia. de } \\
\text { Entre Ríos, } \\
\text { 1897) }\end{array}$ & $\begin{array}{l}\text { Maestro Rural (1916), } \\
\text { egresado de una } \\
\text { Escuela Norma Rural } \\
\text { de la Pcia. de Entre } \\
\text { Ríos. } \\
\text { Prof. en ciencias } \\
\text { biológicas, Instituto } \\
\text { Nacional del } \\
\text { Profesorado (1924) }\end{array}$ & $\begin{array}{l}\text { 1925-27 (curso } 7 \text { materias y se le } \\
\text { reconocieron 6) } \\
\text { Especialidad: Zoología } \\
\text { Dr. en c. nat. (1929). } \\
\text { Tesis sobre revisión sistemática y } \\
\text { determinación de una nueva especie } \\
\text { entomológica (un año antes había } \\
\text { presentado otra tesis que fue } \\
\text { rechazada) }\end{array}$ & & $\begin{array}{l}\text {-Prof. de Cs. Nat. y Geografía en varios Colegios } \\
\text { Nacionales } \\
\text {-Adscripto Honorario al Museo de Buenos Aires } \\
\text { (1926), a la Cátedra de Zoología de la Fac. de } \\
\text { Agr. y Vet., UBA, 1933 } \\
\text {-Zoólogo de la División de Fomento Agrícola y } \\
\text { Colonización de los FFCC del Estado 1928-1930 } \\
\text {-Jefe del Dto. de Herpetología del Jardín } \\
\text { Zoológico de Bs. As. hasta } 1937 \\
\text {-Encargado de Acridiología del Instituto de } \\
\text { Sanidad Vegetal del Ministerio .de Agr. y Vet., } \\
\text { desde 1937. } \\
\text { Publicó trabajos en Anales de la Sociedad } \\
\text { Cientifica, y de divulgación en: Riel y Fomento, } \\
\text { Rev. Centro Profesores Diplomados Enseñanz }\end{array}$ \\
\hline
\end{tabular}




\begin{tabular}{|c|c|c|c|c|c|}
\hline & & & & & $\begin{array}{l}\text { Secundaria, La Chacra, Billiken, La Razón, } \\
\text { Atlántida, Pampa Argentina, El Hogar, entre } \\
\text { otros. }\end{array}$ \\
\hline \multirow[t]{4}{*}{1925} & $\begin{array}{l}\text { Pedro } \\
\text { Eduardo } \\
\text { Coria } \\
\end{array}$ & $\begin{array}{l}\text { Instituto Nacional del } \\
\text { Profesorado }\end{array}$ & $\begin{array}{l}1925 \text { (2 materias) } \\
\text { Geología y mineralogía }\end{array}$ & & \\
\hline & $\begin{array}{l}\text { Anavadro } \\
\text { Gnecco }\end{array}$ & & 1926-30 (19 materias) & & \\
\hline & $\begin{array}{l}\text { Ernesto } \\
\text { Cordeviola }\end{array}$ & & 1926 (1 aplazado) & & \\
\hline & Carlos Ruiz & & & & \\
\hline 1926 & $\begin{array}{l}\text { Angel L. } \\
\text { Cabrera } \\
\text { (n. Madrid, } \\
\text { 1908-1999) }\end{array}$ & & $\begin{array}{l}\text { 1926-30 (18 materias) } \\
\text { Especialidad: Botánica } \\
\text { Dr en cs. nat. (1931) } \\
\text { Tesis: "Contribución al estudio de } \\
\text { las Psammofitas" }\end{array}$ & $\begin{array}{l}\text { Jefe de Trabajos prácticos y } \\
\text { encargado de la Sección de } \\
\text { Botánica, en la década de } \\
1930 . \\
\text { Luego Prof. de botánica } \\
\text { general y Jefe de la División } \\
\text { de Botánica }\end{array}$ & $\begin{array}{l}\text { Prof. del Colegio Nacional de La Plata } \\
\text { Publicó numerosos trabajos científicos, recibió } \\
\text { premios y formó estudiantes. }\end{array}$ \\
\hline \multirow[t]{3}{*}{1926} & $\begin{array}{l}\text { Elisa } \\
\text { Hirschhorn }\end{array}$ & & $\begin{array}{l}\text { 1926-31, } 1935 \text { ( } 17 \text { materias) } \\
\text { Dr. en cs. nat., especialidad botánica } \\
\text { (1938) }\end{array}$ & $\begin{array}{l}\text { En la década de } 1940 \text { era } \\
\text { asistente adhonorem de la } \\
\text { Sección Micología }\end{array}$ & $\begin{array}{l}\text { Profesora del Colegio Secundario de Señoritas, } \\
\text { UNLP. } \\
\text { Realizó trabajos de investigación sobre hongos en } \\
\text { una estación experimental }\end{array}$ \\
\hline & $\begin{array}{l}\text { Lucia } \\
\text { Platnikoff }\end{array}$ & & $1928-29(5$ materias $)$ & & \\
\hline & $\begin{array}{l}\text { Luis María } \\
\text { Bergna }\end{array}$ & & $\begin{array}{l}\text { 1928-35 (9 materias) } \\
\text { Prof. de enseñanza secundaria en cs. } \\
\text { biológicas, Fac. de Humanidades, } \\
\text { UNLP }\end{array}$ & $\begin{array}{l}\text { Hacia } 1947 \text { era Jefe de } \\
\text { Trabajos Prácticos } \\
\text { adhonorem en Antropología }\end{array}$ & \\
\hline
\end{tabular}




\title{
Planes de estudio de Ciencias Naturales (1906-1930)
}

\author{
PLAN VIGENTE 1906-1909
}

Primer ciclo: Licenciatura

\section{Primer año}

Complementos de Física

Complementos de Química

Complementos de Matemáticas

Zoología (Morfología y fisiología)

Botánica (Morfología y fisiología)

Geografía astronómica y física

Dibujo

\author{
Segundo año \\ Botánica especial (primer curso) \\ Geología dinámica \\ Mineralogía \\ Antropología \\ Dibujo \\ Tercer año \\ Zoología especial (vertebrados) \\ Botánica especial (segundo curso) \\ Geología cronológica \\ Petrografía \\ Paleontología \\ Antropología (segundo curso) \\ Etnología
}

Zoología especial (primer curso, invertebrados)

Segundo ciclo: grado de Doctor

\author{
Cuarto año \\ Geología \\ Mineralogía y petrografía \\ Zoología \\ Botánica \\ Paleontología \\ Etnología y lingüística
}

"Los cursos que se dicten de estas materias, versarán únicamente sobre la República Argentina".

\section{Quinto año}

"En este año, los alumnos vigilados directamente por los respectivos profesores, verificarán estudios especiales sobre asuntos relacionados con cada una de las materias correspondientes al cuarto año, y al propio tiempo efectuarán excursiones". 


\section{$\underline{\text { PLAN VIGENTE 1910-1914 }}$}

Licenciado: tres años de estudios y un examen general sobre la materia principal y dos complementarias a elección del alumno.

Doctorado: cuatro años y examen de tesis. (Para esto se debía haber aprobado el examen de Licenciatura)

Se reconocían cuatro Escuelas en ciencias naturales que ofrecían diferentes especialidades. Al inscribirse, el alumno elegía una materia principal, que comprendía los cursos teóricos y prácticos que se dictaran de ella en el Instituto. Los alumnos debían aprobar los cursos que se dictaran de la materia principal y de las otras complementarias a elección.

Las materias complementarias correspondían a los cursos de carácter general que se dictaran en el Instituto del Museo o en otros Institutos o Facultades de la Universidad, reservándose el Consejo Académico el derecho de determinar para cada especialidad el carácter y extensión de estas asignaturas complementarias. Los alumnos estaban autorizados para cursar las asignaturas complementarias, distribuyéndolas en los distintos años de la carrera, pero siguiendo el orden lógico que señalaran las exigencias de la especialidad.

\begin{tabular}{|l|c|l|}
\hline Escuela & $\begin{array}{c}\text { Especialidad y materia } \\
\text { principal }\end{array}$ & \multicolumn{1}{|c|}{ Materias complementarias } \\
\hline $\begin{array}{l}\text { Geología } \\
\text { geológicas }\end{array}$ & $\begin{array}{l}\text { Mineralogía } \\
\text { (petrografía) } \\
\text { Geografía }\end{array}$ & $\begin{array}{l}\text { Paleontología, Mineralogía (Petrografía), Geografía física, } \\
\text { Topografía } \\
\text { Geología, Geografía física, Química }\end{array}$ \\
\hline Botánica & $\begin{array}{l}\text { Geografía, Topografía, Matemáticas, Astronomía } \\
\text { Geología, Mineralogía, Botánica, Anatomía comparada, } \\
\text { Zoología }\end{array}$ \\
\hline Zoología & $\begin{array}{c}\text { Zoología (anatomía } \\
\text { comparada) }\end{array}$ & Geología, Paleontología, Botánica, Antropología \\
\hline $\begin{array}{l}\text { Ciencias } \\
\text { Antropológicas }\end{array}$ & $\begin{array}{l}\text { Antropología } \\
\text { Etnología }\end{array}$ & $\begin{array}{l}\text { Arqueología, Geografía, Paleontología, Zoología (anatomía } \\
\text { comparada) }\end{array}$ \\
\hline
\end{tabular}




\section{PLAN VIGENTE 1915-1925}

Título: Doctor en Ciencias Naturales en las siguientes especialidades (materias principales): a) Geología y Mineralogía, b) Zoología, c) Botánica, d) Antropología.

A cada especialidad le correspondían cuatro materias accesorias: tres eran obligatorias y una podía ser elegida por el candidato de entre una lista preestablecida, siempre que no hubiera sido cursadas como materia accesoria obligatoria. Además de los exámenes parciales debía aprobar una prueba final escrita y oral y una tesis.

En el Consejo Académico se había aprobado que por cada materia principal, el alumno debía seguir todos los cursos que se dictaran o por lo menos cuatro y dos de trabajos de laboratorio.

\begin{tabular}{|c|c|c|}
\hline $\begin{array}{l}\text { Especialidad y } \\
\text { materia principal }\end{array}$ & Materia accesorias obligatorias & Materias accesorias elegibles \\
\hline Geología y Mineralogía & $\begin{array}{c}\text { Paleontología } \\
\text { Zoología } \\
\text { (inclusive Anatomía comparada), } \\
\text { Química Inorgánica } \\
\text { (incluida analítica) }\end{array}$ & $\begin{array}{c}\text { Geografía física } \\
\text { Topografía } \\
\text { Botánica } \\
\text { Física general } \\
\text { Matemáticas superiores } \\
\text { Metalogenia. }\end{array}$ \\
\hline Botánica & $\begin{array}{c}\text { Química } \\
\text { Zoología } \\
\text { (inclusive Anatomía comparada) } \\
\text { Geología o Microbiología }\end{array}$ & $\begin{array}{c}\text { Geología }(*) \\
\text { Microbiología }(*) \\
\text { Paleontología } \\
\text { Geografía física } \\
\text { Física general } \\
\text { Matemáticas superiores. }\end{array}$ \\
\hline Zoología & $\begin{array}{c}\text { Paleontología } \\
\text { Botánica } \\
\text { Geología o Fisiología }\end{array}$ & $\begin{array}{c}\text { Geología }(*) \\
\text { Fisiología }(*) \\
\text { Microbiología } \\
\text { Antropología } \\
\text { Anatomía de animales domésticos } \\
\text { Física general } \\
\text { Matemáticas superiores. }\end{array}$ \\
\hline $\begin{array}{l}\text { Antropología y Etnología } \\
\text { (inclusive Lingüística y } \\
\text { Arqueología Americana) }\end{array}$ & $\begin{array}{l}\text { Zoología comparada } \\
\text { Geología comparada } \\
\text { Botánica }\end{array}$ & $\begin{array}{c}\text { Paleontología } \\
\text { Fisiología } \\
\text { Geografía Física } \\
\text { Física general } \\
\text { Matemáticas superiores }\end{array}$ \\
\hline
\end{tabular}




\section{$\underline{\text { Plan propuesto alternativamente en } 1925}$}

Titulo único de Doctor en Ciencias Naturales, con presentación de tesis y examen final en la especialidad.

El alumno debía comprobar que se hallaba capacitado para comprender un trabajo de su especialidad en alemán y en ingles, y para Botánica también se exigiría latín.

Este plan fue propuesto por el profesor Miguel Fernández, pero no fue aceptado en el Consejo Académico.

\begin{tabular}{|c|c|c|c|c|}
\hline Materias & $\begin{array}{c}\text { Mineralogía y } \\
\text { Geología } \\
\text { Teóricas - Prácticas }\end{array}$ & $\begin{array}{c}\text { Botánica } \\
\text { Teóricas - Prácticas }\end{array}$ & $\begin{array}{c}\text { Zoología } \\
\text { Teóricas - Prácticas }\end{array}$ & $\begin{array}{l}\text { Antropología, } \\
\text { Etnología y } \\
\text { Arqueología } \\
\text { Teóricas - Prácticas }\end{array}$ \\
\hline Química inorgánica & 6 & & & \\
\hline Química Biológica & & 3 & 3 & 3 \\
\hline Física & 3 & & & \\
\hline Física Biológica & & 3 & 3 & 3 \\
\hline Botánica & 3 & 2 & 2 & 2 \\
\hline Zoología o anatomía comparada & 3 & 2 & 2 & 2 \\
\hline Geología & 2 & 2 & 2 & 2 \\
\hline \multicolumn{5}{|c|}{$2^{\circ}$ año en adelante } \\
\hline Mineralogía & 2 & 2 & & \\
\hline Petrografía & 2 & & & \\
\hline Geografía física & 2 & 2 & & 2 \\
\hline Geología histórica & 2 & & & \\
\hline Topografía y cartografía & 2 & 2 & & 2 \\
\hline Paleontología (vertebrados) & 2 & & 2 & 2 \\
\hline Paleontología (invertebrados) & 2 & & 2 & \\
\hline Botánica 2 & & 2 & 2 & \\
\hline Botánica 3 & & 2 & & \\
\hline Fitogeografía & & 1 & & \\
\hline Microbiología & & 2 & 2 & \\
\hline Anatomía comparada & 2 & 2 & 2 & 2 \\
\hline Embriología & & & 2 & \\
\hline Invertebrados & 2 & & 2 & \\
\hline Sistema nervioso & & & 2 & \\
\hline Herencia & & 2 & 2 & 2 \\
\hline Etnología & & & & 2 \\
\hline Prehistoria americana & & & & 2 \\
\hline Antropología 1 & & & 2 & 2 \\
\hline Antropología 2 & & & & 2 \\
\hline Geografía humana & & & & 2 \\
\hline Química analítica & 6 & 6 & & \\
\hline Zoogeografía & & & 1 & \\
\hline $\begin{array}{l}\text { Trabajos Prácticos I (en la } \\
\text { especialidad) }\end{array}$ & Diario & Diario & Diario & Diario \\
\hline Trabajos prácticos II & Diario & Diario & Diario & Diario \\
\hline
\end{tabular}




\section{$\underline{\text { PLAN VIGENTE DESDE } 1926}$}

Título: Doctor en ciencias naturales.

Se reconocían cuatro especialidades: zoología, botánica, geología y mineralogía, y antropología (se elegían después del tercer año).

Las demás materias se reconocían como complementarias, agregándose en el última año un curso más de la especialidad.

Era obligatorio dos excursiones científicas por los menos, realizadas en los alrededores de la ciudad, durante los cursos. Además se especificaba un plazo de hasta dos años después de terminados los estudios para la presentación de la tesis.

Se debían cursar y aprobar por correlación en otras Facultades de la Universidad las siguientes materias:

- Matemáticas

- Física general

- Química analítica cualitativa y cuantitativa

- Dibujo

- Dos idiomas: latín y alemán o ingles.

\begin{tabular}{|c|c|c|c|c|c|c|c|c|}
\hline Materias & \multicolumn{2}{|c|}{$\begin{array}{c}\text { Primer Año } \\
\text { Teóricas - Prácticas }\end{array}$} & \multicolumn{2}{|c|}{$\begin{array}{c}\text { Segundo Año } \\
\text { Teóricas - Prácticas } \\
\end{array}$} & \multicolumn{2}{|c|}{$\begin{array}{c}\text { Tercer Año } \\
\text { Teóricas - Prácticas } \\
\end{array}$} & \multicolumn{2}{|c|}{$\begin{array}{c}\text { Cuarto Año } \\
\text { Teóricas - Prácticas }\end{array}$} \\
\hline Zoología & $2 \mathrm{hs}$ & 4 & 2 & 4 & 2 & 4 & & \\
\hline Botánica & 2 & 4 & 2 & 4 & 2 & 4 & & \\
\hline Mineralogía & \multicolumn{2}{|c|}{--} & \multicolumn{2}{|c|}{--} & 2 & 4 & & \\
\hline Geología & 2 & 4 & 2 & 4 & \multicolumn{2}{|c|}{--} & \multicolumn{2}{|c|}{--} \\
\hline Paleontología & & & \multicolumn{2}{|c|}{--} & \multicolumn{2}{|c|}{--} & 2 & 4 \\
\hline Antropología & & & 2 & 4 & 2 & 4 & & \\
\hline Etnología & & & & & & & 2 & $4(*)$ \\
\hline $\begin{array}{l}\text { Arqueología } \\
\text { (sudamericana) }\end{array}$ & & & & & & & 2 & $4(*)$ \\
\hline $\begin{array}{l}\text { Topografía y } \\
\text { cartografía }\end{array}$ & & & & & & & 2 & 4 \\
\hline
\end{tabular}

* Estos cursos eran sólo para la especialidad de Antropología. Los demás alumnos en vez de estos tendrían un cuarto curso de la especialidad elegida. 
Modificaciones del plan de estudios introducidas por el Consejo Académico del Museo en diciembre de 1928 y aprobadas por el Consejo Superior en su sección del 18 de abril de 1929 y luego por el Gobierno Provisional de la Nación, con fecha del 21 de Octubre de 1930.

\begin{tabular}{|c|c|c|}
\hline Año & Materia & Profesor o Institución en 1931 \\
\hline $1^{\circ}$ & $\begin{array}{l}\text { Geología } \\
\text { Botánica } \\
\text { Zoología } \\
\text { Matemáticas } \\
\text { Dibujo }\end{array}$ & $\begin{array}{l}\text { W. Schiller } \\
\text { A. Scala } \\
\text { Max Birabén } \\
\text { Fac. de Cs Físico-Matemáticas } \\
\text { Escuela de Bellas Artes }\end{array}$ \\
\hline $2^{\circ}$ & $\begin{array}{l}\text { Geología } \\
\text { Botánica } \\
\text { Zoología } \\
\text { Nomenclatura científica } \\
\text { Física }\end{array}$ & $\begin{array}{l}\text { W. Schiller } \\
\text { A. Scala } \\
\text { Max Birabén } \\
\text { M. de Barrio } \\
\text { Instituto de Física }\end{array}$ \\
\hline $3^{\circ}$ & $\begin{array}{c}\text { Mineralogía } \\
\text { Botánica } \\
\text { Zoología } \\
\text { Antropología } \\
\text { Química analítica (excepto para la especialidad } \\
\text { antropología) }\end{array}$ & $\begin{array}{l}\text { W. Schiller } \\
\text { A. Scala } \\
\text { Max Birabén } \\
\text { M. A. Vignati } \\
\text { Facultad de Agronomía }\end{array}$ \\
\hline $4^{\circ}$ & $\begin{array}{c}\text { Paleontología } \\
\text { Cartografía } \\
\text { Geología } \\
\text { Geografía Física } \\
\text { Botánica } \\
\text { Zoología } \\
\text { Antropología } \\
\text { Etnología y Arqueología Americana }\end{array}$ & $\begin{array}{l}\text { Angel Cabrera } \\
\text { N. Besio Moreno } \\
\text { W. Schiller } \\
\text { W. Schiller } \\
\text { A. Scala } \\
\text { Max Birabén } \\
\text { M. A. Vignati } \\
\text { L. M. Torres }\end{array}$ \\
\hline
\end{tabular}




\title{
DISTRIBUCION NACIONAL DE LAS PUBLICACIONES DEL MUSEO
}

\section{Lista de reparto del tomo XVII de la Revista del Museo y del Catálogo de Antropología (1910):}

\author{
Miembros del Gobierno nacional: \\ Presidente de la República (Roque Sáenz Peña) \\ Ministro de Hacienda (J.M. Rosa) \\ Ministro de Justicia e Instrucción Pública \\ (Juan Garro) \\ Ministro de Marina (Pablo Sáenz Valiente)
}

\section{Instituciones}

Biblioteca Nacional

Museo Nacional

Sociedad Científica Argentina

Director de La Prensa

\author{
Ministro de Agricultura (Eleodoro Lobos) \\ Ministro del Interior (I. Gómez) \\ Ministro de Guerra (J.M. Vélez), \\ Ministro de Relaciones Exteriores (D. E. Bosch)
}

Posteriormente se envío al Director del Jardín Zoológico de Buenos Aires y se propuso canje de publicaciones. También se remitieron para su distribución a la Comisión de Bibliotecas Populares

\section{Particulares:}

Estanislao Zeballos

Ernesto Quesada

Francisco P. Moreno

Director de La Nación,

Junta de Historia y Numismática

Biblioteca de la Facultad de Filosofía y Letras,

Academia Nacional de Ciencias de Córdoba.

Justiniano Posse

Otto Krause

Gral. Julio Roca

Manuel Lainez,

Lucas Ayagarray

Ramón Cárcano

M. Leguizamón

J. C. Amadeo

Juan Pelleschi

Enrique Peña

\author{
A. Rosa,
A. Piñero \\ P.A Arata \\ C.L Frigeiro \\ Coronel J. Garmendia \\ Coronel Benjamín García Aparicio (dir. del \\ Instituto Geográfico Militar) \\ Benito Villanueva (Figura importante de la \\ política provincial) \\ Eliseo Cantón (Diputado y prof. de la Facultad \\ de Medicina, UBA) \\ Eufemio Uballe (Rector de UBA) \\ Juan Delfino
}

\author{
Académicos correspondientes nacionales y honorarios del Museo \\ Miguel Lillo (naturalista de Tucumán) \\ Angel Gallardo (profesor de zoología) \\ Juan J. Kyle (director de la sección de geología de la División de Geología, Mineralogía e Hidrología del \\ Ministerio de Agricultura) \\ Francisco Sergui \\ Francisco Latzina \\ Juan B. Ambrosetti (Director del Museo Etnográfico de Buenos Aires)
}

\author{
Librerías consignatarias de Buenos Aires y La Plata: \\ Martín García y Cia. \\ Juan Roldán, \\ Prudent Hnos. y Moetzel, \\ Espiasse e Hijo, \\ Cabaut y Cia. \\ Agusto Galli
}

Fuente: AHMLP, Copiador 1901-1919. 
Canje y envío de la Revista del Museo: Tomo XIX al XXIII (1913-1919):

\section{Buenos Aires:}

Boletín del Centro Naval

Boletín de Instrucción Pública (Publicación oficial del Ministerio de Instrucción Pública)

Centro de Estudiantes de Ingeniería, Bs. As.

Circulo Médico Argentino y Centro estudiantes de Medicina

Departamento Nacional de Higiene

El Monitor de la Educación Común (Consejo

Nacional de Educación)

Instituto Geográfico Argentino

Ministerio de Agricultura

Museo Social Argentino

Museo Nacional de Historia Natural

Revista de la Universidad de Buenos Aires

Sociedad Rural Argentina

Sociedad Médica Argentina

Sociedad Científica Argentina

\section{Córdoba:}

Academia Nacional de Ciencias

Facultad de Derecho y Ciencias sociales

Universidad Nacional

\section{Catamarca:}

Biblioteca Sarmiento, Catamarca

Biblioteca Sarmiento, Andalgalá
Sociedad Química Argentina

Sociedad Physis

Universidad Popular

Facultad de Filosofía y Letras

Junta de Historia y Numismática americana

Biblioteca Nacional

Universidad Católica

El Salvador, parroquia

Museo Histórico

Museo Mitre

La Prensa

La Nación

El Diario

Facultad de Ciencias Exactas Físicas y

Naturales

Ministerio de Justicia e Instrucción Pública

Ministerio de Relaciones Exteriores

San Juan:

Biblioteca Palacio Episcopal

La Plata:

Observatorio Astronómico

Tucumán:

Biblioteca de la Universidad de Tucumán

Legisladores y profesores a los que se enviaba la Revista del Museo en 1920:

\section{Senadores nacionales:}

Vicente Gallo

Joaquín V. Gonzalez

Leopoldo Melo

Benito Villamayor

\section{Diputados nacionales:}

Leonidas Anastesi

Eduardo Arana,

Alberto de Bary,

Mario Bravo

Mariano Demaría (hijo)

H. González Iramain

Alejandro Miñones

R. Pereyra Rozas

Nicolás Repetto

Fernando de Andreis

\section{Profesores de la Universidad:}

Carlos Melo

Eduardo Huergo

Domingo Selva

Agusto Scala

Agustín Candiotti

Enrique Poussant

Alfredo Ferreira

Enrique Torino
Luis García

Pedro Larlus

Julio Roca

Fernando Sanguier

Marco A. Avellaneda

Valentín Berrondo

Pedro Caracoche

Ernesto Celesia

Juan Luis Ferrarotti

Ernesto Padilla

Federico Pinedo (h),

Matías Sanchez Sorondo

Juan B. Justo

Salvador Debenedetti

Benito Nazar Anchorena

Octavio González Rouda

Atilio Bado

Ferrucio A. Soldano

Ricardo Levene 


\section{Nota sobre las Fuentes consultadas}

Documentos inéditos y Archivos consultados:

El corpus documental más importante utilizado en esta investigación pertenece al Archivo Histórico de la Facultad de Ciencias Naturales y Museo de La Plata (AHMLP) cuyos materiales se comenzaron a reunir y ordenar desde 1998. Principalmente este material es de carácter burocrático y administrativo, vinculado con notas, copiadores y distintos registros de la dirección y secretaria de esta institución. Especialmente, en esta investigación se utilizaron los siguientes tipos de documentos: a) los copiadores de las notas enviadas desde la dirección y la secretaria de la institución; b) Actas del Consejo Académico (Libro I: 1906-1914; Libro II: 1914-1919; Libro III: 1919-1932) y de reuniones extraordinarias de profesores; c) registros de alumnos (Libro de Registro de Alumnos 1906-1936), exámenes, programas de materias, expedientes de concursos y listados de personal, d) informes de algunas secciones, notas internas enviadas por el personal a la dirección, e) cartas enviadas por la Presidencia de la Universidad y de correlación con las otras Facultades, y f) documentos clasificados en la época como: "correspondencia externa": cartas enviadas por instituciones escolares y científicas, dependencias oficiales, bibliotecas, particulares, empresas proveedoras, libreros-editores del país y del extranjero. Esto último permitió observar la amplia red de instituciones e individuos que se vinculaba el Museo de La Plata y una primera aproximación a cómo el público miraba y se relacionaba con esta institución. Asimismo, estos materiales ofrecen pistas y fragmentos de las prácticas culturales vigentes en la época, así como indicios para examinar como se organizaba el trabajo cotidiano de investigar, enseñar y difundir en este particular contexto científico-académico.

En el Archivo General de la Nación (AGN) se consultó el Fondo documental perteneciente a Dardo Rocha (FDR). Los legajos n 2958-2960 reúnen diversas notas, borradores, cartas particulares enviadas a Rocha como rector de la Universidad, expedientes e informes elevados al Ministerio de Instrucción Pública de la Nación relacionados con la creación y funcionamiento de la Universidad Provincial de La Plata. En la Sección Intermedia de este Archivo, se encuentran documentos de 
distintos Ministerios y otras dependencias oficiales que se hallan en proceso de ordenamiento y sistematización, aunque admiten consultas. Allí se consultaron los expedientes vinculados al Ministerio de Instrucción Pública, que principalmente corresponde a los registros de contabilidad general, aunque ello permite observar la contratación de profesores, distribución de presupuesto y subsidios especiales, becas, el personal de las distintas instituciones educativas y científicas que dependían de este Ministerio, entre otras cuestiones. En particular, se han examinado los registros vinculados con la instalación de la Universidad Nacional de La Plata y los primeros años de funcionamiento, ya que para los años posteriores el material todavía no estaba ordenado.

En el Archivo del Museo Etnográfico de la Facultad de Filosofía y Letras, Universidad de Buenos Aires, se consultó material vinculado a las visitas públicas al Museo y su relación con las instituciones escolares, como un referente para contextualizar las prácticas que observamos en el Museo de La Plata. Además se relevaron los libros con recortes de diarios de la época, entre lo que se han guardado noticias vinculadas a los museos nacionales, las exploraciones, los debates científicos, entre otros temas, que nos permitieron observar la visibilidad pública que tenía la práctica de la ciencia en esos años, por lo menos en disciplinas como antropología, arqueología y paleontología.

\section{Periódicos y revistas de la época:}

Publicaciones oficiales de la Universidad y distintas unidades académicas:

- Documentos orgánicos. 1906.

- Asamblea General de Profesores (1907-1913)

- Digesto de la Universidad Nacional de La Plata (1910, 1913,1915)

- Memoria de la Universidad Nacional de La Plata (1909, 1910, 1913, 1917). Con respecto a estas fuentes, es punto importante remarcar las diferencias que se presentaron en los registros del número de alumnos. En parte ello se debía a que en algunos informes se incluían los alumnos oyentes, los inscriptos en el inicio de los cursos y los condicionales, mientras que en otros casos sólo se registraron los alumnos matriculados (los que habían abonado los aranceles) o los que asistieron regularmente a los cursos. En general, las cifras que elevaron las autoridades 
universitarias al Gobierno, así como las que se publicitaron fueron más elevadas que las consignadas en los informes de cada Facultad.

- Actos universitarios (1907-1917)

- Boletín de la Universidad Nacional de La Plata (1918-1935), esta publicación constituye una fuente importante para el análisis institucional de la Universidad, ya que en ella se incluyeron las actas del Consejo Superior y de los Consejos Académicos de las distintas Facultades o Escuelas, las memorias, informes y proyectos, ordenanzas y discursos académicos, entre otros. No obstante, las actas de las reuniones de las asambleas de profesores y Consejos Académicos, como se observa en el caso del Museo de La Plata, no fueron transcripciones textuales del registro que llevó cada institución y en general gran parte de los debates no se publicaron. En ese sentido, consideramos importante para los análisis de este tipo de fuentes, tener en cuenta que "cosas dichas" se hicieron públicas y cuáles no.

- UNLP, Presupuestos para el año....(Años: 1907-1930)

- "Archivos de Pedagogía y ciencias afines", revista publicada por la Sección Pedagógica desde 1906. Al trasformarse esta última en la Facultad de Ciencias de la Educación, la revista cambia de nombre: Archivos de pedagogía y Ciencias de la educación. Luego desde la Facultad de Humanidades y Ciencias de la Educación se edita desde 1921: Humanidades.

- Revista de La Facultad de Agronomía y Veterinaria de La Plata (1895-1921)

- Memoria correspondiente al año... de la Facultad de Ciencias Físicas, Matemáticas y Astronómicas. (años: 1913-1919). La Plata.

- La Facultad de Ciencias Jurídicas y sociales y su Sección Pedagógica en 1907 y 1908. 1909. Buenos Aires: J. Peuser.

- Memoria 1916. Facultad de Ciencias Jurídicas y Sociales. 1917.

Publicaciones del Museo de La Plata:

- Memoria del Museo de La Plata correspondiente al año de 1906. 1907.

- Torres, L. Memoria del Museo de La Plata correspondiente al año.... (1920, 1921, 1922-1923, 1924, 1926,1927,1928-29).

- Revista del Museo de la Plata (1890-1935)

- Anales del Museo de La Plata

- "Biblioteca de Difusión científica del Museo de La Plata" (tomos I-IV) 
Para contextualizar los debates universitarios de la época y la emergencia del proyecto de la Universidad Nacional de La Plata así como para otras cuestiones tratadas en esta tesis se consultaron fuentes relacionadas con distintos sectores. Especialmente se relevaron las siguientes publicaciones:

- $\quad$ Anales de la Sociedad Científica Argentina (1897-1922).

- Physis, publicada desde 1912 por la Sociedad Physis, luego llamada Sociedad Argentina de Ciencias Naturales.

- $\quad$ Revista de Derecho, Historia y Letras (1898-1920)

- Revista de la Universidad de Buenos Aires (1904-1924).

- Revista del Centro Universitario (1900-1903): revista de los estudiantes de la Universidad Provincial de La Plata, en 1903 cambia de nombre: Ciencias y Letras (1903).

- $\quad$ el Boletín de la Biblioteca Pública de la Provincia de Buenos Aires (1899-1905, 1906)

- $\quad$ El Siglo Ilustrado (1903-1904), revista platense de orientación católica.

- Diarios de Sesiones de las Cámaras de Senadores y Diputados de la Nación (1897-1918).

- Diarios de Sesiones de las Cámaras de Senadores y Diputados de la Provincia de Buenos Aires (1897-1906).

- Memoria presentada al Congreso Nacional por el Ministro de Justicia e Instrucción Pública. Años consultados: 1900-1924.

- Revue Internacionale de l'Enseignement, publicada por la Société de 1’Enseignement Supériur de Francia. (1897-1915).

- Periódicos de circulación nacional y producidos en Buenos Aires: La Nación, La Argentina (se consultaron los años 1906-1908) y El País (se consultaron los años 1900-1909, disponibles en el Archivo de la Provincia de Buenos Aires).

- Periódicos editados en La Plata: El Día (el más antiguo de la ciudad, fue creado a fines del siglo XIX y durante la década de 1910 apoyó a los sectores radicales y a los críticos de la Universidad. Es el único periódico platense que esta microfilmado, lo que facilita su consulta) y El Argentino (creado en 1906 y donde se publicaban extractos y resúmenes de las conferencias y cursos especiales organizados, y numerosas noticias de las actividades de divulgación científico-cultural organizadas por los estudiantes y desde la Universidad). 
Junto a estos materiales también se consultaron publicaciones editadas por los centros de estudiantes de La Plata, instituciones de cultura popular y entidades educativas nacionales, con el objeto de examinar, por un lado, qué tipo de actividades y otros aspectos del mundo académico se difundían; y por otro, cómo se organizaban las prácticas de divulgación científica. Para ello se consultaron:

- Revista del Centro Estudiantes de Ciencias Naturales, 1906, luego cambia de nombre: El Museo 1907-1908.

- Revista del Centro Estudiantes de Química y Farmacia (La Plata) (1912-1914).

- Revista del Centro de Estudiantes de Ingeniería (La Plata), publicada desde 1913.

- Ciencias Sociales (Revista del Centro Estudiantes de Ciencias Jurídicas y Sociales de La Plata) 1910-1912.

- Ciencias Económicas (1915), revista mensual del "Centro de Estudiantes Nacionales de Comercio" de La Plata, en ella se publicaron varias noticias sobre las organización de actividades de extensión universitaria por parte grupos de estudiantes, especialmente los ligados al Colegio Nacional.

- Revista del Centro de Estudiantes de la Facultad de Ciencias de la Educación (1915)

- Boletín del Centro de Estudiantes de Ciencias de la Educación (1920)

- Atenea (1918), publicación de la Asociación de ex-alumnos del Colegio Nacional de La Plata.

- sagitario

- El Monitor de la Educación Común, publicación oficial del Consejo Nacional de Educación

- El Libro (1906-1908), publicación bimestral de la Asociación Nacional del Profesorado.

- Boletín de la Instrucción Pública (publicación oficial del Ministerio de Instrucción Pública) 1909-1914.

- La Universidad Popular (revista mensual de la Universidad Popular de Buenos Aires) 1905-1910.

- Revista Socialista (1909), luego cambia de nombre por Humanidad Nueva (19101915), donde se difunden las actividades del Ateneo Popular y asociaciones similares. 
Otras fuentes consultadas:

- Los discursos y proyectos parlamentarios y textos literarios de Joaquín V. González, recopilados en los 25 tomos de sus Obras Completas.

- La colección de "Folletos de Instrucción Pública" pertenecientes a Joaquín V. González, que se encuentran en la sala histórica de la Biblioteca Pública de la Universidad Nacional de La Plata.

Diccionarios biográficos:

- Quién es quién en la Argentina. Biografias contemporáneas, editado por la casa Guillermo Kraft de Buenos Aires, desde 1937.

- Cutolo, O. V. 1968. Nuevo Diccionario Biográfico Argentino (1750-1930). Buenos Aires: Elche.

- Napolitano, A. (ed.). Quién es Quién en La Plata (Argentina). 1972. s/d. 


\section{Bibliografía}

Abreviaturas utilizadas:

UNLP: Universidad Nacional de La Plata

BULP: Boletín de la Universidad Nacional de La Plata

Bibliografía citada:

AAVV. 1963. Universidad "nueva" y ámbitos culturales platenses. Trabajos conferencia y comunicaciones. La Plata: Dpto. de Letras, Facultad de Humanidades y Ciencias de la Educación de la UNLP.

AAVV. 1989. El Krausismo y su influencia en América Latina. Madrid: Fundación Friedrich Ebert e Instituto Fe y Secularizad.

Alba, A. de 1995. Curriculum: Crisis, Mito y Perspectivas. Buenos Aires: Miño y Dávila.

Albisetti, J., McClelland, C., Turner, R. S. 1989. "Comentary. Science in Germany". En: Olesko, K.(ed.). Op. cit., pp .: 285-304.

Altamira, R. 1911. Mi viaje a América. Madrid: Victoriano Suárez.

Alonso, P. 1997. "En la primavera de la historia. El discurso político del roquismo a través de su prensa.". Boletín del Instituto Ravignani, 15: 35-69.

Ameghino, F. 1904. Paleontología Argentina. La Plata: Publicaciones de la Universidad de La Plata.

1932. Obras Completas y correspondencia cientifica. La Plata: Taller de Impresiones Oficiales.

Anónimo. 1896. "Basta de Abogados". Revista de la Facultad de Agronomía y Veterinaria de La Plata, II, 19: 223-224.

Anónimo. 1898. "El problema de la Organización Universitaria". Anales de la Sociedad Cientifica Argentina, XLVI: 268-278. 
Anónimo. 1899. "La reorganización universitaria. Opinión del Consejo Superior". Anales de la Sociedad Cientifica Argentina, XLVIII: 5-13.

Anónimo. 1902. "La Universidad. Nuevas fuentes de recursos". Revista del Centro Universitario, II, 6:130-131.

Anónimo. 1912. "La autonomía económica de las universidades". Archivos de Pedagogía y ciencias afines, X: 370-373.

Argumedo, M. 1999. "De entornos, planes de estudio y curriculum". Pensamiento Universitario, VI, 6: 27-47.

Armus, D. (comp.) 1990. Mundo urbano y cultura popular. Estudios de Historia Social Argentina. Buenos Aires: Sudamericana.

Azzarini, E. 1963. "Los estudiantes en la era provincial de la Universidad (18971904)". En: AAVV. Op. cit., pp.: 151-167.

Babini, J. 1949. Historia de la ciencia argentina. México-Buenos Aires: Fondo de Cultura Económica.

1963. La ciencia en la Argentina. Buenos Aires: Eudeba.

Barba, F. 1972. "Orígenes de la Universidad Provincial de La Plata". Trabajos y Comunicaciones, 21: 11-31.

-------- 1995. "Una Universidad en la nueva capital". Todo es Historia, $\mathrm{n}^{\circ}$ 330: 8-14.

--------- (dir.). 1998. La Universidad Nacional de La Plata en su centenario 1897-

1997. La Plata: UNLP-Banco Municipal de La Plata.

- (dir.) 1999. Historia de la Municipalidad de La Plata 1882-1998. La Plata:

Banco Municipal de La Plata.

- 2000. "Marcelino Ugarte, la Provincia y la Nación. Estilos de Gobierno". Anuario del Instituto de Historia Argentina, 1:25-44.

Barcia, P. L. (comp.) 1992. La Plata vista por los viajeros 1882-1912. La Plata:

Ediciones del 80-Librería Juvenilla.

Bargero, M. 1998. "Protestas estudiantiles en el proceso de profesionalización de la medicina en la Facultad de ciencias médicas de la U.B.A.". Documento de Trabajo $\mathrm{n}^{\mathbf{o}}$ 11, Instituto de Estudios Sociales de la Ciencia y la Tecnología, Universidad Nacional de Quilmes. 
2002. "Condiciones institucionales y culturales de la enseñanza de la medicina en Buenos Aires: reformas académicas y movimientos estudiantiles en 1874 y 1906". Entrepasados, XI, 22: 91-112.

Barrio; M. de. 1923. El Museo de La Plata y sus tres épocas. Buenos Aires: Coni. 1927. "Biblioteca. Reseña general". En: Torres. Op. cit., pp.: 294-310.

Barrancos, D. 1987. Anarquismo, educación y costumbres en la Argentina de principios de siglo. Buenos Aires: Contrapunto.

1991. Educación, cultura y trabajadores (1890-1930). Buenos Aires:

Centro Editor de América Latina.

1995. "El proyecto de extensión universitaria: el movimiento obrero entre 1909 y 1918". En: Arnaiz, M. (comp.). Movimientos sociales en la Argentina, Brasil y Chile, 1880-1930. Buenos Aires: Biblos, pp. 77-112.

1996. La escena iluminada. Ciencia para trabajadores 1890-1930.

Buenos Aires: Plus Ultra.

Baruch Bertocchi, N. 1987. Las universidades católicas. Buenos Aires: Centro Editor de América Latina.

Ben-David, J. 1971. The Scientific's Rol in Sociaty. New Jersey: Engelwood Cliffs. 1991. Scientific Growth. Essays on the Social Organization and Ethos of Science. Berekeley/Los Angeles/Oxford: University of California Press.

Bencerra Ardilla, D. y Restrepo Forero, O. 1993. "La Universidad Colombiana: actividades científicas y formación de investigadores". Quipu, X, 1: 75-108.

Benson, K. 1988. "The Naples Staziones Zoologica and its Impact on the Emergence of American Marine Biology". Journal of the History of Biology, 21: 331-334.

Berger P. y Luckmann, T. 1979. La construcción social de la realidad. Buenos Aires: Amarrortu.

Bertoni, L. 2001. Patriotas, cosmopolitas y nacionalista. La construcción de la nacionalidad argentina a fines del siglo XIX. Buenos Aires: Fondo de Cultura Económica.

Besio Moreno, N. 1913. "Facultad de Ciencias Físicas, Matemáticas y Astronómicas". En: UNLP. 1913a. Op. cit., pp: 87- 155. 
1915. Sinopsis histórica de la Facultad de Ciencias Exactas, Físicas

y Naturales de Buenos Aires y de la enseñanza de las matemáticas y la física en la Argentina. Buenos Aires: "La Ingeniería".

1917. "Facultad de Ciencias Físicas, Matemáticas y Astronómicas".

En: UNLP. Op. cit., pp. 133-194.

1921. "El profesorado de enseñanza secundaria en matemáticas en

la Argentina". Humanidades, I: 406-426.

Biagini, H. 1985. El movimiento positivista argentino. Buenos Aires: Belgrano. 1987. "La Huelga Grande de La Plata". Todo es Historia, 330: 17-35. 1989 . Filosofia americana e identidad. Buenos Aires: Eudeba. 1997. "Un sugestivo capítulo en blanco: los primeros congresos de

estudiantes americanos". Estudios Latinoamericanos. Solar, 7: 83-90. - (comp.). 1999a. La Universidad de La Plata y el movimiento estudiantil desde sus orígenes hasta 1930. La Plata: Universidad Nacional de La Plata. 1999b. "El movimiento estudiantil-reformista y sus mentores". En: Biagini, H. (comp.). Op. cit., pp. 153-209.

Bianchi Lischetti, A. 1962. "Palabras del Doctor Angel Bianchi Lischetti en el Cincuentenario de la Fundación de la Asociación Argentina de Ciencias Naturales 1911-1961". Physis, XXIII, 64: 118 -119.

Bibiloni, J. A. 1900. "La Reforma Universitaria". Revista de Derecho, Historia y Letras, VII: 242-351.

1903. "La cuestión universitaria". Revista de Derecho, Historia y Letras, XVII: 413-421.

Birabén, M. 1961. "Ciento cincuenta años de zoología argentina". Physis, T.XXII, 63: $1-20$.

Birgin, A. 1999. El trabajo de enseñar. Entre la vocación y el mercado: las nuevas reglas del juego. Buenos Aires: Troquel.

Blanckaert, C.; Cohen, C.; Corsi, P. y Fischer, J. L. (coord.) 1997. Le Muséum au primier siécle de son histoire. Paris: Muséum National d'Historie Naturelle.

Bondesio, P. "Cien años de Paleontología en el Museo de La Plata". En: Obra del Centenario del Museo de La Plata. La Plata: Museo de La Plata. Tomo I: 75-87.

Bosch, B. 1993. "Irradiación del normalismo paranaense". Investigaciones y Ensayos, 43: 209-235. 
Botana, N. 1985. El orden Conservador. La política Argentina entre 1880 y 1916. Buenos Aires: Sudamericana.

Botana, N. y Gallo, E. 1993. De la República posible a la República verdadera. Buenos Aires: Ariel.

Bourdieu, P. 1984. Homo Academicvs. Paris: Éd. de Minuits. 1994. "El campo científico". Redes, I, 2: 129-160.

1999. "The Specificity of the Scientifc Field and the Social Conditions of the Progress af Reason". En: Biagioli, M. (ed.). The Science Studies Reader. New York-London: Routledge.pp: 31-50.

Braslavsky, C. y Birgin, A. 1992. Formación del Profesorado. Impacto, pasado y presente. Buenos Aires: Miño Dávila.

Buch, A. 1996. "Bernardo Houssay y la conflictiva inauguración de la dedicación exclusiva en la Universidad Argentina". Estudios Interdisciplinarios de América Latina y el Caribe, VII, 1: 57-71.

-------- 2000. Forma y Función de un sujeto moderno. Bernardo Houssay y la fisiología argentina (1900-1943). Tesis doctoral presentada en Facultad de Filosofía y Letras, Universidad Autónoma de Madrid.

Buchbinder, P. 1997. Historia de la Facultad de Filosofía y Letras. Universidad de Buenos Aires. Buenos Aires: Eudeba. 2000. "El Movimiento Reformista de 1918: una perspectiva desde la historia interna de la Universidad de Buenos Aires". Estudios Sociales, X, 19: 37- 63.

Buisson, F. (comp.) s/f. La educación popular de los adultos en Inglaterra. Madrid: España Moderna. [1898].

Bunge, C. O. 1903. La Educación. La educación contemporánea. Madrid: Daniel Jorro.

Burrage, M. 1996. "De la educación práctica a la educación profesional académica: pautas de conflicto y adaptación en Inglaterra, Francia y Estados Unidos.". En: Rothblatt, S. y Wittrock, B. (eds.). Op. cit., pp: 156-206.

Cabrera, A. 1926. "Los estudios geográficos actuales en Paleontología". Humanidades, 14: 103-121. 
Caldelari, M. y Funes, P. 1997. Escenas Reformistas. La reforma Universitaria 19181930. Buenos Aires: Oficina de Publicaciones del CBC, Universidad de Buenos Aires..

Camacho, H. 1971. Las ciencias naturales en la universidad de Buenos Aires. Estudio histórico. Buenos Aires: Eudeba.

------------ 2001. "Las ciencias geológicas en la argentina, hasta 1939". Saber y Tiempo, 12: 177-220.

Camis, M. 1915. "El Laboratorio de Fisiología en la Facultad de Agronomía y Veterinaria". Revista de la Facultad de Agronomía y Veterinaria, XI, 2: 11-23.

Cané, M. 1950. Juvenilia y otras páginas argentinas. Buenos Aires: Colección Austral

Cárcano, R. 1892. Universidad de Córdoba. Algunas palabras sobre su organización. Buenos Aires: Felix Lajouane.

Carli, S. 2002. Niñez, pedagogía y política. Transformaciones de los discursos acerca de la infancia en la historia de la educación argentina entre 1880 y 1955 . Buenos Aires: Miño Dávila.

Castellanos, T. 1892. Informe Anual del rector Telémaco Castellanos, Universidad nacional de Córdoba, Curso escolar de 1891. Córdoba: Imprenta "La Minerva". 1894 Informe Anual del rector Telémaco Castellanos, Universidad nacional de Córdoba, Cursos escolar 1893.Córdoba: Imprenta "La Minerva".

Castiñeiras, J. 1985. Historia de la Universidad de La Plata. La Plata: Universidad Nacional de La Plata. [1938]

Cattáneo, L. y Rodríguez, F. 2000. "Ariel exasperado: avatares de la Reforma Universitaria en los años veinte". Prismas, 4: 47-57.

Charle, C. 1990. "Les professeurs des facultés des sciences en France: une comparaison Paris-Province (1880-1900)". Revue d'Histoire des Sciences, XLIII, 4: 427-450.

Chartier, R. 1992. El mundo como representación. Historia cultural: entre práctica y representación. Barcelona: Gedisa.

1994. El orden de los libros. Lectores, autores y bibliotecas en Europa entre los siglos XIV y XVIII. Barcelona: Gedisa. 
Manantial.

1996. Escribir las prácticas. Foucault, De Certeau, Marin. Buenos Aires:

---------- 1999. Cultura escrita, literatura e historia. Conversaciones con Roger Chartier. México: Fondo de Cultura Económica.

Christmann, F. E. 1992. Vivencias y testimonios (de mis últimos 80 años). La Plata:

Agremiación Médica Platense.

Ciappa, F. 1987. “La 'colonia científica' alemana en La Plata”. Todo es Historia, 244: 34-44.

Cigliano, M y Palma, N. 1977. "Cien años de Antropología en el Museo de La Plata". En: Obra del Centenario del Museo de La Plata. La Plata: Museo de La Plata. Tomo I: $39-48$.

Ciria, A. y H. Sanguinetti. 1983. La Reforma Universitaria. Buenos Aires: Centro Editor de América Latina.

Clark, B. R. 1991. El sistema de Educación Superior. Una visión comparativa de la organización académica. México: Nueva Imagen.

Cortelezzi, J. 1907. "Espíritu, doctrina y método de la Botánica. Su enseñanza en el nuevo Colegio Secundario". El Museo, I, 16: 93-95.

Cossío, C. 1923. La reforma universitaria. La ideología. El mecanismo. El pasado histórico. La acción futura. Buenos Aires: Rosso. 1927. La reforma universitaria o el problema de la nueva generación. Buenos Aires: Espasa-calpe.

Crespo, H. 1999. "Problematizar la historia de la universidad", en: Pensamiento Universitario, 8: 105-112.

Crispiani, A. 1999. "La "universidad nueva" de Joaquín V. González y el proyecto de 1905". En: Biagini, H. (comp.). Op. cit., pp.: 61- 86.

Cueto, M. 1989. Excelencia cientifica en la periferia. Actividades científicas e investigación biomédica en el Perú 1850-1950. Lima: Grade-Cocytec.

Dalmazzo, G. 1997. “Línea Recta: estudiantes en lucha”. Todo es Historia, 360: 74-92. 
Darnton, R. 1984. The Great Cat Massacre and Other Episodes in French Cultural History. Nueva York: Basic Books Inc. 1996. O Iluminismo como negócio. São Paulo: Companhia das Letras.

De Buen, O. 1910. "El mar. Centro de la vida y escuela de inagotables enseñanzas". Boletín de la Instrucción Pública, VI: 243-259.

De Lucia, O. 1999. "La tradición laica en la "ciudad universitaria". El movimiento librepensador en La Plata (1896-1919). En: : Biagini, H. (comp.). Op. cit., pp.: 13- 26.

Dellepiane, A. 1910. La Universidad y la vida. Buenos Aires: Coni Hermanos.

De Marco, M. A. (h) 1998. "Educación Pública Santafesina en tiempos de inestabilidad política y transformación estatal 1883-1898". Investigaciones y Ensayos, 48: 225-266.

Demaría, E. 1902. "Las universidades alemanas". Revista de Derecho, Historia y Letras, XIII: 428-597.

Demolins, E. s/f. A quoi tient la supériorité des Anglos-saxones? París: Fermin Didot et Cia. [1897].

----------- 1898. L'éducation nouvelle. L'école des Roches. París: Fermin Didot et Cia. 1899. Nos éleves en Angleterre. L'École des Roches. París: Fermin Didot e Cia.

Drouin, J. M. y Bensaude- Vincent, B. 1996. "Nature for the people". En: Jardine et. al. (eds.). Op. cit., pp.: 408-425.

Dussel, I. 1997. Curriculum, humanismo y democracia en la enseñanza media (18631920). Buenos Aires: Oficina de Publicaciones del CBC, Universidad de Buenos Aires-FLACSO.

Endere, M. L. y Podgorny, I. 1997. "Los gliptodontes son argentinos. La ley 9080 y la creación del patrimonio arqueológico nacional". Ciencia Hoy, VII, 42: 54-59.

Espinas, A. 1892. "L'extension des Universités en Angleterre, en Éosse et aux ÉtatsUnis". Revue internationale de l'enseignement, XXII: 201-219. 
Etchichury, L. M. 1914. La Plata. Estudio histórico-estadísticos-demográfico. 18821914. La Plata: Taller de Imprenta Municipal.

Eujanian, A. s/f. "Profesión, objetividad y estilo. El rol de la controversia en la profesionalización de la historiografía argentina entre 1910 y 1920”. Ponencia en: VII Jornadas Inter-escuelas-departamentos de historia. Versión on-line.

Facultad de Agronomía y Veterinaria, UNLP. 1915. Ingreso, Plan de Estudios. Informaciones diversas. La Plata: Talleres Gráficos Christmann y Crespo.

Facultad de Ciencias Físico-Matemáticas. Universidad Nacional de Córdoba. 1883. Plan de estudios. Córdoba: Imprenta de Comercio.

Farro, M. y Podgorny, I., 1998. “Frente a la tumba del sabio: Florentino Ameghino y la 'santidad' del científico en el Plata”. Ciencia Hoy, VIII, 47: 28-36.

Federación Universitaria de Buenos Aires. 1912. Relación Oficial del $2^{\circ}$ Congreso Internacional de Estudiantes Americanos. Buenos Aires: Talleres Gráficos de la Penitenciaria Nacional. Tomo I.

Fehér, M. 1990. "Acerca del papel asignado al público por los filósofos de la ciencia". En: Ordoñez y Elena 1990, op. cit.: 421-443.

Fernández, J. R. 1898. "Reforma Universitaria". Revista de Derecho, Historia y Letras, I: 595-597. 1899. "Reforma Universitaria". Revista de Derecho, Historia y Letras, IV: 291-331 y 594-611.

Fernández, M. 1918a. "Informe del Jefe de la Escuela de Biología, correspondiente al año 1917". En: Lafone Quevedo, S. Op. cit,: 117-118.

------------- 1918b. "Las facultades de ciencias naturales y el profesorado secundario". BUNLP, I, 2: 88-94.

Figueirõa, S. 1997. As ciências geológicas no Brasil: uma história social e institucional, 1875-1934. Sâo Paulo: Hucitec.

- 1998. "Mundialização da ciência e respostas locais: sobre a institucionalizaçâo das ciências naturais no Brasil (de fins do século XVIII à transição ao século XX). Asclepio, L, 2: 1907-123. 
Finnegan, T. 1989. "Promoting "Responsible Freedon" Administrators and Social Fraternities at the University of Illinois, 1900-1931". History of Higher Education Annual, 9: 33-59.

Finocchio, S. (coord) 2001. Facultad de Humanidades y Ciencias de la Educación. Documentos y notas para su historia. La Plata: Al Margen -UNLP.

Foucault, M. 1970. La arqueología del saber. México: Siglo XXI.

Fox, R. y Weisz G. (eds) 1980. The Organization of Science and Technology in France, 1808-1914. Cambridge/Paris: Cambridge University Press- Editions de la Maison des Sciences.

Gallardo, A. 1898. "La Reforma Universitaria". Anales de la Sociedad Científica Argentina, XLVI: 193-222.

1906. "Fundación de un laboratorio marino en Mar del Plata". Revista de la Universidad de Buenos Aires, VI, 3: 20-32. 1907. "La enseñanza de la zoología". Revista de la Universidad de Buenos Aires, VII: 118-119. 1918-19. "Los estudios biológicos en la República Argentina". En: Primera Reunión nacional de la Sociedad Argentina de Ciencias Naturales, Tucumán, 1916. Buenos Aires: Coni. pp: 1-26.

Gandolfi, F. 1999. "Pretérito imperfecto. los días de la primera universidad de la Plata (1890/97-1905)”. En: Biagini, H. (comp.). Op. cit., pp.: 27- 59.

Gans, R. 1918. Las universidades alemanas. Buenos Aires: Unión de Libreros Alemanes.

García, S. 2000. “"Embajadores intelectuales': El apoyo del Estado a los congresos de estudiantes americanos a principios del siglo XX". Estudios Sociales, X, 19: 65-84. - 2001. "La instrucción popular en los museos: El Museo de La Plata a fines del siglo XIX y principios del XX". Museo, III, 15: 51-55.

García, S. y Podgorny, I. 2000. "El sabio tiene una patria. La primera Guerra mundial y la comunidad científica argentina". Ciencia Hoy, X, 55: 24-34.

2001. "Pedagogía y nacionalismo en la Argentina: lo internacional y lo local en la institucionalización de la enseñanza de la arqueología". Trabajos de Prehistoria, LVIII, 2: 9-26.

Garcíadiego, J. 1999. "La Universidad Nacional de México: trasformación y sobrevivencia". Estudios, 11-12: 27-39. 
Geertz, C. 1988. La interpretación de las culturas. Barcelona: Gedisa.

Geiger, R. 1984. "The Conditions of University Research, 1900-1920". History of Higher Education Annual, 4: 3-29.

-------- 1992. "The Historical Matrix of American Higher Education". History of Higher Education Annual, 12: 7-28.

Gellner, E. 1988. Naciones y nacionalismo. Madrid: Alianza.

Gentile, E. y Vallejo, G. 1999. "De los internados al hogar estudiantil. El hábitat de los proyectos pedagógicos de la UNLP (1905/10-1924)". En: Biagini, H. (comp.). Op. cit., pp.: 87- 111.

Gilson, G. 1914. Le Musée d'Histoire Naturelle Moderne. Sa mission, son organization, ses droits. Bruxelles: Hoyez.

Giner de los Ríos, F. s/f. Pedagogía Universitaria. Madrid: Manuales Soler.

Ginzburg, C. 1981. El queso y los gusanos. El cosmos según un molinero del siglo XVI. Barcelona: Muchnik Ed..

---------- 1994. Mitos, emblemas, indicios. Morfología e historia. Barcelona: Gedisa.

González, Joaquín V. 1935. Obras Completas. Buenos Aires: Universidad Nacional de La Plata.

pp.: 27-58. 1913. "Memoria de la Presidencia". En: UNLP. 1913a. Op. cit.,

González, Julio V. 1922. La revolución universitaria 1918-1919. Buenos Aires: J. Menéndez.

1927. La reforma Universitaria. Buenos Aires: Revista Sagitario. 1945. La universidad. Teoría y acción de la reforma. Buenos Aires:

Claridad

González Leandri, R. 1997. "Académicos, doctores y aspirantes: la profesión médica y la reforma universitaria: Buenos Aires: 1871-1876". Entrepasados, VI, 12: 32-46. 1999. Curar, persuadir, gobernar. La construcción histórica de la profesión médica en Buenos Aires, 1852-1886. Madrid: Consejo Superior de Investigaciones Científicas. 
2000. "Notas acerca de la profesionalización médica en Buenos Aires durante la segunda mitad del siglo XIX". En: Suriano, J. (comp.), La cuestión social en Argentina 1870-1943. Buenos Aires: La Colmena. pp: 217-243.

Goodson, I. 1991. "La construcción social del curriculum. Posibilidades y ámbitos de investigación de la historia del curriculum". Revista de Educación (Madrid), 297: 7-37. --------- 1995. Historia del curriculum: la construcción social de las disciplinas escolares. Barcelona: Pomares-Corredor.

Graciano, O. F. 1998. "Universidad y Economía Agroexportadora: el perfil profesional de los ingenieros agrónomos 1910-1930". En: Girbal-Blancha, N. (comp.), Agro, Universidad y enseñanza. Dos momentos de la Argentina rural (1910-1955). La Plata: Editorial de la UNLP; pp. 13-72.

Grendi, E. 1996. ¿¿Repensar la microhistoria?". Entrepasados: V, 10: 131-140.

Griffin, C. 1917. "Memoria del decano. Facultad de Agronomía y Veterinaria". En: UNLP. Op. cit., pp.: 261-267.

Grupioni, L. D. B. 1998. Os etnólogos e o conselho de fiscalização das expedições científicas e artísticas no Brasil. São Paulo: Hucitec- Anpocs.

Guarrera, S. A. 1977. "El desarrollo de la Botánica en el Museo de La Plata". En: Obra del Centenario del Museo de La Plata. La Plata: Museo de La Plata. Tomo I: 49-57.

Guichard, E. B. 1911. “Asociaciones estudiantiles francesas”. Revista del Centro de Estudiantes de Derecho (Buenos Aires), 5, 24.

Guntau, M. 1996. "The natural history of the earth". En: Jardine et. al. (eds.). Op. cit., pp.: 211-229.

Gutierrez, L. y Romero, L. A. 1995. Sectores populares , cultura y política. Buenos Aires en la entreguerra. Buenos Aires: Sudamericana.

Gvirtz, S. (dir.) 2000. El color de lo incoloro. Miradas para pensar la enseñanza de las ciencias. Buenos Aires: Novedades Educativas.

Hall, S. 1984. "Notas sobre la desconstrucción de « lo popular»”. En: Samuel, R. (ed.). Op. cit., pp.: 93-110. 
Halperín Donghi, T. 1962. Historia de la Universidad de Buenos Aires. Buenos Aires: EUDEBA. 2000. Vida y muerte de la república verdadera (1910-1930).

Buenos Aires: Ariel.

Hawkins, H. 1993. "American Universities and the inclusion of profesional schools". History of Higher Education Annual, 13: 53-67.

Henson, P. 2000. "A Invasão da Arcadia: As cientistas no Campo na América Latina, 1900,1950". Cuadernos Pagu, 15: 165-197.

Herrero Ducloux, E. 1907a. "Qué es un Museo?. El Museo, I, 15: 14-18. -- 1907b. "Institutos Científicos Argentinos. El Museo de La

Plata". La Prensa, 1/1/1907.

1909. "La enseñanza de la química en la Universidad Nacional de La Plata". Archivos de Pedagogía y ciencias afines, VI: 309-340.

1910. "El espíritu de investigación científica en la República Argentina". Boletín de la Instrucción Pública, I: 765-773.

1923. Evolución de las ciencias en la República Argentina. Las ciencias químicas. Buenos Aires: Sociedad Científica Argentina.

Hicken, C. 1923. Evolución de las ciencias en la República Argentina. VII Estudios Botánicos. Buenos Aires: Sociedad Científica Argentina.

Hylton Scott, M. I. 1928. "Sobre el desarrollo intraovarial de "Fitzroyia lineata" (Jen.) Berg". Anales del Museo Nacional de Historia Natural de Buenos Aires, XXXIV: 361-424.

Hobsbawm, E. 1991. Naciones y nacionalismos desde 1780. Barcelona: Crítica. 1998. La Era del Imperio, 1875-1914. Buenos Aires: Crítica.

Hobsbawm, E. y Ranger, T. (eds.) 1983. The invention of tradition. Cambridge: Cambridge University Press.

Hopwood, N. 1999. "Giving Body" to Embryos. Modeling, Mecahism, and Microtome in late Nineteenth-Century Anatomy". Isis, 90: 462-496.

Hurtado de Mendoza, D. y Busala, A. 2002. Los ideales de universidad "cientifica" (1931-1958). Elitismo y función social de la ciencia en Argentina. Buenos Aires: Libros del Rojas-Universidad de Buenos Aires. 
Instituto Nacional del Profesorado Secundario en la primera década de su existencia, 1905 a 1915, 1916. Buenos Aires: T. Paumbo.

Jardine, N., Secord, J. A. y Spary, E. C. (eds.) 1996. Cultures of Natural History. Cambridge: Cambridge University Press.

Jauss, H. R. 1986. Experiencia Estética y hermenéutica literaria. Ensayos en el campo de la experiencia estética. Madrid: Taurus.

Kaplan, F. S. (ed.) 1994. Museums and the making of "ourselves". The role of objects in national identity. London- New York: Leicester University Press.

Kantasalmi, K. 1999. "Educación universitaria de adultos en Finlandia: explorando los impactos sociales y la efectividad en un contexto histórico". Revista Internacional Paideia, II, 2: 78-134.

Kantor, M. 1913a. "La geología como ciencia teórica". Boletín de la Instrucción Pública, III, 36: 312-331.

--------- 1913b. “La geología como ciencia aplicada". Boletín de la Instrucción Pública, III, 38: 26-39.

---------- 1913c. “Los yacimientos de minerales útiles”. Boletín de la Instrucción Pública, III, 39: 263-278.

Karady, V. 1980. "Educational Qualifications and University Careers in Science in Nineteenth-Century France". En: Fox, R. y Weisz, G. (eds.). Op. cit., pp.: 95-124. 1990 . "Las funciones sociales de los sistemas educativos en perspectiva comparada: la educación superior en Francia y Hungría en los siglo XIX y XX". Revista de Educación (Madrid), n extraordinario: 165-198.

Keiper, W. 1919. La enseñanza secundaria en Alemania. Buenos Aires: Germania. [1912].

Kemmis, S. 1980. El curriculum: más allá de la teoría de la reproducción. Madrid: Morata.

Kohlstedt, S. G. (ed.) 1991. The origins of Natural Science in America. The Essays of George Brawn Goode. Washington: Smithsonian Institution Press. 
Knorr-Cetina, K. 1996. ¿Comunidades científicas o arenas transepistémicas de investigación? Una crítica de los modelos cuasi-económicos de la ciencia". Redes, III, 7:131-160.

Lafone Quevedo, S. 1907. "El futuro del Museo de La Plata". UNLP. Memoria del Museo de La Plata correspondiente a 1906. Buenos Aires: Imprenta Coni Hermanos., pp. 29-32

84. 1913. "Instituto del Museo". En: UNLP. 1913a. Op. cit.,pp.: 631917. "Instituto del Museo". En: UNLP. Op. cit.,pp.: 85-130. 1918. "Memoria del director del Instituto del Museo correspondiente al año 1917". BUNLP, I, 3: 106-122.

Lafuente, A.; Elena, A. y Ortega, M. L. (eds.) 1993. Mundialización de la ciencia y cultura nacional. Madrid: Universidad Autónoma de Madrid/Doce Calles.

Lahille, F. 1898. “Una estación marítima provincial”. Revista del Museo de La Plata, VIII: $392-436$.

---------- 1907. "Los laboratorios de biología acuática”. Anales de la Sociedad Cientifica Argentina, LXIV: 278-321.

Latour, B. 1983. "Give Me a Laboratory and I will Raise the World". En: Knorr-Cetina y Mulkay, M. (eds.). Science Observed: Perspectives on the Social Study of Science. Londres: Sage, pp.: 141-170.

1992. Ciencia en Acción. Barcelona: Labor.

Leclerc, M. 1892. Le rôle sociale des Universités. Paris: Armand Colin. 1894. Les professions et la société en Angleterre. Paris: Armand Colin. 1899. L'éducation des classes moyonnes et dirigeantes en Angleterre.

Paris: Armand Colin et cie.

Lehmann- Nitsche, R. 1899. "Antropología y craneología". Revista del Museo de La Plata, IX: 123-140.

1906. "La división del año de estudios en semestres". Revista de la Universidad de Buenos Aires, VI, 27-30: 254-257.

Plata. Buenos Aires: Coni. 1910a. Catálogo de la Sección Antropológica del Museo de La 1910b. "El Parque Paleontológico de La Plata". EL Día, 25/9/1910. 1915. "Proyecto de una escuela preparatoria de medicina de la Universidad Nacional de La Plata". Revista de la Universidad de Buenos Aires, XXVII: 197-200.

Humanidades, I: 3-17. 1921. "La antropología en la enseñanza universitaria argentina". 
Levi, G. 1993. "Sobre la microhistoria". En: Burke, P. Formas de hacer la Historia. Madrid: Alianza. pp. 119-143.

Limoges, C. 1980. "The development of the Muséum d'Historie Naturalle of Paris,c.1800-1914". En: Fox, R. y Weisz, G. (eds.). Op. cit., pp.: 211-240.

Lopes, M. M. 1997. O Brasil descobre a pesquisa cientifica. Os Museus e as ciências naturais no século XIX. Sâo Paulo: Hucitec.

1999. "Aspectos da Institucionalização das Ciências Naturais no Brasil, no Século XIX". Quipu, XII, 2:217-230.

2001. "Viajando pelo campo e pelas coleções: aspectos de uma controvérsia paleontológica". História, Ciências, Saúde - Manguinhos, VIII (suplemento): 881-897.

Lopes, M. M. y Podgorny, I. 2000. "The Shaping of latin American museums of natural History, 1850-1890". Osiris, 15:108-118.

López, H.L. y Mariazzi, A. A. 1994. "Limnology in Argentine: An Historical Account". Freshwater Forum, VI, 3:169-178.

Loyarte, R. 1924. Evolución de las ciencias en la República Argentina, II. La evolución de la fisica., Buenos Aires: Sociedad Científica Argentina.

Lugones, L. 1903. La reforma educacional. Un ministro y doce académicos. Buenos Aires: s/d.

Luzuriaga; L. 1957. La Institución Libre de enseñanza y la educación en España. Buenos Aires: Departamento Editorial de la Universidad de Buenos Aires.

Madrid, S. de 1901. "Las pruebas de suficiencias exigidas. Factor de atraso en nuestras instituciones universitarias". Revista de Derecho, Historia y Letras, XI: 227241

Magnasco, O. 1899. Plan de Instrucción General y Universitaria. Buenos Aires:

Talleres de la Penitenciaria nacional.

Maienschen, J. 1989. 100 Years of Exploring Life: The Marine Biological Laboratory at Woods Hole. Boston: Jones \& Batlett. 
Manganaro, A. 1919. Leguminosas bonaerenses. Buenos Aires: Imprenta Coni.

Mayer, L. y Chazaro, L. 1992. "La idea de universidad en el último cuarto del siglo XIX: los silencios culturales". Quipu, IX, 3: 327-347.

Mazo, G. del. 1926/1927. La reforma universitaria. Juicio de los hombres de la nueva generación acerca de su significado y alcance (1918-1926). Buenos Aires: Ferrari. 1945. Estudiantes y gobierno universitario. Buenos Aires: El Ateneo.

Melgar Bao, R. 1999. "Las universidades populares en América Latina 1910-1925". Estudios, 11-12: 41-57.

Melón Pirro, J.C. 1994. "La Ley Sáenz Peña de Ugarte o el éxito de la Reforma Conservadora de la Provincia de Buenos Aires". En: Devoto, F. y Ferrari, M. (comp.), La construcción de las democracias rioplatenses: proyectos institucionales y prácticas políticas, 1900-1930. Buenos Aires: Biblos. pp.: 107-135.

Memoria correspondiente a 1913 de la Facultad de Ciencias Físicas, Matemáticas y Astronómicas. 1913. La Plata.

Memoria correspondiente a 1916 de la Facultad de Ciencias Físicas, Matemáticas y Astronómicas. 1918. La Plata.

Memoria del Museo de La Plata correspondiente al año de 1906. 1907. Buenos Aires: Imprenta Coni.

Memoria presentada al Congreso nacional de 1902 por el Ministro de Justicia e Instrucción Pública. 1903. Buenos Aires: Taller Tipográfico de la Penitenciaria Nacional.

Mercante, V. 1907. "La Sección Pedagógica. La labor del Año 1906". Archivos de Pedagogía y ciencias afines, II : 253-285.

Cabaut y cia.

1911. Metodología especial de la enseñanza primaria. Buenos Aires:

1913. "Sección Pedagógica: Colegio Secundario de Señoritas y Escuela Graduada de Varones." En: UNLP. 1913a. Op. cit.,pp.: 191-253.

1918. "Memoria del Decano de la Facultad de Ciencias de la Educación, correspondiente al año 1917". BUNLP, I, 2: 61-69.

1944. Una vida realizada (Mis memorias). Buenos Aires: Imprenta

Ferrari Hnos. 
Mignone, E. F. 1999. Política y Universidad. El Estado legislador. Buenos Aires: Lugar Editorial.

Miranda, E. 1993. La formación del sistema universitario nacional. Desarrollo y crisis. 1880-1946. Córdoba: Dirección General de Publicaciones-Universidad Nacional de Córdoba.

Montserrat, M. 1993. Ciencia, historia y sociedad en la Argentina del Siglo XIX. Buenos Aires: Centro Editor de América Latina.

Moreno, F. P. 1890. "El Museo de La Plata. Rápida ojeada sobre su fundación y desarrollo". Revista del Museo de La Plata, I: 28-55.

Moreno, J. del C. 1909. "Extensión Universitaria. Influencia social de las Universidades". Archivos de Pedagogía y ciencias afines, VI: 10-35.

Myers, J. 1992. "Antecedentes de la conformación del complejo Científico y tecnológico, 1850-1958". En: Oteiza, E. (comp.) La política de investigación científica y tecnológica argentina: historia y perspectiva: historia y perspectivas. Buenos Aires: Centro Editor de América Latina. pp: 87-125.

1994. "Sísifo en la cuna o Juan María Gutiérrez y la organización de la enseñanza de la ciencia en la Universidad argentina". Redes, I,1:113-131.

Nágera, J. J. 1962. "Homenaje a los fundadores de Physis". Physis, XXIII, 64: 119127.

Nassif, R. 1967. Joaquín V. González. Pedagogo de la Universidad. Buenos Aires: Talleres Pellicer.

Neave, G. 2001. Educación superior: historia y politica. Estudios comparativos sobre la universidad contemporánea. Barcelona: Gedisa.

Nelson, E. 1914. Hacia la universidad Futura. Valencia: F. Sempere y compañía.

Nyhart, L. 1995. Biology takes form. Animal Morphology and the German Universities 1800-1900. Chicago- Londres: University of Chicago Press.

1998. "Civic and Economic Zoology in Nineteenth-Century Germany. The

"Living Communities" of Karl Möbius". Isis, 89: 605-630. 
Olesko, K. (ed.). 1989. Science in Germany. The Intersection of Institutional and Intellectual Issues. Osiris, 5. 1989a "Introduction". En: Olesko, K.(ed.). Op. cit., pp.: 7-14. En: Olesko, K.(ed.). Op. cit., pp.: 94-120.

Ordoñez, J. y Elena, A.(eds.). 1990. La ciencia y su público. Madrid: Consejo Superior de Investigaciones científicas.

Ortiz, E. 1995. “A Convergence of Interests: Einstein's Visit to Argentina in 1925”, Ibero-Amerikanisches Archiv. Zeitschrift für Sozialwissenschaften und Geschichte, XXI, 1-2: 67- 126.

Outes, F. 1912. Guía Sumaria para la visita de la Sala XIX. UNLP. Museo de La Plata. Buenos Aires: Imprenta Hermanos Coni.

Outes, F. y Bruch, C. 1910. Texto explicativo de los cuadros murales "Las viejas razas argentinas". Buenos Aires: Comp. Sud-Americana de Billetes de Banco.

Palacios, A. 1957. La Universidad nueva. Desde la Reforma Universitaria hasta 1957. Buenos Aires: Gleizer.

Palacios, L. 1904. Las universidades populares. Valencia: F. Sempere y Comp. ${ }^{\text {. }}$

Palacios Lis, H. 1985. "Cuestión social y educación: un modelo de regeneracionismo educativo". Historia de la educación, 4: 305-319.

Palcos, A. 1934. "Síntesis sobre la fundación y organización actual de la Biblioteca". BUNLP, XVIII, 4: 5-36.

Panattieri, J. 1983. Devaluaciones de la moneda (1822-1935. Buenos Aires: Centro Editor de América Latina.

Pastore, F. 1925. Evolución de las Ciencias en Argentina. VI. Nuestra Mineralogía y Geología durante los últimos cincuenta años (1872-1922).Buenos Aires: Sociedad Científica Argentina.

Pascual, R. 1961. "Panorama Paleozoológico Argentino: Vertebrados". Physis, XXII, 63: 87-103. 
Paula, A. de. 1987. La ciudad de La Plata, sus tierras y su arquitectura. Buenos Aires: Ediciones del Banco de la Provincia de Buenos Aires.

Perdiel, H. 1903. "Doctormanía". Revista de Derecho, Historia y Letras, XV: 11-16.

Pérez Gollán, J. A. 1995. "Mr. Ward en Buenos Aires: los museos y el proyecto de nación a fines del siglo XIX". Ciencia hoy, V, 28: 52-58.

Pérez Lindo, A. 1985. Universidad, política y sociedad. Buenos Aires: Eudeba.

Pereyra, D. 1998. Antes de Germani. La sociología en la Universidad de Buenos Aires en los albores del siglo veinte. Tesis de Maestría, Facultad de Ciencias Sociales, Universidad de Buenos Aires.

Pickstone, J. V. 1993. "Ways of knowing: towaeds a historical sociology of science, technology and medicine". British Journal for the History od Science, 26: 433-458.

----------- 1994. "Museological science? The place of the analytical/comparative in nineteenth-century science, technology anda medicine". History of Science, XXXII: 111-138.

Pineau, P. 1997. La Escolarización de la Provincia de Buenos Aires (1875-1930). Una versión posible. Buenos Aires: Oficina de Publicaciones del CBC, Universidad de Buenos Aires-FLACSO.

Pinkasz, D. 1992. "Orígenes del profesorado secundario en la Argentina. Tensiones y conflictos". En: Braslavsky, C. y Birgin, A., op. cit.,pp. 59-82.

Pizzurno, P. 1903. "La reforma de la enseñanza secundaria y normal". Anales de la Sociedad Cientifica Argentina, LVI: 145- 191.

Podgorny, I. 1994. Arqueología y educación: la inclusión de la arqueología pampeana en la educación argentina. Tesis doctoral, Fac. de Cs. Naturales y Museo, UNLP. 1995. De Razón a Facultad: Ideas acerca de las funciones del Museo de La Plata en el Período 1890-1918”. Runa, 22: 89-104.

--------- 1996. "Egresados del país: es necesario reaccionar!” Ciencia Hoy, 6: 6064. 1997. "De la santidad laica del científico: Florentino Ameghino y el espectáculo de la ciencia en la Argentina moderna". Entrepasados: 13: 27-61. 
1999a. "De la Antigüedad del hombre en el Plata a la distribución de las antigüedades en el mapa: los criterios de organización de las colecciones antropológicas del Museo de La Plata entre 1890 y 1930". ". História, Ciências, Saúde - Manguinhos, VI, 1: 81-100.

- 1999b. Arqueología de la educación. Textos, indicios, monumentos. La imagen del indio en el mundo escolar. Buenos Aires: Sociedad Argentina de Antropología, Serie Tesis Doctorales.

--------- 2000. El argentino despertar de las faunas y de las gentes prehistóricas. Coleccionistas, museos, estudiosos y universidad en la Argentina, 1875-1913. Buenos Aires: Eudeba/Libros del Rojas.

---------- 2001. "Los científicos alemanes y la política argentina". Todo es Historia, 413: 32-38.

----------- 2002a. "La clasificación de los restos arqueológicos en la Argentina, 18901940. Segunda Pare. Algunos hitos de las décadas de 1920 y 1930". Saber y Tiempo, 13: 5-31.

2002b. "'Ser todo y no ser nada': Paleontología y trabajo de campo en la Patagonia argentina a fines del siglo XIX". En: Visacovsky, S. y Guber, R. (comp.) 2002. Historia y estilos de trabajo de campo en Argentina. Buenos Aires: Editorial Antropofagia. pp. 31-77.

--------- e.p. "La Derrota del Genio: Cráneos y cerebros en la búsqueda de la filogenia de la raza argentina" Sciences et Techniques en perspective. Revue internationale d'Histoire et de Philosophie des Sciences et des Techniques. Vol.: El positivismo en las ciencias y su impacto en América entre los siglos XIX y XX. Nantes, Ginebra, México.

Podgorny, I. y Plöger, T. 1999. "El largo viaje al Plata del Diplodocus carnegii". Ciencia Hoy, IX, 51: 50-51.

Podgorny, I. y Politis, G. 2000. "It is not all roses here. Ales Hrdlicka's travelong and his trip to Argentina in 1910". Revista História da Arte e Arqueología. (Campinas) 3:95-105.

Podgorny, I. y Schâffner, W. 2000. "'La intención de observar abre los ojos' Narraciones, datos y medios técnicos en las empresas humboldtianas del siglo XIX". Prismas (Universidad Nacional de Quilmes), 4: 217-227.

Popkewitz, T. 1997. Sociología política de las reformas educativas. El poder/saber en la enseñanza, la formación del profesorado y la investigación. Madrid: Morata Fundación Paideia.

Portantiero, J. 1978. Estudiantes y politica en América Latina. México: Siglo XIX.

Posada, A. 1892. Ideas pedagógicas modernas. Madrid: Victoriano Suárez. 
1908. "Mi Universidad". Archivos de Pedagogía y Ciencias afines, III, $265-$

271.

1911. En América. Una campaña. Madrid: Librería de Francisco Beltran.

Prego, C. 1998. "Los laboratorios experimentales en la génesis de una cultura científica: la fisiología en la universidad argentina a fines de siglo". Redes, V, 11: 185205.

--------- 2001. "Estado, Universidad y prácticas experimentales en el campo biomédico: Génesis del primer Instituto Universitario". Saber y Tiempo, 11: 51-70.

Prieto, A. 1988. El discurso criollista en la formación de la Argentina moderna. Buenos Aires: Sudamericana.

Prislei, L. 1992. "Itinerario intelectual y político de los Maestros-ciudadanos (Del fin del siglo a la década del '20)". Entrepasados, II, 2: 41-58.

Proyecto de reformas universitarias. Informe del Consejo Superior a la Comisión de Instrucción Pública de la Cámara de Diputados. 1899. Buenos Aires: Imprenta M. Biedma é hijos.

Puiggrós, A. 1990. Sujetos, Disciplina y Curriculum en los orígenes del sistema educativo argentino. Buenos Aires: Galerna.

Pyenson, L. 1978. "The incomplete transmission of a European image: physics at greater Buenos Aires and Montreal, 1890-1920". Proceedings of The American Philosofhical Society, 122, 2:

1984. "In partibus infidelium: Imperialist Rivalries and Exact Science in

Early Twentieth-Century Argenine". Quipu, I, 2: 253-303.

-----1985a. Cultural Imperialism and Exact Sciences. German Expansion overseas, 1900-1930. New York: Peter Lang.

1985b. 'Functionaries and seekers in Latin America: missionary diffusion of exact sciences, 1850-1930'. Quipu, 2, 3:387-420.

Pyenson, L y Sheets-Pyenson, S. 1999. Servants of Nature: a history of scientific institutions, enterprises, and sensibilities. New York-London: W.W. Norton \& Company.

Quesada, E. 1893. Reseñas y criticas. Buenos Aires: Felix Lajouane.

- 1906. La Facultad de Derecho de París. Estado actual de su enseñanza.

Buenos Aires: Coni Hermanos.

- 1910. La enseñanza de la historia en las universidades alemanas. Buenos Aires: Coni Hermanos. 
1915- "La fusión del Instituto Nacional del Profesorado Secundario con al Facultad de Filosofía y Letras de la Universidad de la Capital". Archivos de Pedagogía y Ciencias de la Educación, I, 2: 137-159.

Rajschmir, C. 2000. "Los museos escolares argentinos. De la enseñanza de las ciencias a la construcción de lo nacional". En: Gvirtz, S. (dir.). Op. cit., pp.:149-175.

Ranea, A. 1994. "Origin and (Mis) Fortune of the Collection of Scientif Instruments of the Departament of Physics, La Plata, Argentina". Dragoni, G., Mc Connell, A. y Turner, G. (ed.). Proceedings of The Eleventh International Scientific Instrument Symposium. Bologna University, Italy, 9-14 September 1991. Bologna: Grafis Edizioni.

Recalde, H. 1985. La Iglesia y la cuestión social (1874-1910). Buenos Aires: Centro Editor de América Latina. 1994. Vida Popular y salud en Buenos Aires (1900-1930). Buenos Aires: Centro Editor de América Latina.

Revel, J. 1996. "Microanálisis y construcción de lo social". Entrepasados, V, 10: 141160.

Ricardi, A.C. 1992. Las ideas de ciencia y naturaleza que dieron origen al Museo de La Plata. Serie técnica y didáctica ${ }^{\circ} 18$, Fac. de Cs. Naturales y Museo, UNLP.

Ringer, F. 1990. "Dos culturas académicas Francia y Alemania en torno a 1900". Revista de Educación (Madrid), ${ }^{\circ}$ extraordinario: 137-156.

1994. "Patterns of access to the modern European Univesities: rates of enrollment". History of High Education Annual,14: 101-125.

1995. El ocaso de los mandarines alemanes 1890-1930. Barcelona:

Pomares- Corredor.

Ringuelet, E. J. 1997. "Acerca del distintivo de los universitarios platenses". Revista de la Universidad (La Plata), 31: 33- 36. [1959].

Ringuelet, R. 1977. "Cien años de Zoología en el Museo de La Plata". En: Obra del Centenario del Museo de La Plata. La Plata: Museo de La Plata. Tomo I: 89-96.

Rivarola, R. 1904. "Reformas á los Estatutos. Exposición y proyecto, presentado al Consejo Superior por el consejero Rodolfo Rivarola". Revista de la Universidad de Buenos Aires, I, 1: 52-45 
Aires, III, 13: 300-307.

1905. "La Reforma Universitaria". Revista de la Universidad de Buenos

---------- 1906. "Un nuevo aspecto de la cuestión universitaria". Revista de la

Universidad de Buenos Aires, V, 22: 111-129.

-------- 1913. "Facultad de Ciencias Jurídicas y Sociales". UNLP 1913a. Op. cit., pp.: 173-187.

1915. "La formación del Profesorado Secundario". Archivo de Pedagogía y Ciencias de la Educación, I, 2: 131-136.

----------- 1918. "Memoria de la Presidencia de la Universidad correspondiente al año 1917". BUNLP, I, 3: 100-106.

1919a. "Discurso de apertura de los cursos". BUNLP, II, 10: 3-9.

1919b. "Proyecto de organización del Museo y de creación del Instituto

de Química". BUNLP, II, 13: 100-102.

--------- 1941. Selección de escritos pedagógicos. Buenos Aires: Instituto de

Didáctica, Facultad de Filosofía y Letras de la Universidad de Buenos Aires.

Roca, J. 1941. Mensajes del Presidente Roca. Buenos Aires: Comisión Nacional de Monumento al Teniente General Roca.

Rodríguez Bustamente, N. (ed.). 1985. Debate parlamentario sobre la ley Avellaneda. Buenos Aires: Solar. [1959]

Rojas, R. 1909. La restauración nacionalista. Informe sobre educación. Buenos Aires: Ministerio de Justicia e Instrucción Pública, imprenta de la Penitenciaría.

Real de Azúa, C. 1985. "Prólogos”. En: Rodó, J. E. Ariel. Motivos de Prometeo. Caracas: Biblioteca Ayacucho. pp. IX-XXX1.

Roldán, D. 1993. Joaquín V. González, a propósito del pensamiento político-liberal (1880-1920). Buenos Aires: Centro Editor de América Latina.

Romero, J. L. 1987. Las ideas en la Argentina del siglo XX. Buenos Aires: Biblioteca Actual.

Rothblatt, S. y Wittrock, B. (eds.) 1996. La Universidad europea y americana desde 1800. Barcelona: Pomares-Corredor.

Rudwick, M. 1996. "Minerals, strata and fossils". En: Jardine et. al. (eds.). Op. cit., pp.: 266-286.

Sabato, H. 1986. "La historia intelectual y sus límites". Punto de Vista, IX, 28: 27- 31. 
Sadler, M. s/f. "La extensión universitaria". Buisson, F. (comp.). Op. cit., pp.: 99-130.

Safford, F. 1985. "Acerca de la incorporación de las ciencias naturales en la periferia: el caso de Colombia en el siglo XIX". Quipu, II, 3: 423-435.

Salas, C. 1908. El periodismo en la Provincia de Buenos Aires. Año 1907. La Plata: Taller de Impresiones Oficiales.

Saldaña, J. J. y Cuevas Cardoña, C. 1999. "La invención en México de la investigación científica profesional: el Museo Nacional 1868-1908". Quipu, XII, 3: 309-332.

Samuel, S. (ed.) 1984. Historia popular y teoría socialista. Barcelona: Crítica.

Scala, A. 1915. Clave universal para la determinación de las familias de las plantas. Buenos Aires: Librería Científica de Augusto Galli.

1929. La enseñanza de la botánica en la Escuela Primaria. Cuadernos de temas para la Escuela Primaria, tomo XIII, Facultad de Humanidades y Ciencias de la Educación, UNLP. La Plata: Coni.

Schwartzman, S. 1985. "The Quest for University Research: Policies and Research Organization in Latin America". En: Wittrock, B. y Elzinga, A. (eds.) 1985. The University Research System-The Public Policies of the Home of Scientists. Stockholm: Almqvist \& Wisksell International. pp: 101-116.

Seignobos, C. 1901. "Monsieur Desmolins". Revista de Derecho, Historia y Letras, IX: 212-215.

Semillosa, F. 1900a. "Causas de la superioridad actual de los pueblos de origen anglosajón (Refutación á Mr. Demolins)", Revista de Derecho, Historia y Letras, VII: 8191. 1900b. "Educación de Sajones y Latinos", Revista de Derecho, Historia y Letras, VIII: 98-107.

Sheets-Pyenson, S. 1988. Cathedrals of science.The development of colonial natural history museums in the late nineteenth century. Kingston y Montreal: McGill-Queen's University Press. 
Sisson, E. 1902. "El Museo Nacional". Anales de la Sociedad Científica Argentina, LIII: 257-262.

Soler, R. 1968. El positivismo Argentino. Pensamiento filosófico y sociológico. Buenos Aires: Paidos.

Sorkau, W. 1912. "La carrera del profesorado secundario en Prusia", en: Boletín de la Instrucción Pública, IV: 75-88.

1915. "El profesorado profesional en la enseñanza secundaria" en: Revista de la Universidad de Buenos Aires, XXVII, 113: 254- 275.

Stearn, W. T. 1998. The Natural History at South Kensington. London: The Natural History Museum.

Stocking, G. (ed.). 1985. Objects and Other. Essays on museums and material culture. History of Anthropology, vol. 3. Wisconsin: University of Wisconsin Press.

Tedesco, J. C. 1983. "La Universidad y su reforma". En: Romero, J.L. y Romero, L. A., Buenos Aires. Historia de cuatro siglos. Buenos Aires: Abril. Tomo II: 121-129. ----------- 1986. Educación y Sociedad en la Argentina (1880-1945). Buenos Aires: Solar.

Terán, O. 1987. Positivismo y Nación en la Argentina. Buenos Aires: Puntosur. --------- 2000. Vida intelectual en el Buenos Aires fin-de-siglo (1880-1910). Derivas de la "cultura científica". Buenos Aires: Fondo de Cultura Económica.

Teruggi, M. 1963. "Pequeño y aleccionante capítulo en la vida del Museo de La Plata". En: AAVV. Op. cit., pp.:115-127. 1977. "Cien años de Geología en el Museo de La Plata". En: Obras del Centenario del Museo de La Plata. La Plata: Museo de La Plata. Tomo I: 59-73. 1988 Museo de La Plata 1888-1988 Una centuria de honra. Avellaneda: Fundación Museo de La Plata.

Thackray, J. y Press, B. 2001. The Natural History Museum. Nature's Treasurehouse. London: The Natural History Museum.

Tiana Ferrer, A. 1991. "La educación de adultos en el siglo XIX: los primeros pasos hacia la constitución de un nuevo ámbito educativo". Revista de Educación (Madrid), 294: 7-26. 
Tognetti, L. 2000. "La introducción de la investigación científica en Córdoba a fines del siglo XIX: la Academia Nacional de Ciencias y la Facultad de Ciencias FísicoMatemáticas (1968-1878)". En: Montserrat, M. (comp.) 2000. La ciencia en la Argentina de entre siglos. Textos, contextos e instituciones. Buenos Aires: Manantial, pp: 345-365.

Torres, L. M. 1924. Memoria del Museo de La Plata correspondiente a los años 1922 y 1923. Buenos Aires: Coni.

1925. "Memoria del Instituto del Museo correspondiente al año académico 1924". BUNLP, IX, 2: 52-59.

------------ (dir.) 1927. Guía para visitar el Museo de La Plata. La Plata. 1934. Doce años de labor en la dirección del Museo de La Plata (19201932). Buenos Aires: Imprenta y casa editora "Coni".

Torstendahl, R. 1996. "La trasformación de la educación profesional". En: Rothblatt, S. y Wittrock, B. (eds.). Op. cit., pp.: 121-174.

Turner, F. 1980. "Public Science in Britain, 1880-1919". Isis, LXXI, 259: 589-608.

Universidad de La Plata 1897. Leyes, Decretos, Estatutos, Ordenanzas y Reglamentos que rigen la Universidad de La Plata, La Plata: Talleres Solá, Sesé y comp.

UNLP. 1906. Documentos orgánicos. La Plata: Talleres Argo. 1907. Primera Asamblea General de Profesores. Buenos Aires: Librería Nacional de Lajouane \& Cía.

------- 1908. Segunda Asamblea General de Profesores. Buenos Aires: Librería Nacional de Lajouane \& Cía.

------- 1909. Memoria de la Universidad (marzo 1906-Agosto 1909). Buenos Aires: "Imprenta Nacional" de Lajouane \& Cía.

------- 1910. Digesto de la Universidad Nacional de La Plata. Buenos Aires: Coni Hermanos

------- 1911. Asamblea General de Profesores (18 de Marzo de 1910). Buenos Aires: "Imprenta Nacional" de Lajouane \& Cía.

------- 1913a. Memoria correspondiente al año 1912. Buenos Aires: Imprenta Coni. ------- 1913b. Digesto de la Universidad Nacional de La Plata. Suplemento (19101913). Buenos Aires: Coni Hermanos. ------- 1915. Digesto de la Universidad Nacional de La Plata. Suplemento (19131915). Buenos Aires: Coni Hermanos.

------ 1917. Memoria General correspondiente a los años 1913, 1914,1915. Buenos Aires: Imprenta Coni. 
Uría, J. 1994. "La Universidad de Oviedo en el 98. Nacionalismo y regeneracionismo en la crisis finisecular española. En: Uría González, J. (ed.). Asturias y Cuba en torno al 98. Sociedad, economía, política y cultura en la crisis de entre siglos. Barcelona: Labor. pp.: 169-220.

Vallejos, G. 2000. "De los Apeninos a La Plata. Los italianos en la construcción de la "nueva capital"'". Anuario del Instituto de Historia Argentina, 1:153-173.

Vásquez, C. 2000. "Intelectuales y política: la "nueva generación" en los primeros años de la Reforma Universitaria". Prismas, 4: 59-75.

Vessuri, H. 1987. "El proceso de profesionalización de la ciencia venezolana: la Facultad de Ciencias de la Universidad Central de Venezuela". Quipu, 4, 2 :253-281

von Reichenbach, C., Hara, M. y López D’Urso, M. 2002. "Tebaldo Ricaldoni: ¿Inventor o científico?". Saber y Tiempo, IV, 13, 2002: 73-93.

Weinmann, R. 1994. Argentina en la primera Guerra Mundial. Neutralidad, transición política y continuismo económico. Buenos Aires: Biblios.

Weisz, G. 1983. The Emergence of Modern Universities in France, 1863-1914. Princeton: Princeton University Press.

Wells, J. 1903. Oxford and its colleges. London: Metheven \& co.

Winsor, M. 1991. Reading the shape of nature. Comparative zoology at the Agassiz Museum. Chicago-Londres: The University of Chicago Press.

Wittrock, B. 1996. "Las tres transformaciones de la universidad moderna". En: Rothblatt, S. y Wittrock, B.. Op. cit., pp. 331-394.

Zimmerman, E. 1992. "Los intelectuales, las ciencias sociales y el reformismo liberal 1890-1916". Desarrollo Económico, XXXI, 124:545-564.

------------ 1995. Los liberales reformistas. Buenos Aires: Sudamericana. 1998. "La prensa y la oposición política en la Argentina de comienzos de siglo. El caso de La Nación y el partido Republicano". Estudios Sociales, VIII, 15: 45-70. 
Zubiaur, J. B. 1904. La enseñanza en Norte América. Buenos Aires: Juan Canter.

Zwerling, C. 1980. "The emergence of the École Normale Supérieure as a Centre of Scientific Education in the Nineteenth Century". En: Fox, R. y Weisz, G. (eds.). $O p$. cit., pp.: 50-58. 